\title{
WEATHERING AND CONSERVATION OF MONUMENTS CONSTRUCTED FROM TUFF AND SANDSTONE IN DIFFERENT ENVIRONMENTAL CONDITIONS
}

Case Studies from Mexico, Germany, Jordan and Cambodia

\author{
Dissertation \\ zur Erlangung des mathematisch-naturwissenschaftlichen Doktorgrades \\ "Doctor rerum naturalium" \\ der Georg-August-Universität Göttingen \\ im Promotionsprogramm Geowissenschaften / Geographie \\ der Georg-August University School of Science (GAUSS)
}

vorgelegt von

Wanja Wedekind

aus Göttingen

Göttingen 2016 


\section{Betreuungsausschuss}

\section{Prof. Dr. Siegfried Siegesmund}

Abteilung Strukturgeologie und Geodynamik

Geowissenschaftliches Zentrum der Georg-August-Universität Göttingen

\section{Prof. Dr. Robert Sobott}

Abteilung für angewandte Geowissenschaften

Friedrich-Alexander-Universität Erlangen-Nürnberg

\section{Mitglieder der Prüfungskommission}

\section{Referent: Prof. Dr. Siegfried Siegesmund}

Geowissenschaftliches Zentrum der Georg-August-Universität Göttingen

Prof. Dr. Robert Sobott

Friedrich-Alexander-Universität Erlangen-Nürnberg

\section{Weitere Mitglieder der Prüfungskommission}

\section{Prof. Dr. Jonas Kley}

Abteilung Strukturgeologie und Geodynamik

Geowissenschaftliches Zentrum der Georg-August-Universität Göttingen

Prof. Dr. Bernhard Middendorf

Abteilung Werkstoffe des Bauwesens und Bauchemie

Institut für konstruktiven Ingenieurbau der Universität Kassel

\section{PD Dr. Michael Hoppert}

Institut für Mikrobiologie und Genetik

Fakultät für Biologie der Georg-August Universität Göttingen

\section{PD Dr. Tobias Licha}

Abteilung Angewandte Geologie

Geowissenschaftliches Zentrum der Georg-August-Universität Göttingen

\section{Tag der mündlichen Prüfung:}

18.07.2016 


\section{Preface}

The thesis incorporates the following publications and manuscripts:

R. López-Doncel, W. Wedekind, T. Leiser, S. Molina-Maldonado, A. Velasco-Sánchez, R. Dohrmann, A. Kral, A. Wittenborn \& S. Siegesmund (2016) Salt bursting tests on volcanic tuff rocks from Mexico. Environ Earth Sci, 75:212. Published online: 25 January 2016

W. Wedekind, C. Gross, A. van den Kerkhof \& S. Siegesmund (2016) Contour scaling at the Angkor Temples: causes, consequences and conservation. Accepted article for the $13^{\text {th }}$ International Congress on Deterioration and Conservation of Stone, Glasgow 2016.

W. Wedekind, C. Poetzl, R. Lopéz-Doncel, T.V. Platz \& S. Siegesmund (2016) Surface hardness testing for the evaluation consolidation of porous stones. Accepted article for the $13^{\text {th }}$ International Congress on Deterioration and Conservation of Stone, Glasgow 2016.

T. Wangler, W. Wedekind, R. J. Flatt \& S. Siegesmund (2016) Microstructure and moisture expansion relationship in sandstones and tuffs. Accepted article for the $13^{\text {th }}$ International Congress on Deterioration and Conservation of Stone, Glasgow 2016.

W. Wedekind, R. López-Doncel, R. Dohrmann, M. Kocher \& S. Siegesmund, (2013) Weathering of volcanic tuffrocks used as natural building stone caused by moisture expansion. Environmenthal Earth Science. 69:1203-1224.

R. López-Doncel, W. Wedekind, R. Dohrmann \& S. Siegesmund (2013) Moisture expansion associated to secondary porosity. An example of the Loseros Tuff of Guanajuato, Mexico. Environmenthal Earth Science. 69:1189-1202.

K. Jauregui Arreola, W. Wedekind \& S. Siegesmund: Weathering, Conservation and Restoration of the Santa Mónica Church in Guadalajara, Mexico. Article for the Proceedings of the $12^{\text {th }} \mathrm{In}$ ternational Congress on Deterioration and Conservation of Stone, Columbia University, 22 26 Oktober 2012, New York, USA (in print).

W. Wedekind, J. Ruedrich \& S. Siegesmund (2011) Conservation inventory systems for monitoring and protection of cemeteries and tomb facades. In: Marcel Stéfanaggi, Véronique VergésBelmin. Jardins de pierres. Conservacion de la pierre dans les parcs, jardins et cimetiéres. 14es journées d'étude de la SFIIC PARIS, Institut national du patrimoine, 22-24 juin 2011, Saint-Etienne 2011:181-191.

W. Wedekind, J. Ruedrich \& S. Siegesmund (2011) Natural Building Stones of Mexico-Tenochtitlán: their Use, Weathering and Rock Properties at the Templo Mayor, Palace Heras Soto and the Metropolitan Cathedral. Environmental Earth Sciences, Volume 63, Numbers 7-8, August 2011:1787 - 1798 . 
W. Wedekind, J. Ruedrich, T. Kracke, T. Licha \& S. Siegesmund (2008) Object-specific Desalination of Tomb Monuments. In: Jadwiga W. Lukaszewicz \& Piotr Niemcewicz (Hrsg.) $11^{\text {th }}$ International Congress on Deterioration and Conservation of Stone. 15 - 20 September 2008. Torún. Poland. Proceedings Volume II, Torún 2008:1339 - 1347.

W. Wedekind, J. Ruedrich (2006) Salt-Weathering, Conservation Techniques and Strategies to protect the rock cut Facades in Petra/Jordan. In: R. Fort, M. Álvarez de Buergo, M. GomezHeras \& C. Vazquez-Calvo (eds.). Heritage, Weathering and Conservation. Taylor \& Francis, London 2006:261 - 268. 


\section{Abstract}

The present work deals with the weathering and conservation of natural stone used in historical monuments made from tuff and sandstone. Using different case studies, which are located around the world in different climates and environments, the different forms of weathering are described and their causes investigated.

For this purpose, object-specific weathering models have been developed and the main forms of damage were identified and evaluated by quantified mapping. The weathering forms investigated in detail are the formation of alveolars, contour scaling and substance loss due to flaking, sanding and crumbling decay.

In the case studies individual monuments are picked and processed separately. These are located at important historical places in Mexico, Germany, Jordan and Cambodia.

In Mexico, this study focused on the building stones that occur in numerous buildings in three historical cities, Guanajuato, Mexico City and Guadalajara. Two exemplary case studies were chosen: the Tzompantli Altar at the site of Templo Mayor in Mexico City and the baroque church of Santa Monica in Guadalajara. In Germany, three different monumental tombs were investigated in the Bartholomew Cemetery in Goettingen, in Jordan the facade no. 826 in the ancient city of Petra and in Angkor (Cambodia) the main sanctuary of the Phnom Bakheng Temple.

The experimental conservation work focused on the development and application of object-specific salt reduction methods (Guadalajara, Goettingen and Petra) and the conservation treatment of weathering crusts (Angkor).

The building rocks were analyzed for their petrophysical properties and mineralogical composition. The mineralogical investigations were carried out by different microscopic methods (scanning electron microscopy, transmitted and polarized light microscopy) and x-ray diffraction (XRD). The petrophysical investigations included the water transport and pore volume characteristics, the mechanical properties and the change of the volume at different humidity and temperature conditions.

One emphasis of the work focuses on the investigation of two main weathering processes that are associated with moisture: 1. the hygric and hydric dilation, the volume changes of the rock material by the change in drying and humidification. 2 . The material loss of the rock material by the crystallization and hydration of salt.

For both rock types different material properties are characterized, which determine both the hygroscopic dilatation as well as the resistance to the salt bursting test. For the different case studies object-specific solutions for conservation are developed and were successfully applied and ascertai- 
ned. The intensity of weathering on the various sites is discussed in the light of geomorphological studies and new challenges are formulated for the conservation sciences. 


\section{Zusammenfassung}

Die vorliegende Arbeit beschäftigt sich mit der Verwitterung und Konservierung von Naturstein an historischen Monumenten aus Tuffstein und Sandstein. Anhand von unterschiedlichen Fallbeispiele, die rund um den Globus in unterschiedlichen Klimazonen und Umgebungen angesiedelt sind, werden die verschiedenen Formen der Verwitterung beschrieben und ihren Ursachen nachgegangen.

Hierzu wurden objektspezifische Verwitterungsmodelle entwickelt und die Hauptschadensformen über quantifizierende Kartierungen ermittelt. Bei den Verwitterungsformen wurde sich auf Substanzverlust durch Absanden und Bröckelzerfall, die Bildung von Alveolen und oberflächenparallele Abplatzungen konzentriert.

Als Fallbeispiele werden einzelne Monumente herausgegriffen und gesondert bearbeitet. Diese befinden sich an bedeutenden historischen Orten in Mexiko, Deutschland, Jordanien und Kambodscha.

In Mexiko wurde sich auf die Werksteine konzentriert, die an zahlreichen Gebäuden in drei historische Städten, Guanajuato, Mexico City und Guadalajara als Hauptbausteine auftreten. Als konkrete Fallbeispiele wurden der Tzompantli-Altar auf dem Gelände des Templo Mayor in Mexiko Stadt und in Guadalajara die Barockkirche Santa Monica bearbeitet. In Deutschland wurden drei verschiedene Grabmale auf dem Bartholomäus-Friedhof in Göttingen, in der Felsenstadt Petra in Jordanien die Fassade Nr. 826 und im kambodschanischem Angkor das Hauptsanktuarium des Phnom Bakheng Tempels untersucht und bearbeitet.

Die experimentellen Konservierungsarbeiten konzentrierten sich auf die Entwicklung und Anwendung von objektspezifischen Salzreduzierungsmethoden (Guadalajara, Göttingen und Petra) und die Behandlung von Verwitterungskrusten (Angkor).

Die verbauten Gesteine wurden hinsichtlich ihrer petrophysikalischen Eigenschaften und mineralogischen Bestandteile untersucht. Die mineralogischen Untersuchungen erfolgten mittels unterschiedlicher mikroskopischer Methoden (SEM, Durchlicht- und Polarisationsmikroskopie) und Röntgendiffraktrometrie (RDX). Weitere Untersuchungen umfassten die Wassertransport- und Porenraumeigenschaften, die mechanischen Eigenschaften und die Veränderung des Volumens bei unterschiedlichen Feuchte- und Temperaturbedingungen sowie den Substanzverlust bei Salzkristallisation.

Ein Schwerpunkt der Arbeit liegt auf der Untersuchung von zwei zentrale Verwitterungsprozessen die im Zusammenhang mit Feuchtigkeit stehen. 1. Die hygrische und hydrische Dilatation, die Volumenänderungen des Gesteinsmaterials durch den Wechsel von Trocknung und Befeuchtung. 2. 
Die Auflockerung des Gesteinsmaterials durch die Kristallisation und Hydratation von Salzen.

Für beide Gesteinstypen konnten unterschiedliche Materialeigenschaften charakterisiert werden, die sowohl die Dilatation bei Feuchteaufnahme als auch die Resistenz gegenüber dem angewandten Salzsprengtest bestimmen.

Für die unterschiedlichen Fallstudien könnten objektspezifische Konservierungslösungen entwickelt, erfolgreich angewandt und eruiert werden. Die Intensität der Verwitterung an den unterschiedlichen Standorten wurde vor dem Hintergrund geomorphologischer Studien diskutiert und abschließend neue Herausforderungen für die Konservierungswissenschaften formuliert. 


\section{Contents}

$\begin{array}{ll}1 \text { General introduction } & 15\end{array}$

1. 1 Aims of the thesis 15

1. 1. 1 Stone in heritage $\quad 15$

1. 1. 1. a) Tuffs and volcanites $\quad 15$

$\begin{array}{ll}\text { 1. 1. 1. b) Sandstones } & 17\end{array}$

1. 2 Agents of weathering and deterioration $\quad 19$

1. 2. 1 Physical deterioration 19

1. 2. 2 Thermal expansion and contraction $\quad 21$

1. 2. 3 Chemical deterioration 22

1. 2. 4 Biological deterioration 24

1. 3 Environmental and climatic impacts 25

1. 4 Main weathering forms in sandstones and tuffstones 28

1. 4. 1 From description to explanation 29

1. 4. 1. a) Sanding and flaking $\quad 30$

1. 4. 1. b) Alveolar weathering 31

1. 4. 1. c) Contour Scaling 32

1. 4. 2 Weathering forms and case studies 33

1. 5 Properties of sandstones and tuffs 34

1. 5. 1 Classification of tuffs and sandstones 35

1. 5. 1 Porosity and bulk density 35 
1. 5. 2 Pore radii classes $\quad 36$

1. 5. 3 Capillary water absorption $\quad 37$

1. 5. 4 Hygric expansion 38

1. 5. 5 Splitting tensile strength $\quad 40$

1. 5. 6 Ultrasonic velocity 41

1. 5. 7 Salt resistance $\quad 42$

1. 6 Stone conservation 43

1. 6. 1 History of stone conservation 43

1. 6. 2 Stone Conservation Science 44

1. 6. 3 Research studies in stone conservation 45

1. 6. 4 Scientific stone conservation in academic restoration 47

$\begin{array}{ll}\text { 1. } 7 \text { Strategies for sustainable conservation } & 47\end{array}$

1.7. 1 Preventive conservation $\quad 47$

1. 7. 1. a) Conservation inventory 48

1.7. 2 Active conservation $\quad 49$

1. 7. 2. a) Cleaning 49

1.7. 2. b) Desalination 50

1. 7. 2. c) Consolidation $\quad 50$

2 Methodology 53

2. 1 On-site observations, sampling and investigations 53

2.1.1 On-site observations and mapping 53

2. 1.2 Electrical conductivity 53

2. 1. 4 Drilling dust and core sampling $\quad 54$

2. 2 Laboratory investigations $\quad 54$ 
2. 2. 2 Microscopic analyses $\quad 54$

2. 2. 3 Porosity, density and pore size distribution $\quad 55$

2. 2. 4 Pore size distribution $\quad 55$

2. 2. 5 XRPD analyses $\quad 55$

2. 2. 6 Analyses of the clay content 56

2. 3 Water transport and retention properties 56

2. 3. 1 Capillary water absorption 56

2. 3. 2 Water vapor diffusion resistance 56

2. 4 Petrophysical properties $\quad 57$

2. 4. 1 Splitting tensile strength $\quad 57$

2. 4. 2 Uniaxial compressive strength 58

2. 4.3 Ultrasonic velocity $\quad 58$

2. 4. 4 Surface hardness measurements $\quad 58$

2. 5 Artificial weathering $\quad 60$

2. 5. 1 Salt resistance tests $\quad 60$

$\begin{array}{ll}3 \text { Case studies } & 63\end{array}$

3. 1 Areas of investigations and rock material 63

3. 1.1 Geography and geology of the case studies located in Mexico 63

3. 1. 2 Geography and geology of the German case study 63

3. 1. 3 Geography and geology of the Jordan case study 63

3. 1. 4 Geography and geology of the Cambodian case study 64

3. 2 Case study Mexico City / Mexico 65

3. 2. 1 Introduction $\quad 65$ 
3. 2. 1. a) Tenochtitlán

3. 2. 1. b) Climate and environmental conditions 67

3. 2. 2. a) Deterioration and weathering forms $\quad 70$

3. 2. 3 Case study Tzompantli 70

3. 2. 3. a) Weathering model 71

3. 2. 3. b) Quantified mapping 72

3. 2. 4 The salt of Mexico City 73

3. 2. 5 Palace of the dukes of Heras Solo 74

3. 2. 5. a) Deterioration and weathering forms 75

3. 2. 6 The Metropolitan Cathedral 75

3. 2. 7 Rock fabrics and petrophysical properties 77

3. 2. 7. a) Tezontle basalt (I) 77

3. 2. 7. b) Tenayocátetl rhyolitic ignimbrite (II) 79

3. 2. 7. c) Remedios tuff (Gris de los Remedios, III) 81

3. 2. 7. d) Chiluca: fresh (IV) and altered (Cathedral), (V) 83

3.2. 8 Discussion $\quad 84$

3. 2. 8. a) Sample I 84

3. 2. 8. c) Sample III $\quad 85$

3. 2. 8. d) Sample IV, V 86

3. 2. 9. Salt weathering test $\quad 87$

3. 3 Guanajuato / Mexico $\quad 89$

3. 3. 1 Introduction $\quad 89$

3. 3. 1. a) Climate and environmental conditions 90

3. 3. 1. b) Geological setting and utilization of the rock material 90 
3. 3. 1. c) Main weathering forms 91

3.3. 2 Rock materials 93

3. 3. 2. a) Bufa Tuff 93

3. 3. 2. b) Loseros Tuff 94

3. 3. 2. c) Horizontal petrophysical properties 100

3. 3. 2. d) Comparative compressive and splitting tensile strength 101

3. 3. 2. e) Porosity and pore size distribution 105

3. 3. 2. f) Moisture properties (hygric and hydric expansion) 106

3. 3. 2. g) Salt weathering test 108

3. 3. 3 Discussion 109

3. 4 Santa Mónica Church Guadalajara / Mexico 113

3. 4. 1 Introduction 113

3. 4. 1 a) Climatic and environmental conditions 114

3. 4. 1 b) Main weathering forms 115

3. 4. 1 c) Quantified mapping 116

3. $4.1 \mathrm{~d})$ Observations, further investigations and weathering model 117

3. 4. 2 The salts of Guadalajara, their sources and damage potential 118

3. 4. 3 a) Petrophysical experiments 121

3. 4.3 b) Petrophysics 121

3. 4.3 c) Salt resistance test 123

3. 4. 4 Discussion 124

3. 5 Bartholomew Cemetery Goettingen / Germany 127

3. 5. 1 Introduction 127

3. 5. 1 a) The Bartholomew Cemetery and its tombs 127 
3. $5.1 \mathrm{~b}$ ) Climatic and environmental conditions

3. 5.1 c) Geological setting and rock material

3. 5. 2 Rock material and fabrics

3. 5.2 a) Petrophysical properties

3. 5.2 b) Salt resistance test

3. 5. 3 Main weathering forms

3. 5. 3 a) Main weathering and deterioration factors

3. 5. 4 Salts at the cemetery, their sources and damage potential

3. 5. 5 Investigated tombs and mappings

3. 5. 5. a) The Adolf Ellissen Tomb

3. 5. 5. b) The Strohmeyer Tomb

3. 5. 5. c) The Lejeune-Dirichlet Tomb

3. 5. 6 Weathering models

3. 5. 6. a) Weathering model of the Adolf Ellissen Tomb

3. 5. 6. b) Weathering model of the Strohmeyer Tomb

3. 5. 6. b) Weathering model of the Lejeune-Dirichlet Tomb

3. 5. 7 Discussion

3. 6 Monument Nr. 826 Petra / Jordan

3. 6. 1 Introduction

3. 6. 1 a) Petra, the capital of the Nabateans

3. 6. 1 b) Climate and environmental condition

3. 6. 2 Rock material

3. 6. 2 a) Mineralogy and fabric

3. 6. 2 b) Petrophysical properties 
3. 6. 3 Typical weathering forms

3. 6. 4 The salt of Petra and its sources

3. 6. 4 a) Distribution of the different ions at depth

3. 6. 5 Forms of damage and weathering model

3. 6. 5. a) Damage forms

3. 6. 5. b) Weathering model

3. 6. 6 Damage mapping, preliminary examinations and findings

3. 6. 6. a) Description of tomb no. 826

3. 6. 6. b) Quantified mapping

3. 6. 6. c) Surface temperature and relative humidity

3. 6. 7 Laboratory examinations

3. 6. 7 a) Salt bursting test experiments

3. 6. 7 Discussion and conclusions

3. 7 Phnom Bakheng Temple Angkor / Cambodia

3. 7. 1 Introduction

3. 7. 1. a) Climate and environmental condition

3. 7. 2 Main weathering forms, quantification and weathering model

3. 7. 2. a) Quantified mapping

3. 7. 2. b) Weathering model

3. 7.3 Rock material

3. 7.3 a) Physical properties

3. 7. 4 The salts of Angkor, their sources and damage potential

3. 7. 5 Investigations and sample material

3. 7. 5. a) The laterites 
3. 7. 5. b) The sandstones

3. 7. 5. c) Cathodoluminescence microscopy

3. 7. 5. d) Salt resistance test

3. 7. 6 Experimental studies

3. 7. 6. a) Contour scaling due to hydric expansion?

3. 7. 6. b) Thermal expansion experiment

3. 7. 6. c) Contour scaling due to thermal expansion?

3. 7. 7 Discussion

3. 7. 8 Conclusions

4 Main weathering factors related to humidity

4. 1 Introduction

4. 1. 2 Moisture impact

4. 2 Hydric expansion and hygric swelling

4. 3 Examined rock material

4. 3. 2 Petrophysical properties

4. 3. 2. a) Porosity 204

4. 3. 2. b) Density 204

4. 3. 2. c) Microporosity 205

4. 3. 2. d) Pore radii distributions 205

4. 3. 2. f) Moisture expansion 207

4. 3. 1. h) Capillary water absorption 209

4. 3. 2. g) Water vapour diffusion 209

4. 3. 2. h) Swelling pressure 209

4. 3. 2. i) Sorption and saturation degree 
4. 4. 1 Swellable clay mineral content based on XRD and CEC results 213

4. 4. 2 Moisture expansion as a function of the CEC value

4. 4. 3 Moisture expansion as a function of the microporosity and average pore radius

4. 4. 4 Softening properties as a function of moisture content

4. 4. 5 Moisture expansion related to the physical properties

4. 5 Conclusions

4. 6 Outlook

5 Salt weathering

5. 1 Introduction

5. 1. 2 Salt impact

5. 2. 1. a) Gris Oscura Tuff of San Miguel de Allende (SG)

5. 2. 1. b) Black and Gray Tuff of San Miguel de Allende (GF black, GF gray)

5. 2. 1. c) Black Tuff of Querétaro (Qro black)

5. 2. 1. d) Escolásticas Tuff of Querétaro (ESC)

5. 2. 1. e) Cathedral Tuff of Zacatecas (Zac Cath)

5. 2. 1. f) Quarry Tuff of Zacatecas (Zac quarry)

5. 2. 1. g) El Salto Tuff of Zacatecas (Zac El Salto)

5. 2. 1. h) La Cuava Lapilli Tuff of Zacatecas (LC)

5. 2. 1. i) Escolasticas Tuff of Querétaro (ESC)

5. 2. 1. j) Cathedral Tuff of Zacatecas (Zac cath) 
5. 2. 1. k) Quarry Tuff of Zacatecas (Zac quarry) 234

5. 2. 1. 1) El Salto Tuff of Zacatecas (Zac El Salto) 234

5. 2. 1. m) La Cuava Lapilli-Tuff of Zacatecas (LC) 234

5. 3 Experimental investigation and results 234

5. 3. 1 Petrophysical properties 234

5. 3. 2 Pore radii distributions 238

5. 3. 3 Water uptake, water absorption 240

5. 3. 4 Splitting tensile strength versus surface hardness 242

5. 3. 5 Splitting tensile strength versus ultrasonic velocity 244

5. 3. 6 Ultrasonic velocity versus surface hardness 244

5. 3. 7 Splitting tensile strength versus porosity 245

5. 4 Salt weathering tests 250

5. 4. 1 General observations 252

5. 5. Discussion 254

5. 5. 1 Characterization of the pore space 254

5. 5. 2 Characterization of the physical and moisture properties 255

5. 5. 3 Conclusions 261

5. 6 Weathering behavior related to the environment 261

5. 6. 1 The Mexican case studies 261

5. 6. 2 The case studies from sandstone 264

$\begin{array}{ll}6 \text { Practical conclusions - conservation } & 267\end{array}$

6. 1 General introduction $\quad 267$

6. 2 Case study: Templo Mayor, Mexico City, Mexico 267

6. 2. 1 Introduction 267 
6. 2.1 a) Conservation history 267

6.2. 2 Preventive conservation 268

6. 2. 3 Active conservation 268

6.2. 4 Conservation model 268

6. 3 Case study: Santa Mónica, Guadalajara, Mexico 269

6. 3. 1 Introduction 269

6.3. 1. a) Conservation history 269

6. 3. 1 b) Consequences of investigations for conservation 269

6. 3. 1. a) Strategy of conservation/restoration and treatments 269

6. 3. 2 Conservation model 270

6. 3. 3 Preventive conservation 270

6. 3. 5 Active conservation/restoration 275

6. 3. 6 Conclusions 276

6. 4 Case study: Bartholomew Cemetery, Goettingen, Germany 277

6. 4. 1 Introduction 277

6. 4. 2 Conservation model 277

6. 4. 3 Preventive conservation 277

6. 4. 4 Conservation inventory 277

6. 4. 5 Conservation model for the tomb monuments 278

6. 4. 4 Active conservation 278

6. 4. 4. a) Salt reduction bath (Lejeune Dirichlet Tomb) 279

6. 4. 4. b) Cyclical sprinkling (Strohmeyer Stele) 280

6. 4. 4. c) Capillary flow (Ellissen Tomb) 282

6. 4. 5 Conclusions 283 
6. 5. 1 Introduction 285

6.5. 1 a) Conservation history 285

6. 5.2 Preventive conservation 285

6. 5. 2. a) Conservation inventory 285

6. 5. 2. b) Exemplary case study: The drainage situation at the Ad Dayr monument

6. 5.3 Conservation model 288

6. 5. 4 Active conservation 289

6. 5.4 b) Sprinkling method 291

6. 5.4 c) The sampling of the compresses 292

6. 5. 4 d) The calculation of the extracted amount of salt 292

6. 5. 4 e) Closing remarks and prospects 293

6. 6 Case study Phnom Bakheng, Angkor, Cambodia 295

6. 6. 1 Introduction 295

6. 6. 2 Conservation model 295

6. 6. 3 Preventive conservation 296

6. 6. 4 Active conservation 296

6. 6. 4 a) Treatment of contour scaling 296

$\begin{array}{ll}7 \text { Final discussion } & 299\end{array}$

7. 1 Introduction 299

7. 2 Case studies 299

7. 3 Weathering forms 301

7. 3. 1 Sanding and flaking 301

7. 3. 2 Alveolar weathering 301

7. 3. 3 Contour scaling 301 
7. 4 Moisture expansion

$\begin{array}{ll}7.5 \text { Salt weathering } & 303\end{array}$

7. 5. 1 The source of salts 303

7. 5. 2 Petrophysical aspects 304

7. 6 Implications $\quad 305$

7.6. 1 New experimental methods 305

7. 6. 2 Weathering models 305

7. 6. 3 Consequences for practical conservation 305

$\begin{array}{ll}\text { 7. } 7 \text { Future studies } & 307\end{array}$

8 Acknowledgments 311

9 References 313 


\section{General introduction}

\section{1 Aims of the thesis}

\section{1. 1 Stone in heritage}

Monuments constructed from natural stones are a witness that suggests the architects and builders created something for all eternity, or as a monumental testimony to the fact of their mortal existence. Stone necropolises around the world illustrate this claim of having the memory of a person's existence or exploits represented in stone which will outlive their lifespan. For good reason the most famous building of world heritage is a mausoleum, the Taj Mahal in Agra, India (Fig. 1b). However, even the ravages of time erode away the monuments and objects made of stone. The understanding of weathering processes, their documentation and mapping of damages is a prerequisite for their conservation. To understand the processes involved and to develop case-specific solutions to conservation problems is the main concern of this study.

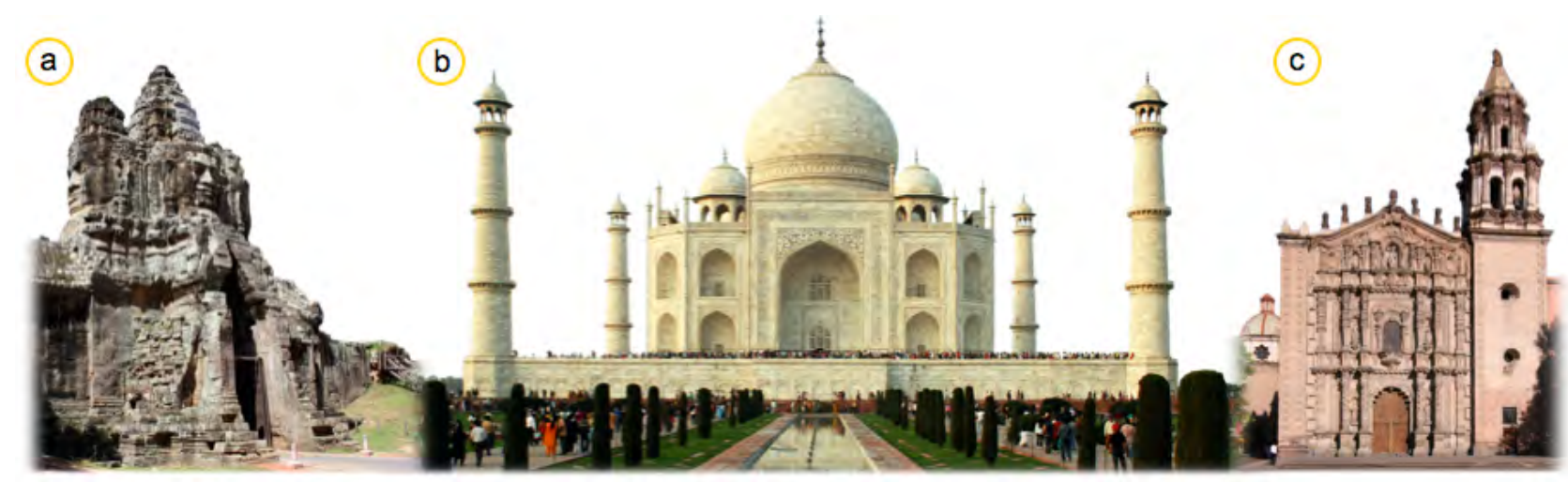

Figure 1: Outstanding monuments of the world made from stone. a) The monumental gate of Angkor Thom (Cambodia) nuilt from sandstone. b) The Taj Mahal (India), the masterpiece of islamic architecture made from marble. c) the church El Carmen in San Luis Potosì (Mexico) constructed with tuffstone.

\section{1. 1. a) Tuffs and volcanites}

Volcanic rocks have been an important natural building material since the beginning of time. Their use varies from monumental sculptures in cultures of antiquity to modern buildings all over the world. The reason these rocks are so appreciated as natural building stones is mainly due to three facts: (1) Some of these rocks, in particular tuffs, are relatively soft and easy to work with. (2) They are available worldwide, since tuffs occur in many places and (3) tuffs exist in a great assortment of colors, composition, grain size, sorting and textures, which makes these rocks very attractive for construction and artwork (Fig. 2).

From a geological point of view, tuffs are volcanic rocks with matrix grain sizes ranging from fine 
clay minerals up to silt-sized material (matrix normally present in ash form), in which sand, crystals or rock fragments up to gravel and block-sized clasts and lithics (also known as lapilli), as well as volcanic blocks and bombs, are embedded. The arrangement between these components and the lithology allows a very wide spectrum of porosities to occur, very different fabrics (Fischer 1961; Le Maitre et al., 2004) and normally large amounts of clay minerals in the matrix. However, at the same time, these characteristics cause tuffs to be less resistant to deterioration, particularly if they are exposed to moisture and humidity (Steindlberger 2003; Ruedrich et al., 2011 (a); Timothy et al., 2011).

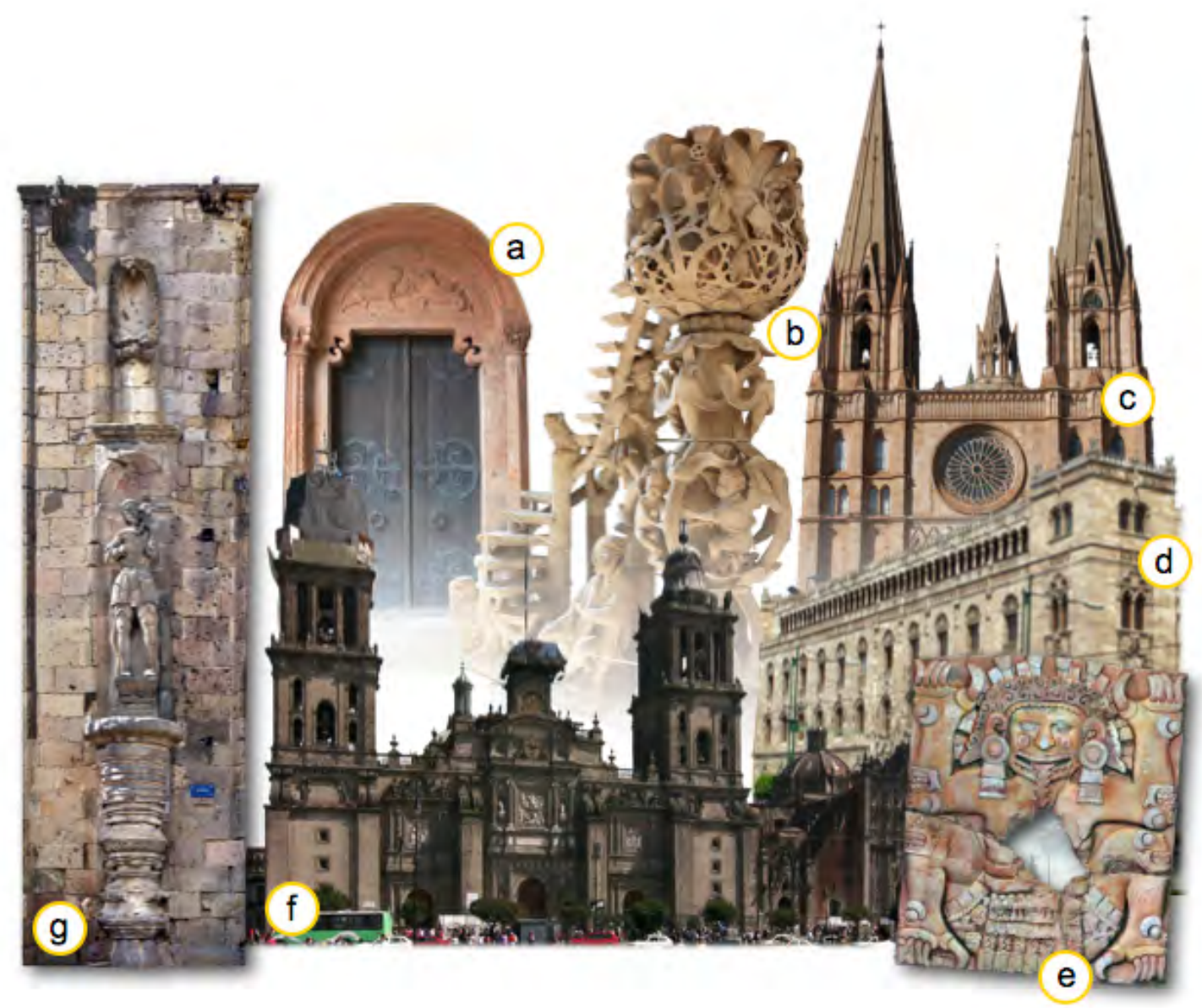

Figure 2: Volcanites used as building stones and for artwork: a) Rochlitz Tuff, RP (portal at monastery Wechselburg/ Germany), b) Hilbersdorf Tuff, HD (tulip pulpit in cathedral of Freiberg/Germany), c) Cantera Rosa San Miguel el Alto, CR (cathedral Arandas/Mexico), d) Blanca de Pachuca Tuff, BP (Palacio Postal Mexico City), e) Tenayocátetl Tuff, TY

(Aztec sculpture Tlatecuhtli, Templo Mayor, Mexico City), f) Chiluca, CH, and Cantera Gris de los Remedios, GR (cathedral of Mexico City), and g) Cantera Amarilla Tuff, CA (Santa Monica Church, Guadalajara/Mexico).

Besides sandstones and limestones, volcanites are one of the main important building materials used by mankind. Volcanites are found along the areas where volcanic activity occurs today or in the geological past (Fig. 3). Tuffstones are an easily workable material, which have been used throughout human history as building stones, for architectural monuments or sculptures (e.g. Easter Islands, Fig. 3 c). The softness of a high number of tuffs made them easy to carve even with other 
hard stones or wooden tools (Fig. 2 b, c, d). The first artworks made from tuffstone are the rock art of Cailagua, the island of El Muerto and Montelimar in Nicaragua as well as the famous statues of the Easter Islands of Chile (Fig. 3 c).

The important centers where cultural heritage sites were built from volcanites occur in Europe and Asia such as in Italy, Armenia and Turkey (Capadocia), Japan and China. In Africa rock cut churches constructed from volcanics are found in Ethiopia. And in the Americas, many sites are known from California, Texas, Mexico, Guatemala, Peru and Chile (Fig. 3).

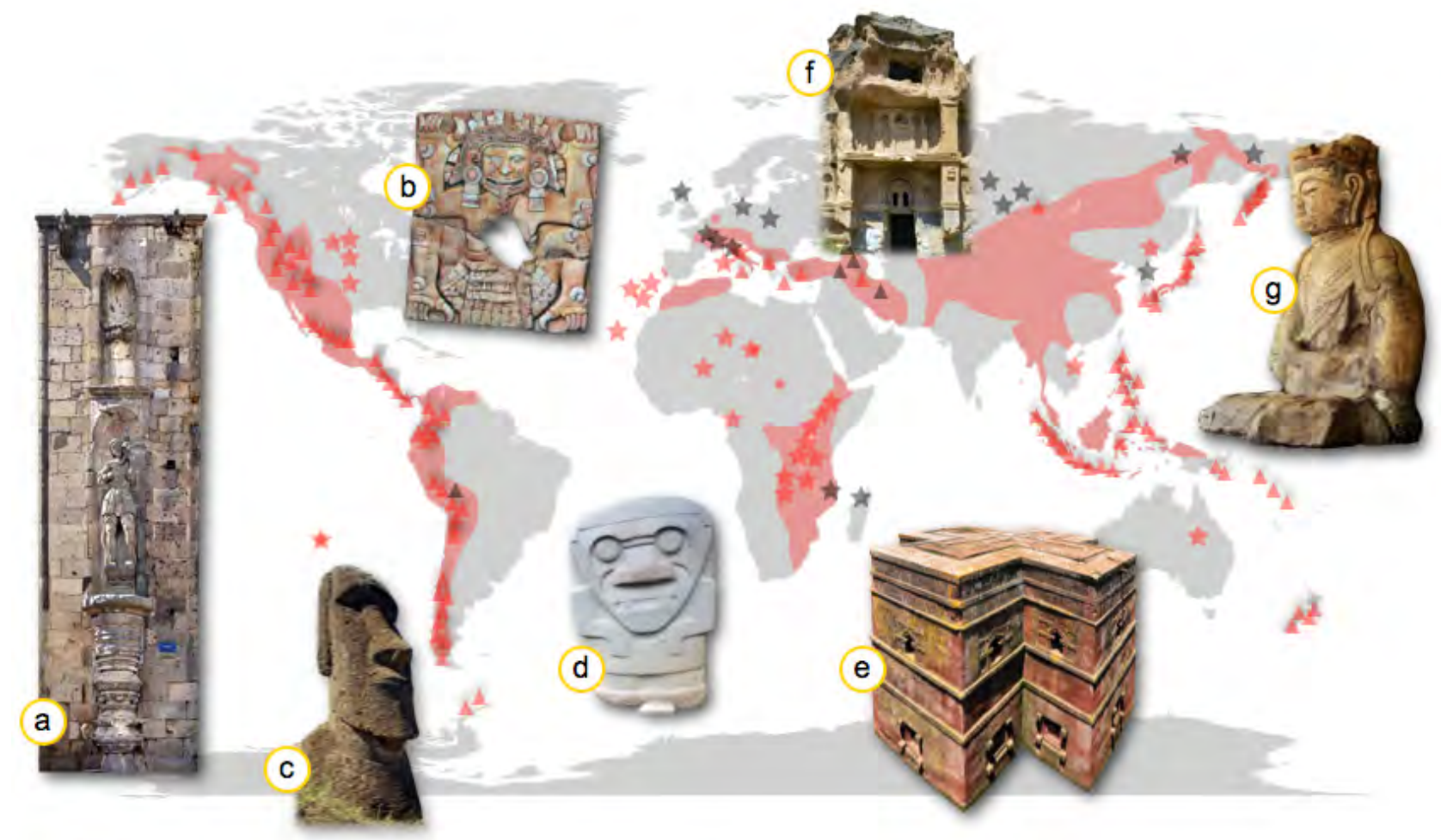

Areas where volcanites can be found

active volcano

Hotspot volcano extinct volcano

extinct hot-spot volcano source (volcanoes): Pichler, Pichler 2005

Figure 3: Areas were volcanites can be found and associated cultural heritage sites. a) Santa Monica Church, Guadalajara/Mexico, b) Aztec sculpture Tlatecuhtli, Templo Mayor, Mexico City (Mexico), c) stone heads on the Easter Islands (Chile), d) sculpture in San Augustin (Columbia), e) Lalibela Church in Ethiopia, f) rock cut facade in Capadocia (Turkey) and g) rock cut Buddha in Usuki (Japan).

\section{1. 1. b) Sandstones}

Sandstones have always been a popular and commonly used material for monuments as well as secular and sacred buildings in all continents of the world. Similar to tuffs, sandstones are relatively soft and easy to work with, but in contrast to tuffs comparably homogeneous. Therefore, sandstone was often used for decorative artwork in architecture and sculptures. 
Sedimentary rocks are by far the most common rocks on the earth's surface. Buildings and artwork made from sandstones are found worldwide because they make up to 10 to $20 \%$ of all sedimentary rocks. In contrast to tuffs, most of the sandstones used as dimensional stone are found in river basins, ancient sand dunes, and sandstones formed in ancient marine environments (Fig. 4).

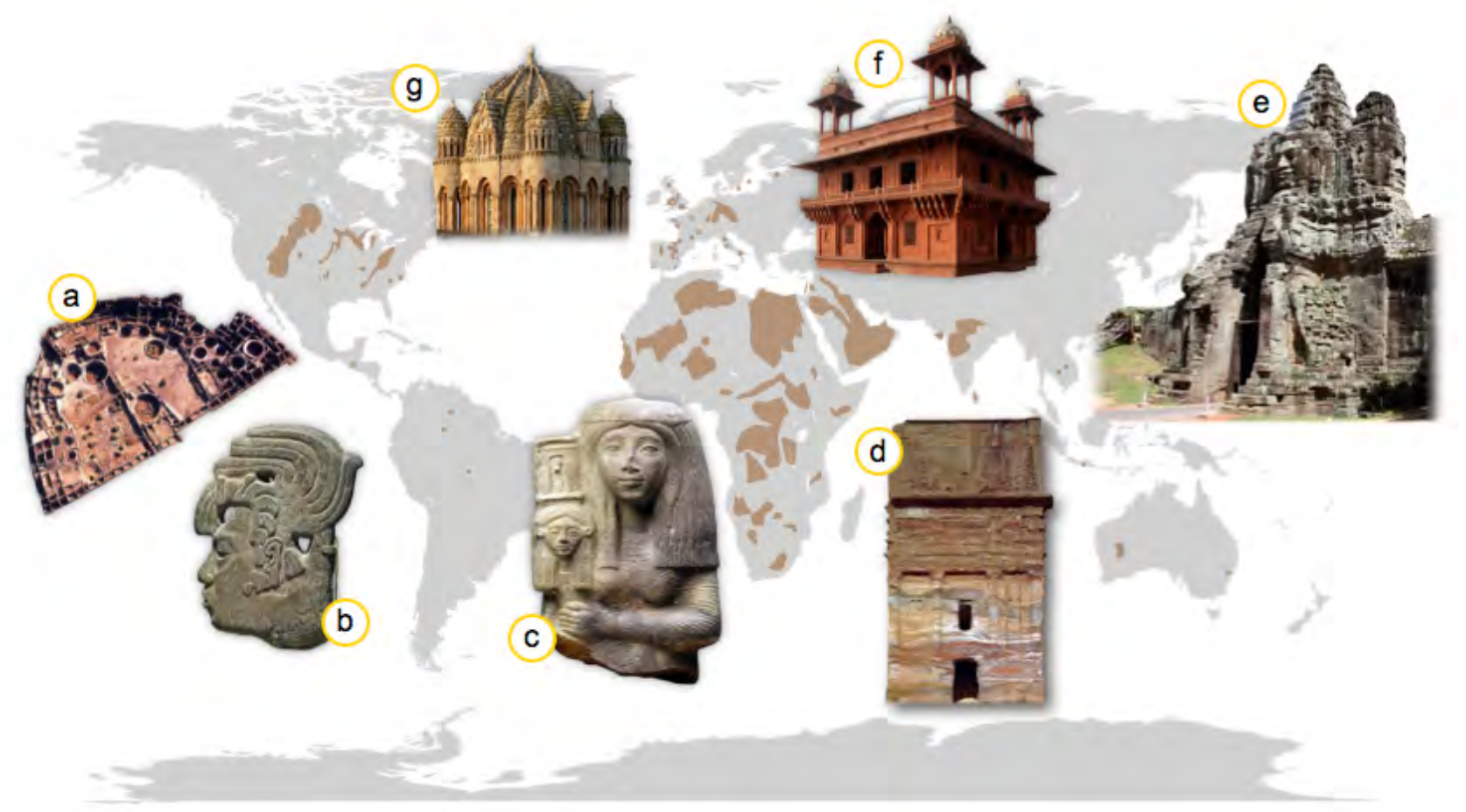

Figure 4: Examples of cultural heritage objects, monuments and building constructed from sandstones worldwide (brown areas : archived agiuveres mainly from sandstone; brown spots: important quarry areas related to cultural heritage sites. a) Pueblo Bonito ruins in the Chaco Canyon, USA, b) Mayahead sculpture from Guatemala, c) ancient woman sculpture from Egypt, d) the Silktomb in Petra, Jordan, e) the Angkor Thom gate in Cambodia, f) audience hall „Diwan-i-Khas“ at the Fatehpur Sikri site in India and g) the tower of the cathedral of Zamora, Spain.

Most sandstones are composed of quartz with or without significant proportions of feldspar, since these are the most common minerals in the Earth's crust. Sandstone is composed of sand-sized $(0.0625 \ldots 2 \mathrm{~mm})$ mineral grains and sometimes organic material (Pettijohn et al., 1972 and 1987). Some sandstones can contain rock fragments, or pieces of fossil fragments, which are held together by a mineral cement. Sandstones are characterized by their grain sizes and binding cement. Quartz is the most common silicate mineral that acts as cement. Clay or calcite can also be found as common cements. Other minerals that can act as cements include hematite, feldspars and gypsum. In general, sandstones are characterized by its structure defined by bedding, grain size and the binding cement. These three components dominate most of the petrophysical properties of the material. Graywackes can contain organic remains, significant contents of volcanic material as well as unstable minerals (Brown et al., 2014, Giese et al., 1994). 


\section{2 Agents of weathering and deterioration}

The weathering of building stone in historical monuments is a slow process of decay. However, natural disasters such as earthquakes and human related disasters, e.g. wars can lead to sudden damage. Both forms have a destructive affect on the man-made surface as well as to the rock material.

The decay of building stones proceeds from an increasing loss of strength to the final collapse of the binding forces of the material. The deterioration processes are influenced by both intrinsic and extrinsic aspects (Fig. 5). The intrinsic aspects are dominated by the texture, the pore space, the particle size and the (chemical) composition that characterizes the material (Camuffo 1995). The extrinsic factors are all environmental impacts that affect the material, like climate and object-specific environmental conditions. Both factors interact with each other and influence the properties of the material, their resistance and weathering and weathering forms.

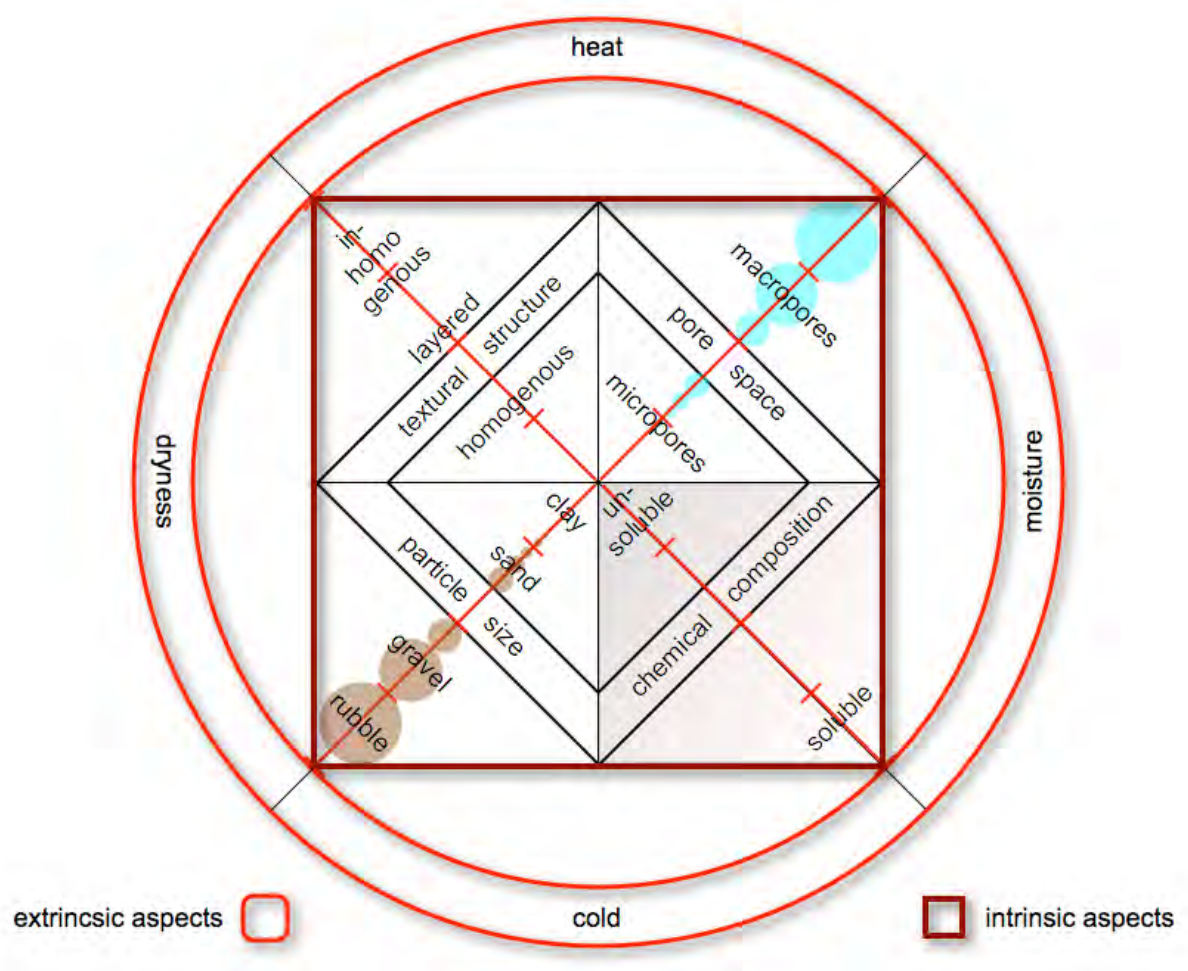

Figure 5: Schematic design of intrinsic and extrinsic aspects and factors that characterize the material and influence the weathering as well as the stability of a stone within the environment.

\section{2. 1 Physical deterioration}

In general, physical deterioration consists of the interplay of different conditions like expansion or contraction of the stone's material. This can be done by thermal expansion and contraction, frost disintegration, salt crystallization and hydration, hydric swelling and shrinking and a biogenic physical impact. Usually this is implied by mechanical stress, material fatigue or load exceeding the mechanical resistance of the stone (Fitzner 1978; Snethlage 1984). 
Structural deterioration phenomena related to physical deterioration consist of fissures and cracks and structural disintegration. Phenomena that affect the surface area of the material are sanding, flaking and scaling.

Extrinsic factors that are ascribed to physical deterioration are water, frost and salts as well as heat and cold. Stress takes place by water due to swelling or shrinking during water uptake and shrinking and swelling by drying. A constant alternation of the two conditions can lead to a weakening of the material, especially between zones that are wet and other ones that are still dry. Possible consequences can be the formation of flakes and crusts as is shown in Figure 6.
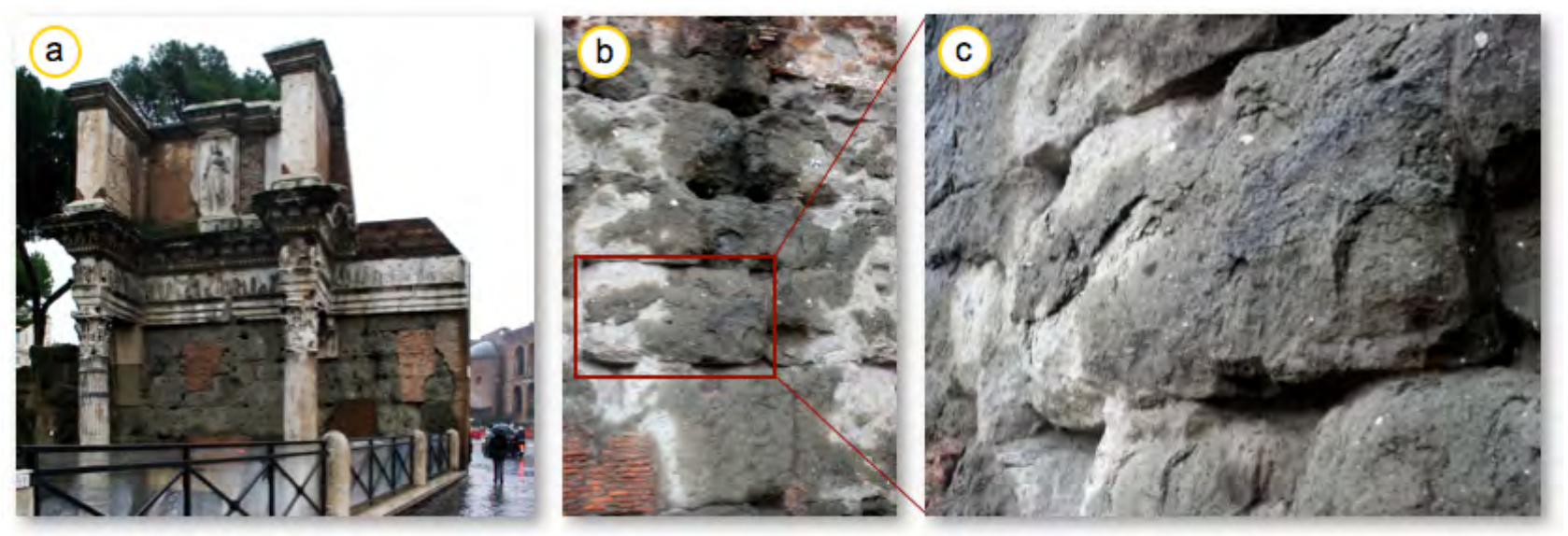

Figure 6: a) The main wind and rain direction in Rome comes from the west. During a rainfall the front facade of the Nerva temple at the Forum Augustus is completely wet, whereas on the back the water runs down in veins. b) In these zones weathering intensity is the greatest. c) Where the stone is wet, weathering crusts flake away from the dry stone underneath.

Crystallization of salt or ice is another important extrinsic factor in weathering and deterioration. For both forms of weathering water as well as changes in temperature is necessary: for salt weathering water acts as a transport media and for ice crystallization it is temperature dependent. For frost action cracking is a typical weathering form (Ruedrich et al., 2011 b). Salt crystallization shows different forms of weathering, often sanding and rounding (Charola 2000) (Fig. 7 a) and is related to temporary moisture infiltration and evaporation (Fig. 7 b and c).

For the mechanical disintegration of rock by salt weathering three mechanisms may be involved: 1 . crystallization of salts in pore spaces, 2. thermal expansion of crystals in response to changes in temperature, and 3. the hydration of salts due to changes of relative humidity (Cooke, Smalley 1968). In the case of the last two mechanisms thermal and hydric expansion or shrinking plays a role. 

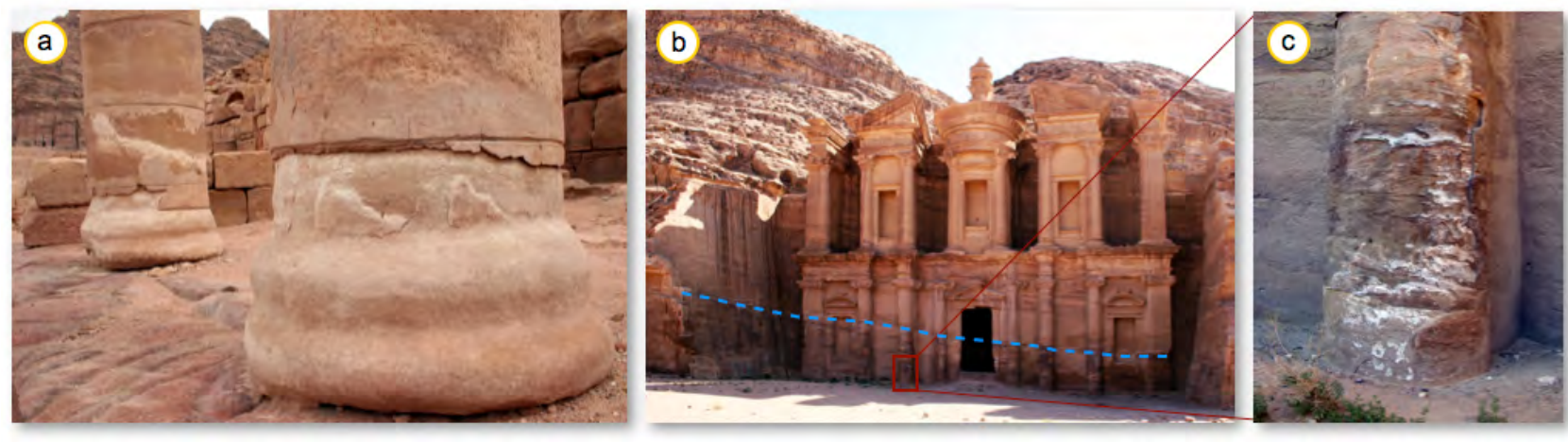

Figure 7: a) Rounding of ancient column bases made from sandstone in Petra due to salt weathering by rising moisture, b) extent of moisture front due to the modern reservoir located to the left of the monument (blue line) and c) leads to the accumulation of salt at the surface, crystallization and weathering.

\section{2. 2 Thermal expansion and contraction}

When materials are heated they expand, as they cool the material contracts. Thermal expansion in natural building stones is considered one of the most important factors affecting their weathering and deterioration. Minerals have different linear thermal expansion coefficients (Fig. 8). Some minerals like calcite also show a negative thermal expansion coefficient perpendicular to the c-axis of the crystal (Fig. 8).

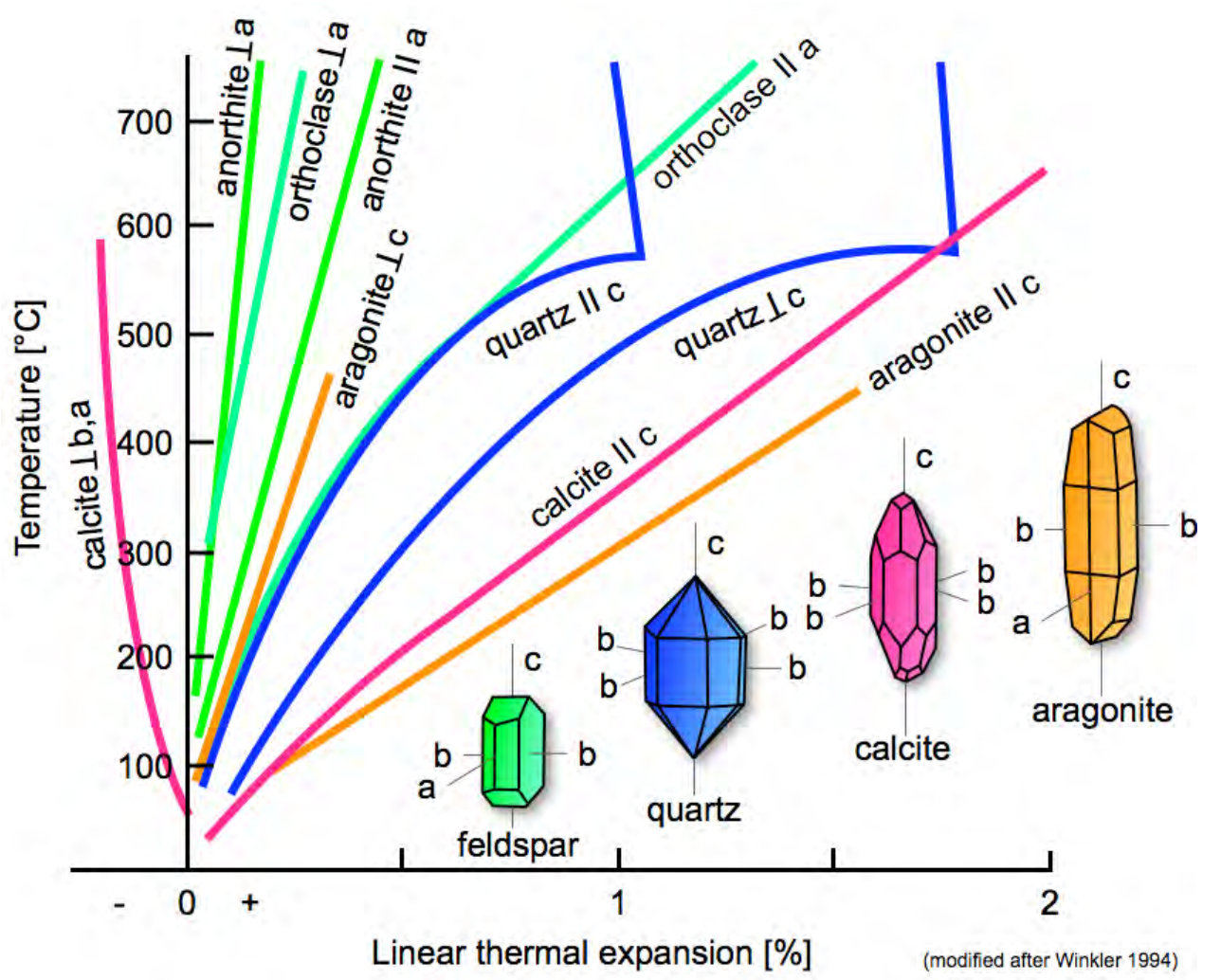

Figure 8: Thermal expansion of different minerals. 
In rocks with many crystals or minerals with a high thermal expansion coefficient like marble (calcite), this expansion and contraction can cause mechanical fracturing and cracks like it is shown in Figure 9 a (Siegesmund et al., 1999). Cyclic temperature changes are generally assumed to drive stone decay through the temperature gradients generated within the stone and the thermal expansion mismatch between minerals (e.g. Halsey et al., 1998). In interaction with humidity the effect of expansion decreases (Weiss et al., 2004). Also the color of the stone as well as the density plays a critical role. Black stones with a high density or a closed porosity are susceptible to cracking resulting in fluctuations of the surface temperature.

Good examples where thermal expansion may be the main deterioration process for cracking phenomena are the stair stringers of the Quetzalcotl Pyramid of Teotihuacan, Mexico (Fig. 9 b and c). The main facade of this building is subject to complex deterioration phenomena that include decay caused by the presence of water and soluble salts, as well as inappropriate conservation treatments carried out in past decades (Villasenor 2006).
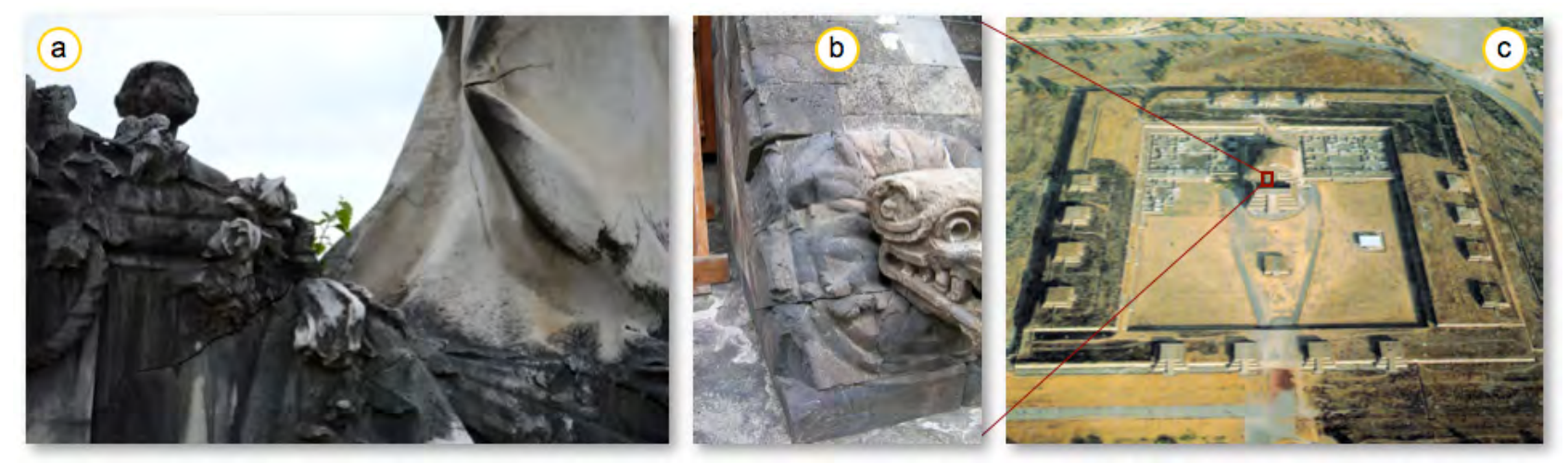

Figure 9: a) Cracks formed in a statue of marble in Lugano (Swizerland) probably due to thermal stress, b) massive cracks and material lost at the stair stringers of the Quetzalcotl Pyramid of Teotihuacan (Mexico) and c) the Quetzalcotl complex.

While most of the decorations are made from tuff, the stair stringers are made from black basalt containing non-cross linked gas pores. During the daytime in April and May the temperature can reach around $27{ }^{\circ} \mathrm{C}$ and can cool down to around $7{ }^{\circ} \mathrm{C}$ at night. Surface temperature on the dark colored stone varieties can reach nearly $70{ }^{\circ} \mathrm{C}$ because the main facade is oriented towards the west and heats up until the afternoon. At around 3:00 pm the lower part of the stair stringer facade is in shadow because another building is located right in front of it (Fig. 9 c). This leads to a significant decrease of surface temperature and probably leads to the shrinking, cracking and scaling of the stone (Fig. 9 b).

\section{2. 3 Chemical deterioration}

Chemical weathering is caused by rainwater, organic or inorganic acids as well as atmospheric gases, reacting with minerals in rocks to form new minerals (clays) and soluble salts (Carroll 2012). 
The most common types of chemical weathering are minerals altered by dissolution, oxidation, hydrolysis, carbonation and biogenic chemical impacts. Some elements leach out, whereas other minerals disintegrate by altering the geochemistry (Colman 1982). Mobilization of chemical elements derived from the leachable minerals depends on the intensity of weathering, which is controlled by the climatic impact (Middelburg et al., 1988). Chemical weathering of rock begins at the very surface and penetrates into the material over time, forming a rind in the case of most volcanic and sedimentary rocks (Ogburn et al., 2013).
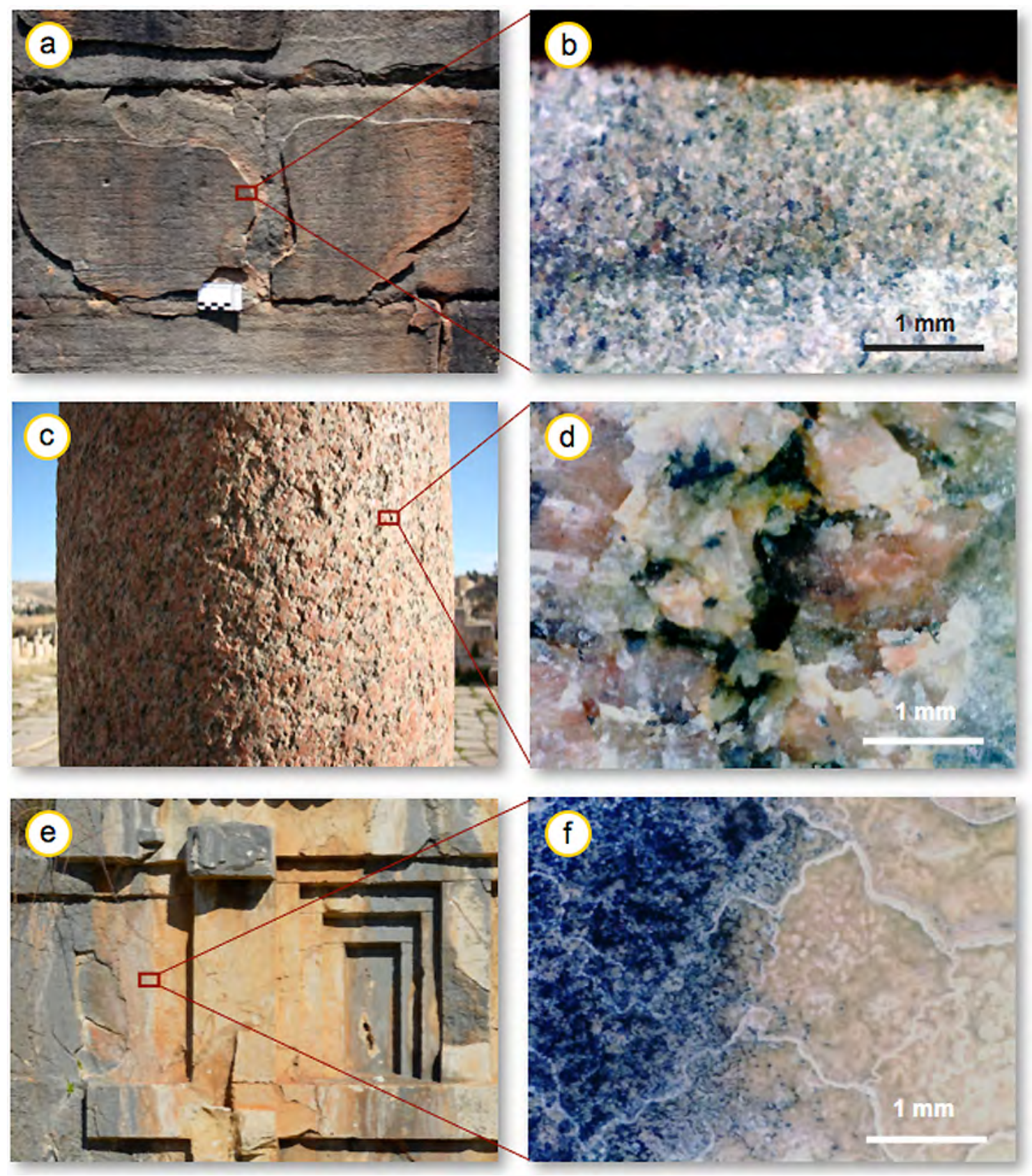

Figure 10: a) Discoloration by iron oxidation and contour scaling at the Phnom Bakheng Temple in Angkor (Cambodia) and b) zonation of the weathering crust. ) Granite weathering of a ancient column in Jerash (Jordan) and d) weathering of biotite and feldspar crystals. e) Weathering crusts at a Lycian monument in Myra (Turkey) and f) amorphous precipitations and discolorations probably due to micro-biological growth. 
Chemical weathering processes need water, and occur more rapidly at higher temperature, so warm and damp climates like in tropical environments are the most suited. Tuffs and volcanites contain many amorphous leachable minerals and sandstones sometimes contain feldspar and calcite.

Biotite and/or amphibole undergo alteration paths from hydrolysis to form clay, and oxidation to form iron oxides often forming weathering crusts red in color (Lee 1993) (Fig. 10 a). Na-feldspar and $\mathrm{K}$-feldspar undergo hydrolysis to form kaolinite (clay) and $\mathrm{Na}^{+}$and $\mathrm{K}^{+}$ions. Both weathering forms are often found in granites by the weathering of selected minerals (Fig. $10 \mathrm{c} \& \mathrm{~d}$ ). Through the so-called "carbonation weathering", minerals are structurally changed, dissolved and precipitated or else dissolved completely (Press, Siever 2003). Precipitation can create different forms of crusts and amorphous crust-like structures on the surface of the rock material (Wedekind et al., 2016 a, Fig. 10 e \& f).

\section{2. 4 Biological deterioration}

The impact of biological deterioration on the weathering process will not be discussed in detail in this study. First of all biological growth has an asthetic impact and often leads to an discoloration like it is shown in Figure 11 a and d (Hallmann et al., 2013). However, even microbiological activity can enhance physical weathering shown in Figure 11 b and c (Papida et al., 2000), but most deterioration is traced back to biochemical processes (Caneva, Altieri 1988; Jones et al., 2000). Chemical action that leads to degradation is exercised by the acidity of the rootlets and by excretion of inorganic and organic compounds, with aggressive or chelating capabilities. If these compounds contain acids, especially when reacting with carbonaceous stone material, their weathering may increase like it is shown in Figure $11 \mathrm{e}-\mathrm{f}$ (Tioano 1995). The weathering form of pitting is often associated to dissolution by acids (Kumar, Kumar 1999). Organic acids produced from some bacteria and fungi can also form metal organic complexes with cations dissolved from the crystal grid of minerals (Palmer et al., 1991). While these complexes stay stable, the metal ions remain diluted and precipitate as ions (Press, Siever 2003). This may enhance the hydrolytic weathering of feldspar found in sandstone, tuffs and other silica rocks.

The colonization with lithotrophic bacteria and fungi can produce ionic compounds and salts. By the oxidation of inorganic substances calcium sulfate dihydrate can be formed (Fassini 1988; Zappia et al., 1998). Nitrifying bacteria oxidize nitrous gases (NOx-components) to nitric acid, which again leads to dissolution and the deterioration of the stone material (Sand, Bock 1991).

In general, the presence of micro-organisms indicates a higher amount of humidity which may enhance deterioration processes (Wihr 1986). This humidity is only a relevant factor in several life zones and is closely connected to microclimatic conditions like shaded areas like in the case of some temples in Angkor shown in Figure $11 \mathrm{a}$ and b (Wedekind et al., 2016 a). Microbiological 
growth is not always visible, but it can be tested quite easily by enzymatic indicators (Warscheid et al., 1990). However, due to climatic changes the relative humidity increases in some regions like in northern Europe, which can also have an influence on physical deterioration processes such as hygric and hydric dilatation (Schubert, Wedekind 2014).

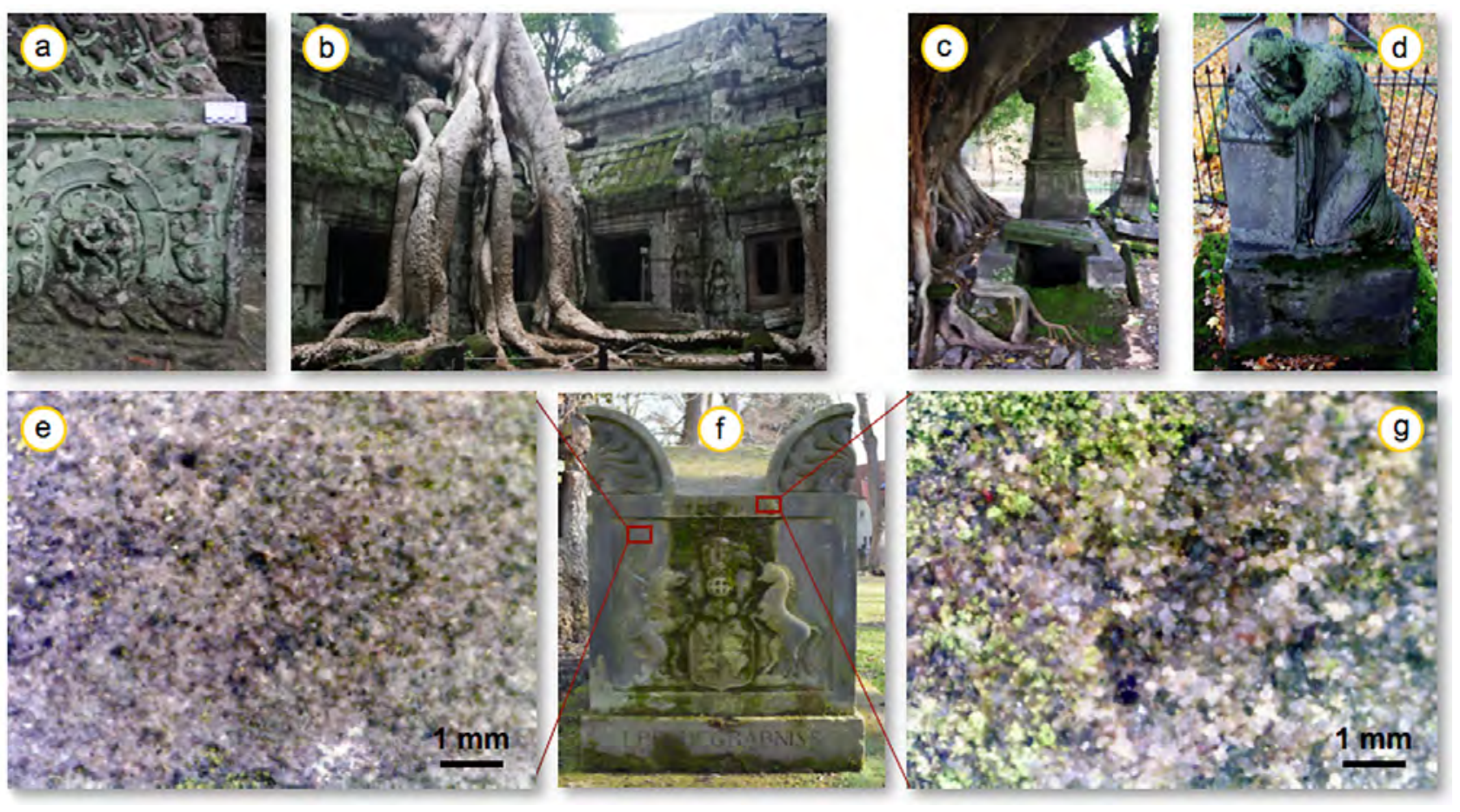

Figure 11: a) Massive biological growth on decorations and b) overgrowth of mangrove trees at the Ta Phrom Temple in Angkor and c) of a tomb et the Ek Balem cemetery in Guadalajara (Mexico). d) Massive microbiological growth on a marble statue at the Bartholomew cemetery in Goettingen (Germany). e, f. \& g) Micro- and macroscopic observations of a tomb athe Albani cemetery in Goettingen (Germany). e) Microscopic foto of an undamaged surface and g) of a damaged surface with microbiological growth.

\section{3 Environmental and climatic impacts}

Temperature and humidity are the main factors that control the intensity of weathering in regards to the climatic impact. Geomorphology seeks to understand why landscapes look the way they do. In geomorphology weathering is discussed in the context of the weathering of landscapes. Conservation science focuses mainly on the weathering factors affecting monuments. Most of the processes involved in the development of landscapes are controlled by the topography and climate. Four different climatic zones are defined: cold zones, tempered zones, tropical zones and subtropical zones (Fig 12 a). Within these zones nine different types of latitudinal regions, defined by Trewartha and Trewartha and Horn $(1966,1980)$ can be found as shown in Figure 12 b. Peltier (1950) presented a model that shows the intensity of weathering related to climatic conditions and different types of climate provinces (Fig. 12 a). The case studies investigated in this study are located in three different climatic zones (Fig. 12 b). The three Mexican case studies and the Cambodian case studies are located in the tropical zone, the Jordan one in the subtropical zone and the German one in the tem- 

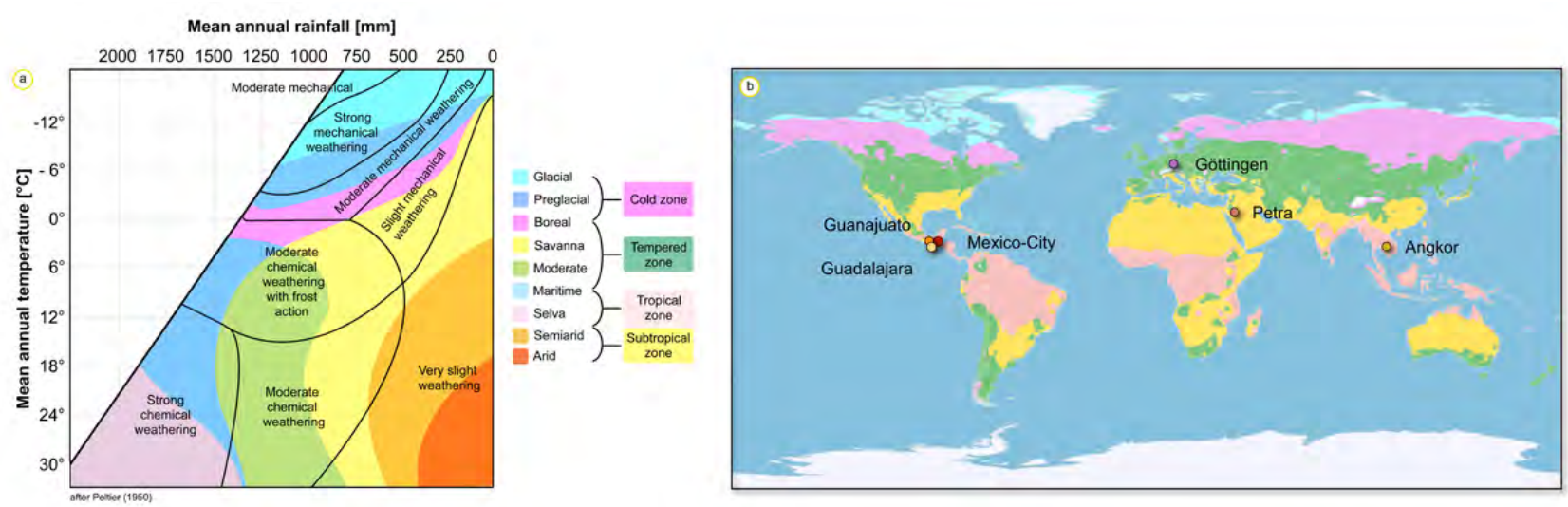

Figure 12: a) Weathering model after Peltier (1950) and b) the locations of the case studies within the different climatic zones.

The Koeppen climate classification first published in 1884, modified by Koeppen and Geiger several times, is one of the most widely used systems for climate classification and is also applied in this thesis. The system divides the world climate into 29 different types (Fig. 13). Trewartha (1966) modified the classification and addressed some of the deficiencies (mostly that the middle latitude climate zone was too broad) in the Koeppen system.

In this thesis bioactivity is used on the basis of the Holdridge life zones system, published by Leslie Holdridge in 1947, and updated twenty years later within the book „life zone ecology“. The system is based on empirical data such as the potential evapotranspiration ratio, annual precipitation and humidity provinces.

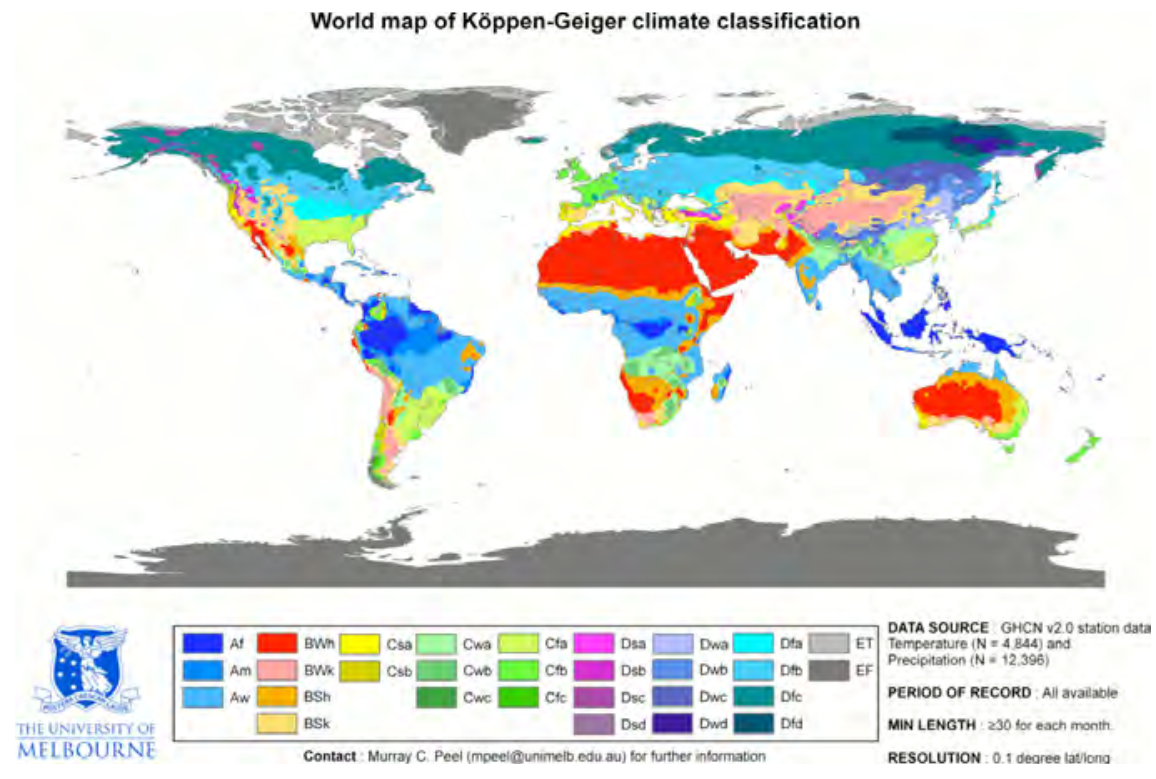

Figure 13: World map of the Koeppen-Geiger classification (source: University of Melbourne). 


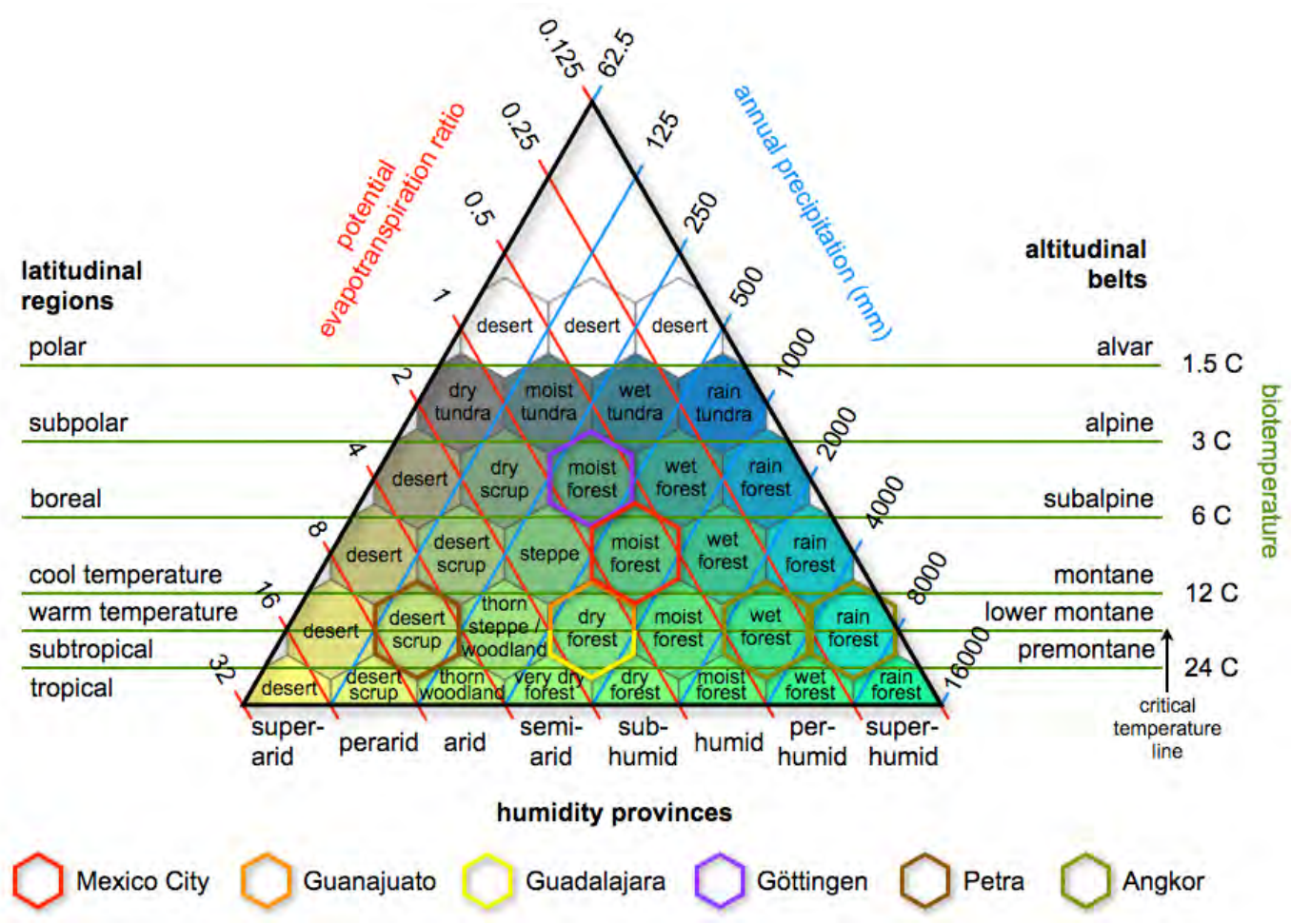

Figure 14: Holdridge life zones system as applied to the present case studies.

The case studies discussed in this thesis are located in three different climatic zones and various landscape types with five different climates as shown in Figure $12 \mathrm{~b}$ and listed in Table 1. According to the Holdridge life zone system, the case studies can be divided into six different zones (Fig. 14, Tab. 14).

Table 1: The different case studies and their geographical and climatic conditions and life zones

\begin{tabular}{|c|c|c|c|}
\hline Case studies & Climatic zone & $\begin{array}{l}\text { Climate after Trewartha and Köppen } \\
\text { climate classification (Cwb) }\end{array}$ & Life zone after Holdridge \\
\hline Mexico City & tropical & $\begin{array}{l}\text { Savanna / Subtropical highland climate } \\
\text { (Cfa) }\end{array}$ & $\begin{array}{l}\text { Cool temperate moist forest } \\
\text { biome }\end{array}$ \\
\hline Guanajuato & tropical & $\begin{array}{l}\text { Savanna / Humid subtropical climate } \\
\text { (Cwa) }\end{array}$ & $\begin{array}{l}\text { Warm temperate dry forest } \\
\text { biome }\end{array}$ \\
\hline Guadalajara & tropical & $\begin{array}{c}\text { Savanna - Arid / Humid subtropical } \\
\text { climate (Cwa) }\end{array}$ & Subtropical dry forest biome \\
\hline Göttingen & tempered & $\begin{array}{l}\text { Moderate / Oceanic climate } \\
\text { (Cfb) }\end{array}$ & Boreal moist forest biome \\
\hline Petra & subtropical & $\begin{array}{l}\text { Semiarid / Cold semiarid climate } \\
\text { (Bsk) }\end{array}$ & Warm desert scrub biome \\
\hline Angkor & tropical & $\begin{array}{l}\text { Selva / wet tropical (monsoon) climate } \\
\qquad(A m / A w)\end{array}$ & Warm wet to rain forest biome \\
\hline
\end{tabular}




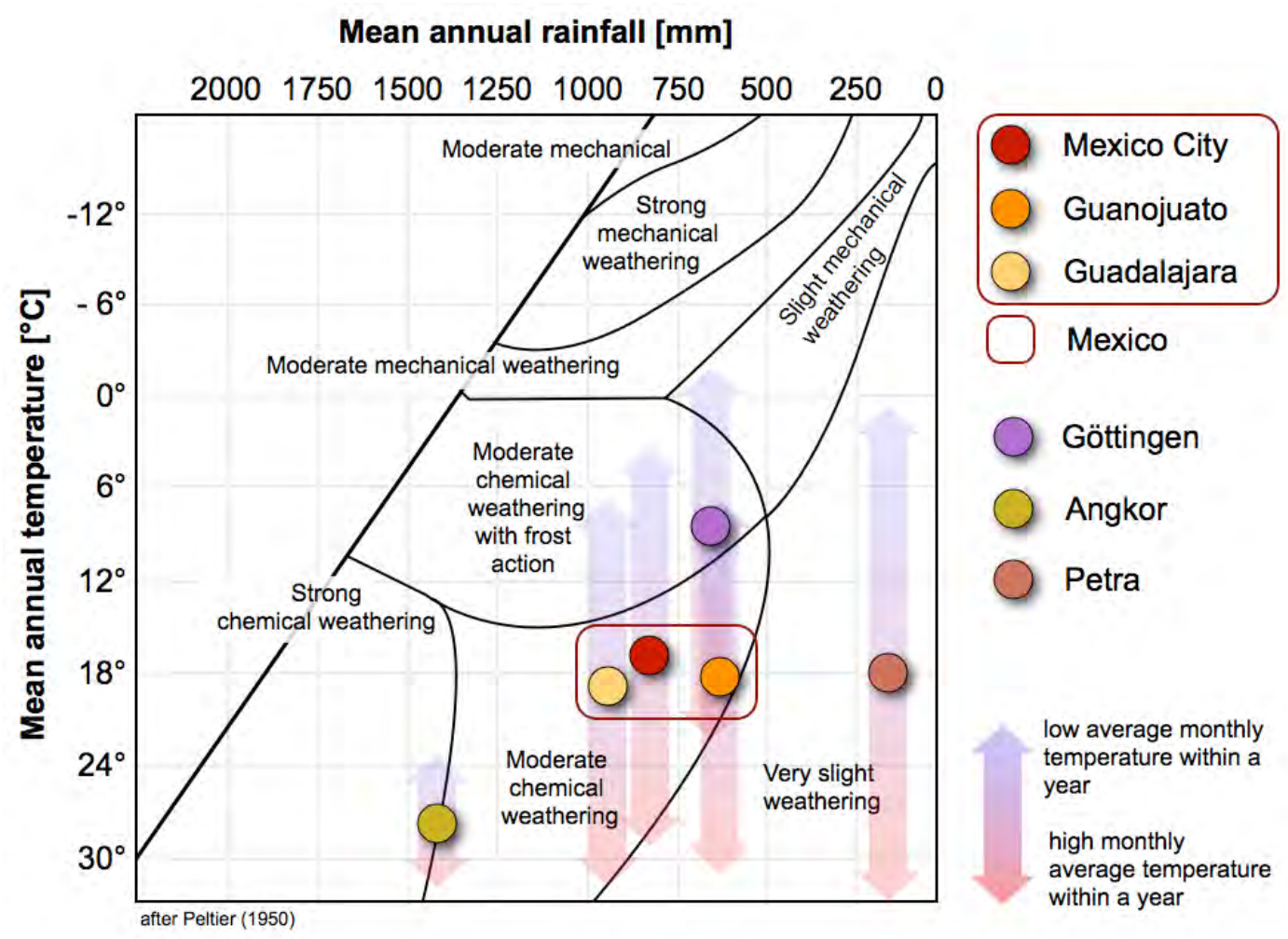

Figure: 15: The different case studies within the weathering model after Peltier (1950).

Utilizing the classification of Peltier (1950), the different areas investigated in this study are located in regions with different intensities of weathering (Fig. 15). These range from strong chemical weathering (Angkor) to moderate chemical weathering in the case of Göttingen, Guadalajara und Guanojuato. Moreover, in Göttingen the weathering is also associated with frost action. In the Petra region as well as in Guanojuato weathering is only very slight according to the model of Peltier.

\section{4 Main weathering forms in sandstones and tuffstones}

The dominant weathering forms in sandstones are delamination, sanding and flaking. Delamination occurs parallel to the bedding (Fig. $16 \mathrm{a}, \mathrm{d}$ and e) and sanding causes a uniform material loss parallel to the stone surface (Fig. $16 \mathrm{~b}$ ). This is similar to flaking whereby some stone types lose even greater fragments, which is the case for the Elbe-Sandstone where the material loss is connected to the flaser-like bedding of the rock (Fig. $16 \mathrm{c}$ ). Alveolar weathering, which is a hole-creating phenomenon, often occurs in connection with a high salt contamination (Fig. $16 \mathrm{f}$ and $18 \mathrm{a}$ and $\mathrm{b}$ ). Some rock types, especially those that contain calcitic cement show a susceptibility to crust formation, crack development and contour scaling (Fig. 10 a and16 g).

Tuffstones often show scale formation, scale-like deterioration, the weathering out of specific rock components and crack formation (Fig. $17 \mathrm{a}, \mathrm{b}$ and c). Even flaking of greater fragments is a commen weathering form (Fig. $17 \mathrm{~d}$ ). 

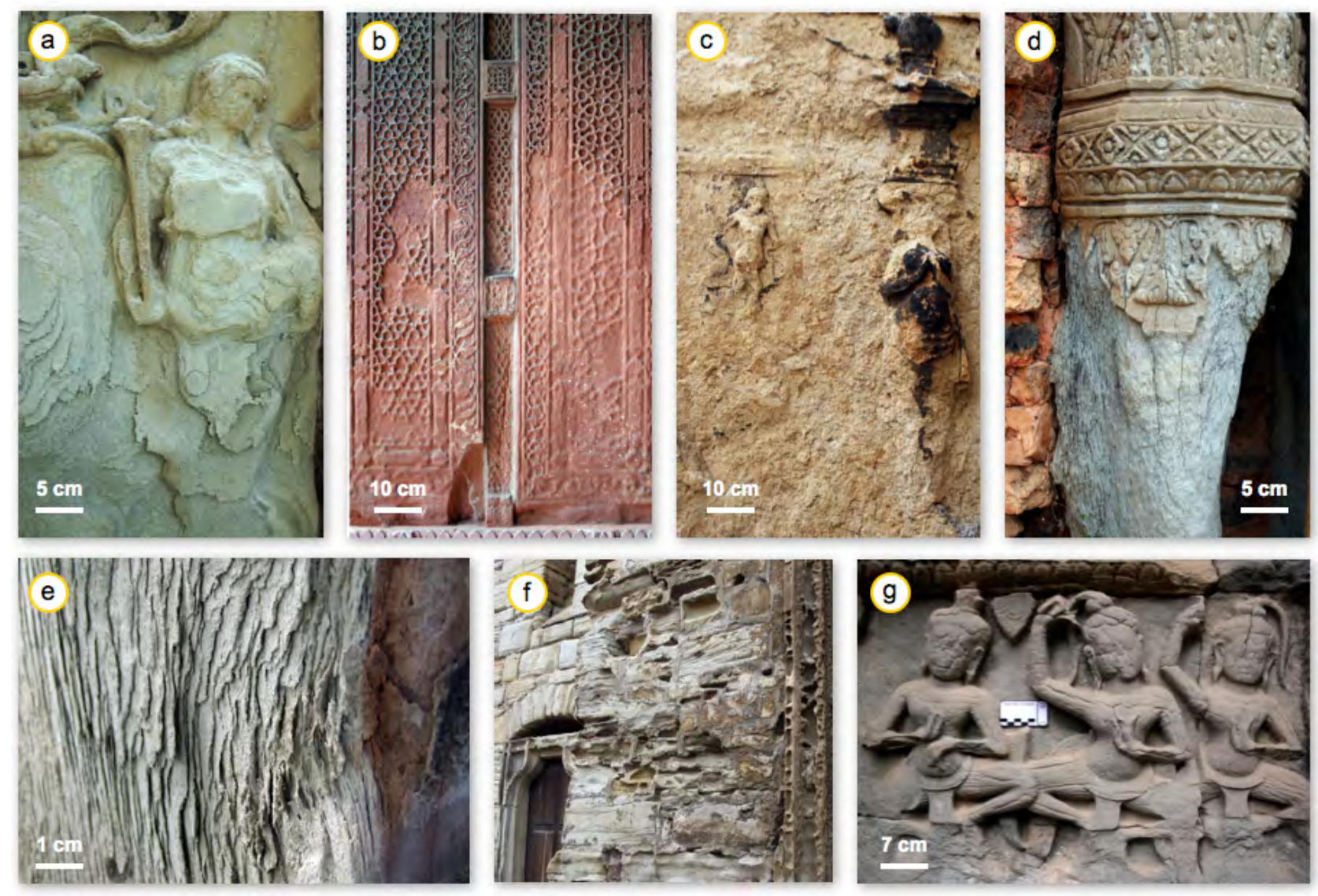

Figure 16: Weathering phenomena in sandstones: a) delamination parallel to the surface (Zeitz, Germany). b) Sanding parallel to the surface (Fatehpur Sikri, India). c) Flaking (Wittenberg, Germany). d) Crust formation, cracking and lamination parallel to the bedding (Angkor, Cambodia). e) Lamination parallel to the bedding (Goettingen, Germany). f)

Alveolar weathering (Zeitz, Germany). g) Cracking and contour scaling (Angkor, Cambodia).

Some varieties also exhibit a back-weathering similar to the sanding of sandstones (Fig. $17 \mathrm{f}$ ). In rarer cases contour scaling and delamination develops (Fig. $17 \mathrm{c}$ ). During the process of alveolar weathering salt contamination occasionally occurs (Fig. 17 e).

\section{4. 1 From description to explanation}

Weathering takes place due to frequent stress induced by environmental impacts like heat, moisture, cold, wind, natural, urban and industrial attacks and the interaction of internal compounds and structures.

Weathering forms in stone conservation are described and illustrated in different catalogues and glossaries and include all the different types of rocks (Fitzner, Heinrichs 2004; Vergès-Belmin 2008). The focus of these studies is usually related to the phenomenological aspects (descriptive work) and less to the processes that create the different weathering forms.

Only a few studies deal with the causes or explain the specific weathering forms found in different types of rocks (Snethlage, Wendler 1997; Durnan 2008; Muir 2008; Ruedrich 2003; Kemp 2008: Graue 2013; Stueck 2013). 

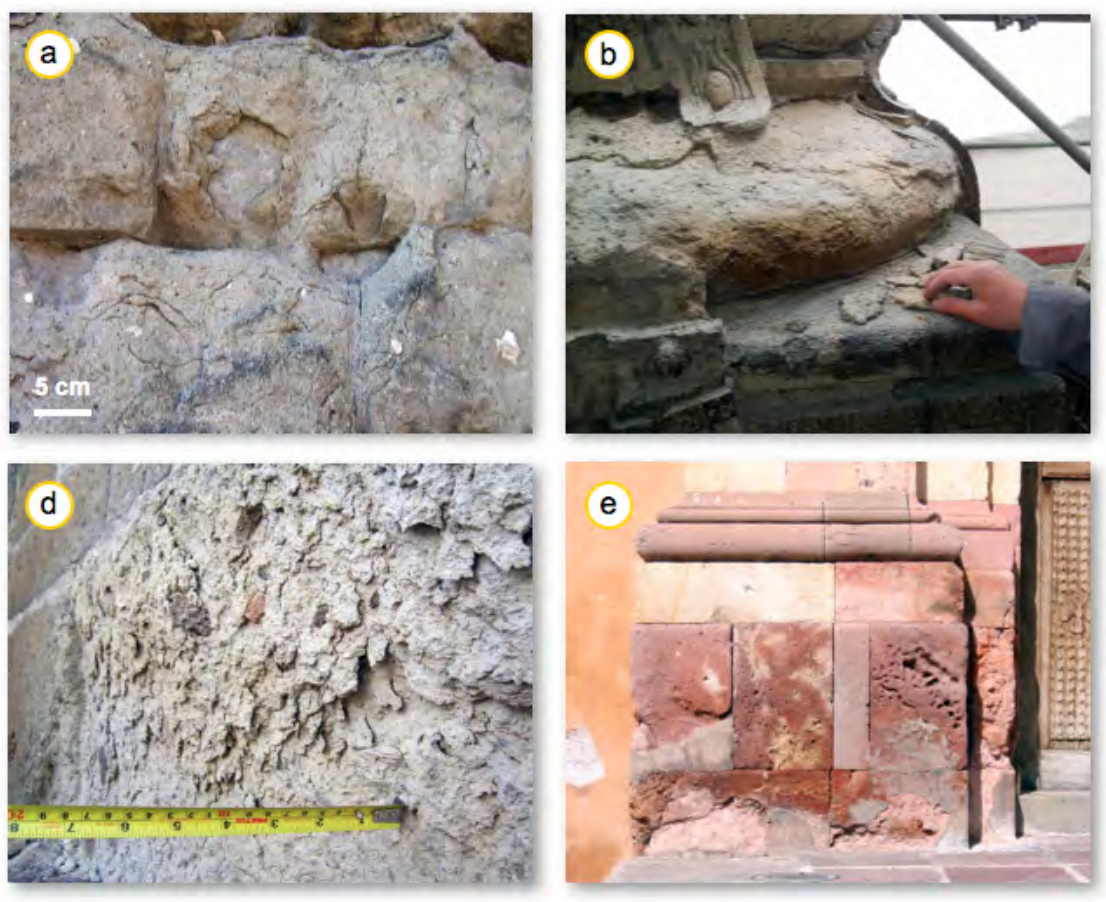
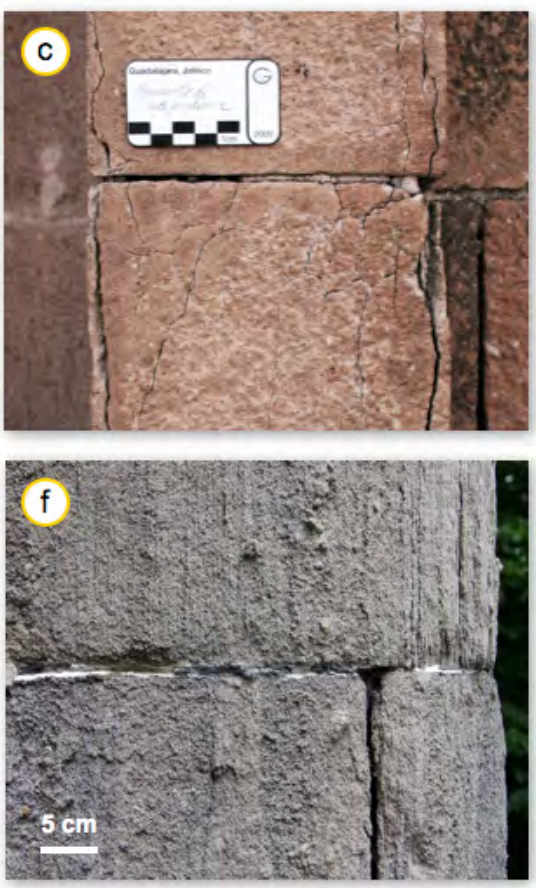

Figure 17: Weathering phenomena in tuffstones. a) Structural cracking and scaling (Rome, Italy). b) Cracking and scaling parallel to the surface (Berlin, Germany). c) Cracking and crust formation (Guadalajara, Mexico). d) Structural flaking (Guadalajara, Mexico). e) Alveolar weathering (Guanojuato, Mexico). f) Disintegration parallel to the surface (Kassel, Germany).

The knowledge of specific weathering behaviors of different rock types, however, is the main point for generating a suitable conservation treatment. This thesis will focus on three different weathering forms: a) sanding and flaking, with emphasis on structural flaking or disintegration, b) alveolar weathering and c) contour scaling.

\section{4. 1. a) Sanding and flaking}

Sanding and flaking only affect the outer $10-20 \mathrm{~mm}$ of a stone and is a deterioration form mostly observed in relation to salt weathering (Warke, Smith 2000; Muir 2008; Myrin 2006). Sanding off will occur when the maximum of salt is reached near the surface of the stone (Snethlage, Wendler 1997) as is shown in Figure 16 b. Flaking of sandstone as well as volcanic stone can be traced back to a combined salt contamination, if gypsum and low soluble salts can be found in the urban environment (Graue 2013). Flaking in tuff appears to be connected to selective dissolution, hygric cycling, lichen hyphae, and calcite precipitation in stone fractures under tropical environments (Doene et al., 2005).

In the case of rhyolitic lapilli tuffs structural flaking can reach a material depth of six centimeters. Cracking and structural flaking is due to a different hydric expansion of the matrix and clast material often combined with salt crystallization (this study and Jauregui et al., 2012). 


\section{4. 1. b) Alveolar weathering}

Alveolar weathering describes a honeycomb-like weathering form that creates local back-weathering with a hole diameter of $10 \mathrm{~cm}$ (Fig. $18 \mathrm{~b}-\mathrm{d}$ ). If the weathering hole is greater than $10 \mathrm{~cm}$, a cavernous depression is formed which is called tafoni (Turkington 1998). Exemples can be found at the rocks in the Petra region (Fig. 18 a).
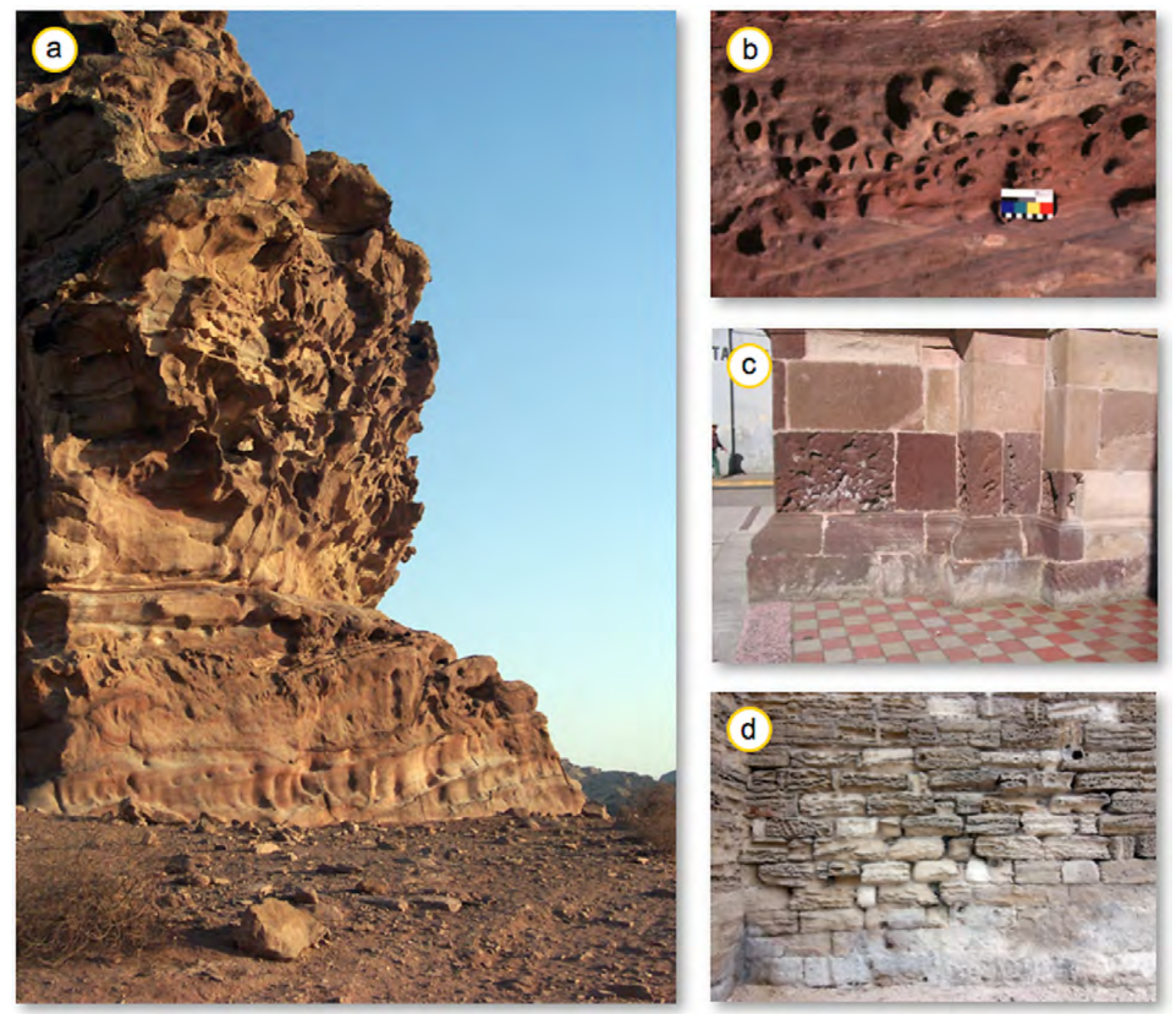

Figure 18: Tafoni and alveolar weathering. a) Tafoni weathering in the region of Petra (Jordan), b) alveolar weathering in Petra, c) alveolar weathering of tuff at the San Francisco Church in Zamora, Michoacan/Mexico and d) alveolar weathering at the historical city wall of Avignon (France).

Various theories account for alveolar weathering: Some authors assume that chemical weathering takes place due to so-called core weathering (Abu-Safat 1988) or partly results from the reaction of water and organic acids with iron and silica (Johnson 1974). Various mechanisms are assumed to be responsible for the physical forms of weathering as well. Some authors assume that alveolar weathering is caused by abrasion due to wind (Quayle 1992). Others consider the pressure induced by swelling clay minerals in combination with the effects of salts to be the major causes (Pye, Motters- 
head 1995). However, the majority of authors are convinced that salt weathering due to salt crystallization is responsible for the development of tafoni especially in coastal and desert environments (Bradley et al., 1978; Matsukuta, Matsuoka 1991; McGreevy 1985; Smith 1978, Kirchner 1995, Wedekind, Ruedrich 2006). Recent research states that different drying processes in the affected zones cause tafoni weathering (Huinink et al., 2004). The largest amount of salt settles in zones in which the drying process is slow and therefore causes damage.

During the process of alveolar formation due to salt weathering, it is assumed that the damage-creating salts concentrate in the back-weathering zones due to moisture transport and drying, thus giving rise to the described damages. The pore space in the back-weathering zones has specific pore radii (micropores), which need to be critically assessed in regards to the explosive affect associated with salt crystallization. In rock zones that have a corresponding microporosity or a low average pore radii an explosive affect through salt crystallization and back-weathering preferentially occurs (Seidel 2004, Siedel 2010 a).

\section{4. 1. c) Contour Scaling}

According to Fitzner et al., (1995), contour scaling describes the detachment of large, platy stone elements parallel to the stone surface, but not following the stone structure (Fig. 19). Contour scaling is often observed on buildings, especially built from clay-rich sandstones (Fig. 19 b). Scales show that a soluble salt enriched zone and a decrease of the flexural strength below the stone surface can be detected even if damage is not yet visible (Wendler et al., 1991). Some authors assume that contour scales will form when the crystallization of salt is situated in the interior of the stone (Snethlage, Wendler 1997).

Clay might be an explanation for the swelling, but not nessesarily the reason for the formation of crusts that are creating contour scaling. In many studies contour scaling can be observed in cases of a clay-rich arkose or greywacke-like sandstone (Sebastián et al. 2007, Leisen 2002). However, the interplay of a soluble mineral like calcite for crust formation was only taken into account by a few authors (Hosono et al., 2006). Many of the stone types that show contour scaling as the dominant weathering form contain a significant calcite content. This is the case for the sandstone of Puerta Perdón (Sebastián et al., 2007) 5-10 \% CaO, for the Darney Stone, a Carbonifrous sandstone (Smith, Mc Greevy 1988), oolitic limestones (Smith et al., 2003), Brownstone (Wangler, Scherer $2008 \mathrm{a}$ and b) and nearly all sandstones found in Angkor, where contour scaling is the main damage form.

Some authors take into account the changes in porosity induced by salt, mainly gypsum in the formation of crusts and contour scaling (Adamovic et al., 2011). 

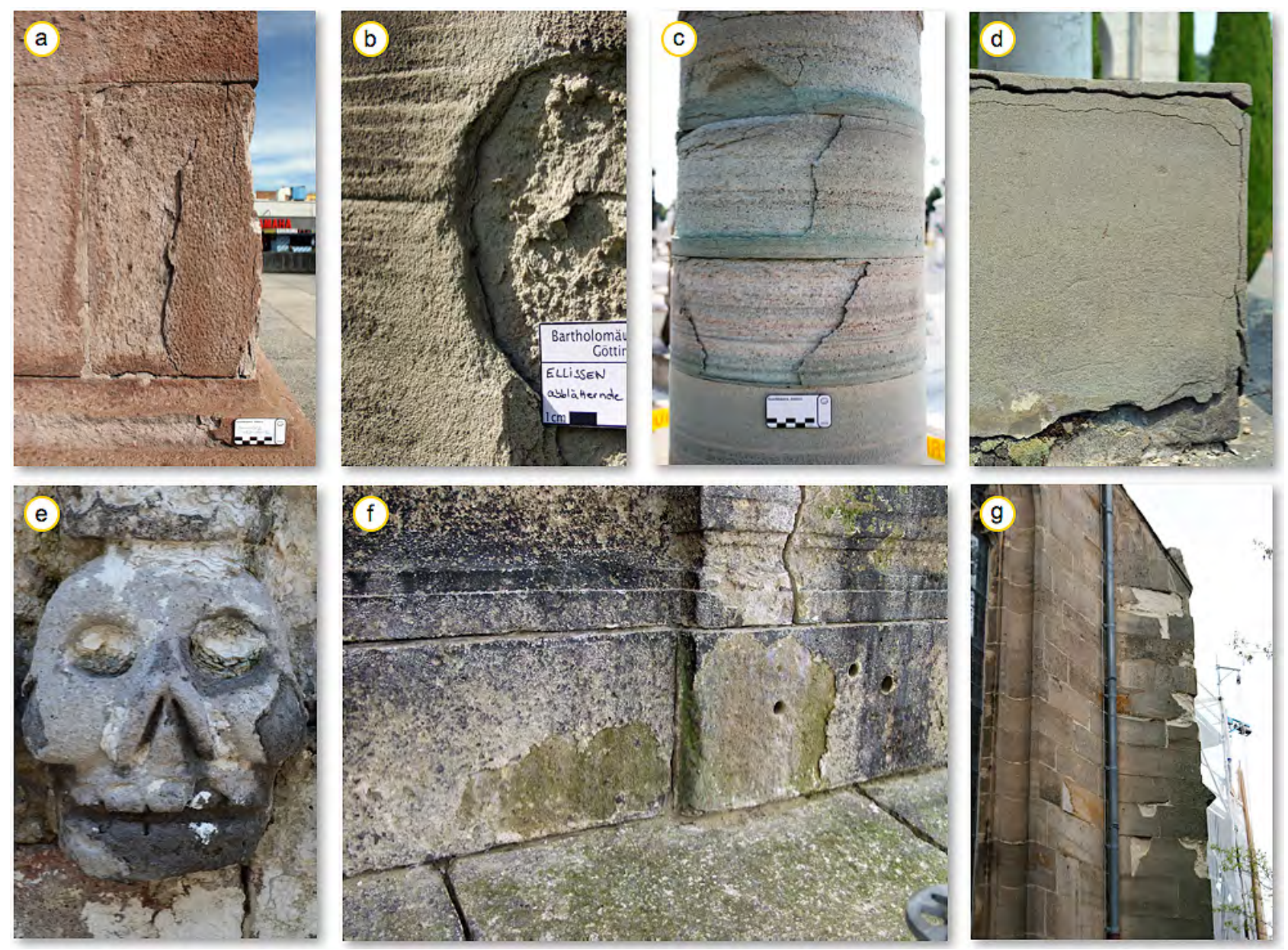

Figure 19: a) Scale formation due to gypsum accumulation at the monument of independence in Guadalajara, Mexico (tuff), and b) perpendicular to the bedding due to gypsum accumulation at a sandstone tomb in Göttingen, Germany. c) Contour scaling perpendicular to the bedding due to calcite accumulation at a tomb in Guadalajara, Mexico (tuff). d)

Massive crust formation and contour scaling at a tomb in Lugano, Switzerland (clay-rich sandstone). e) Contour scaling due to hydrophobization at the Templo Mayor in Mexico City, Mexico (tuff), and f) at the Charlottenburg Gate in Berlin, Germany (tuff) as well as g) at the Servatius Church in Duderstadt, Germany (sandstone).

According to their study, armored rock crusts on fine-grained clayey sandstone show a reduced volume and size of macropores, since these are filled with clay mineral aggregates and gypsum crystals. In another study, near-surface temperature cycling on limestone was shown to lead to stress by expansion and the implication of scales (Smith et al., 2011), probably due to the high thermal expansion coefficient of calcite.

Crust formation and contour scaling can also take place due to the input of material by conservation treatments. Crust formation could be observed due to hydrophobization and consolidation (see Fig. 19). Contour scaling often takes place combined with the accumulation of salt crystallization.

\section{4. 2 Weathering forms and case studies}

Sanding and structural flaking are discussed in chapters 3.2, 3.4 and 3.5 for sandstones and tuffstones corresponding to the Mexico City, Guadalajara and Goettingen case studies. Alveolar weathe- 
ring is discussed in the chapter outlining the sandstones of Petra and contour scaling in the chapters for sandstones and tuffs in Guadalajara and Angkor. The causes and processes that are responsible for their development and their consequences for conservation will be discussed for the Angkor case studies.

\section{5 Properties of sandstones and tuffs}

Tuffs and sandstones are formed by sedimentary processes. Pyroclastic sedimentation resulting from volcanic eruptions gives rise to tuffstones, whereas sandstones develop from the sedimentation of rock fragments generated by weathering processes. The duration of the sedimentation process however occurs under different time periods. For tuffstones the sedimentation history only needs a few weeks or months, while the sedimentation history of sandstones occurs over a time span of millions of years. The distinguishing characteristics of tuffstones are primarily compaction processes and flow structures that occur immediately after the volcanic eruption and accumulation. In contrast, the sedimentary conditions of sandstones can change considerably and are directly connected to changes in climatic and topographic conditions. These factors require the flow velocity of bodies of water and the possible influx and sedimentation of clay minerals.

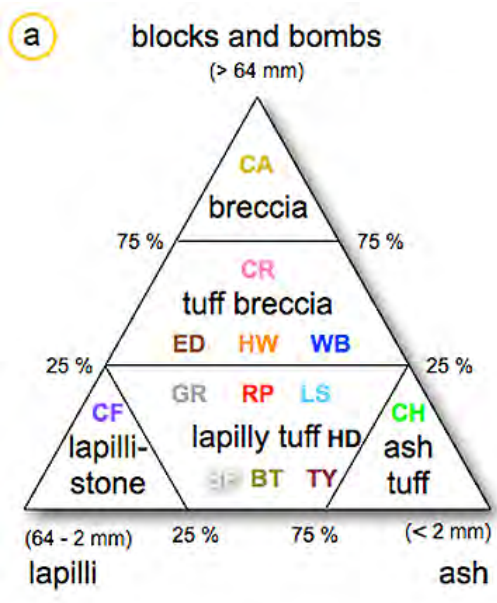

after Fisher 1966

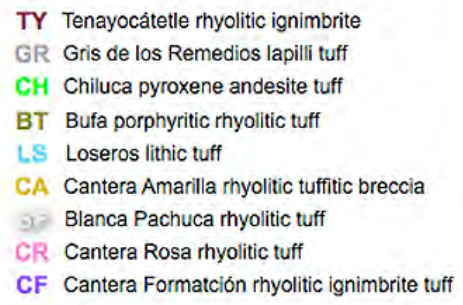

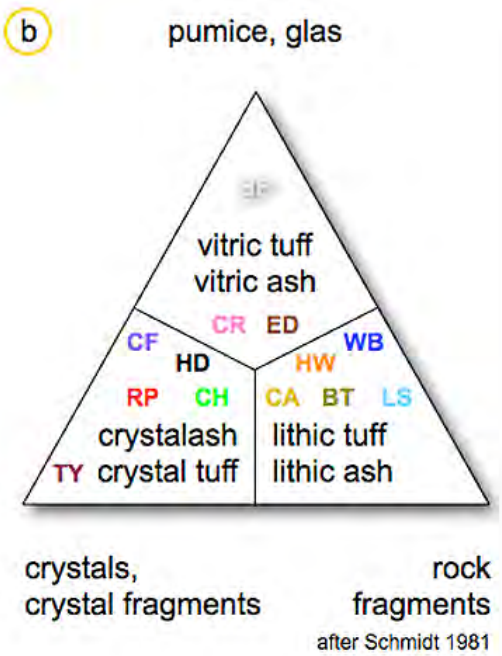

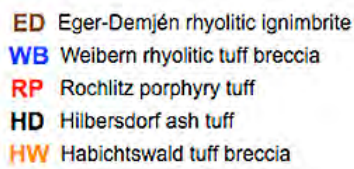

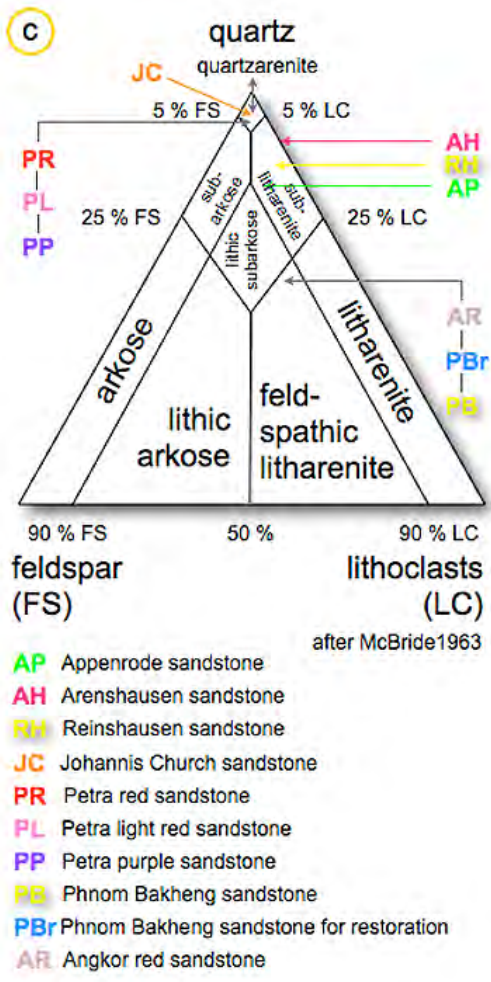

Figure 20: Different schemes for categorizing tuffs and sandstones in comparison to the types of tuffs and sandstones investigated in this thesis. a) Tuff classification based on type of material, b) tuff classification based on the size of the material and c) sandstone classification based on the composition of framework grains. 


\section{5. 1 Classification of tuffs and sandstones}

To categorize tuffs and sandstones different systems were developed. The most commonly used scheme for classifying tuffs is a system based on the grain size and type of materials or fragments present (Fig. 20 a and Fig. 20 b). McBride (1963) developed a descriptive classification for sandstones based on the composition of framework grains (Fig $20 \mathrm{c}$ ).

\section{5. 2 Structural aspects}

Anisotropies describe the structural differences of a material. These differences are caused by mineralogical and microstructural differences in the fabric of marbles (Zezza 1992; Siegesmund et al., 2000; Leiss, Weiss 2000) or in regards to sedimentary processes the differences are created by layering, bedding, flow structures or the presence of clasts (Meng et al., 1991; Wedekind et al., 2011). In this thesis a wide range of different tuff and sandstone varieties were analyzed with regard to their anisotropy. The results obtained were acquired by investigations on specimens oriented parallel and perpendicular to bedding, flow structures or different types of layering. The anisotropies of different properties related to the microstructure was used to define the predisposition to weathering.

Different physical properties are compared for both stones types, by contrasting the various structural features evident in both rock types. These properties include the porosity and bulk density, the pore radii class, capillary water absorption, hydric expansion, splitting tensile strength and the ultrasonic velocity.

\section{5. 1 Porosity and bulk density}

Porosity and density are important factors that control the properties of compressive strength and water transport. Both rock types show different but comparable properties. For example, both rock types show a comparable bulk density. Mosch (2008) statistically evaluated thousands of published values from the stone industry for various stone types. In his study he also considered sandstones and volcanites. The results from Mosch (2008) not only include different tuffstones, but also other volcanic rock types such as basalts, which as a rule have a high density and low porosity. The boxplot calculations and values determined by Mosch (2008) are used as a comparative basis for the 20 tuffstones and 20 sandstones investigated in this study (Fig. 21 b). The mean value (mean median) of the bulk density for the sandstones and volcanites varies by $2.5 \mathrm{gm} / \mathrm{cm}^{3}$ with a comparable anisotropy of around $8 \%$ for both stone types. The value of the bulk density for the tuffstones investigated in this study has an average value of $1.81 \mathrm{gm} / \mathrm{cm}^{3}$, the sandstones value is $2.25 \mathrm{gm} / \mathrm{cm}^{3}$, and thus a comparable anisotropy of $20 \%$ is attained. Furthermore, the majority of the values for the tuffstones as well as for the sandstones do not fall into the tolerance range (quantile) of the specified stone industry values. In the case of the tuffstones only seven attain a value that is located in the 
quantile and in the sandstones it is only one variety.
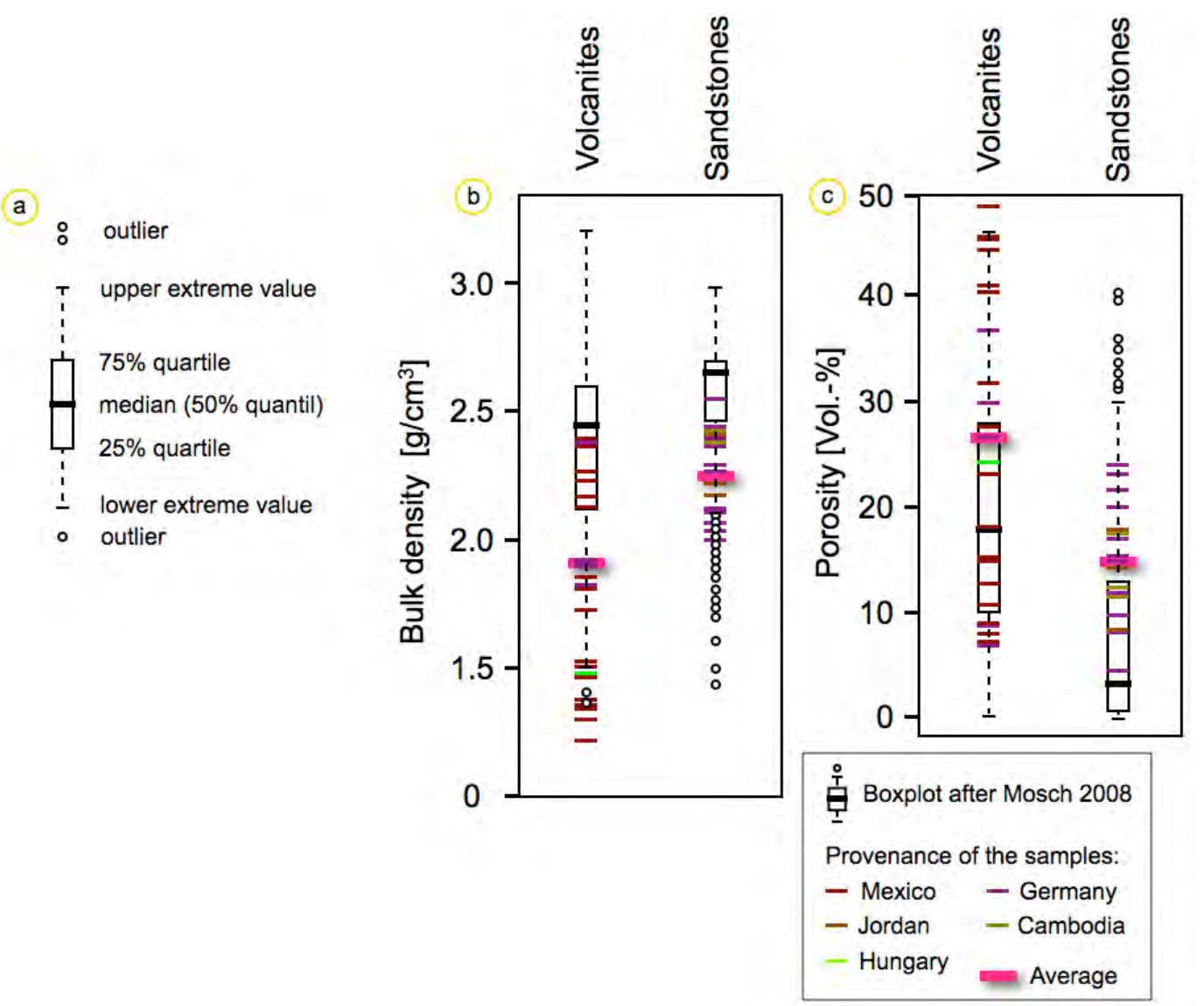

Figure 21: a) Legend, b) bulk density and c) porosity of volcanites and sandstones after Mosch (2008) completed with the values of the samples investigated in this study.

Similar holds true for the porosity of both rock types. According to Mosch (2008), the porosity attains on average a value less than $5 \%$ for sandstones and around $18 \%$ for volcanites (Fig. $21 \mathrm{c}$ ). The investigated stones in this study also show considerable variation. For the tuffs the average porosity is $27 \%$ and for the sandstones $15 \%$. Both values lie significantly above those known in the stone industry, whereby the median of the investigated tuffstones are located in the upper quarter of the specified quantile given in Mosch (2008).

\section{5. 2 Pore radii classes}

Pore radii distribution is divided into five different classes. The two classes with the smallest pores are defined as microporosity (Fig. 22 a). Water transport in this pore class takes place by vapor. The class with the smallest pores ranges from $0.001-0.01 \mu \mathrm{m}$ and the second smallest one from 0.01 $0.1 \mu \mathrm{m}$. The three classes with the larger pores consist of capillary pores. They have pores ranging $0.1 \leq 10 \mu \mathrm{m}$ (Fig. $21 \mathrm{a})$. 
A statistical evaluation of the pore classes of all sandstones and tuffstones investigated in this study shows the differences of the two types of stone according to their pore radii distribution (Fig. 22). Sandstone shows a unimodal pore radii distribution dominated by capillary pores, whereas volcanites exhibit a bimodal pore system (Fig. 22 a). The largest anisotropy in the pore classes are found in the pores $>10 \mu \mathrm{m}$ with more than $60 \%$ (Fig. $22 \mathrm{~b}$ ). The lowest anisotropy occurs in the next smaller pore size class ranging between $1 \mu \mathrm{m}$ and $10 \mu \mathrm{m}$ with $17 \%$. The anisotropy related to the micropores is around $40 \%$ (Fig. 22 b).
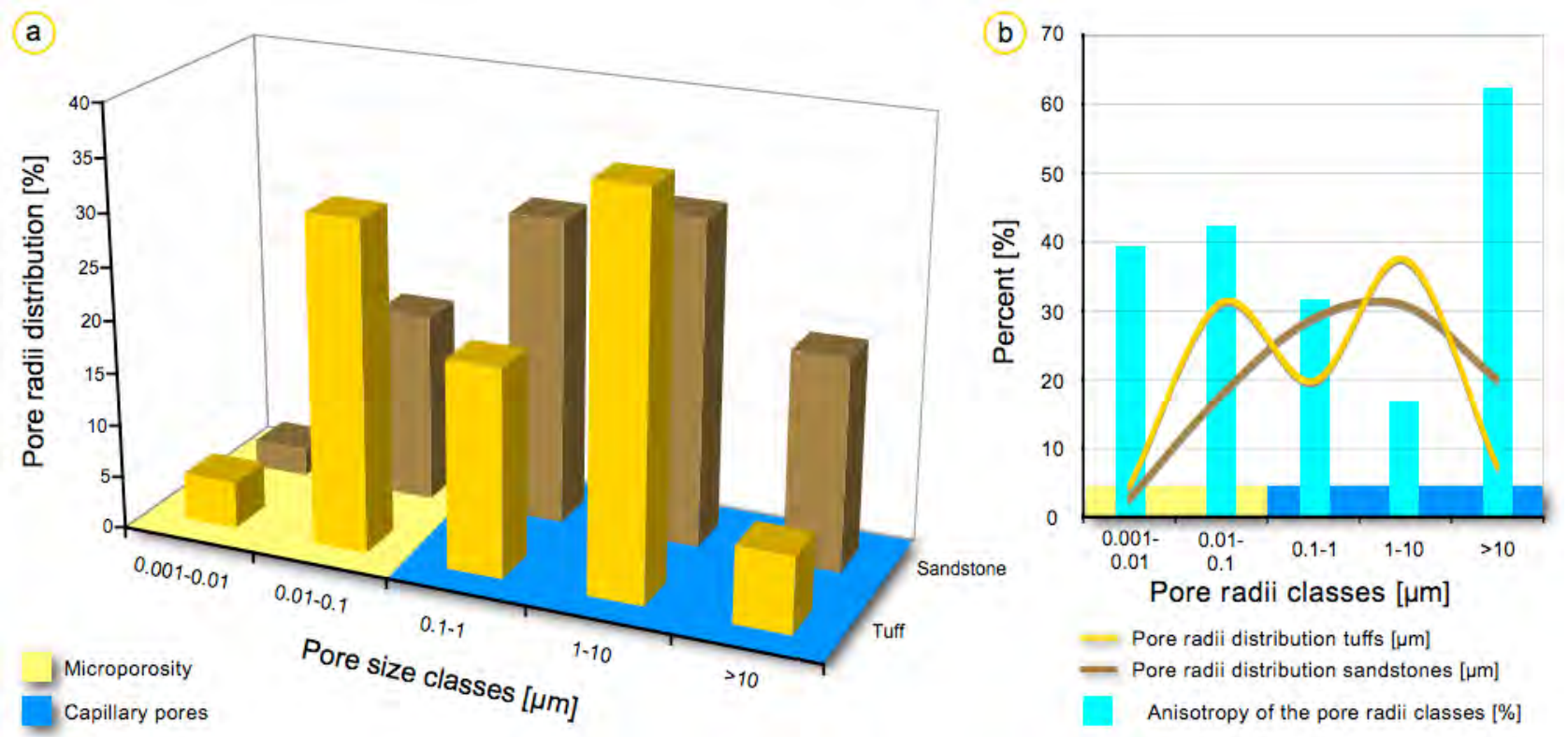

Figure 22: a) The pore size classes of the sandstones and tuffs investigated in this study. B) The anisotropy of the single classes comparing sandstones and tuffs.

\section{5. 3 Capillary water absorption}

A value that is closely linked with the porosity is the water uptake coefficient, which also describes the structural character of a rock. This value is calculated by the amount of water in liters that a stone can absorb by capillary uptake during a specific amount of time (see also capillary water uptake, section 3.2.1) On average the tuffs in this investigation are able to absorb $4.6 \mathrm{~kg} / \mathrm{m}^{3}$ of water within one hour. The sandstones with $6.3 \mathrm{~kg} / \mathrm{m}^{3}$ absorb much more (Fig. $23 \mathrm{a}$ ).

The anisotropy of the water uptake in dependence of the different directions describes the effect of a possible layering or other structural features. The average anisotropy of the water uptake coefficient is $30 \%$ for the investigated tuffs, whereas the sandstones only reach a value of $18 \%$ and is thus lower by almost a half. Even the spread of the measured values differs considerably. In the case of the tuffstones the anisotropies can attain a value of $98 \%$, whereas the highest anisotropy in the sandstones only reaches $40 \%$ (Fig. 23 b). To summarize, tuffstones show considerable structural differences with respect to the water uptake. These are indicated by a factor of $40 \%$ in comparison to sandstones. 

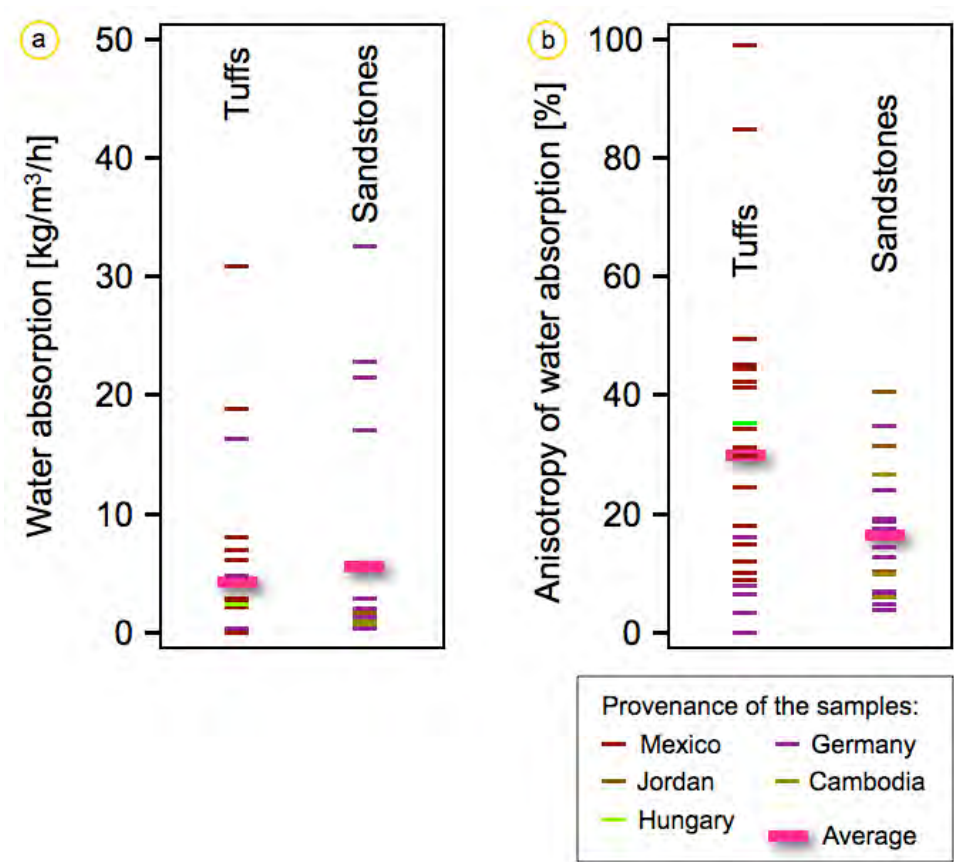

Figure 23: a) Water absorption in the sandstones and tuffs and b) anisotropy of water absorption in the tuffs and sandstones.

\section{5. 4 Hygric expansion}

Deterioration on buildings is often concentrated in areas affected by temporary moisture infiltration and leads to different damage phenomena (see Fig. $17 \mathrm{a}$, d, e and $18 \mathrm{c}$ and d)). Moisture expansion is clearly recognized as one of the most important factors contributing to the weathering and deterioration of building stones (Ruedrich et al., 2011 (a); Weiss et al., 2004), and this is mostly associated with the swelling and shrinking of clay minerals (Schuh 1987; De la Calle, Suquet 1988; Snethlage et al., 1995; Jimenez Gonzalez, Scherer 2004; Dixon, Weed 1989; Moore and Reynolds 1997; Graf v. Reichenbach, Beyer 1995). The intensity of moisture expansion varies markedly depending on the type of stone and can have a significant anisotropy in regards to the bedding. In general, volcanic stones, and primarily tuffs, have a wide range of moisture expansion, which, as measured in this study, can reach a dilatation of up to $6 \mathrm{~mm} / \mathrm{m}$ (Fig. 24).

Besides clay minerals the disjoining pressure can lead to moisture expansion, especially if the rock material contains a pore space dominated by micropores. The disjoining pressure $\left(\Pi_{d}\right)$ arises from an interaction between two flat and parallel surfaces. The value of the disjoining pressure can be calculated as the derivative of the Gibbs energy of interaction per unit area with respect to distance. This energy, also known as free energy, is defined as a thermodynamic potential that measures the process-initiating work obtainable from a thermodynamic system at a constant temperature and pressure (Greiner et al., 1995). The disjoining pressure will be affected when the distance between them is less than two times the thickness of adsorbed moisture on a free surface, where the force 
needed to keep the forced distance is determined by the so-called "disjoining pressure equation" (Nielsen 1994).

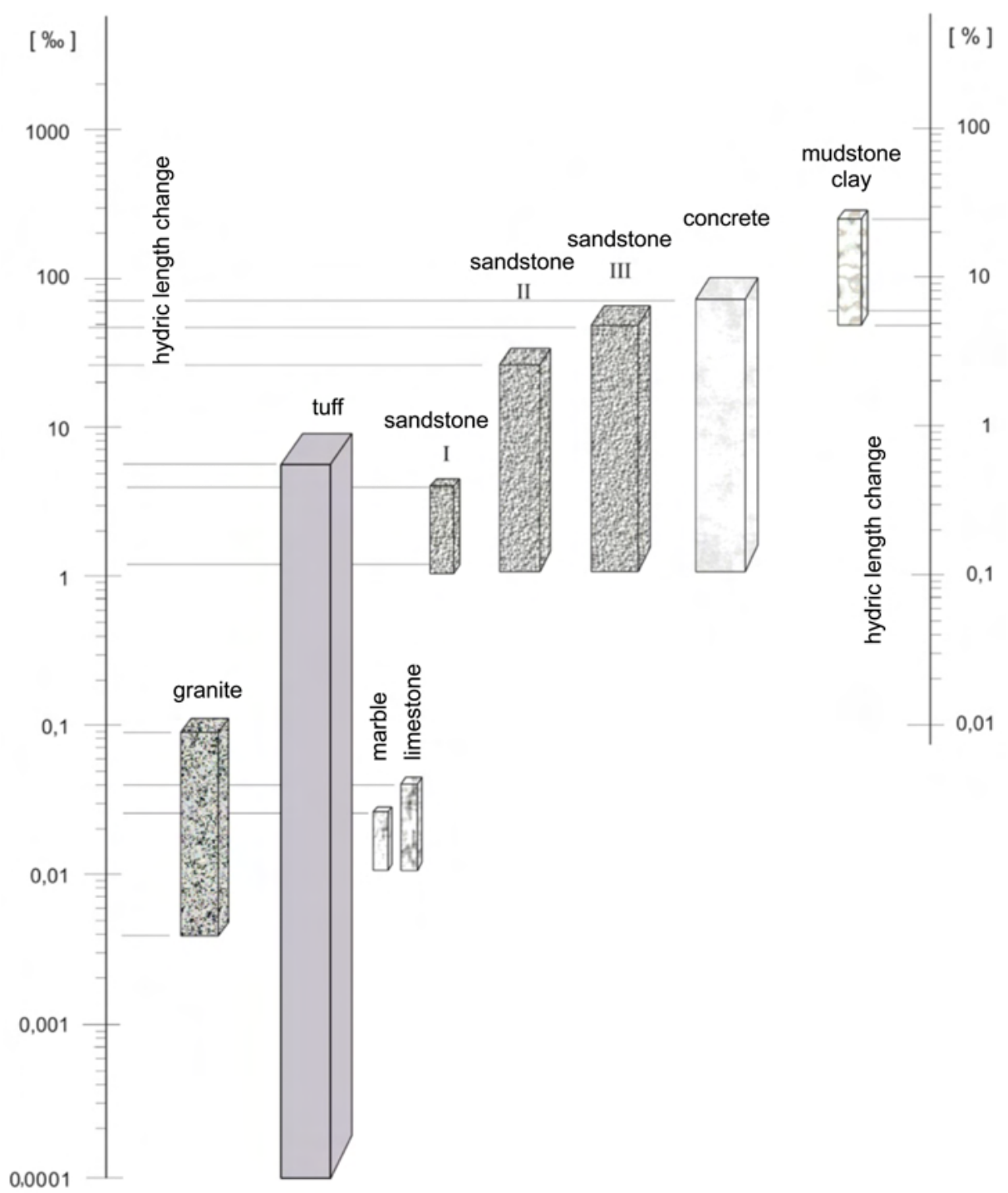

Figure 24: Swelling and moisture expansion of building stones (data from different authors and from this study). Modified from Kocher (2005): Granite, marble und sandstone I from Hockmann and Kessler (1950), from Snethlage (1984), limestone from Lukas (1990), sandstones II from Schuh (1987), sandstones III from Snethlage and Wendler (1997), concretes from Wesche (1977), mudstones from Madson (1976) and Madson and Nueesch (1990).

Ruedrich et al., (2011 a) presented a detailed overview of the different types and causes of moisture expansion. Whatever the cause of the moisture expansion may be, the water uptake and distribution into the rock is the principal mechanism allowing water (moisture and humidity) to interact with the clay minerals present and is only realizable through the porosity. The porosity, therefore, is one of the most important parameters that must be known and determined. 

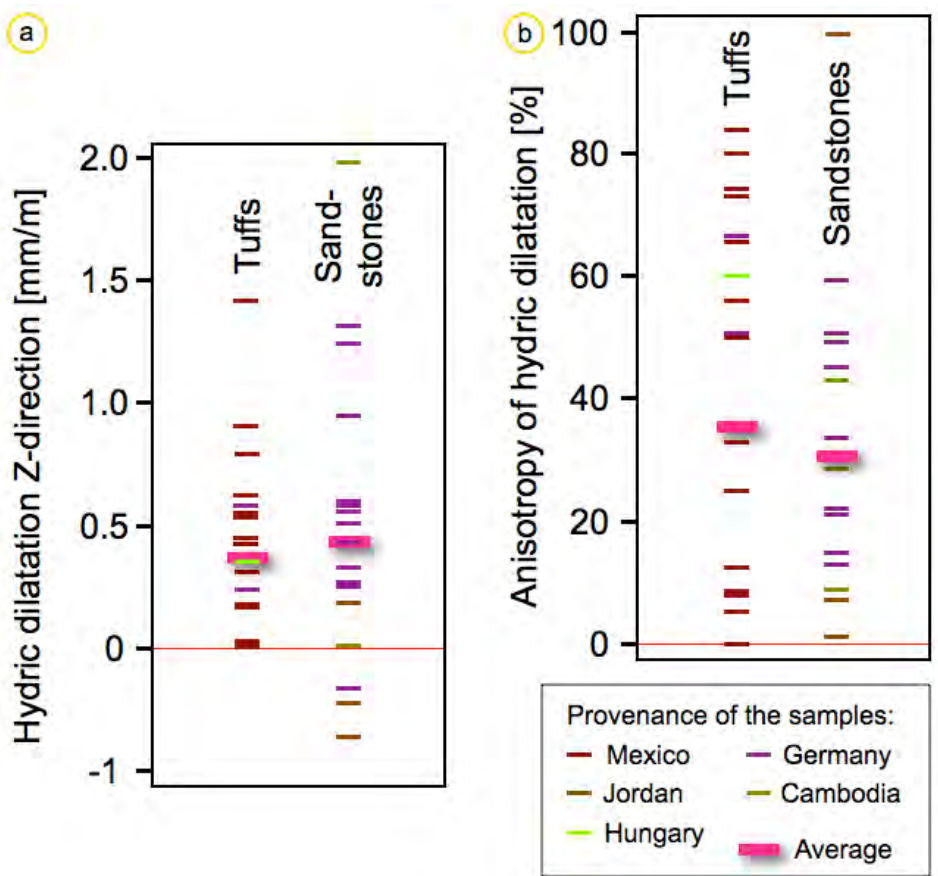

Figure 25: a) Hydric dilatation in the Z-direction of the tuffs and sandstones and b) the anisotropy of hydric dilatation of both rock types.

The tuffs and sandstones investigated in this study show different values of hydric dilatation. Moisture dilatation in the Z-direction of the different sandstones can show very high expansion but even shrinking by reaching an average value of $0.48 \mathrm{~mm} / \mathrm{m}$ (Fig. 25 a). By eliminating the extreme values the average value of $0.56 \mathrm{~mm} / \mathrm{m}$ becomes higher. Comparably the hydric expansion of all tuff samples is smaller and only attains a value of $0.37 \mathrm{~mm} / \mathrm{m}$ (Fig. $25 \mathrm{a}$ ). In the case of the anisotropy the opposite relation can be seen. The directional dependence of the anisotropy in the sandstones attains a value of $34 \%$ and $38 \%$ for the tuffs. The spread of the values for the tuffs is much larger than for the sandstones (Fig. 25 b). By eliminating the extreme value in the case of the sandstones, the anisotropy only reaches a value of $30 \%$.

\section{5. 5 Splitting tensile strength}

Splitting tensile strength tests are done on slices of drill core material. To understand weathering processes as well as conservation treatments in relation to the bedding, the splitting tensile strength can give more information in general than the compressive strength tests because less strength is needed to split the sample. The strength and anisotropies according to textual properties like the bedding is sometimes small as well as the increase of strength due to consolidation. Therefore a smaller force to the sample can give a clearer result.

Sandstone samples show a significant directional dependence of the tensile strength to the loading direction (Siegesmund, Duerrast 2011). The same situation was determined for the tuffstones in this study. To perform the test under water-saturated conditions, information about the presence and 
bedding of clay minerals can be determined because this leads to a decrease in the strength.
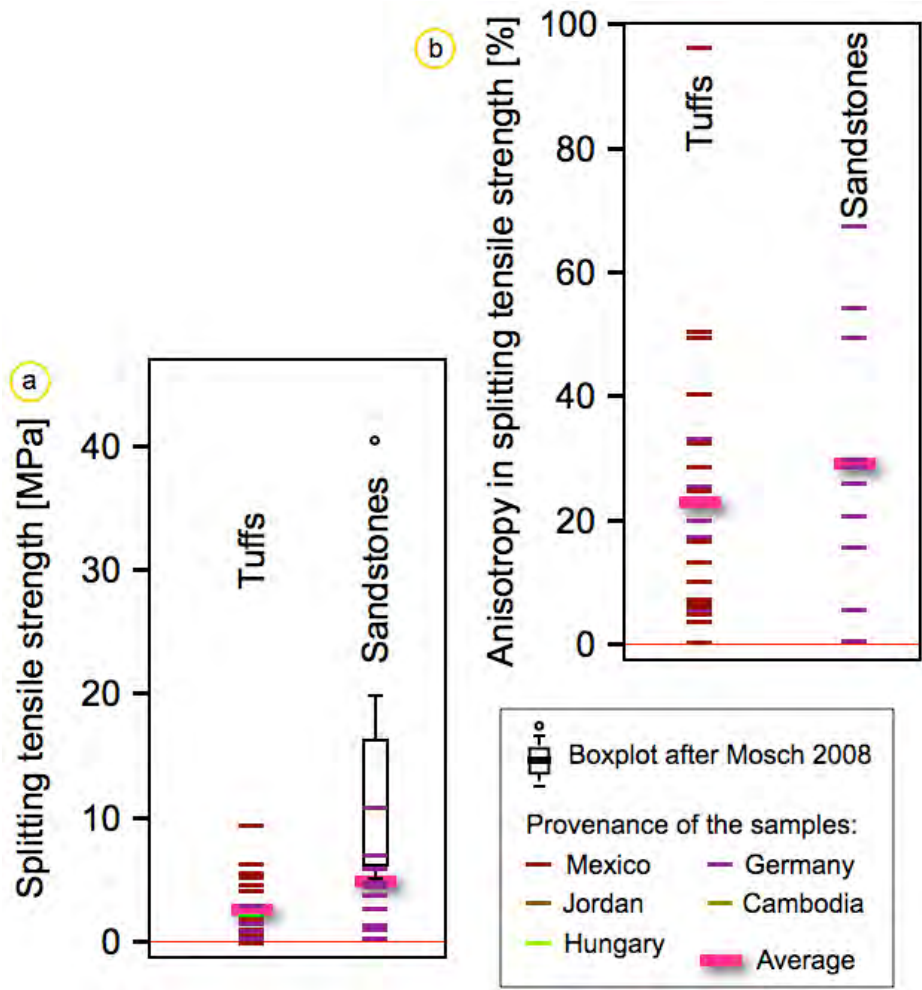

Figure 26: a) Splitting tensile strength of the tuffs and sandstones and b) anisotropy in splitting tensile strength.

The other reason why splitting tensile strength tests should be preferred is that less material is required to obtain significant results. Therefore, the intervention on historical materials studied can be limited.

The tuffs measured in this thesis reach an average value of $3.43 \mathrm{MPa}$, whereas the sandstones show a greater strength with around $5 \mathrm{MPa}$ (Fig 26 a). The anisotropic behavior of the directional dependence of splitting tensile strength of the sandstone is $23 \%$ (Fig. 26 b). By ignoring the outliers the value is only $19 \%$. In contrast the tuffs have an average value of $29 \%$, ten percent more than the sandstones (Fig. 26 b).

\section{5. 6 Ultrasonic velocity}

Ultrasonic velocity measurements are an important non-destructive tool for the evaluation of structural damage on historical architectural elements and artwork created from stone (Siegesmund, Duerrast 2011). The P-wave velocity ( $\mathrm{Vp}$ ) is determined by a transducer and measured by a receiver. The ultrasonic velocity (V) is calculated with respect to the distance between transducer and receiver, respectively. The material thickness is determined by an ultrasonic testing machine. The V-value is given in units of distance over time $(\mathrm{km} / \mathrm{sec})$. 


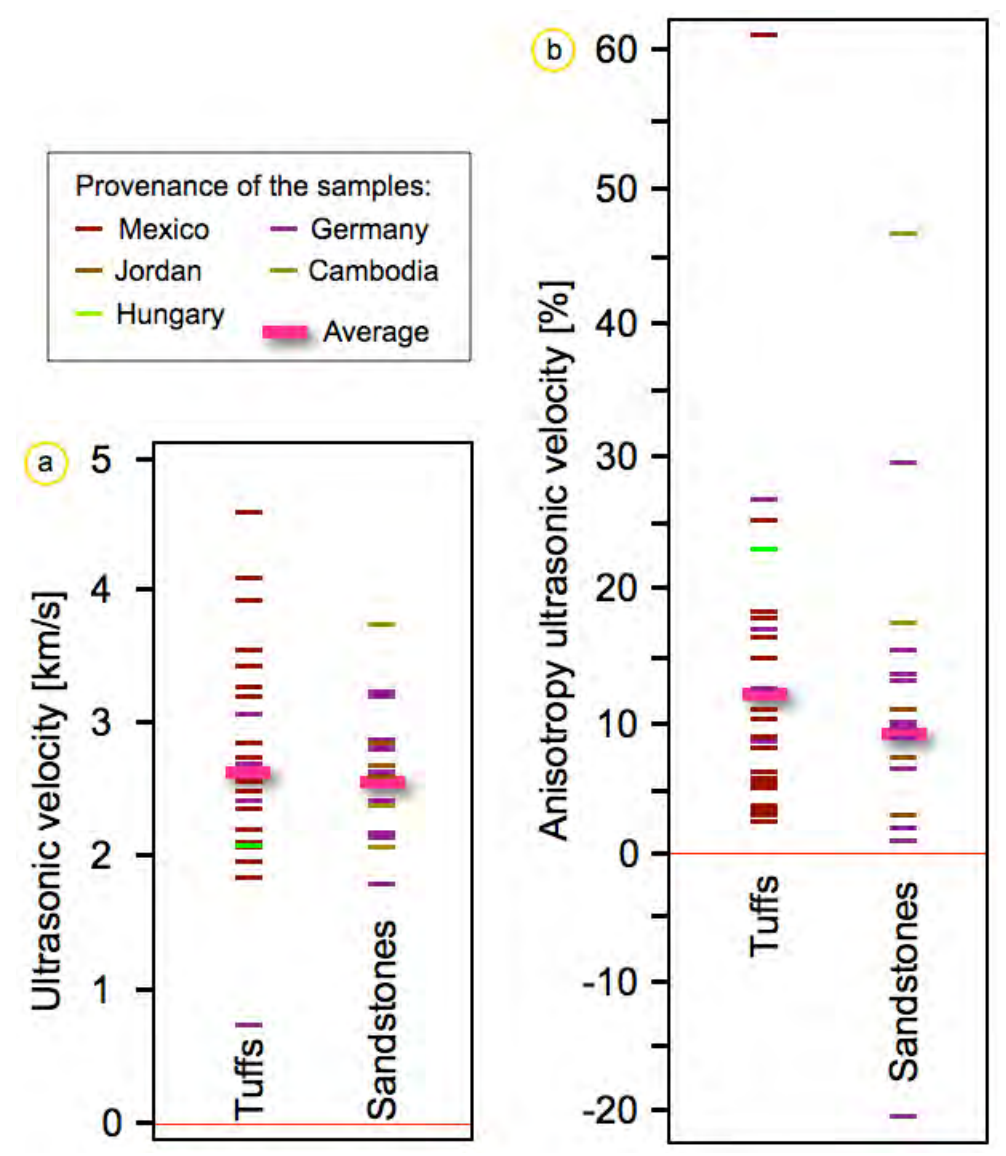

Figure 27: a) Ultrasonic velocity of the tuffs and sandstones and b) their anisotropy.

The average values for the tuffs and sandstones seem to be quite similar. The tuffs attain a velocity of $2.72 \mathrm{~km} / \mathrm{sec}$ and the sandstones a value of $2.68 \mathrm{~km} / \mathrm{sec}$ (Fig. $27 \mathrm{a}$ ). The anisotropic behavior of the directional dependence of the sandstone is $9.73 \%$ (Fig. 27 b) and without the outliers $7.78 \%$. In the tuffs the anisotropy reaches a value of $12.78 \%$ (Fig. $27 \mathrm{~b}$ ) and without the outliers $10.94 \%$.

A clear correlation in the increase of porosity due to fabric damages is evident. Furthermore there is a correlation to salt resistance, probably controlled by the density and strength of the rock (see section 1.5.7).

\section{5. 7 Salt resistance}

Crystallization tests on stone samples for determining salt resistance is a common method. In this test a sample is soaked in a salt solution and afterwards dried in an oven. The index used to characterize salt resistance in this study is the number of cycles until a $30 \%$ material loss has taken place.

The tuffs show a wide range of resistance against salt bursting with an average of 24 cycles until a $30 \%$ material loss is reached (Fig. 28 a). One half of the tuffs show a low salt resistance with 5 to 20 cycles. Other samples with 20 to nearly 70 cycles show a high resistance to salt bursting. The investigated sandstones have a lower salt resistance with an average value of 19 cycles until a $30 \%$ material loss is attained (Fig. 28 b). Similar to the tuffs the sandstones show two groups: a larger 
group that is markedly below 20 cycles and a smaller one that shows resistance up to 44 cycles (Fig. 28 a).

Salt resistance in general is related to the presence of a special pore size distribution (Benavante 2011). Stone material with a high amount of micropores is classified as less resistant towards salt crystallization (Wellmann, Willson 1965; Siegesmund et al., 2010). On average the investigated tuffs attain a value of $38 \%$ microporosity, the sandstones $22 \%$ (Fig. 28 b). Most sandstones only show a microporosity of less than $10 \%$, whereas the spread of the values in the case of the tuffs is highly diversified (Fig. 28 b).

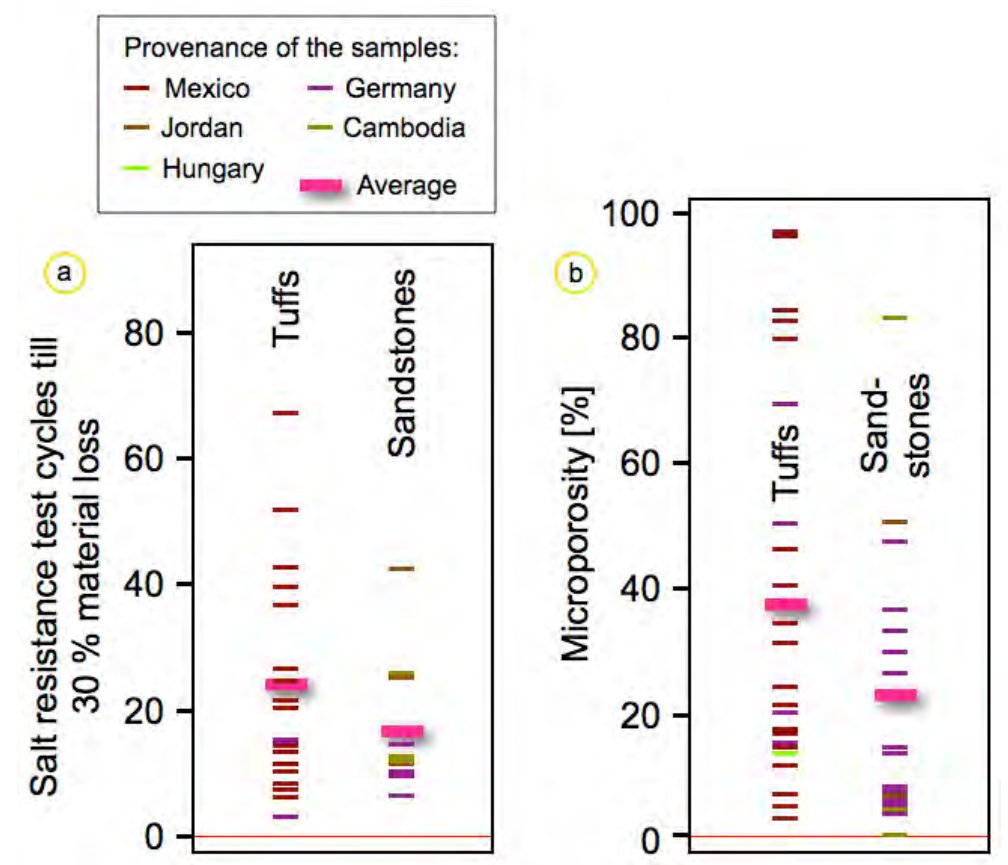

Figure 28: a) Salt resistance in the tuffs and sandstones and b) the microporosity.

\section{6 Stone conservation}

\section{6. 1 History of stone conservation}

Scientific studies in stone conservation of monuments in outdoor environments have a relatively recent history. It began with observations on the impact of the industrial revolution on stone buildings and monuments.

The restoration of sculptures from stone has a longer history and reaches back into early antiquity. A peak was reached in the 19th century parallel to the formation of the big museums and sculpture collections (Gossmann et al., 2003) as illustrated in Figure 29. This continued in the master classes for painting and sculpture in several schools for art and crafts like the one in Vienna (Krack 2012). 


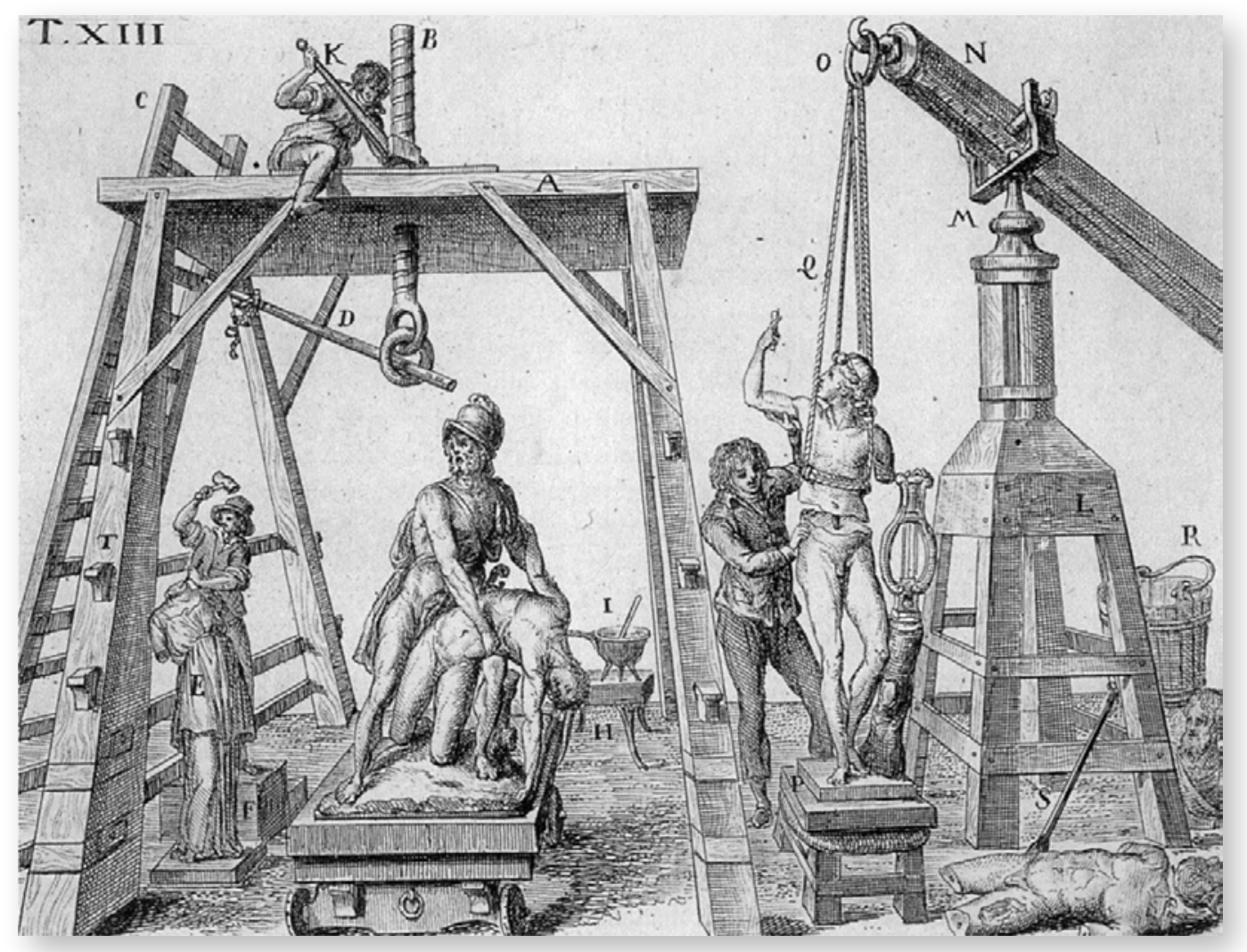

Figure 29: Restorers of ancient sculptures at work (source: Carradori 1802).

Hirschwald and Rathgen authored the first paper in Germany in 1908 on rock weathering and the preservation of artifacts from antiquity, which reflected the state of research at the turn of the century (Weber 1990). In Germany this has remained as the central topic and field of responsibility for state commissions as well as established agencies that deal with the protection of cultural monuments. One of these commissions applied sample areas on stone structures and conducted weathering experiments on the preserved stones. The results of these experiments were published in 1934 by Rathgen and his colleague Koch in a paper summarizing their research on weathering and the preservation of natural stone materials (Rathgen, Koch 1934).

\section{6. 2 Stone Conservation Science}

The birth of stone conservation science occurred in the 1960's through the research of Wieslaw Domaslowski at the Copernicus University in Thorn, Poland (Fig. 30 middle). For about 20 years stone conservation as an applied science and art is now taught as an individual course of study in some technical colleges and universities in Germany. Domaslowski has advised some German degree programs (e.g. Cologne) and graduates from the Polish major were and are now professors (e.g. Cologne and Hildesheim). According to the Hornemann Institute around 300 theses related to stone conservation were completed at German universities since 1990. Unfortunately only a few of them were published (less then 1\%). These scientific conservation studies from practical working conservators are thus nearly inaccessible to the scientific community. 
After the Second World War a larger research project funded by the Volkswagen Foundation (1979 1983) and the BMFT Project (Bundesministerium für Forschung und Technik) laid the essential groundwork for stone conservation in Germany. The project was directed by Rolf Snethlage in the 1980's (Fig. 30 b).
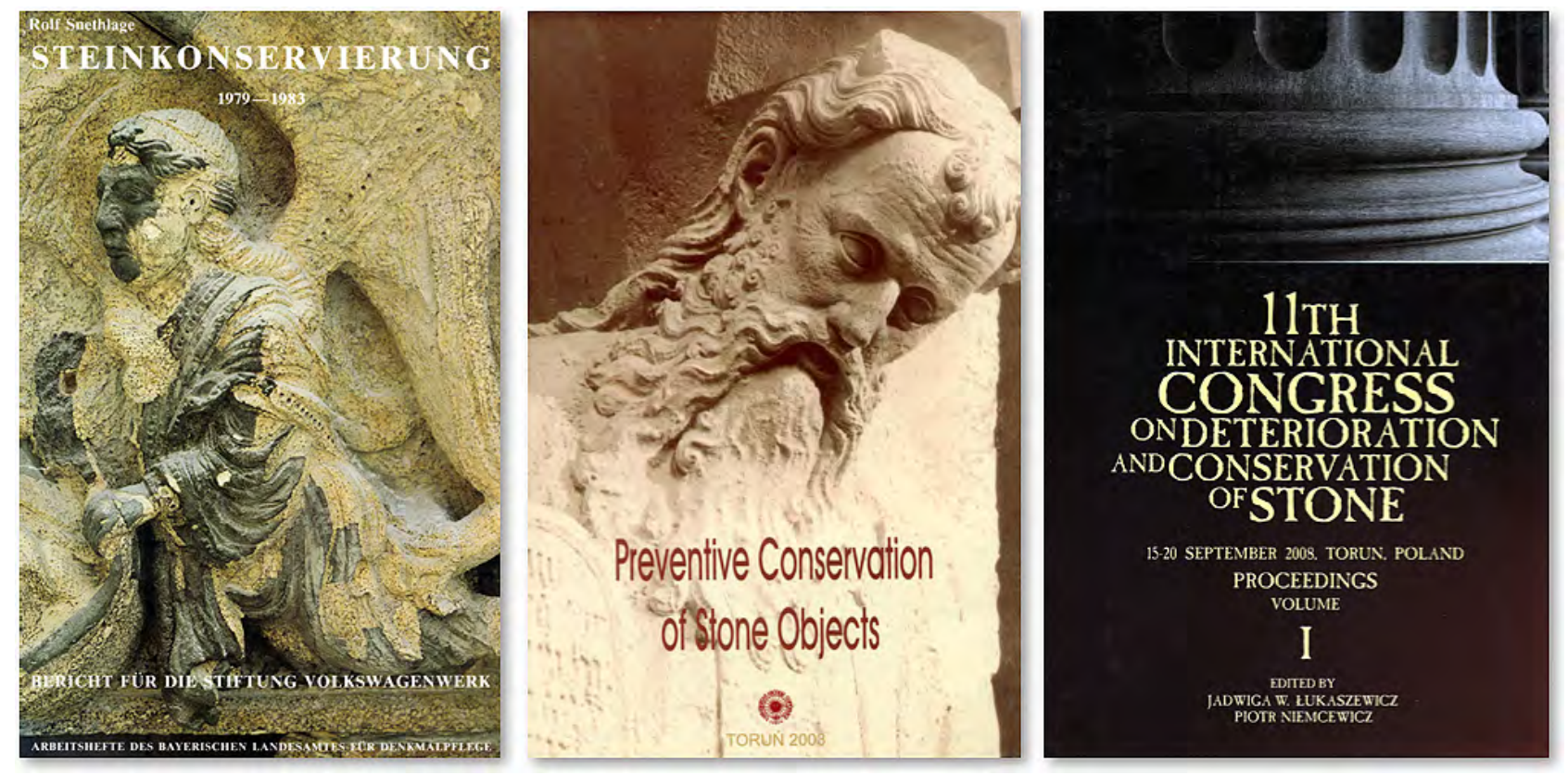

Figure 30: Left the cover of the publication of the research project of the Volkswagen Foundation. In the middle a book by Wieslaw Domaslowski (2003) and to the right the last printed proceedings of the stone conference (2008).

In 1961, the UNESCO continued their mission for conservation in Spain, which had been suffering under dictatorship and isolation, by appointing Paul Coremans, an outstanding scientist and conservator (Laborde-Marqueze 2013).

During the last 10 years further degree programs have been established in Spain, Ireland, England, Italy, Switzerland, Japan, China, South-Korea, Turkey and in the United States. In many parts of the world no separate degree programs in stone conservation exist, even though monuments built from stone are widespread throughout the world. This is the reason why the ICCROM (International Centre for the Study of Preservation and Restoration of Cultural Property) has established a course program in stone conservation that takes place every 2 years. The course was held 2015 for the $19^{\text {th }}$ time.

\section{6. 3 Research studies in stone conservation}

The most important forum for scientific stone conservation is „The International Congress on the Deterioration and Conservation of Stone" (Fig. 30 right image). The first congress was held in La Rochelle in 1972, and then Athens (1976), Venice (1979 and 2000), Louisville (1982), Lausanne (1985), Torun (1988 and 2008), Lisbon (1992), Berlin (1996), Stockholm (2004) and New York in 
2012. In the early years it was held triennially, but since 1988 the conference takes place every four years. Since no relevant international journal for heritage conservation has been established after the end of the ICOMOS-Journal „Monumentum“ in 1984, the conference proceedings have become the standard form documenting the innovations and developments in the field of stone conservation science.

The fundamentals of rock weathering and stone conservation are now researched worldwide at numerous universities. Moreover, the most important German research group is at the University of Goettingen under the direction of Siegfried Siegesmund, which has been investigating stone conservation for about 15 years.

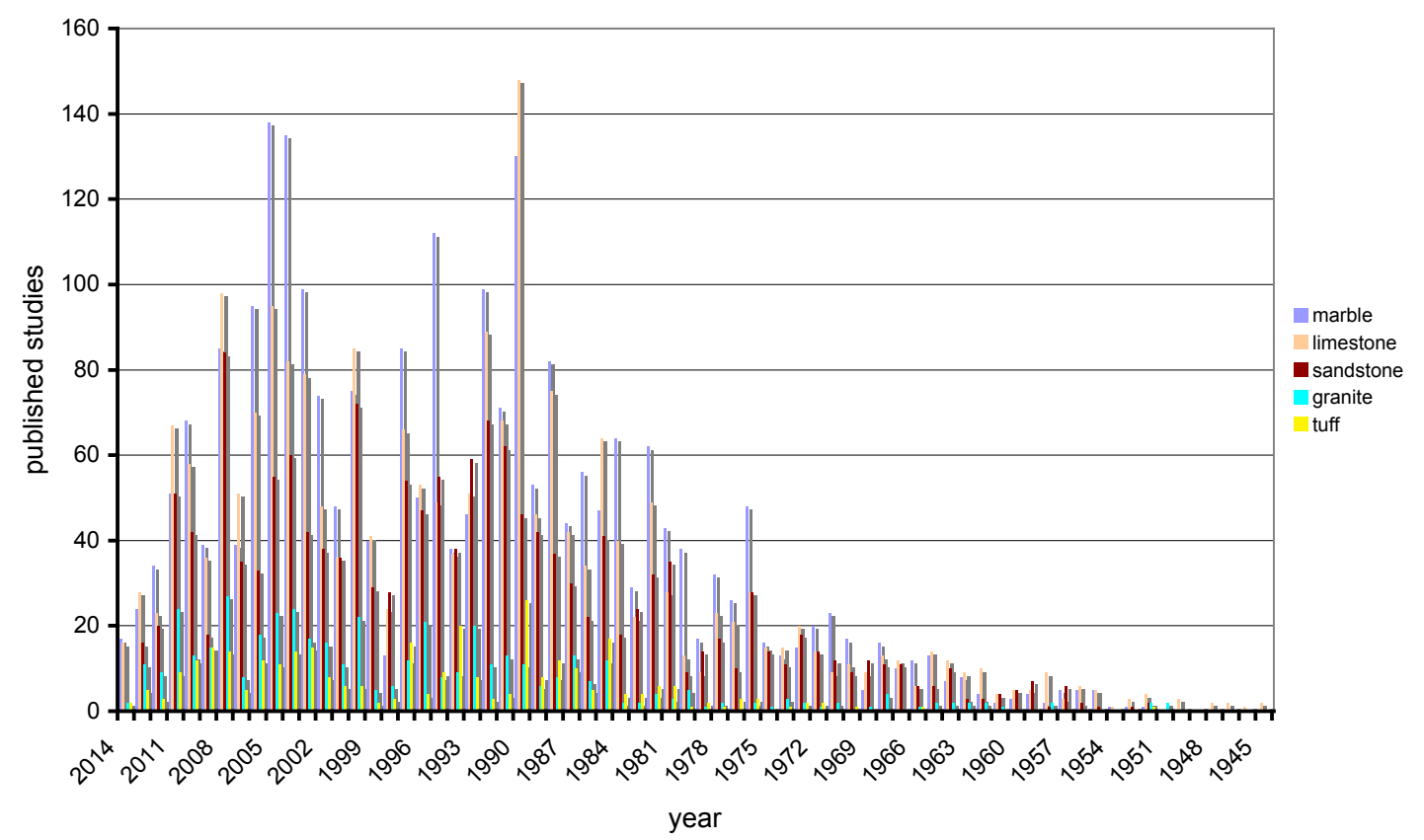

Figure 31: Published papers on scientific stone conservation within the AATA-Getty database related to different stone types from 1945 till 2014.

The high numbers of papers within conservation science have been written on marble, limestone and sandstone. According to the AATA Online (Abstracts of International Conservation Literature), 2616 papers deal with marble, 2260 with limestone, 1619 with sandstone, 458 with granites and only 330 with tuffs (Fig. 31).

By taking into account all the listed papers beginning from the end of World War II until today, it becomes clear that in the case of marble there is a continuous increase of published studies reaching their peak in 2005 (Fig. 31). One can assume that there is a lack of studies concerning tuffs and other volcanites and still an imbalance of studies on sandstones. Therefore, this thesis will focus on the deterioration and weathering of tuffs and volcanites as well as sandstones. 


\section{6. 4 Scientific stone conservation in academic restoration}

The service profile of academic restoration work encompasses a wide spectrum of different operations and qualifications. This covers the entire range from investigation to planning, the conceptual and material development and the implementation of the conservation measures and restoration on the object and monument.

A successful restoration requires the training of a multi-disciplinary expertise from different disciplines such as art history, the natural sciences that also includes technical engineers and even craftsmen trained in specific art technical skills. The necessary prerequisites for practical restoration are the training of artistic and craftsmen-like skills based on the natural sciences as well as a tactile knowledge of the material properties.

As an academic conservator in the field of monument conservation, construction skills are also acquired that are continually being developed by scientific pursuits, which deal with the different problems faced when analyzing respective objects and monuments. Life-long learning is required in this discipline so that the best of one's knowledge can be passed on by the development of values, which future generations can also perceive and appreciate.

\section{7 Strategies for sustainable conservation}

Sustainable conservation strategies place emphasis on the need for required remedial action. Damages that pose a danger for the structure or monument need to be repaired and further deterioration needs to be prevented by suitable measures in the future. Understanding the main deterioration factors and the weathering processes involved is of great importance.

Deterioration factors are dealt with by measures applied in preventive conservation that influence and control the environmental conditions. Damages are repaired by active conservation treatments on the object.

\section{7. 1 Preventive conservation}

The environmental conditions control the extrinsic stress factors, for example heat, moisture and the contamination through salts. However, earthquakes, acts of war and even vandalism are existential threats for humanity's cultural heritage. The decisive aspect is to identify those factors which represent the actual threats.

The determination of the main deterioration factors is part of the planning phase for conservation measures, which includes comparative observations and quantitative mapping in regards to topography and hydrology. Moreover, this also takes into consideration the main wind and rain direction and the climate and micro-climate. Measures implemented in preventive conservation can decisive- 
ly aid in reducing the dynamics of weathering and alleviate the systematic destruction of cultural monuments.

Practical procedures for preventive conservation are associated with simplified and regular maintenance measures and in a society that considers their cultural heritage sites with high value, expensive architectural measures may need to be implemented. These can take the form of protective roof coverings, shelters, the construction of drainage systems or the repair of damaged protective structures. The prerequisite for determining the damage factors is a systematic acquisition of the condition of the monument with respect to a conservation inventory (Wedekind et al., $2011 \mathrm{~b}$ ).
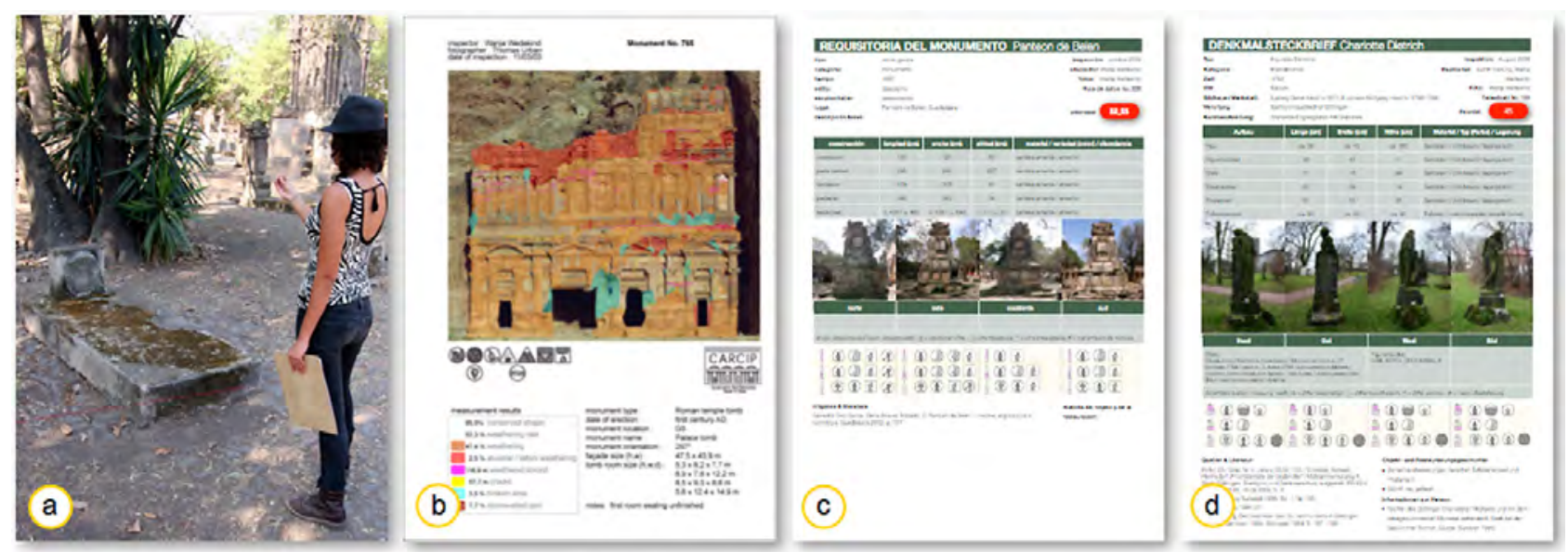

Figure 32: Conservation inventory. a) Practical mapping and quantification of a tomb at the Panteón de Belén-cemetery in Guadalajara, Mexico. b) Data sheet of the palace tomb in Petra, Jordan, c) data sheet of a monumental tomb at the Belem-cemetery and d) data sheet of a sculptural tomb at the Bartholomew-cemetery in Goettingen, Germany.

\section{7. 1. a) Conservation inventory}

Because of the sheer number of objects and the limited funds dedicated to preservation, questions have to be asked, regarding priorities and what can be realistically achieved. The main task of a conservation inventory is to assess the degree of deterioration and to offer recommendations for a conservation strategy.

In general, a conservation inventory can embrace many scientific fields and questions. The range of data acquired during systematic investigations can be used for different purposes, for example, in the study of art and cultural history, the usage of materials and the identification of weathering processes.

Historical monuments frequently provide sites of study for geologists, geomorphologists and conservators. The focus of their work is the observation, measurement and statistical evaluation of various weathering phenomena. The need to document cultural heritage and historic areas worldwide was first highlighted by the United Nations Education, Scientific and Cultural Organization, 
UNESCO (UNESCO 1976). Following in their footsteps, the German National Commission for Heritage Conservation provided further recommendations on this topic (Deutsches Nationalkomitee 1982), and the International Commission on Monuments and Sites, ICOMOS, adopted guidelines for the recording of monuments (ICOMOS 1996). Based on these general guidelines a documentation system was developed which attempts to collate all the relevant information on the investigated objects, in the case of the present study (Petra, Jordan and the Bartholomew Cemetery in Goettingen, Germany). The conservation inventory used includes the name of the monument and in the case of a tomb the name of the buried person, together with details on the type of monument, date of erection, current or historical inventory numbers, artist, sculptor or builder, location and a short inscription (Fig. 32 b-c). The date of inspection and the people in charge are also documented. All the details concerning the dimensions of architectural building parts, the type of materials, varieties and their manufacture are tabulated. Centered photos of the object are inserted corresponding to the date of erection of the monument. Below these photos information is provided on all inscriptions, including details of the font, font style, damaged or missing characters and extended words as well as their sources. Key information for future planning is given by the evaluation of the state of preservation by the observation and quantification of different weathering forms (Fig. 32 a).

\section{7. 2 Active conservation}

Active conservation deals with different treatments on the object. These can be divided into three main treatments: cleaning, desalination and consolidation.

\section{7. 2. a) Cleaning}

The cleaning of the material surface is in most cases clearly observable by the optical effects of the restoration. During the restoration and cleaning of the object or monument, it is important to be able to differentiate between dirt-covered damaged surfaces and the surfaces worth preserving (i.e. the patina or the traces of early human activity) first, without damaging the original substance when removing the weathered material.
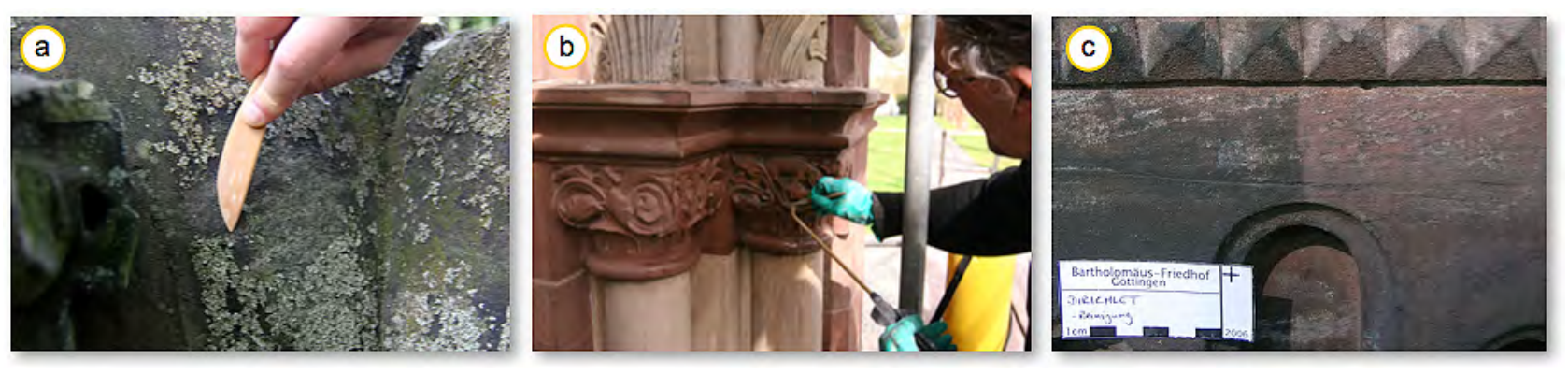

Figure 33: a) Cleaning of microbiological growth with a wooden tool. b) Wet cleaning of dust and lose deposits.

c) Cleaning effect by using the micro-abrasive method on sandstone.

Different methods including physical, manual (Fig. 33 a), chemical (Fig. 33 b) and abrasive proce- 
dures (Fig. 33 c) are at one's disposal for cleaning and removing the weathered or damaged surfaces. These include conventional manual cleaning methods using the appropriate brushes, scrubbers and sponges as well as more mechanical procedures involving the use of the micro-dry blasting process, steam cleaning and the vacuum washing method.

\section{7. 2. b) Desalination}

Salt reduction is a basic prerequisite for a sustainable restoration. The most suitable desalination method is dependent on a number of factors. Factors that need to be taken into account are the rock material, the degree of contamination and depth and type of salt responsible for the damage.

The goal of desalination or salt treatment by conservation measures is the removal and reduction of structurally damaging salt compounds or their immobilization by chemical ionic exchange and subsequent precipitation. Salt contamination can be kept stable by climatically stabilizing the salt phases in interior spaces so that no further damage can occur (Laue 1995).
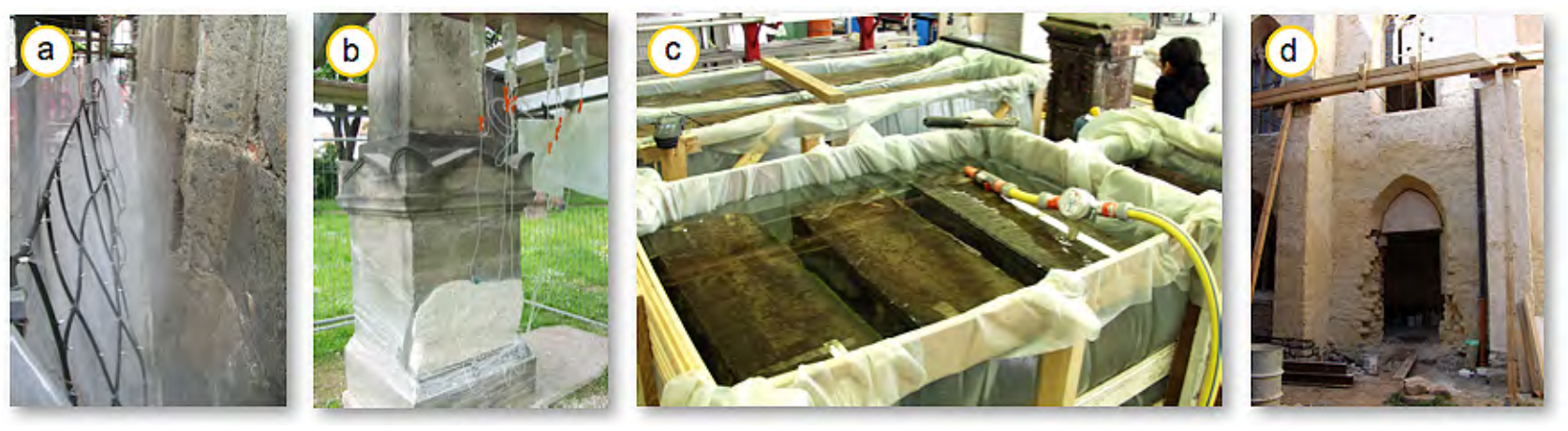

Figure 34: Different methods of desalination. a) sprinkling, b) combined injection and poultice method, c) desalination bath and d) poultice.

Methods applied include the application of a sacrificial plaster layer, compresses (Fig. 34 b and d), the washing and sprinkling procedure (Fig. 34 a), the desalination bath (Fig. 34 c), chemical salt conversion and the process of electro-osmosis. Through architectural and other technical means the interior climate can be adjusted and kept constant. Thus damaging salts can become ineffective.

\section{7. 2. c) Consolidation}

In natural stone consolidation friable material zones can be adjusted to the mechanical properties of the intact material by the injection of a solidifying agent. Organic and inorganic solidifying agents are available for stone consolidation, which can be introduced in liquid form by different application techniques into the unconsolidated original material. Methods for consolidation include the conventional impregnation technique by means of syringes and spraying bottles (Fig. 35 a), but also the drip and compress impregnation procedure (Fig. 35 b) and different vacuum methods (Fig. 35 c). 
Material consolidation and stabilization are deemed to be one of the most sensitive interventions undertaken in stone conservation. These procedures are a direct intervention into the stone and are inevitably connected to changes in the physical and mechanical properties of the treated material.
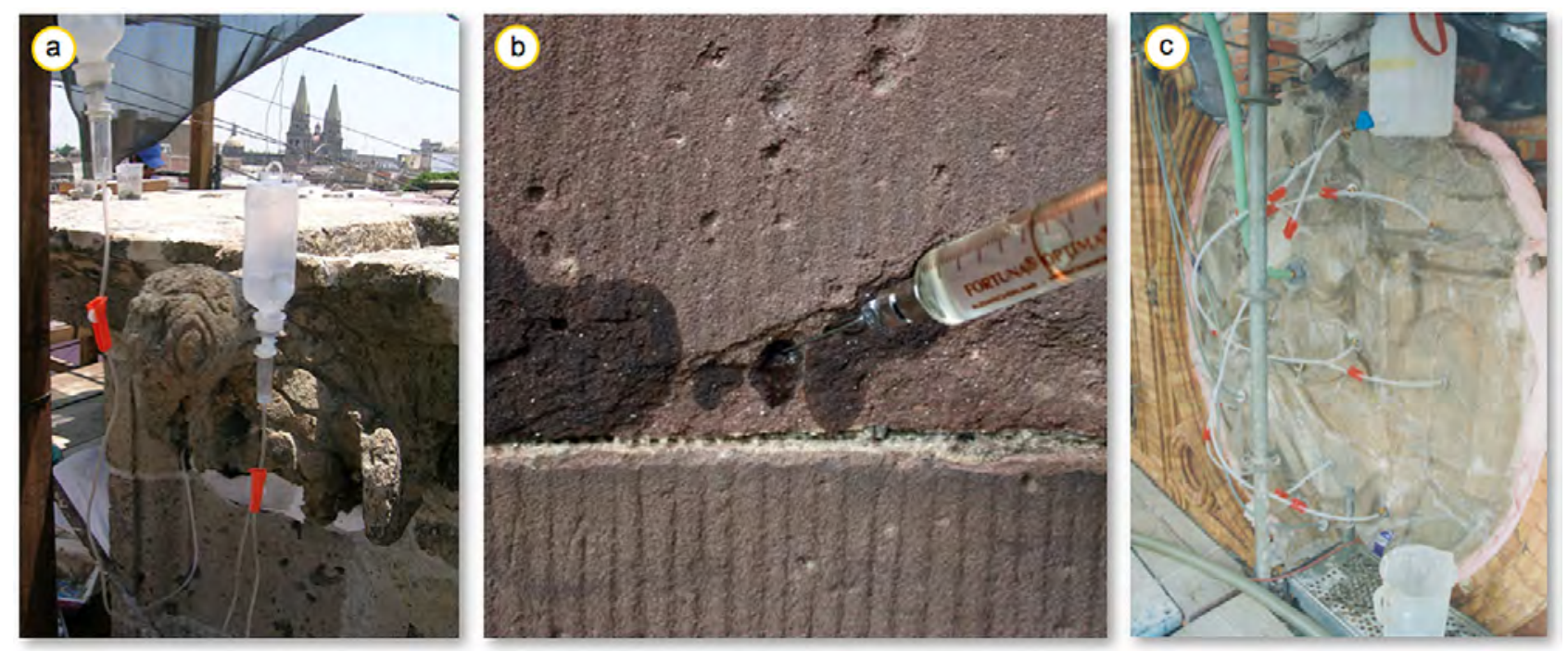

Figure 35: Consolidation of weathered areas a) by using injection and poultice, b) by syringe and c) by the vacuum method (Foto: Th. Schubert). 


\section{Methodology}

\section{1 On-site observations, sampling and investigations}

\subsubsection{On-site observations and mapping}

Describing deterioration patterns is an essential requisite when studying exposed stone objects. Mapping is an established non-destructive procedure for in situ studies (Fitzner 2014). Deterioration patterns are the visible consequences of the impact of environmental factors on the stone objects. They serve as key-indicators of the decay processes and of the possible causes of the observed damages (Rodrigues 2013). Mapping helps in understanding the problems by creating refined and detailed visual maps of damage zones (Fig. $36 \mathrm{a}$ and b). This leads to the identification of conservation needs and to a definition of conservation actions.
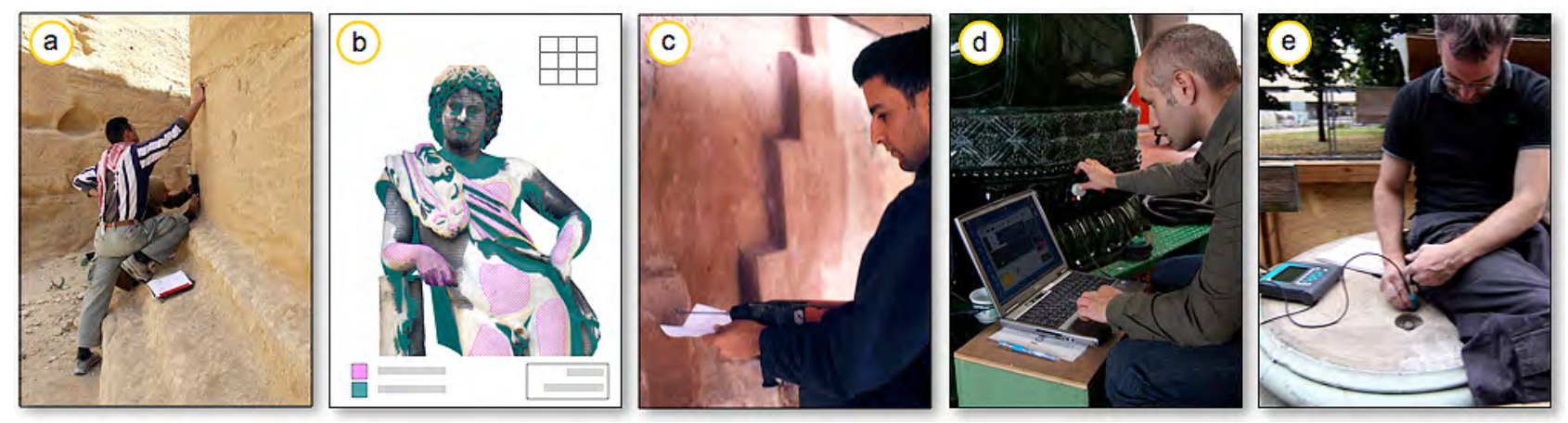

Figure 36: Sampling and diagnostic measurements, a) by detailed observations, b) mapping, c) sampling of drilling dust powder, d) in situ ultrasonic velocity measurements, e) in Situ surface hardness testing.

By quantifying the different deterioration patterns mapping can also be used as a measuring tool. Quantified mapping was done based on distortion-free photographs by using the mapping software Medigo-Map (Medigo GmbH, Leipzig).

\section{1. 2 Electrical conductivity}

Water and moisture are some of the main decay agents in natural building stones. Several non-invasive methods are used to quantify moisture in building stones, many of them based on the fact that moist stones exhibit different electrical properties than dry stones. Resistance-based sensing equipment such as the "Protimeter" (GE Sensing, EMEA Shannon, Co.) is a portable moisture meter that shows the electrical conductivity of the tested material. This was used for several investigations in the present thesis. 


\section{1. 3 Surface temperature measurements}

Heat and cold can lead to an expansion and shrinkage of the stone and other material. Therefore, temperature fluctuations can be an important decay agent in building stones. Surface temperature was measured with a surface thermometer using the Protimeter device.

\section{1. 4 Drilling dust and core sampling}

To understand weathering processes as well as to evaluate suitable conservation techniques, one needs know what kind of salt is present and how the salt is distributed in the porous stone material. Drilling dust and core samplings were done at several buildings and objects studied in this thesis in order to evaluate the depth of salt contamination. Drilling dust samples were obtained in a stepwise fashion by collecting the drilling powder separately in one to two centimeter steps (Fig. $36 \mathrm{c}$ ). The drill core samples were taken by dry drilling using compressed air to cool down the drilling equipment.

\section{2 Laboratory investigations}

\section{2. 1 Salt analyses}

The salt-induced weathering of the monuments was determined using eluates from the drill cuttings. The samples were retrieved at different heights on the structure and at depth. Salt analyses were done using an ion chromatograph (IC) and by measuring the electrical conductivity.

\section{2. 2 Microscopic analyses}

Petrographic analyses (in polarized and transmitted light) on standard thin sections of all samples were performed to obtain a qualitative description of different fabric parameters like mineralogical composition and properties of different components like mineralogical composition, grain boundary geometry, average grain size and sorting.

Cathodoluminescence microscopy (CL) was done on thin sections of the Angkor Wat sandstone varieties to delineate alteration processes, to visualize possible microstructures and to determine what the differences are between the unaltered and altered building stones.

For the analysis of the microfabrics a scanning electron microscope (SEM) ESEM FEI Quanta 600 FEG was used. The SEM was operated in the low-vacuum mode (0.6 mbar). The microscope is equipped with an Apollo XL (AMETEK) EDX detector for microchemical analysis. The SEM sample is obtained by gently breaking the rock fragment with a small cutter. Sample preparation must be done in a clean way in order to prevent cutting shards or other materials from contaminating the sample under analysis. Optimal size for the final sample is generally around $5 \times 10 \times 10$ $\mathrm{mm}$. 


\section{2. 3 Porosity, density and pore size distribution}

In order to acquire the matrix and bulk density as well as the porosity, hydrostatic weighing was carried out. The open (effective) porosity, as well as the density, of six and a half centimeter long cubic stone samples were measured using hydrostatic weighing (DIN 52 102). The water-saturated mass, the buoyancy mass of the samples measured after water saturation under vacuum, and the dry sample mass were used to calculate the porosity. The pore radii distribution was analyzed by using the mercury injection porosimetry (e.g., Brakel et al., 1981).

\section{2. 4 Pore size distribution}

Pore size distribution was measured using the mercury intrusion porosimeter (MIP). The pore space was investigated by mercury pore size distribution as well as by thin section analysis and SEM photographs. The water transport properties closely related to the properties of the pore space were measured by the water uptake rate and the water vapor resistance. Capillary active pores are defined as those having a cross-sectional dimension ranging from 0.1 to $100 \mu \mathrm{m}$ (Klopfer 1985).

\section{2. 5 XRPD analyses}

X-ray powder diffraction (XRPD) is a common technique that can be used to identify any crystalline substance, such as most minerals. It can also be used to quantify the proportions of different minerals or other substances when they are present in a mixture.

XRD analyses were done on stone powder with a grain size $>0.063 \mathrm{~mm}$ for the mineral content and $<2 \mu \mathrm{m}$ for clay minerals and clay-size fraction analysis. From the XRPD analyses a graphical peak scan is obtained that is characterized by different peaks according to their 2 Theta degree position (Fig. 36). In the case of clay analyses, the XRD degree between 5 and 30 is relevant.

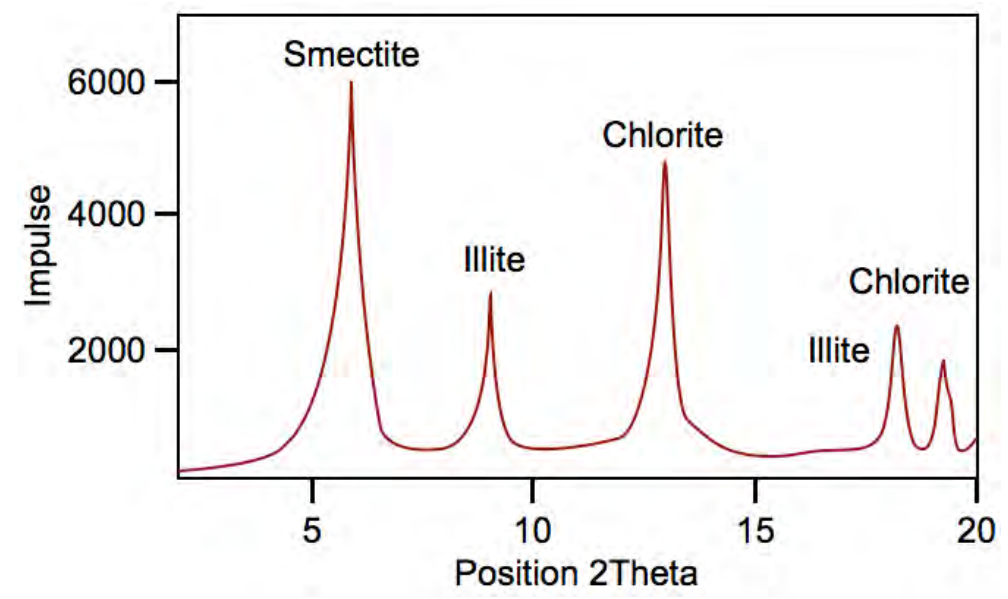

Figure 36: Typical graphical peaks of different clay minerals from XRPD analysis. 


\section{2. 6 Analyses of the clay content}

Chemical and mineralogical analyses of the clay fraction, which included XRD of oriented slides and cation exchange capacity (CEC) analyses, were performed in order to determine the total amount of swellable clay minerals and to clarify what role the presence of 1:1 or 2:1 layered clay minerals play.

\section{3 Water transport and retention properties}

\section{3. 1 Capillary water absorption}

The capillary water absorption or water uptake was measured on cubes $(65 \mathrm{~mm})$ with respect to the $\mathrm{X}, \mathrm{Y}$ and $\mathrm{Z}$ directions. The cubes were placed into water to measure the weight increase over time (Fig. 37 a).

Capillary water uptake was determined by capillary suction in a closed cabinet while weighing according to the standard EN 1925 on cubic samples $(65 \mathrm{~mm})$. The measurements were done in all directions parallel and perpendicular to the bedding of the stone. The water uptake coefficient (wvalue) describes how much water can be absorbed during a definite time in regards to the area of suction and was calculated after the DIN 52617 with units in $\mathrm{kg} / \mathrm{m}^{2} \sqrt{ } 1 \mathrm{~h}$.

\section{3. 2 Water vapor diffusion resistance}

The water vapor diffusion gives information about the network of the pore system, the drying behavior and the transport mechanism controlled by the pore size distribution (Ruedrich, Siegesmund 2006). The water vapor diffusion characterizes the diffusion resistance of a porous material compared to an equally dimensioned inactive air film. It is one of the most important water transport mechanisms and is defined by the vapor diffusion resistance coefficient ( $\mu$-value). The measuring method gives information about the network of the porous system, the drying behavior and the transport mechanism controlled by the pore size distribution (Ruedrich, Siegesmund 2006). Slices of the different stones were prepared in all directions $(\mathrm{X}, \mathrm{Y}, \mathrm{Z})$ with a diameter of $4 \mathrm{~mm}$ and a thickness of $10 \mathrm{~mm}$ and were attached as covers on Teflon cups filled with water (Fig. 38 b). These cups were then placed into a climate chamber at $50 \%$ relative humidity $(\mathrm{RH})$ and a temperature of $20{ }^{\circ} \mathrm{C}$. The weight losses of the cups were measured every $24 \mathrm{~h}$ by calculating the moisture flow through the material.

The water vapor diffusion resistance value, $\mathrm{m}$, of samples was evaluated using the wet-cup method. This value characterizes the diffusion resistance of a porous material compared to an equal inactive air film. Slices of the stones $(40 \times 10 \mathrm{~mm})$ were used as covers on the cups. The relative humidity difference caused moisture to flow through the porous material from the side with higher moisture 
(inside at $100 \%$ ) to the side with lower relative humidity (outside at $50 \%$ ). The moisture flow was obtained by weighing the cups at various times until a steady state was reached.
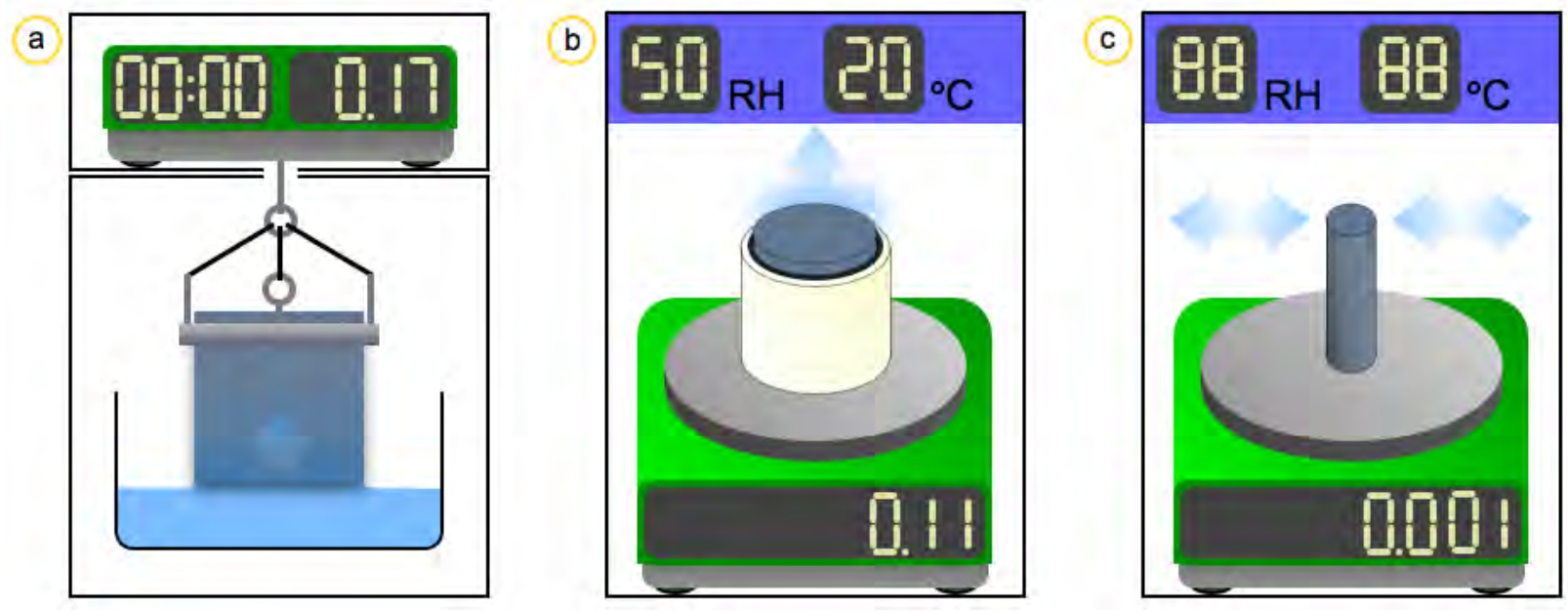

Figure 38: Schematic drawing for the measurement of water transport and retention properties.

a) Capillary water absorption, b) water vapor diffusion resistance and c) sorption and saturation degree.

\section{3. 3 Sorption and saturation degree}

Hygroscopic water sorption was measured between 20 and $95 \% \mathrm{RH}$ at $30{ }^{\circ} \mathrm{C}$ in a climate chamber. The measurements were carried out on drilling core slices with a diameter of $20 \mathrm{~mm}$ and a thickness of $50 \mathrm{~mm}$, respectively (Fig. $38 \mathrm{c}$ ). The amount of absorbed water is given in $\mathrm{g} / \mathrm{cm}^{3}$ or percent of the tested material.

\section{4 Petrophysical properties}

\section{4. 1 Splitting tensile strength}

The splitting tensile strength was determined by means of the 'Brazilian test', which involves discshaped specimens according to the standard DIN 22024. The diameter of the samples was $\varnothing 40 \mathrm{~mm}$ and the length was $20 \mathrm{~mm}$ (Fig. 39 a). In order to calculate the average value, a minimum of six samples was used, while the normal amount was 10 samples. The splitting tensile strength was measured perpendicular to the $\mathrm{XY}$ and $\mathrm{XZ}$ planes, where $\mathrm{XY}$ is the bedding plane. Tensile strength tests were conducted under dry and water-saturated conditions.

The resistance against tensile stresses in all kinds of rocks, including the tuffs and sandstones, is one of the most important parameters for all physical weathering processes. This is true if the stones show a distinct layering and spatial orientation of any foliation or sedimentary layering. Splitting tensile strength tests can aid in the understanding of the role of binding forces between different components and expandable minerals, such as in some clay minerals (Siegesmund, Duerrast 2011). 


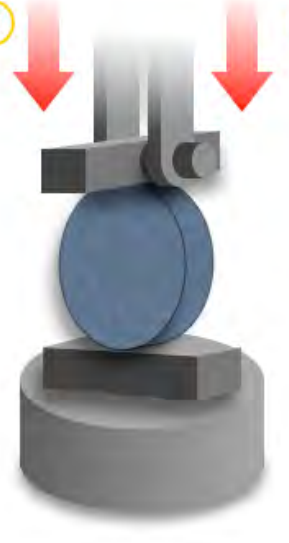

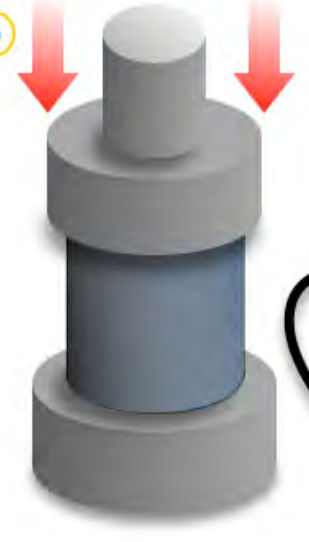

c

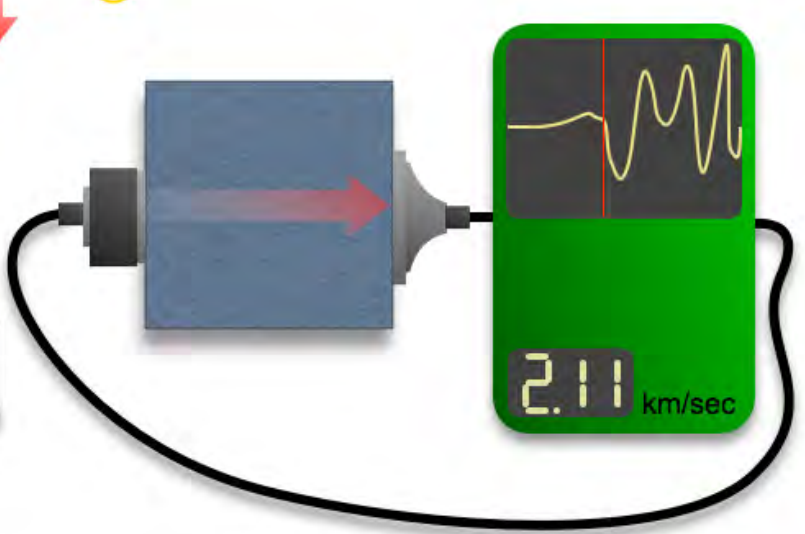

d

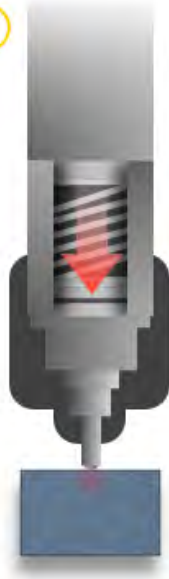

Figure 39: Measuring setup for determining mechanical properties: a) the splitting tensile strength, b) uniaxial compressive strength, c) ultrasonic velocity, and d) Leep surface hardness invented by Dietmar Leep.

\section{4. 2 Uniaxial compressive strength}

For the compressive strength tests, standard cylindrical specimens of $50 \mathrm{~mm}$ in diameter and $50 \mathrm{~mm}$ in length with co-planar end-faces were used. After grinding, all specimens were dried at $50{ }^{\circ} \mathrm{C}$ until weight constancy was achieved. This weight is defined as the dry status of the specimens. Each stone type analyzed for the uniaxial compressive strength was measured in the X-, Y- and Z-direction 10 times for each direction under dry and water-saturated conditions. The compressive load was applied by a servo-hydraulic testing machine with a very stiff testing frame $\left(3.000 \mathrm{kN} / \mathrm{mm}^{2}\right)$ and a class 1 load range up to $300 \mathrm{kN}$ (Fig. 39 b). The load was applied to the end-faces of the specimen with a strain rate of $10^{-5} \mathrm{~s}^{-1}$ until failure. The maximum load is defined as the uniaxial compressive strength.

\section{4. 3 Ultrasonic velocity}

Ultrasonic velocity measurements were carried out on cubic rock samples (65 x $65 \times 65 \mathrm{~mm})$ and cylindrical samples $(\varnothing 15 \mathrm{~mm}$ x $50 \mathrm{~mm}$ ). Transient times of ultrasonic pulses (piezoceramic transducers, resonant frequency $1 \mathrm{MHz}$ ) were measured in three orthogonal directions (Fig. $39 \mathrm{c}$ ) using the pulse transmission technique (Birch 1960, 1961).

\section{4. 4 Surface hardness measurements}

Testing stone objects with a low impact affect can be performed by using a Schmidt hammer. The method is a well known portable field test. The testing tool applies an impact force and the rebound of the hammer applying the force is measured. Different types of hammers are in use, but the testing tool in general was developed for the testing of cement and not for weak and soft materials such as weathered building stones. In some cases the hammer will damage the material tested. The rebound hammer used in this study is comparable with a micro-rebound hammer with a low impact force. An overview on surface hardness measurements in geomorphology and heritage science can be 
found in Viles et al., 2010. Booth et al., (2012) show that the device used in this study could be used to detect the effect of different consolidation materials on stone.

Surface hardness measurements were done in situ as well as on stone samples in the laboratory. The testing instrument works with the rebound method. Like the well-known Schmidt-hammer it indirectly measures the loss of energy of a so-called impact body (Fig. 39 d). Dietmar Leep, the inventor of this method defined his own hardness value called the Leep hardness value: HL. For the measurements an Equotip 3 (proceq) portable testing device with an impact device D was used (Fig. 39 d). Thus, the final results are given in HLD. The instrument offers extended capabilities such as measurements on almost all parts with different geometries, with a high accuracy of $\pm 4 \mathrm{HL}(0.5 \%$ at $800 \mathrm{HL}$ ) and automatic correction for impact direction. For each investigated area 10 individual measurements were done and the average value calculated. In the laboratory the measurements were done on dry and water-saturated samples.

\section{4. 5 Thermal expansion}

The thermal expansion behavior of the samples was measured on cylindrical specimens $(\varnothing 15 \times 50$ $\mathrm{mm}$ ). Thermal expansion was determined as a function of temperature. For this dilatation experiment, a heating cycle from $20^{\circ}$ to $90{ }^{\circ} \mathrm{C}$ was used (Fig. 40 b). The thermal expansion coefficient, a, expresses the volume change of a material as a function of temperature. The procedure was done for five cycles to determine an eventual residual (irreversible) strain.

\section{4. 6 Moisture expansion}

The hygric expansion is a property of some materials (e.g., clay minerals), which causes them to swell in contact with water. This behavior is controlled by the amount of swelling clay minerals and the proportion of micropores present in the rock (see discussion in Weiss et al., 2004 or Ruedrich et $a l ., 2005)$. The hygric expansion of the stones was determined on cylindrical samples (Ø $40 \mathrm{~mm}$, length $50 \mathrm{~mm}$ ), which were preconditioned at $30 \%$ relative humidity and room temperature. Afterwards the samples were completely immersed in distilled water (Fig. 40 a). The resolution of the displacement transducer is $0.1 \mu \mathrm{m}$ and the accuracy is about $0.5 \mu \mathrm{m}$. The measurements were carried out on all samples parallel to the $\mathrm{X}, \mathrm{Y}$, and $\mathrm{Z}$ axes.

\section{4. 7 Hygric moisture expansion}

The hygric moisture expansion was performed in a special measurement environment connected to a climate chamber (Fig. 40 c). The moisture expansion was measured step by step, beginning from 


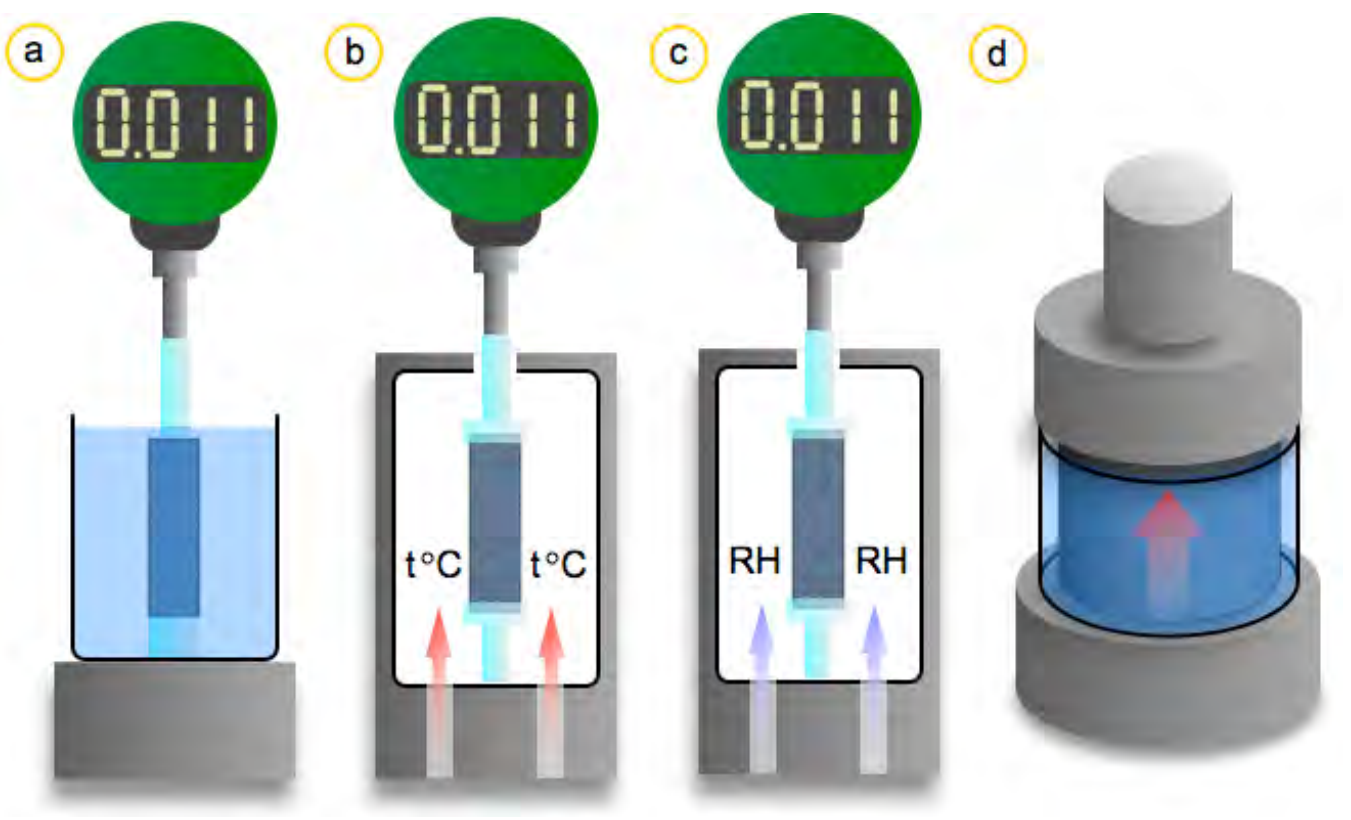

Figure 40: Expansion and swelling measurement setup. a) Hydric expansion, b) thermal expansion,

c) hygric expansion and d) swelling pressure.

$20 \%$ relative humidity $(\mathrm{RH})$ and gradually increasing up to $95 \%$ at a constant temperature of 30 ${ }^{\circ} \mathrm{C}$. For water-saturated conditions, the samples were completely immersed in distilled water. The resolution of the displacement transducer is $0.1 \mu \mathrm{m}$ and the accuracy is about $0.5 \mu \mathrm{m}$. The measurements were carried out on all samples parallel to the $\mathrm{X}, \mathrm{Y}$, and $\mathrm{Z}$ axes.

\section{4. 8 Swelling pressure}

Pressure will develop if the strain in the sample's dilatation is mechanically inhibited during water uptake (cf. Kocher 2005). Ruedrich et al., (2011 a) shows that, for sandstone, there is a clear correlation between moisture expansion and swelling pressure. Swelling pressure in this thesis was measured for five selected cylindrical samples with a diameter of $5 \mathrm{~cm}$ and a length of $2.5 \mathrm{~cm}$. The samples were measured in the $\mathrm{Z}$ direction while a preload of $0.021 \mathrm{MPa}$ was used (Fig. $40 \mathrm{~d}$ ). A universal testing machine in combination with a commercial odometer (Kocher 2005) was used.

\section{5 Artificial weathering}

\section{5. 1 Salt resistance tests}

To assess the salt weathering sensitivity of the investigated tuffs in this study, a salt-weathering test according to the DIN EN 12370 was performed. Stone cubes with a dimension of $6.5 \mathrm{~cm}$ were used in the testing procedure. The samples were dried until the constant weight was reached and then placed into a closed basket for four hours containing a $10 \%$ solution of sodium sulfate $\left(\mathrm{Na}_{2} \mathrm{SO}_{4}\right)$. Afterwards the samples were blotted and put into a heating chamber $\left(60^{\circ} \mathrm{C}\right)$ for at least $24 \mathrm{~h}$. After 
cooling down to room temperature, the weight change was determined. The procedure was repeated until a mass loss of $30 \%$ could be determined. This $30 \%$ material loss was used like an index to define salt resistance of the material.

The salt used for the test is sodium sulfate, which produces a tensile strength up to around $50 \mathrm{MPa}$ depending on the molarity of the supersaturated solution. Therefore, it has the potential to damage nearly all the known natural rocks (Steiger 2005).

The processes that induce stress in the porous material are well investigated in this testing procedure: by drying at $60^{\circ} \mathrm{C}$ anhydrous $\mathrm{Na}_{2} \mathrm{SO}_{4}$ crystals are formed while the impregnation leads to their rehydration. The destructive effect is due to the growth of mirabilite crystals precipitated from the highly supersaturated solution originating from the dissolution of anhydrous $\mathrm{Na}_{2} \mathrm{SO}_{4}$ during re-wetting (Flatt 2002). 


\section{Case studies}

\section{1 Areas of investigations and rock material}

For the on site studies different monuments were consisting of tuff-stone and sandstone on different continents and climatic zones. The case studies are located in Mexico, Germany, Jordan and Cambodia (Fig. 11). The case studies in Mexico deal with tuffs and volcanites, the case studies in Germany, Jordan and Cambodia with sandstone.

\section{1. 1 Geography and geology of the case studies located in Mexico}

In Mexico three cities, Mexico-City, Guanajuato and Guadalajara, were chosen that are located in the Trans-Mexican Volcanic Belt (TMVB). The Trans-Mexican Volcanic Belt (TMVB) is a $1000 \mathrm{~km}$ long Neogene continental arc showing a large variation in composition and volcanic style, and intra-arc extensional tectonics (Ferrari et al., 2012). In the capital of Mexico investigations were done at the Templo Mayor and its Tzompantli monument and the Palace Heras Soto and the Metropolitan Cathedral (Fig. 42).

In Guanojuato monuments constructed from two typical tuff varieties in the area, the Bufa tuff from the church „Compañía de Jesús“ and the Leseros-Tuff were studied. In Guadalajara the monument of Independencia made from Cantera Rosa and as well as a monumental tomb made out of the Leseros tuff were investigated. Further studies in Guadalajara are focus on the the „Santa-Moníca Church“. In geological past many areas of the Guadalajara area was covered by a 2 to 3 meter thick layer of volcanic tuff called the Cantera Amerilla. Today only one outcrop is accessible.

\section{1. 2 Geography and geology of the German case study}

The city of Goettingen is situated right in the center of Germany $\left(52^{\circ} 32^{\prime} 02^{\prime \prime} \mathrm{N}, 09^{\circ} 56^{\prime} 08^{\prime \prime} \mathrm{E}\right.$, altitude around 300 meters above sea level). The city is located in the Leine Uplands, a region in Germany's Central Uplands, which forms a part of the Lower Saxony Hills and lies along the Leine River. The Leine flows in the Leine Valley from Goettingen in the south to Hanover in the north. In the southeastern part of the Leine Uplands, east of the valley on the plateau of the Goetting-Northeim forest, limestone and Bunter sandstone is exposed. Historical queries are located here. The sandstone belong to the Hardegsen Formation, which is for the small town Hardegsen $15 \mathrm{~km}$ north-west of Goettingen. The rock is dated to the Triassic period. In Goettingen several monumental tombs constructed from sandstone in the historical Bartholomeow-Cemetery were investigated and their damages treated.

\section{1. 3 Geography and geology of the Jordan case study}

The ancient stone city of Petra is located $\left(30^{\circ} 19^{\prime} 45^{\prime \prime} \mathrm{N}, 35^{\circ} 26^{\prime} 37^{\prime \prime} \mathrm{E}\right)$ about 260 kilometers south of the capital Amman at an altitude of about 900-1500 meters. The distance from Petra to the Dead 
Sea is around $100 \mathrm{~km}$. When following the historical entrance to Petra through the Siq, one will first pass through the white Disi Sandstone and then the underlying thick red Umm Ishrin sandstone into which most of the monuments were carved (Abed et al., 1998). The rocks are located at the northern end of the Arabian plate. It is part of the old African continental mass with the neighboring mountain range of Ethiopia, Eritrea and parts of Egypt (Nubia).

The region around Petra is mainly composed of sedimentary rocks of Lower Paleozoic age. The relevant stratigraphic units with respect to most of the rock-cut monuments are made up of the middle and upper part of the Cambrian Umm Ishrin Sandstone Formation and the Ordovician Disi Sandstone Formation (Jaser, Barjous 1992, Jordan National Resources Authority 1991) In Petra the Monument no. 826 was investigated and the damages treated by methods discussed in this thesis.

\section{1. 4 Geography and geology of the Cambodian case study}

The ruins of Angkor are located amid forests and farmland north of Tonlé Sap lake in north-western Cambodia. The geology of the region is called the the Greater Mekong Subregion (GMS) and is closely connected to the development of the Mekong River. About 40 million years ago, its precursor drained into the sea roughly where the Red River now flows. Most of the historical quarries can be found along the river beds. Not all of the sandstones used for the temples of Angkor the provenience have been found. Most of the natural building stones were brought from the Kulen Mountains located in a WNW - ESE direction from Angkor, where different historical quarries could be identified (Carò 2009). These hill-like ranges, also known as the Phnom Kulen are an isolated chain of small mountain plateaus of moderate altitudes. 


\section{2 Case study Mexico City / Mexico}

\section{2. 1 Introduction}

Mexico City is located in the center of the republic of Mexico at $19^{\circ} 23^{\prime} \mathrm{N}$ and $99^{\circ} 10^{\prime} \mathrm{W}$ with an altitude of $2309 \mathrm{~m}$ above sea level. Mexico City is the capital of the country and with more than 20 million inhabitants the largest city in the Americas, along with being one of the largest cities in the world.

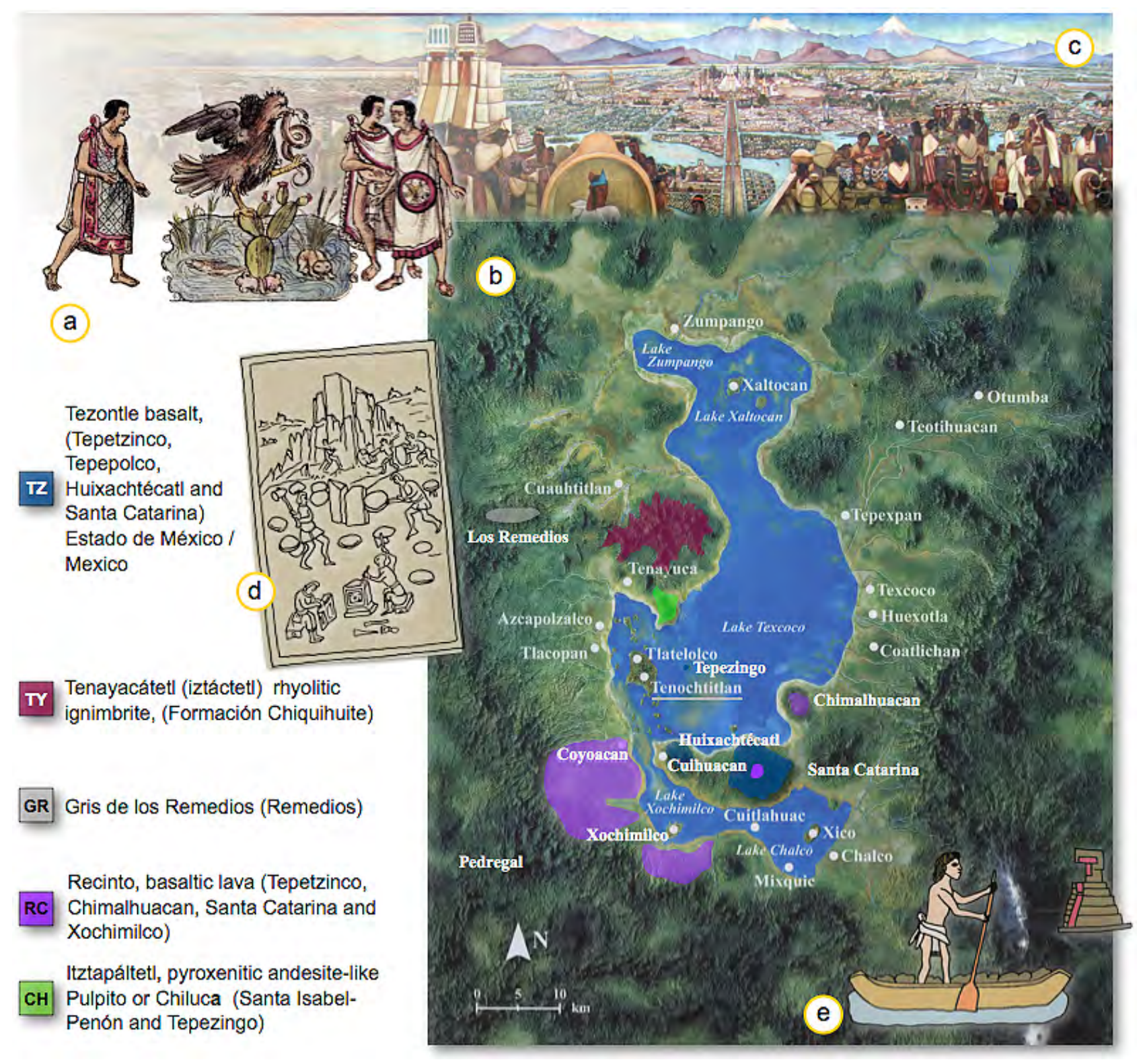

Figure 41: Tenochtitlán and its building stones: a) The eagle with the snake on a cactus plant (Opuntia) grown on a rock placed in a lake, illustrating the founding of Tenochtitlán and the arrive al of the Aztecs at the site of Tenochtitlán between 1320-1350 AC (source: Codex Durán). b) Tenochtitlán and its surroundings and the location of historical quarries. c) The historical Tenochtitlán mural painting of Diego Rivera within the Palace of the Republic in Mexico City. d) Historical quarry in the mountains of Mexico (source: Códice Florentino). e) Aztec ferryman transporting stones (source: Codex Mendoza). 


\section{2. 1. a) Tenochtitlán}

Human settlements in the Valley of Mexico have a very long and illustrious history (Fig. 40). Initial traces of agriculture occur around the lake about 7,000 years BCE (Niederberger 1979) and the first evidence of villages are found between 1,700 and 1,250 BCE, which developed the first identifiable cultures (Niederberger 1996). In 1325 CE the Aztec people founded their capital of Tenochtitlán.

The city's' beginnings originated from a legend: The new center for the wandering tribes of the Mexica people would be built at the place where an eagle was fighting with a snake while perched atop a cactus (Opuntia). This place was originally a small swampy island located in the western part of Lake Texcoco. This legend is pictured in many historical sources: it shows an eagle and cactus located on a symbol for a rock-like island in a lake (Fig. 41 a). Today this image is immortalized in Mexico's coat of arms and on the Mexican flag.

The public buildings were located in the center of the city with a ceremonial center inside a walled $(300 \times 300 \mathrm{~m})$ square. The chronicler Sahagun reported that around 28 temples and religious facilities were located within the ceremonial precinct (Sanders 2008). The largest conserved remains is the Templo Mayor, a towering pyramid topped by two sanctuaries. The profane architecture of the rulers and priests were amazing multi-storied building complexes. The architecture for the people were simple houses built from adobe but often plastered and painted as we know from the many models of popular housing scenes (Soisson, Soisson 1978). The city expanded to around $13 \mathrm{~km}^{2}$ and was cross cut by many channels. Swimming gardens called "Chinampas" were constructed in these channels that provided food and flowers for the local population.

The city of Tenochtitlán was destroyed under the command of Hernan Cortes (1485-1557) in the summer of 1521. The once largest city (Sanders 2008) of the Americas had been razed to the ground and an estimated 240,000 Aztecs were killed (Hassig 1994) during the fall of their capital. The Aztec culture and the Spanish Conquistadors left behind a large stone building legacy. Within the 9 $\mathrm{km}^{2}$ area of the historical city center, around 1,500 historical buildings and 200 monuments are preserved. Moreover 80 museums are also located here.

In 1987 the UNESCO declared the historical center of Mexico City a World Heritage Site. Today many campaigns for restoration and the rehabilitation of the historical center were done or are still in the planning stage. Weathering and stone deterioration in this region is affected by four main factors: the extreme pollution of the metropolitan area, the semi-arid to subtropical climate, the specific hydrological situation, and the frequent seismic activity. In general, weathering and deterioration of building stones in Mexico City have been poorly investigated.

Different publications exist concerning the restoration of the Metropolitan Cathedral, but they mostly focus on structural surveys (Ortiz Lajous 1980; Tamez et al., 1997). Publications dealing with 
petrophysical investigations on the building materials are rare. For example, geotechnical investigations by Pirella and Ramirez (2001) were done on just one column of the cathedral.

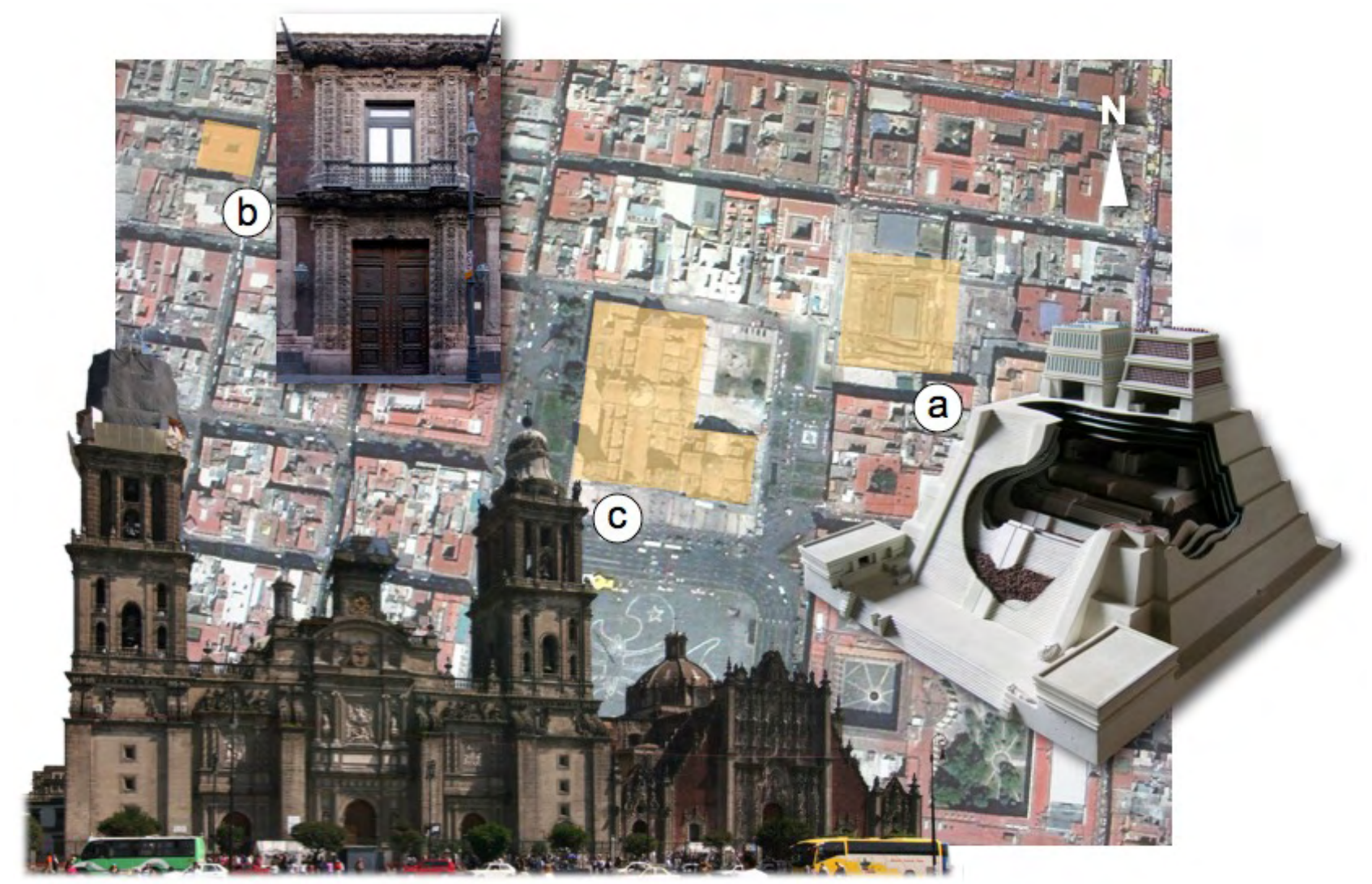

Figure 42: The investigated buildings within the historical center: a) location and model of the Templo Mayor, b) the palace of the dukes of Heras Soto and c) the Metropolitan Cathedral with the left tower under restoration.

Other investigations studied just one type of volcanic tuff variety, which is used on many historical facades in the city (Suárez Pareyón Aveleyra 2002). The influences of urban and industrial pollution on stone were discussed by Martínez and Martínez (1991) for three types of stone also investigated in this thesis. Five different types of the main building stones from the Valley of Mexico were investigated for mineralogical and petrophysical characterization. Altogether six large-scaled samples of the original historical and already weathered material from the cathedral and Templo Mayor as well as fresh building material from different local quarries were selected. The sample from the cathedral is from the roof covering of the left tower and the samples from the Templo Mayor are fragments of historical floor plates.

\section{2. 1. b) Climate and environmental conditions}

Mexico City has a humid subtropical summer climate that is mild with dry winters, mild rainy summers and moderate seasonality. This climate is usually found in the highlands of some tropical countries and has the classification Cwb after Köppen-Geiger.

The mean temperature is $16^{\circ} \mathrm{C}$. Average monthly temperatures vary by $5{ }^{\circ} \mathrm{C}$. In the wintertime re- 
cords indicate temperatures by day reach $21.7^{\circ} \mathrm{C}$ on average falling to $5.3^{\circ} \mathrm{C}$ through the night. In springtime temperatures climb to $26.3{ }^{\circ} \mathrm{C}$, generally in the afternoon with overnight lows of $8.7^{\circ} \mathrm{C}$ (Fig. 43). During the summer, average high temperatures are $24{ }^{\circ} \mathrm{C}$ and average low temperatures are $11{ }^{\circ} \mathrm{C}$. Come autumn temperatures decrease achieving average highs of $22{ }^{\circ} \mathrm{C}$ during the day and lows of $8.7^{\circ} \mathrm{C}$, generally shortly after sunrise. Total annual precipitation averages $709 \mathrm{~mm}$. According to the Holdridge life zones system of bioclimatic classification, Mexico City is situated in or near the cool temperate moist forest biome (Fig. 13).

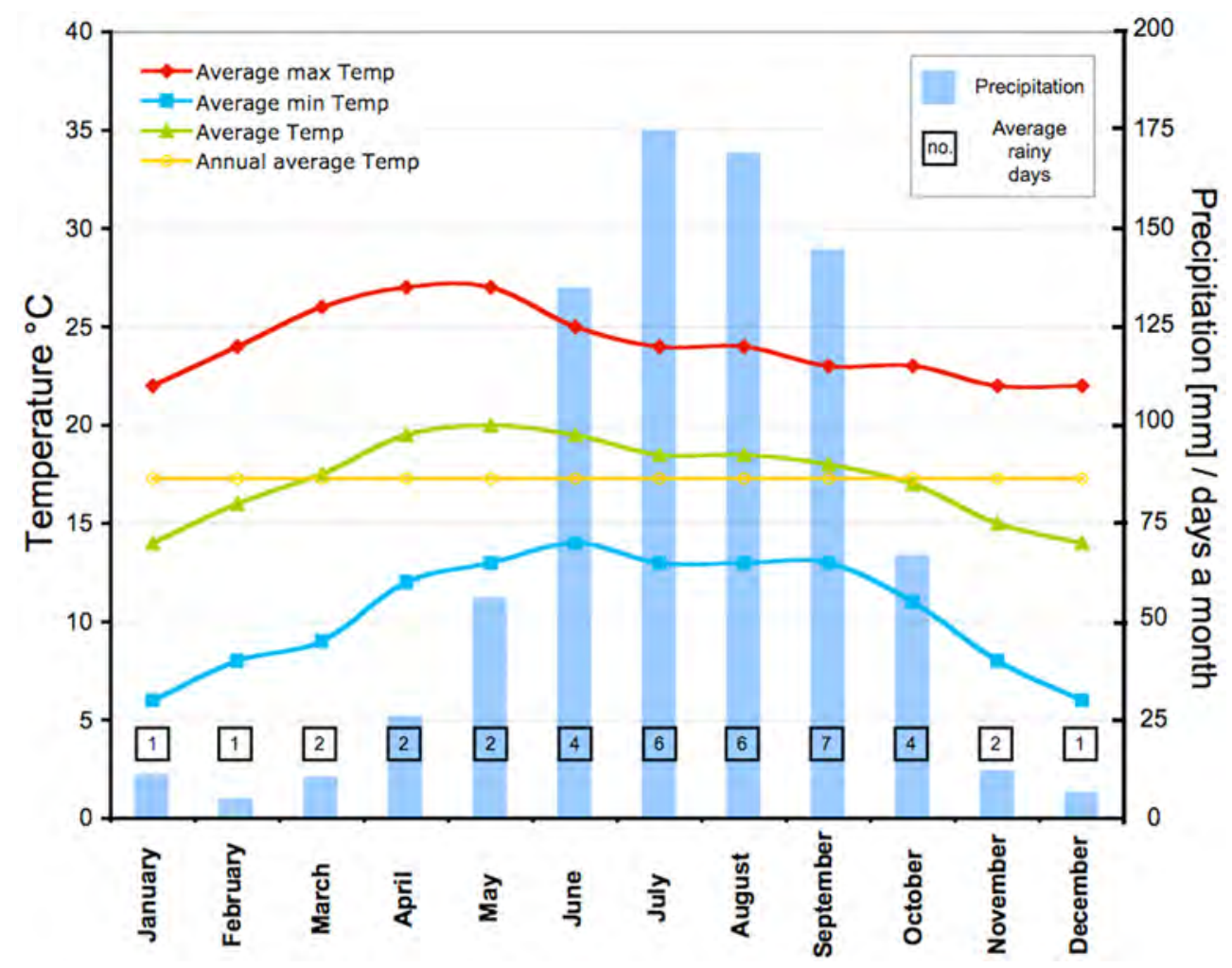

Figure 43: Climate Graph for Mexico-City.

\section{2. 1. c) Geological setting and rock material}

Volcanic rocks are the most prevalent rock types in the Valley of Mexico because of its geological setting. Mexico City, formerly called Mexico -Tenochtitlán by the Aztecs, is located in the Valley of Mexico in the center of the Trans-Mexican Volcanic Belt. Located on the high plateaus of southcentral Mexico, it has a minimum altitude of 2,200 m above sea level. Mountains and volcanoes that attain elevations of over $5,000 \mathrm{~m}$ surround the once characteristic lakeland area of the valley. Today only small remnants of the historical Lake Texcoco are left, which once had dimensions of $72 \mathrm{~km}$ by $35 \mathrm{~km}$.

The laboratory tests are complemented by field observations consisting of mapping and diagnostic measurements on the objects such as surface temperature, electrical conductivity and shore-hardness tests on the stone surfaces. 


\section{2. 2. The Templo Mayor}

The Templo Mayor was one of the main temples of the Aztecs in their capital city of Tenochtitlán, which today represents Mexico City. The temple is located in the center of the historical town and was once the central part of the ceremonial center of Tenochtitlán. The Templo Mayor was originally a towering pyramid topped by two sanctuaries (Fig. 42 a). The outline of the temple measured approximately 100-80 $\mathrm{m}$ at its base and dominated a sacred precinct. The construction was based on hundreds or even thousands of fencepost-sized supporting piles within the porous marshy terrain to stabilize the building (Sanders 2008). Construction of the first temple started around 1324. The sixth and last rebuild took place in 1487 (Parker 1995) (Fig. 42 a). In 1521 the Spanish systematically destroyed the temple. The first fragments of the temple were recovered at the end of the nineteenth century and the first half of the twentieth century. Systematic excavations took place from 1978 to 1982 by the demolition of 13 younger buildings. In 1980, the site was restored and treated with impregnation materials using silanes and hydrophobizantes (Franco 1987; Wacker, Meyer 1997). Since 1987, the site has been added to the UNESCO World Heritage List.
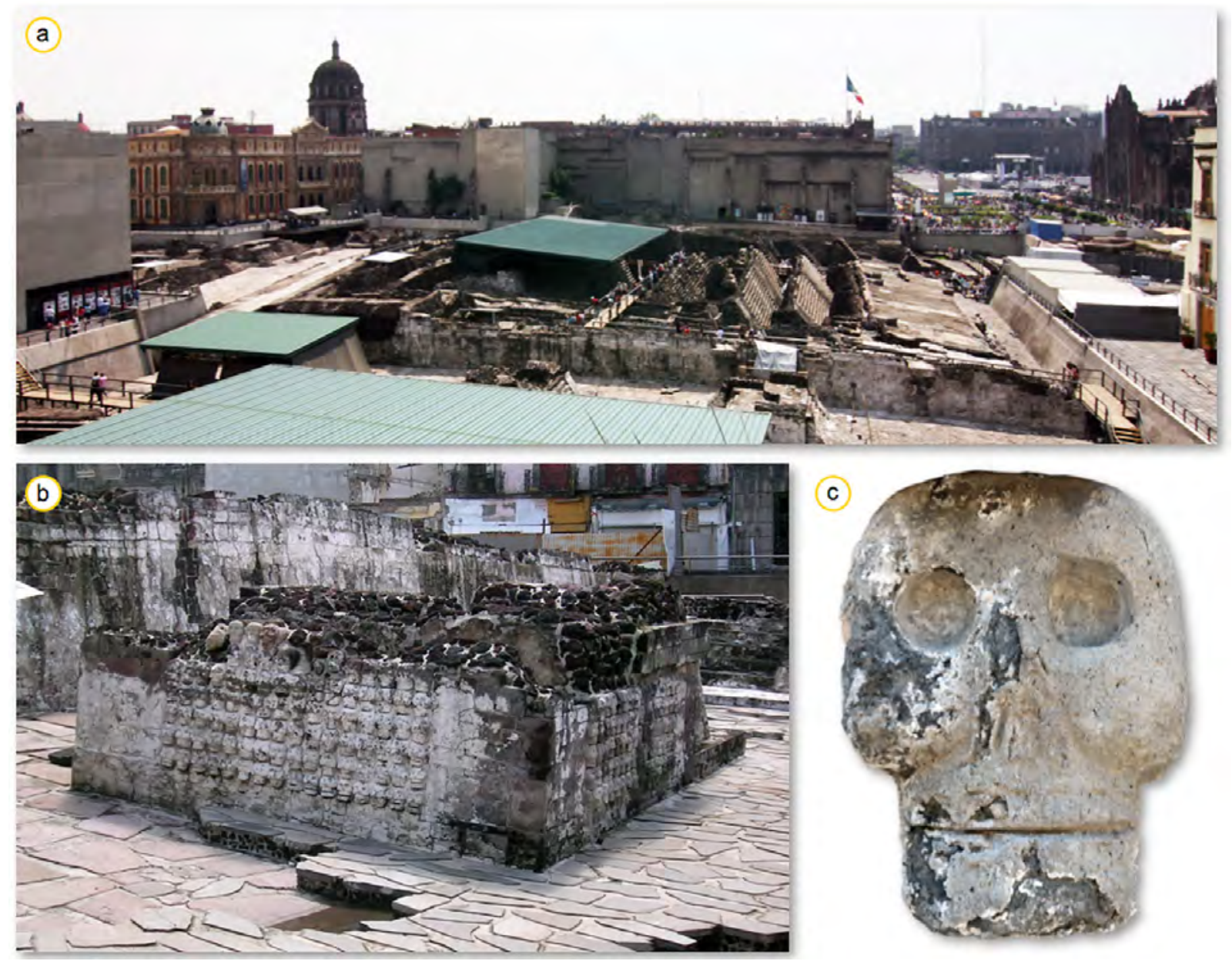

Figure 44: a) The historical site of the Templo Mayor, b) the Tzompantli altar decorated with 240 individually designed human skulls from which some c) are suffering from salt weathering and contour scaling. 
Stone, adobe, wood, and lime mortar were the main building materials used in Aztec architecture (López Luján et al., 2003). In the Templo Mayor, the main building stone is called "tezontle", sample I), which in the Aztec language, Nuatle, is the appellation for an extrusive volcanic basaltic andesite scoria. These dominant building materials are followed by other types of andesite, and rarely by basalts popularly known as "recinto" as well as limestones. Weathering is mostly visible in the tezontle and a reddish basaltic hornblende andesite, in Nuatle known as tenayocátetl (sample II). This material was used as floor or facing plates or for platform structures.

\section{2. 2. a) Deterioration and weathering forms}

The most recognizable deterioration in the tezontle consists of fractures and cracks (Fig. 45 a), whereas the weathering feature observable in the tenayocátetl is a scaling parallel to the surface with a thickness of 2-5 mm (Fig. $45 \mathrm{~b}$ ). Both weathering forms are specific for each single type of stone. Especially in the case of the tenayocátetl, the damages are observable on many plates in the platform. In this study, tezontle from a quarry in the state of Mexico D.F., which is used for restoration projects today, and the tenayocátetl from the Templo Mayor have been investigated.
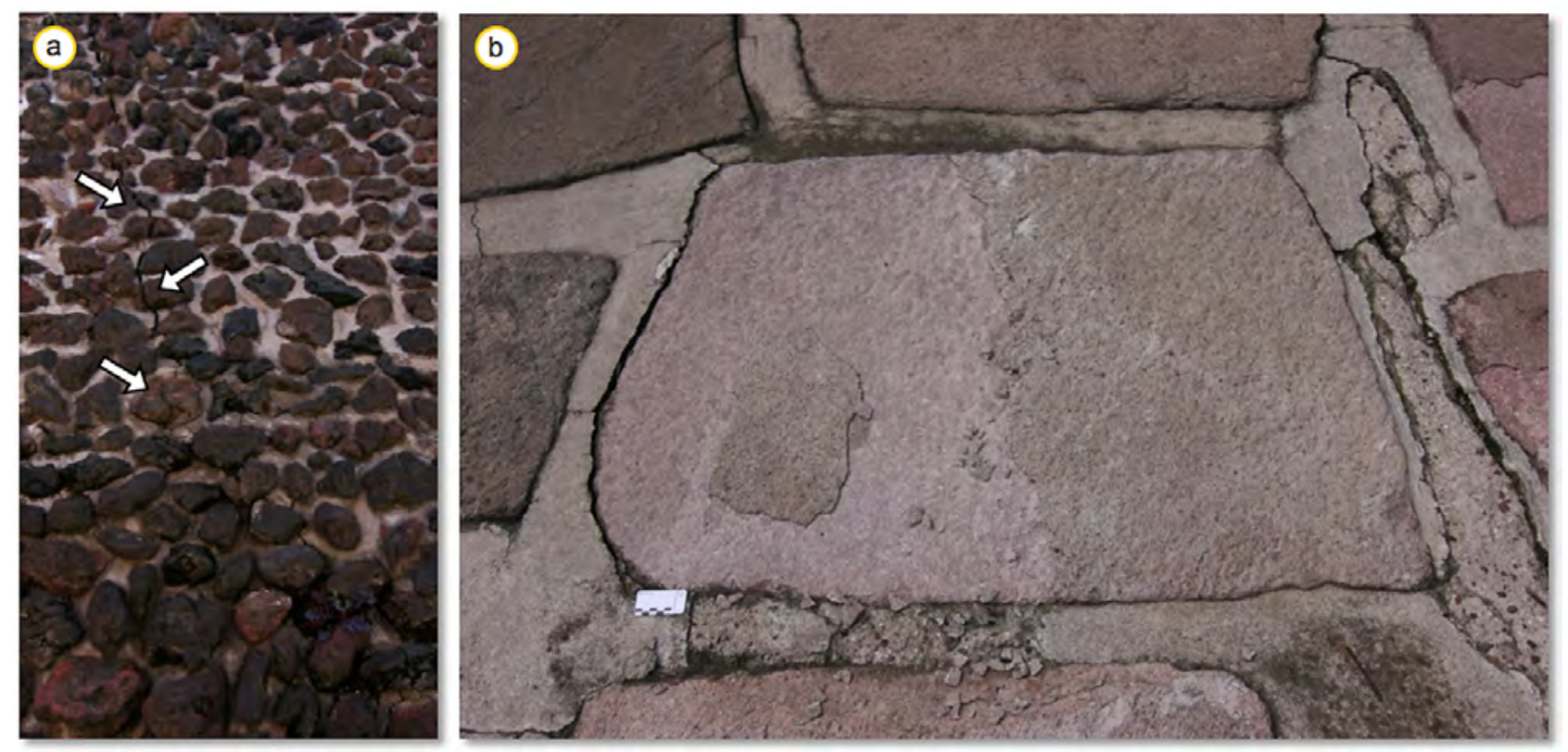

Figure 45: a) Structural cracks observable in the tezontle (arrows) and

b) scaling of tenayocátetl plates parallel to the surface.

\section{2. 3 Case study Tzompantli}

As a case study the weathering situation at the Tzompantli altar was studied. The altar is a square building decorated with 240 individually designed skulls from different stones like tezontle, recinto and different tuff varieties (Fig $44 \mathrm{~b}$ ). The skulls are placed in rows at the north, east and the south sides in the center of the wall. On the west side stairways once lead to the platform of the altar. The skulls were once covered with a lime wash and colored. 
The building has a dimension of around five by five meters and a height of around two meters. The skulls are found on the east, north and south side of the building. The main weathering form on the skulls is contour scaling due to the accumulation of salt (Fig. $44 \mathrm{c}$ ). Weathering mainly takes place in the different tuff stone varieties, whereas the tezontle and recinto varieties are still in good condition.

\section{2. 3. a) Weathering model}

In the case of the Tzompantli altar its position changes continuously after excavation. The temple area is located around four meters deeper than the ground level of the city today (Fig. 44 a and 46 a). The enormous weight of the buildings around the national palace and the cathedral leads to a pressing of the Templo Mayor, whereby the cathedral is sinking into the muddy ground. This also affects the topographic position of the Tzompantli and has an influence on its hydrological situation.

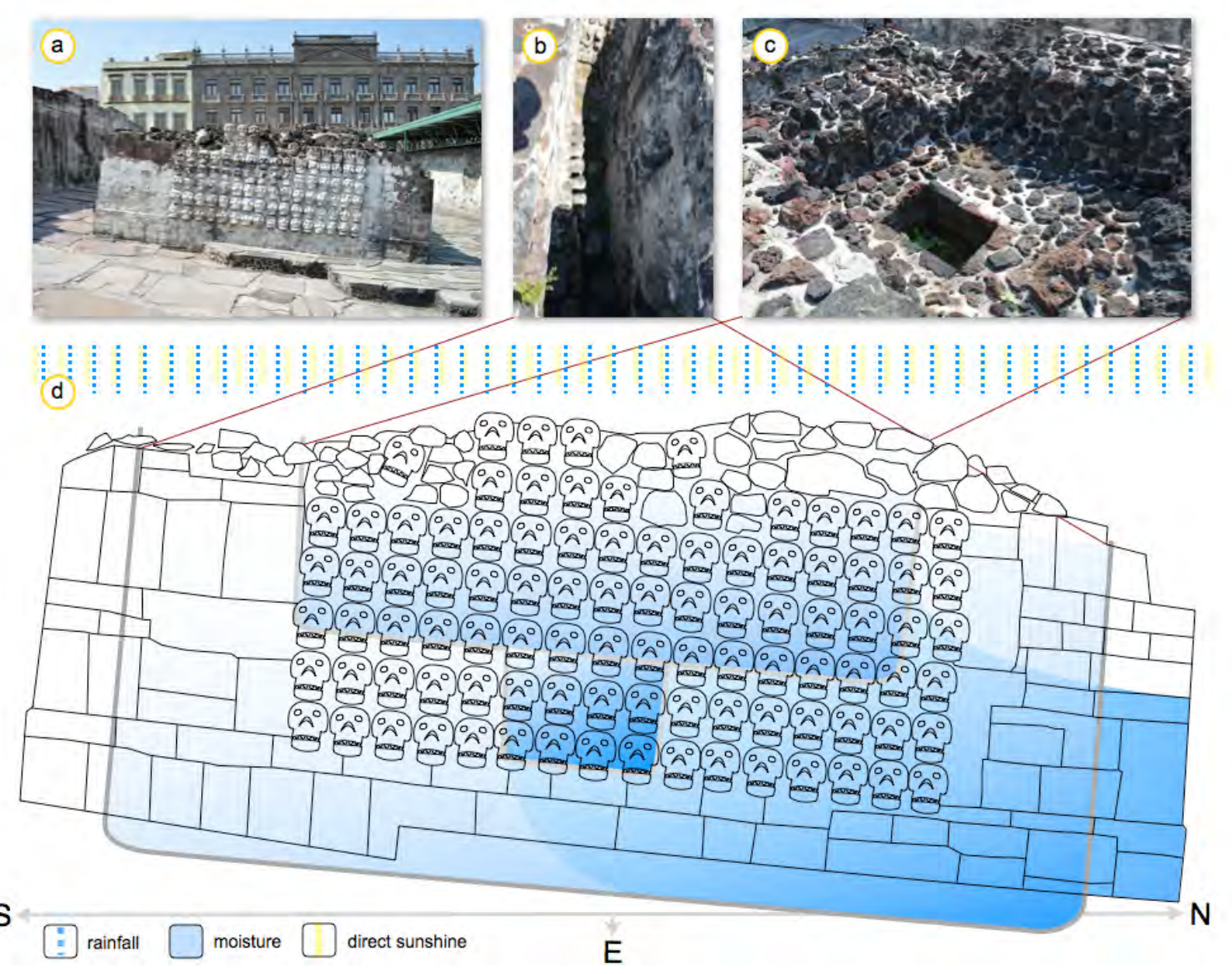

Figure 46: a) The movement of the whole structure of the Tzompantli altar is noticeable by the historical buildings in the background. b) The trench-like structure behind the east side. c) The stepwise lowered building structure at the top of the center. d) The hydrological situation of the Tzompantli Temple leads to an accumulation of humidity at the north side. 
The south side is raised while the north side is fallen (Fig. 46 a). Parallel behind the east side of the altar building a deep trench is located (Fig. 46 b). The enclosing walls of the rest of the building are stepwise lowered as is shown in Figure $46 \mathrm{c}$ and d. Within the deepest parts of the structure plants are growing, which indicates that there is much humidity. During the rainy season the building acts like a bathtub. The water stream is directed to the north side (Fig. $46 \mathrm{~d}$ ). Most weathering phenomena such as sanding, flaking, loss of the lime wash and color at the skulls, salt efflorescences and contour scaling are located on the skulls of the north side.

\section{2. 3. b) Quantified mapping}

The three walls of skulls were mapped. The areas where a lime wash still occurs and in parts where residual colors are found were mapped in green and defined as still conserved. Surface loss due to different weathering forms were mapped in red, wet areas in blue (Fig. 47).
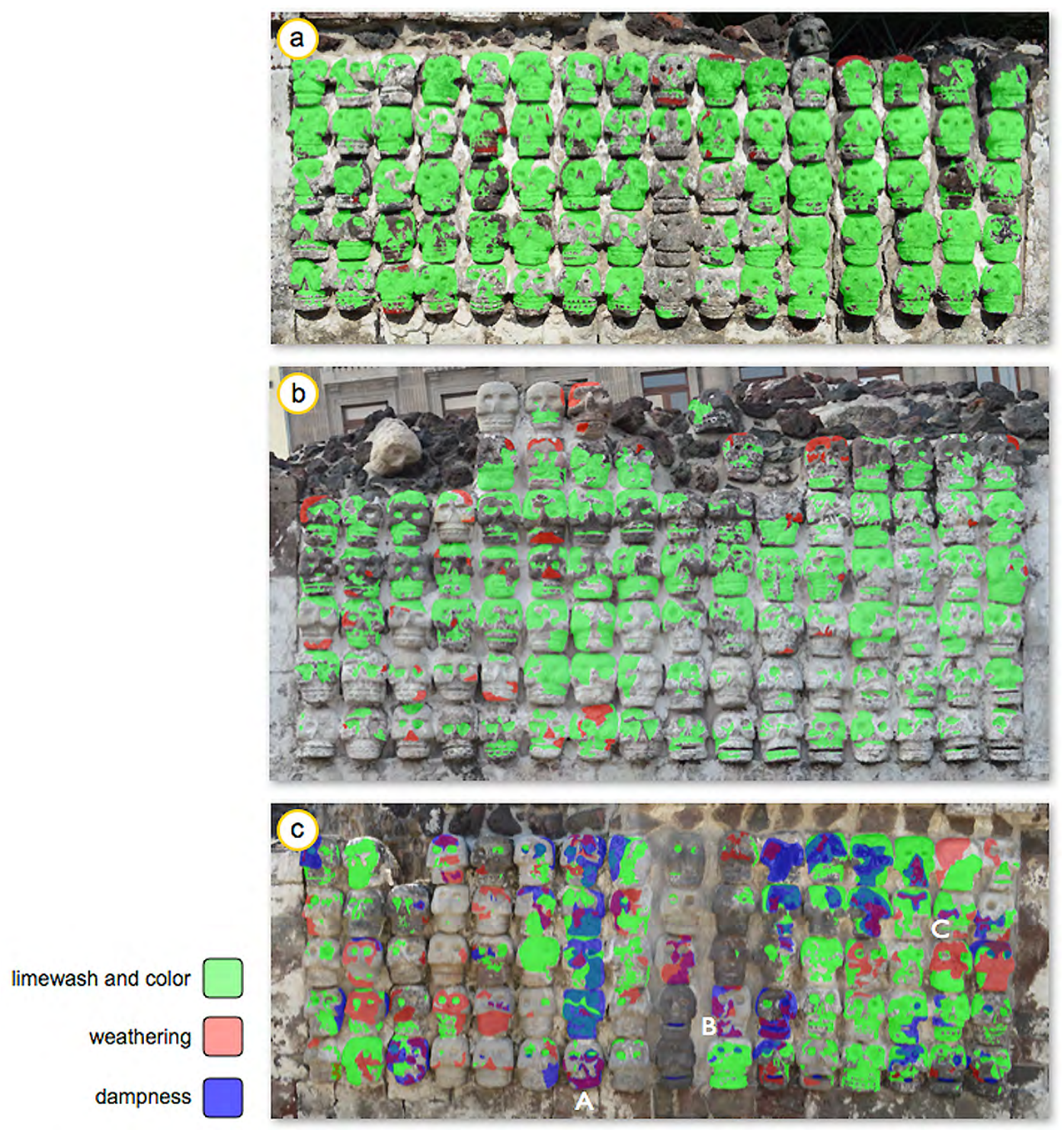

Figure 47: a) The skull wall at the south side with forms of weathering and conditions, b) the east side and c) the north side, complete with the sampling points of the salt samples. 
The best state of conservation is seen on the south side: $51 \%$ of the area is still covered with the original lime wash and color. Only $0.3 \%$ of the surface is affected by weathering. Weathering forms found here are delamination and also microorganisms can be found (Mora Navarro 2015). Twenty percent of the surface of the east side is still colored with lime wash (Fig. 47 a). Areas of weathering with less than $1 \%$ show the same results like the south side (Fig. 43 b). The main weathering form found here is fragmentation (Mora Navarro 2015). The north side only shows $18 \%$ lime wash (Fig. $47 \mathrm{c}$ ). Twelve percent were wet at the time of investigation in October 2014 and $9 \%$ exhibits weathering forms mainly as contour scaling but also fragmentation (Mora Navarro 2015). These weathering forms are often associated with salt efflorescences.

The bad condition of the north site can be traced back to its critical topographic position to moisture accumulation, further conservation treatments as well as to the fact, that most sculls are made from high porous tuffstones. A petrografic mapping made by Mora Navarro (2015) shows that 43 sculls $(54 \%)$ are made from tuff, 31 (39\%) from tezontle and $5(6 \%)$ from basalt like resinto. At the east site $23(23 \%)$ sculls consist of tuff, $63(66 \%)$ tezontle and $10(8 \%)$ from basalt. The south site is clearly dominated by 79 sculls of texontle (99\%). Only one skull is made from tuff.

\section{2. 4 The salt of Mexico City}

Parts of the building are affected by dampness and salt weathering. The famous Tzompantli altar decorated with 240 human skulls made of different types of volcanic stones suffers from an extreme salt weathering. The salt-mixture collected at three skulls, taken from the north side of the monument are presented in Table 2 .

Table 2: lonic distribution of the salt taken from the different skuls.

g/kg TS

\begin{tabular}{lcccc}
\hline lons & Skull A & Skull B & Skull C & Average \\
chloride & 3.09 & 1.23 & 0.626 & 1.64 \\
nitrate & 18.9 & 24.7 & 10.8 & 18.13 \\
sulfate & 750 & 99.3 & 420 & 423.1 \\
bromide & $<1$ & $<1$ & $<1$ \\
sodium & 346 & 6.6 & 173 & 182.33 \\
potassium & 6.85 & 0.293 & 0.776 & 4.742 \\
magnesium & 0.373 & 22.1 & 0.32 & 0.328 \\
calcium & 1.6 & 24.3 & 16 \\
\hline
\end{tabular}


The high calcium content in sample B and $\mathrm{C}$ is probably residual lime wash that can be found at both skulls (Fig. 46 c). Sodium sulfate is the dominant salt. Its damage potential is well known, and therefore used in standardized salt resistance tests like those performed in this thesis.

\section{2. 5 Palace of the dukes of Heras Solo}

The Palace of the Dukes of Heras Soto was built during the period, 1753-1760, and was the representative domicile of Adrián Ximénes de Alendral, a rich tradesman for silver (Fig. 37 b). The name given to the palace-like residence was because of its aristocratic inhabitant in the nineteenth century (Demm 1991). The building in style and construction is a typical exponent of the baroque colonial palace in Mexico City. The residence is nearly 40 by 40 meters in size and is a two-storied building with a center court and arcaded sidewalk. The domicile is located at a distance of two blocks northwest from the cathedral. The first comprehensive restoration took place in 1978. In 1931, the building was declared a historic monument and is part of the UNESCO World Heritage List of Mexico City. The bare brickwork of the typical palaces and houses are made of bricks and adobe, whereas different building stones cover the façades. The same construction is found in the Palace Heras Soto. Beside tezontle, recinto, and tenayocátetl, the most dominant building stone is "cantera" Gris de los Remedios (sample III.). The ornamental sculpture of the facade is made from these devitrified tuffs (Fig. $42 \mathrm{~b}$ and $48 \mathrm{a}$ ).
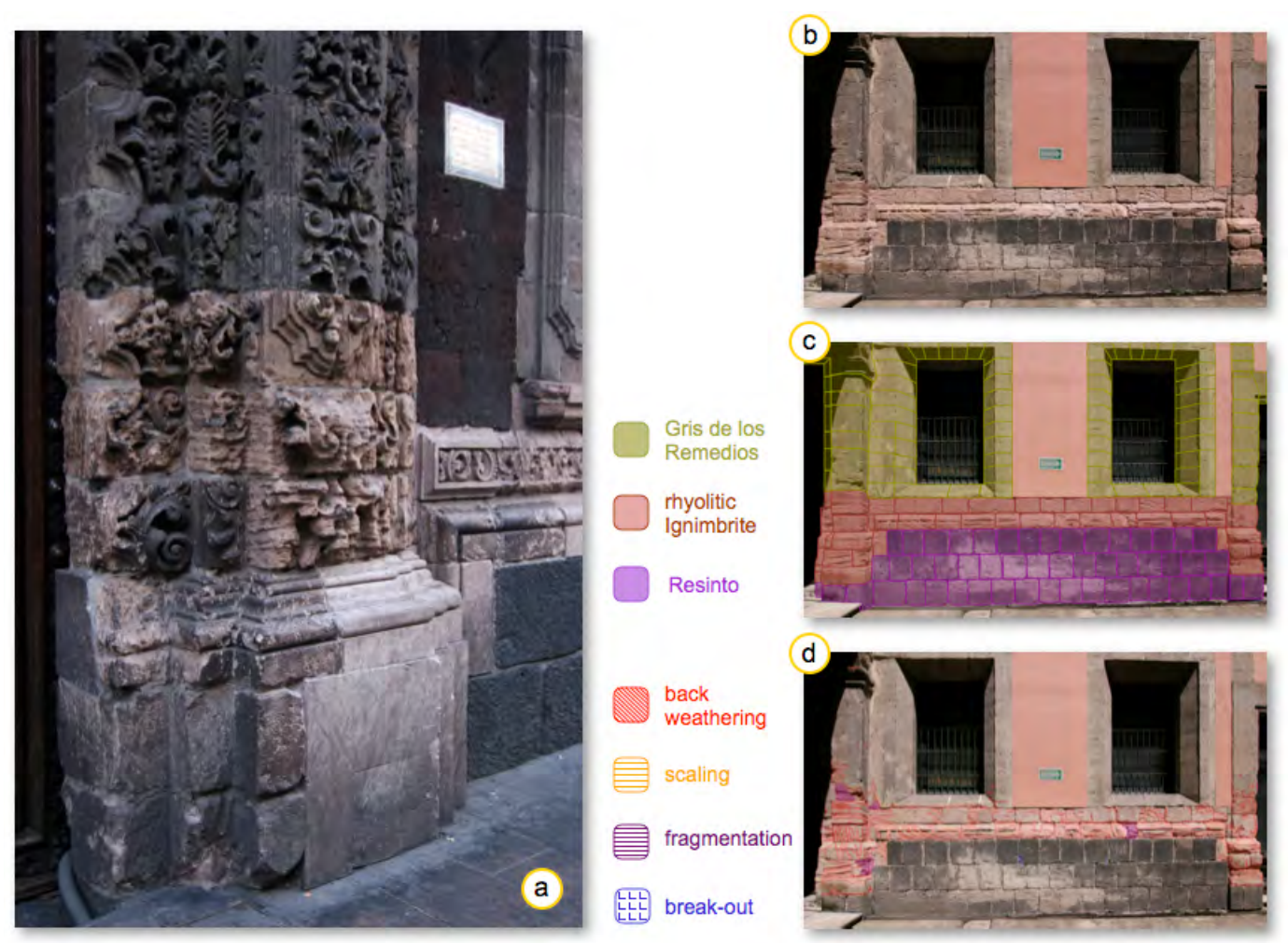

Figure 48: a) Weathered and replaced building stones at the ground level, b) mapping area, c) lithographic mapping, and d) map of damages. 


\section{2. 5. a) Deterioration and weathering forms}

Weathering can be recognized in the basement area of the building, especially where the sunlit façades are affected by deterioration (Fig. 48 a and d). In the case of this colonial building, the material of the tenayocátetl variety is used as building blocks, mostly horizontal to the observable bedding or flow structure. The tenayocátetl variety shows extreme back-weathering of layers and partial detachment by fragmentation. Ashlars are used like plates, which means perpendicular to the flow structure. At many of these ashlars scaling is observable. Consequently, the outline of single ashlars shows rounding (Fig. 48 a and d). Weathering also takes place on the tuff stone connected to the basement area. Two weathering forms can be distinguished: scaling with a thickness up to $1 \mathrm{~cm}$ parallel to the surface and rounding by splitting and sanding (Fig. 48 c). In general, the Gris de los Remedios shows a high resistance to weathering. Only in building parts exposed to wet-dry conditions, like the foundations or balconies, can back-weathering be detected.

\section{2. 6 The Metropolitan Cathedral}

The Metropolitan Cathedral of Mexico City was constructed from 1573 to 1813 on the former Aztec ceremonial center. The cathedral is the largest and oldest in the Americas (Fig. $42 \mathrm{c}$ ). The cathedral facades are oriented to the south and are approximately $54.5 \mathrm{~m}$ wide and $110 \mathrm{~m}$ long. The two bell towers were constructed in the latter half of the eighteenth century. The building combines different architectural styles like the Baroque, Neo-Renaissance, and Neo-Classic.
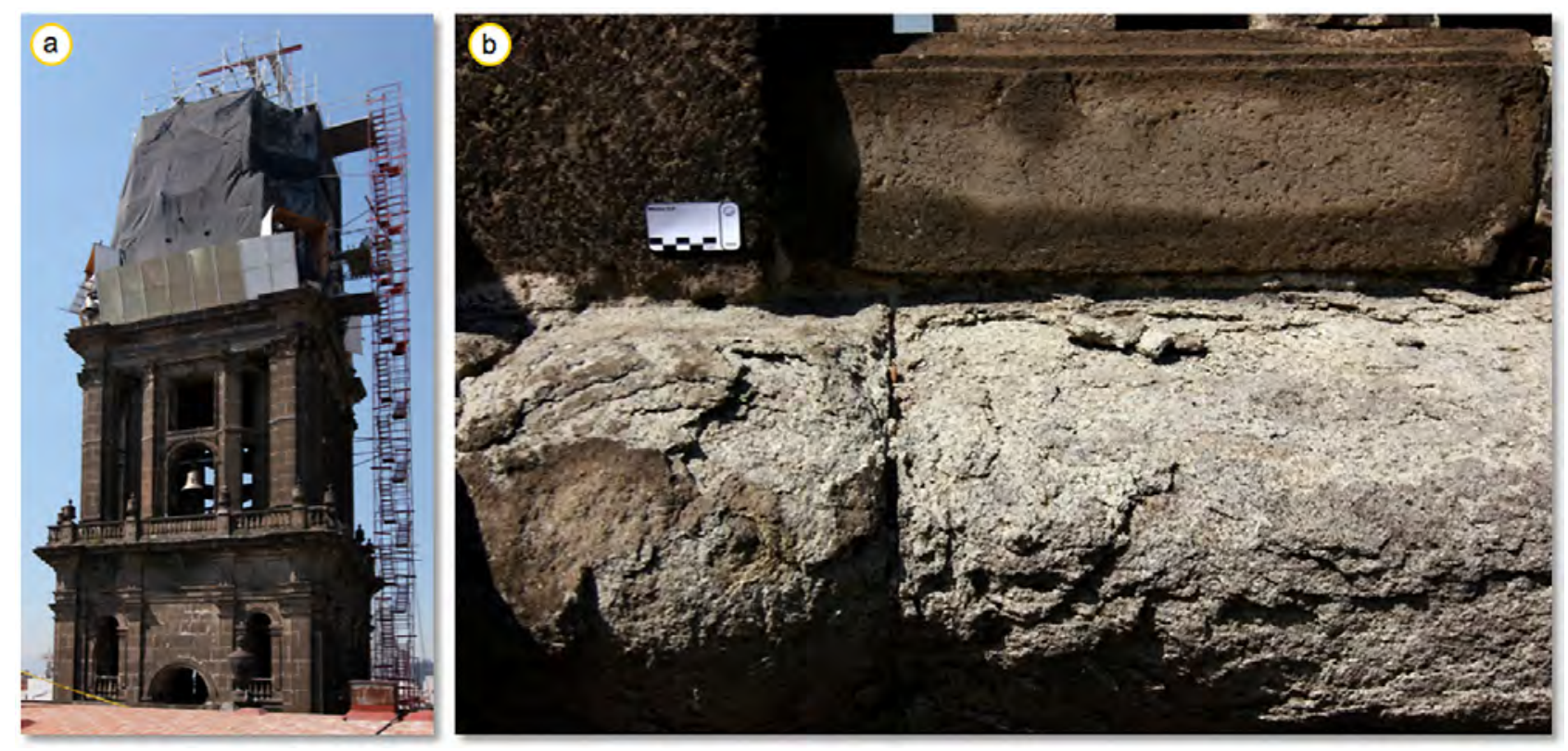

Figure 49: a) The left tower of the cathedral under restoration in 2009. b) Typical weathering forms consisting of gypsum crust formation, scaling and rounding of a sculpture at the Metropolitan Cathedral.

Seismic activity and ground subsidence in the area has affected the cathedral's construction. Besides the structural problems, weathering takes place especially on building parts exposed to wet-dry 
conditions. Restorations have been carried out throughout the entire history of this large building. After the restoration of the cupola during the last several years, the bell towers are now currently undergoing restoration. Because the cathedral was constructed over a period of more than two centuries, the building shows a mixture of different architectural styles, but also a mixture of various building stones was used on different parts of the building that originated from the Valley of Mexico. The main building stones consist of tezontle, tuffstone, and andesite (Pirella, Ramírez 2001). A gray to green colored pyroxene andesitic tuff (IV) was used for the main facade and the two towers. Present-day restoration work uses a similar variety originating from the Chiluca quarries (sample V.). This study focuses on the building materials used because of their significant weathering features and their importance as historical building materials. The pyroxene andesite of the Metropolitan Cathedral shows a typical weathering form starting with crust formation, probably due to gypsum and then scaling due to flaking and rounding (Fig. 49 b). During the process of weathering, the first centimeter of the stone material is especially affected by crust formation and delamination.
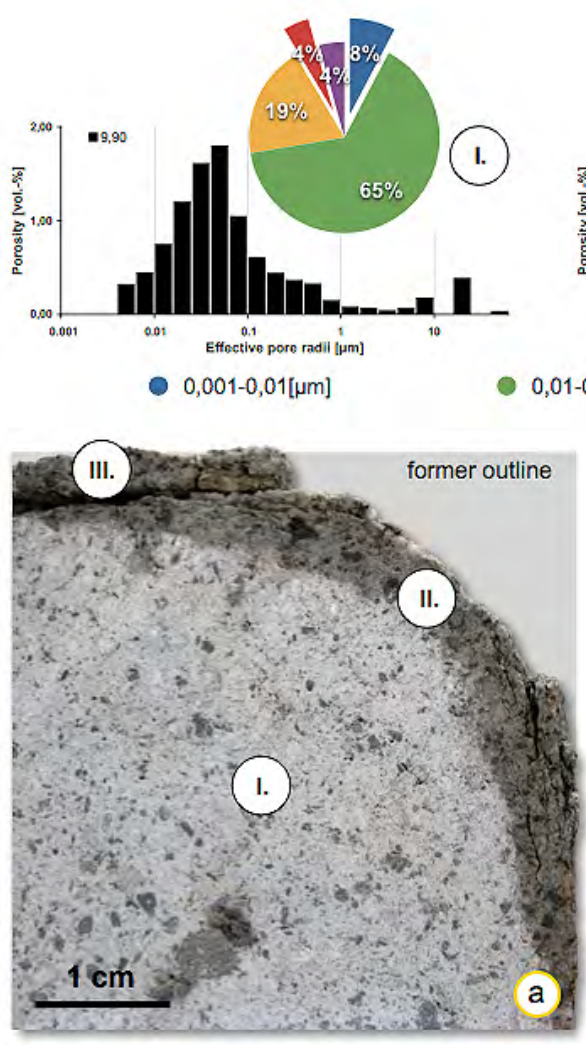

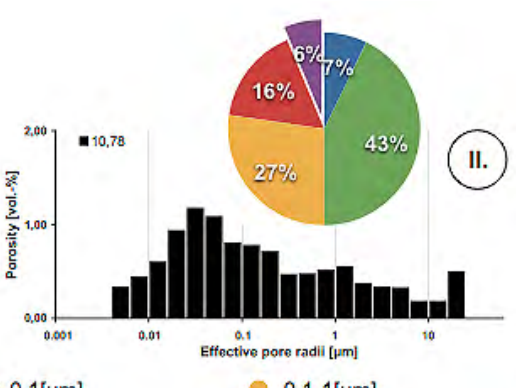

$0,1-1[\mu \mathrm{m}]$

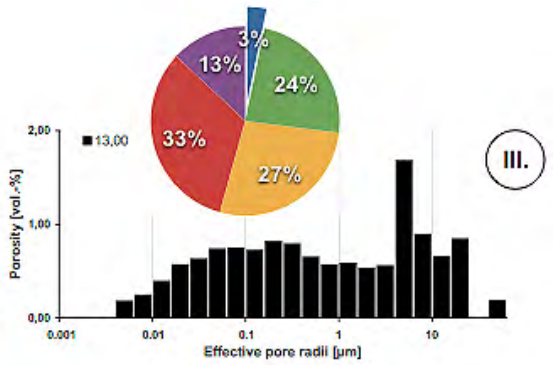

- $1-10[\mu \mathrm{m}]$

$10-100[\mu \mathrm{m}]$

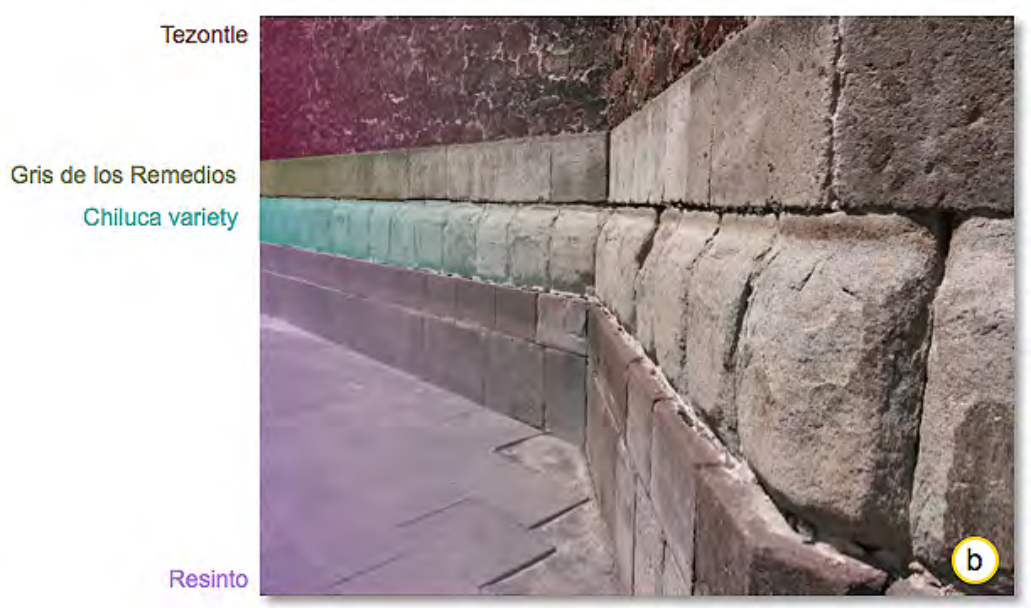

Figure 50: a) I, II and III depict changing pore radii distributions corresponding to the different zones of weathering. b) Truncated stone sample of pyroxene andesitic tuff from the Metropolitan Cathedral. c) Typical arrangement of the different rock types used in a historical building in Mexico City. Crust formation and rounding are visible in the

Chiluca variety.

Crust formation takes place by the formation of gypsum within the first few millimeters because of the sulfatic pollution and the quite high $\mathrm{CaO}$ content $(4.5 \%)$ of the stone. Thus, the pore radii distribution, porosity, capillary water uptake, and hardness change. Tests conducted in the laboratory 
with this weathered material clearly demonstrated this process. After the moistening of a truncated stone sample, the water penetrates and remains in the weathered zone only (Fig. 50 b). Here the pore size contribution changes for the benefit of a higher amount of capillary active pores from 27 to $76 \%$ in comparison to the unweathered material (Fig. 50 I-III). Porosity increases from 10 to 13 $\%$ (Fig. 50 I-III), whereas the surface hardness measured with a durometer DO (ASTM D 2240), decreases down to $70 \%$ in comparison to the intact material. Today the outlines and sharp edges of cut stones are often back-weathered. These weathering processes take place especially in the pedestal area (Fig. 50 c) or in building parts, which are exposed to rain and downward flowing water.

\section{2. 7 Rock fabrics and petrophysical properties}

\section{2. 7. a) Tezontle basalt (I)}
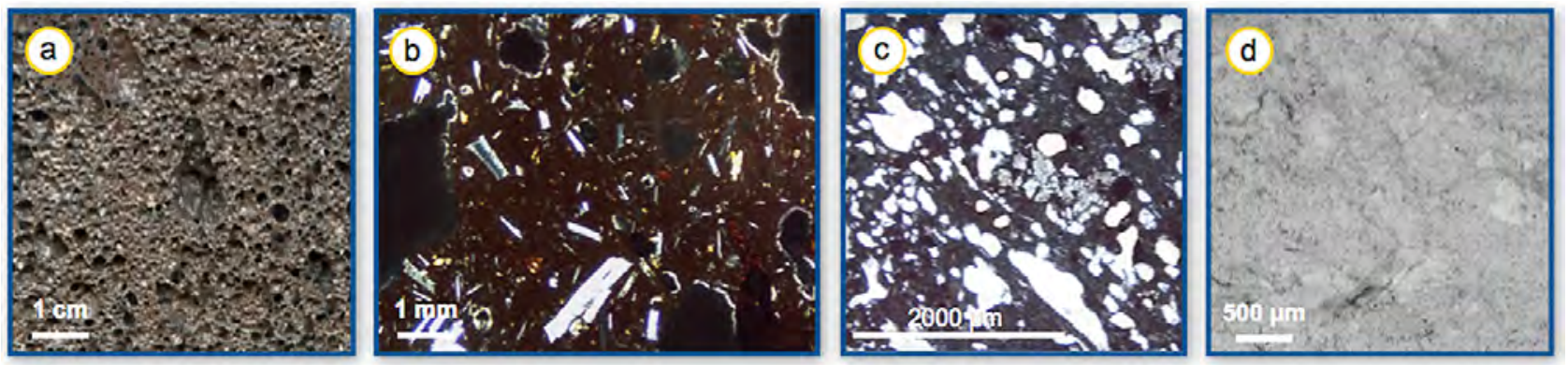

Tezontle basalt, Estado de México / Mexico

Figure 51: The Tezontle basalt: a) macroscopic view, b) thin section in polarized light shows a cryptocrystalline fabric with acicular plagioclase crystals, c) thin section in transmitted light showing the vesicular fabric and d) SEM photograph showing the surface of the cryptocrystalline fabric.

Fresh material of the vesicular Tezontle basalt (I) was investigated, which was obtained from a nearby quarry in Mexico City. Macroscopically it shows a typical cellular fabric (Fig. 51 a). The voids are predominantly $8 \mathrm{~mm}$ in diameter. Locally, partially melted rock fragments from older volcanic rocks are incorporated. These fragments show irregular shapes with a red colored rim, which can be traced back to iron oxide minerals (Fig. 51 b). Microscopically the cell walls of the cellular rock fabric show a cryptocrystalline fabric with acicular plagioclase crystals. Only isolated small pyroxene and amphibole crystals as well as hematite impregnations occur (Fig. 51 b). X-ray fluorescence analyses after Acevedo-Dávila et al., (2007) show that the Tezontle basalt contains approximately $60 \% \mathrm{SiO}_{2}, 12 \% \mathrm{Al}_{2} \mathrm{O}_{3}, 8 \% \mathrm{MgO}, 5 \% \mathrm{Fe}_{2} \mathrm{O}_{3}, 4 \% \mathrm{CaO}$ and $3 \% \mathrm{Na}_{2} \mathrm{O}$. The material is permeated by fractures and small cracks. The porosity in non-weathered parts ranges from 35 to 66 $\%$ with an average value of 52 vol.- $\%$. This strong variation in the porosity can be traced back to its heterogeneous cellular structure. Due to the high porosity the bulk density with a value of $1.4 \mathrm{~g} / \mathrm{cm}^{3}$ is very low. The particle or matrix density reaches a value of about $2.71 \mathrm{~g} / \mathrm{cm}^{3}$. Mafic minerals like pyroxene and amphibole probably cause this relatively high value. The average w value only reaches $0.40 \mathrm{~kg} \mathrm{~m}^{-2} \mathrm{~h}^{-1 / 2}$. Active capillary pores amount to $76.2 \%$ of the pore radii distribution by a 
considerable outbalance of larger capillary pores $(10 \mu \mathrm{m}=43.7 \%)$ and macropores (Tab. 3). Furthermore, the basalt exhibits no measurable hygric swelling but with $7.0 \mathrm{~mm} / \mathrm{m}$ at $90^{\circ} \mathrm{C}$ a relatively high thermal dilatation coefficient (Tab. 5). A residual strain after five cycles could not be detected. Under dry conditions, the compressive strength ranges from 12 to $32 \mathrm{~N} / \mathrm{mm}^{2}$. The highest values are reached in the $Z$ direction with an average of $27 \mathrm{~N} / \mathrm{mm}^{2}$. The lowest values were measured in the $Y$ direction with an average of around $21 \mathrm{~N} / \mathrm{mm}^{2}$. The anisotropy amounts to nearly $21 \%$ (Tab. 4). The modulus of elasticity ranges from 3.57 to $8.34 \mathrm{kN} / \mathrm{mm}^{2}$ with an anisotropic behavior of around $13 \%$. The uniaxial compressive strength is with $23.8 \mathrm{~N} / \mathrm{mm}^{2}$ very low. Under dry sample conditions, the strength varies between 21.33 and $26.90 \mathrm{~N} / \mathrm{mm}^{2}$. In contrast, the uniaxial compressive strength values of the water-saturated specimens are $3 \%$ higher and range between 27.76 and 22.31 $\mathrm{N} / \mathrm{mm}^{2}$ (Tab. 6). This is caused by the rock heterogeneity, and thus the rock strength does not depend on the water content. The Young's modulus of the Tezontle rock is around $5.7 \mathrm{kN} / \mathrm{mm}^{2}$ (Tab. $6)$.

Table 3: Pore space and density properties of the investigated rocks.

\begin{tabular}{cccccccccc}
\hline Rock type & $\begin{array}{c}\text { Porosity } \\
{[\text { Vol.-\%] }}\end{array}$ & $\begin{array}{c}\text { Bulk } \\
\text { density } \\
{\left[\mathbf{g}^{-} \mathbf{c m}^{-3}\right]}\end{array}$ & $\begin{array}{c}\text { Particle } \\
\text { density } \\
{\left[\mathbf{g} \cdot \mathbf{c m}^{-3}\right]}\end{array}$ & $\begin{array}{c}\text { Average } \\
\text { pore radius } \\
{[\mathbf{\mu m}]}\end{array}$ & $\begin{array}{c}0.001-0.01 \\
{[\mu \mathrm{m}]}\end{array}$ & $\begin{array}{c}\text { Pore radii distribution [\%] } \\
0.01-0.1 \\
{[\mu \mathrm{m}]}\end{array}$ & $\begin{array}{c}0.1-1[\mu \mathrm{m}] \\
1-10[\mu \mathrm{m}]\end{array}$ & $>10[\mu \mathrm{m}]$ \\
\hline Tezontle & 51.8 & 1.40 & 2.71 & 1.870 & 8.3 & 15 & 10 & 22.5 & 43.7 \\
Cathedral & 10.6 & 2.40 & 2.68 & 0.114 & 5.9 & 56.3 & 23.8 & 2.9 & 10.9 \\
Chiluca & 8 & 2.37 & 2.58 & 0.358 & 4 & 22.8 & 40 & 30 & 3.2 \\
Tenayocátetl & 7.3 & 2.27 & 2.45 & 0.303 & 9.2 & 37.8 & 15.8 & 19.6 & 17.5 \\
Remedios & 28.2 & 1.82 & 2.55 & 1.285 & 0 & 15.3 & 18.8 & 55 & 10.9 \\
\hline
\end{tabular}

Table 4: Moisture transport properties of the investigated rocks in non-weathered condition (anisotropy calculated with $\left.A=n_{\max }-n_{\min } / n_{\max } * 100\right)$.

\begin{tabular}{|c|c|c|c|c|}
\hline \multirow{2}{*}{ Rock type } & \multicolumn{3}{|c|}{$\mathrm{w}$-value $\left[\mathrm{kg} \mathrm{m}^{-2} \mathrm{~h}^{-1 / 2}\right]$} & \multirow{2}{*}{$A$ [\%] } \\
\hline & $x$ & $\mathrm{Y}$ & Z & \\
\hline Tezontle & 0.39 & 0.45 & 0.38 & 15.5 \\
\hline Tenayacátetle & 0.11 & 9.16 & 0.1 & 98.9 \\
\hline Remedios & 8.3 & 9.08 & 6.21 & 30.8 \\
\hline Cathedral & 0.3 & 0.37 & 0.32 & 18.9 \\
\hline Chiluca & 0.39 & 0.34 & 0.38 & 1.3 \\
\hline
\end{tabular}




\section{2. 7. b) Tenayocátetl rhyolitic ignimbrite (II)}
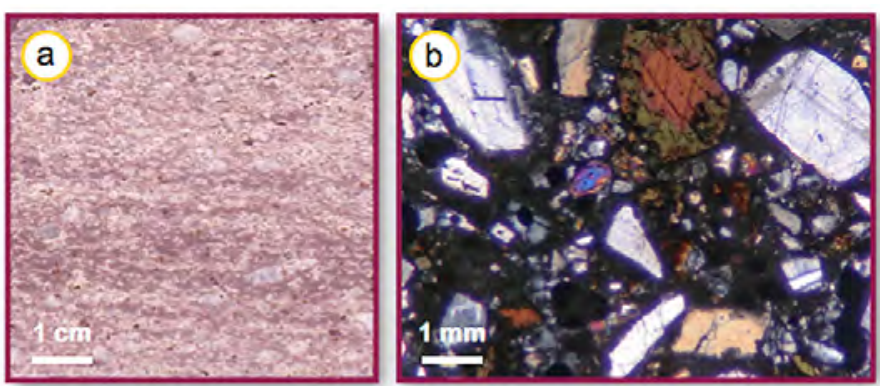

$\pi Y$

Tenayacátetl rhyolitic ignimbrite, Estado de México / Mexico
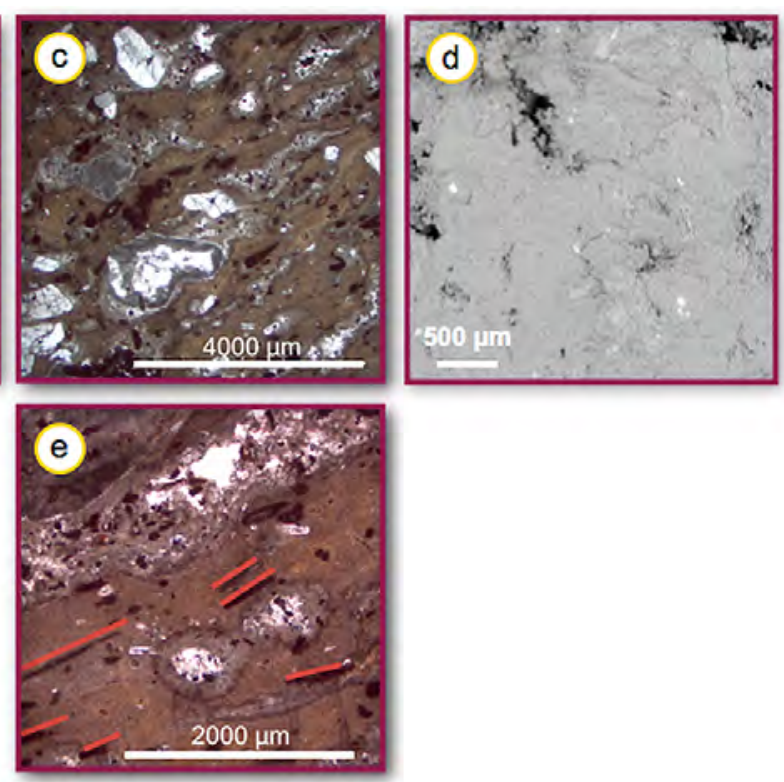

Figure 52: The Tenayocátetl rhyolitic ignimbrite: a) macroscopic view, b) thin section in polarized light showing altered crystals of plagioclase, hornblende, andesine, oligoclase, labradorite and augite, c) thin section showing former gas space vesicles, d) SEM photograph showing the surface of the fabric, and e), small acicular crystals define the flow direction in the fine matrix (red lines).

The Tenayocátetl (II) volcanic rock is grayish to red in color and is characterized by a porphyritic fabric. The rock exhibits a rhyolitic composition and represents a welded ash tuff with a small portion of lapilli fragments. This rock shows the characteristic foliation that is caused by flow structures (Fig. $52 \mathrm{a}$ and e). The lapilli fragments mainly show rounded quartz. Altered crystals of plagioclase, hornblende, andesine, oligoclase, labradorite and augite are observable (Fig. 52 b). Within the fine matrix, small acicular crystals define the flow direction (Fig. 52 e). This matrix is colored in layers from light red to dark red because of kaolinite and hematite (Fig. 52 a).

Table 5: Thermal expansion coefficients $(\alpha)$ and the residual strain of one heating cycle $\left(20^{\circ} \mathrm{C}-60^{\circ} \mathrm{C}\right.$ $20^{\circ} \mathrm{C} / 20^{\circ} \mathrm{C}-90^{\circ} \mathrm{C}-20^{\circ} \mathrm{C}$ ) as well as the hygric expansion of the investigated rocks in non-weathered condition (anisotropy calculated with $A=n_{\max }-n_{\min } / n_{\max } * 100$, n.d. $=$ not detectable).

\begin{tabular}{ccccccccc}
\hline \multirow{2}{*}{ Rock type } & \multicolumn{3}{c}{ Thermal dilatation $(\boldsymbol{\alpha})$} & \multicolumn{4}{c}{ Hygric expansion } \\
\cline { 2 - 8 } & $\begin{array}{c}\mathrm{X} \\
{\left[\mathrm{mm} \mathrm{m}^{-1}\right]}\end{array}$ & $\begin{array}{c}\mathrm{Y} \\
{\left[\mathrm{mm} \mathrm{m}^{-1}\right]}\end{array}$ & $\begin{array}{c}\mathrm{Z} \\
{\left[\mathrm{mm} \mathrm{m}^{-1}\right]}\end{array}$ & $\mathrm{A}[\%]$ & $\begin{array}{c}\mathrm{X} \\
{\left[\mathrm{mm} \mathrm{m}^{-1}\right]}\end{array}$ & $\begin{array}{c}\mathrm{Y} \\
{\left[\mathrm{mm} \mathrm{m}^{-1}\right]}\end{array}$ & $\begin{array}{c}\mathrm{Z} \\
{\left[\mathrm{mm} \mathrm{m}^{-1}\right]}\end{array}$ & $\mathrm{A}[\%]$ \\
\hline Tezontle & $/ 0.70$ & $/ 0.69$ & $/ 0.75$ & 7.3 & $\mathrm{n} . \mathrm{d}$. & $\mathrm{n} . \mathrm{d}$. & $\mathrm{n} . \mathrm{d}$. & - \\
Cathedral & $0.43 / 0.79$ & $0.49 / 0.77$ & $0,53 / 0.75$ & 5.1 & 3.05 & 2.98 & 3.05 & 2.3 \\
Chiluca & $0.52 / 0.78$ & $0,48 / 0.84$ & $0.54 / 0.68$ & 18.6 & 2.82 & 2.81 & 3.02 & 6.9 \\
Tenayocátetl & $0.58 / 0.97$ & $0.48 / 0.96$ & $0.58 / 0.98$ & 2.2 & 2.76 & 3.14 & 5.68 & 51.4 \\
Remedios & $/ 0.67$ & 0.57 & $0.28 / 0.60$ & 14.9 & 4.94 & 5.88 & 6.21 & 20.4 \\
\hline
\end{tabular}


Table 6: Compressive strength, ultrasonic velocity and surface hardness in dry and water-saturated conditions as well as the elastic modulus.

\begin{tabular}{|c|c|c|c|c|c|c|}
\hline Rock type & $\begin{array}{l}\text { Direction I } \\
\text { Anisotropy }\end{array}$ & Tezontle & Cathedral & Chiluca & Tenayocátetl & Remedios \\
\hline \multirow{4}{*}{$\begin{array}{c}\text { Compressive } \\
\text { strength dry } \\
{\left[\mathrm{N} / \mathrm{mm}^{2}\right]}\end{array}$} & $x$ & 23.40 & 105.02 & 91.94 & 50.82 & 17.25 \\
\hline & $Y$ & 21.33 & 97.78 & 83.2 & 50.86 & 16.58 \\
\hline & Z & 26.90 & 91.88 & 90.58 & 50.82 & 18.08 \\
\hline & $\mathrm{A}[\%]$ & 20.7 & 12.5 & 20.7 & 7 & 8.29 \\
\hline \multirow{4}{*}{$\begin{array}{c}\text { Compressive } \\
\text { strength water } \\
\text { saturated }\left[\mathrm{N} / \mathrm{mm}^{2}\right]\end{array}$} & $x$ & 23.67 & - & 76.45 & - & 10.03 \\
\hline & $\mathrm{Y}$ & 22.31 & - & 68.73 & - & 9.67 \\
\hline & Z & 27.76 & - & 71.29 & - & 10.82 \\
\hline & $\mathrm{A}[\%]$ & 19.6 & - & 10.0 & - & 10.62 \\
\hline $\begin{array}{c}\text { Compressive } \\
\text { strength Reduc- } \\
\text { tion [\%] }\end{array}$ & & +3.01 & - & -19.6 & - & -41.2 \\
\hline \multirow{4}{*}{$\begin{array}{l}\text { Ultrasonic velocity } \\
{[\mathrm{km} / \mathrm{s}] \text { dry }}\end{array}$} & $x$ & 3.470 & 2.728 & 3.979 & 3.933 & 2.596 \\
\hline & $\mathrm{Y}$ & 3.452 & 2.740 & 4.098 & 3.975 & 2.531 \\
\hline & Z & 3.365 & 3.02 & 3.991 & 3.741 & 2.581 \\
\hline & $\mathrm{A}[\%]$ & 3 & 9.6 & 2.2 & 5.8 & 3.2 \\
\hline $\begin{array}{c}\text { Surface Hardness } \\
\text { dry [HLD] }\end{array}$ & - & 248 & 719 & 678 & 639 & 323 \\
\hline $\begin{array}{c}\text { Surface Hardness } \\
\text { water saturated } \\
\text { [HLD] }\end{array}$ & - & 241 & 678 & 635 & 612.5 & 281 \\
\hline $\begin{array}{c}\text { Surface hardness } \\
\text { reduction [\%] }\end{array}$ & - & -2.8 & -5.7 & -6.3 & -4 & -13 \\
\hline \multirow{4}{*}{$\begin{array}{l}\text { Young's modulus } \\
{\left[\mathrm{kN} / \mathrm{mm}^{2}\right]}\end{array}$} & $X$ & 58 & 98 & 1270 & 1481 & 314 \\
\hline & Y & 61 & 845 & 1426 & 1342 & 285 \\
\hline & Z & 53 & 102 & 1412 & 1213 & 385 \\
\hline & $\mathrm{A}[\%]$ & 131 & 171 & 109 & 168 & 26 \\
\hline
\end{tabular}

Because of the limited amount of original historical material available, compressive strength tests could only be done in the fabric directions parallel (Y) and perpendicular to the flow direction under dry conditions. Tenayocátetl has a porosity of $7.3 \%$ and a density of $2.45 \mathrm{~g} / \mathrm{cm}^{3}$ (Tab. 3). The w value shows extreme anisotropic behavior of nearly $99 \%$. The $\mathrm{w}$ values in the $\mathrm{Z}$ and $\mathrm{X}$ direction only reach $0.10-0.11 \mathrm{~kg} \mathrm{~m}^{-2} \mathrm{~h}^{-1 / 2}$ and the $\mathrm{Y}$ direction with a value of $9.16 \mathrm{~kg} \mathrm{~m}-2 \mathrm{~h}-1 / 2$ is nearly ten times higher (Table 2). The pore radii distribution shows an amount of nearly $53 \%$ as the sum of all fractions of capillary active pores $(0.1$ to $[10 \mu \mathrm{m})$ as well as a proportionate dominance of micropores $(0.01-0.1 \mu \mathrm{m})$ of nearly $38 \%$ (Tab. 3 ). Thermal dilatation reaches $0.971 \mathrm{~mm} / \mathrm{m}$ with a very low anisotropy of $2.2 \%$ (Tab. 5). Also for the rhyolitic ignimbrite a residual strain after five heating cycles could not be detected. Hygric swelling shows an extreme anisotropic behavior of $51.4 \%$ : hygric swelling in the $Z$ direction with $5.68 \mathrm{~mm} / \mathrm{m}$ reaches a value nearly two times higher than in the other fabric directions (Tab. 3). Compressive strength attains a value of $50.83 \mathrm{~N} / \mathrm{mm}^{2}$ by isotropic 
behavior (Tab. 6). The e-module ranges from 12.13 to $14.81 \mathrm{kN} / \mathrm{mm}^{2}$ with a moderate anisotropic behavior of almost $17 \%$. While the stone shows nearly the same values according to its mechanical properties, the water uptake capacity and the hygric dilatation show extreme anisotropic values (Tab. 4, 5). Water suction only seems to be possible parallel the direction of lineation (Y). Hygric expansion shows an anisotropic value of $51.4 \%$. The expansion perpendicular to the flow direction is almost two times higher than parallel to the direction of foliation or lineation. The thermal expansion shows high values and isotropic behavior (Tab. 5). Thermal expansion attains $5.6 \mathrm{~mm} / \mathrm{m}$ at 60 ${ }^{\circ} \mathrm{C}$ and $9.8 \mathrm{~mm} / \mathrm{m}$ at $90{ }^{\circ} \mathrm{C}$.

\section{2. 7. c) Remedios tuff (Gris de los Remedios, III)}

The volcanic rock of Remedios represents a lapilli tuff (III), supported by an ash matrix. The color of this tuff is gray to light gray. Two types of lapilli fragments are distinguished, one is white in color, and the other is dark. The ash matrix is more or less gray. Within the matrix, dark spots occur that can be traced back to mafic minerals. The mafic minerals often show prismatic crystal shapes and represent mostly idiomorphic developed hornblende crystals. The white lapilli fragments are dominated by pumice. Microscopic examinations revealed the presence of minerals and compounds like crystobalite, clays, sodium plagioclase and hornblende. While the crystals within the inclusions are unaltered, the crystals within the matrix show alteration. Both the matrix and the inclusions are closely connected. Between these two components, no pore space is observable (Fig. $53 \mathrm{~d}$, e, f). The porosity and density of the matrix and the inclusions differ at around $45 \%$. The pore radii distribution also differs in the same dimension (Fig. 53, I and II). The matrix (I) shows a distinct concentration of capillary active pores $(1-10 \mu \mathrm{m})$, while the inclusions (II) show nearly the same volume of capillary active macropores and micropores $(0.001-0.1 \mu \mathrm{m})$. The inclusions define a flow orientation, whereas an orientation of the single crystals within the matrix cannot be discerned. Secondary precipitated calcite is located in small cracks and in the pore space.

Chemical analyses indicate that the calcite comprises $0.8 \mathrm{wt}-\%$. The porosity of Gris de los Remedios ranges from 24.5 to $31.5 \%$, whereas their bulk density is around $1.78-1.92 \mathrm{~g} / \mathrm{cm}^{3}$. The average $\mathrm{w}$ value reaches $7.8 \mathrm{~kg} \mathrm{~m}^{-2} \mathrm{~h}^{-1 / 2}$ with an anisotropy value of $30.8 \%$ (Tab. 2). The amount of capillary active pores comprises $84.7 \%$. From the capillary active pores, a $55 \%$ fraction ranges between 1 and $10 \mu \mathrm{m}$ (Tab. 3). Thermal dilatation reaches an average of $6.14 \mathrm{~mm} / \mathrm{m}$ with a moderate anisotropy of nearly $15 \%$ (Tab. 5). A low residual (irreversible) strain during the five cycles of measurement could be detected. Hygric swelling averages show a value of $5.67 \mathrm{~mm} / \mathrm{m}$ with an anisotropy of $20.4 \%$ (Tab. 5). Under dry conditions, the compressive strength of single samples ranges from 15.8 to $19.3 \mathrm{~N} / \mathrm{mm}^{2}$. The anisotropy amounts to $8.29 \%$ (Tab. 2). 


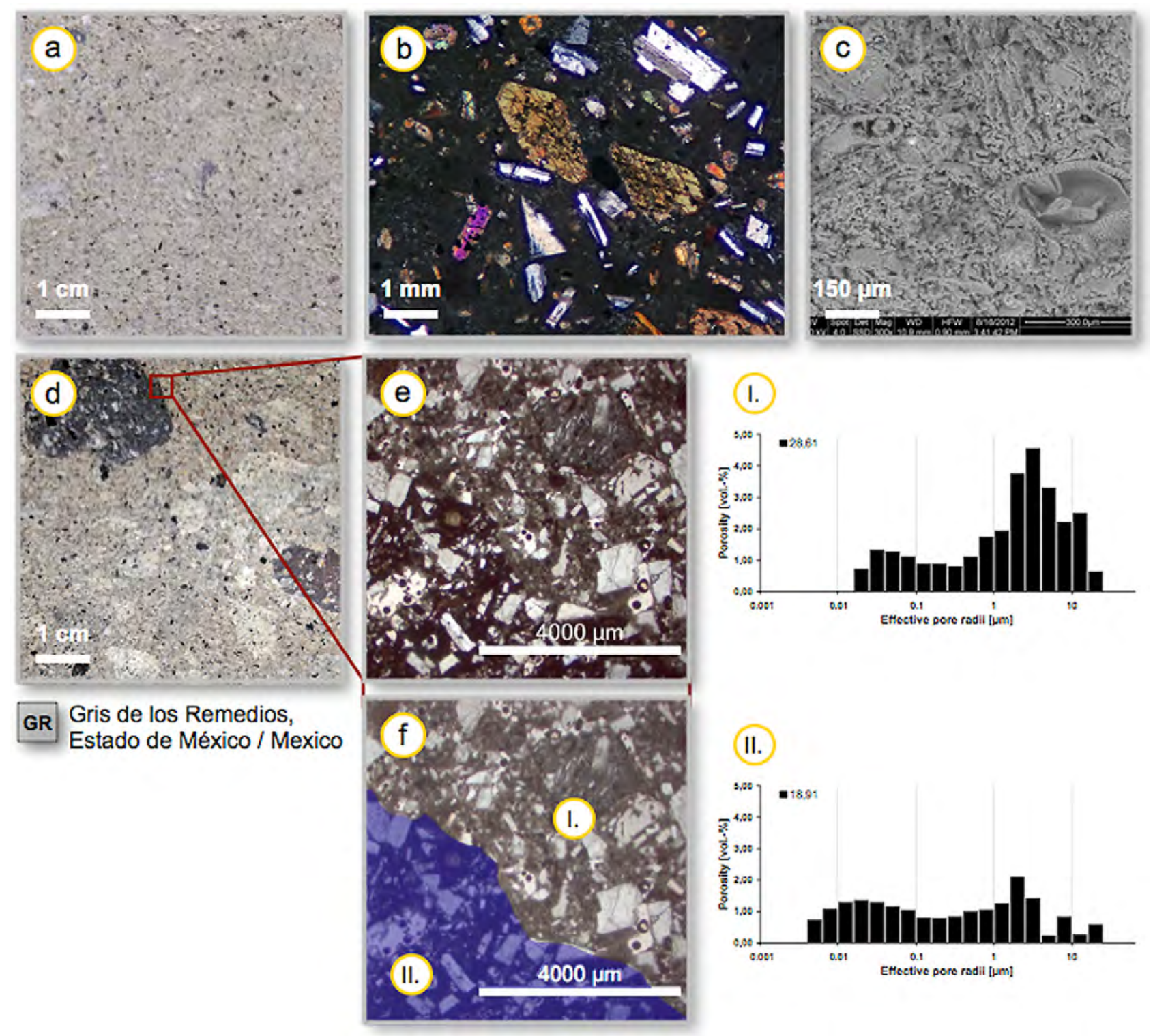

Figure 53: The Gris de los Remedios tuff: a) macroscopic view, b) thin section in polarized light shows altered minerals and compounds like crystobalite, clays, sodium plagioclase and hornblende, c) SEM photograph shows the surface of the fabric, d) dark and light inclusions within the fine matrix, e) well welded matrix and inclusions (blue $=$ dark inclusion) and f) I. pore size distribution of the matrix and II of a dark inclusion.

The elastic modulus ranges from 3 to $5 \mathrm{kN} / \mathrm{mm}^{2}$ with an anisotropic behavior of around $26 \%$. The Remedios variety has an average compressive strength of $17.3 \mathrm{~N} / \mathrm{mm}^{2}$ and an e-module of $8.29 \mathrm{kN} /$ $\mathrm{mm}^{2}$. At water saturation, the compressive strength decreases down to $10.17 \mathrm{~N} / \mathrm{mm}^{2}$ by a moderate anisotropy of $10.6 \%$ (Tab. 6). Compressive strength decreases to $41.2 \%$ according to the measurements under dry conditions (Tab. 6). The stone has a high $\mathrm{w}$ value $\left(7.8 \mathrm{~kg} / \mathrm{m}^{2}\right)$ and a high hygric dilatation and reaches an average value of $5.6 \mathrm{~mm} / \mathrm{m}$. Both values clearly show anisotropy. The wvalue is nearly $31 \%$ and the hygric dilatation $20 \%$ (Tab. 4, 5). Average compressive strength values only reach $17.3 \mathrm{~N} / \mathrm{mm}^{2}$ under dry conditions and decreases to $10.1 \mathrm{~N} / \mathrm{mm}^{2}$ in the water-saturated state, a reduction of $41 \%$ according to the measurements under dry conditions (Tab. 6). The thermal dilatation also reaches critical values of around $4 \mathrm{~mm} / \mathrm{m}$ at $60{ }^{\circ} \mathrm{C}$ and around $6 \mathrm{~mm} / \mathrm{m}$ at 90 ${ }^{\circ} \mathrm{C}$. The curve does not follow a linear gradient. When heating up to $60{ }^{\circ} \mathrm{C}$, a small depression is Wanja Wedekind 
recognized. This reduction is probably caused by the dehydration of crystal water within the material. After five cycles, a residual strain could not be detected. The investigated material originates from the quarries of Los Remedios located in the mountains northwest of Mexico City.

\section{2. 7. d) Chiluca: fresh (IV) and altered (Cathedral), (V)}
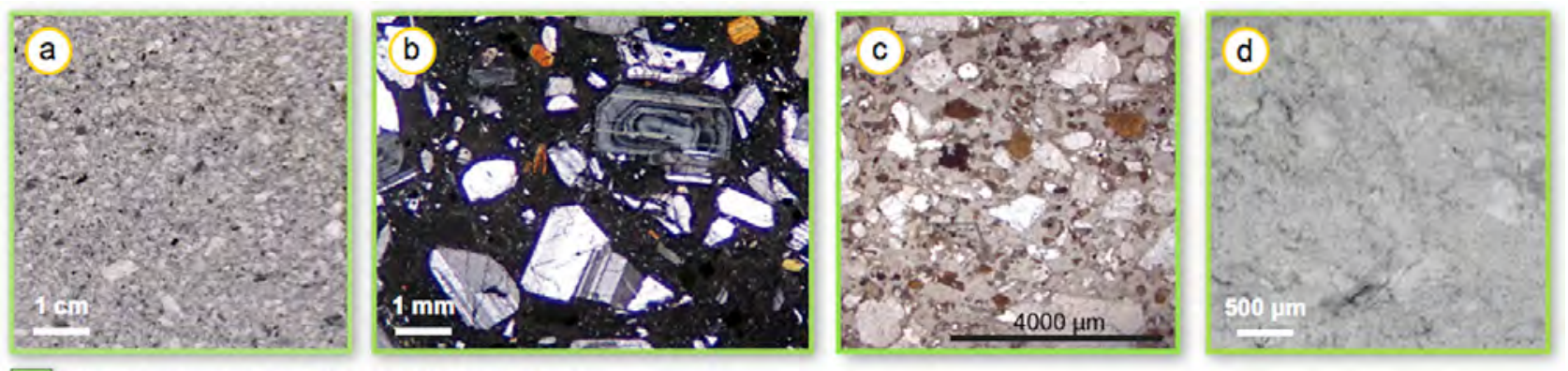

$\mathrm{CH}$ Chiluca andesite tuff, Estado de México / Mexico

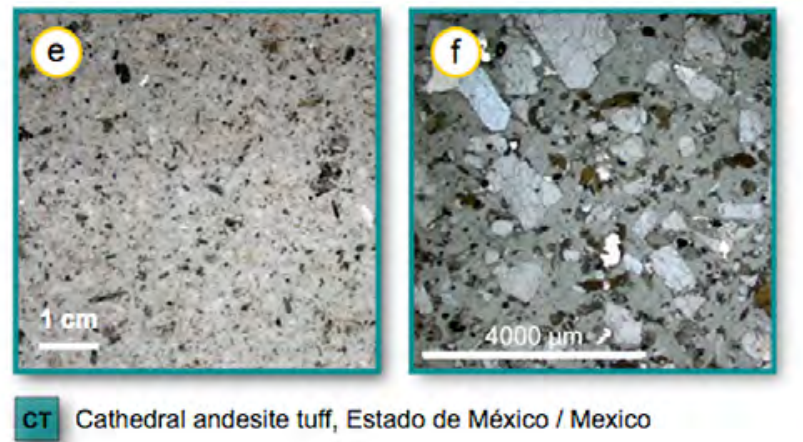

Figure 54: The Chiluca tuff $(\mathrm{CH})$ and the Itztapáltetle andesite $(\mathrm{CT})$ of the cathedral in Mexico City: a) macroscopic view, b, c, and f) microscopic examinations show a vesicular phenoporphyritic texture and microcrystalline matrix consisting of andesite constituents. d) SEM photograph shows the surface of the fabric, e) macroscopic view of the cathedral andesite tuff and $\mathrm{f}$ ) thin section of the alteration of the crystals in the matrix.

Two varieties of the Chiluca pyroxene andesite tuff have been investigated, an altered sample from the cathedral (designated Cathedral), and a fresh sample from a quarry (designated Chiluca). The altered Chiluca tuff sample was removed from the cathedral during the current restoration campaign. The properties of the Chiluca type from the cathedral differ from the fresh sample. The Chiluca tuff represents an ash tuff with a high proportion of fragmented feldspar single crystals, giving the rock a porphyritic appearance. The tuff is gray in color with dark inclusions of mafic minerals, probably amphibole. Feldspar single crystals occur in a fine-grained matrix. Microscopic examinations show that both stone varieties have a vesicular phenoporphyritic texture and microcrystalline matrix consisting of andesite constituents (around $85 \%$ ). In both varieties hornblende crystals are present (around 15 \%) (Martínez, Martínez 1991). Some crystals show alteration (Fig. 54 f) in the sample from the cathedral, whereas the crystals within the matrix of the new stone from the Chiluca quarry are mostly still intact (Fig. 54 b). The Chiluca variety also shows isolated augite crystals and plagioclase (Fig. 54 b). An orientation within the fine matrix cannot be discerned by standard microscopic techniques. Macroscopic observations detected an orientation in the elongated hornblende 
crystals. The porosity measured in the altered cathedral variety is $10.6 \%$ with the density being $2.68 \mathrm{~g} / \mathrm{cm}^{3}$ (Tab. 3). The Chiluca variety comes with a porosity of $8 \%$ and a density of $2.58 \mathrm{~g} / \mathrm{cm}^{3}$ (Tab. 3). Both varieties differ in porosity and density by only $2 \%$. The w value of the cathedral variety averaged $0.33 \mathrm{~kg} \mathrm{~m}^{-2} \mathrm{~h}^{-1 / 2}$ with an anisotropy of nearly $19 \%$, whereas the Chiluca variety shows a w value of $0.37 \mathrm{~kg} \mathrm{~m}^{-2} \mathrm{~h}^{-1 / 2}$ with a moderate anisotropy of around $13 \%$ (Tab. 4). Active capillary pores in the case of the altered cathedral variety reach $37.6 \%$ and in the sample from Chiluca $73.2 \%$ (Tab. 3 ). The highest amount of pore fractions $(56.3 \%)$ within the pore radii distribution in the cathedral variety can be found for micropores with a pore radii size of $0.01-0.1 \mu \mathrm{m}$, whereas the Chiluca variety has a concentration of $40 \%$ for the pore radii fraction ranging from 0.1 to 1 $\mu \mathrm{m}$ (Tab. 3). Thermal dilatation of the altered variety averaged around $7.73 \mathrm{~mm} / \mathrm{m}$ with a low anisotropy of $7.3 \%$ (Tab. 5). Only for the samples from the cathedral, a low residual strain could be detected. Hygric swelling shows a value of $3.02 \mathrm{~mm} / \mathrm{m}$ with a very low anisotropy of only $2.3 \%$ (Tab. 5). In the fresh quarry Chiluca sample, the value of thermal dilatation averaged $7.69 \mathrm{~mm} / \mathrm{m}$ and is comparable to the altered stone, but it has a clear anisotropy of around $19 \%$ (Tab. 5). Hygric swelling reaches an average of $3.1 \mathrm{~mm} / \mathrm{m}$ and is slightly higher than the sample from the cathedral as well as showing an anisotropy of nearly $7 \%$ (Tab. 5). Both varieties have a high compressive strength. The altered variety averaged $98.2 \mathrm{~N} / \mathrm{mm}^{2}$ with an anisotropy of $12.5 \%$, whereas the Chiluca variety shows a value of $88.6 \mathrm{~N} / \mathrm{mm}^{2}$ with an anisotropy of $21 \%$ (Tab. 6). The modulus of elasticity of the cathedral variety ranges from 8.45 to $10.2 \mathrm{kN} / \mathrm{mm}^{2}$ with an anisotropic behavior of around $17 \%$, whereas the Chiluca only shows an anisotropy of $11 \%$ and a averaged e-module of $13.7 \mathrm{kN} / \mathrm{mm}^{2}$. Because of the limited amount of the original historical material, compressive strength by water saturation could only be measured for the fresh Chiluca variety. By compressive strength tests at water saturation, a decrease of nearly $20 \%$ took place in this variety (Tab. 6).

\section{2. 8 Discussion}

All five building stones show different petrophysical properties and specific weathering and deterioration forms under the same environmental conditions. In historical buildings the Tezontle, Resinto and Gris de los Remedios samples show a significant resistance towards weathering, whereas the andesite varieties are more vulnerable for different weathering phenomenon. In field studies the building structure and position of the different building stones within the construction was also regarded.

\section{2. 8. a) Sample I}

I. The main building material in Aztec times, Tezontle, could be easily collected and mined by fracturing because of the moderate hardness with a compressive strength average of $23.8 \mathrm{~N} / \mathrm{mm}^{2}$. The scoria consists mainly of glass and makes the material highly fragile. The low specific density also allowed the stone to be transported by boats (Tab. 3). The material was mostly used as rubble-stone. 
Big building blocks were an exception. Therefore, tezontle could not be used for larger self-supporting structures. The moderate hardness and its premature fracture formation during the lava cooling process seems to be the reason why the material is so susceptible to crack formation. Tezontle nearly shows no hygric swelling and a low w value (Tab. 4) by a moderate compressive strength and a low Young's modulus (Tab. 6). These properties, on the other hand, are ideal for compact structures on muddy ground. The specific material properties seem to be the one contributing factor for the formation of the typical compact outline discernible in Aztec architecture. Water uptake only takes place in the compact mostly reddish colored areas of the material. Only these areas come with a capillary active porosity. These linked pore space areas are sporadic within the material. Therefore, Tezontle does not show any susceptibility neither for rising dampness nor capillary action. Tezontle nearly shows no hygric swelling but a high thermal dilatation (Tab. 5). In Tezontle, crack formation is also detectable because of the improper masonry mortar (Fig. 45 a, Sagarra Lagunes 1993), where the Young's modulus is potentially to high according to the moderate values for Tezontle of $5.73 \mathrm{kN} / \mathrm{mm}^{2}$ (Tab. 6).

Natural building stones were selected in colonial times not only because of their use for decoration but also for building construction purposes. This systematic construction also exemplifies the mapping of the pedestal area as well as the first floor of the Palace of Heras Soto (Fig. 48 c, d). Basalts like Recinto with a low capacity for water uptake and a high resistance towards hygric swelling were mostly used for the basement area followed by an array of an andesitic variety (Figs. $48 \mathrm{c}, 5 \mathrm{~b}$ ). To this day the different basaltic varieties show almost no weathering.

\section{2. 8. b) Sample II}

While the Tenayocátetl variety shows nearly the same values according to its mechanical properties, the water uptake capacity and the hygric dilatation show extreme anisotropic values (Tab. 3, 4). Water suction seems to be possible only more or less through the fluidal direction of the material (Z). Hygric expansion also shows extreme anisotropic values: The expansion perpendicular to the flow direction is almost two times higher than parallel to the direction of foliation or lineation. Thermal expansion shows high values but nearly isotropic behavior (Tab. 5) by reaching a value of $0.56 \mathrm{~mm} /$ $\mathrm{m}$ at $60{ }^{\circ} \mathrm{C}$ and $0.98 \mathrm{~mm} / \mathrm{m}$ at $90^{\circ} \mathrm{C}$. The anisotropic properties in the Tenayocátetl variety with respect to the $\mathrm{w}$ value and the hygric expansion are responsible for the described weathering forms. Water transport, swelling and shrinking pressure and salt seems to be responsible for the deterioration. Scaling of the platform plates of the Templo Mayor can also be increased because of the hydrophobization in the 1980s (Wacker, Meyer 1997).

\section{2. 8. c) Sample III}

In the tuff variety Gris de los Remedios, one reason for its general resistance can be found in the 
bond of the matrix and the inclusions. Both components are closely connected. This bonding seems to be why we find no back-weathering of clastic material. Normally the clastic material weathers out. This is an often recognized phenomenon of many rhyolitic tuffs (Toeroek et al., 2005) and is also found in different tuff varieties of Mexico, like for example in Guadalajara (Jáuregui, Wedekind 2009). Compositionally the stone is classified as an andesitic or trachytic andesitic tuff (Ordonez, Ezequiel 1996). The tuff shows a low residual strain, but hair cracks or craquele, which are often found in sun-exposed surfaces of different Mexican tuff varieties, could not be observed. The field observations and the results of the investigations lead to the conclusion that hygric expansion probably in combination with the action of salt weathering is the main factor for the weathering of the tuff variety Gris de los Remedios. Salt efflorescences can often be recognized in combination with weathering phenomena and are an indicator for wet-dry conditions. This hypothesis is confirmed by the use of the tuff variety as a part of the architectural structure: The Remedios tuff was mainly used for architectural sculptures in areas that are not directly affected by water. In the tuff that was used for the ground floor in the Palace of Heras Soto weathering can be recognized. This part of the building is affected by wet-dry conditions (Fig. 48 c).

\section{2. 8. d) Sample IV, V}

New mining methods at the beginning of industrialization (late eighteenth century) created means for excavating large amounts of the phenoporphyritic andesite for the Metropolitan Cathedral's main facade and bell towers. Before this time these types of andesites were normally used for the construction of the ground floor and pedestal areas. Both building parts, the bell towers as well the foundation zones are affected by wet-dry conditions. In the phenoporphyritic andesite the limited depth of weathering seems to be connected to the low w-value measured in both varieties (Tab. 4). Chiluca contains a low porosity; the w-value is a littler higher than the original material of the cathedral (Tab. 4). This is due to the different pore radii distributions in both varieties. The active capillary pore space of Chiluca accounts for $73.2 \%$, whereas the original material of the cathedral only attains a value of $37.6 \%$ (Tab. 1). During a water uptake of $4 \mathrm{~h}$, suction of only $0.5 \mathrm{~cm}$ could be determined. This correlates with the depth profile of weathering and crust formation (Fig. 50). The concentration of weathering in the outline of the stone can be traced back to the high hygric dilatation of the material and associated shear forces. During this process, insulation weathering also seems to play a role because of the thermal dilatation. The pyroxene andesitic tuff of the cathedral shows a critical thermal expansion of around $4 \mathrm{~mm} / \mathrm{m}$ by heating up to $60^{\circ} \mathrm{C}$ and reaching nearly $8 \mathrm{~mm} / \mathrm{m}$ at $90{ }^{\circ} \mathrm{C}$. The Chiluca stone shows similar values. A tendency towards anisotropy in the fabric direction of foliation $(\mathrm{Z})$ can be detected. By heating up to $68{ }^{\circ} \mathrm{C}$ a dent can be recognized during the linear gradient. This reduction is probably caused by the dehydration of crystal water within the material. Thermal expansion by heating up to $60{ }^{\circ} \mathrm{C}$ is reached at around $4.2 \mathrm{~mm} / \mathrm{m}$ in the fabric directions $\mathrm{X}$ and $\mathrm{Z}$ and $5.3 \mathrm{~mm} / \mathrm{m}$ in the $\mathrm{Y}$ direction. A similar anisotropic behavior occurs 
when the material is heated up to $90{ }^{\circ} \mathrm{C}$ (Tab. 5). These two critical property values, the high thermal dilatation and the high hygric swelling associated with shear and tension stress gives an explanation for weathering forms like scaling and rounding. For the variety of the cathedral a low residual strain could be detected. Today Chiluca is used as a restoration material for the replacement of ashlars affected by weathering at the cathedral and other historical buildings. In comparison with the original stone of the cathedral, the investigated Chiluca samples show adverse properties towards weathering, especially when considering its higher water uptake capacity and lower compressive strength.

\section{2. 9. Salt weathering test}

Salt weathering tests were done for the Chiluca tuff, the Tenayocátetl rhyolitic ignimbrite and the Gris de los Remedios tuff. For the Tezontle basalt the test was not done because no relevant deterioration effects were observed in field studies related to salt weathering.

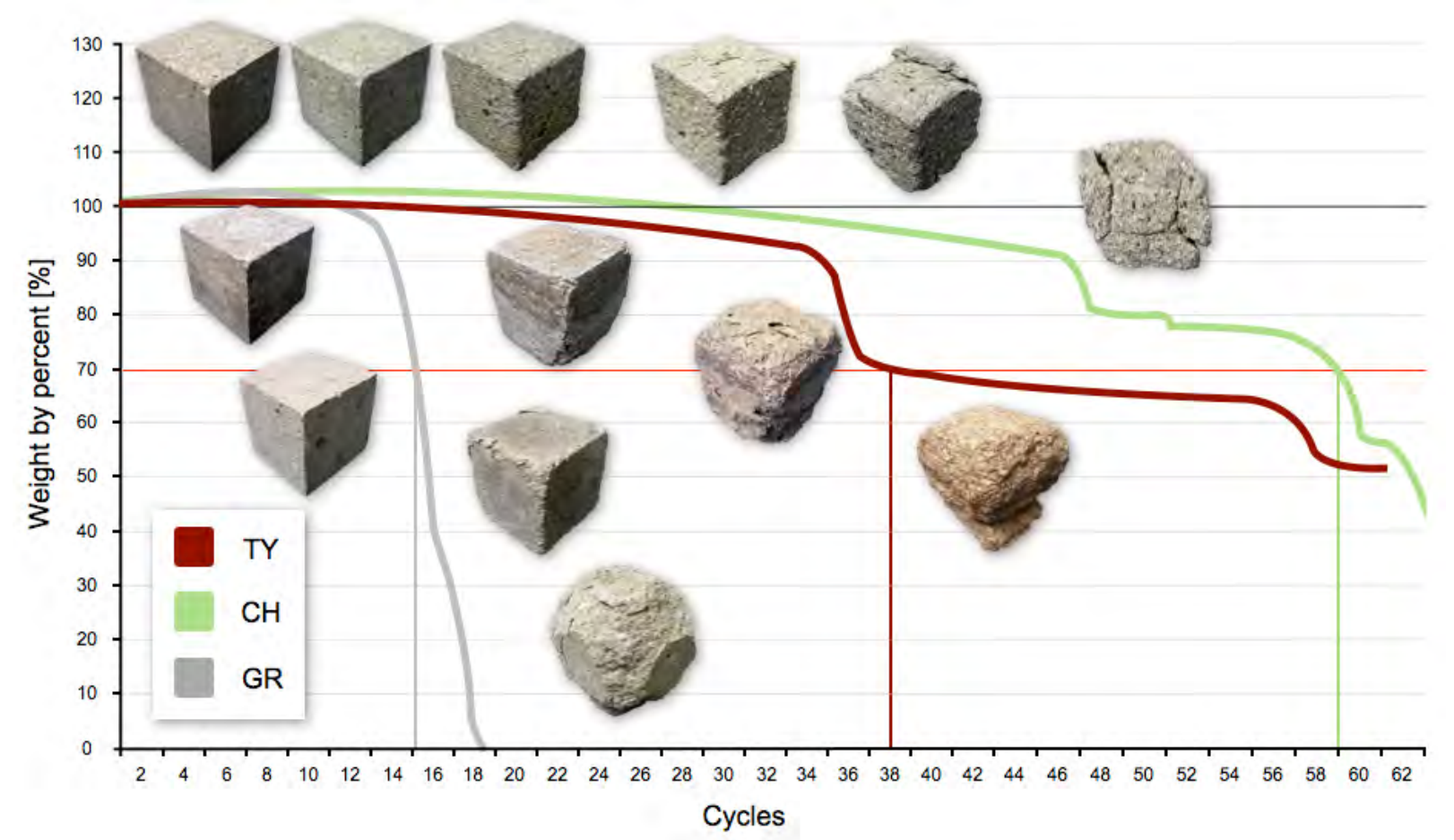

Figure 55: Salt bursting test of the Chiluca tuff, the Tenayocátetl andesite and Gris de los Remedios tuff.

\section{-CH Chiluca}

The deterioration of the Chiluca tuff starts with a rounding of the edges after the $15^{\text {th }}$ cycle (Fig. 55). Later on, after the $45^{\text {th }}$ cycle the splitting of a crust with a thickness of around $1.5 \mathrm{~cm}$ occurs. This starts at the upper area of the sample and leads to a stepwise reduction and rounding (Fig. 50). Similar weathering forms can be observed onsite at the cathedral and in several other palaces in Mexico City (Fig. 49). 


\section{-TY Tenayocátetl}

The stone shows two different stages of weathering. After the $14^{\text {th }}$ cycle some grains are lost at the edges (Fig. 55). The Tenayocátetl tuff first develops a crust on the surface of the material even perpendicular to the bedding. After this, the crust splits away in scales and by the $35^{\text {th }}$ cycle a rounding by flaking takes place (Fig. 55). Both weathering forms can be found in the field, e.g. at the Templo Mayor in Mexico City (Fig. 45 b).

\section{- GR Gris de los Remedios}

After the first cycles the stone shows a darkening in color. After four cycles a rounding at the upper edges starts by the flaking of the matrix as well as in the inclusions. After 10 cycles the sample shows a nearly rounded form (Fig. 55). Only the inner flat areas remain nearly undamaged by forming a crust. In the field the same weathering phenomena can be observed. 


\section{3 Guanajuato / Mexico}

\section{3. 1 Introduction}

The old mining city of Guanajuato in central Mexico belongs to a long list of important historical cities in Latin America and preserves one of the most important historical legacies in colonial buildings. The city is located at $21^{\circ} 0^{\prime} \mathrm{N}, 101^{\circ} 16^{\prime} \mathrm{W}$ in the southern Cordillera between the Mesa Central and the Transmexican Volcanic Belt (TMVB) with an altitude of $1999 \mathrm{~m}$ above sea level (Fig. 56).

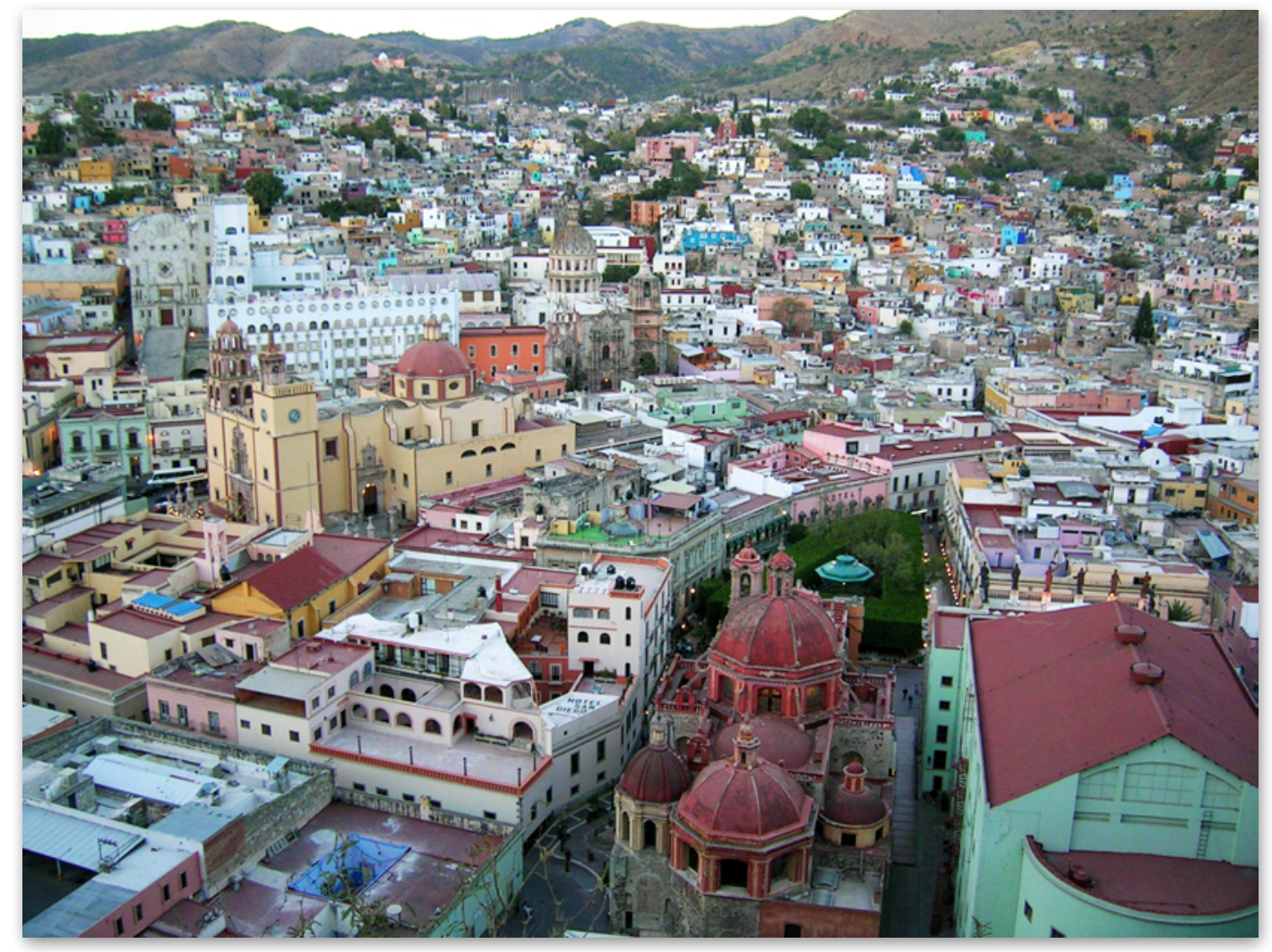

Figure 56: The city of Guanajuato is situated in a valley in the mountains of the southern Cordillera.

The establishment of this city in New Spain was basically due to the discovery of silver and gold deposits in 1548 that initiated the beginnings of the mining industry. This resulted in the legal foundation of the town of Santa Fe de Guanajuato in 1570. During the seventeenth, nineteenth and early twentieth centuries a number of buildings were erected that would play important roles in Mexico's battle for independence like the Alhóndiga de Granaditas. Guanajuato became an important economic, cultural and religious center in Mexico as reflected in the remarkable growth that has occurred during the twentieth century. This is evident in the increasing preservation of old churches, the construction of notable buildings such as the Teatro Juarez, the building of the University of Guanajuato and the Iglesia de la Compañía de Jesús Church (Fig. 1A, 1B). In 1988 the city was declared a World Heritage Site by the UNESCO. 


\section{3. 1. a) Climate and environmental conditions}

Guanajuato has a humid subtropical summer climate that is mild with dry winters, mild rainy summers and moderate seasonality. This climate is usually found in the highlands of some tropical countries with the classification Cwb after Köppen-Geiger (Fig. 3).

The annual average temperature is $18.1^{\circ} \mathrm{C}$, whereas the average monthly temperatures vary by 7.2 ${ }^{\circ} \mathrm{C}$ (Fig. 57). In the winter time records indicate temperatures by day reach $22.1{ }^{\circ} \mathrm{C}$ on average falling to $7.7{ }^{\circ} \mathrm{C}$ overnight. In spring time temperatures climb to $27.9{ }^{\circ} \mathrm{C}$ generally in the afternoon with overnight lows of $12^{\circ} \mathrm{C}$. During the summer average high temperatures are $26.7^{\circ} \mathrm{C}$ and average low temperatures are $14.3{ }^{\circ} \mathrm{C}$. Come autumn temperatures decrease and achieve average highs of $24.5^{\circ} \mathrm{C}$ during the day and lows of $11.5^{\circ} \mathrm{C}$ generally shortly after sunrise. Total annual precipitation averages $698 \mathrm{~mm}$ (Fig. 15). According to the Holdridge life zones system of bioclimatic classification, Guanajuato is situated in or near the warm temperate dry forest biome (Fig. 14).

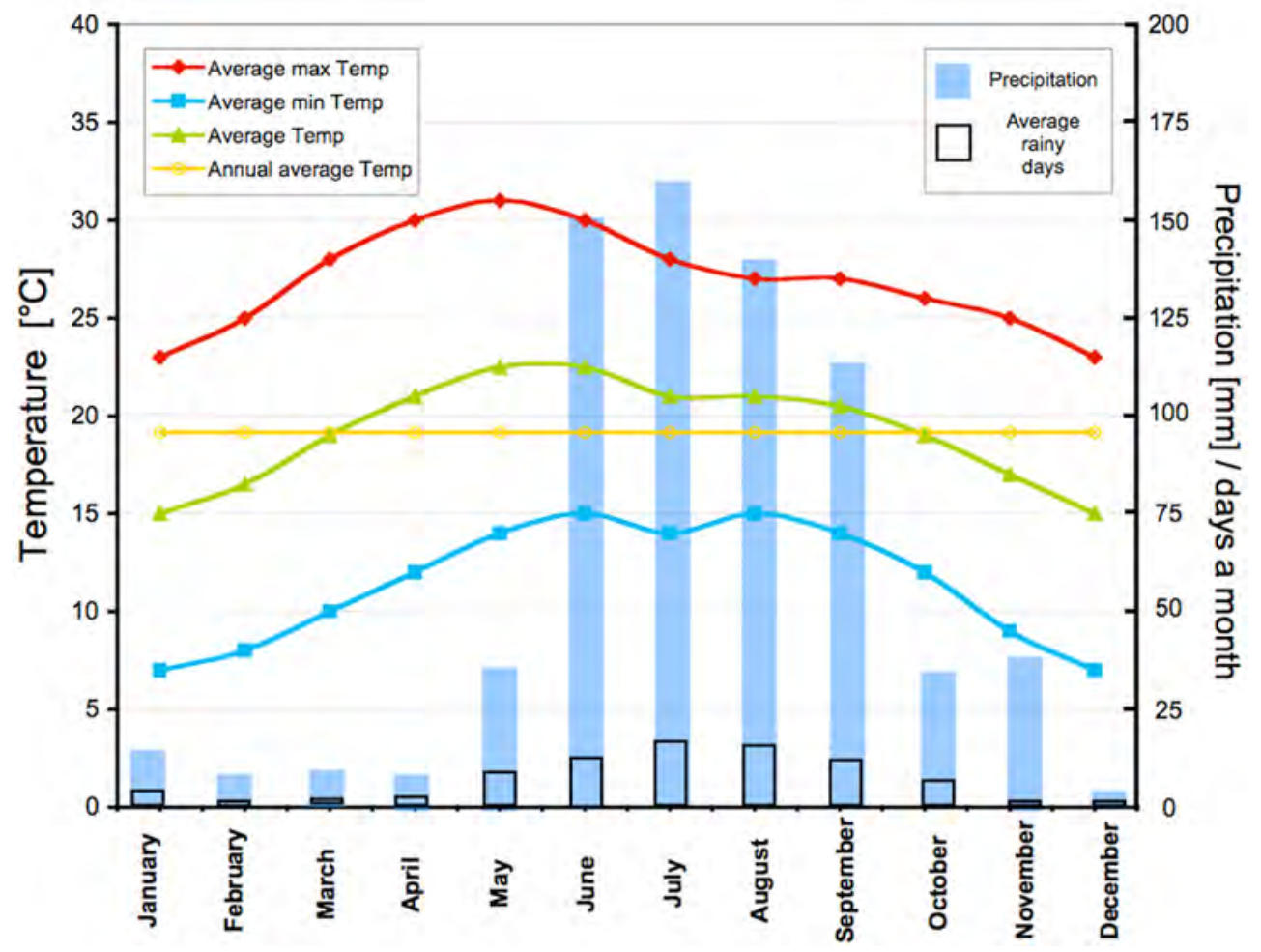

Figure 57: Climate Graph for Guanajuato.

\section{3. 1. b) Geological setting and utilization of the rock material}

The geology around the city of Guanajuato is specially interesting because of the great diversity of the rocks, the quality of the outcrops, and the large number of clearly exposed structures (ArandaGómez et al., 2003). The most important building material found in Guanajuato is the Loseros Tuff and the Bufa rhyolite Tuff located in a distance of around 5 to $10 \mathrm{~km}$ in north east direction to the 
historical town (Buchanan 1979). Important querries for the Loseros Tuff and Bufa Tuff can be found in Cerro Tepozan (Salazar-Hernández 2015).

Practically all the colonial constructions were built with natural stones from the surrounding region. These include the greenish to reddish volcanite, called the Loseros tuff and the reddish to grayish rock known as the Bufa rhyolite tuff (Fig. 53 b).

The utilization of the Loseros Tuff and the Bufa rhyolite as natural building materials include filler rocks for roads, walls, bridge facades and especially the construction of a complex system of underground tunnels that cross the city of Guanajuato.

When the Loseros Tuff is cut along the lamination (X-axis), or it is finely reworked perpendicular to the lamination it is used as fine masonry for many important cultural, religious and governmental buildings as well as for decoration elements of ordinary houses (Fig. 58 a). In the nineteenth century and early twentieth century the Loseros Tuff was widely used as a popular material especially for tomb monuments in central Mexico. Examples can be found in Guadalajara (Fig. $58 \mathrm{c}$ ) as well as in Mexico City.
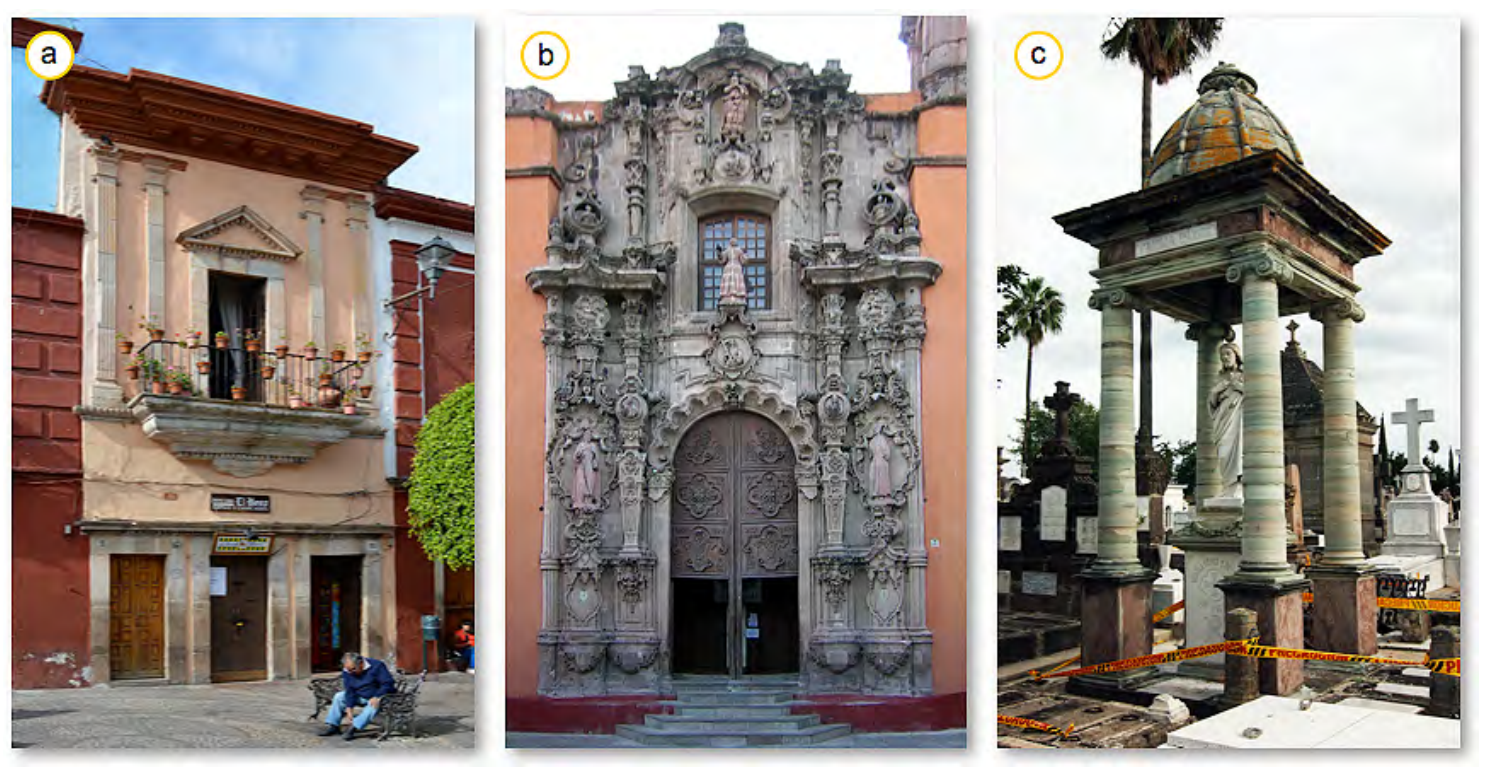

Figure 58: a) A $19^{\text {th }}$ century house in the historical city of Guanajuato with decorative parts made from Loseros Tuff. b) The portal of the San Diego Church in Guanajuato mainly made from Bufa Tuff c) Monumental tomb at the Mazquitlan Cemetery in Guadalajara made from Loseros Tuff.

\section{3. 1. c) Main weathering forms}

Although both volcanic rocks are widely used, they show significant deterioration and weathering effects, first of all by delamination (Fig. 59 a), contour scaling (Fig. 59 b), and crumbling (Fig. 59 c and d). These destructive phenomena are mostly found in areas of the building where moisture and water are permanently or temporarily present like in columns, fountains, balconies or external staircases. 

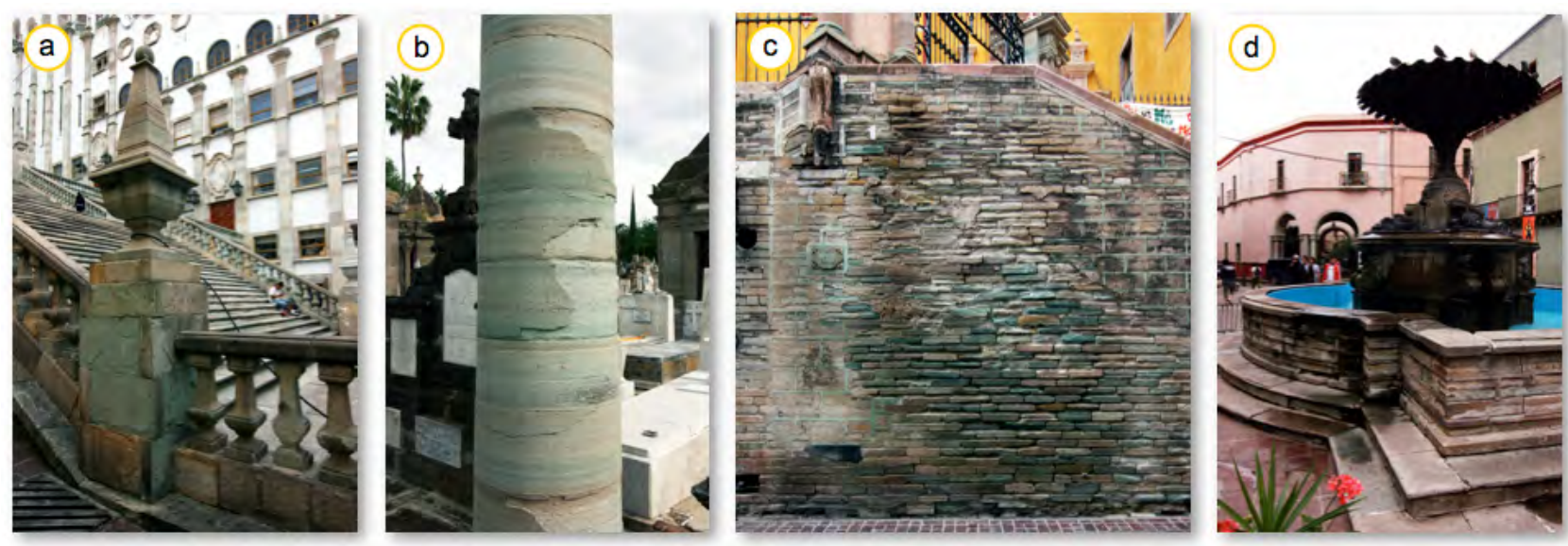

Figure 59: Appearance of the different damage and deterioration types observed in the Loseros Tuff. a) Delamination at the stairway of the main building of the university. b) Contour scaling perpendicular to the lamination at a column of a tomb in Guadalajara. c) Flaking and crumbling in the lower part of a wall affected by moisture infiltration and d) at a basin wall of a fountain in Guanajuato.

A detailed view of the rock deterioration in the construction clearly shows that in the Loseros Tuff the horizons formed by coarser grain sizes are more affected than those of finer fractions (LópezDoncel et al., 2012). Furthermore, coarser horizons have an apparent higher porosity because the pores reach the grain size of sand, or even larger. Also the binding cement, relocation processes and the concentration of this cement near the surface seems to play a role especially in the forming of scales. On the other hand, the Bufa rhyolite exhibits deterioration caused mainly by structural cracking and crumbling (Fig. 60 b, c, and d).
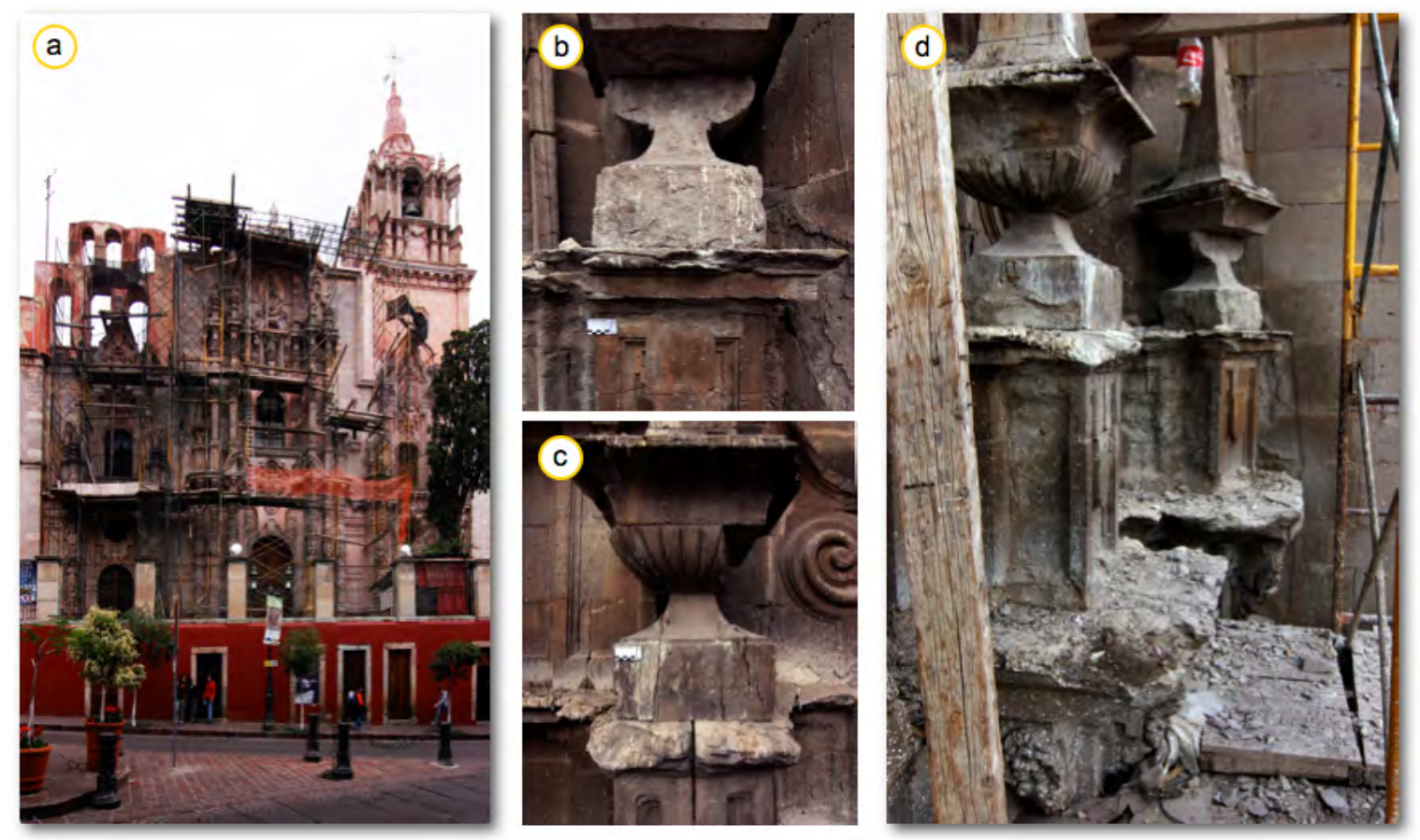

Figure 60: Massive deterioration of the Bufa Tuff at the Compañía de Jesús Church. a) The church under construction, $\mathrm{b}$ and c) structural cracks in detail at a pillar in the facade and d) the weathering situation at the facade. 


\subsection{Rock materials}

\section{3. 2. a) Bufa Tuff}

The Bufa Tuff (BT) is a grayish, light pink/red to orange porphyritic rhyolitic tuff, which has around $10 \%$ quartz and sanidine phenocrysts, together with isolated well-flattened pumice (Fig. 61 a). More important in this tuff are the angular to subangular, abundant lithic components (15-20\% of the rock), which can be up to $15 \mathrm{~cm}$ in diameter.

The lithic fragments are basically red to dark red in color. Subhedral to euhedral quartz, plagioclase, and biotite flakes and dispersed pyroxenes and olivine crystals are present in a microcrystalline and partially devitrified glassy matrix (Fig. 61 b). The fine-grained matrix is composed of calcite, hematite (principle cause of the pinkish, reddish color) and small amounts of illite plus illite-smectite mixed layer of different ordering types.
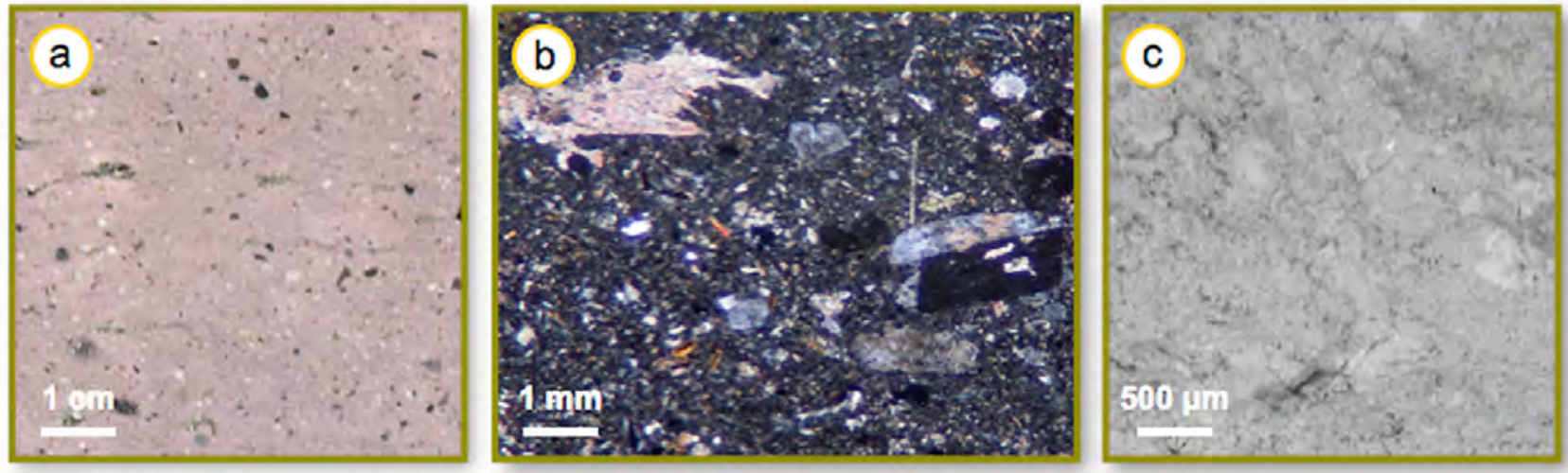

BT Bufa Tuff, Guanajuato / Mexico

Figure 61: The Bufa Tuff of Guanajuato. a) hand specimen, b) thin section in polarized light and c) SEM micrograph.

Table 7: Pore space properties of the Bufa Tuff used for the Compañía de Jesús Church.

\begin{tabular}{lc} 
Effective porosity [Vol.-\%] & 18.39 \\
Particle density $\left[\mathrm{g} / \mathrm{cm}^{-3}\right.$ ] & 2.61 \\
Bulk density [g/cm ${ }^{-3}$ ] & 2.13 \\
Average pore radius [ $\mu \mathrm{m}]$ & 0.06 \\
Micropore porosity [\%] & 82 \\
\hline
\end{tabular}


Tabble 8: Water transport properties and hygric and hydric dilatation of the Bufa Tuff used for the Compañía de Jesús Church.

\begin{tabular}{lccccc}
\hline Directions $(\mathbf{X}, \mathrm{Y}, \mathbf{Z}) /$ Anisotropy $(\mathbf{A})$ & $\mathbf{X}$ & $\mathbf{Y}$ & $\mathbf{Z}$ & $\mathbf{A} \%$ & Average $\varnothing$ \\
$\mathbf{w}$ value $\left[\mathrm{kg} / \mathrm{m}^{\mathbf{2}} \sqrt{\mathrm{h}}\right]$ & 0.18 & 0.21 & 0,17 & 16 & 0.186 \\
$\boldsymbol{\mu}$ value & 16.7 & 14.08 & 19.28 & 15.5 & 16.68 \\
Sorption $95 \% \mathrm{rh}\left[\mathbf{g} / \mathrm{cm}^{3}\right]$ & & 0.054 & & & \\
Hydric dilatation $[\mathrm{mm} / \mathrm{m}]$ & 0.361 & 0.55 & 0.79 & 55 & 0.53 \\
Hygric dilatation $\mathbf{9 5 \%} \mathrm{RH}[\mathrm{mm} / \mathrm{m}]$ & 0.18 & 0.203 & 0.33 & 45 & 0.24 \\
\hline
\end{tabular}

Table 9: Ultrasonic velocity of the Bufa Tuff in dry and water-saturated conditions

\begin{tabular}{lcc}
\hline Ultrasonic velocity [km/s] & dry & water-saturated \\
$X$ & 3.37 & 3.21 \\
$Y$ & 3.31 & 3.18 \\
$Z$ & 2.53 & 2.14 \\
Averrage & 3.07 & 2.843 \\
Anisotropy [\%] & 25 & 33.3 \\
Reduction $\varnothing[\%]$ & 0 & -7.5 \\
\hline
\end{tabular}

Tabel 10: Petro-mechanical properties of the Bufa Tuff used for the Compañía de Jesús Church

\begin{tabular}{lccccc}
\hline Directions (X, Y, Z) / Anisotropy (A) & X & Y & Z & A [\%] & reduction [\%] \\
Compressive strength dry [N/mm ${ }^{2}$ ] & 66.69 & 64.34 & 59.59 & 11 & nd \\
Splitting tensile strength dry Bsz [MPa] & 6.04 & -- & 6.95 & 7 & \multirow{2}{*}{37.6} \\
Splitting tensile strength water-saturated Bsz [MPa] & 3.65 & -- & 4.57 & 20 & \\
Surface hardness dry [HLD] & & 574 & & \multirow{2}{*}{11.3} \\
Surface hardness wet [HLD] & & 509 & & \\
\hline
\end{tabular}

\section{3. 2. b) Loseros Tuff}

The Loseros Formation belongs to the Cenozoic volcanic rocks that form the Sierra de Guanajuato Area. This area is divided into two main rock successions. A succession that represents the basement composed principally of volcanic and sedimentary sequences of Jurassic to Upper Cretaceous in age. These rocks are the oldest units that crop out in this region. These Mesozoic rocks belong to the so-called "Mesozoic Basement or Basement Complex of the Sierra de Guanajuato" (OrtizHernández et al., 1992; also called the "Guanajuato Volcanic Arc" by Monod et al., 1990). A second succession overlies the Mesozoic sequence. More than 2,500 m of Tertiary to Quaternary volcanic rocks are exposed, which show diverse chemical compositions varying from basaltic to ande- 
sitic to rhyolitic. The extrusions of these Cenozoic volcanites are associated with the extensional tectonism at the end of the Laramide Orogeny in western and central Mexico (Nieto-Samaniego et al. 1992). The Loseros Tuff is a felsic volcanoclastic rock that consists of well-sorted, sand-sized crystals and detrital rock fragments, which are embedded in an ash-rich altered groundmass. The Loseros Tuff appears in a wide variety of color shades, which can range from reddish brown, pink, green and even white, but the green variety is the most requested and used rock.
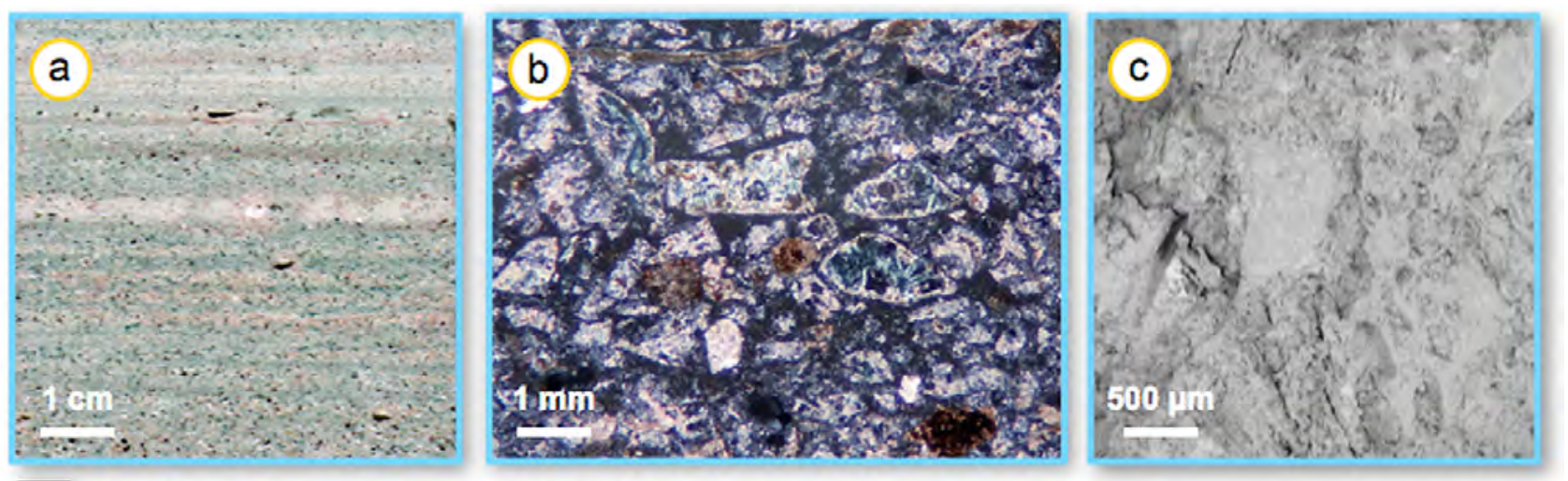

LS Loseros Tuff, coarse, Guanajuato / Mexico
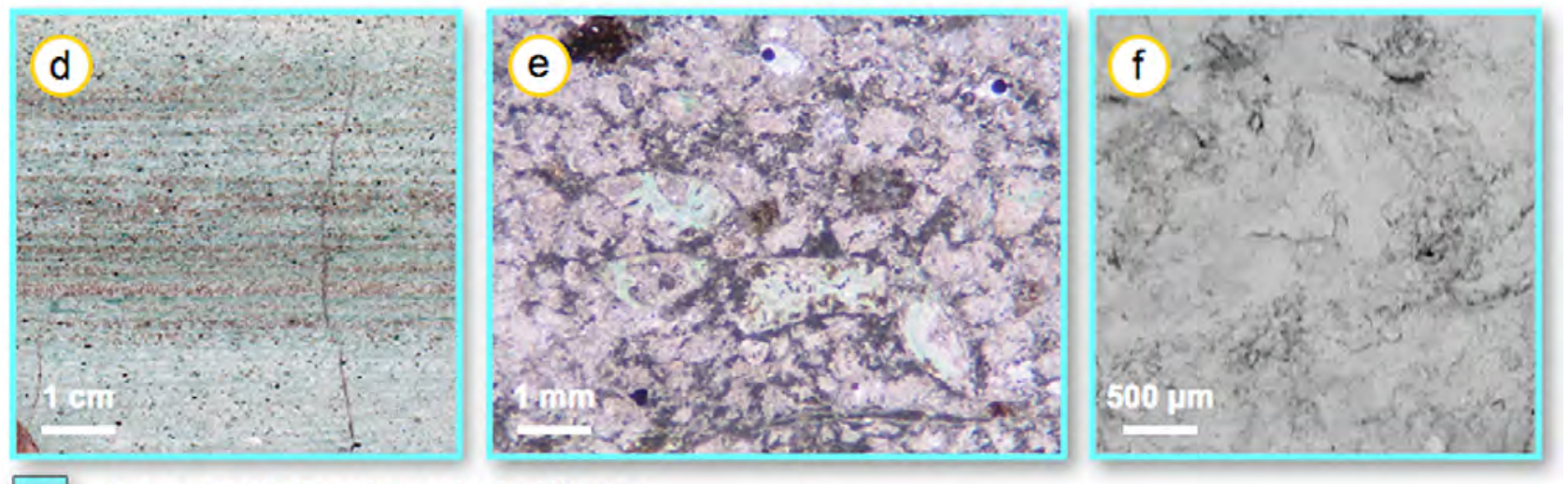

Loseros Tuff, fine, Guanajuato / Mexico

Figure 62: a) Macroscopic view of the coarse Loseros Tuff. b) Thin section in polarized light and c) overview under the SEM. d) Macroscopic view of the fine-grained Loseros Tuff. e) Thin section and f) overview under the SEM.

The grain size can also vary locally from gravel (granule), up to the clay fraction but the sand grain size dominates. Lithic fragments also found in the sand fraction are the reason why some authors classify the Loseros Tuff as a sandstone (Salazar-Hernández et al., 2015). Loseros Tuff is a volcanic pyroclastic rock (Fisher 1961; Fisher, Schmincke 1984; Le Maitre et al., 2004) with a significant amount of epiclastic detrital material. In the field this tuff exhibits protruding pseudo-stratification with gradational beds composed of 5 to $50 \mathrm{~cm}$ thick layers (locally accretional lapilli layers are thicker than $1 \mathrm{~m}$ ). Together with the lamination a series of very characteristic sedimentary structures are observable, such as cross-bedding, ripples, flame and cut-and-fill structures. Edwards (1956) noted that the majority of the grains are quartz, plagioclase and volcanic lithic fragments. In thin 
section the Loseros Tuff shows a glassy matrix, which in polarized light appears almost completely opaque and its texture ranges from hypocrystalline to holohyaline. Crystals consist of altered angular to subhedral plagioclase, angular quartz, and also altered biotite flakes (Fig. 62 b and e). Under the microscope "fissile-like" laminae are also recognizable, which result from intercalations of fine sand and clay. XRD analysis showed a significant amount of $\mathrm{CaCO}_{3}$ (calcite) that under the microscope is recognizable as cement in the matrix. Thin section evidence shows that the greenish coloration of the tuff comes from a large number of small albite crystals with an altered appearance (initial stage of transformation to clay minerals, Fig. $63 \mathrm{a}$ and b).
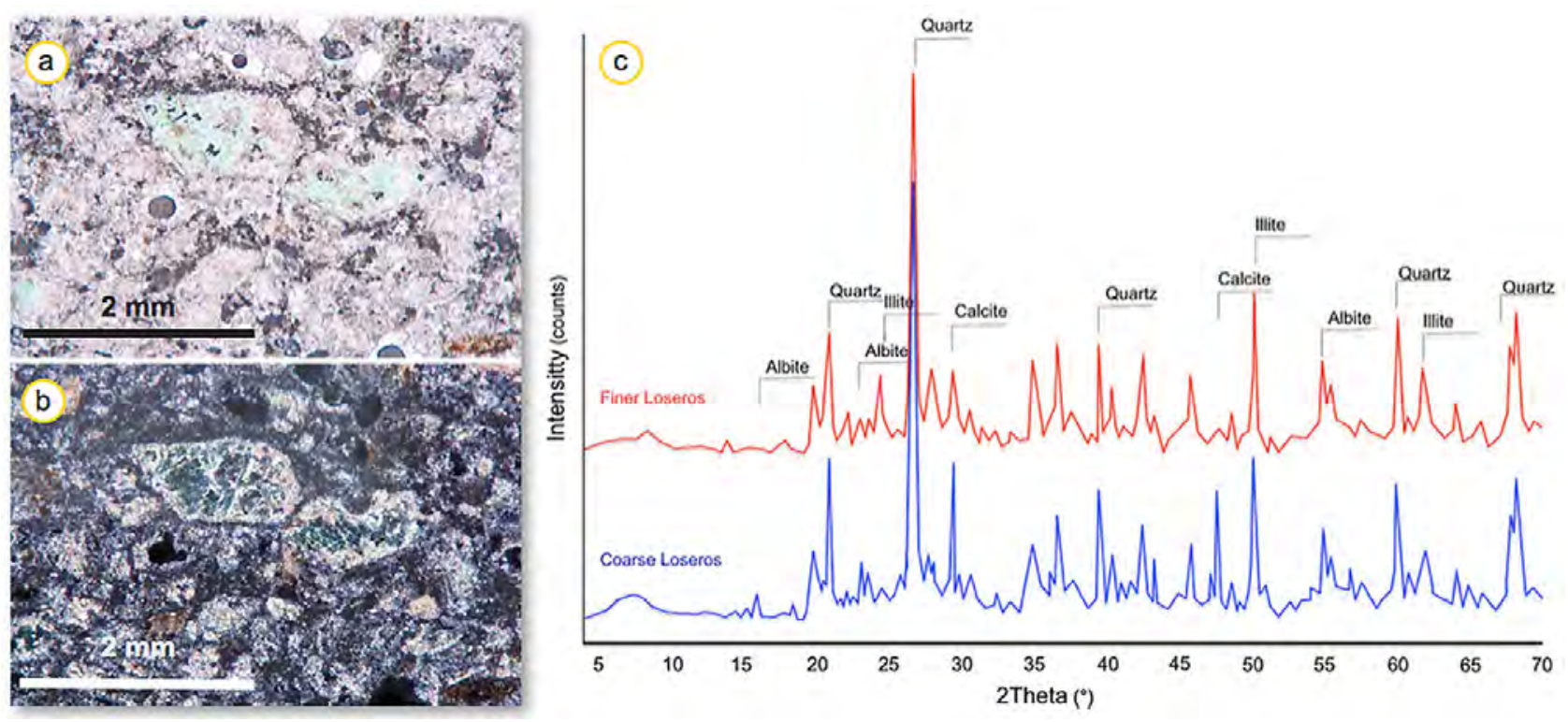

Figure 63: Thin section photomicrographs of the studied tuff. a) Green coloration of an altered albite crystal (centre of image, compare with Fig. 7a) is observable in transmitted light. The matrix consists of poorly recognizable calcite, volcanic glass and small quartz crystals. b) Observable under polarized light is a matrix consisting of opaque components (volcanic glass) with small crystals of calcite (crystals with third-order colors) and the altered plagioclase. These show rare interference colors. c) Diffractograms showing the primary mineralogy of the two tuff varieties: coarse Loseros

(blue) and fine-grained Loseros (red).

The matrix is also made up of volcanic glass, which shows different stages of devitrification. The green color was not recognized in the matrix. Buchanan (1980) attributes the greenish coloration in this tuff to alteration (chloritization) of the lithic fragments, but the geochemical analyses do not show the presence of chlorite in the Loseros Tuff. Wedekind et al., (2013) noted: "the matrix has more than $20 \%$ calcite and also contains kaolinite.

However, most common are the dioctahedral clay minerals like illite plus R3-ordered illite (0.95) smectite mixed layers, which add up to a CEC value of $7 \mathrm{meq} / 100 \mathrm{~g}$ ". No mineralogical difference is evident between the finer and the coarser varieties of this tuff. The XRD patterns of both show only a major amount of albite and calcite in the coarser fraction (Fig. 63 c). On the other hand, the SEM indicates that the tuff is relatively dense with very fine-grained feldspar and illite-smectite 
particles (Fig. $62 \mathrm{c}$ and f).

Based on the macroscopic observation a marked difference in the type and form of damage was identified. The hypothesis is that the integrity of the tuff is probably affected by the particle (grain) size and by the apparent porosity. In order to analyze these differences two different varieties of the tuff were studied: (1) a coarse-grained specimen, which has been separated into seven different horizons and designated $1 \mathrm{~g}-7 \mathrm{~g}$ (Fig. 66). And (2) a fine-grained specimen, that was separated into five horizons labeled 1f-5f (Fig. 67). All the coarse-grained horizons have a grain size that ranges from fine sand-size (1g and $2 \mathrm{~g}$ ), sand-size ( $3 \mathrm{~g}$ and $6 \mathrm{~g}$ ), and coarse sand-size (5g and $7 \mathrm{~g}$ ) to very coarse sand-size, and to very fine pebbles $(4 \mathrm{~g})$. The horizons of the fine-grained variety vary from very fine sand ( $4 \mathrm{f}$ and $5 f$ ) to silt-size ( $1 \mathrm{f}$ and $3 \mathrm{f}$ ), and locally even clay fractions (2f).
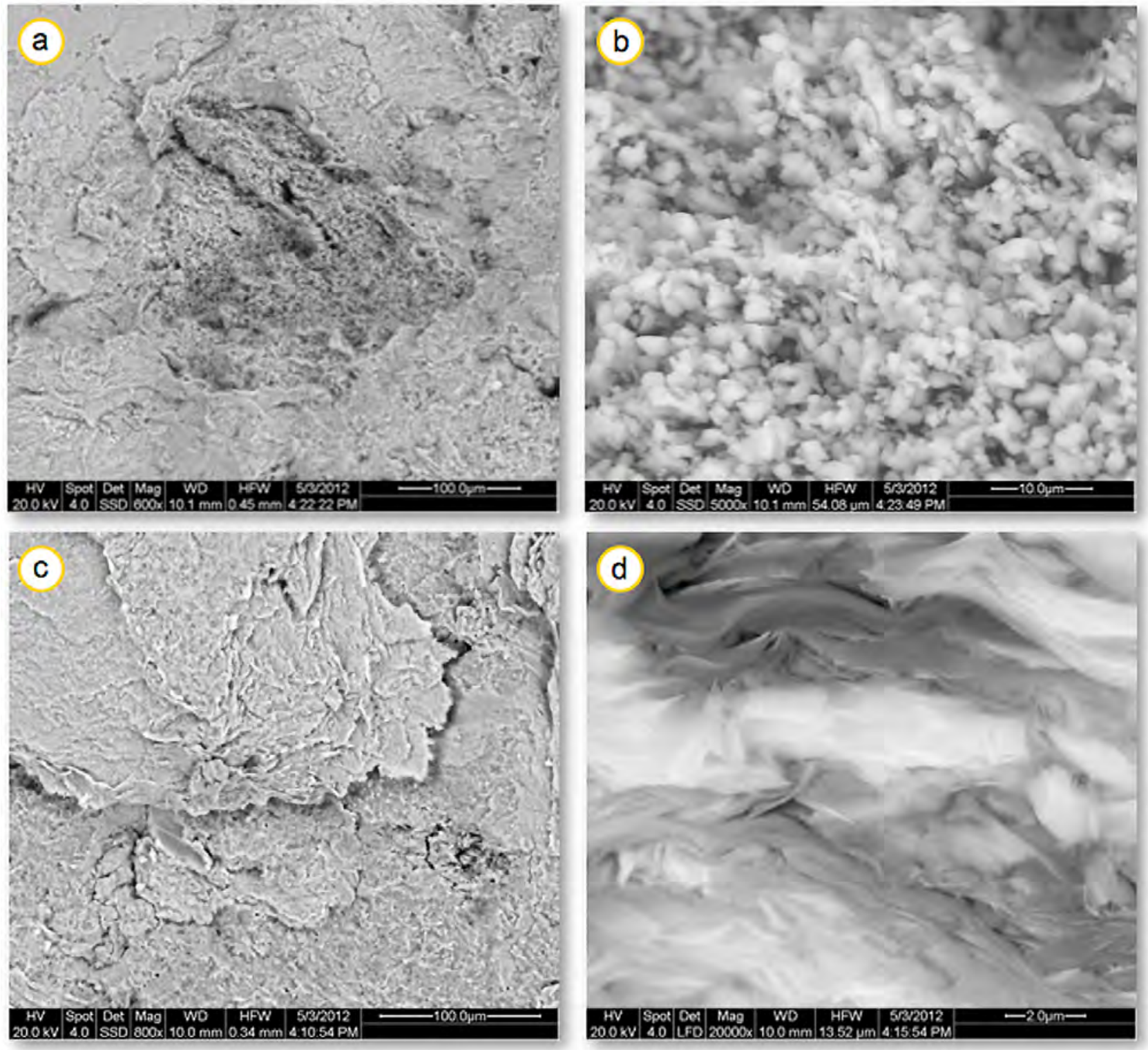

Figure 64: a) Typical large pore of relict crystals in the finer tuff embedded in a dense matrix as observed under SEM. b) Tenfold magnification of the central region indicates the presence of very fine-grained albite crystals. c) Clay minerals (illite-smectite) are densely packed and d) identified under high magnification. 
The petrographic analyses were performed on oriented thin sections of the coarser and finer varieties utilizing a polarizing microscope. Mineralogical and geochemical analyses were performed using XRD (whole rock samples, and oriented slides of clay fractions smaller $2 \mu \mathrm{m}$, along with $\mathrm{XRF}$, elemental carbon and sulphur analysis, and CEC analyses (compare Ruedrich et al., 2011 a, b).
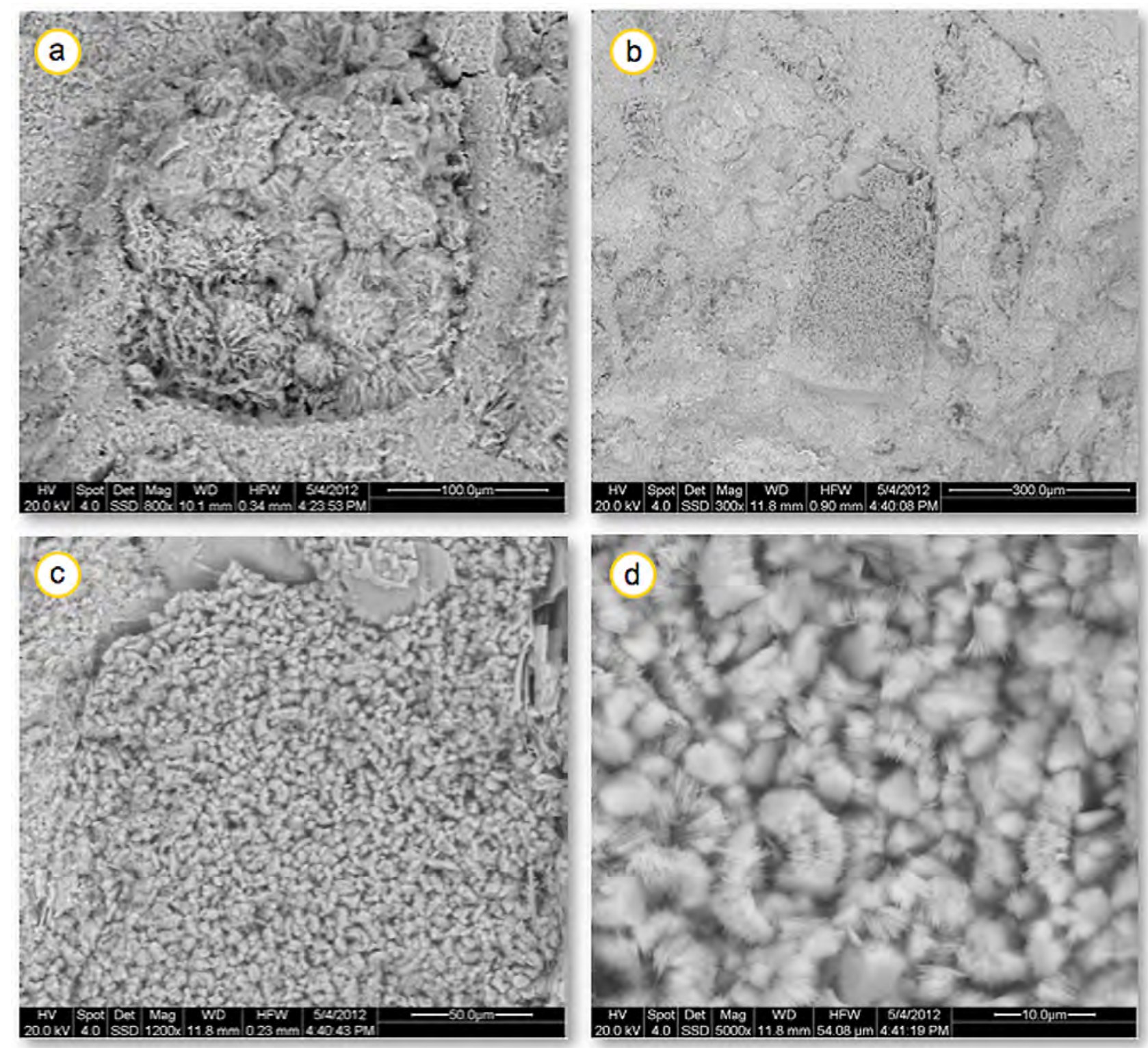

Figure 65: a) Larger pore with plenty of relict crystals or zeolites in the coarser tuff embedded in a dense matrix as observed under SEM. b) Feldspar crystal showing kaolinisation and c) the kaolinite booklets. d) Booklets in detail.

Hydrostatic weighing was carried out to determine the matrix and bulk density as well as the porosity of each horizon. Water uptake coefficient (w value) was determined with the help of the capillary suction in a closed cabinet while weighing. The water vapor diffusion resistance value (l) was measured using the wet-cup method. The pore radii distribution was determined using mercury injection porosimetry (Brakel et al., 1981, see also Siegesmund, Snethlage 2011). 
The hydric and hygric expansion of each horizon was measured on cylindrical samples (diameter 15 $\mathrm{mm}$, length $100 \mathrm{~mm}$ ). For hydric expansion measurements the cylinders were completely immersed in distilled water (water-saturated). For hygric dilatation analysis an initial relative humidity (RH value) of $20 \%$ was used, which was increased gradually to a $\mathrm{RH}$ value of $95 \%$. The temperature was kept constant at $30{ }^{\circ} \mathrm{C}$ during the whole experiment. Cylindrical samples with co-planar endfaces of $50 \mathrm{~mm}$ in diameter and $50 \mathrm{~mm}$ in length and $40 \mathrm{~mm}$ in diameter and $20 \mathrm{~mm}$ in length, respectively, were used for the compressive and tensile strength tests. The compressive strength load was realized with the help of a servo-hydraulic testing machine with a stiff testing frame $(3.000 \mathrm{kN} /$ $\mathrm{mm}^{2}$ ) and a load range up to $300 \mathrm{kN}$. The tensile strength measurements were determined by means of the "Brazilian test".
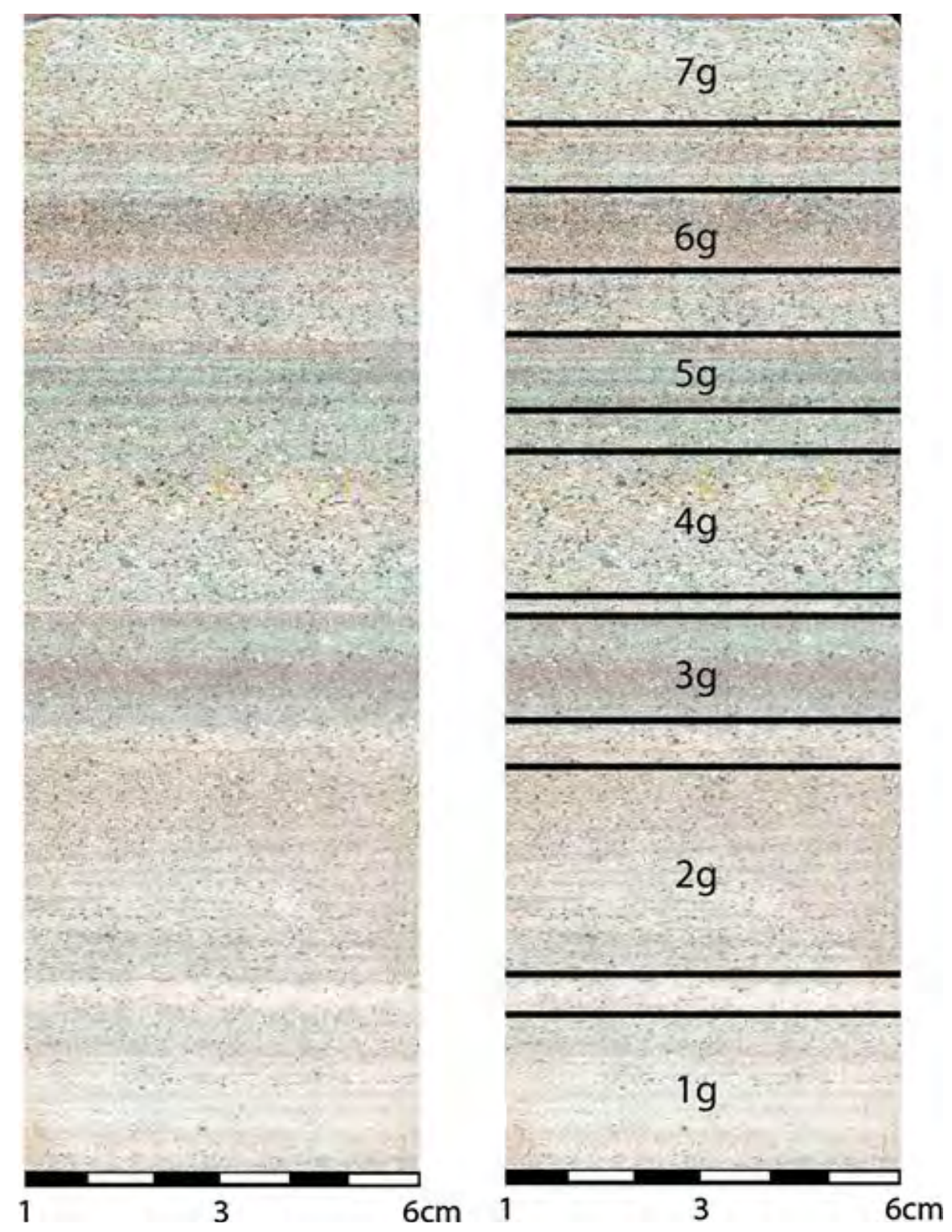

Figure 66: Appearance of the coarse Loseros Tuff variety and its separation into the different studied horizons. 

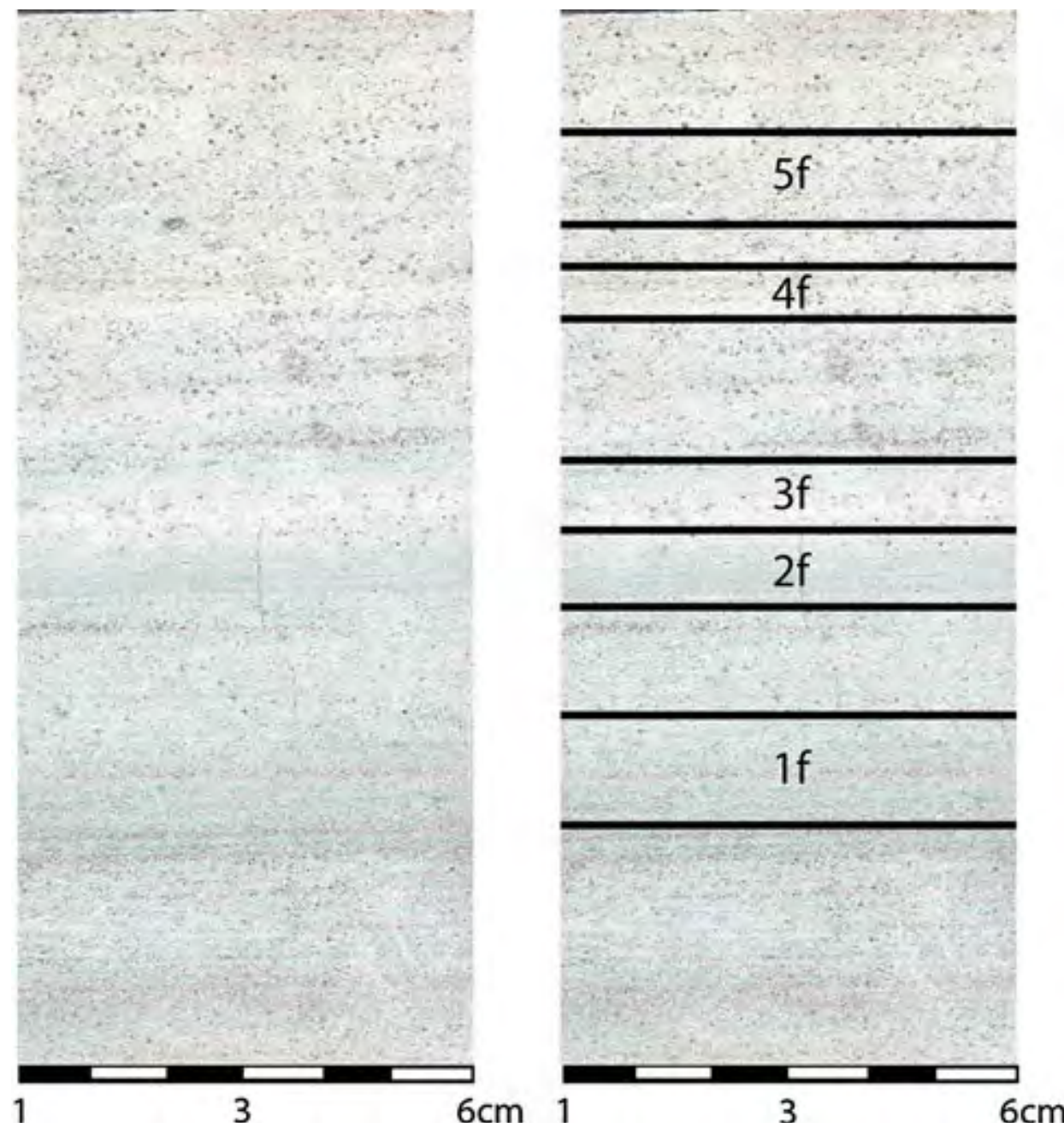

Figure 67: Appearance of the finer Loseros Tuff variety and its separation into the different studied horizons.

\section{3. 2. c) Horizontal petrophysical properties}

Analyses of each of the studied horizons were performed, in order to determine the density and porosity of both, the fine $(\mathrm{g} 1-\mathrm{g} 5)$ and the coarse fraction $(\mathrm{g} 1-\mathrm{g} 7)$. The results of the determination of the porosity, bulk density, particle density and average pore radius are presented in Table 11. As shown in the table, fine-grained horizons have a greater particle density than the coarse-grained ones, with an average of 2.63 and $2.37 \mathrm{~g} / \mathrm{cm}^{3}$, respectively. The same occurs with the bulk density. Contrary to expectations, the fine-grained varieties have a higher porosity and in some horizons even a larger average pore radius than the coarser ones. Sedimentary rocks such as siltstones and claystones (similar to the f1-f5 samples) usually have much lower porosities than sandstones (equivalent to g1-g7 samples) because decreasing grain sizes typically correlate with decreasing pore sizes. The studied tuffs were deposited principally in a similar way (as pyroclastic and epiclastic rocks), so they should have a similar behaviour, which in this case does not occur. This phenomenon is related to the type and distribution of the porosity (micro or capillary porosity), which will be discussed below. 
Table 11: Porosity and density of the investigated tuff horizons

\begin{tabular}{|c|c|c|c|c|}
\hline Name & Porosity [Vol \%] & $\begin{array}{l}\text { Bulk density } \\
{\left[\begin{array}{l}{\left[\mathrm{g} / \mathrm{cm}^{3}\right]}\end{array}\right.}\end{array}$ & $\begin{array}{l}\text { Particle density } \\
{\left[\mathrm{g} / \mathrm{cm}^{3}\right]}\end{array}$ & $\begin{array}{c}\text { Average pore } \\
\text { radius [m] }\end{array}$ \\
\hline \multicolumn{5}{|c|}{ Loseros Formation fine-grained } \\
\hline $1 f$ & 13.05 & 2.30 & 2.65 & 0.033 \\
\hline $2 f$ & 12.02 & 2.30 & 2.65 & 0.017 \\
\hline $3 f$ & 17.33 & 2.20 & 2.66 & 0.030 \\
\hline $4 f$ & 15.12 & 2.22 & 2.62 & 0.037 \\
\hline $5 f$ & 17.41 & 2.16 & 2.61 & 0.037 \\
\hline Average $\varnothing$ & 14.84 & 2.23 & 2.63 & 0.0308 \\
\hline \multicolumn{5}{|c|}{ Loseros Formation coarse-grained } \\
\hline $1 \mathrm{~g}$ & 10.05 & 2.17 & 2.41 & 0.009 \\
\hline $2 g$ & 8.19 & 2.16 & 2.35 & 0.08 \\
\hline $3 g$ & 6.79 & 2.20 & 2.36 & 0.008 \\
\hline $4 g$ & 9.83 & 2.21 & 2.46 & 0.07 \\
\hline $5 \mathrm{~g}$ & 7.70 & 2.13 & 2.30 & 0.006 \\
\hline $6 g$ & 8.89 & 2.13 & 2.33 & 0.011 \\
\hline $7 \mathrm{~g}$ & 10.50 & 2.17 & 2.42 & 0,05 \\
\hline Average $\varnothing$ & 8.85 & 2.167 & 2.37 & 0.033 \\
\hline
\end{tabular}

\section{3. 2. d) Comparative compressive and splitting tensile strength}

The compressive strength tests show that the coarser type of the Loseros Tuff has values that range from 74.3 to $58.0 \mathrm{~N} / \mathrm{mm}^{2}$, where the largest value occurs in the X-axis and the lowest value in the Z-axis. This condition is associated with the lamination of the tuff. The anisotropy in the coarser Loseros is $22 \%$ and its modulus of elasticity ranges from 6.3 to $10.0 \mathrm{kN} / \mathrm{mm}^{2}$ with an anisotropic behaviour of around $37 \%$ (Tab. 12).

The uniaxial compressive strength of the finer Loseros Tuff ranges from 42.3 to $57.3 \mathrm{~N} / \mathrm{mm}^{2}$, with an anisotropy of $26 \%$. In contrast to the coarser variety, the greatest value of compression occurs in the direction of the Z-axis and the smallest value in the direction of the Y-axis (Tab. 12). This can be explained by the much finer lamination in the Loseros Tuff, and therefore the sample appears more homogeneous. Measured tensile strength values follow the same trend as the compression test, where the higher values occur in the coarser variety. The tensile strength values of the coarser Loseros Tuff range from 50.1 to $66.0 \mathrm{Mpa}$, with an anisotropy of $24 \%$. The fine-grained Loseros shows a maximum value of 59.2 and a minimum value of $30.6 \mathrm{Mpa}$ with an anisotropy of $48 \%$. 
Table 12: Tensile and compressive strength, surface hardness as well as the elastic modulus of the studied tuffs partly water-saturated

\begin{tabular}{|c|c|c|c|c|c|c|c|c|}
\hline \multirow[t]{2}{*}{$\begin{array}{l}\text { Loseros } \\
\text { Formation } \\
\text { tuff type }\end{array}$} & \multicolumn{2}{|c|}{$\begin{array}{c}\text { Tensile strength } \\
\text { [MPa] }\end{array}$} & \multicolumn{2}{|c|}{ Compressive } & \multicolumn{2}{|c|}{$\begin{array}{c}\text { Surface hardness } \\
{[H L D]}\end{array}$} & \multicolumn{2}{|c|}{$\begin{array}{c}\text { E-modulus } \\
{\left[\mathrm{kN} / \mathrm{mm}^{2}\right]}\end{array}$} \\
\hline & Fine & Coarse & Fine & Coarse & Fine & Coarse & Fine & Coarse \\
\hline$X$ dry & 5.919 & 6.6 & $50.30^{a}$ & 74.26 & $501[\varnothing]$ & $378[\varnothing]$ & nd & 10.00 \\
\hline Y dry & nd & nd & $42.26^{a}$ & 66.90 & 581 (max) & $442(\max )$ & nd & 9.86 \\
\hline Z dry & 4.107 & 5.013 & $57.27^{a}$ & 57.98 & $423(\min )$ & $310(\min )$ & nd & 6.26 \\
\hline Anisotropy [\%] & 30.6 & 24 & 26.2 & 21 & - & - & & 37.4 \\
\hline$X$ water saturated & 5.887 & 5.919 & nd & nd & $465[\varnothing]$ & $331[\varnothing]$ & nd & nd \\
\hline Y water saturated & nd & nd & nd & nd & $521(\max )$ & $412(\max )$ & nd & nd \\
\hline$Z$ water saturated & 2.707 & 4.107 & nd & nd & 408 (min) & $298(\min )$ & nd & nd \\
\hline Anisotropy [\%] & 54 & 30.6 & - & - & - & - & - & - \\
\hline Reduction $\varnothing$ [\%] & -18.8 & -14.2 & - & - & -7.1 & -12.4 & - & - \\
\hline
\end{tabular}

(a) Sánchez González (2004), p 93

Table 13: Ultrasonic velocity of the Loseros Tuff varieties under dry and water-saturated conditions

\begin{tabular}{lcccc}
\hline $\begin{array}{l}\text { Ultrasonic velocity } \\
{[\mathrm{km} / \mathbf{s}]}\end{array}$ & Fine (dry) & Coarse (dry) & Fine (ws) & Coarse (ws) \\
$\boldsymbol{X}$ & 3.711 & 3.918 & 3.469 & 3.102 \\
$\mathbf{Y}$ & 3.607 & 3.533 & 3.474 & 3.104 \\
$\mathbf{Z}$ & 3.172 & 2.857 & 2.982 & 2.519 \\
Averrage & 3.49 & 3.46 & 3.308 & 2.908 \\
Anisotropy [\%] & 16 & 17.4 & 14 & 6.4 \\
Reduction Ø [\%] & 0 & 0 & -5.4 & -16.2 \\
\hline
\end{tabular}


Table 14: Pore radii distribution of each of the studied horizons

\begin{tabular}{|c|c|c|c|c|c|}
\hline \multirow[t]{3}{*}{ Sample } & \multicolumn{5}{|c|}{ Pore radii distribution [\%] } \\
\hline & \multicolumn{2}{|c|}{ Micropores } & \multicolumn{3}{|c|}{ Capillary pores } \\
\hline & $0.001-0.01$ & $0.01-0.1$ & $0.1-1$ & $1-10$ & $>10$ \\
\hline \multicolumn{6}{|c|}{ Fine-grained Loseros Tuff } \\
\hline $1 f$ & 13.84 & 76.42 & 7.98 & 0.87 & 0.88 \\
\hline $2 f$ & 21.16 & 73.17 & 3.35 & 0.93 & 1.43 \\
\hline $3 f$ & 9.91 & 78.97 & 9.66 & 0.87 & 0.59 \\
\hline $4 f$ & 10.77 & 63.08 & 23.84 & 1.24 & 1.07 \\
\hline $5 f$ & 11.97 & 65.41 & 20.70 & 0.82 & 1.10 \\
\hline Average $\varnothing$ & 13.53 & 71.41 & 13.10 & 0.94 & 1.008 \\
\hline \multicolumn{6}{|c|}{ Coarse-grained Loseros Tuff } \\
\hline $1 \mathrm{~g}$ & 32.13 & 59.42 & 5.20 & 1.34 & 1.90 \\
\hline $2 g$ & 8.659 & 68.93 & 17.57 & 4.83 & 0 \\
\hline $3 g$ & 54.46 & 35.87 & 5.10 & 1.54 & 3.03 \\
\hline $4 g$ & 10.49 & 52.66 & 31.47 & 5.37 & 0 \\
\hline $5 g$ & 48.09 & 43.47 & 5.88 & 1.09 & 1.47 \\
\hline $6 \mathrm{~g}$ & 32.79 & 53.44 & 7.18 & 4.54 & 2.04 \\
\hline $7 \mathrm{~g}$ & 7.56 & 54.70 & 30.89 & 4.82 & 2 \\
\hline Average $\varnothing$ & 27.73 & 52.64 & 14.75 & 3.36 & 1.49 \\
\hline
\end{tabular}

The distribution of the pores in both varieties is unequal unimodal (Figs. 68, 69). Most of the studied horizons are dominated by micropores with pore sizes ranging from 0.001 to $0.1 \mathrm{~lm}$ (Table 14 ; Figs. 68, 69). Horizons $1 \mathrm{f}$ and $2 \mathrm{f}$ only show a microporosity of 76.4 and $78.9 \%$, respectively. These are also the horizons with the finest grain sizes (Fig. 68). Moreover, in the horizons of the coarsegrained variety $(1 \mathrm{~g}-7 \mathrm{~g})$ the microporosity also dominates; however, absolute percentages are smaller. Horizons $4 \mathrm{~g}$ and $7 \mathrm{~g}$ reach high values of about $30 \%$ capillary porosity and as expected these horizons have the coarsest grain size (Tab. 14; Fig. 61). Horizon $3 \mathrm{~g}$ has the widest pore size distribution, including more than $3 \%$ of pores showing sizes of $10 \mu \mathrm{m}$ and the horizon $4 \mathrm{~g}$ includes more than $5 \%$ of capillary pores in the size range of $1-10 \mu \mathrm{m}]$. Sànchez-Gonzàlez (2004) reported water absorption values in the fine-grained Loseros Tuff of around $0.8-2.4 \%$ and for the coarser type the values vary from 6.3 to $6.5 \%$. Wedekind et al. (2012 a) reported absorption values of $0.1 \mathrm{~kg} / \mathrm{m}^{2} \sqrt{ } \mathrm{h}$ for the fine-grained tuff (see also Wesche 1996).

The capillary water absorption measured is dependent on the three principal directions $(\mathrm{X}, \mathrm{Y}, \mathrm{Z})$ on sample cubes of $65 \mathrm{~mm}$ length. The cubes were set with the bottom plane into water and the weight Wanja Wedekind 
increase over time was measured. On average both varieties have a low water uptake coefficient of $0.04 \mathrm{~kg} / \mathrm{m}^{2} \sqrt{\mathrm{h}}$ for the coarse variety and $0.057 \mathrm{~kg} / \mathrm{m}^{2} \sqrt{\mathrm{h}}$ for the fine variety. The coarse variety shows an anisotropy of $46 \%$ and the fine variety $43 \%$. Both varieties have different vapor diffusion resistances. The coarse variety has a resistance that is more than a factor of two greater than the fine one. The fine variety has an averaged vapor diffusion resistance value of 26.3 with an anisotropy of $36 \%$. The $\mu$ value with 57.3 and an anisotropy of $39 \%$ for the fine variety is nearly three times higher. The calculated water absorption coefficient (w value) and the water vapor diffusion resistance value ( $\mu$ value) are given in Table 8 for all directions. Petrophysical studies conducted on the tuffs show a relationship between the parameters porosity, pore radius, pore size and pore distribution.

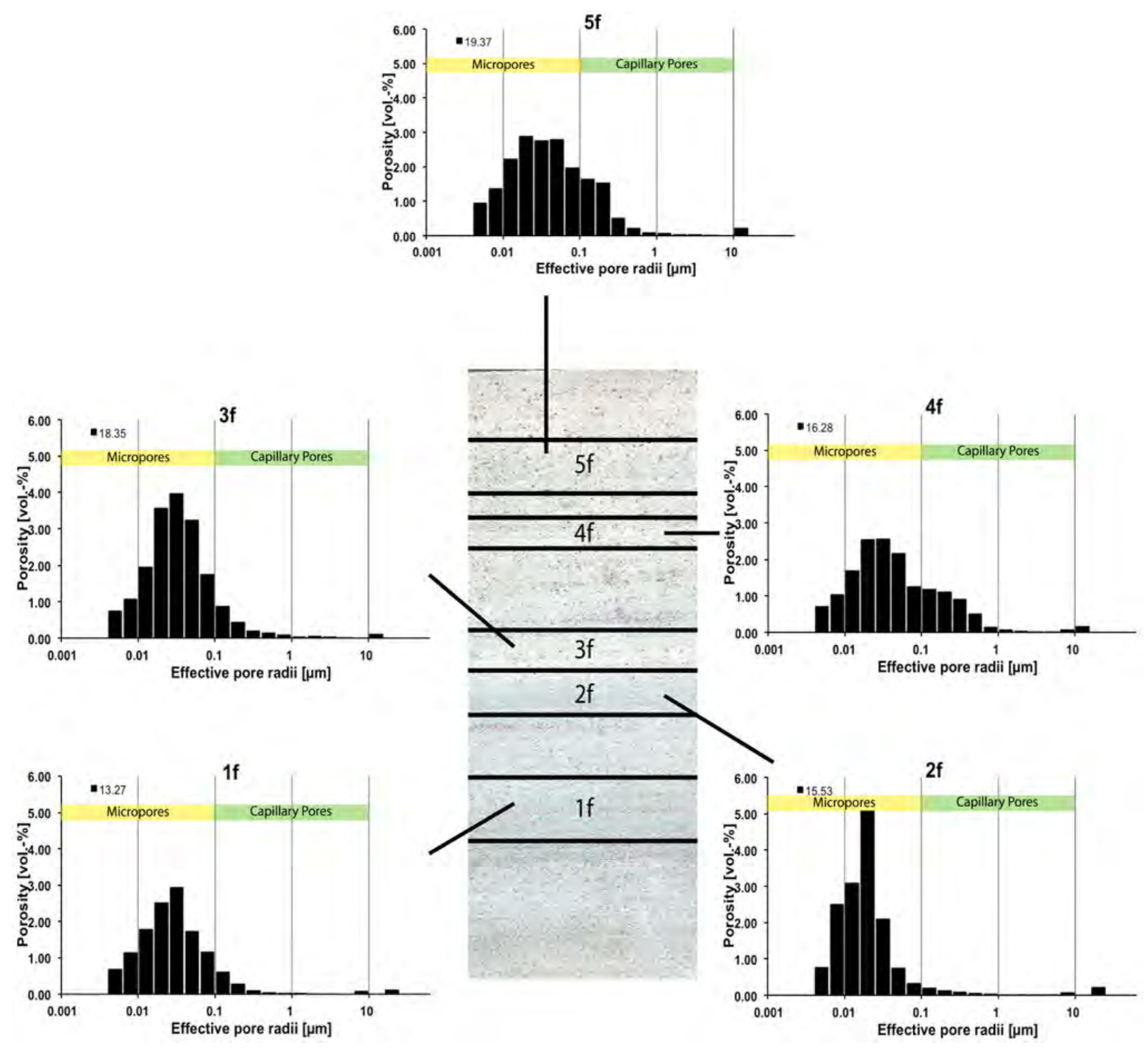

Figure 68: Pore radii distribution of the different studied horizons of the fine Loseros variety.

The finer variety has a greater average pore radius, which remains very regular in the different horizons and is always located in the area of microporosity (Tab. 14; Fig. 68). On the other hand, the 
average value in the coarse-grained variety is smaller (Tab. 14), but its distribution is wider and includes horizons with an average pore radius greater than any horizon in the fine variety (g2, g4, g7). Nevertheless, it has horizons with a very small average close to zero (g3 and g5) (Fig. 69).

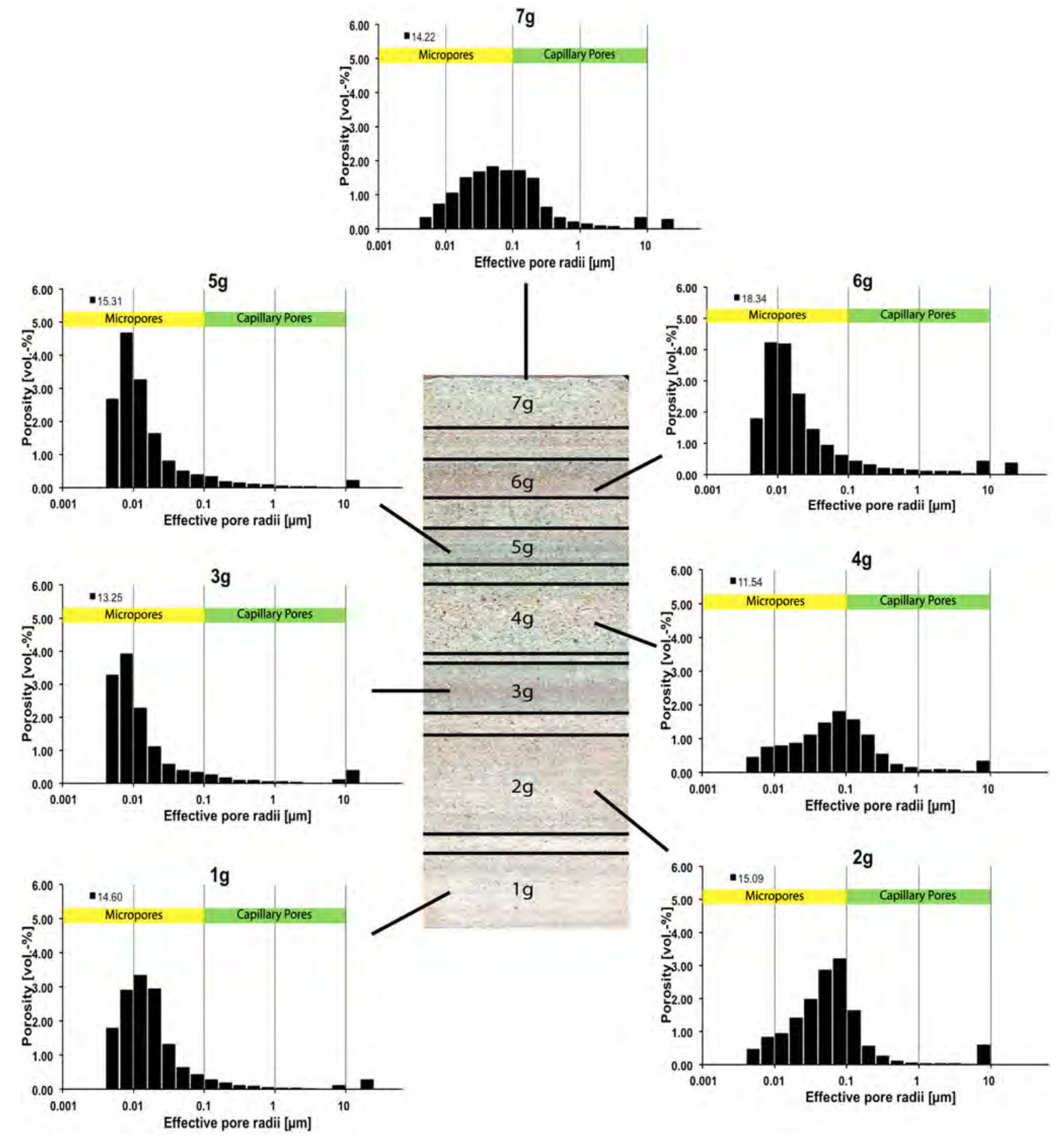

Figure 69: Pore radii distribution of the different studied horizons of the coarse Loseros variety.

\section{3. 2. e) Porosity and pore size distribution}

Grain sizes and pore size vary greatly from one horizon to the other. Table 14 shows that the average pore radius is larger in the fine-grained horizons, which influences the effectivity of the porosity. In general, the fine-grained variety has a larger effective porosity (average of $16 \%$ ), and even the horizon $5 \mathrm{f}$ (Tab. 14) reaches almost $20 \%$. Moreover, the coarse variety shows a lower effective po- 
rosity with an average of $14 \%$. The horizon $4 \mathrm{f}$ has the lowest effective porosity with only $11 \%$; interestingly this horizon is the one with the coarsest grain size of all samples (Tab. 14).

\section{3. 2. f) Moisture properties (hygric and hydric expansion)}

Tests were performed with both tuff varieties in order to probe the response of hygric moisture (related to the relative humidity $\mathrm{RH}$ ) and hydric moisture (under water immersion). To investigate each horizon individually the experiments were conduced in the X-axis direction (parallel to stratification). Then tests were made in the direction of the Z-axis for each variety, which includes all the studied horizons together. The behavior of the hygric dilatation in the $\mathrm{X}$-axis direction both in the finer as in the coarser variety was very discrete and the values hardly reach the expansions of 0.05 $\mathrm{mm} / \mathrm{m}$ (finer Loseros) to up $0.1 \mathrm{~mm} / \mathrm{m}$ (coarser sample).
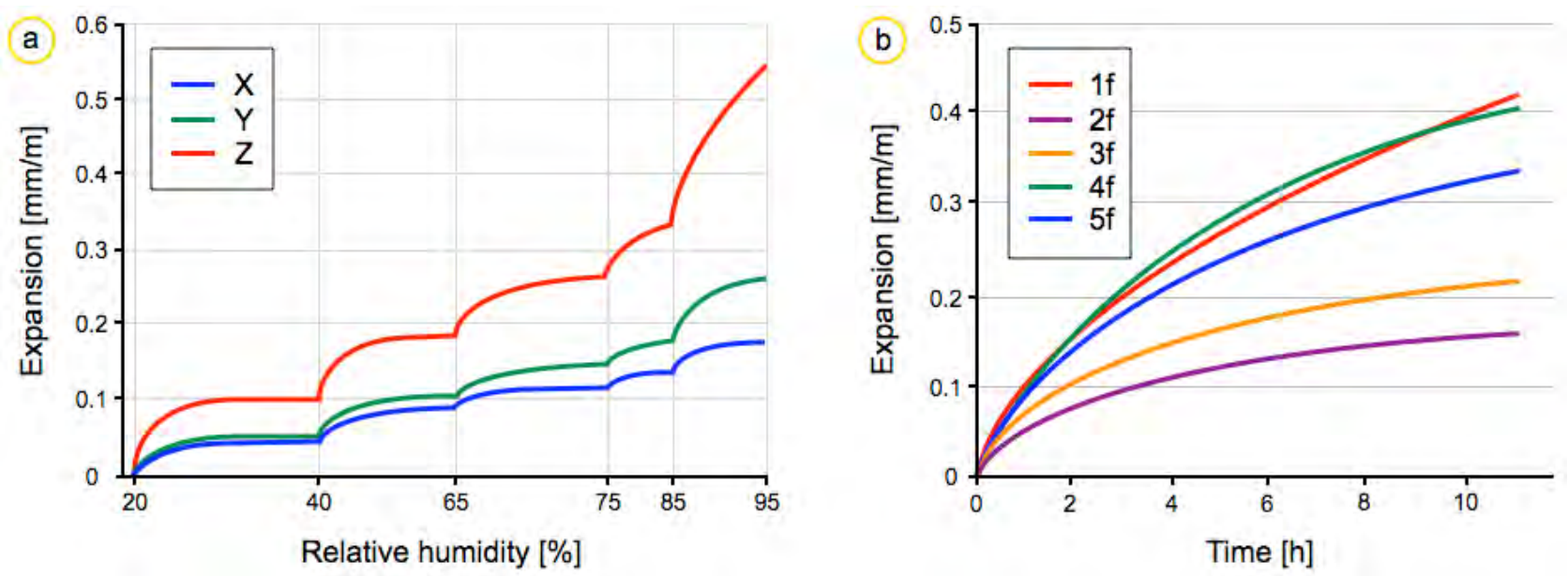

Figure 70: a) Hygric expansion of the Loseros Formation and b) hydric expansion of the finer Loseros variety.

The maximum values were reached at a relative humidity of $95 \%$. In order to study the moisture anisotropy, the direction perpendicular to the Z-axis of the coarse-grained variety was also measured (Fig. 71). Results indicate that the hygric expansion in the direction of the Z-axis was slightly higher than in the previously measured direction of the X-axis. Hygric expansion values had a maximum of $0.54 \mathrm{~mm} / \mathrm{m}$ parallel to the bedding (Fig. 70 a). The fine-grained horizons were then tested under water-saturated conditions resulting in smaller values for the hydric than for the hygric experiments (Fig. $70 \mathrm{~b}$ ). In the direction of the X-axis values between $0.17 \mathrm{~mm} / \mathrm{m}$ in the horizon $2 \mathrm{f}$ up to $0.42 \mathrm{~mm} / \mathrm{m}$ in the $1 \mathrm{f}$ horizon were measured. The $1 \mathrm{f}$ horizon has the smallest effective porosity of $13 \%$. The grain size in this horizon was the coarsest of all horizons examined in this variety (Fig. $70 \mathrm{~b}$ ), however the dilatation was not very pronounced. The same experiment was also performed in the $\mathrm{X}$ direction of the horizons in the coarse-grained variety. Six of the seven horizons show moderate responses to water immersion, with expansion values ranging from $0.17 \mathrm{~mm} / \mathrm{m}$ in horizon $5 \mathrm{~g}$ to $0.35 \mathrm{~mm} / \mathrm{m}$ in horizon $3 \mathrm{~g}$ (Fig. $71 \mathrm{a}$ ). The hydric expansion values of these six samples were comparable to the fine variety except one particular horizon $(4 \mathrm{~g})$ with a much larger expansion and a 
dilatation value of $1.55 \mathrm{~mm} / \mathrm{m}$ (Fig. 71 a). The pronounced hydric expansion value of horizon $4 \mathrm{~g}$ can be explained by: (1) the highest average pore radius value (Tab. 14), (2) the highest absolute capillary porosity (Tab. 11), and (3) by the coarsest grain size (Fig. 71 a). However, horizon $4 \mathrm{~g}$ has the smallest effective porosity of all the analyzed horizons (Tab. 11). The same kind of experiment was repeated, but this time the hydric expansion of the coarse-grained variety was measured along the direction of the Z-axis (perpendicular to the lamination). This analysis sums up the properties of the horizons $2 \mathrm{~g}, 3 \mathrm{~g}, 4 \mathrm{~g}, 5 \mathrm{~g}$ and $6 \mathrm{~g}$ together. The measured hydric expansion along the Z-axis (Fig. $71 \mathrm{~b})$ that results from subjecting the sample to water-saturated conditions shows very interesting aspects. Initially the sample displays a very regular trend with expansion values up to $1.44 \mathrm{~mm} / \mathrm{m}$ during the first $16 \mathrm{~h}$ of the experiment, but immediately after this point an extremely quick expansion with an increase of almost a factor of two in a span of about 2-3 h was detected. Measured values ranged from 1.5 to $3.5 \mathrm{~mm} / \mathrm{m}$ and the slope of the curve was almost vertical (Fig. $71 \mathrm{~b}$ ).
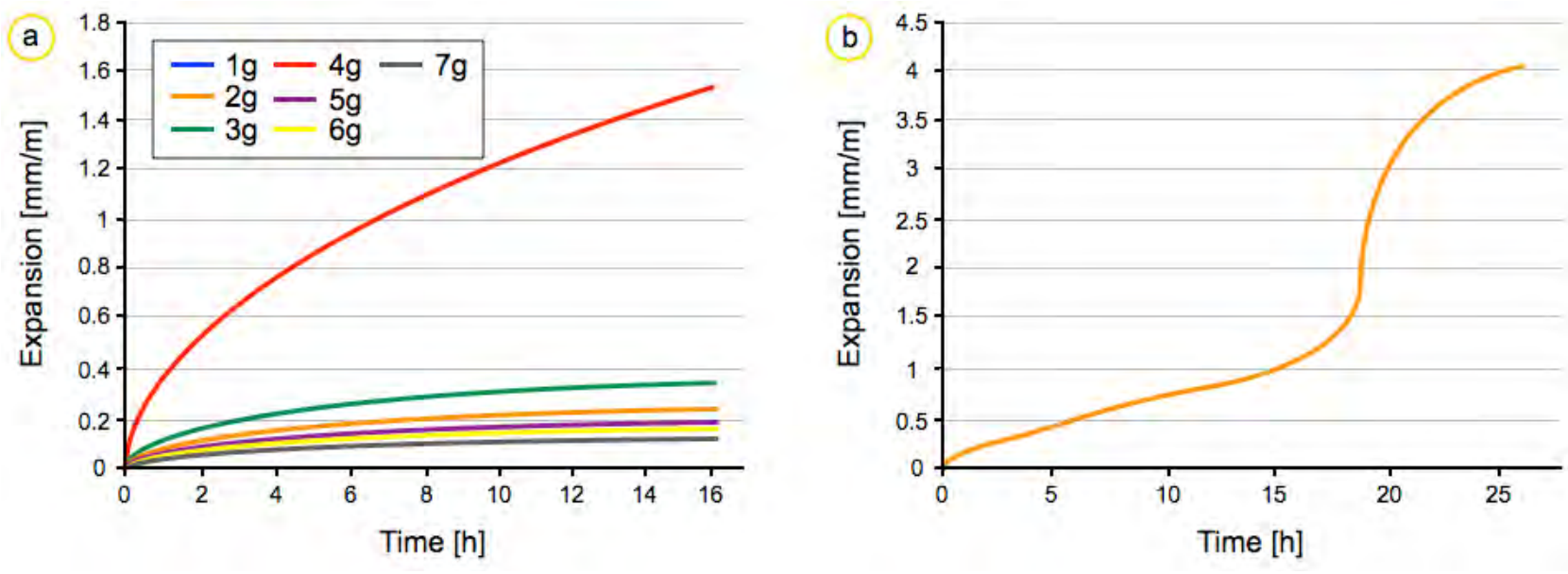

Figure 71: a) Hydric expansion of the coarser Loseros variety and b) hydric expansion of the coarser Loseros variety in the Z-axis.

This is again followed by a weaker increase, with values ranging from 3.5 to $4.1 \mathrm{~mm} / \mathrm{m}$ expansion in approximately $6 \mathrm{~h}$ (Fig. $71 \mathrm{~b}$ ). After 26 hours the sample began to stabilize and eventually the expansion ceased (Fig. 71 b). At the end of the experiment a thin layer of sediment was deposited at the bottom of the vessel that contained the sample for immersion. Crumbling also occurred at the end of the experiment and eventually the sample started to break. The collapse phenomenon (scaling and crumbling) was not observed in any other test used to check the moisture properties of the Loseros Tuff, but was widely recognized during the fieldwork on the buildings in Guanajuato. The main damage in the sample was due to collapse and breakup in horizon $4 \mathrm{~g}$. A lack of cementation between the grains was clearly recognizable. This is the cause for the formation of scaling and crumbling. This observations appear with the results of the surface hardness and the ultrasonic velocity. A significant increase of surface hardness of $12.4 \%$ takes place expacially in the case of the coarse variety (Tab. 12). The same applies to the ultrasonic velocity with a reduction of $16.2 \%$ 
(Tab. 13).

\section{3. 2. g) Salt weathering test}

Salt weathering tests were done on the two varieties of the Loseros Tuff and the Bufa Tuff (Fig. 72).

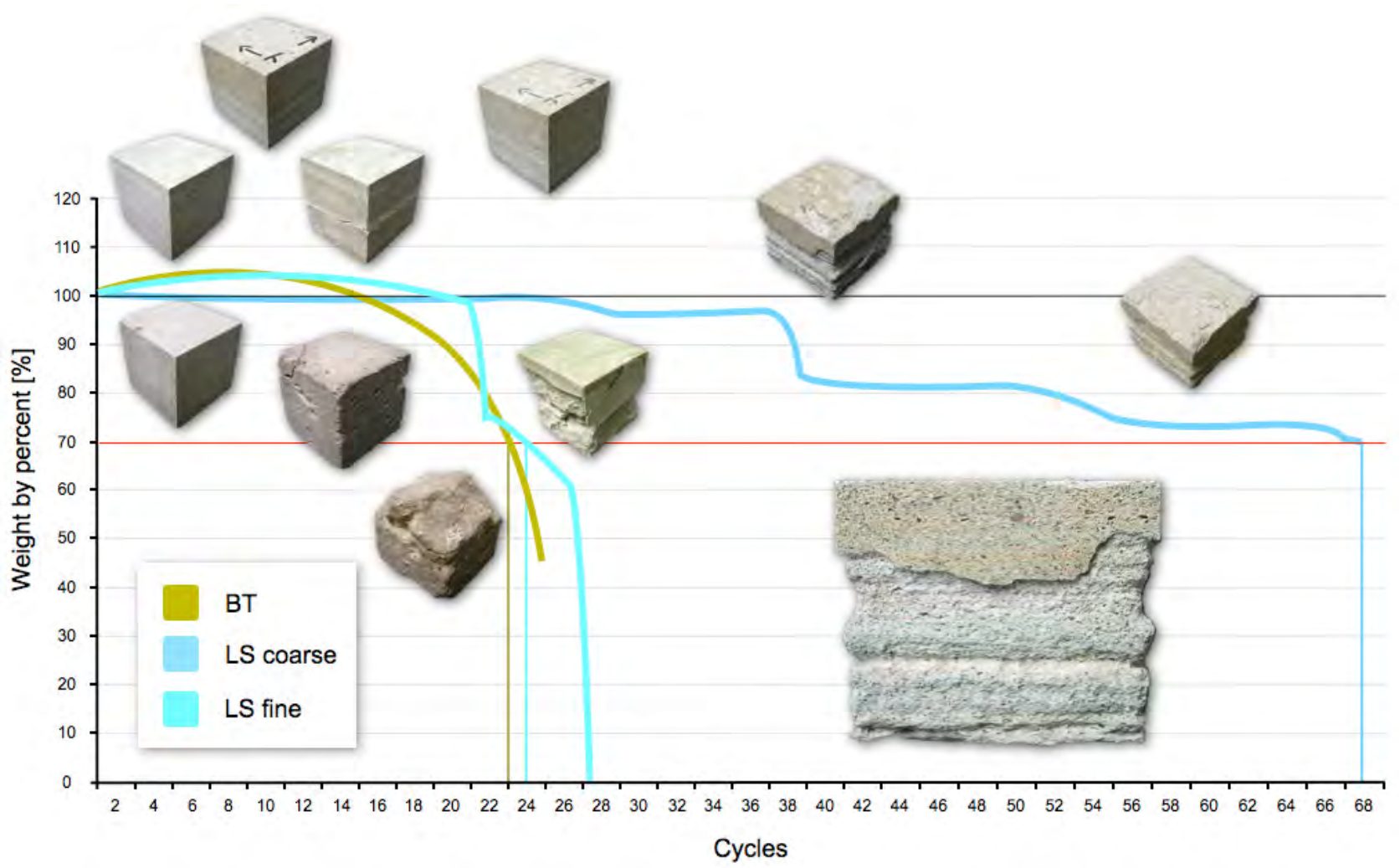

Figure 72: Salt bursting tests of the two Loseros varieties and the Bufa Tuff.

- BT Bufa Tuff

The deterioration of the Bufa Tuff starts by the back-weathering of soft bound whitish inclusions. After eight cycles the first cracks break away at the corners. The matrix starts to flake from the upper edges during the following cycles. After 12 cycles cracks form parallel to the flow or bedding structure of the stone. The same weathering phenomena can be observed at the Compañía de Jesús Church (Fig. 60).

- LS Loseros Tuff, fine variety

The deterioration of the fine-grained variety starts by the weathering of defined layers after 10 cycles. At the same time a crust also forms that breaks away parallel to the surface but perpendicular to the bedding.

- LS Loseros Tuff, coarse variety

The deterioration of the coarse-grained variety begins by the weathering of defined layers after 26 
cycles. At the same time a crust also forms that breaks away parallel to the surface but perpendicular to the bedding. This weathering form is shown in detail in Figure 72.

These weathering forms can be observed at some buildings in Guanajuato as well as in an extreme form in Guadalajara, where the stone was used for tomb monuments (Fig. $59 \mathrm{a}$ and b).

\section{3. 3 Discussion}

The causes of the deterioration of both varieties of the Loseros Tuff cannot be attributed to a single factor but includes a number of causes including composition, texture and physical properties (see also Yavuz 2006; Klinkenberg et al., 2009). In the field it was initially recognized that the most problems do not occur in fine-grained layers, but in areas where the grains and crystals show grain sizes in the sand fraction. The grain shapes are mostly angular to sub-angular and the fabric varies between matrix-supported and grain-supported, which depends on the content of the matrix. The matrix in this case was identified as a mixture of volcanic glass, silt to clay-sized particles and calcite. Fine-grained rocks composed of particles in the clay-silt fraction have a better consolidation than rocks with particles in the sand fraction (Hjulström 1935; Sundborg 1956). This obviously plays an important role during the weathering of the Loseros Tuff, but another important factor that must be considered is the composition of the cement, which keeps the grains bonded to one another. High amounts of calcium carbonate (calcite, $\mathrm{CaCO}_{3}$ ) are found in the matrix. This mineral may be the reason for the observed differences, because calcite is relatively soluble under weathering conditions. Therefore, the matrix may have been partially dissolved, which greatly reduces the cohesion of the particles promoting flaking and crumbling. The petrographic study also showed a high content of glass micro-shards and ash in the matrix. Plutonic rock fragments and other lithic fragments are embedded in the matrix. Under the microscope the rock looks weakly welded (Fig. $62 \mathrm{~b}$ and e and Fig. $63 \mathrm{a}$ and b). Other important factors are the porosity and the average radius of the different horizons, which are related to the water transport in the rock. Volcanic rocks such as tuffs show a large variability in the porosity (Siegesmund, Duerrast 2011). The effective porosity in the Loseros Tuff varies from 11 to $20 \%$ but almost always with an average radius in the micropore size range (Klopfer 1985). The fact that the coarse-grained $4 \mathrm{~g}$ horizon has the largest pore radius and at the same time the lowest effective porosity shows that the pores are not well interconnected, which allows water uptake but restricts transport (Kraus 1985; Graue et al., 2011). In the fine-grained horizons the similarities between the pore sizes and grain sizes (well-sorted) allow for a better interconnection between the pores. The results of the moisture hygric dilatation in the fine-grained variety show a normal trend related to its average pore radius and effective porosity, mainly because the water uptake and its transport occurs almost exclusively across the micropores and restricts the contact between the water vapor and the swellable clay minerals (Larsen, Cady 1969; Siegesmund, Duerrast 2011). A very different behavior was observed when the coarse-grained tuff was saturated in 
water. On the one hand, an initial moderate expansion can be seen, which means that moisture is introduced slowly into the sample causing a gradual and slow expansion. At the same time the water, which now fills the low primary effective porosity, begins to dissolve the carbonate matrix, causing a secondary porosity, releasing new spaces (pores) where the water now invaded the rock. This process of dissolution was clearly identifiable in the hydric test. After the dissolution, moisture and water contacted the clay minerals in the matrix that previously had no interaction with it and this process was accompanied by a sudden expansion. The hydric dilatation values reached very high values, which also caused disaggregation of crystals and fragments that were cemented. The dissolution of the matrix in this case was irreversible because the cement material dissolved out in the infiltrating water flows, which happens in natural rock exposures and even in buildings stones. The time required for the expansion varies greatly according to the rock type and it depends mainly on the pore space properties. Rocks with a well connected pore network and higher porosities show faster expansion and rocks with less connected pores and lower porosity values display lower expansion velocities (Siegesmund, Duerrast 2011; Morales Demarco et al., 2007; Ruedrich et al., 2005). The Loseros Tuff shows both behaviors (velocities), which can only be explained with a change in the pore space properties. Finally, hydric dilatation is another process that is not necessarily irreversible. When it happens, it contributes to the separation of the crystals and rock fragments, especially if the cement is partially dissolved, causing the collapse of the rock, as happened during our experiments.
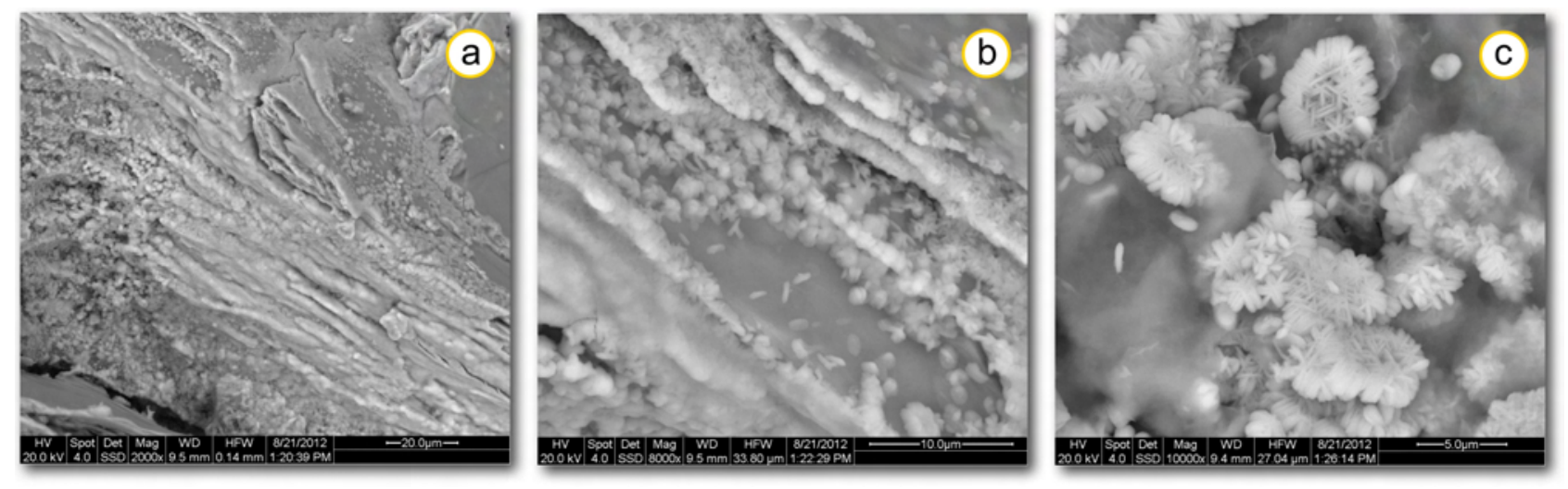

Figure 73: a) Bufa Tuff (BT) with oriented iron-rich minerals, b) recrystallization of Fe-oxide on the surface and c) close-up view with well-crystallized Fe-oxides.

Rocks with a well connected pore network and higher porosities show faster expansion and rocks with less connected pores and lower porosity values display lower expansion velocities (Siegesmund, Duerrast 2011; Morales Demarco et al., 2007; Ruedrich et al., 2005). The Loseros Tuff shows both behaviors (velocities), which can only be explained with a change in the pore space properties. Finally, hydric dilatation is another process that is not necessarily irreversible. When it happens, it contributes to the separation of the crystals and rock fragments, especially if the cement is partially dissolved, causing the collapse of the rock, as happened during our experiments. 
The better salt resistance of the coarse-grained variety compared to the fine-grained one is probably the higher compressive and splitting tensile strength as well as the higher ultrasonic velocity. In the case of the Bufa Tuff another weathering process might be the dominant factor for its typical weathering form: crack formation. The SEM images show other iron-rich minerals besides the presence of some clay minerals (Fig. 73 a). The observed dilatation in this tuff may also be associated with an expansion due to the oxidation and crystallization of these minerals (Fig. $73 \mathrm{~b}$ and c). A closer look reveals well-crystallized and star-like Fe-oxide crystals. 


\section{4 Santa Mónica Church Guadalajara / Mexico}

\section{4. 1 Introduction}

Guadalajara, Mexico is located at $20^{\circ} 40^{\prime} \mathrm{N}$ and $103^{\circ} 19^{\prime} \mathrm{W}$ with an altitude of $1589 \mathrm{~m}$ above sea level. It is the capital of the state of Jalisco and is the second largest city in Mexico today. Guadalajara was founded in 1532 under the name of Espiritu Santo by the Spaniards and was built as a grid of streets. Throughout the $17^{\text {th }}$ and $18^{\text {th }}$ centuries, Guadalajara increased its wealth and influence by importing goods from the Pacific coast and distributing them to the rest of Mexico. The region also achieved a greater stability by negotiating peaceful settlements with the indigenous tribes.

During the war for independence, the people of Guadalajara freed themselves by defeating the loyalist militia at Zacoalco on the $4^{\text {th }}$ of November 1910, which opened the way for Hidalgo's new army to take the city of Guadalajara a few weeks later. Moreover, during the Mexican Revolution of 1910 the state of Jalisco and Guadalajara became a battleground again. Shooting-marks can be also found at some walls of the church.

The church of Santa Mónica is located in the historical centre of Guadalajara and is one of the oldest churches in the city. This building was once part of a monastery and was erected in the first half of the $17^{\text {th }}$ century. The church is an outstanding representation of Mexican Baroque because of the richly decorated facades (Fig. 75) and has a dimension of 12 x 64 meters in size and 14 meters in height (Fig. 74). Two portals with Solomonic twisted columns decorate the baroque facade, where they are covered with rich and intricately carved ornamentations, including grapes, cobs of maize, angels, double eagles and symbols of religious orders. As a model for the different decorations, the cathedral of Cajamarca in Peru (built from 1682-1762) was possibly used as an example. On one corner of the church an early and impressive statue of St. Christopher looks down upon the passing traffic (Fig. 75 a \& c). Furthermore, a large dimensioned cross is carved into the northern facade.

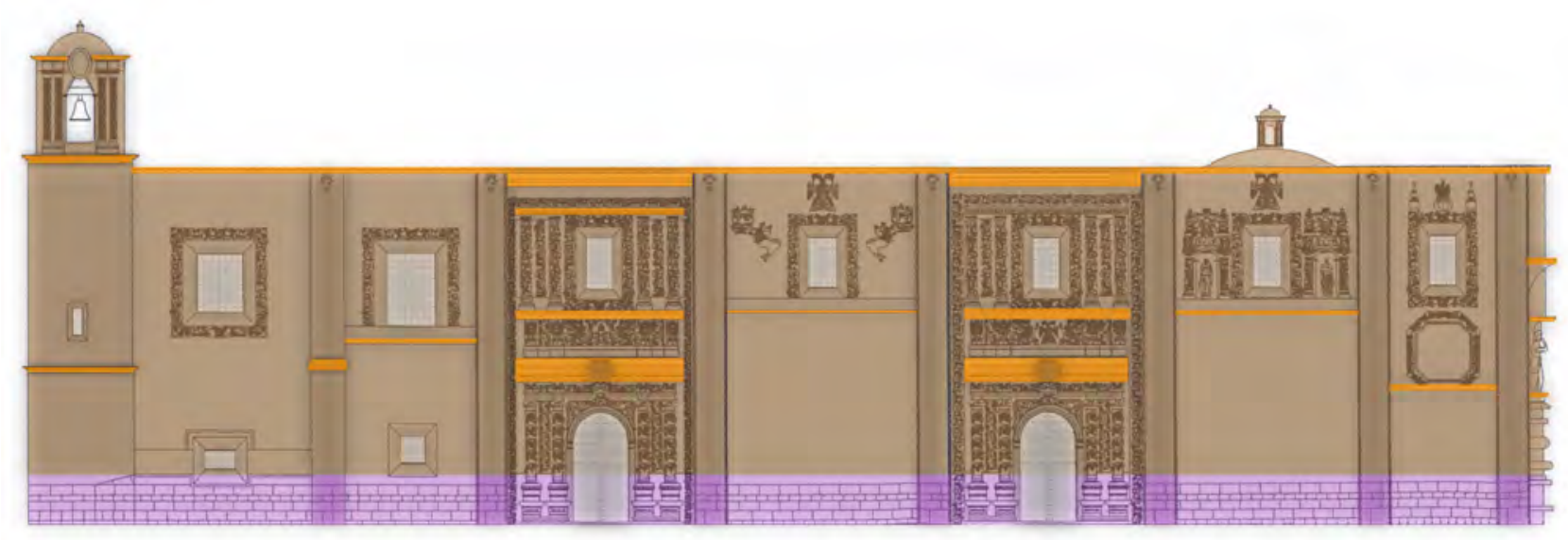

Figure 74: Architectural drawing of the Santa Mónica Church in the historical center of Guadalajara with different arichtectural areas. Mangenta - lower ground floor, brown - walls and architectural decoration, orange - cornices. 
The metropolitan zone of Guadalajara has a high seismic potential. Over the last several centuries large destructive earthquakes have occurred in the region (Chavez 2000). One large event is historically documented before the erection of the church in December of 1568 with an estimated magnitude of 7 after the Modified Mercalli Intensity scale (MMI), (Suarez et al., 1994). Another earthquake took place in 1845 with a similar magnitude of 7 . Thirty years later in 1875 another event occurred with an estimated magnitude of $7 \mathrm{MMI}$, depth 10 to $15 \mathrm{Km}$, and an epicenter distance of about $30 \mathrm{~km}$ northwest of Guadalajara. This event produced a maximum MMI of 9-10 in the center of the town and caused further destruction (Figueroa 1987).

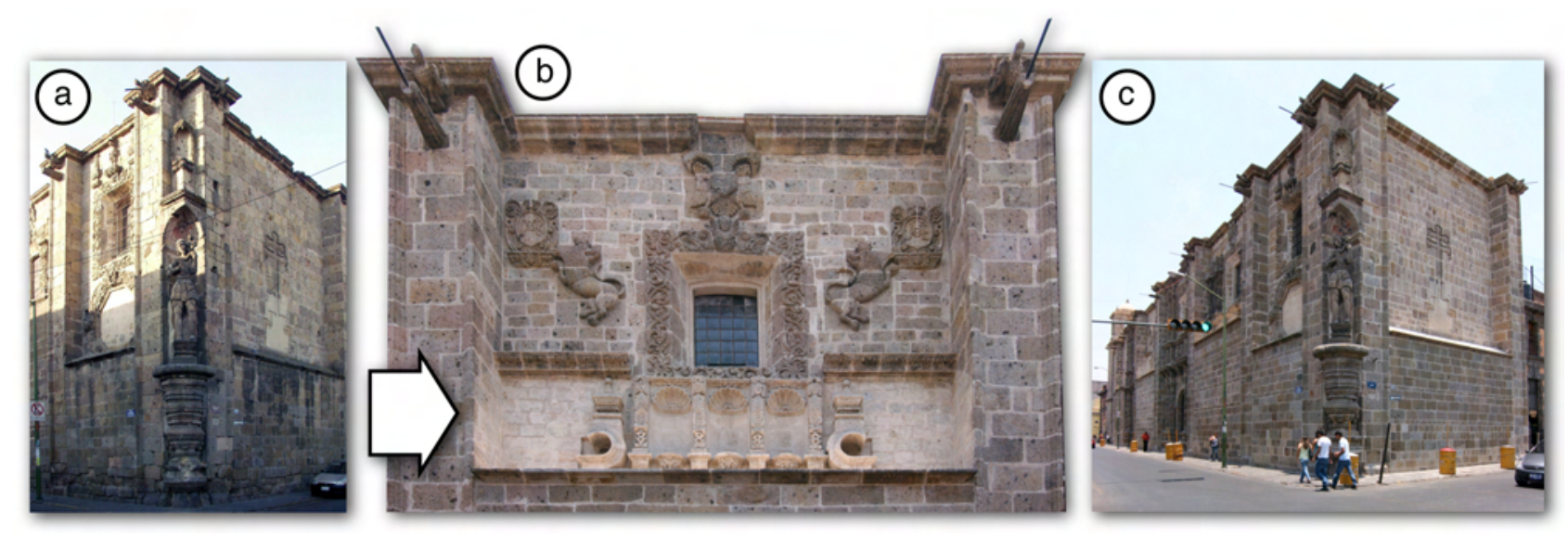

Figure 75: a) Church before restoration. b) Area where architectural elements were discovered (arrow) that include three niches for the placement of religious sculptures. c) Church after restoration.

\section{4. 1 a) Climatic and environmental conditions}

The climate in Guadalajara is humid and subtropical featuring dry, mild winters and hot humid summers with a very strong seasonal variation in precipitation (Fig. 76). Climatic classification is Cwa after the Köppen-Geiger system (Tab. 1). The northward movement of the Inter-Tropical Convergence Zone, especially from June to September, brings a great deal of rain, whereas for the rest of the year, the climate is very arid.

The annual average temperature is $19^{\circ} \mathrm{C}$ (Fig. 76). Average monthly temperatures vary by $8^{\circ} \mathrm{C}$. In the spring, the hottest time of the year, temperatures climb reaching $30^{\circ} \mathrm{C}$, generally in the afternoon with overnight lows of $11.3^{\circ} \mathrm{C}$. During the summer average high temperatures are $27^{\circ} \mathrm{C}$ and average low temperatures are $15.7^{\circ} \mathrm{C}$. Come autumn temperatures decrease achieving average highs of $25.3{ }^{\circ} \mathrm{C}$ during the day and lows of $12{ }^{\circ} \mathrm{C}$ generally shortly after sunrise. Total annual precipitation averages $914 \mathrm{~mm}$.

According to the Holdridge life zones system of bioclimatic classification, Guadalajara is situated in or near the subtropical dry forest biome (Tab. 1). The city of Guadalajara is similar to many other metropolitan areas in Latin America and has grown considerably in the period from 1970 to 2000, more than at any other time in its history. 


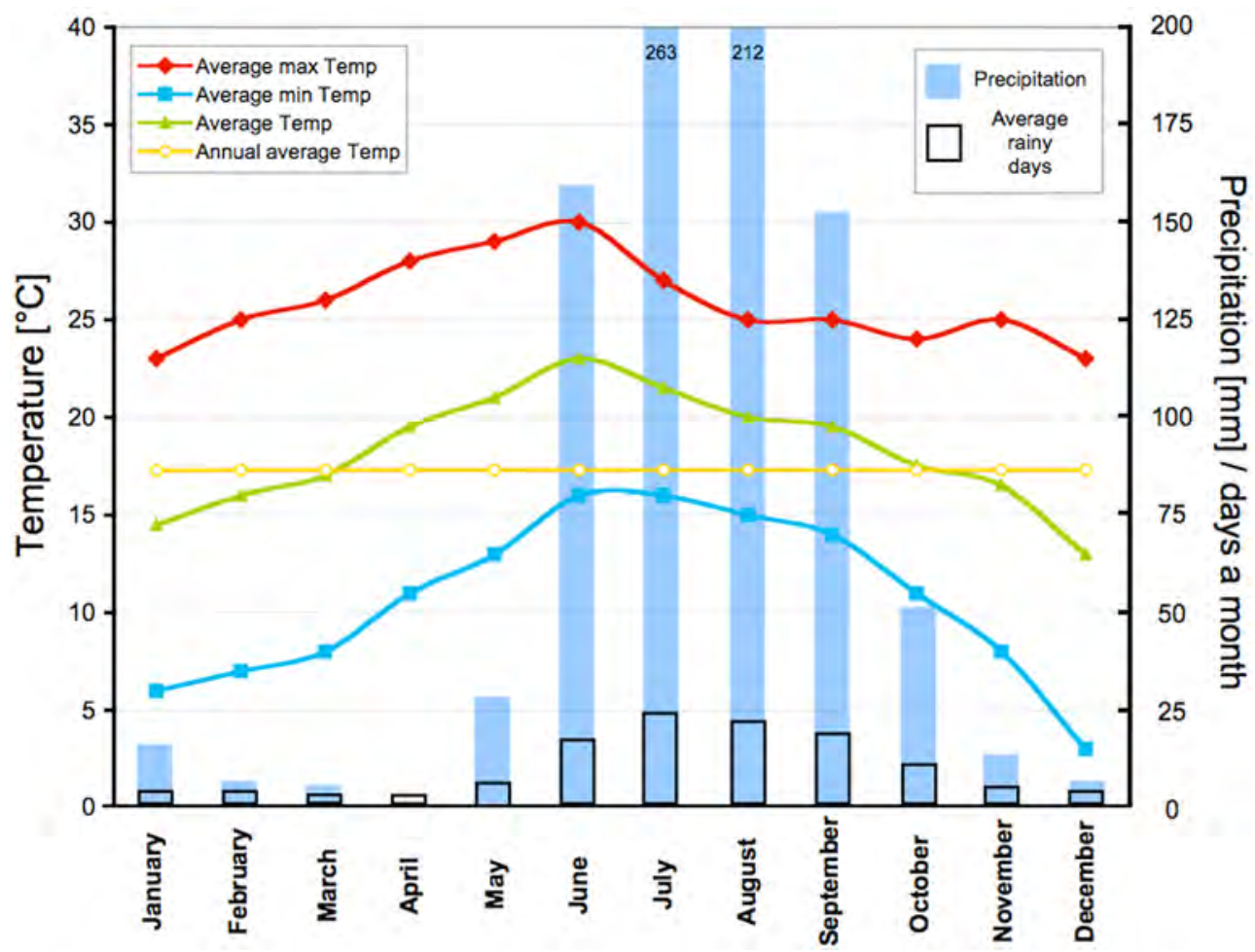

Figure 76: Guadalajara Climate Graph.

This growth took place without control, clear regulations and often outside the law (Cruz et al., 2005). According to Cruz et al., (2005), the surrounding municipalities have shown signs of an extremely high rate of growth between 1970 and 1990. In contrast, the central municipality and the historical center of Guadalajara have shown a lower rate of growth since the 1980's, and in the 1990 's it even achieved a negative rate of growth.

Government officials were following the concept of a car-friendly city. The streets were widened and green areas were paved. The historical center and many historical buildings were neglected. For the last several decades individual traffic and smog has been and still is a serious problem. However, today city planners are following a new ambitious plan for the revitalization of the historical center. Just one block away from the Santa Mónica Church pedestrian precincts are being created and trees are being planted.

\section{4. 1 b) Main weathering forms}

In the foundation area of the Santa Mónica Church as well as other historical buildings extensive back-weathering due to disaggregation and distinct fragmentation is observable (Fig. $77 \mathrm{c}$ ). Mapping results indicate a yearly back-weathering rate of $1.7 \%$ in the foundation area (Fig. 80 e, f and g). Most of the stones concerned were installed like plates, which mean perpendicular to the bedding. Salt efflorescence is recognizable on many building stones.

Cantilevering and overhanging building components such as the numerous gargoyles, mouldings 
and ornamental elements especially at the eaves areas often contain many fractures (Fig. 77 b).

Crack formation in these areas can be traced back to thermal and hygric fluctuations, dilatation and material fatigue. Temperature measurements show a heating up of the surface to $65^{\circ} \mathrm{C}$, whereas after sunset and with a periodically rising cool wind, the surface temperature can be reduced by 15-20 ${ }^{\circ} \mathrm{C}$.
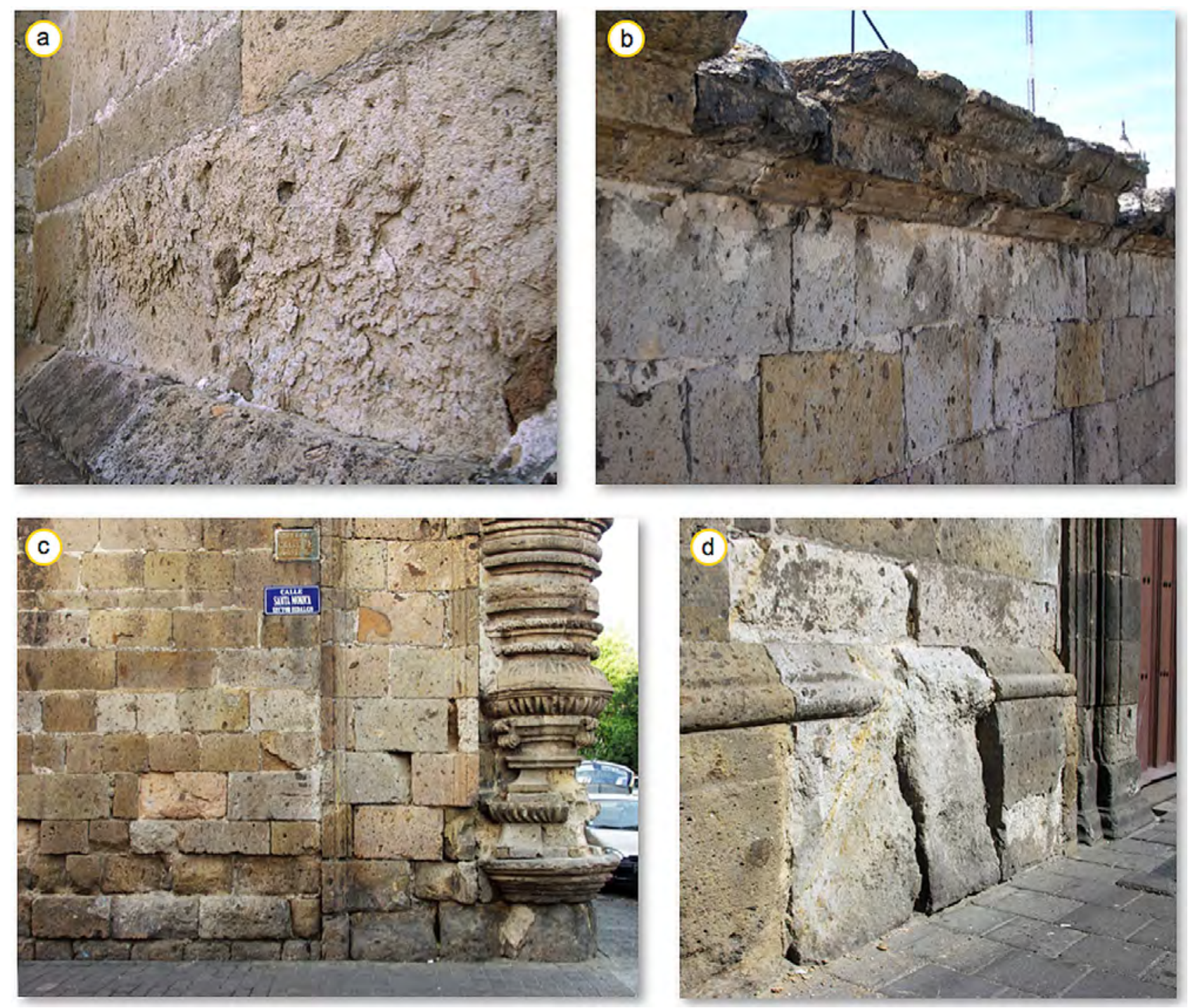

Figure 77: Typical weathering forms of the Cantera Amarilla Tuff, a) shows structural flaking and disaggregation, b) broken areas and crack formation, c) massive back-weathering at the foundation (Santa Mónica Church) and d) material loss due to crust formation and weathering (Museo Regional).

\section{4. 1 c) Quantified mapping}

Quantified mapping of the main pillar at the edge of the building clearly shows that back-weathering phenomena occupy a surface area of $6.8 \%$ (Fig. 78 a). Disaggregation is $1.7 \%$, whereas the weathering out of clastic material is only $0.09 \%$. Weathering in the form of flaking is concentrated at the podium zone, where it amounts to $67 \%$ of this area. Also disaggregation is concentrated in the podium zone with nearly $75 \%$. Cracks are found at the eave area while salt-efflorescence is 
only found in the podium zone. Dark deposits are evenly distributed but concentrated at exposed building parts as well as at the eave and podium zone. These deposits are related to microbiological growth, and therefore, an indicator for the accumulation of moisture.

Results of the quantified mapping underline the assumption that salt weathering is the main reason for disaggregation as well as flaking. Formation of cracks seems to be related to the interplay of wetting due to rain and the drying out to sunshine and wind.
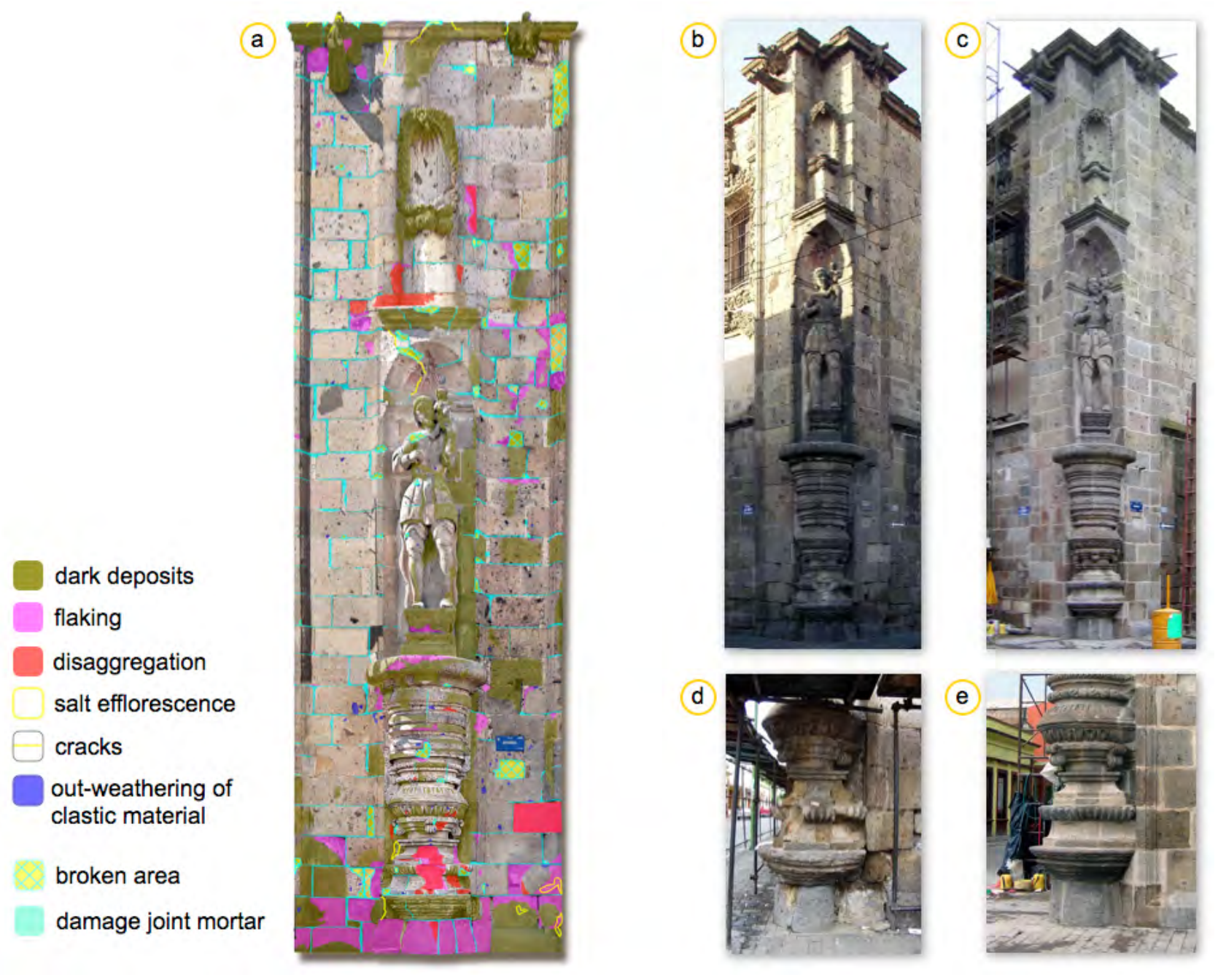

Figure 78: a) Mapping of the main pillar of the Santa Mónica Church. b) The pillar before and c) after restoration.

d) Podium zone of the statue of St. Christopher before and e) after restoration.

\section{4. 1 d) Observations, further investigations and weathering model}

During the rainy season parts of the streets are flooded and the drainage systems are often not able to drain the water away in a proper fashion. The problem is furthermore reinforced by the damaged drainage and water supply systems.

Under these circumstances evaporation often takes place through the porous building materials such as volcanic tuffs, bricks or adobe constructions, which are mostly used in historical buildings. Wet- 
ting and drying produces a cyclical softening of the materials and damages by salt-weathering. During the rainy season uprising capillary water up to two meters in the stone occurs in numerous historical buildings as well as in the Santa Mónica Church (Fig. 77 c and d). These have been measured with a portable hygrometer.

Most of the back-weathering observed occurs in this area, when considering the total surface area of the monuments (Fig. 79 a-c and e-g). The moisture content in this area as measured by drilling powder analysis is 8-15 M\% in the beginning of the dry season at the end of September. Backweathering in the pedestal area of the Santa Mónica Church is recognizable all around the building and also leads to structural problems.
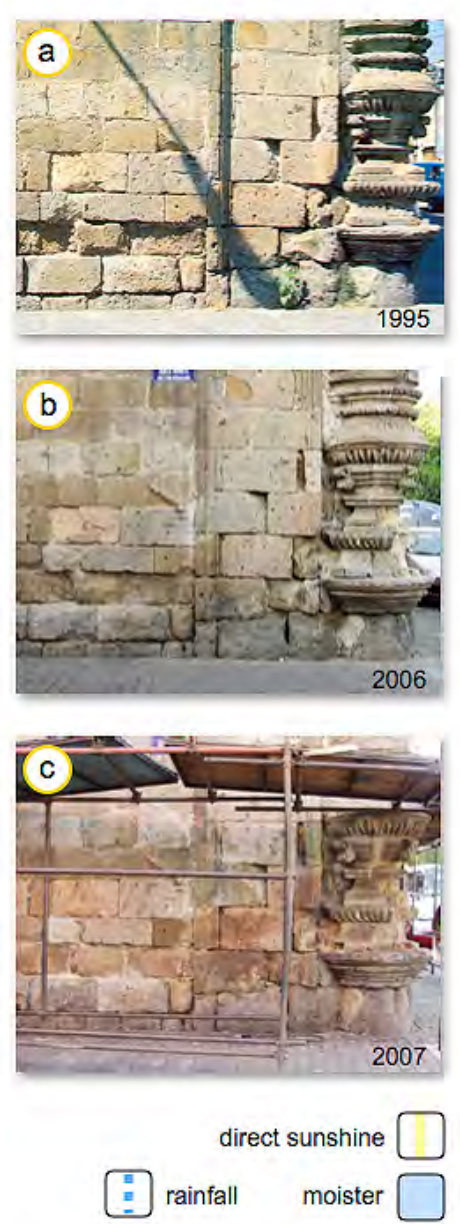
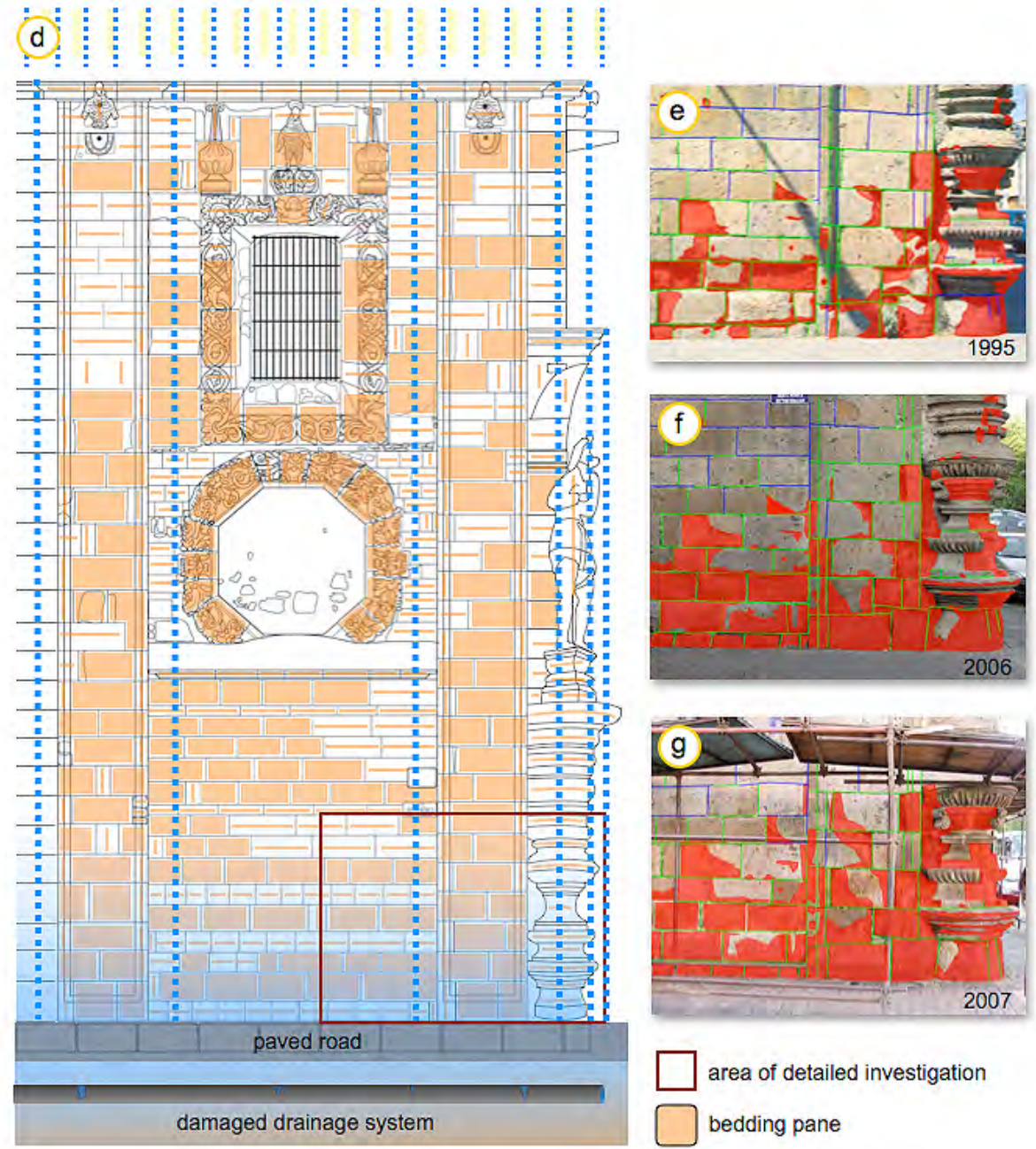

area of detailed investigation

bedding pane

Figure 79: Weathering and weathering model of the Santa Mónica Church. a-c) The weathering situation at the edge of the building (lower part) from 1995 until 2007 before the restoration began. d) Weathering model of the building as defined by water infiltration coming from the damaged drainage system during the rainy season and direct sunshine. e -

g) Depiction of the ongoing surface loss (red), lost joints (green) or damaged joints (blue).

\section{4. 2 The salts of Guadalajara, their sources and damage potential}

The main salt found is sodium nitrate $\left(\mathrm{NaNO}_{3}\right)$ and gypsum analyzed by X-ray diffraction (XRD) measurements. The highest concentration of contamination occurs near the surface and in the first 
two centimeters of the stone material as evaluated by the drilling powder analysis method (Fig. $80 \mathrm{~b}$ and c).

The danger from $\mathrm{NaNO}_{3}$ results in its hygroscopic potential. Experimental laboratory studies show a rise of the moisture uptake of $\mathrm{NaNO}_{3}$ contaminated stone blocks in relation to the temperature and humidity (Goudi, Viles 1997). The critical conditions for a significant hygroscopic behavior start with a relative humidity of $80 \%$ and $35{ }^{\circ} \mathrm{C}$, which are the climatic conditions very common in Guadalajara. Salt crystallization may enforce the flaking effect often found at areas confronted by water infiltration (Fig. $80 \mathrm{a}$ and b).

A possible source of the salt can be derived from the stone material itself (e.g. plagioclase), whereas the source of the nitrates occur in high concentrations in many examples of environmental pollution.
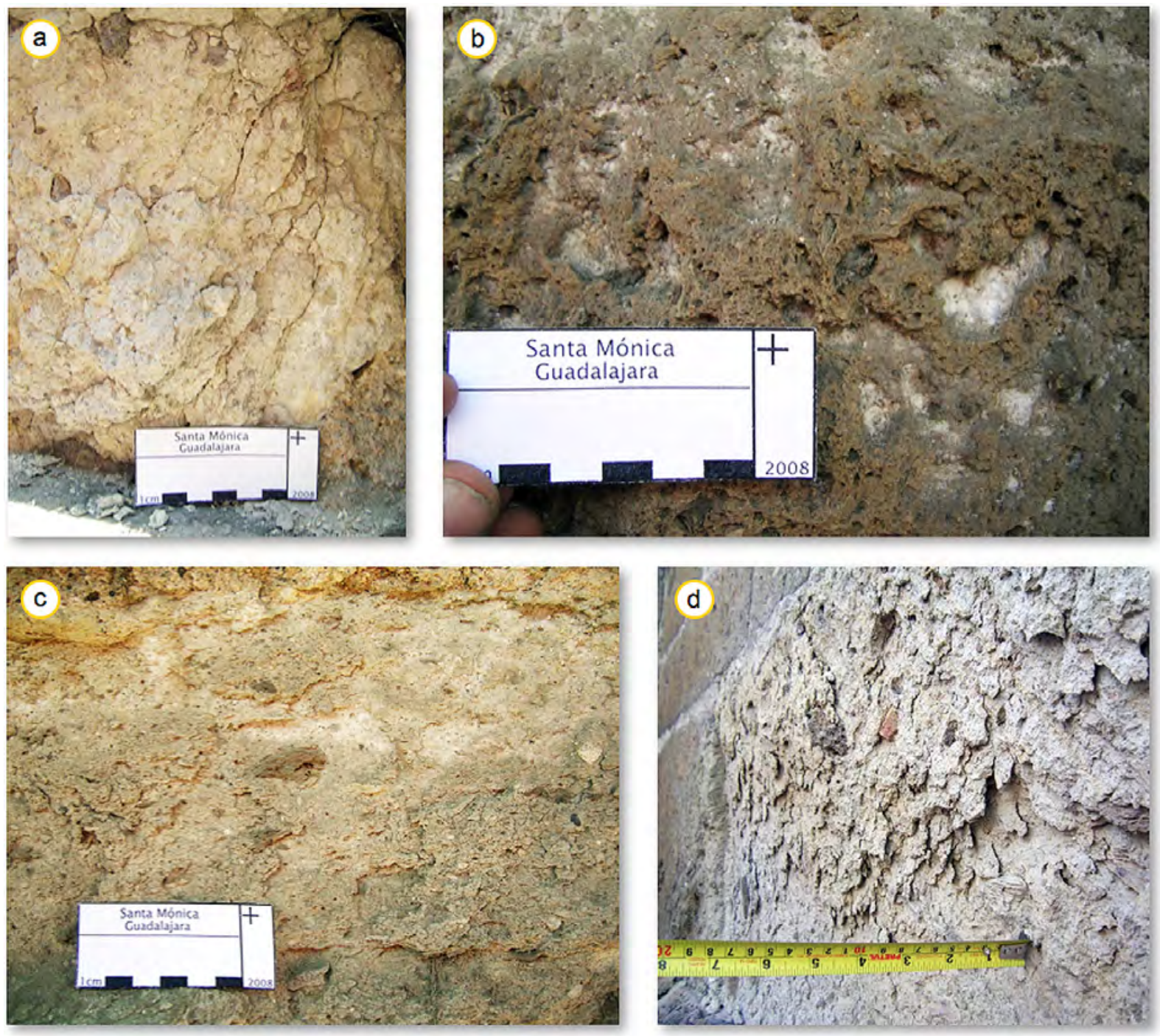

Figure 80: Close-ups of the typical weathering forms of the Cantera Amarilla Tuff show a) internal crack formation and crumbling, b) alveolar weathering clearly related to salt, c) flaking also related to salt accumulation as well as d) structural flaking. 


\section{4. 3 Rock material}

The Cantera Amarilla Tuff (CA) belongs to the Quaternary volcanics in the Guadalajara area and occurs one to two meters beneath the soil. Today most of the deposits are covered by the present urban area. Only a small outcrop is still available for mining the stones for restoration purposes.

The Cantera Amarilla Tuff is a yellowish to orange-brownish porphyritic tuff (hypercrystalline to aphanitic texture) containing clasts of very different sizes. The macroclasts are mainly pumice, but other lithic clasts such as basalt and other pre-existing volcanic fragments occur (Fig. $81 \mathrm{a}, \mathrm{d}$ and e). Grain sizes vary from a few $\mathrm{mm}$ (fine-grained sand) up to $10 \mathrm{~cm}$ and sometimes even coarser (Fig. 81 c). The Cantera Amarilla Tuff is rich in K-feldspar and plagioclase (Fig. 81 b). Crystobalite and tridymite also occur along with accompanying clay minerals. Smectite, kaolinite and halloysite were identified in separated clay fractions. Most of the pumice inclusions are not well cemented to the matrix (Fig. 81 e).
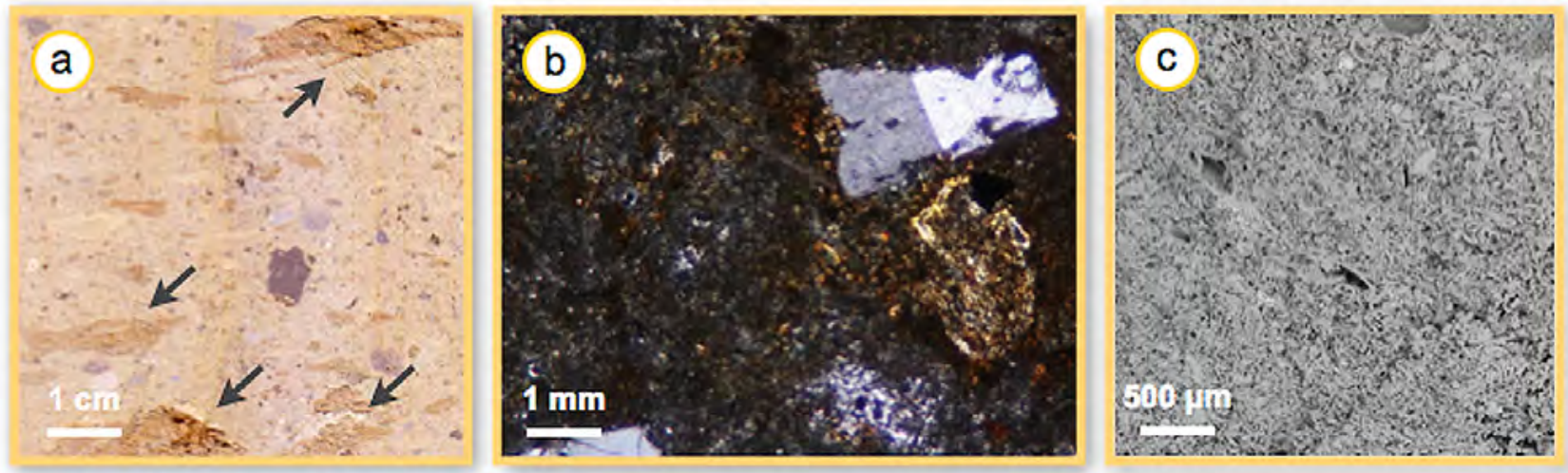

CA Cantera Amarilla tuff, Jalisco / Mexico
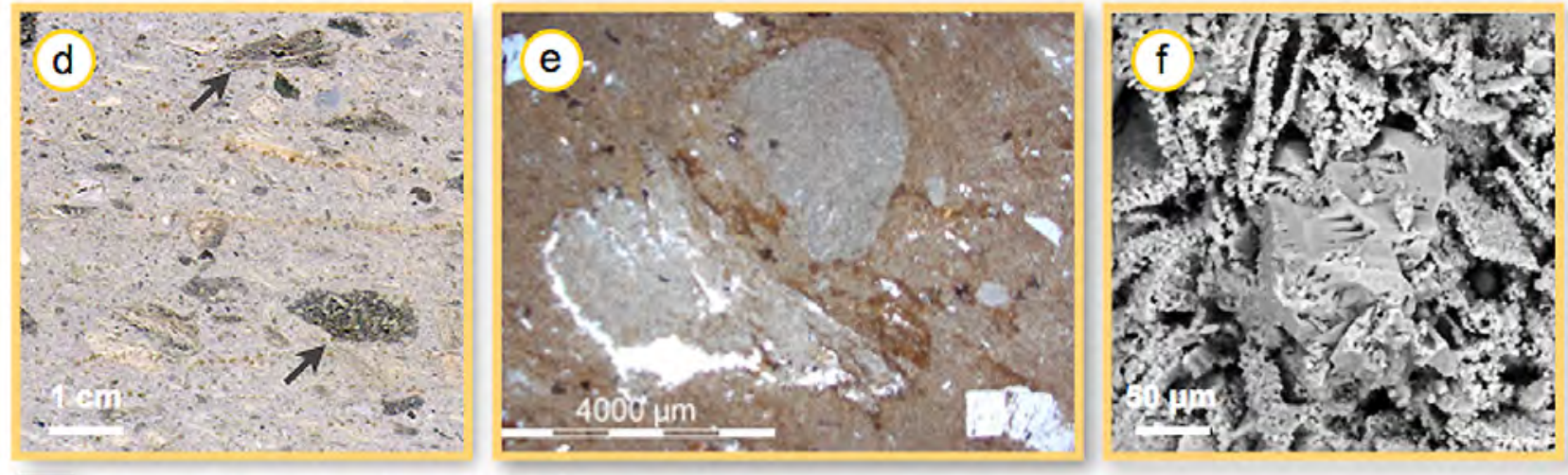

Cantera Amarilla tuff, gray variety, Jalisco / Mexico

Figure 81: a) The Cantera Amarilla Tuff shows a secondary iron-rich cementation with a vertical orientation and brown iron-rich pumice inclusions (arrows). b) Thin section showing the glassy to microcrystalline matrix. C) Overview of the matrix by SEM. d) The grey variety of the Cantera Amarilla with dark colored inclusions, rock fragments and pumice (arrows). e) In the center a fragment of feldspar and pumice occurs that only shows a poor cementation within the matrix. f) Single sharp egded crystals within the microcrystallin poorly welded matrix shown by SEM. 
The thin section in Fig. 81 b shows a hypocrystalline to aphanitic texture. The matrix is reddish to yellowish, glassy to microcrystalline and poorly welded (Fig. $81 \mathrm{f}$ ). Crystals are essentially platy and tabular and subhedral to euhedral (Fig. $81 \mathrm{~b}$ and e). They consist of well-twinned alkali-feldspar phenocrysts, subrounded to angular reworked quartz and unidentified opaque crystals (Fig. $81 \mathrm{c}$ and f).

The XRD analysis shows that the Cantera Amarilla Tuff is rich in clay minerals, principally kaolinite, but smectite and altered illite-montmorillonite also occurs. Halloysite, crystobalite/tridymite and larger amounts of K-feldspar and plagioclase have also been determined. The cation exchange capacity (CEC) of 4.2 attains a moderate value (Wedekind et al., 2013).

The chemical analyses (wt.-\%) show that the rock mainly consists of $71.4 \%$ quartz components $\left(\mathrm{SiO}_{2}\right)$ and $14.4 \%$ alumina $\left(\mathrm{Al}_{2} \mathrm{O}_{3}\right)$. It also contains relevant amounts of potassium oxide $(4.8 \%$ $\left.\mathrm{K}_{2} \mathrm{O}\right)$, sodium oxide $\left(4.6 \% \mathrm{Na}_{2} \mathrm{O}\right)$ and traces of phosphorus pentoxide, calcium oxide, magnesium oxide and sulfur trioxide (Wedekind et al., 2012).

\section{4.3 a) Petrophysical experiments}

To evaluate the affect of clasts within the bedding in regards to tension and dilatation, experimental measurements were undertaken on a $10 \times 10 \mathrm{~cm}$ cube of Cantera Amarilla. The dilatation was measured in a $1.5 \mathrm{~cm}$ grid in the Z-direction (Fig. $82 \mathrm{~b}$ ). The stone block was totally immersed in water until the entire block was completely saturated.

\section{4. 3 b) Petrophysics}

The porosity of the samples ranges between $42 \%$ (CA) to $51 \%$ (CA gray), with a particle density of around $2.5 \mathrm{~g} / \mathrm{cm}^{3}$ and a bulk density of $1.48 \mathrm{~g} / \mathrm{cm}^{3}$. The microporosity reaches $18 \%$ for the yellow variety and $22 \%$ for the gray variety. Pore radii distribution is characterized by a bimodal system consisting of a high amount of macropores, where capillary moisture transport takes place and a significant amount of mircropores probably responsible for hygric and hydric dilatation. The calculated water absorption coefficients (w value) show a more or less similar value of around $3.5 \mathrm{~kg} /$ $\mathrm{m}^{2} \sqrt{\mathrm{h}}$ for the $\mathrm{X}$ and $\mathrm{Y}$ direction, while the $\mathrm{Z}$ direction only has a value of $0.5 \mathrm{~kg} / \mathrm{m}^{2} \sqrt{ }$ (Tab. 15). The avarage $\mu$ value with 75.2 is high (Tab. 15).

In the hydric expansion measurements the values for the $\mathrm{X}$ and $\mathrm{Y}$ direction are around $0.13 \mathrm{~mm} / \mathrm{m}$, while the expansion perpendicular to the bedding is $0.9 \mathrm{~mm} / \mathrm{m}$ with an anisotropy of $82 \%$ (Tab. 15). Expansion with a $95 \% \mathrm{RH}$ is reached at a value of $0.17 \mathrm{~mm} / \mathrm{m}$ and a low anisotropy of only 11 $\%$. Swelling pressure attains a moderate value of $0.011 \mathrm{MPa}$. 
Table 15: Water transport properties and hygric and hydric dilatation of the Cantera Amarilla Tuff used for the Santa Mónica Church

\begin{tabular}{lccccc}
\hline Directions $(\mathbf{X}, \mathbf{Y}, \mathbf{Z})$ / Anisotropy $(\mathbf{A})$ & $\mathbf{X}$ & $\mathbf{Y}$ & $\mathbf{Z}$ & $\mathbf{A} \%$ & Average $\varnothing$ \\
$\mathbf{w}$ value $\left[\mathrm{kg} / \mathrm{m}^{2} \sqrt{ } \mathbf{h}\right]$ & 3.34 & 3.78 & 0.51 & 85 & 2.54 \\
$\boldsymbol{\mu}$ value & 72.7 & 75.8 & 77.2 & 6 & 75.2 \\
Hydric dilatation $[\mathrm{mm} / \mathrm{m}]$ & 0.16 & 0.11 & 0.90 & 82 & 25 \\
Hygric dilatation $\mathbf{9 5 \%} \mathbf{R H}[\mathrm{mm} / \mathrm{m}]$ & 1.8 & 1.6 & 1.7 & 11 & 17 \\
Thermal expansion $\left[\mathrm{mm} / \mathrm{m}, \mathbf{6 0}{ }^{\circ} \mathrm{C}\right]$ & 0.68 & 0.66 & 0.62 & 9 & 0.65 \\
\hline
\end{tabular}

Sorption reached a value of $0.036 \mathrm{~g} / \mathrm{cm}^{3}$ at a relative humidity of $95 \%$, is mostly linear and attains a point of significant decrease at around $80 \% \mathrm{RH}$. During the process of desorption, the water output is slightly reduced when compared to the sorption, especially when the relative humidity ranges between $20-80 \%$.

Measurements by the surface hardness tester after water saturation show an average reduction of surface hardness of $21 \%$. The results also show that there is no significant influence of long-term water storage to the reduction of surface hardness. Following the saturation and measurement the values remained constant every $12 \mathrm{~h}$ for a period of two days. The hardness of the pumice inclusions is $34 \%$ less than the matrix of the tuff, and is further reduced by $20 \%$ in water-saturated conditions.

With an average value of $9.12 \mathrm{~N} / \mathrm{mm}^{2}$ the Cantera Amarilla Tuff has a low compressive strength; however, under water-saturated conditions its internal stability decreases down to only $5.81 \mathrm{~N} / \mathrm{mm}^{2}$, a reduction of more than $37 \%$. The anisotropy of the specimens measured under water-saturated conditions is double when compared to the dry tested samples (Tab. 16).

Tabel 16: Petro-mechanical properties of the Cantera Amarilla Tuff, Santa Mónica Church.

\begin{tabular}{|c|c|c|c|c|c|}
\hline Directions (X, Y, Z) / Anisotropy (A) & $\mathbf{x}$ & $\mathbf{Y}$ & $\mathbf{z}$ & A [\%] & reduction [\%] \\
\hline Compressive strength dry $\left[\mathrm{N} / \mathrm{mm}^{2}\right]$ & 9.45 & 8.21 & 9.72 & 16 & \multirow{2}{*}{37} \\
\hline Compressive strength water-saturated [N/mm²] & 5.06 & 5.33 & 7.06 & 28 & \\
\hline Splitting tensile strength dry ßsz [MPa] & 0.99 & -- & 1.05 & 6 & \multirow{2}{*}{49} \\
\hline Splitting tensile strength water-saturated Bsz [MPa] & 0.49 & -- & 0.56 & 13 & \\
\hline Surface hardness dry [HLD] & \multicolumn{4}{|c|}{332} & 20 \\
\hline Surface hardness wet [HLD] & \multicolumn{4}{|c|}{266} & \\
\hline
\end{tabular}

By comparing the results of the dry to the water-saturated specimens a reduction of the splitting tensile strength of nearly $50 \%$ could be determined. The anisotropy increase of more than three times the amount shows a clear weakening of the binding forces parallel to the bedding due to water saturation (Tab. 16). The breakage parallel to the bedding often took place at the material boundary between pumice and matrix. 
Table 17: Ultrasonic velocity of the Cantera Amarilla Tuff varieties under dry and water saturated conditions (ws)

\begin{tabular}{lcccc}
\hline Ultrasonic velocity & Amarilla (dry) & Gray (dry) & Amarilla (ws) & Gray (ws) \\
{$[\mathbf{k m} / \mathbf{s}]$} & 2.649 & 2.047 & 1.97 & 1.31 \\
$\boldsymbol{X}$ & 2.461 & 2.022 & 1.914 & 1.438 \\
$\mathbf{Y}$ & 2.158 & 1.807 & 1.688 & 1.173 \\
$\boldsymbol{Z}$ & 2.423 & 1.959 & 1.857 & 1.307 \\
Average & 17 & 24 & 14.7 & 9 \\
Anisotropy [\%] & 0 & 0 & -23.6 & -33.6 \\
Reduction Ø [\%] & & & &
\end{tabular}

The results of the dilatation experiment on the stone block emphasize the influence of the bedding towards moisture expansion. What becomes clear is that the periphery of the stone shows a higher moisture expansion than the center of the block (Fig. 82 a). Furthermore, the large pumice inclusions seem to play a role in keeping the moisture values low. Above the large inclusion there is also a tendency to lower dilatation values, probably due to the lower amounts of matrix. In the sample cube where the concentration of clasts is lower, the dilatation is higher (Fig. $82 \mathrm{a}$ ).
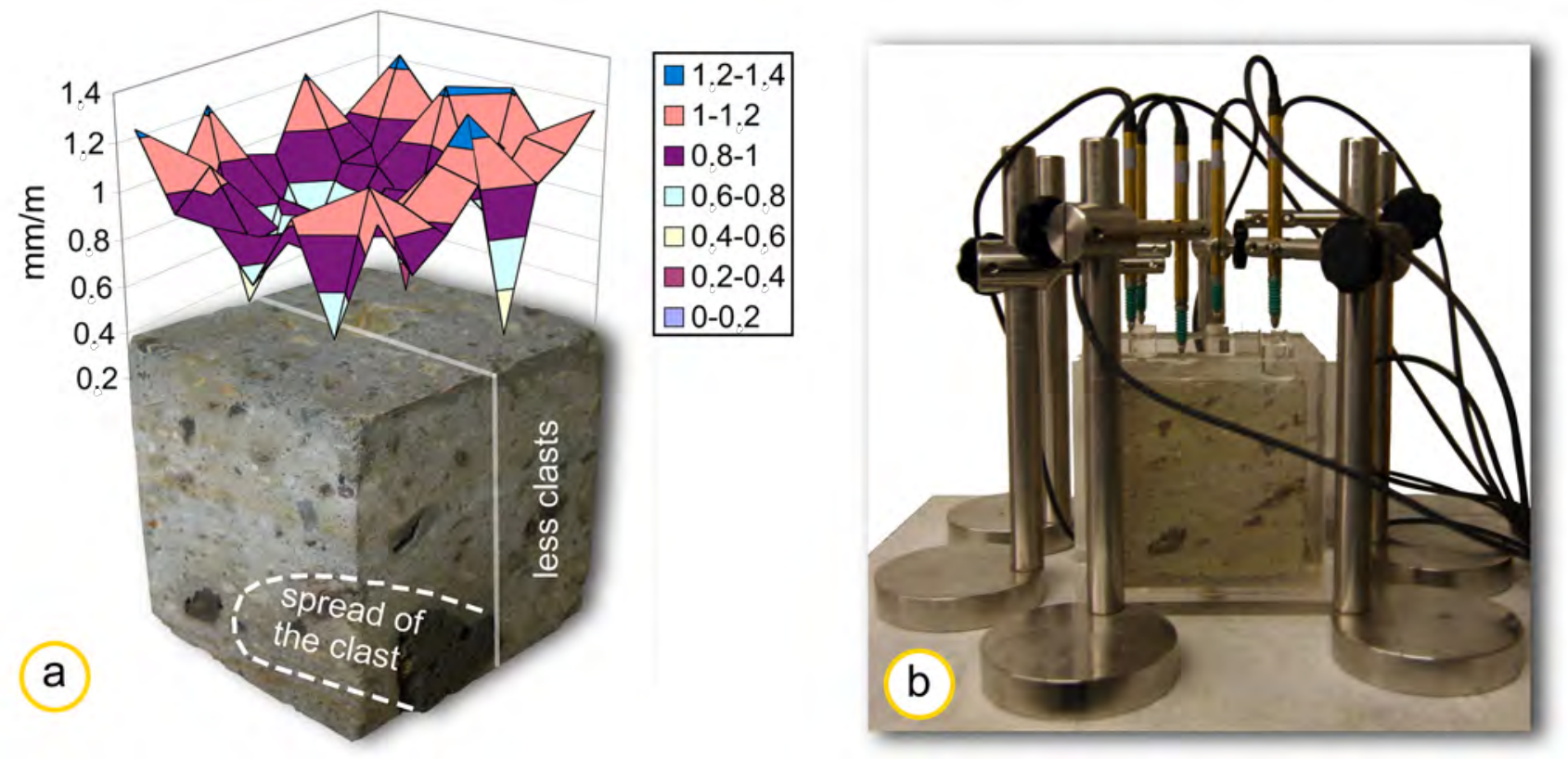

Figure 82: a) Stone block and results of the dilatation experiment. b) The measuring equipment.

\section{4.3 c) Salt resistance test}

Salt resistance tests were done on both varieties of the Cantera Amarilla Tuff (Fig. 83). 


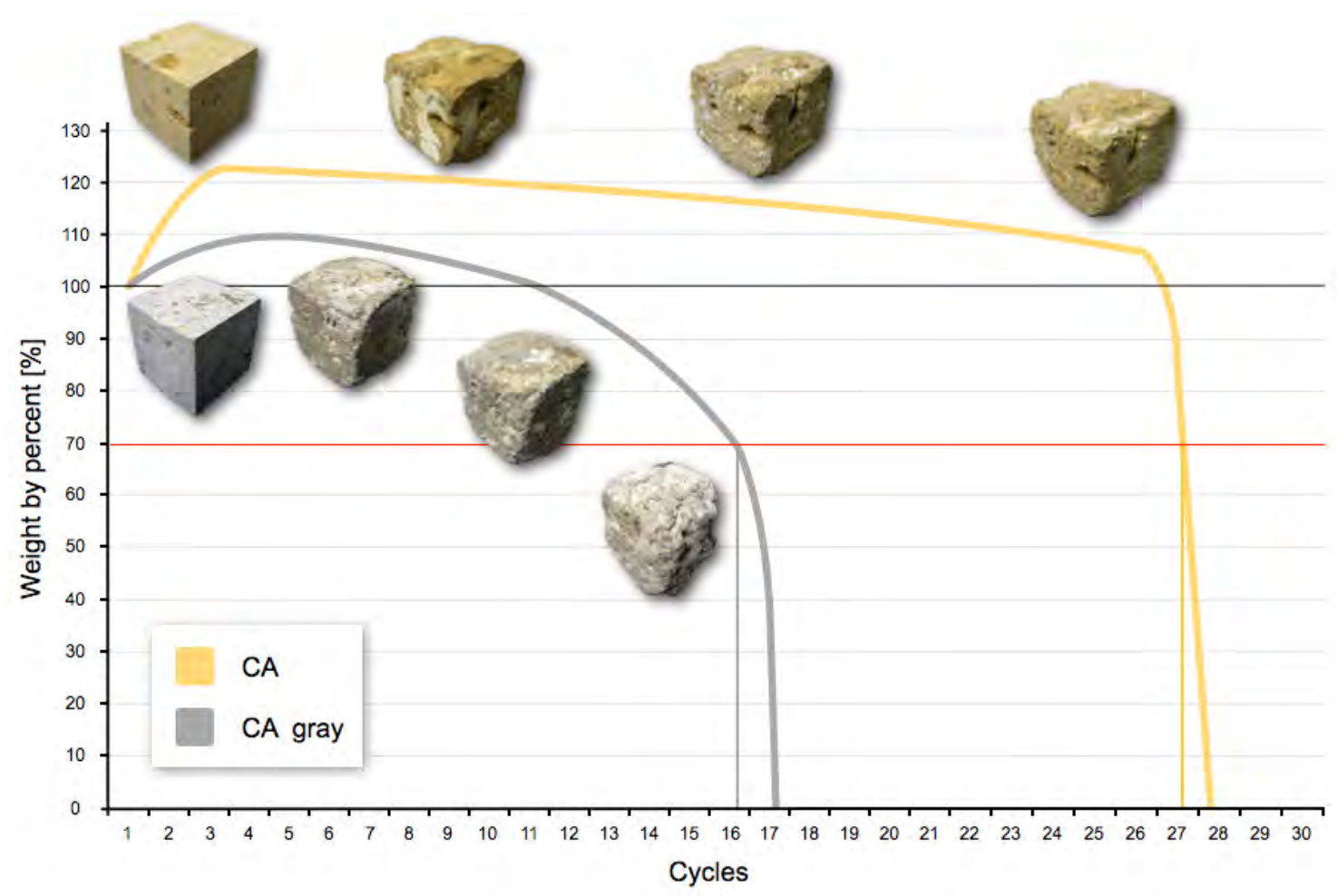

Figure 83: Salt weathering test of the Cantera Amarilla Tuff varieties.

\section{- CA, Cantera Amarilla Tuff}

The loss of material starts within the yellow pumice inclusions. They weather out after the second cycle. A tendency towards rounding also takes place. After total saturation by salt within the highly porous structure the stone starts to break after the $20^{\text {th }}$ cycle, which leads to total destruction at the $27^{\text {th }}$ cycle.

\section{- CA, Cantera Amarilla Tuff/gray variety}

The loss of material starts with a rounding at the edges. Continuous breakdown takes place after the $16^{\text {th }}$ cycle with a material loss of $30 \%$. Total destruction occurs after the $17^{\text {th }}$ cycle.

\section{4. 4 Discussion}

The situation at the Santa Mónica Church is like that of many other historical buildings and structures in the urban areas of Mexico and is characterized by its problematical hydraulic situation. Since the roads are paved, moisture infiltration during the rainy season leads to an accumulation of huge amounts of aggressive salts within the pedestal area of the monuments.

Rising water infiltration is also influenced by the bedding of the stone material due to its high anisotropy of more than $80 \%$ of the w-value and the high hydric dilatation with a remarkable anisotropy of up to $25 \%$. This becomes relevant because most of the ashlars are used as panel-like cladding, which means perpendicular to the bedding plane (Fig 79 d). Surface loss at singular ashlars are 
found preferentially at those which are built perpendicular to the stones' bedding plane (Fig. 79 a, b, c, e f, and g).

The different weathering resistance of the investigated rocks is possibly attributed to their varying content of secondary imbedded iron oxides. Compressive strength of the yellow CA is low and around $20 \%$ higher than for the gray CA variety. Also the porosity of both varieties is in general very high, but the gray $\mathrm{CA}$ is even $18 \%$ higher than the yellow CA. However, especially the yellow CA variety shows a comparably good salt resistance related to its low compressive and splitting tensile strength, propably due to secondary embedded iron compounds. 


\section{5 Bartholomew Cemetery Goettingen / Germany}

\section{5. 1 Introduction}

The origins of Goettingen go back to a village called Gutingi, which was first mentioned in a document in 953 AD. Today the city is famous for its old university, the Georgia-Augusta and several Nobel prize winners. The Bartholomew Cemetery was once located outside the mediaeval town walls, but today is situated in the center of the city on the opposite side of the main campus of the university (Fig. 84).

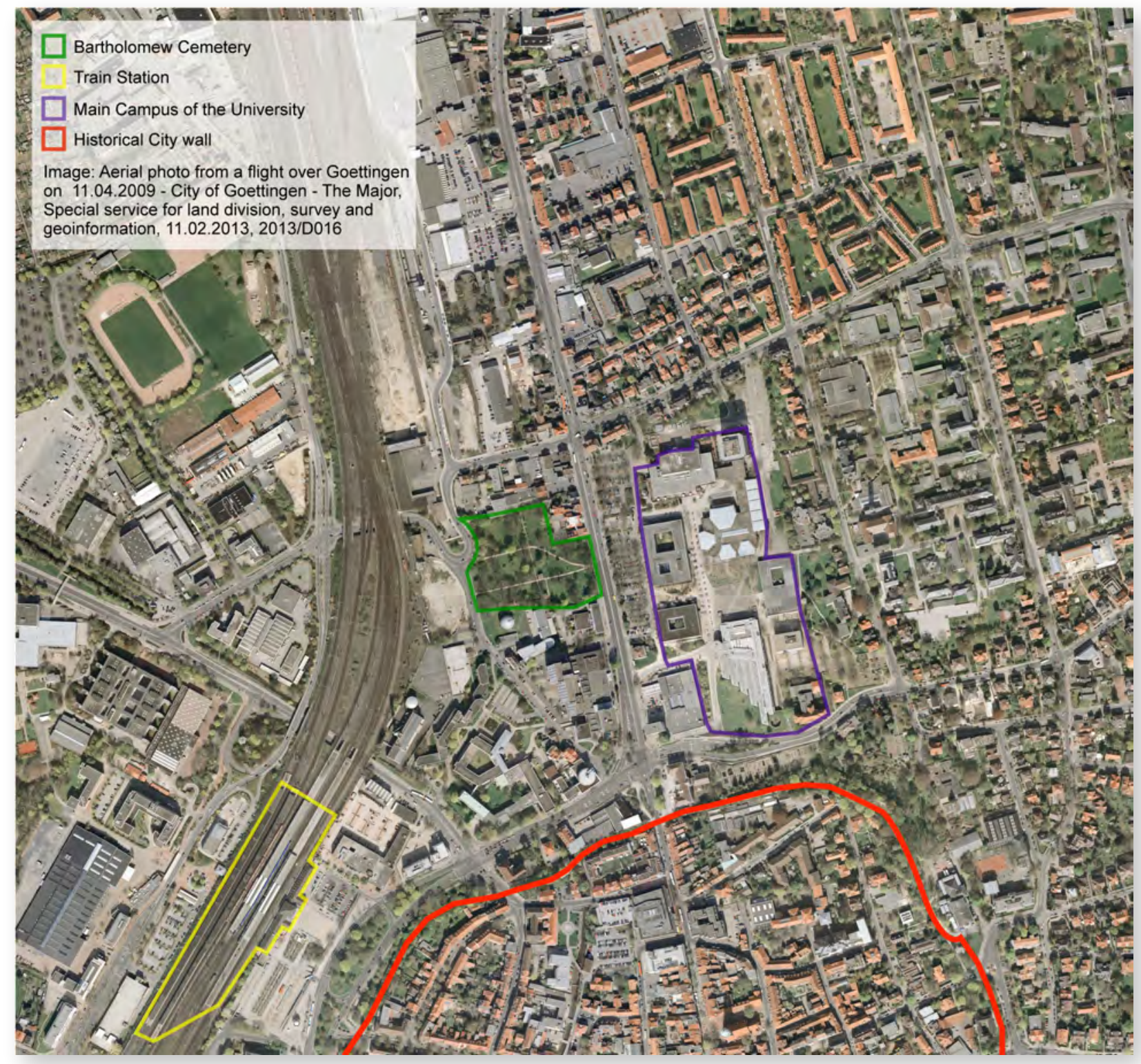

Figure 84: Location of the Bartholomew Cemetery in the city of Goettingen today.

\section{5.1 a) The Bartholomew Cemetery and its tombs}

The historical Bartholomew Cemetery is closely connected to the Georgia-Augusta University of Goettingen, which was one of the most important centers of science in Europe during the 19th cen- 
tury. The cemetery is the last resting place for many distinguished German and European personalities involved in the humanities and scientific research. From 2006 to 2008 a project of applied conservation science was undertaken with support from the „Deutsche Bundestiftung Umwelt“, the German Environmental Foundation (Fig. 85).

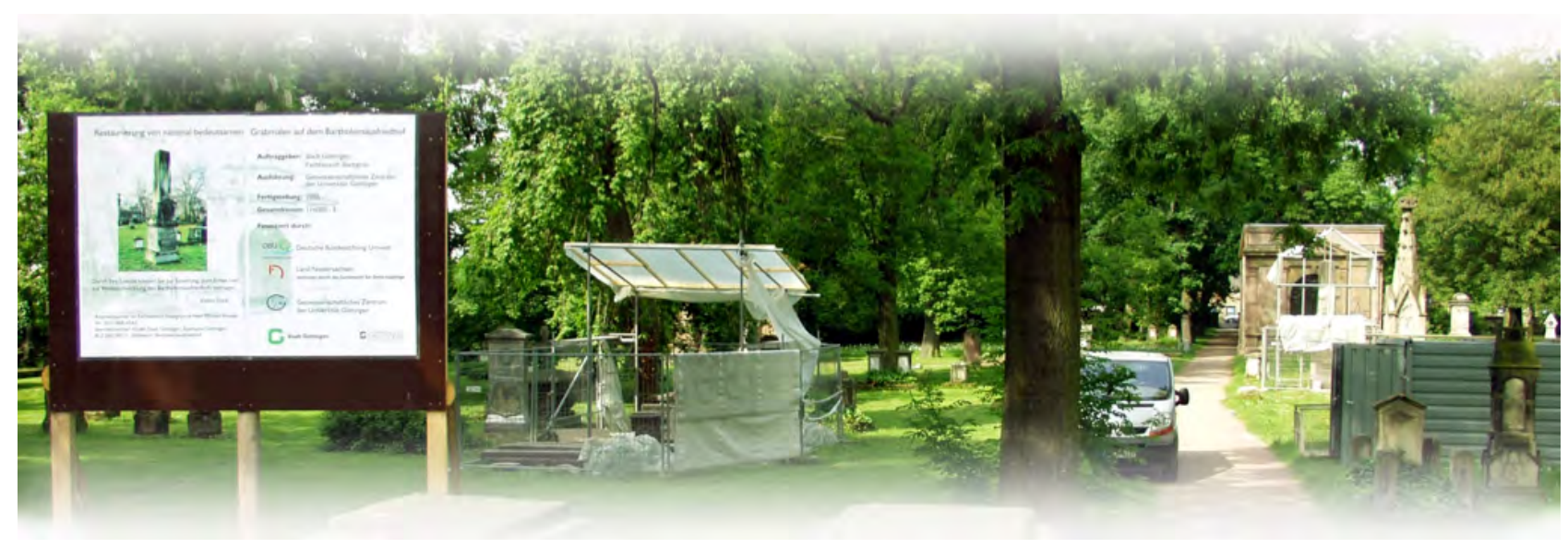

Figure 85: The Bartholomew Cemetery in Goettingen during restoration works.

From 1747 until the closure of the cemetery in 1881, thirty professors who taught and became renown at the University of Goettingen found their last resting place here. Examples are the physicist and writer Georg Christoph Lichtenberg, the poet Gottfried August Buerger, the mathematician and philosopher Abraham Gotthelf Kaestner as well as the church historian Gottlieb Jacob Planck. The number of tombs preserved today comprises a total of 167. Many of the tombs only show fragmentary preservation. The types of graves found at the cemetery consist of simple enclosure graves, tomb slabs, steles, gravestones, stone pillars, gothic pinnacle-pillars, obelisks, cubic-shaped columns and two mausoleums.

\section{5.1 b) Climatic and environmental conditions}

Goettingen is located in the valley of the Leine River. The climate is temperate, but cold. Significant amounts of rainfall occur throughout the year (Fig. 86). Even the driest month still has high amounts of precipitation according to the classification of the climate by Köppen and Geiger (Dfb).

The average annual temperature is $8.5^{\circ} \mathrm{C}$. Around $650 \mathrm{~mm}$ of precipitation fall on average within one year. March is the driest month with a precipitation of $38 \mathrm{~mm}$. Seventy-nine millimeters fall on average in June, making it the wettest month of the year. July is the warmest month with an average temperature of $16.8{ }^{\circ} \mathrm{C}$. In January, the temperatures are at their lowest with an average of $-0.4{ }^{\circ} \mathrm{C}$. The difference in precipitation between the driest month and the wettest month is $41 \mathrm{~mm}$. The average temperatures vary during the year to $17.2{ }^{\circ} \mathrm{C}$. 


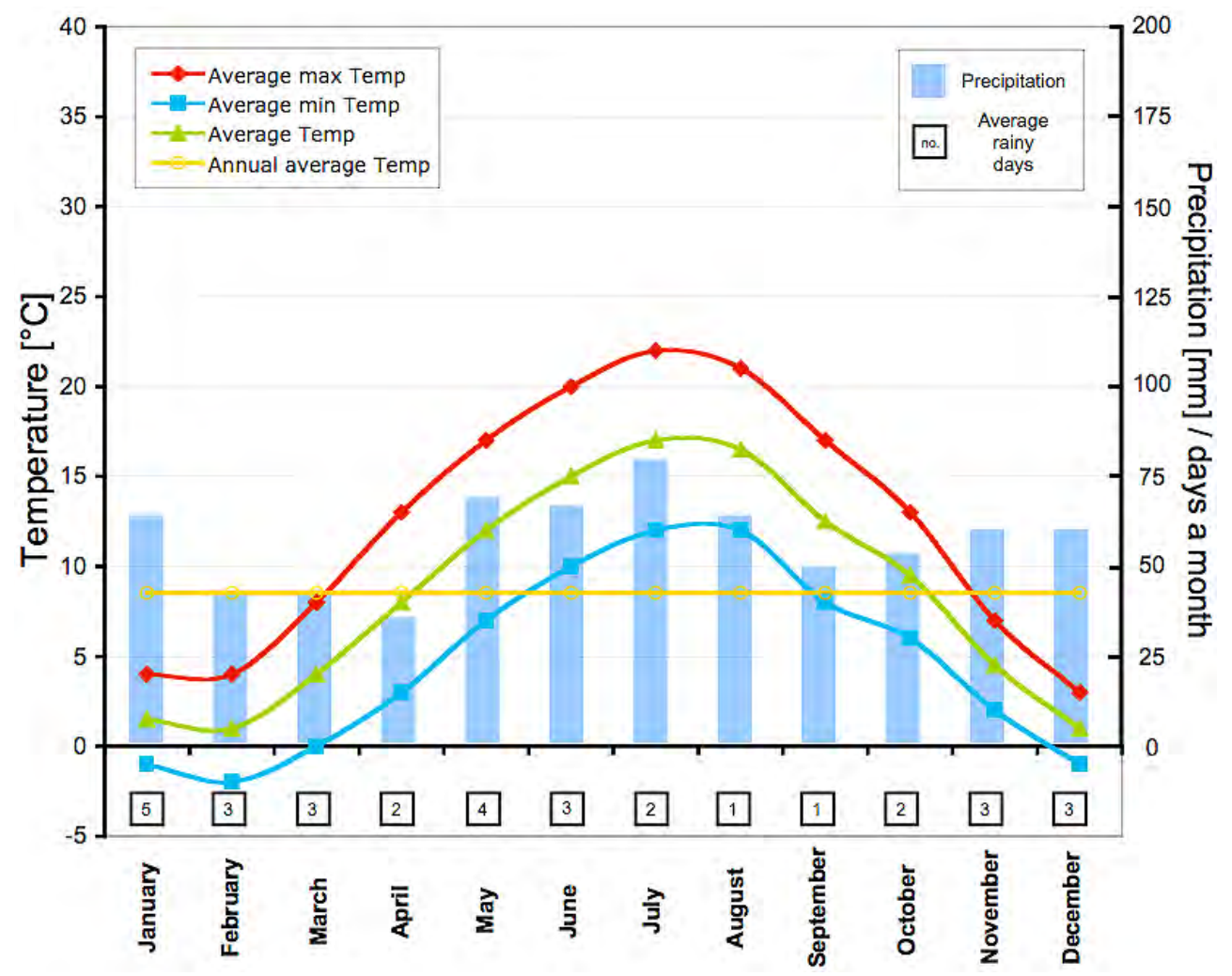

Figure 86: Goettingen, Climate Graph.

According to the Holdridge life zones system of bioclimatic classification, Goettingen is situated in or near the subtropical dry forest biome (Fig. 13).

\section{5.1 c) Geological setting and rock material}

The construction material predominately used for the tombs at the Bartholomew Cemetery is the highly porous Bunt-sandstone (Fig. 90). Here, the rocks of the Solling Formation of the Middle Buntsandstein are especially significant. The Middle Bunt-sandstone is generally divided into four sequences: the Volpriehausen-, Detfurth-, Hardegsen- and Solling and consist of siliciclastic deposits originating from the Germanic Basin. Sedimentation of this deposit continued after the Variscan Orogeny in the Upper Carboniferous (Bachmann, Hoffmann 1997).

The physical properties of the Bunt-sandstone were determined on four local sandstone samples, which are comparable to the building materials of the Bartholomew Cemetery. The sandstone materials investigated were selected from abandoned regional quarries (e.g. Appenrode, Arenshausen and Reinhausen). Altered material from the Johannis Church originated from the quarry in Reinhausen (Fig 89). 

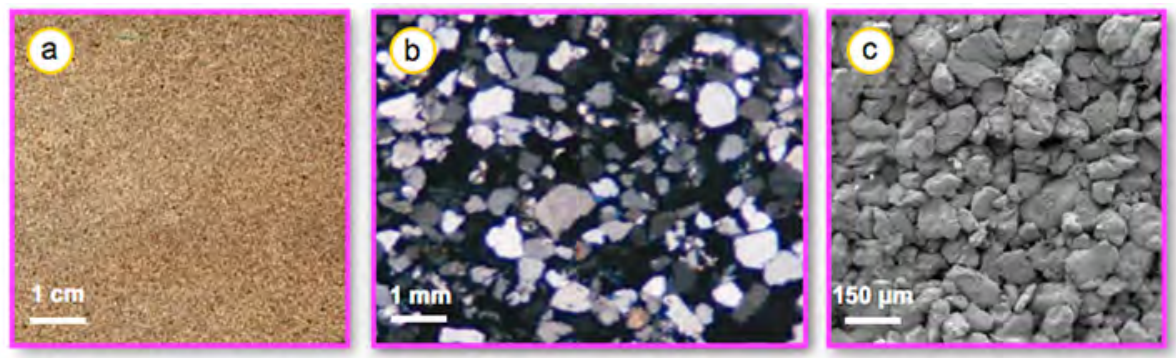

AH Arenshausen sandstone, Lower Saxony / Germany

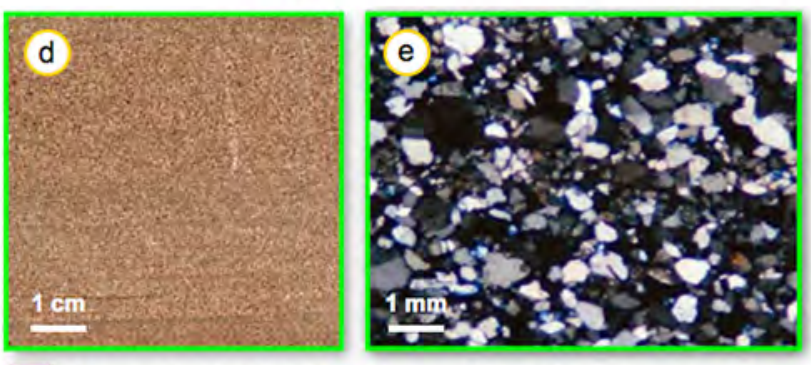

Appenrode sandstone, Lower Saxony / Germany
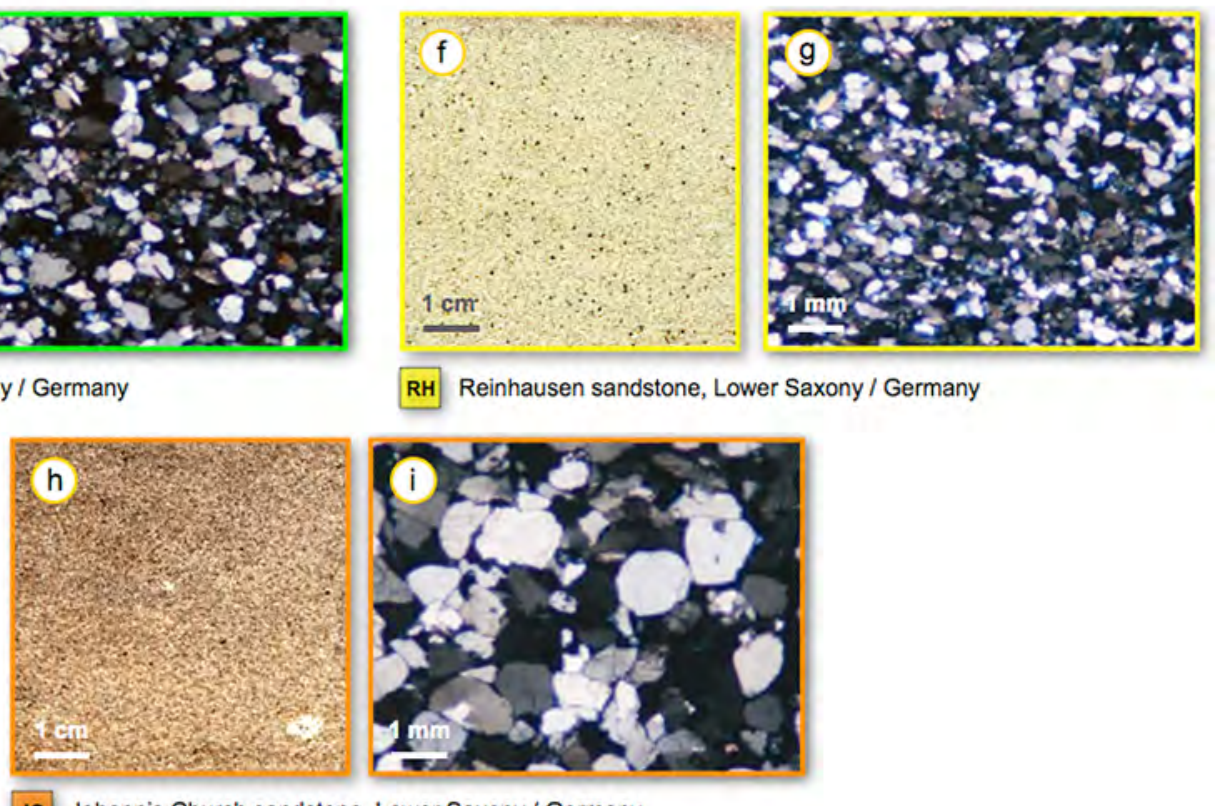

RH Reinhausen sandstone, Lower Saxony/ Germany

RH Reinhase

Johannis Church sandstone, Lower Saxony / Germany

Figure 89: The investigated sandstone varieties of Goettingen: a) AH Arenshausen sandstone, b) thin section in polarized light, c) SEM Image, d) AP Appenrode sandstone, e) thin section in polarized light, f) RH Reinhausen sandstone, g) thin section in polarized light, h) JC Johannis Church sandstone and i) thin section in polarized light.

\section{5. 2 Rock material and fabrics}

The rock fabrics of the four sandstones investigated are macroscopically characterized by layers of varying thickness, variations in color and grain size. Microscopically the sandstones show rounded grains with punctual to concave-convex grain boundaries. The sorting is predominantly moderate with varying grain size distributions. The sandstones can be mainly classified as sublitharenites (Tab. 18), based on the abundant content of detrital quartz grains, followed by lithoclasts, feldspar and rare mica. 

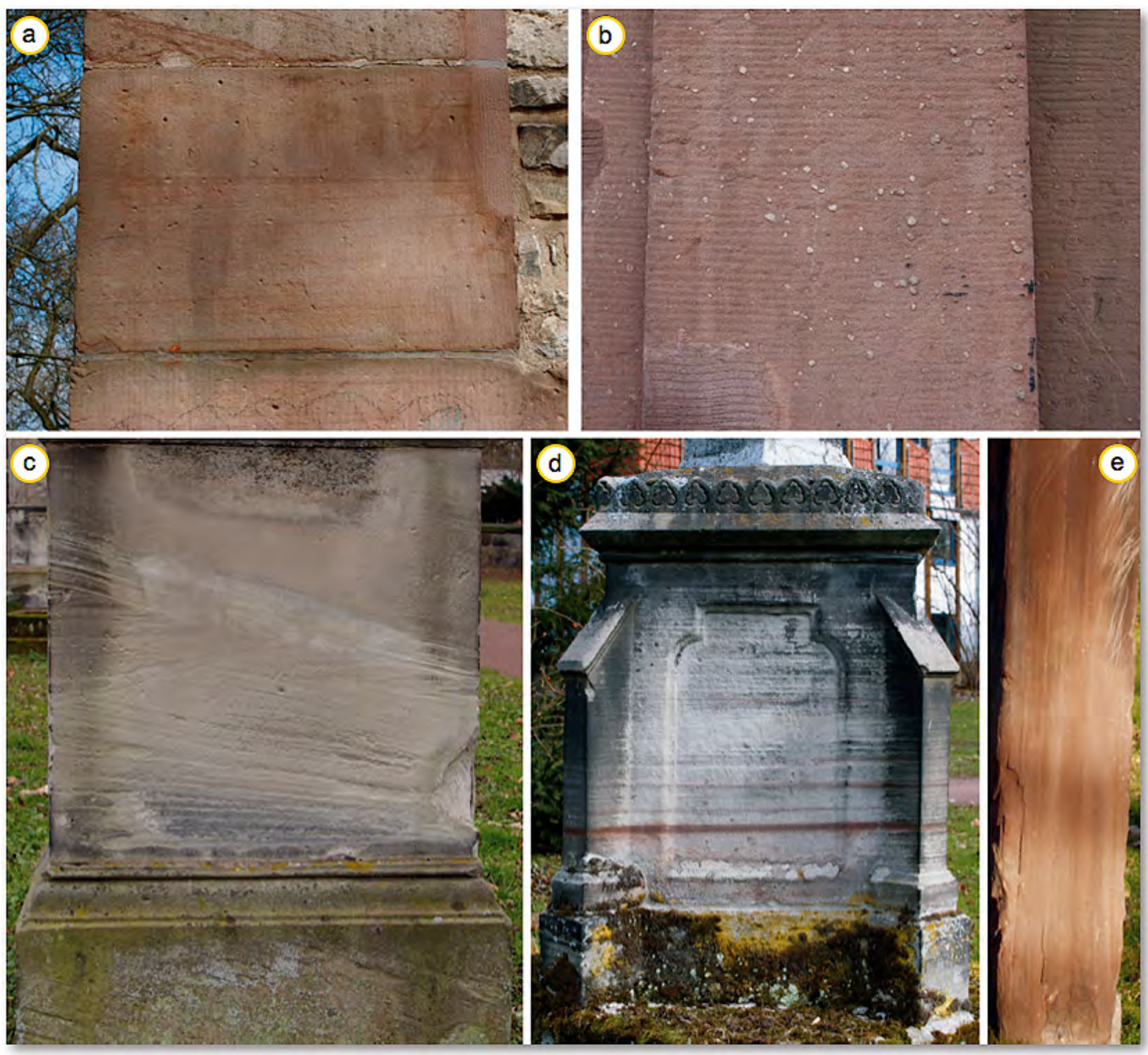

Figure 90: Characteristic sandstone materials of the Bartholomew Cemetery in Goettingen: a) coarsely bedded red sandstone, b) massive red sandstone with white nodules, c) massive gray sandstone with cross-bedding, d) finely bedded sandstone with red-gray interbedded strata and e) finely bedded red sandstone.

Table 18: Selected fabric properties of the investigated Buntsandstein from Goettingen

\begin{tabular}{|c|c|c|c|c|c|c|c|c|}
\hline \multirow[t]{2}{*}{ Sample } & \multicolumn{4}{|c|}{ Main phases [\%] } & \multirow[t]{2}{*}{$\begin{array}{l}\text { Average grain } \\
\text { size }[\mu \mathrm{m}]\end{array}$} & \multirow[t]{2}{*}{$\begin{array}{l}\text { Round- } \\
\text { ness }\end{array}$} & \multirow[t]{2}{*}{ Sorting } & \multirow[t]{2}{*}{ Classification } \\
\hline & Quartz & Feldspar & Clasts & Mica & & & & \\
\hline $\begin{array}{l}\text { Aren- } \\
\text { shausen }\end{array}$ & 90 & $<1$ & 9 & $<1$ & $<100-250$ & rounded & moderate & sublitharenite \\
\hline Appenrode & 80 & 9 & 10 & $<1$ & $100-400$ & rounded & poorly & $\begin{array}{l}\text { sublitharenite to } \\
\text { subarkose }\end{array}$ \\
\hline $\begin{array}{l}\text { Johannis } \\
\text { Church }\end{array}$ & 95 & 1 & 2 & - & $100-600$ & $\begin{array}{l}\text { well-roun- } \\
\text { ded }\end{array}$ & moderate & quartz arenite \\
\hline $\begin{array}{l}\text { Rein- } \\
\text { hausen }\end{array}$ & 80 & 5 & 10 & 5 & $<100-200$ & rounded & well & sublitharenite \\
\hline
\end{tabular}

Wanja Wedekind

Weathering and Conservation of Monuments 

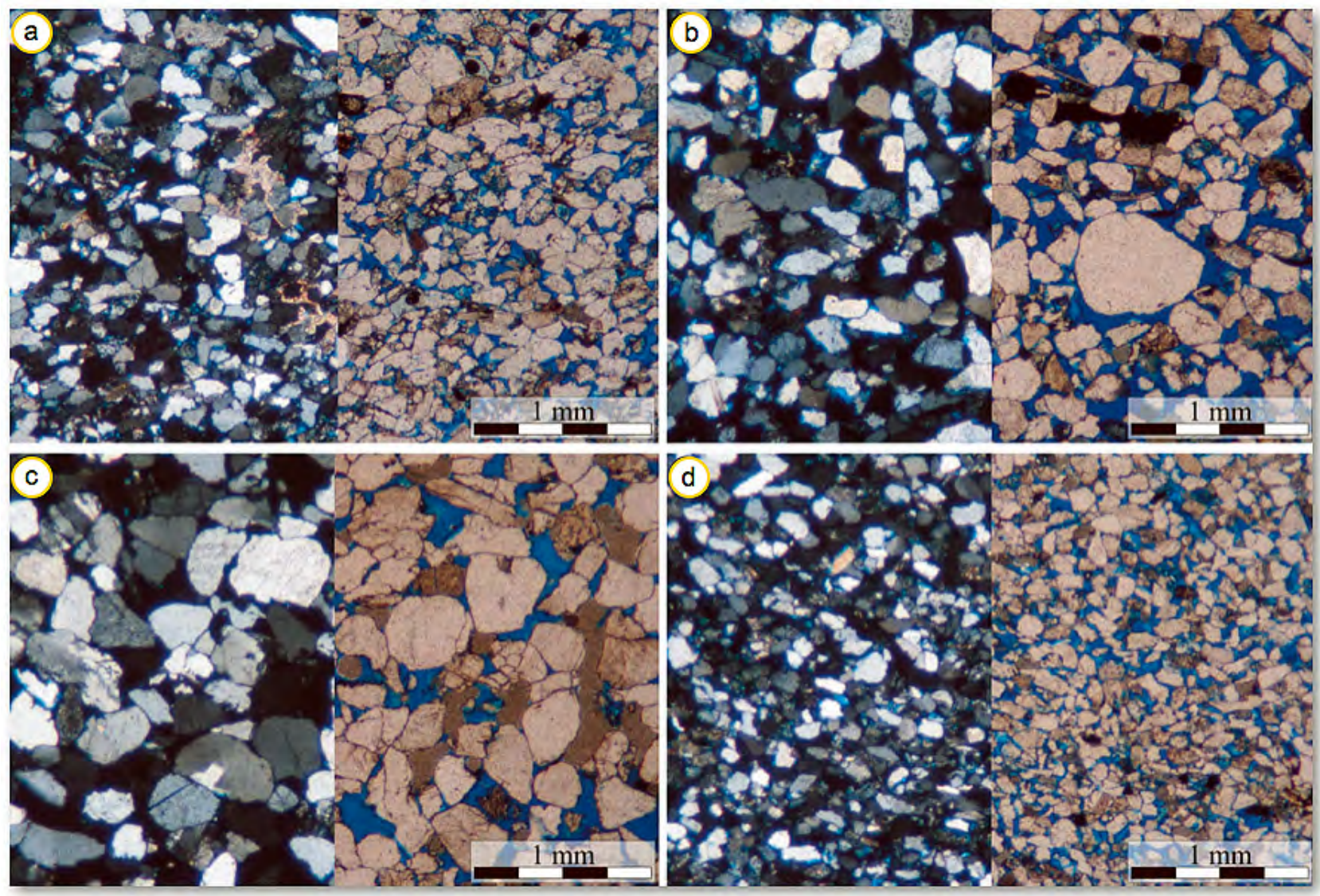

Figure 91: Microstructure of the sandstones under linear polarized (right) and crossed polarized conditions (left): a) sandstone of Arenshausen with relict carbonate cements (left); b) sandstone of Appenrode with partly non-uniform sorting and solidification; c) sandstone of the Johannis Church Goettingen showing tectonized quartz grains and a partly high content of lithoclasts (right); d) fine-grained sandstone of Reinhausen with alignment of grains parallel to the bedding and some relict carbonate cement.

\section{5. 2 a) Petrophysical properties}

The sandstones of the Goettingen region can be characterized as medium porous sandstone types with a porosity ranging between $17 \%$ und $24 \%$ (Tab. 19). The pore radii distribution is dominated by macropores between $1-100 \mu \mathrm{m}$ (Tab. 19). Microporosity is smaller than $10 \%$. The main pore space properties of the described sandstones are listed in table 19.

The layering in the different rocks can be characterized by its directional, varying and distinct water absorption. The water absorption value ranges between 5.52 to $30.59 \mathrm{~kg} /(\mathrm{m} 2 \cdot \sqrt{ } \mathrm{h})$ and the anisotropy of the different samples between $9 \%$ to $17 \%$ (Tab. 20). The directional anisotropy of ultrasonic wavelengths is quite lower and reaches only $1 \%$ to $9 \%$ (Tab. 20). In general, the ultrasonic velocity of all samples ranging between $1.828 \mathrm{~km} / \mathrm{s}$ and $2.468 \mathrm{~km} / \mathrm{sm}$ is low. The same also applies for the splitting tensile strength, which ranges from 3.3 to $1.4(\mathrm{MPa})$ and shows significant values of anisotropy from 30.8 to $55 \%$. 
Table 19: Pore space properties of the sandstones from Goettingen

\begin{tabular}{|c|c|c|c|c|c|c|c|c|c|}
\hline \multirow[t]{2}{*}{ Sample } & \multicolumn{4}{|c|}{ Pore space } & \multicolumn{5}{|c|}{ Pore radii distribution [\%] } \\
\hline & $\begin{array}{l}\text { Porosity } \\
\text { [Vol.-\%] }\end{array}$ & $\begin{array}{c}\text { Bulk dens- } \\
\text { ity } \\
\text { [g/cm3] }\end{array}$ & $\begin{array}{l}\text { Particte } \\
\text { density } \\
\text { [g/cm3] }\end{array}$ & $\begin{array}{l}\text { Pore radii } \\
\quad[\mu \mathrm{m}]\end{array}$ & $\begin{array}{c}0.001-0.01 \\
{[\mu \mathrm{m}]}\end{array}$ & $\begin{array}{c}0.01-0.1 \\
{[\mu \mathrm{m}]}\end{array}$ & $\begin{array}{c}0.1-1 \\
{[\mu \mathrm{m}]}\end{array}$ & $\begin{array}{c}1-10 \\
{[\mu \mathrm{m}]}\end{array}$ & $\begin{array}{c}10-100 \\
{[\mu \mathrm{m}]}\end{array}$ \\
\hline Arenshausen & 17.18 & 2.19 & 2.65 & 2.31 & 2.57 & 7.47 & 10.92 & 71.91 & 7.13 \\
\hline Appenrode & 23.98 & 2.01 & 2.64 & 9.12 & 1.88 & 3.02 & 3.68 & 11.70 & 79.72 \\
\hline $\begin{array}{l}\text { Johannis } \\
\text { Church }\end{array}$ & 19.93 & 2.11 & 2.64 & 13.14 & 2.66 & 2.86 & 2.09 & 5.74 & 89.10 \\
\hline Reinhausen & 21.6 & 2.08 & 2.65 & 3.29 & 2.50 & 5.06 & 6.46 & 78.47 & 7.51 \\
\hline
\end{tabular}

Hygric dilatation with exception of the Appenrode sample that reaches $0.5 \mathrm{~mm} / \mathrm{m}$ in Z-direction is low. The sample of the Johannis Church shows contraction in the Y-direction. The thermal expansion measured at $60{ }^{\circ} \mathrm{C}$ ranges between $0.66 \mathrm{~mm} / \mathrm{m}$ and $0.98 \mathrm{~mm} / \mathrm{m}$ with an anisotropy from 2.5 to $20 \%$ (Tab. 20). The highest values could be measured in the Arenshausen $(0.81 \mathrm{~mm} / \mathrm{m})$ and the Reinhausen sandstone $(0.89 \mathrm{~mm} / \mathrm{m})$.

Table 20: Pore space properties, moisture transport, and mechanical properties of the sandstones

\begin{tabular}{|c|c|c|c|c|}
\hline Stone type & Arenshausen & Appenrode & Johannis-church & Reinhausen \\
\hline Effective porosity [Vol.-\%] & 17.18 & 23.98 & 19.93 & 21.6 \\
\hline Particle density $\left[\mathrm{g} \cdot \mathrm{cm}^{-3}\right]$ & 2.65 & 2.64 & 2.64 & 2.65 \\
\hline Bulk density $\left[\mathrm{g} \cdot \mathrm{cm}^{-3}\right]$ & 2.19 & 2.01 & 2.11 & 2.08 \\
\hline Average pore radius $[\mu \mathrm{m}]$ & 2.31 & 9.12 & 13.14 & 3.29 \\
\hline Micropore porosity [\%] & 10.04 & 4.9 & 5.52 & 7.56 \\
\hline \multicolumn{5}{|l|}{$\mathrm{w}$ value $\left[\mathrm{kg} / \mathrm{m}^{2} \sqrt{ } \mathrm{h}\right]$} \\
\hline$x$ & 6.73 & 30.13 & 21.11 & 17.66 \\
\hline$Y$ & 6.97 & 30.59 & 21.80 & 17.04 \\
\hline$z$ & 5.82 & 34.34 & 19.76 & 15.08 \\
\hline Average $\varnothing$ & 6.50 & 31.68 & 20.89 & 16.59 \\
\hline Anisotropy [\%] & 16.5 & 12 & 9 & 14.6 \\
\hline \multicolumn{5}{|l|}{$\mu$ value } \\
\hline$x$ & 18.86 & 13.79 & 15.88 & 16.16 \\
\hline$Y$ & 20.01 & 13.60 & 13.79 & 15.85 \\
\hline$z$ & 21.70 & 14.40 & 15.55 & 17.11 \\
\hline \multicolumn{5}{|l|}{ Average $\varnothing$} \\
\hline \multicolumn{5}{|l|}{ Anisotropy [\%] } \\
\hline \multicolumn{5}{|l|}{$\begin{array}{l}\text { Ultrasonic velocity [km/ } \\
\text { s] }\end{array}$} \\
\hline$x$ & 2.201 & 2.468 & 1.828 & 2.384 \\
\hline$Y$ & - & - & - & - \\
\hline
\end{tabular}




\begin{tabular}{|c|c|c|c|c|}
\hline 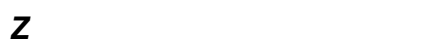 & 2.084 & 2.441 & 1.937 & 2.158 \\
\hline Average $\varnothing$ & 2.162 & 2.454 & 1.885 & 2.217 \\
\hline Anisotropy $[\%]$ & 5.32 & 1.09 & 5.63 & 9.48 \\
\hline \multicolumn{5}{|l|}{$\begin{array}{l}\text { Splitting tensile strength } \\
\text { [MPa] }\end{array}$} \\
\hline$x$ & 2.299 & 1.041 & 0.914 & 1.411 \\
\hline \multicolumn{5}{|l|}{$Y$} \\
\hline$z$ & 3.327 & 2.314 & 2.852 & 2.852 \\
\hline Average $\varnothing^{1}$ & 2.641 & 1.465 & 1.56 & 1.891 \\
\hline Anisotropy $[\%]$ & 30.8 & 55 & 68 & 50.5 \\
\hline $\begin{array}{l}\text { Surface hardness [HLD] } \\
\text { dry }\end{array}$ & 574 & 400 & 341 & 486 \\
\hline $\begin{array}{l}\text { Surface hardness [HLD] } \\
\text { wet }\end{array}$ & 539 & 379 & 355 & 488 \\
\hline \multicolumn{5}{|l|}{ Reduction [HLD] } \\
\hline \multicolumn{5}{|l|}{ Hydric dilatation } \\
\hline$x$ & 0.218 & 0.550 & 0.010 & 0.224 \\
\hline$Y$ & - & - & - & - \\
\hline$z$ & 0.273 & 0.430 & -0.156 & 0.338 \\
\hline \multicolumn{5}{|l|}{ Average $\varnothing$} \\
\hline Anisotropy [\%] & 20 & 21.9 & - & 33.7 \\
\hline \multicolumn{5}{|l|}{$\begin{array}{l}\text { Thermal expansion } \\
{\left[\mathrm{mm} / \mathrm{m}, 60^{\circ} \mathrm{C}\right]}\end{array}$} \\
\hline$x$ & 0.82 & 0.72 & 0.66 & 0.9 \\
\hline$Y$ & 0.82 & 0.66 & 0.8 & 0.98 \\
\hline$z$ & 0.8 & 0.76 & 0.64 & 0.8 \\
\hline Average $\varnothing$ & 0.81 & 0.71 & 0.7 & 0.89 \\
\hline Anisotropy [\%] & 2.5 & 13 & 20 & 18 \\
\hline
\end{tabular}

after Kracke et al. 2008 and Kracke 2008

\section{5.2 b) Salt resistance test}

Salt resistance tests were done for all Buntsandstein varieties investigated in this study from the Goettingen region (Fig. 95). Their salt resistance, defined by the number of cycles up to a $30 \%$ material loss, occurs between the $9^{\text {th }}$ to the $17^{\text {th }}$ cycle.

- AP Appenrode sandstone

Weathering starts at the edges and after the sixth cycle parallel to the bedding. At this stage the weathering showed a continuous progression and reached a material loss of $30 \%$ at the $17^{\text {th }}$ cycle. Similar weathering phenomena can be observed in the field at several tomb monuments. 


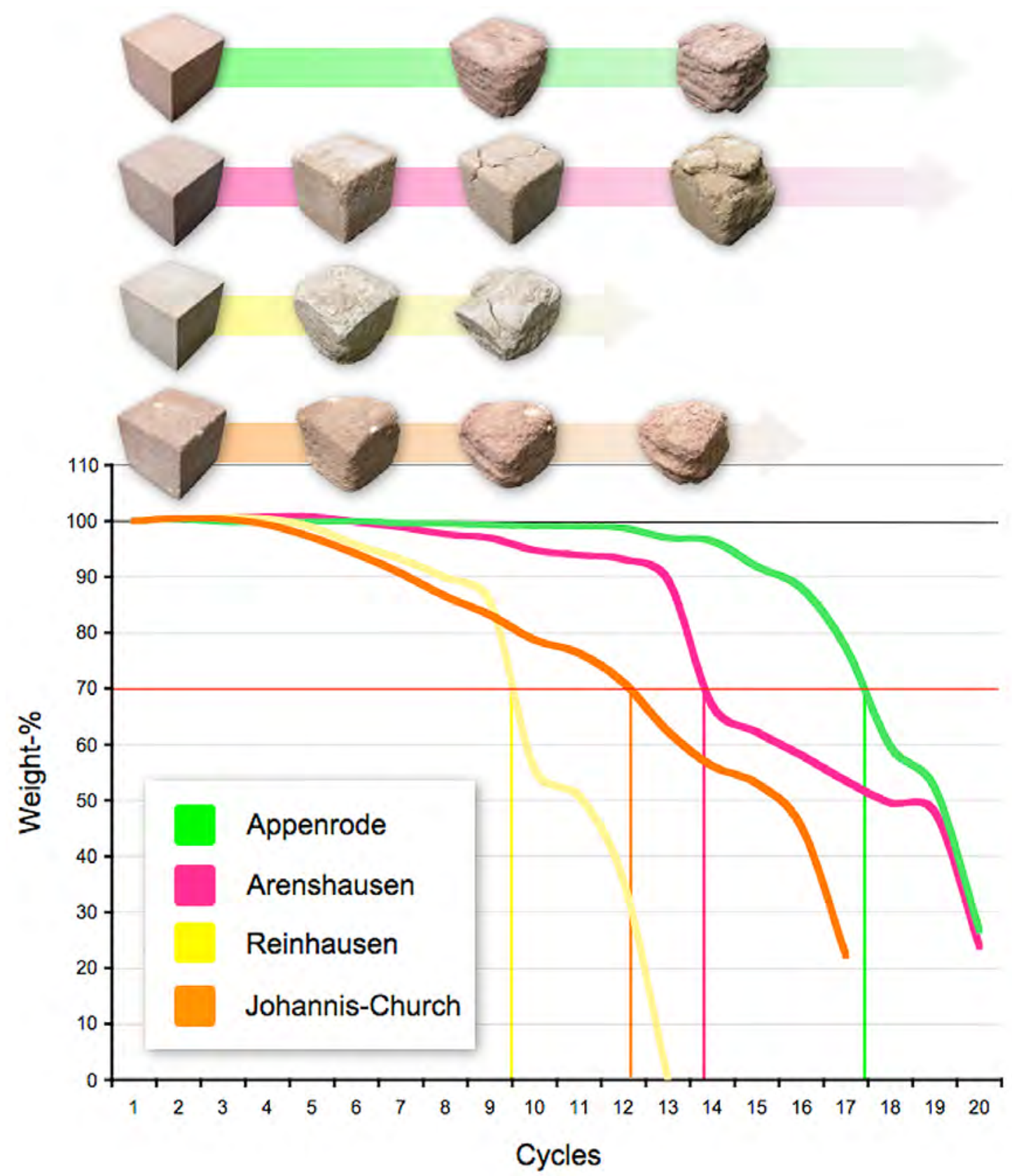

Figure 92: Salt bursting test of the Goettingen sandstones.

\section{- AH Arenshausen sandstone}

Salt weathering leads to a continuous sanding. After the $10^{\text {th }}$ cycle massive cracks are recognizable. At the $13^{\text {th }}$ cycle parts of the upper top of the cube break away. This leads to a material loss of more than $30 \%$ at cycle 14 .

\section{- RH Reinhausen sandstone}

The Reinhausen sandstone shows massive material loss all around the lower part of the cube by flaking and at the top by blasting of massive scales. This leads to a stepwise out-breaking of fragments and to a material loss of $30 \%$ at the $9^{\text {th }}$ cycle. The Reinhausen sandstone shows various 
forms of weathering in the field similar to the ones analyzed by experiment.

- Johannis Church sandstone

The Johannis Church sandstone sample shows continuous sanding starting from the top combined by a rounding at the edges. Rounding and sanding can also be found at the Johannis Church.

\section{5. 3 Main weathering forms}
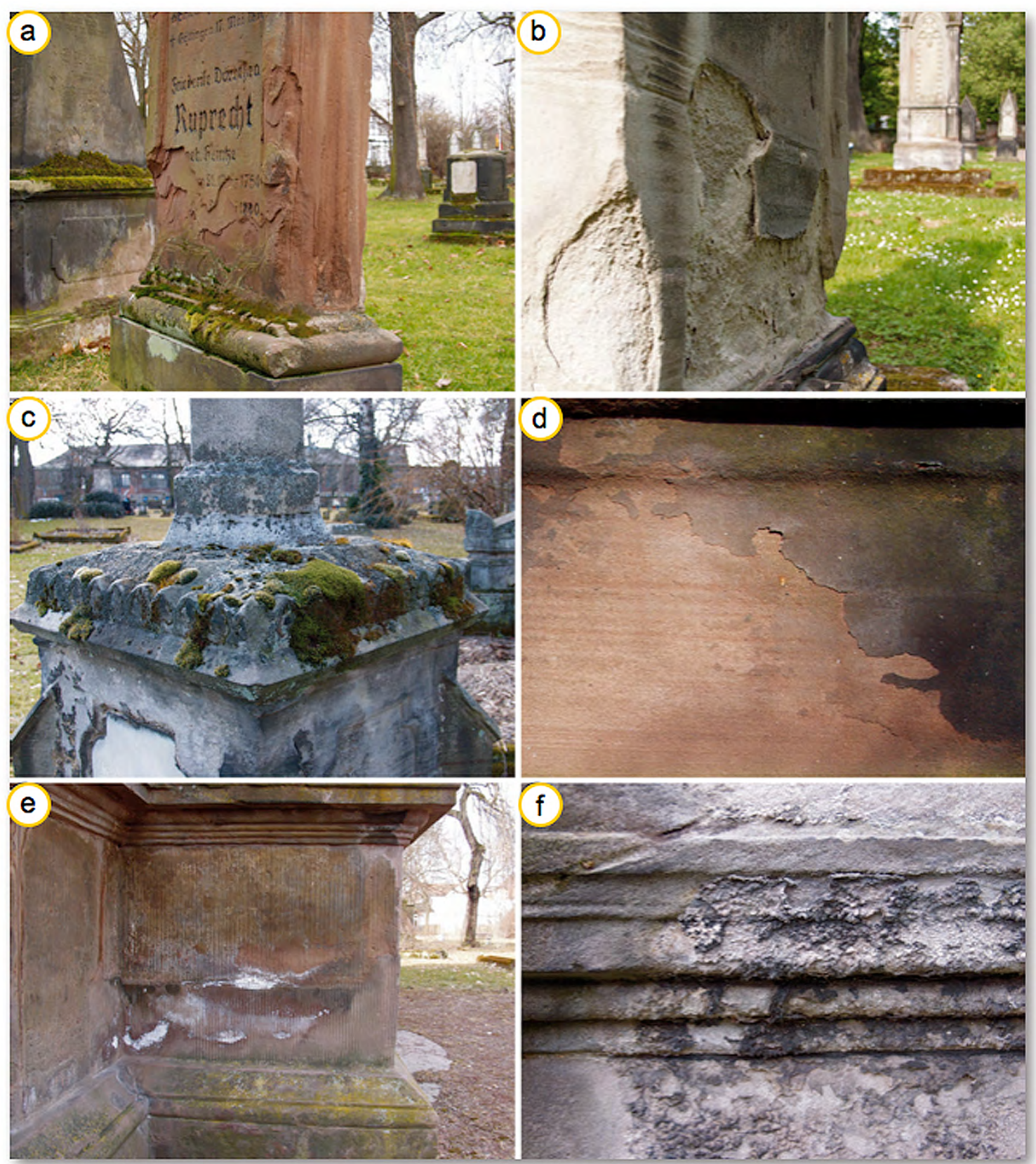

Figure 93: Typical weathering forms of the sandstones from the Bartholomew cemetery in Goettingen: a) scaling parallel to the bedding; b) contour scaling perpendicular to the bedding with secondary detachment of small flakes; c) biological colonization; d) flaking combined with black crusts; e) salt efflorescences; and f) formation of gypsum crusts. 
Weathering forms range from locally-formed holes to finely sanded surfaces, crack formation, flaking and crusts as well as conchoidal fractures leading to material loss (Fig. 93).

\section{5. 3 a) Main weathering and deterioration factors}

The causes for the damages on the tombs might be due to different reasons. Weathering phenomena are observable but also man made destruction.

Down to the present day a large part of the damages to the monuments can be ascribed to vandalism. Around $70 \%$ of all grave monuments show indications of being damaged. Thus, for example $<90 \%$ of the gravestone crosses are predominantly broken off. A continuous loss of ornamental decorations and individual structural elements can be documented based on photos from the 1980's.

However, not only acts of vandalism are responsible for the total loss of valuable monuments. From the 1950's until more recent times questionable interventions have come from private initiatives and municipal authorities.

According to Bruch (2002), around three-quarters of the inventory at the Bartholomew Cemetery have disappeared since 1945. For example, in the 1950's the Laporte Tomb was removed and in the 1980's removal of the iron grave fencing with sandstone columns from the Junker Tomb occurred. Furthermore, in 1965 the gravestone for Papet was replaced with a simplified replica. A couple of years later the bronze bust dedicating the anniversary of Gottfried August Bürger's death was unceremoniously moved to a street carrying his name. Even in the year 2005 the largely intact gravestone cross of the Lichtenberg Tomb, which is the most well-known tomb of the cemetery, was partly replaced with replicas along with a renovation of the gravesite enclosure in the manner of the historical period (Wedekind 2008).

Only a small percentage of the original tombs have outlasted the ravages of time. The number of preserved tombs comprises a total of 167 . And from these only fragments have been mainly preserved.

Different types of damage and stress-strain phenomenon are evident on the stones. Regarding the observed damages, back-weathering caused by sanding on the east-facing surfaces of $87 \%$ of all monuments has been shown (Kracke et al., 2007). The same phenomenon was observed on $41 \%$ of the south- and $35 \%$ of the north-facing sides followed by $18 \%$ of the west-facing sides of the monuments. An explanation of the deterioration related to the orientation can be given by the prevailing direction of the wind, mostly coming from the west and north. Methods for conservation and materials for the restoration of the tombstones were defined and used during a research project in 2006/2007 (Ruedrich et al., 2008). During this project, however, investigations and analyses have shown that in large part the material loss is due to the high salt concentration resulting in crystal salt 
wedging. The best example of this type of salt weathering can be seen on the Adolf Ellissen obelisk (cf. Kracke et al., 2007).

\section{5. 4 Salts at the cemetery, their sources and damage potential}

The Ellissen monument chosen as a case study object, shows a huge surface loss at the south-site of the pedestal. The loss takes place by contour scaling (Fig. 85 b, 87 a). The affected surface shows sanding and flaking. The salt-induced weathering of the monuments was determined using eluates from drill cuttings. The samples were retrieved at different heights on the structure and at depth. The analyses were done using an ion chromatograph (IC) and by measuring the electrical conductivity (EC). An x-ray diffraction investigation was also performed on the salt efflorescence's on the obelisk's surface.
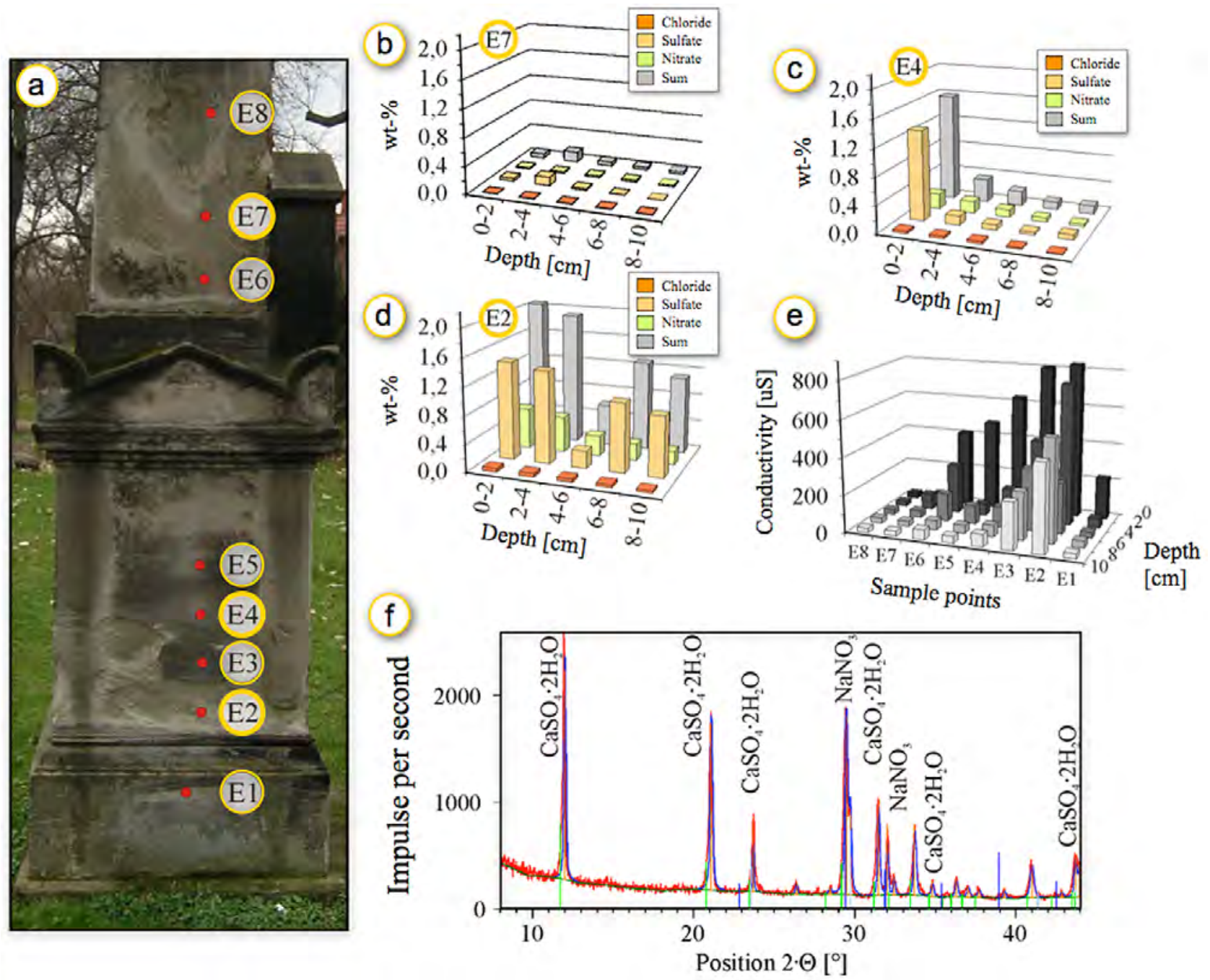

Figure 94: Salt-induced weathering on the Adolf Ellissen Tomb: a) sample points; b-d) ion chromatograph analyses; e) conductivity analyses and f) x-ray diffractometer analyses.

The analyses reveal that the main weathering stress of the sandstone is due to sulfates and a subordinate amount of nitrates. Chlorides are verifiable in only small amounts in the lower part of the 
gravestone. In general, the salt-induced weathering decreases from the lower to the upper part of the obelisk (cf. Arnold, Zehnder 1990). This shows that the salt crystallization can be directly related to capillary rise. Likewise the front part of the obelisk also exhibits a high salt-induced degradation.

The salt contamination decreases with depth in the monument. X-ray diffraction measurements of the solids from the eluate solution not only revealed gypsum $\left(\mathrm{Ca}\left[\mathrm{SO}_{4}\right] \cdot 2 \mathrm{H}_{2} \mathrm{O}\right)$ enrichment, but also a contamination by $\mathrm{NaNO}_{3}$ (nitratine, Fig. $94 \mathrm{f}$ ). The analyses on the other tomb monuments also exhibit comparative degradation, as well as salt phases showing a similar distribution and concentration as in the Ellissen Tomb.

\section{5. 5 Investigated tombs and mappings}

Three different tombs will be described in detail in this thesis. The Adolf Ellissen Tomb, the tomb of Strohmeyer and the Lejeune-Dirichlet Tomb.

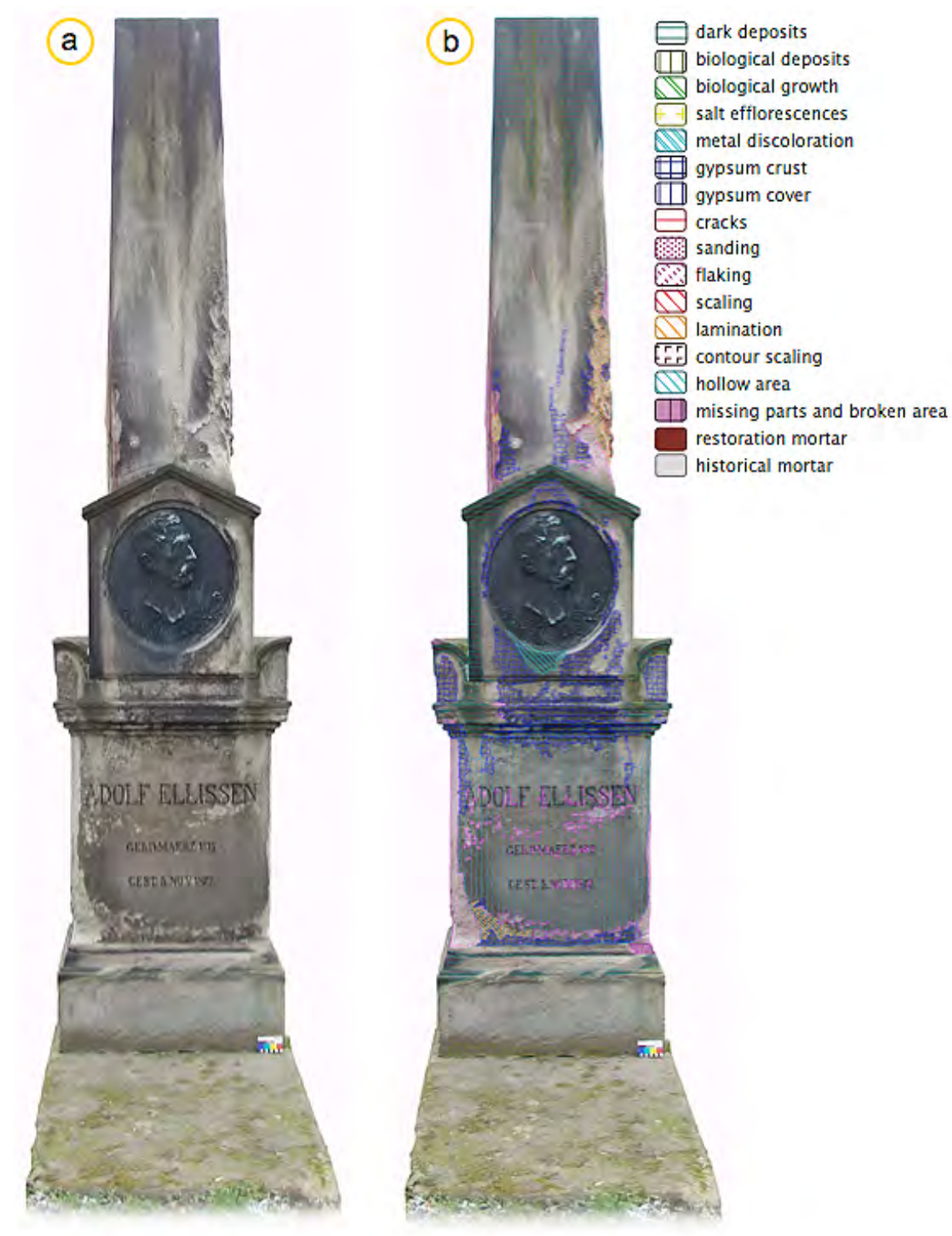

Figure 95: The Ellissen-Tomb. a) The tomb before conservation/restoration. b) Damage mapping of the tomb. 


\section{5. 5. a) The Adolf Ellissen Tomb}

The cenotaph of Adolf Ellissen erected after his death in 1872. This is an obelisk-like tomb with a height of 4 meters (Fig. 95 a). It was built from the light sandstone of the Reinhausen variety. Damages are concentrated at the northern side of the obelisk and at the southern side of the pedestal. Different weathering forms are found like lamination, sanding and the formation of gypsum crusts (Fig. 95 b).

\section{5. 5. b) The Strohmeyer Tomb}

The tomb of Strohmeyer is a typical stele with an object height of $2.30 \mathrm{~m}$. It is made from a light sandstone variety similar to the Reinhausen sandstone, whereas the pedestal zone is made from Arenshausen sandstone. The damages are concentrated in the center of the stele and characterized by sanding and flaking (Fig. 96).

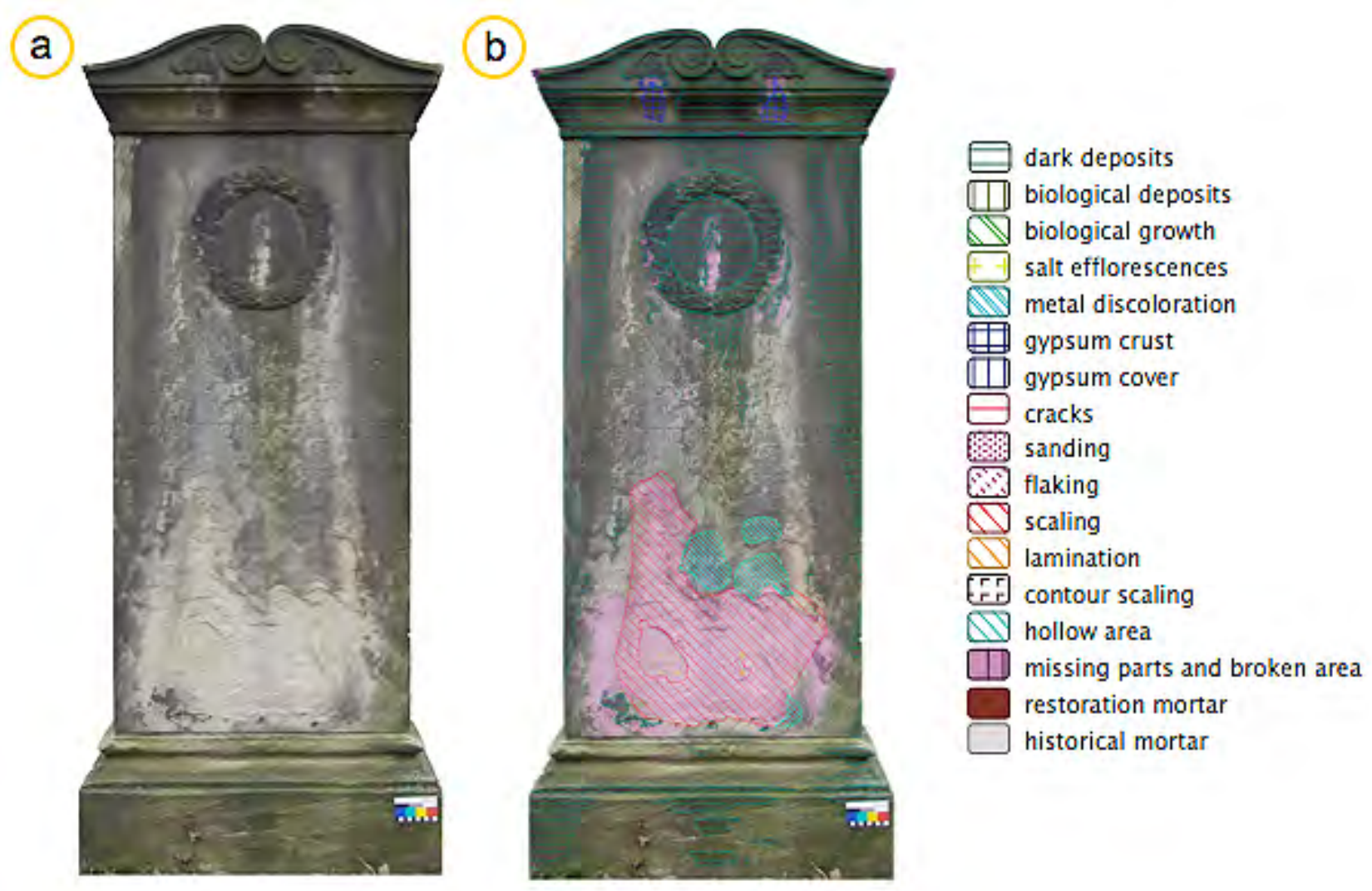

Figure 96: a) The Strohmeyer Tomb before conservation/restoration and b) damage mapping.

\section{5. 5. c) The Lejeune-Dirichlet Tomb}

The Lejeune-Dirichlet Tomb is a balustrade tomb built using a rectangular floor plan with dimensions of 4 by 4 meters and a height of $1.20 \mathrm{~m}$. It was erected after 1859 and built using a light sandstone similar to the Reinhausen variety and the red sandstone of Appenrode. The main weathering form found is sanding (Fig. 97). 


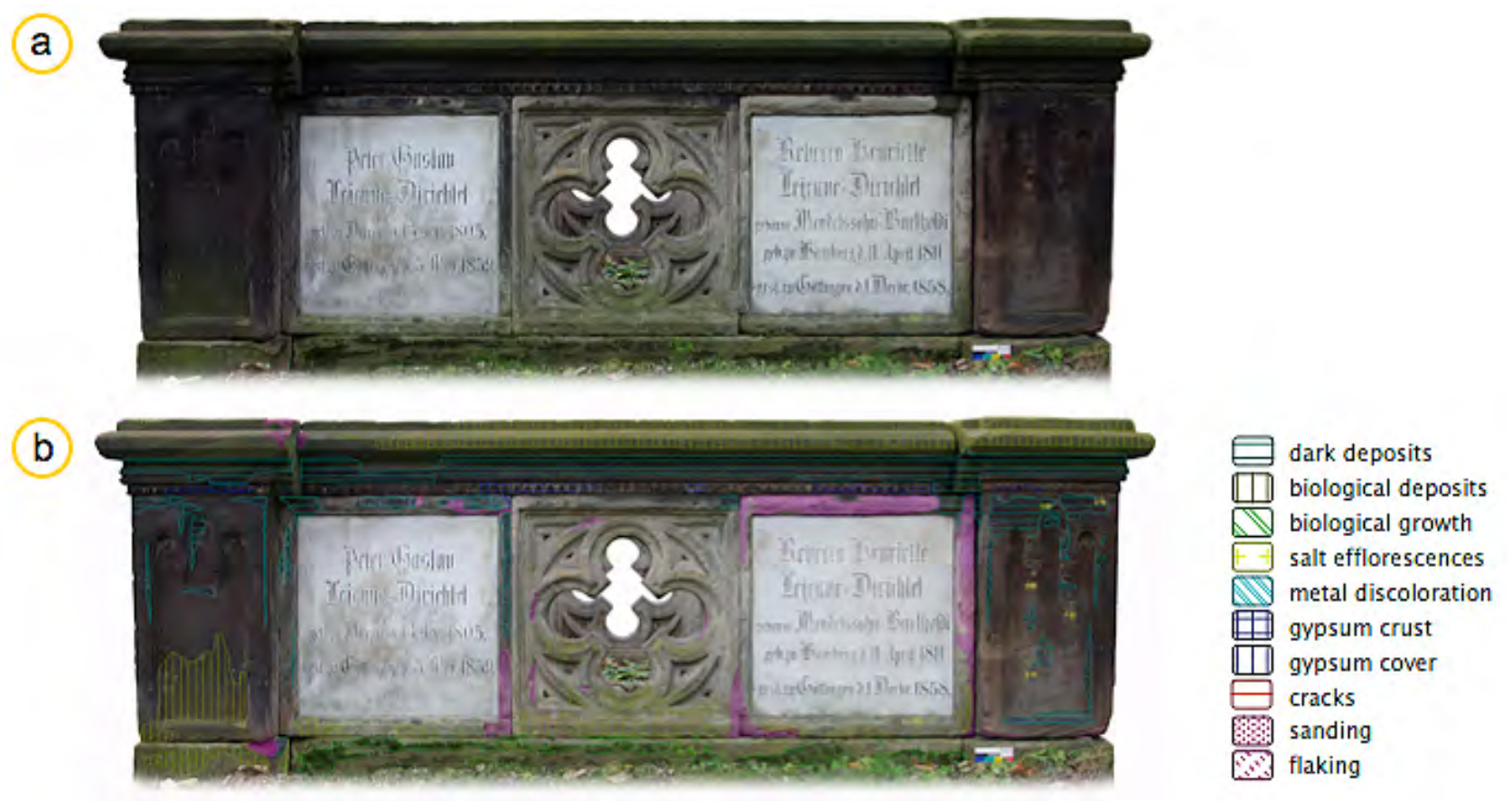

Figure 97: a) The Lejeune-Dirichlet Tomb before conservation/restoration and b) damage mapping.

\section{5. 6 Weathering models}

Three weathering models have been developed in order to understand the dynamics of weathering, which are based on the onsite observations and investigations at the Ellissen Tomb, the Strohmeyer Tomb and the Lejeune-Dirichlet Tomb. The models include the main wind and rain direction, the orientation to the sun as well as the bedding plane of the single ashlars. These three components leads to specific weathering phenomenon.

\section{5. 6. a) Weathering model of the Adolf Ellissen Tomb}

The observations as well as the investigations at the Ellissen Tomb show that the weathering occurs as salt weathering and sanding, which are mostly found at the south and east side (Fig. 98 a and b). The largest area affected by salt weathering is found at the pedestal. This is probably due to the bedding situation of the affected ashlar. Capillary water infiltrates into the weathering zone and leads to an accumulation of salts. The main wind and rain direction is at the northern and western side. On the north side of the obelisk, a delamination is found that is connected to hydric dilatation probably due to the presence of clay minerals. No sanding can be found where water runs down the monument. Next to the water runoff veins on the east and south side gypsum crusts are formed (Fig. $99 \mathrm{a}$ and $b)$. 


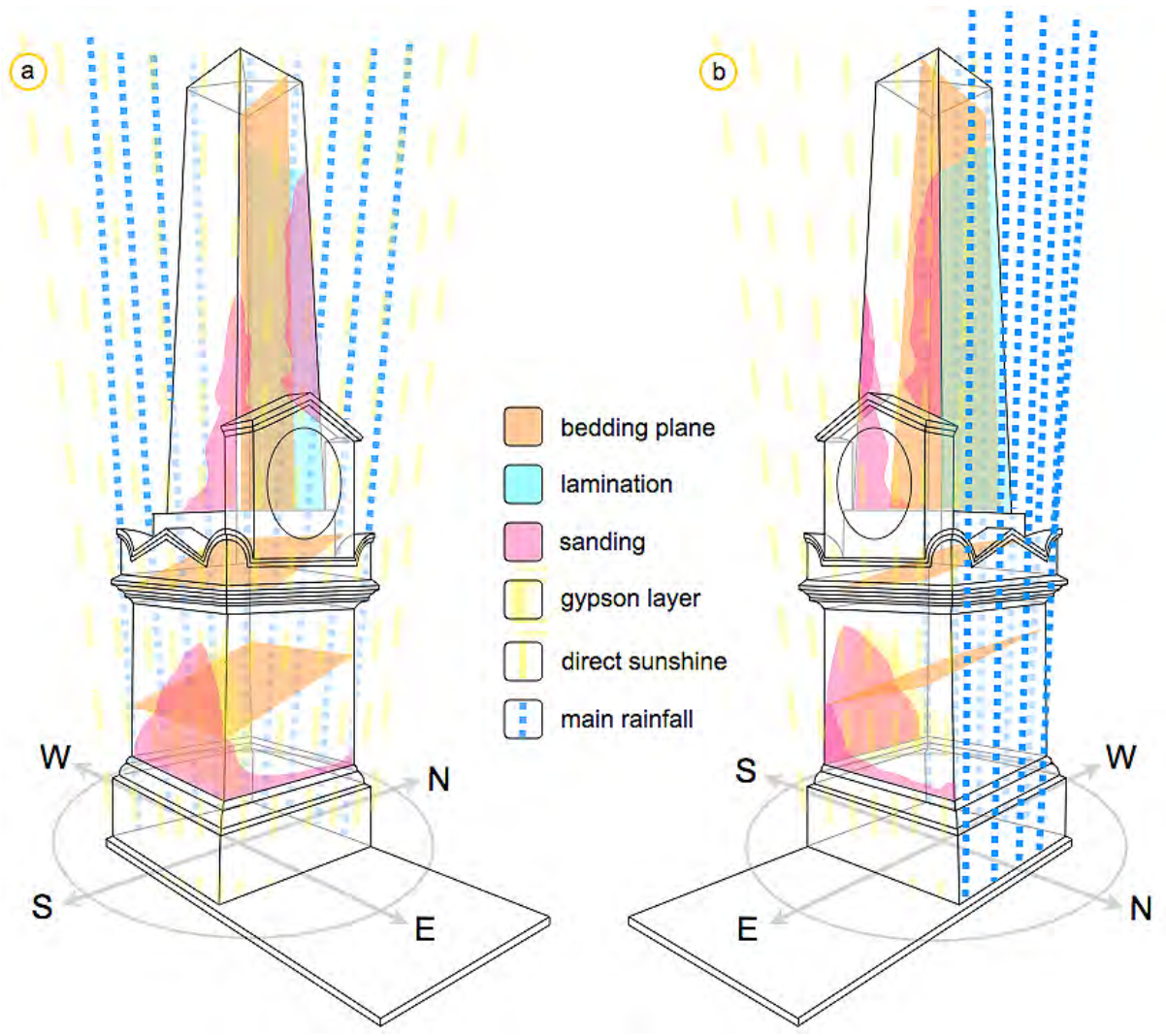

Figure 98: $a$ and b) weathering model of the Ellissen Tomb monument related to sanding by salts.

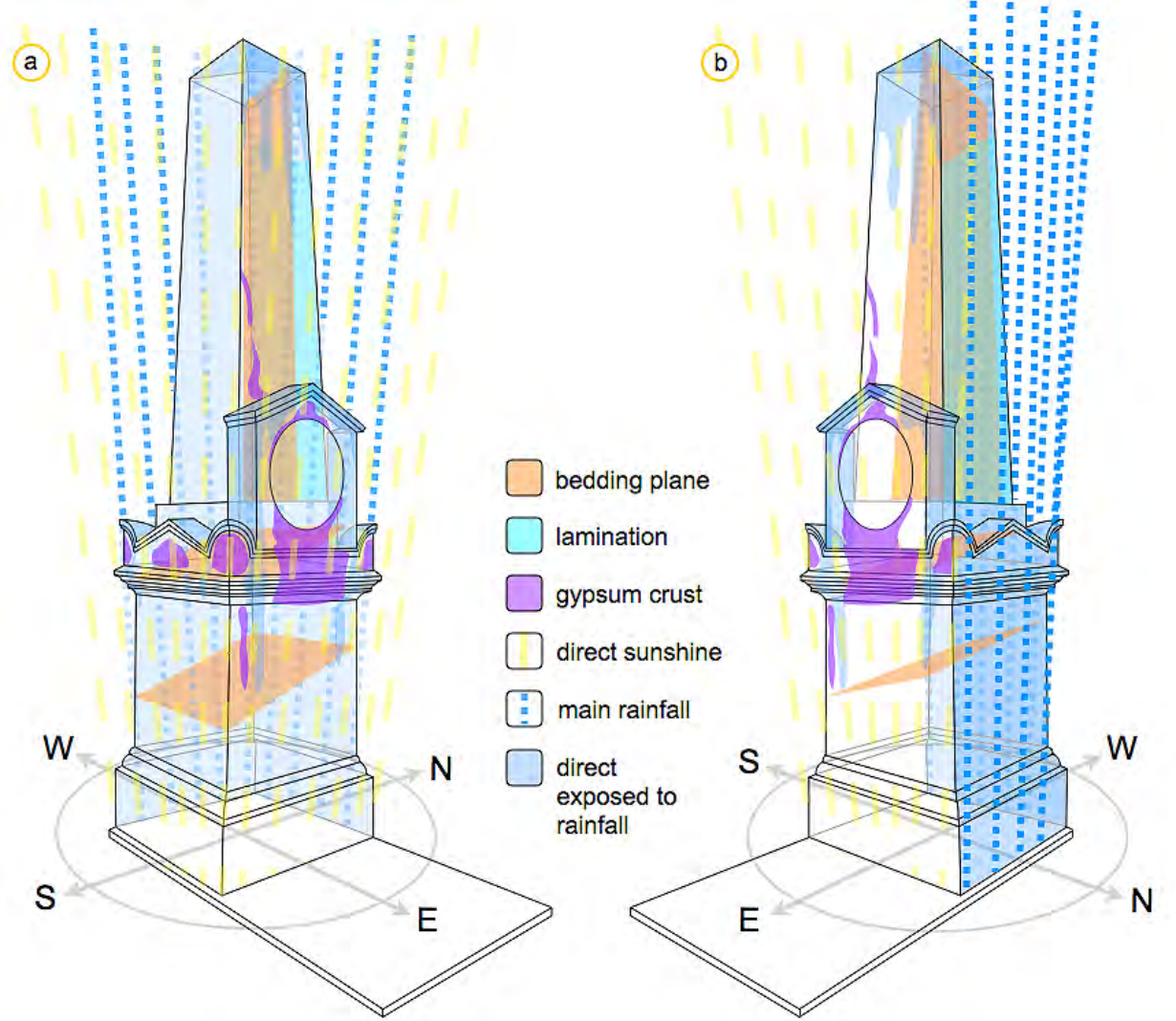

Figure 99: $a$ and b) weathering model of the Ellissen Tomb monument related to moisture and the formation of gypsum crusts. 


\section{5. 6. b) Weathering model of the Strohmeyer Tomb}

Similar observations can be made for the Strohmeyer Tomb: Sanding is concentrated at the east side in the lower part of the stele. Gypsum crusts are formed at the top of the monument where no rainwater flows down the stele (Fig. 100). No delamination takes place on the west side, possibly due to the low amount of clay in this sandstone.

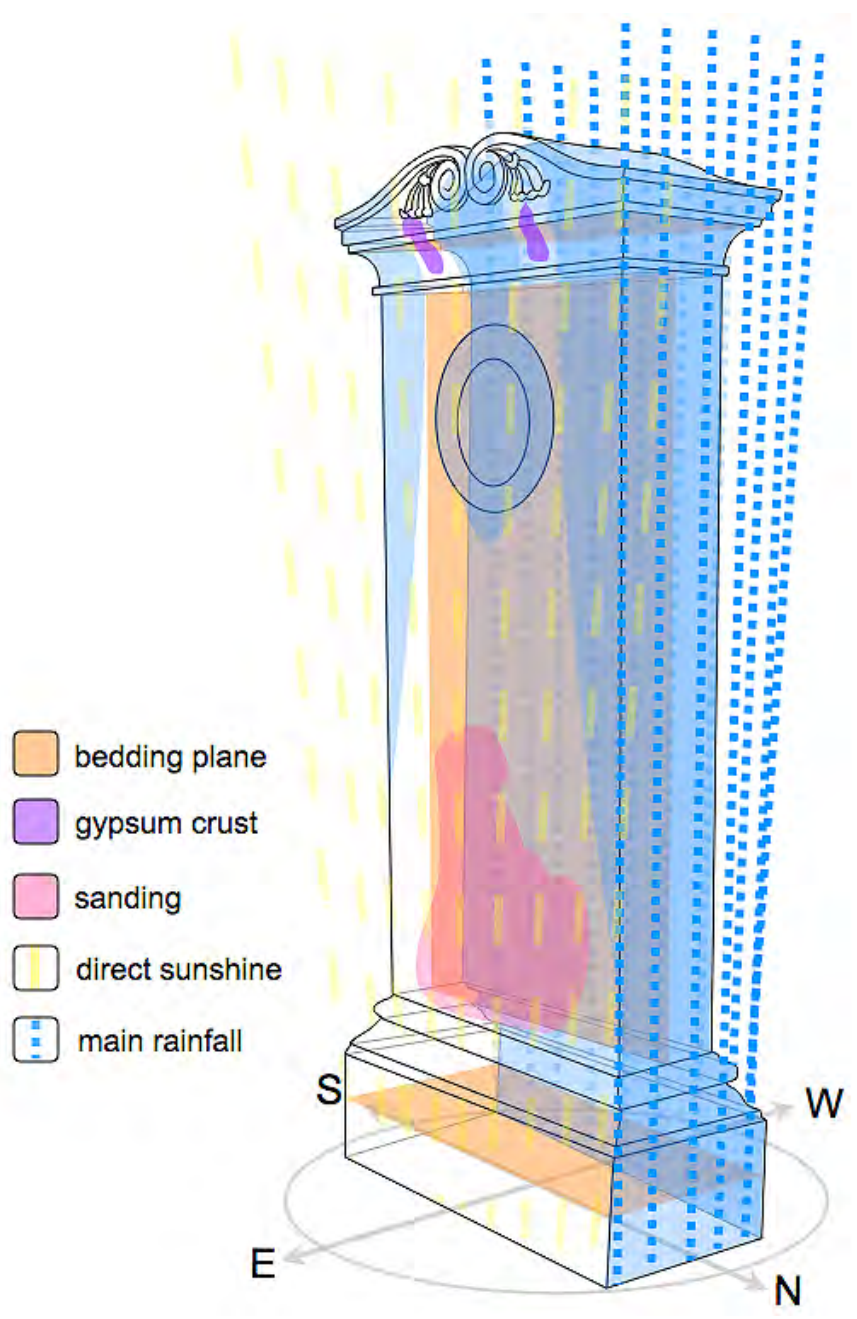

Figure 100: Weathering model of the Strohmeyer Tomb.

\section{5. 6. b) Weathering model of the Lejeune-Dirichlet Tomb}

In the case of the Lejeune-Dirichlet balustrade tomb the amount of sanding occurs mostly on the south and east sides (Fig. 101). The results of the quantitative mapping evaluations can be well correlated with the results obtained from the general observations. The tomb shows the highest intensity of weathering on the south side of the monument with a damage rate of $44 \%$ in relation to the surface. The east side follows with $41 \%$, then the north side with $34 \%$ and lastly the western side with $27 \%$ (Fig. 101). Biological colonization affected the northern and western sides (each $12 \%$ ). Mechanical deterioration, including blistering, exfoliation and sanding, affected the eastern (18\%) 
and southern (27\%) sides (Fig. 101). However, while the east and south side is nearly free from microbiological growth and dark deposits, the west and north side show a large amount of these two phenomena that are the main wind and rain directions. The drying gradient is directed to the east and south side where crystallization take place and weathering phenomena occur.
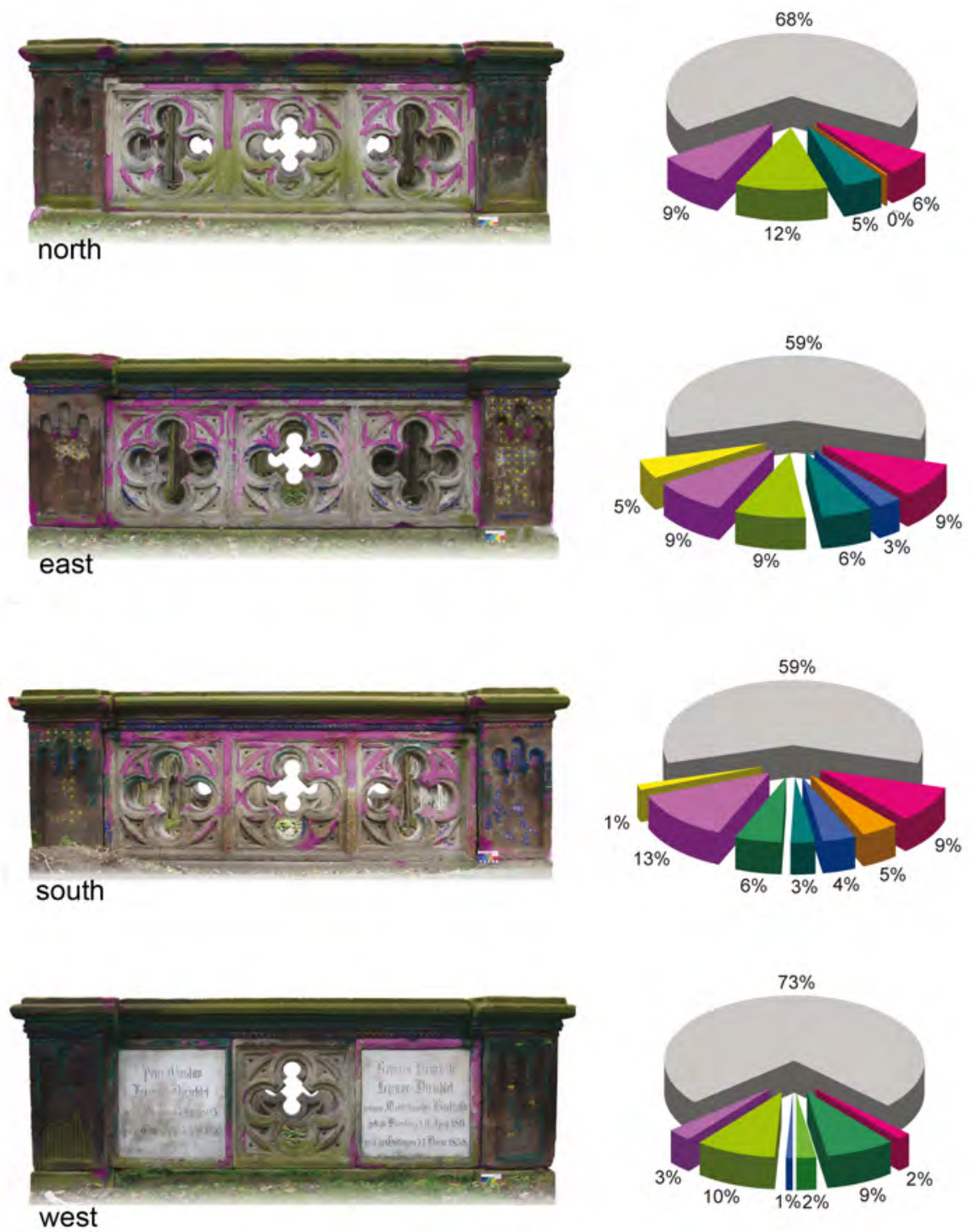

$\begin{array}{lll}\square \text { intact } & \square \text { natural cover } & \\ \square \text { salt } & \square \text { dark film } & \text { flaking } \\ \square \text { damaged } & \square \text { crust } & \square \text { peeling } \\ \square \text { biofilm } & \square \text { gypsum film } & \text { sanding }\end{array}$

Figure 101: Quantitative mapping of all sites of the Lejeune-Dirichlet tomb. 


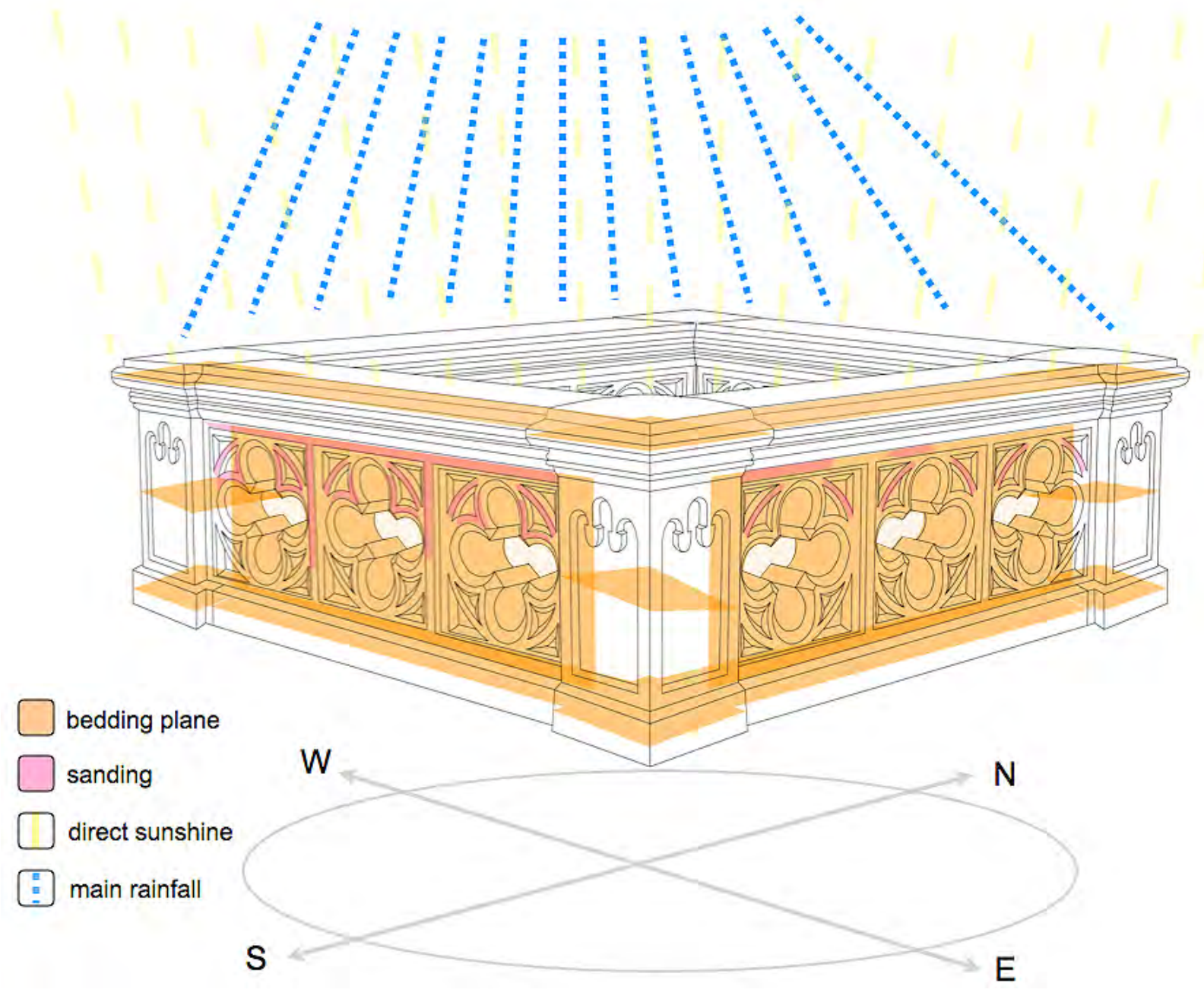

Figure 102: Weathering and bedding situation of the Lejeune-Dirichlet balustrade tomb.

\section{5. 7 Discussion}

The weathering situation of the tombs in Goettingen represents a characteristic study for a historical cemetery in northern Europe. The tombs are located in a wooded park-like area. The salt contamination is in general moderate with no or little contamination from urban pollution sources.

The source of the sulfur seems to come from the aerosols and rainwater. If calcite is present as binding cement within the stone, gypsum crusts can be formed. These crusts occur in damp areas that are not directly affected by rainfall.

All investigated varieties have a high porosity and a low splitting tensile strength making them vulnerable to weathering. The weathering resistance and behavior of the investigated rocks is quite similar. Differences may be attributed to their varying pore space distribution in combination with their varying splitting tensile strength. In general, the weathering behavior for all varieties in regards to salt weathering is quite similar and comparable to the sandstones of Petra or Angkor. A 30 $\%$ material loss takes place between the $10^{\text {th }}$ and $17^{\text {th }}$ cycle in the samples investigated. The Aren- 
shausen sandstone has the highest value of splitting tensile strength, but also the highest amount of microporosity. The latter seems to be the reason why the sandstone exhibits a lower salt resistance than the Appenrode sandstone.

Hydric expansion in most of the investigated samples is quite low and only the Appenrode sandstone shows a significant value of $0.5 \mathrm{~mm} / \mathrm{m}$. This appears to be connected to the presence of some clay minerals; which also influences the water uptake coefficient. The w-value of this sandstone type is comparably low, and thus indicates the presence of clay minerals (Tab. 20). Thermal expansion in all sandstones investigated is comparably low, probably also due its high porosity. Two varieties reach nearly $1 \mathrm{~mm} / \mathrm{m}$ by heating up to $60{ }^{\circ} \mathrm{C}$. This can be traced back to the calcite content within the cement. 


\section{6 Monument Nr. 826 Petra / Jordan}

\section{6. 1 Introduction}

The ancient rock city of Petra, which lies south of the Dead Sea in the Hashemite Kingdom of Jordan, displays with its unusual sandstone architecture abundant evidence of the Nabatean culture. Petra has gained international recognition for the around 600 hundred rock facades carved out of the sandstone bedrock (Fig. 103). Today, this unique monumental rock architecture is in danger due to the action of flash-floods, decomposition, poor maintenance and the lack of conservation. In collaboration with CARCIP (Conservation and Restoration Center in Petra), onsite fieldwork and research has led to new findings on the process of tafoni weathering of the Cambrian sandstone by the interaction of uncontrolled flowing rainwater and salt deposition.

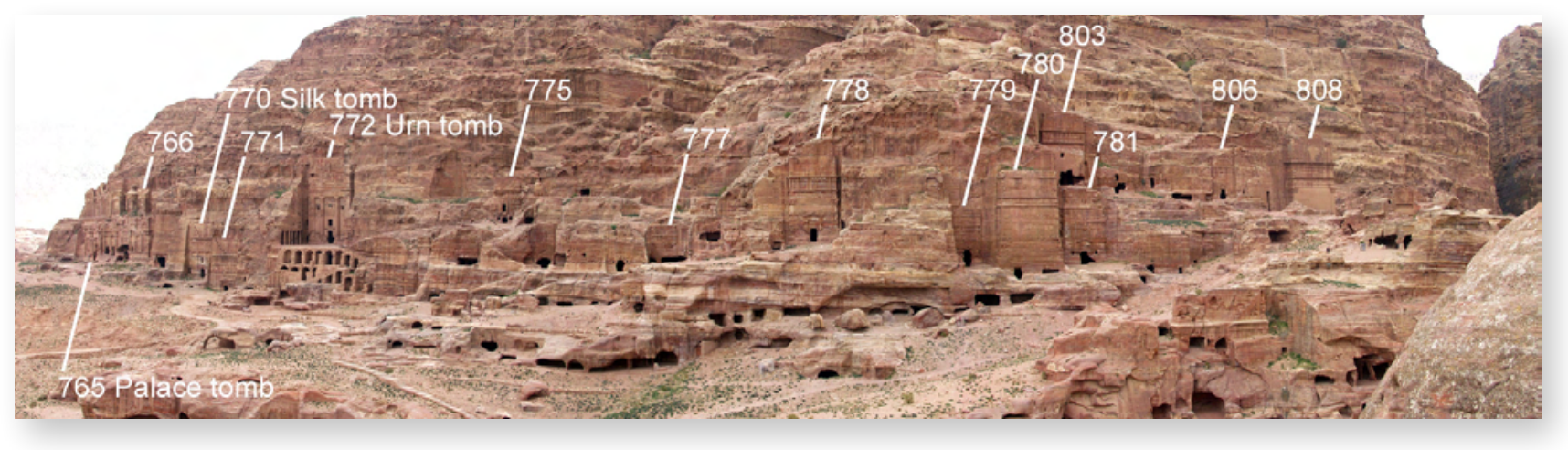

Figure 103: The Kings Wall with several monumental rock cut tombs in Petra, Jordan.

In 1995, the approximately 4000 individual monuments cut from the sandstone rock were added to the list of world cultural monuments of the UNESCO (United Nations Educational, Scientific, and Cultural Organization). Most of the 2000 year old sandstone monuments of Petra are in danger of degradation due to progressive weathering (Wedekind $2005 \mathrm{~b}$ ). Today more than $50 \%$ of the surfaces of the monuments are damaged by weathering phenomena. Nearly $12 \%$ are totally destroyed by tafoni weathering because of high contamination with rock salt (halite, $\mathrm{NaCl}$ ). Therefore, a joint German-Jordanian project for the establishment of a Conservation and Restoration Center in Petra (CARCIP) run by the German Technical Cooperation Society (GTZ) and the Department of Antiquities of Jordan (DOA) developed conservation and restoration methods to protect the sandstone monuments between 1993 and 2002 (Fischer, Kuehlenthal 2000). From 2000 to 2011 several scientific investigations that included scientific studies and diploma theses were undertaken by the Geoscience Center of the University Goettingen (GZG) and the University of Applied Arts and Sciences of Hildesheim (HAWK), Germany. 


\section{6. 1 a) Petra, the capital of the Nabateans}

The ancient stone city was the capital of the Nabateans from about 400 BCE until the fourth century CE and housed 30.000-40.000 people during its heyday. The Arabic tribe of Nabateans achieved great wealth and political-economic significance through caravan trading on the various silk and incense trade routes. In $106 \mathrm{CE}$, the Nabatean Kingdom lost its independence and was incorporated into the Roman Empire as Provincia Arabia. An earthquake in $363 \mathrm{CE}$ dealt a decisive blow to the still important and extremely wealthy city, thus Petra increasingly lost importance as a metropolis. As their territorial independence came to an end, the Nabateans lost the economic and political influence they once had. The Nabatean Era had come to an end. Although the majority of the residential city carved out of ashlars lies literally in ruins due to earthquakes, the nearly 800 facades chiseled in the rock leave a lasting impression of the wealth and importance of this former Arabic metropolis.

\section{6. 1 b) Climate and environmental condition}

The Petra region has a dry arid summer climate that is hot, with wet cold winters. This climate is usually found in deserts of some tropical countries and has the classification BSk after KöppenGeiger (Tab. 1). The Petra region is near to the Dead Sea as well as to the desert area in the south with a classification of BWh.

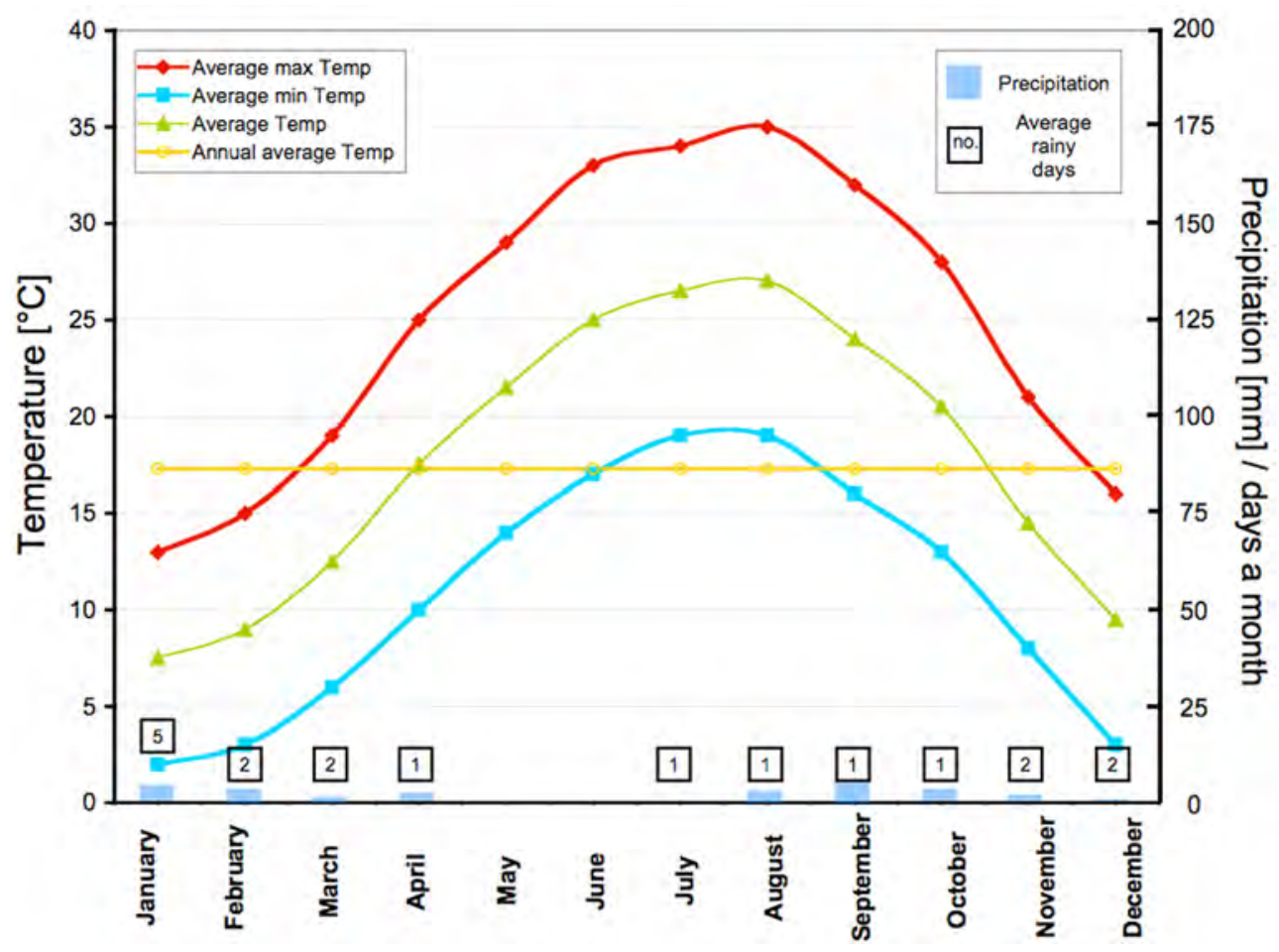

Figure 104: Climate Graph for Petra.

The mean temperature is $18{ }^{\circ} \mathrm{C}$ (Fig. 104). Average monthly temperatures vary by $14{ }^{\circ} \mathrm{C}$. In the winter records indicate temperatures by day reach $16{ }^{\circ} \mathrm{C}$ on average, falling to $3{ }^{\circ} \mathrm{C}$ or sometimes 
lower through the night. In spring temperatures climb up to $29^{\circ} \mathrm{C}$, generally in the afternoon with overnight lows of $14^{\circ} \mathrm{C}$. During the summer, average high temperatures are $24^{\circ} \mathrm{C}$ and average low temperatures are $11{ }^{\circ} \mathrm{C}$. Autumn temperatures decrease, achieving average highs of $34{ }^{\circ} \mathrm{C}$ during the day and lows of $18.5^{\circ} \mathrm{C}$ generally shortly after sunrise. Petra is located in a semi-arid climatic zone with a mean annual rainfall of $190 \mathrm{~mm}$ (Goudi, Viles 1997).

According to the Holdridge life zones system of bioclimatic classification, Petra is situated in or near the desert biome (Tab. 1). The area is free from industrial pollution, but being near the Dead Sea a high load of soluble elements are contained in the rainwater.

\section{6. 2 Rock material}

Most of the tomb facades of Petra were chiseled out of the brown sandstone from the middle Cambrian Umm Ishrin Formation. In the past this sandstone had also been known as the Nubian Sandstone. The rock is mostly reddish-brown, but also multi-colored yellowish-brown or with bright reddish-purple with lamination (Fig. 105 a), liesegang structures (Fig. 105 b) and sometimes affected by fractures (Fig. 105 c). It is medium to fine-grained and of medium porosity (Kuenne, Wanke, 1997).
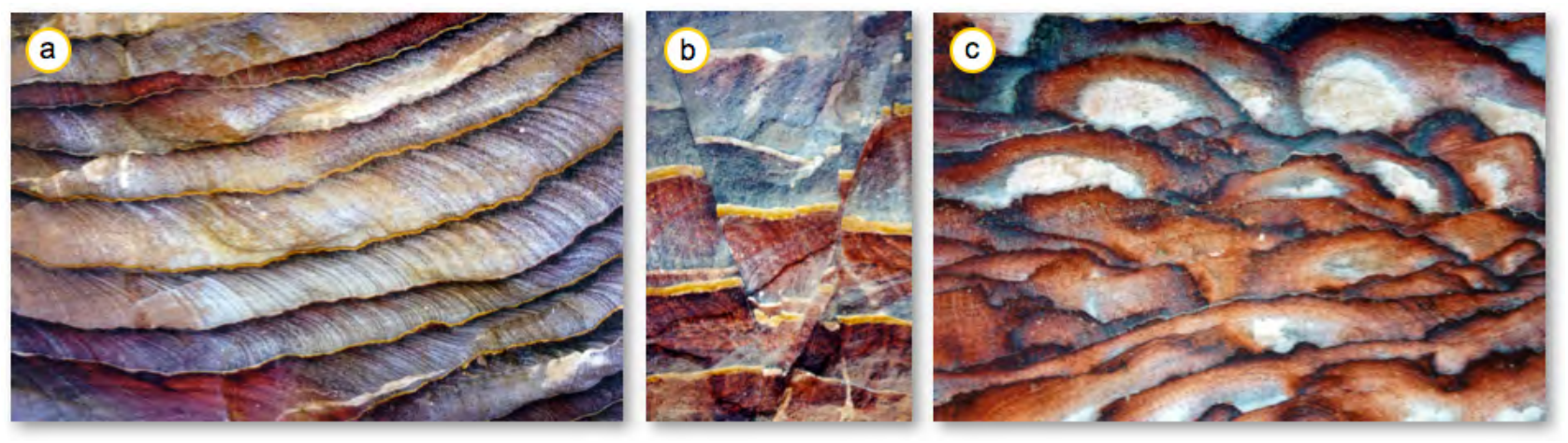

Figure 105: Multicolored sandstones with different bedding structures: a) horizontal laminations, b) strata of iron-rich horizons interrupted by a seismic fracture, and c) liesegang structures.

\section{6. 2 a) Mineralogy and fabric}

In this study four different rock types were investigated (Fig. 106): The Petra red sandstone (PR, Type I) is a homogenous medium- to fine-grained brownish-red variety. PL (Type II) is the Petra light red sandstone, a cloudy reddish medium-grained variation. PP (Type III) refers to the Petra purple sandstone, a fine-grained variation (Fig. $106 \mathrm{f}$ ) and often shows cracks around the single quartz grains (Fig. $106 \mathrm{j}$ ). This type shows quartz grains of different form and size often oriented within the layered structure (Fig. $106 \mathrm{~g}$ ). Some investigations were also made for a sample of the limonite (L), which is yellow in color and fine-grained. The limonite is characterized by single sharp edged quartz grains of difference sizes within a microcrystalline yellowish matrix (Fig. 106 h). Within this matrix single sharp edged quarzitic fragments can be identified (Fig. 106 l). 

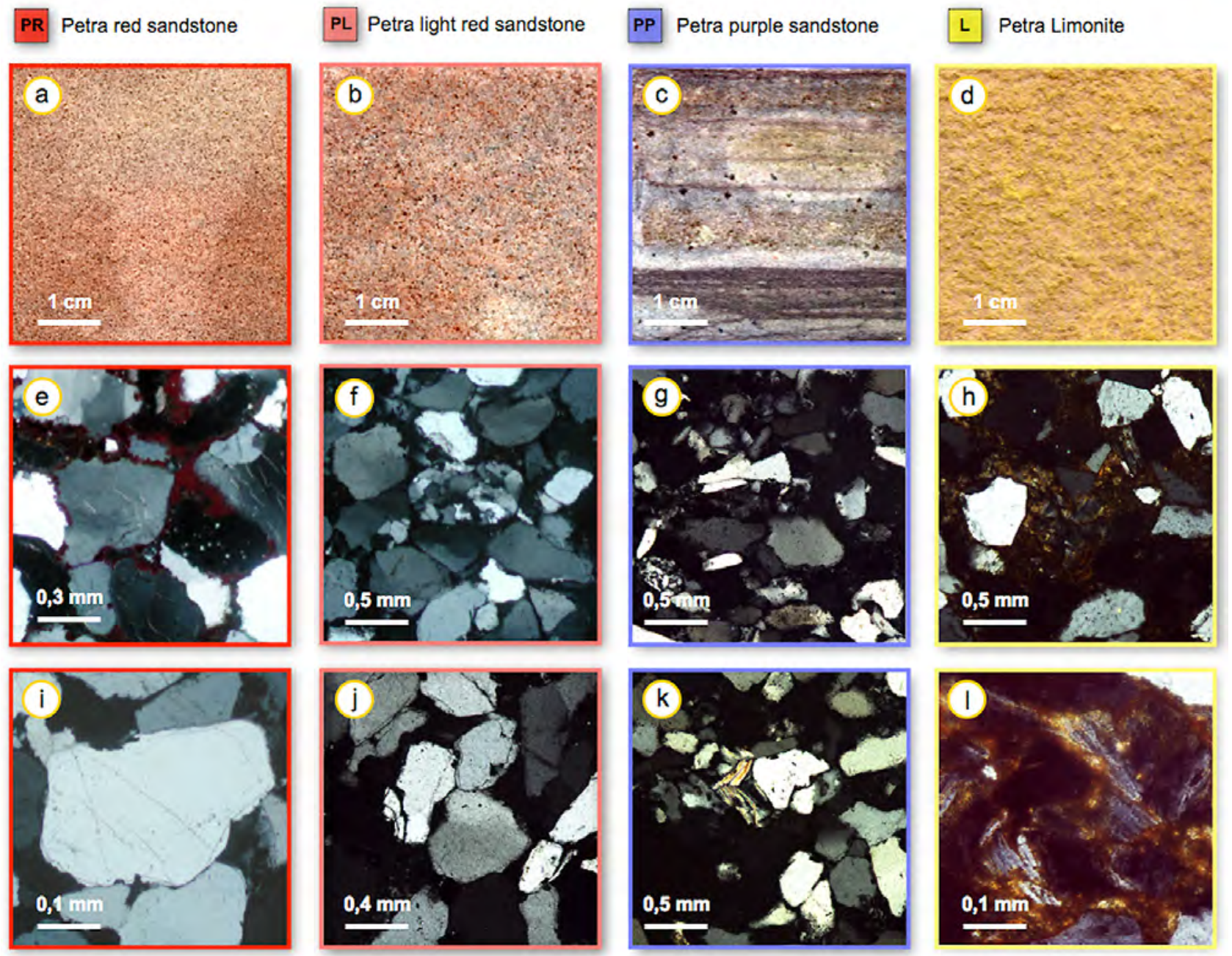

Figure 106: a) a-d) macroscopic images of the different sandstones, a) the PL Petra light red sandstone, b) the Petra red sandstone, c) the Petra purple sandstone and d) the Petra limonite. e-1) Thin sections images in polarized light. e \& i) the PL sandstone, $\mathrm{f} \& \mathrm{~g}$ ) the PR sandstone, $\mathrm{g} \& \mathrm{k}$ ) the PP sandstone and $\mathrm{h} \& \mathrm{l}$ ) the L limonite.

The detrital components of the sandstones from Petra are dominantly quartz and subordinate feldspar grains. Quartz and clay minerals are the main cementation components. Sometimes hematite or calcite can also be found.

The microfabric of the PR sample, taken from monument no. 826 is shown in Figure $106 \mathrm{~b}$. Thin section analyses show that the detrital components are almost predominately quartz grains. The sandstone shows a bimodal sorting with grain sizes ranging between $100 \mathrm{~mm}$ and $300 \mathrm{~mm}$ (Fig. 106 f). The shape of the detrital grains is predominantly angular. Quartz grains often show mineralized microcracks, which may represent fabric properties from the source area (Fig. 106 i). Opened microcracks are common and the result of a fragmentation during the diagenetic compaction of the sediment. The diagenetic cementation is characterized by syntaxial quartz overgrowth on detrital grains (Fig. 106 i). Hematite is also common and occurs in the quartz cements (Fig. 106 f). Similar findings could be made for the PL variation, whereas the hematite content is lower (Fig. 106 e). 


\section{6. 2 b) Petrophysical properties}

The investigated sandstones of the Petra region can be characterized as medium-grained porous sandstone types with a porosity ranging between $8.5 \%$ for the purple variety to $17.84 \%$ for the red one (PR).

The PL variety shows the highest w-value, whereas the lowest one is exhibited by the PR variety (Tab. 21). The microporosity reached its highest value for the limonite (72\%) and the lowest value for the PR variety with $7.4 \%$ (Tab. 21).

The water absorption value ranges between 0.6 to $0.9 \mathrm{~kg} /(\mathrm{m} 2 \cdot \sqrt{ } \mathrm{h})$ and the anisotropy of the different samples between $9 \%$ to $17 \%$ (Tab. 21). The directional anisotropy of ultrasonic wave lengths is quite low and reaches only $11.6 \%$ to $40 \%$ (Tab. .21). In general, the value of ultrasonic velocity of all samples is between $2.661 \mathrm{~km} / \mathrm{s}$ and $2.894 \mathrm{~km} / \mathrm{s}$. The anisotropy measured for Type 1(PR) reaches nearly $10 \%$, which is high as compared to the other samples (Tab. 21).

Hygric dilatation shows an exceptional development. The first measurement of most sandstone samples from Petra exhibit no expansion but shrinking. After drying and further water saturation the PR variety shows a low swelling in the XY-direction, whereas a shrinking takes place in the Z-direction (Tab. 21). The anisotropy of the first measurements reaches a value of less than $1 \%$, while the anisotropy of the PL variety attains $100 \%$ (Tab. 21). Only the PP variety shows a low expansion in the Z-direction probably due to some clay minerals present (Tab. 21). The limonite beds have an average hydric expansion of $1.4 \mathrm{~mm} / \mathrm{m}$ with a significant anisotropy of $94 \%$ (Tab. 21).

Thermal expansion at $60{ }^{\circ} \mathrm{C}$ ranges between 0.87 and $1.15 \mathrm{~mm} / \mathrm{m}$ for the sandstones and reaches its maximum value of only $0.45 \mathrm{~mm} / \mathrm{m}$ for the limonite.

Ultrasonic velocity under dry conditions is similar and ranges between $2.66 \mathrm{~km} / \mathrm{s}$ and $3 \mathrm{~km} / \mathrm{s}$, which is slightly higher than for the sandstones in the Goettingen case study and lower for the sandstones of Angkor, Cambodia. For the PL variety ultrasonic velocity does not increase under saturated conditions in any significant way. This might be related to the effect of hydric shrinking. 
Table 21: Pore space properties, moisture transport, and mechanical properties of the Petra sandstones

\begin{tabular}{|c|c|c|c|c|}
\hline Stone type & PR (Type I) & PL (Type II) & PP (Type III) & $\mathrm{L}$ (limonite) \\
\hline Effective porosity [Vol.-\%] & 17.84 & 14.17 & 8.5 & 7.09 \\
\hline Particle density $\left[\mathrm{g} \cdot \mathrm{cm}^{-3}\right]$ & 2.16 & 2.22 & 2.39 & 2.49 \\
\hline Bulk density $\left[\mathrm{g} \cdot \mathrm{cm}^{-3}\right]$ & 2.63 & 2.59 & 2.62 & 2.67 \\
\hline Micropore porosity [\%] & 7.4 & 8.34 & 50.9 & 71.8 \\
\hline \multicolumn{5}{|l|}{$\mathrm{w}$ value $\left[\mathrm{kg} / \mathrm{m}^{2} \sqrt{ } \mathrm{h}\right]$} \\
\hline$x$ & 1.48 & 1.89 & 1,78 & 0.2 \\
\hline$Y$ & 1.51 & 1.898 & 1.78 & 0.2 \\
\hline $\mathbf{Z}$ & 1.03 & 1.678 & 1.064 & 0.05 \\
\hline Average $\varnothing$ & 1,34 & 1,82 & 1.54 & 0.15 \\
\hline Anisotropy [\%] & 31.7 & 11.6 & 40.4 & 75 \\
\hline \multicolumn{5}{|l|}{ Ultrasonic velocity dry [km/s] } \\
\hline$x$ & 2.757 & 2.785 & 2.776 & nd \\
\hline$Y$ & 2.866 & 2.76 & 2.609 & nd \\
\hline $\mathbf{Z}$ & 3.061 & 2.711 & 2.599 & nd \\
\hline Average $\varnothing$ & 2.894 & 2.752 & 2.661 & - \\
\hline Anisotropy [\%] & 9.9 & 2.6 & 6.27 & - \\
\hline \multicolumn{5}{|l|}{ Ultrasonic velocity wet [km/s] } \\
\hline$x$ & 3.10 & 2.99 & 3.22 & nd \\
\hline$Y$ & 3.10 & 2.905 & 3.13 & nd \\
\hline $\mathbf{Z}$ & 3.01 & 3.05 & 3.13 & nd \\
\hline Average $\varnothing$ & 3.07 & 2.98 & 3.16 & - \\
\hline Anisotropy [\%] & 3 & 5 & 2.7 & - \\
\hline Surface hardnes [HLD] dry & 441 & 444 & 460 & 413 \\
\hline Surface hardnes [HLD] wet & 401 & 404 & 456 & 380 \\
\hline $\begin{array}{l}\text { Surface hardnes reduction } \\
{[\%]}\end{array}$ & 9.07 & 9.0 & 1 & 8 \\
\hline \multicolumn{5}{|l|}{ Hydric shrinking / dilatation } \\
\hline$x$ & $-0.36 / 0.09$ & -0.30 & -0.31 & 2 \\
\hline$Y$ & - & - & - & 2.01 \\
\hline $\mathbf{Z}$ & -0.322 & -0.22 & 0.19 & 0.12 \\
\hline Average $\varnothing$ & -0.346 & -0.27 & -14.3 & 1.37 \\
\hline Anisotropy [\%] & $>1$ & 7 & $<100$ & 94 \\
\hline \multicolumn{5}{|c|}{ Thermal expansion $\left[\mathrm{mm} / \mathrm{m}, 60^{\circ} \mathrm{C}\right]$} \\
\hline$x$ & 0.92 & 1.15 & $1, .07$ & 0.3 \\
\hline$Y$ & 0.95 & 1.15 & 1.05 & 0.3 \\
\hline $\mathbf{Z}$ & 1.13 & 1.16 & 0.878 & 0.45 \\
\hline Average $\varnothing$ & 1 & 1.153 & 1.00 & 0.35 \\
\hline Anisotropy [\%] & 18.6 & 1 & 18 & 33 \\
\hline
\end{tabular}




\section{6. 3 Typical weathering forms}

Areas with arid or semi-arid climatic zones like Petra show an increasing amount of salt deposition (Wellmann, Willson 1965). Therefore, weathering due to salts plays a crucial role. These observations were also supported by laboratory examinations (Sperling, Cooke 1980).

Even the specific visible marks of weathering on the Cambrian sandstone in Petra point to damage caused by extreme salt contamination. Salt crystallization is one of the most important factors that have contributed to the destruction of buildings and rock cut architecture (see Al-Saad, AbdelHalim 2001; Wedekind, Ruedrich 2006; Bala'awi 2008; Eklund 2008 and Heinrichs 2008).

The typical development of alveolar and tafoni weathering is obvious and completely covers the rocks. During the past centuries it has also spread to the monuments. The tafoni comprise locally limited and completely deteriorated areas the size of several meters (Fig. 18 a). This kind of extreme deterioration is surrounded by mostly undamaged rock.

\section{6. 4 The salt of Petra and its sources}

During the tourist season the salt of Petra is nearly invisible, some parts are weathered away and others are covered by a fine dust layer due to its hygroscopicity. Only by observation of the goats can one assume that salt is present because they are licking the rocks.

After the winter rainfalls, the salt becomes observable by whitish efflorescences (Fig. $109 \mathrm{~b}$ and c). A higher salt load on the surface during the winter was also measured by Bala'awi et al., (2012). The rock salt of Petra consists of halite $(\mathrm{NaCl})$. Fitzner and Heinrichs (2000) identified the solid salt crust as halite. In areas behind the crusts poorly soluble calcium sulfate $\left(\mathrm{CaSO}_{4}\right)$, but also highly soluble potassium, nitrates, and magnesium sulfate were also found. Al-Naddaf (2002) also examined the destructive salt of Petra with similar findings. In addition to $\mathrm{NaCl}$ and $\mathrm{CaSO}_{4}$, he also found traces of $\mathrm{KHCO}_{3}, \mathrm{CaCO}_{3}, \mathrm{KNO}_{3}$, and $\mathrm{KCI}$. Various authors mention, in addition to the above-mentioned salts: magnesium chloride $\left(\mathrm{MgCl}_{2}\right)$, thenardite $\left(\mathrm{Na}_{2} \mathrm{SO}_{4}\right)$, potassium sulphate $\left(\mathrm{K}_{2} \mathrm{SO}_{4}\right)$, sodium carbonate $\left(\mathrm{NaCO}_{3}\right)$, magnesite $\left(\mathrm{MgCO}_{3}\right)$, kalicinite $\left(\mathrm{KHCO}_{3}\right)$ and potassium carbonate $\left(\mathrm{KCO}_{3}\right)$ (Al-Saad, Abdel-Halim 2001; Wedekind, Ruedrich 2006; Bala'awi 2008; Eklund 2008; Heinrichs 2008). Gomez-Heras et al., (2011) presented a study of the „Silk Tomb“ where a wide variety of salts such as halite $(\mathrm{NaCl})$, sylvite $(\mathrm{KCl})$, niter $\left(\mathrm{KNO}_{3}\right)$, gypsum $\left(\mathrm{CaSO}_{4} \cdot 2 \mathrm{H}_{2} \mathrm{O}\right)$, syngenite $\left(\mathrm{K}_{2} \mathrm{Ca}\left(\mathrm{SO}_{4}\right)_{2} \cdot(\mathrm{H} 2 \mathrm{O})\right.$, polyhalite $\left(\mathrm{K}_{2} \mathrm{Ca}_{2} \mathrm{Mg}\left(\mathrm{SO}_{4}\right)_{4} \cdot 2\left(\mathrm{H}_{2} \mathrm{O}\right)\right.$ and aphthitalite $(\mathrm{K}, \mathrm{Na})_{3} \mathrm{Na}\left(\mathrm{SO}_{4}\right)_{2}$ can be found. These samples were taken from the lower part of the monument. 
From our own analyses of extracted salt taken from a underground cistern in front of monument no. 676 and by a drilling core taken from tafoni no. 3 of tomb no. 826, the composition of the ions are listed in the following table:

Table 22: Ion distribution of eight different elements within the salt of Petra and the rainwater in Jordan

\begin{tabular}{|c|c|c|c|c|c|c|c|}
\hline \multirow[t]{2}{*}{ lones } & \multirow{2}{*}{$\begin{array}{c}\text { Sample } \\
\text { from the } \\
\text { cistern } \\
{[\%]}\end{array}$} & \multicolumn{4}{|c|}{ Sample from tafoni no. 3 of tomb no. 826} & \multirow{2}{*}{$\begin{array}{c}\text { Elements } \\
\text { within the } \\
\text { rainwater in } \\
\text { Jordan }{ }^{1}\end{array}$} & \multirow{2}{*}{$\begin{array}{c}\text { Elements } \\
\text { within the } \\
\text { rainwater in } \\
\text { the south } \\
\text { of Jordan }{ }^{3} \\
{[\%]}\end{array}$} \\
\hline & & {$[\%]^{2}$} & {$[\%]^{2}$} & {$[\%]^{2}$} & {$[\%]^{2}$} & & \\
\hline Depth profile & & $0-1 \mathrm{~cm}$ & $1-2 \mathrm{~cm}$ & $2-3 \mathrm{~cm}$ & $3-4 \mathrm{~cm}$ & & \\
\hline chloride & 32 & 44.4 & 36.8 & 30.4 & 20.8 & 20.7 & 17.6 \\
\hline nitrate & 30 & 0.46 & 1.9 & 2.9 & 4.1 & 0.004 & 4.8 \\
\hline sulfate & 20 & 6,6 & 16.1 & 21.5 & 29 & 8.9 & 7.5 \\
\hline Bromid & 1 & - & - & - & - & - & - \\
\hline sodium & 20 & 45.3 & 36.8 & 31 & 22.9 & 14.2 & 13.2 \\
\hline potassium & 145 & 0.31 & 1.9 & 3.9 & 6.25 & 1.3 & 2,8 \\
\hline magnesium & 0,1 & 0.51 & 2.5 & 2 & 4.16 & 32.7 & 11.3 \\
\hline calcium & 9.6 & 2.32 & 4.5 & 8.8 & 12.5 & 20 & 23.5 \\
\hline
\end{tabular}

1) according to Al-Khashman. Tarawneh 2006, 2) Dr. Hans Jürgen Schwarz, 3) according to Al-Khashman et al., 2013

The analyzed salt mixture of the cistern in front of facade no. 676 was characterized due to its high hygroscopicity. Therefore, it was necessary to dry the salt for one week at $105{ }^{\circ} \mathrm{C}$ in a drying chamber.

Drilling core examinations and drilling dust samples taken from the depth profile of monument no. 826 determined the contamination with salts. Whereas an invariable low amount of salt was found in the undamaged areas, the concentration of salts was high in the deteriorated tafoni areas to 4 centimeters in depth (Fig. 107 b, and 107 e).

The main salts causing structural damage at Petra are halite (NaCI), some magnesium chloride, some calcium sulfate $\left(\mathrm{CaSO}_{4}\right)$ and traces of magnesium, nitrate and potassium $(\mathrm{K})$. Five of six salt analyses taken by Eklund (2008) at the top of Mount Nebo show a similar composition. Within these samples she found mainly halite $(\mathrm{NaCl})$ and magnesium chloride $\left(\mathrm{MgCl}_{2}\right)$ close to the findings of the ion composition of the rainwater. 


\section{6. 4 a) Distribution of the different ions at depth}

Comparing the distribution of the different ions at depth from tafoni 3 shows a tendency towards a rainwater ions composition. A clear fractionation is evident: In the first two centimeters halite $(\mathrm{NaCl})$ is dominant, forming a crust. Behind the crust calcium and sulfate accumulates forming gypsum (Fig. 102 a). These results indicate that the salt content within the rainwater is the contamination source. The fractionation seems to be connected to the solubility of the salts and the drying regime.
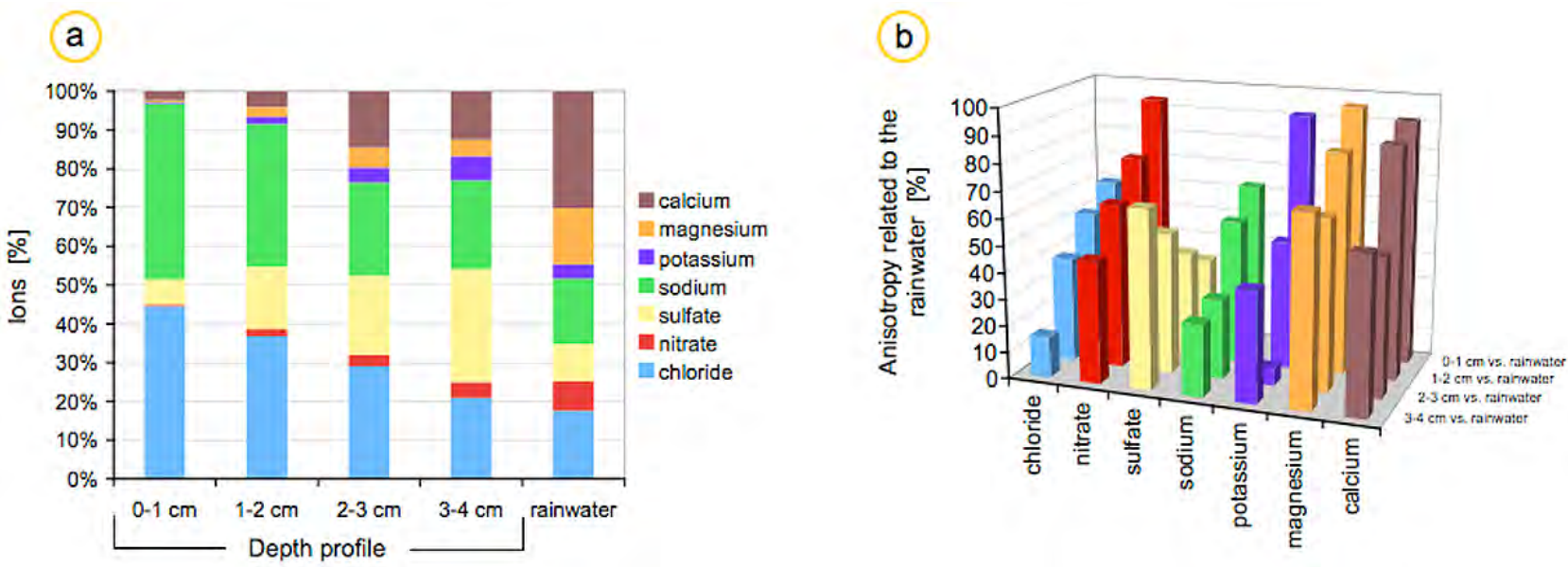

Figure 107: a) The percentage of the different ions according to the profile-depth. The last row is shows the percentage of the rainwater in the Petra region (source: Al-Khashman et al., 2013). b) The anisotropy of the ion content according to the depth profile related to the percentage amount of the different ions of the rainwater.

The evaluation of anisotropy between the percentage distributions of salt in the rainwater and the salt at different profile depths clarifies this evaluation. The different ions measured from a sample at the monument are similar to the composition of the ions in the rainwater. Thus, the rainwater can be considered as the source of contamination. Samples analyzed near the stone surface show a different composition to that of the rainwater (Al-Saad, Abdel-Halim 2001; Wedekind, Ruedrich 2006; Bala'awi 2008; Heinrichs 2008). The ion composition of the sample changes with depth and trends toward that of rainwater (Fig. $101 \mathrm{a}$ ).

In the case of chloride, nitrate, sodium, potassium, magnesium and calcium the anisotropy related to the percentile content of the ions of the rainwater becomes smaller with depth. That means the percentile distribution within the stone approaches the one of rainwater in a nearly linear function (Fig. 101 a). Residual moisture within the rock may be a possible explanation for why this ion composition is still found at depth (4 cm, Fig. $105 \mathrm{~d})$. 


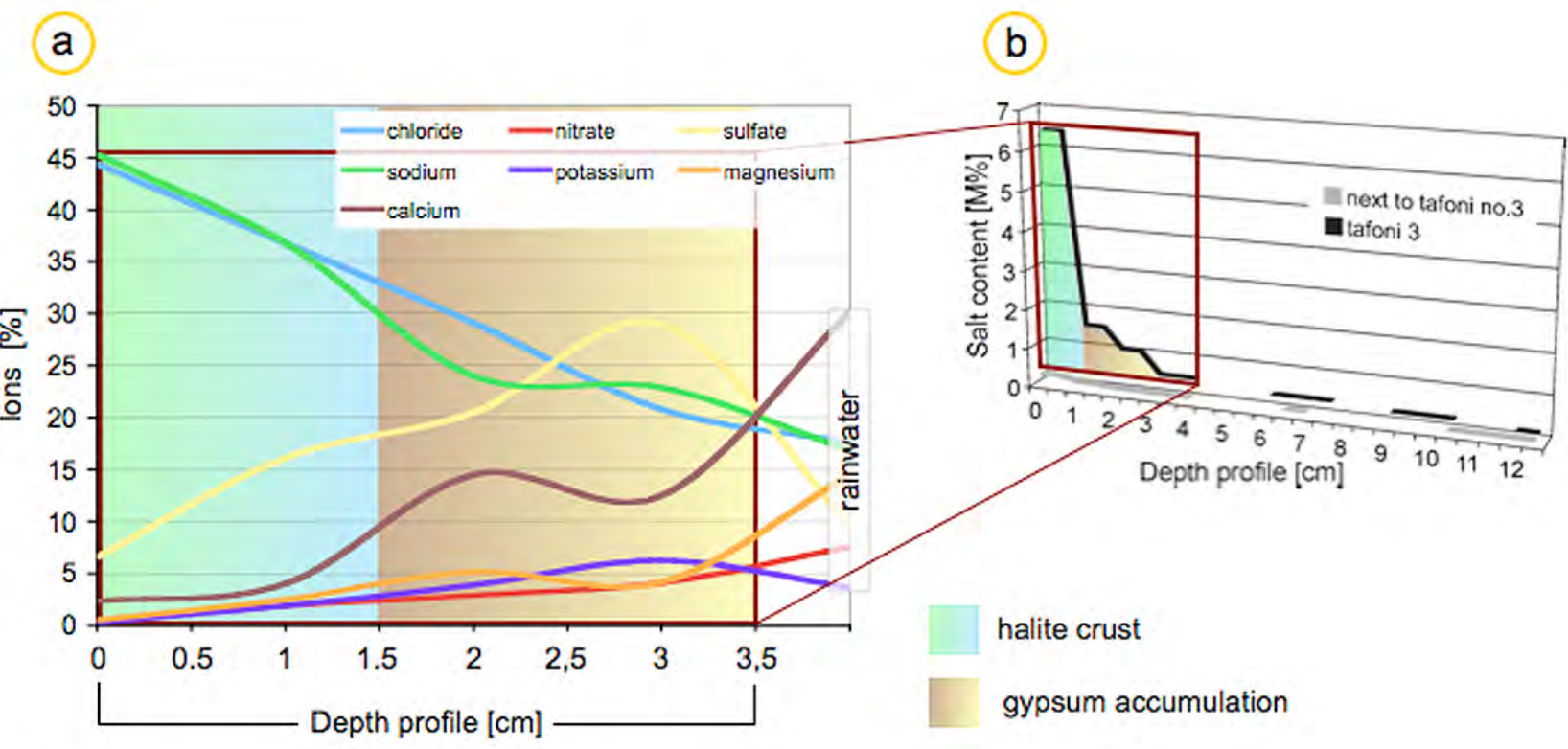

Figure 108: The analysis of drilling dust samples shows a salt concentration of up to 10 mass percent (M\%) for the first centimeter of the depth profile of heavily marked tafoni zones.

The irregularities in the line of calcium and sulfate profiles curves can be traced back to the possible formation of a gypsum accumulation at a profile depth of 2 to $4 \mathrm{~cm}$, which was also measured by Fitzner and Heinrichs (2000). The same goes for magnesium, which possibly forms magnesium sulfate compounds.

The differing ion composition related to depth has to be traced back to the different temperatures induced within the stone due to insolation. Smith et al., (2011) show in an experimental study that during the heating of the surface a temperature of $28{ }^{\circ} \mathrm{C}$ is reached, whereas the temperature at $4 \mathrm{~cm}$ depth ranges between 20 and $22{ }^{\circ} \mathrm{C}$. The internal temperature gradient shows two significant points of depression: The first one at $0.5 \mathrm{~cm}$ beneath the surface (where the crust is normally formed) and the other one at a depth of 2 to $4 \mathrm{~cm}$, the zone where in the present investigation gypsum could be detected.

In general, salt accumulation and salt attack also seems to be influenced by wind and the rapid drying of the surface. Experiments by Gomez-Heras and Ford (2007) have shown that radiation, which involves rapid heating, facilitates the formation of a continuous layer of sub-efflorescences and crystallization of a salt within a porous stone.

These investigations show that different salt mixtures are found at Petra at different locations. At the ground level of the monuments salt mixtures contain ions that cannot be found in atmospheric precipitation in high amounts (Tab. 22). These ions are nitrate and sulphate. Both ions can be produced by domestic cattle and agricultural activities, which is also the case in the studies of Guadalajara (Mexico), Göttingen (Germany) and Angkor (Cambodia). Therefore, domestic cattle seem to be the main cause for the origin of nitrates in Petra, as was also suggested by Heinrichs (2008). 
The results clearly show that by analyzing only the salt efflorescences, a limited conclusion can be drawn as to the possible source of contamination. Salt contamination creates a chromatographical distribution and fractionation at depth. Consequently, samples should not only be taken horizontally at the monument but also at greater depths in the stone material.

\section{6. 5 Forms of damage and weathering model}

\section{6. 5. a) Damage forms}

Comparative examinations of the sandstone monuments of Petra have shown that two varieties of tafoni development can be distinguished. Damaged spots evolve either vertically or horizontally.

Horizontal alveolars usually run below and markedly above the limonite layers that often run through the rock massif towards the sedimentation. The limonite has a low porosity and consists mainly of micropores (Tab. 21, Fig. 109 b). In contrast to the surrounding sandstone, this clay-silicic limonite layer is very soft in the first few millimeters. On the surface they deteriorate faster than sandstone, which is probably due to their high hygric expansion in the XY-direction (Tab. 21). However, drill resistance measurements have shown that at depth these limonite layers have a high hardness and a higher density than sandstone. They are mechanically stronger than feldspar or arkosic sandstones. Apparently, the limonite layers act as water-retarding layers. During evaporation salts accumulate at the surface, which was observed on many examples at Petra after rainfalls (Fig. Fig. 109 c). During precipitation events rainfall infiltrats the sandstone until it reaches the limonite water-retarding layer and flows towards the surface and down the rock face (Fig. $109 \mathrm{~b}$ ).
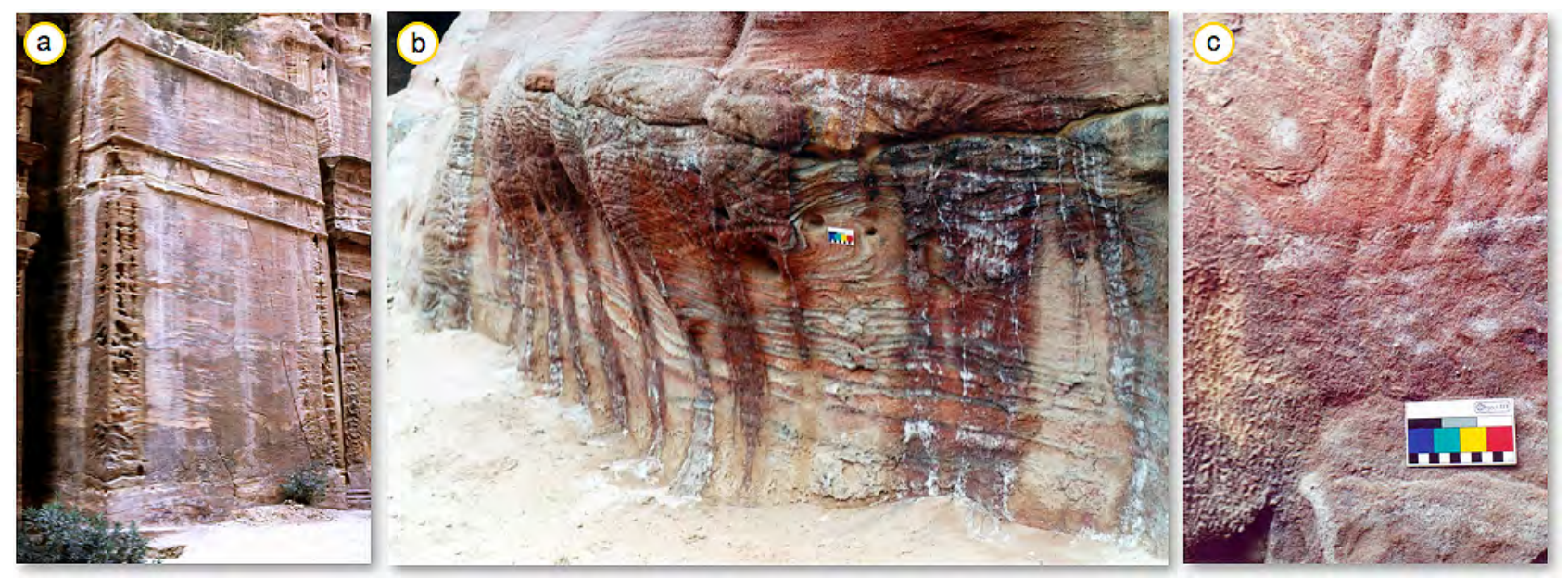

109: a) Wet area due to hygroscopic salts at one monument along the streets of the facades, b) water drainage and salt efflorescences and c) salt efflorescences at monument no. 826 after a heavy rainfall.

\section{6. 5. b) Weathering model}

The development of tafoni with regard to the vertical variation takes place in the zones left and right of where the water runs off (Fig. 110 and $111 \mathrm{a}, 112 \mathrm{~b}$ ). This is where draining water influences ta- 
foni development. Due to the evaporation on the rock surface, a high concentration of salts occurs in the areas close to the surface. The rare but annually occurring heavy rains in the winter and spring dampen all the vacant rocky areas and wash out the salt efflorescence. However, the water does not drain off the back walls of the alveolars, tafoni or semi caves, but merely seeps into these areas because of the radial expansion of the water. The seeping water and the dryness coming along cause an increasingly high concentration of salt in those zones.
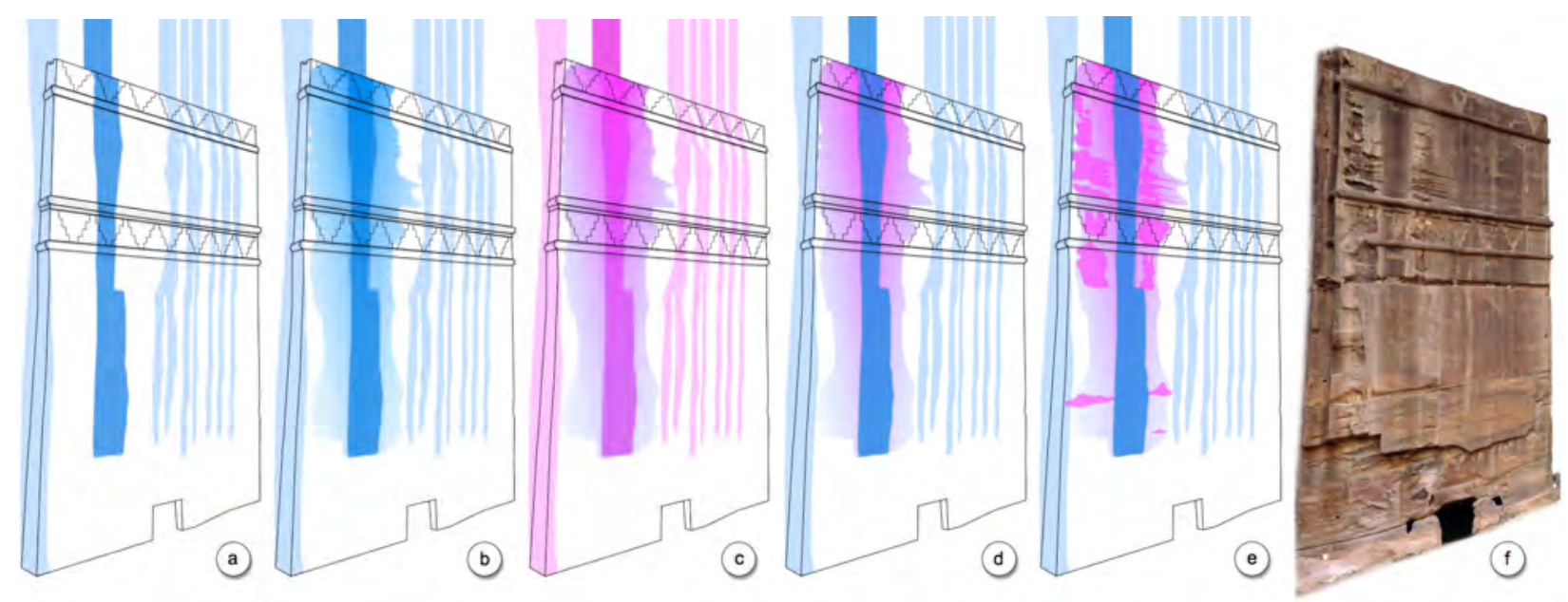

Figure 110: A stepwise weathering model of alveolar and tafoni weathering. a) Rain runs down the facade. b) The water infiltrates radially into the stone behind the flowing stream and laterally to the left and right. c) During the drying phase salt concentrates on the surface by capillary transport and evaporation. d) With the next rainfall the salt is washed away in the zone of the flowing water. e) By constant repetition the salt concentration to the right and left of the flowing stream has reached a critical amount and causes back- and alveolar-weathering.

f) The facade before conservation in 2001 .

Rainfall in Petra creates cascade-like water stains and sometimes dangerous flash floods. Water runs down the mountain even several hours after the rainfall (Fig. $111 \mathrm{c}$ ). After the rainfall the rocks and facades dry up again in only a few hours. The high concentration of salts on the surface results in blast off effects of the sand grain layers close to the surface - a physical process that has not been completely examined yet. The resulting loss of material leads to alveolars and subsequently to tafoni development (Fig. 111). Those areas that are wetted periodically and where salt deposits have been removed are in comparably good condition. This is also where most of the plaster and stucco remains of the formerly rich sculptural decoration on the tomb facades are best preserved. This was also noticeable on the tomb facade no. 826. Thus, the draining water does not lead to an extensive removal of the plaster remains or even the rock. The rock is mainly quartz cemented and therefore does not show any dissolution affects. In addition, the tafoni areas on monument no. 826 run parallel to the traces where the rainwater drains (Fig. $111 \mathrm{a}$ ). 


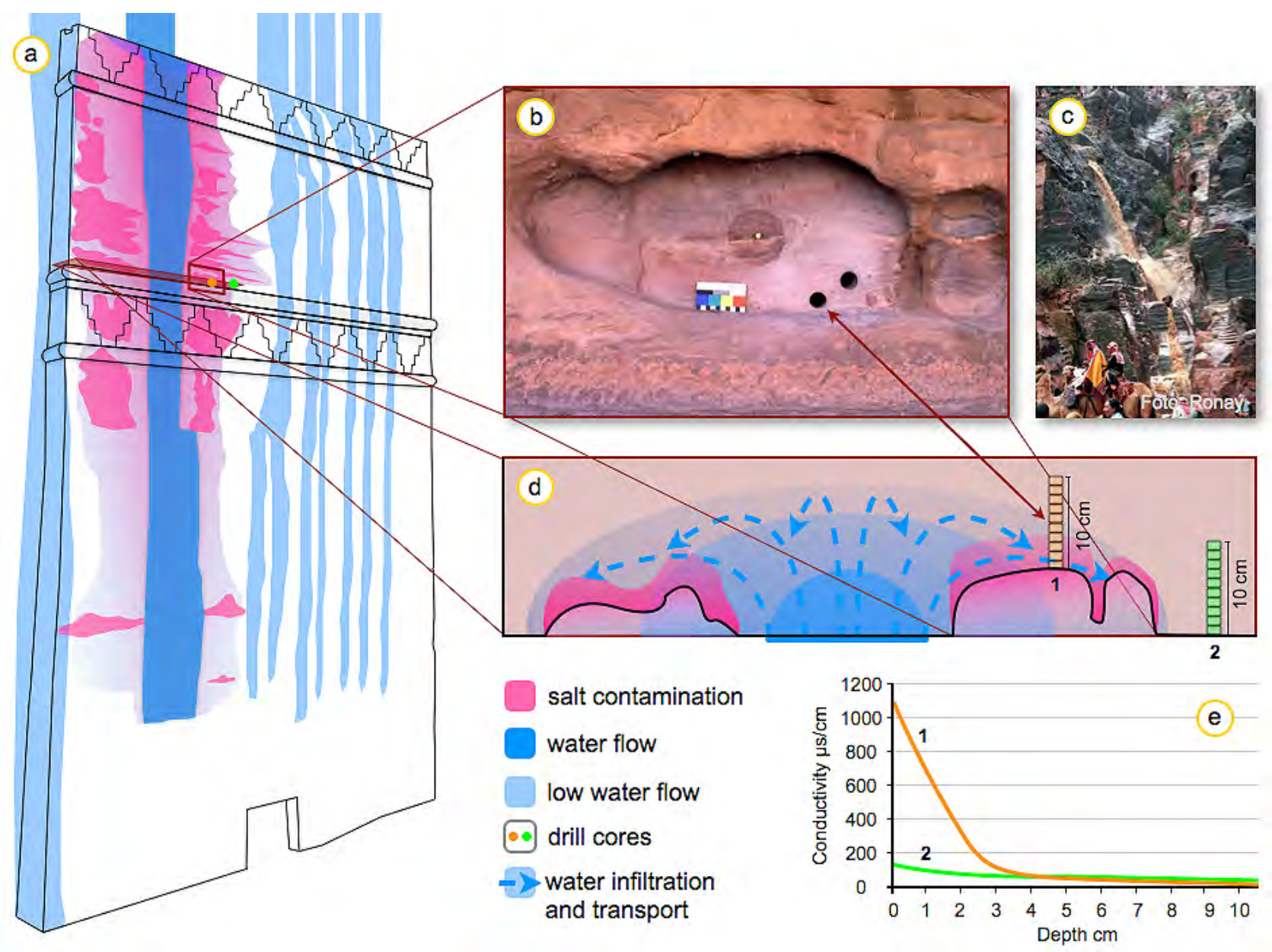

Figure 111: a) Distribution of alveolar weathering and traces where the rainwater drains at façade no. 826. b) Tafoni 3 with sampling points and drill core holes. c) Cascade-like water stains after a rainfall. d) Idealized cross section of the sampling area. e) Contribution of the electrical conductivity of the drill core samples with depth.

The rooms of the tomb facades are partially covered with sand and soil as well as the surroundings of the facades (Fig. 112 a). The drainage channels and cisterns are also filled with soil and rubbish and contaminated by animals and humans (Fig. 112 a). Some cracks and fractures are a serious danher for the monuments and their visitors (112 $\mathrm{a}$ and $\mathrm{b}$ ).

The downward running rainwater seeps into porous rock and during evaporation salts concentrate on the surface. Where the salt is not washed away during the next rainfall, an accumulation takes place by the formation of alveolars and tafoni (Fig. 112 b).

In general, the salt attack also seems to be influenced by the wind and fast drying of the surface. Experiments by Gomez-Heras and Ford (2007) have shown that radiation, which involves rapid heating, facilitates the formation of a continuous layer of sub-efflorescences and crystallization of a salt within a porous stone. 


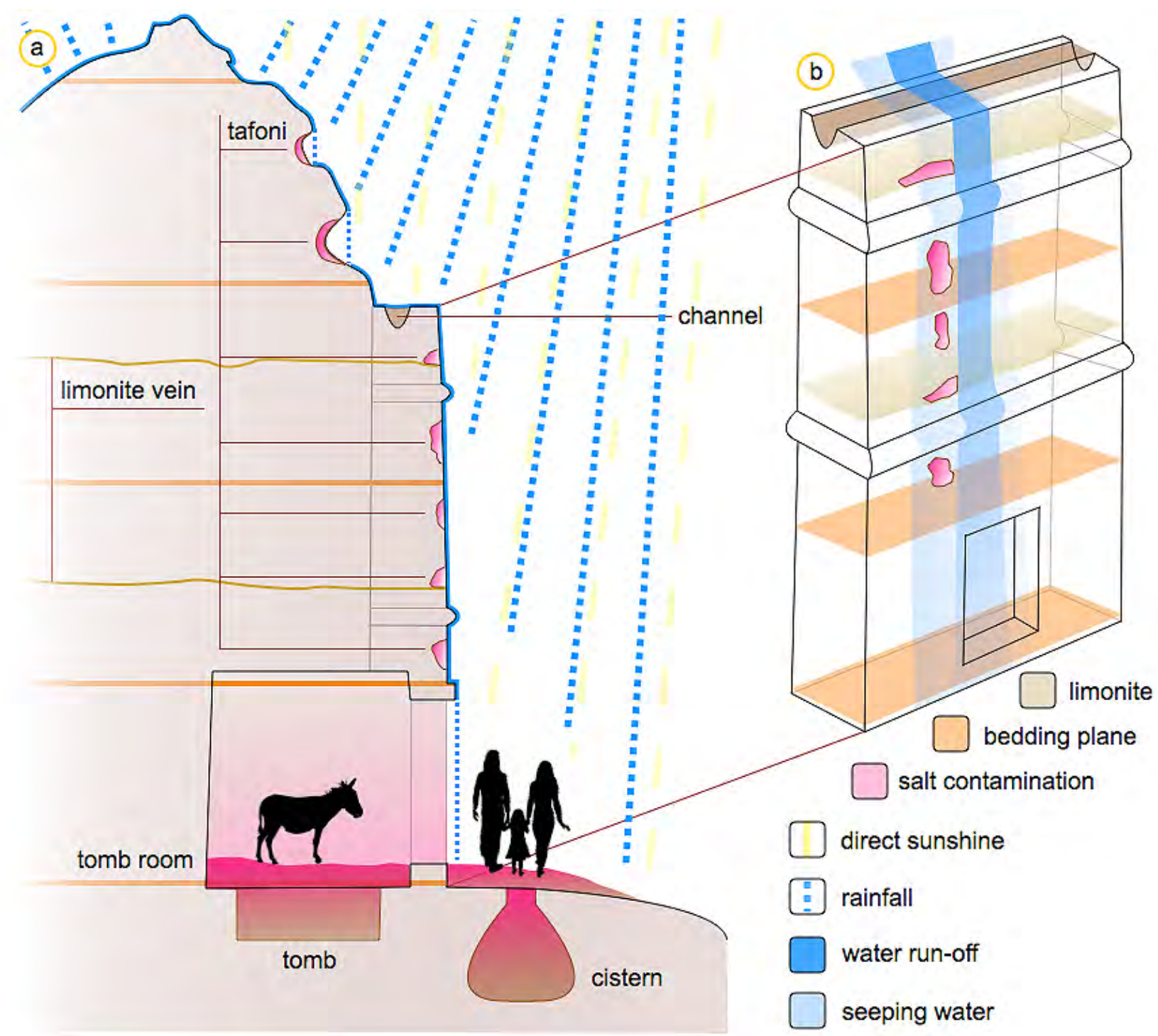

Figure 112: Weathering model of the rock cut monuments in Petra.

The investigations show that salt contamination at the rock cut facades is mainly found within the tafoni areas and at the bottom of the monuments. The source seems to be the dry and wet atmospheric precipitation (halite) and biological activity (nitrate).

\section{6. 6 Damage mapping, preliminary examinations and findings}

\section{6. 6. a) Description of tomb no. 826}

Tomb no. 826 is located along the so-called road of facades in the outer Sik (Fig. 113 a). It is one of the last tomb facades preceding the monumental tombs in the Wadi Musa, the so-called king's wall. Tomb no. 825 is on the left, which is also known as the tomb of the 14 graves (Fig. $113 \mathrm{~b}$ ). It is a Hegr type and was built during or after the construction of the water pipes in the second century. The shape of tomb no. 826 is cubic and has a double tin frieze. It is dated to the second developmental stage (IB) of the Assyrian tomb types and was built during the first half of the first century. The outer shape of the tomb looks like a vertical rectangle. It is about $20.7 \mathrm{~m}$ tall. The maximum 
width of the pedestal part is 12 meters, whereas the top part is about 9.7 meters wide. Today, the monument's actual ground level is invisible because of a one meter high coat of rubble and debris. The tomb sticks out of the nearby rock about 1-1.5 m.

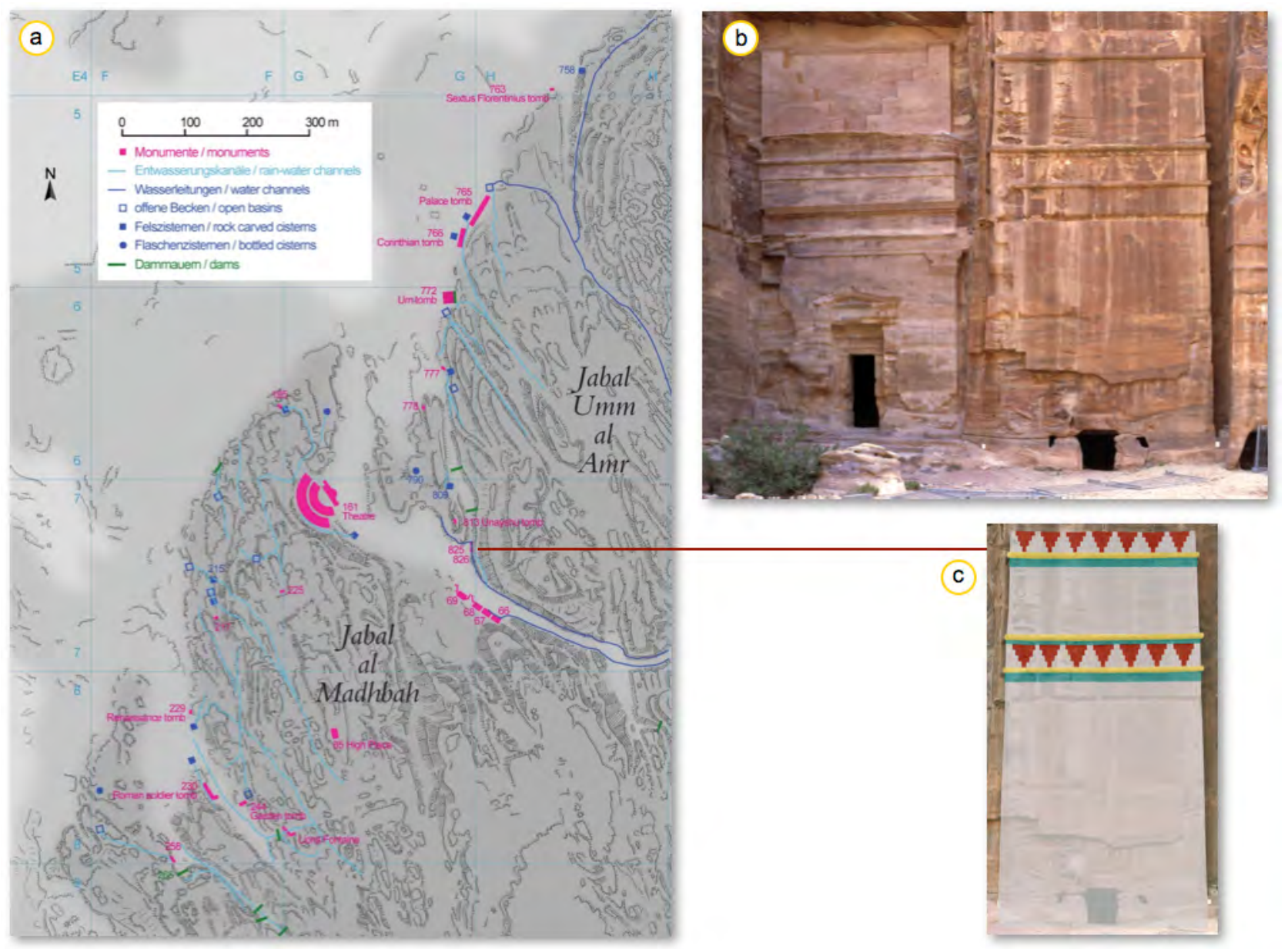

Figure 113: a) Map of the street of facades and the Wadi Farasa with important monuments and drainage systems. b) Tomb no. 285 and 286 and c) tomb no. 825 exhibiting the former decoration system.

\section{6. 6. b) Quantified mapping}

Only $76 \%$ of the original form of monument no. 826 is still preserved (Fig. 114). Two-dimensional back-weathering, the loss of tool traces as well as tafoni and alveolar weathering were distinguished. The latter had already destroyed $7.9 \%$ of the facade surface. Back-weathering caused a loss of $15.2 \%$, whereas $22 \%$ were lost due to blasts during earthquakes. The mapping has shown that the two-dimensional deterioration corresponds to the tafoni weathering observed. About $80 \%$ of the weathering phenomena can be traced back to salt weathering.

Figure 114: Damage map of monument no. 826: a) Location and conservation state of tomb no. 825 after restoration 

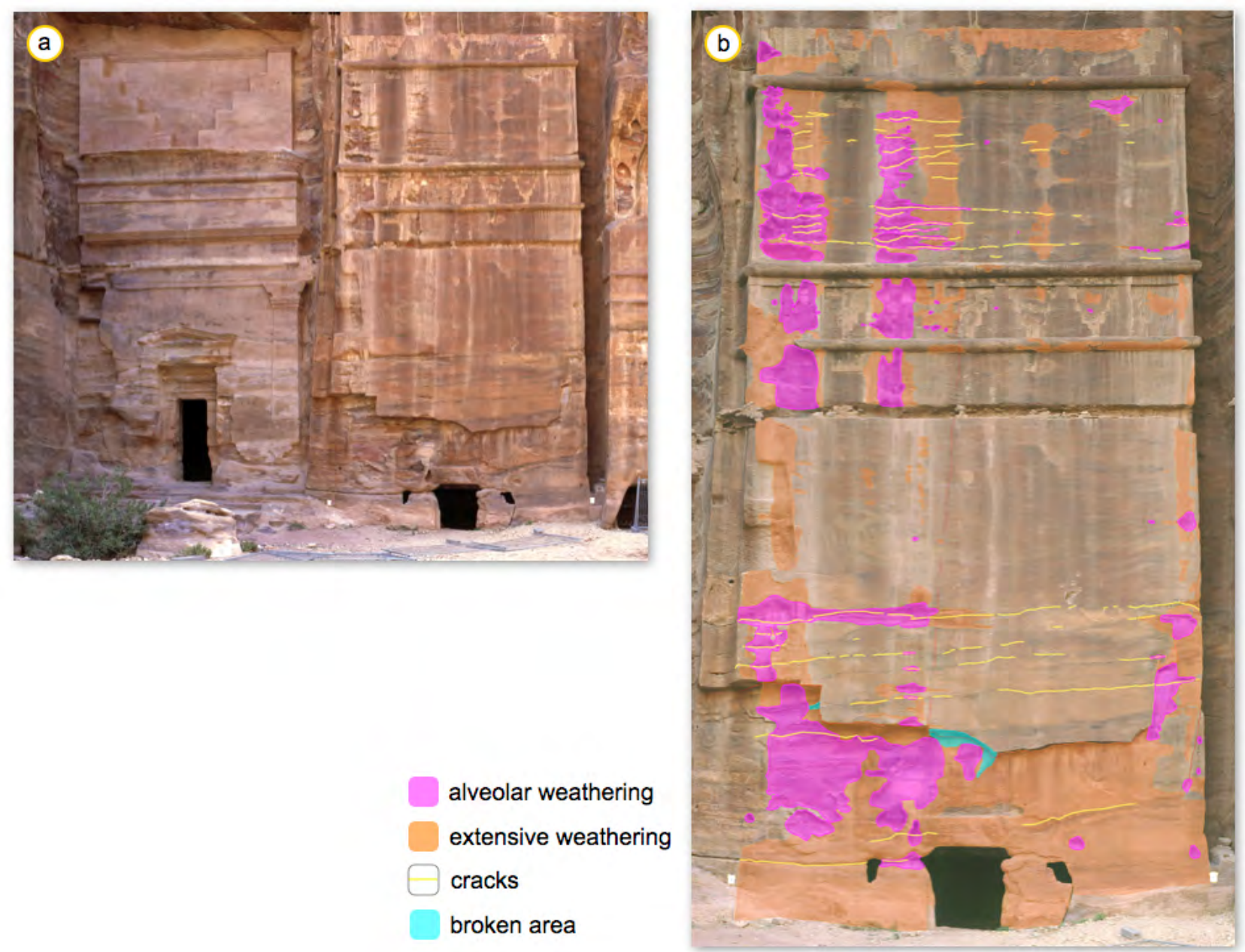

(left) and tomb no. 826 before restoration. b) Quantified mapping of monument no. 826.

All the investigated tafoni of monument no. 826 were assigned numbers. The largest damage zones of the upper half of the left part of the facade represent vertically marked damage features. They run along two parallel lines. Additional smaller areas spread over the whole facade surface.

\section{6. 6. c) Surface temperature and relative humidity}

During the cold period in 2001/2002, comprehensive climatic monitoring of the west-facing facade at tomb no. 826 has shown that the point of deliquescence for $\mathrm{NaCl}$ of $75 \%$ had been exceeded in a period of 35 days (Simon et al., 2004).

On a late summer day in September 2001 at an average temperature of $28^{\circ} \mathrm{C}$, the surface temperature of several monuments on the so-called road of facades was analyzed in connection with the relative humidity. During the afternoon sun, the temperature at facade no. 828 near tomb no. 826 reached $47{ }^{\circ} \mathrm{C}$ and dropped to $22{ }^{\circ} \mathrm{C}$ at night. The humidity varied between about $15 \%$ during the day and $30 \%$ at night.

At places that are in the shade most of the time and only about $100 \mathrm{~m}$ away from tomb no. 826, a relative humidity of $74 \%$ was measured during the early morning hours, which is close to the point 
of deliquescence. The surface temperature ranges between $21^{\circ} \mathrm{C}$ and $25^{\circ} \mathrm{C}$. The examinations illustrate that the relative humidity and the surface temperature vary strongly depending on the alignment and location of the facades. The same is true for the hydrological condition of the weathering zones. All the affected areas of monument no. 826 were dry, whereas the tafoni lines on tomb no. 74 along the road of facades stay damp all year round.

These observations indicate that there is hygroscopic moisture because of salt contamination. On the other hand, destruction results from hygric dilatation due to the cyclical change in the saline phases, which was also discovered on numerous monuments in Egypt (Abd El-Hady 2000; Pinin'ska, Attia 2003). Regarding monument no. 826, however, crystallization processes as well as hydration pressure have to be taken into account as a reason for destruction.

\section{6. 7 Laboratory examinations}

To gather more information on the characteristics of sandstone weathering at Petra, samples were taken from three different sandstone varieties where different investigations were conducted. These investigations included thermal expansion and hydric swelling and different salt resistance tests.

\section{6. 7 a) Salt bursting test experiments}

For the salt tests three sandstone types were used: a homogenous brownish-red sample (PR), a cloudy reddish sample (PL) and a closely-layered reddish purple sample (PP). The porosity of these three varieties range between 9 to $18 \%$ (Tab. 21). Surface hardness values range between 441 to 460 HLD, while the PP sandstone is the hardest one (Fig 116).

An important research question was how to evaluate the interplay of relative humidity, water, salt, and temperature with respect to weathering. The crystallization procedure based on sodium sulfate $\left(\mathrm{Na}_{2} \mathrm{SO}_{4}\right)$ was taken as a guideline for one test row. However, $99 \%$ pure sodium chloride $(\mathrm{NaCI})$ was also applied for another test row, which is equivalent to the predominant stone salt of Petra. Five sample cubes (1-5) $4 \times 4 \mathrm{~cm}$ in size were used for the crystallization tests. Two test variants were carried out.

A trial series was conducted according to the testing procedures VDI 3797 and DIN 52111. The samples were soaked in a $10 \% \mathrm{NaCl}$ solution at $20^{\circ} \mathrm{C}$. Then the samples were dried for 16 hours in a preheated $60{ }^{\circ} \mathrm{C}$ drying closet with circulating air. After the stones cooled the samples were weighed.

Another trial series used the equivalent amount of the same stone variety, with samples tested under differing conditions. After soaking them the sandstone samples were dried for 24 hours at a room temperature of $20-25^{\circ} \mathrm{C}$. 
In summary, the susceptibility of the particular stones to salt resistance varies according to the different drying conditions. The trial series that had dried under regular temperature circumstances did not show any loss of substance. Furthermore, the formation of a salt crust was limited. The absorption of the salt took place in a comparably even manner and leveled out at the level that was equal to the pore volume.

The influence of heat is a considerable determinant in connection with destruction by salt explosion. The samples dried in the drying closet developed a distinctive salt crust formation. However, they varied in shape. Evidently, the formation of a salt crust depends on the drying process. The pore volume of certain layers also seems to have an impact on the formation of salt crusts.

None of the damaged stone samples showed a loss of substance in those zones, in which the salt crust formation occurred, but rather in those areas that had been covered with the solvent during the drying process. So the loss of substance took place at the soaking stage rather than during the drying stage.

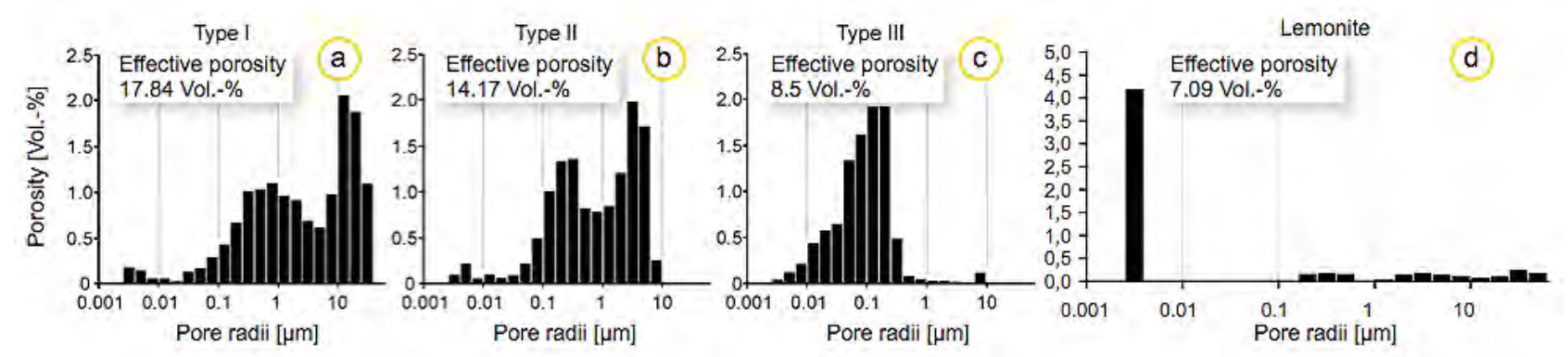

Figure 115: a-c) Pore radii distribution of the different sandstone types and d) of the limonite layers.

Table 23: Pore radii classes in percent.

\begin{tabular}{|c|c|c|c|c|c|}
\hline \multirow[t]{3}{*}{ Sample } & \multicolumn{5}{|c|}{ Pore radii distribution [\%] } \\
\hline & \multicolumn{2}{|c|}{ Micropores [m] } & \multicolumn{3}{|c|}{ Capillary pores [m] } \\
\hline & $0.001-0.01$ & $0.01-0.1$ & $0.1-1$ & $1-10$ & $>10$ \\
\hline I. PR & 0.26 & 7.14 & 28.4 & 28.5 & 35.7 \\
\hline II. PL & 0.01 & 8.33 & 41.66 & 50 & 0 \\
\hline III. PP & 6.5 & 44.44 & 44.44 & 5.5 & 0 \\
\hline IV limonite & 71.84 & 0 & 8 & 9.92 & 10.22 \\
\hline
\end{tabular}

The three varieties were also tested with $\mathrm{NaSO}_{4}$ so as to compare the results to the other stones investigated in this thesis. 


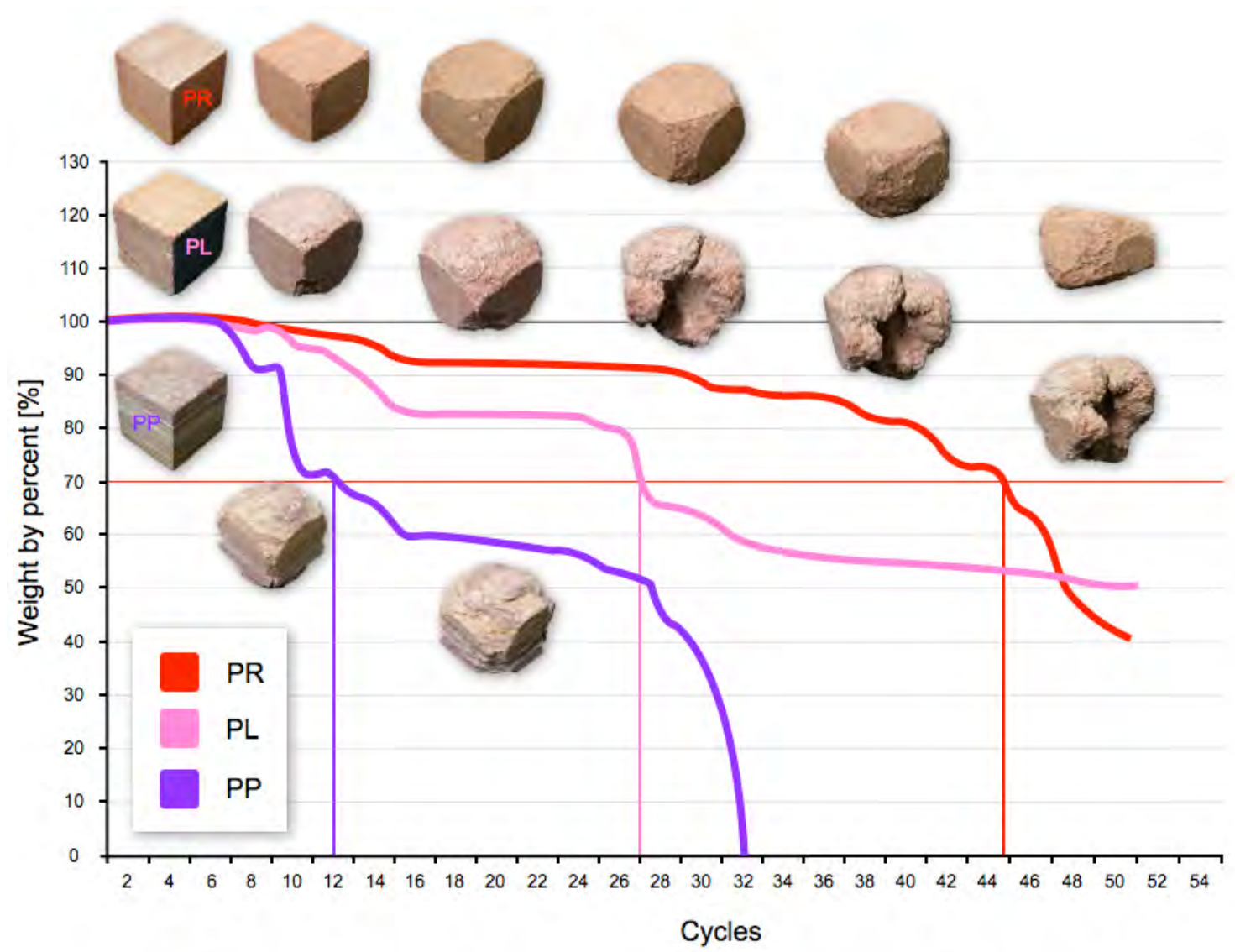

Figure 116: Salt resistance test of the Petra sandstones.

- PR, red Petra sandstone, Type I

At the beginning the red Petra sandstone shows the best salt resistance compared to the other two sandstones (Fig. 116). Weathering starts at the edges of the sample and shows a higher material loss at the bottom of the sample. This leads to the assumption that hydration of $\mathrm{NaSO}_{4}$ plays the main role in salt deterioration. The sample exhibits a continuous but slow material loss. After the 30th cycle more and more material is lost. At the $44^{\text {th }}$ cycle a $30 \%$ material loss is reached.

- PL, light red Petra sandstone, Type II

Salt weathering of the light red Petra sandstone is characterized by continuous rounding, starting with the second cycle. Rounding is a often observed weathering form in Petra (Fig. 7 a). After the $25^{\text {th }}$ cycle the sample displays cracks and parts which break away. Only a low continuous loss takes place after this cycle (Fig. 116).

- PP, purple Petra sandstone, Type III

Salt weathering of the purple variety starts at the edges of the top probably due to salt crystallization. After the $10^{\text {th }}$ cycle a lamination parallel to the bedding develops that leads to a continuous 
back-weathering as well as to a loss of single layers. When 12 cycles are reached a $30 \%$ material loss was determined (Fig. 116).

The tests show that the purple variety (Type III) exhibit the lowest salt resistance followed by the light red one (Type II). After 11 cycles a $30 \%$ material loss is reached for the PP and after the $27^{\text {th }}$ cycle for the PL. The red Petra sandstone (PR) shows the best salt resistance as compared to the other two tested sandstones. For PR after 44 cycles a material loss of $30 \%$ takes place. Over the long term the PL variety exhibits a better salt resistance than the PR sample. Both curves cross each other after the $47^{\text {th }}$ cycle (Fig. 116).

\section{6. 7 Discussion and conclusions}

The different weathering resistance of the investigated rocks may be attributed to their varying pore space distribution. Thus, mercury porosimetry (cf. Brakel et al., 1981) was performed to make a quantitative determination of the pore size distribution. The results for three of the investigated samples are shown exemplarily in Figure 115. The specimens are characterized by a widely spaced pore radii distribution. For sample Type I and II a bimodal distribution is observable, but the details of the spectrum are different. Whereas Type I has its maximum between $10.00 \mu \mathrm{m}$ and $25.12 \mu \mathrm{m}$, the majority of pores of the Type II specimen is between $2.51 \mu \mathrm{m}$ and $6.31 \mu \mathrm{m}$. In contrast, Type III shows a broadly spaced distribution of pore sizes. The maximum is between $0.10 \mu \mathrm{m}$ and $2.51 \mu \mathrm{m}$. For all investigated samples a relatively high content of smaller capillary and micropores is observable. Thus, the samples should be particularly vulnerable against salt attack (cf. Fitzner, Snethlage 1982). The bimodal distribution of Type I and II is caused by two different detrital quartz and feldspar grain sizes and a high amount of quartz cement. This may be the reason that the salt test with $\mathrm{NaCl}$ shows such a good resistance.

The good salt resistance of the red variety can also be traced back to the binding cement of the stone: hematite, observable in the thin section (Fig. $106 \mathrm{f}$ ). The results of the investigation in the socalled Roman Theater (monument no. 161) indicate that the weathering intensity of the sandstone is dependent upon the chemical composition of the matrix. Rocks showing a hematite concentration below $2.2 \mathrm{~g} / \mathrm{cm}^{3}$ in the matrix are especially prone to weathering (Paradise 2000). The lower salt resistance of the PL variation, documented by the material loss of $30 \%$ after only 27 cycles, also can be traced back to the fractured habitus of single quartz grains observed in thin sections (Fig. $106 \mathrm{j}$ ). On the other hand, the better salt resistance of the PL sample in a long term view can also be traced back to the higher surface hardness as compared to the PR variety (Tab. 21).

In contrast, the high amount of smaller pores in Type III results from a high amount of clay minerals. These clay minerals, however, do not seem to be swellable because the sample shows a very low hydric dilatation (Tab. 21). During the salt resistance test the PP (III) sample showed the most 
damage. This can be attributed to a significant amount of clay that creates micropores where salt crystallization produces damage. This hypothesis is also underlined by the hydric expansion of the sample, which generally shows low but in comparison to the other samples the highest values (Tab. 21).

The exact the same stone varieties were sent by the author for further investigations to the Getty Institute in Los Angeles. The question was how relative humidity affects salt contaminated samples of the Petra sandstone. Salt weathering tests were performed within a climate chamber (Doene et al., 2004). These samples were contaminated with $\mathrm{NaCl}$ and the dilatation measured in respect to different ranges of relative humidity $(\mathrm{RH})$. These authors assumed that: „Salt deterioration occurs as a result of subsequent phase transitions between aqueous solution and solid states, which are activated by changes of the environmental parameters. In the case of $\mathrm{NaCl}$ this transition occurs at the deliquescence point $(75.5 \%$, over a broad range independently on the temperature). Experiments performed by both ESEM and stereomicroscopy in RH controlled environment show that RH variation and speed is key factors in the kinetics of dissolution/crystallization of $\mathrm{NaCl}$. Non-equilibrium forms appear preferentially as a result of high-magnitude, high-speed RH changes. These crystal forms correspond to higher supersaturation ratio in the solution and thus to higher crystallization pressure, which may result in greater damage. The effect of other variables on crystallization kinetics such as airflow and the temperature should be further investigated. RH cycling of NaCl-laden Umm Ishrin sandstone, shows that repeated crystallization of salt inside the pore structure results in macro-scale damage similar to that observed in the field. Samples suffer loss of surface material by flaking and granular disintegration.“

In general the salt attack in Petra also seems to be influenced by wind and fast drying of the surface. Experiments by Gomez-Heras and Ford (2007) have shown that radiation, which involves rapid heating, facilitates the formation of a continuous layer of sub-efflorescences and crystallization of a salt within a porous stone. Rodrigues-Navarro et al., (1999 a) also show in experimental studies, that fast drying due to a continuous wind flow can lead to alveolar weathering. 


\section{7 Phnom Bakheng Temple Angkor / Cambodia}

\section{7. 1 Introduction}

The temples and ruins of Angkor are located amid forests and farmland to the north of the Tonle Sap and south of the Kulen Mountains, near Siem Reap City $\left(13^{\circ} 24^{\prime} \mathrm{N}, 103^{\circ} 51^{\prime} \mathrm{E}\right)$, in the Siem Reap Province of Cambodia/Asia. The site was designated as a World Cultural Heritage in 1992.

The legendary Angkor served as the seat of the Khmer Empire, which flourished from approximately the $9^{\text {th }}$ to the $15^{\text {th }}$ century and hosted the largest temples on earth. As with Technochtitlan in Mexico, it was one of the largest cities on earth during the height of their prosperity. And similar to the Aztecs of Technochtitlan on the other side of the globe, the society of the Khmer culture was also dominated by a warrior society.

The building investigated in this study is the main sanctuary of the Phnom Bakheng Temple located at $13.42418^{\circ} \mathrm{N}$ and $103.85601{ }^{\circ} \mathrm{E}$. The pyramid-like temple, located on an artificial hill with a height of $60 \mathrm{~m}$, was erected under the rulership of Yasovarman I from 889 to 910 AD. It is the first and oldest temple at Angkor.
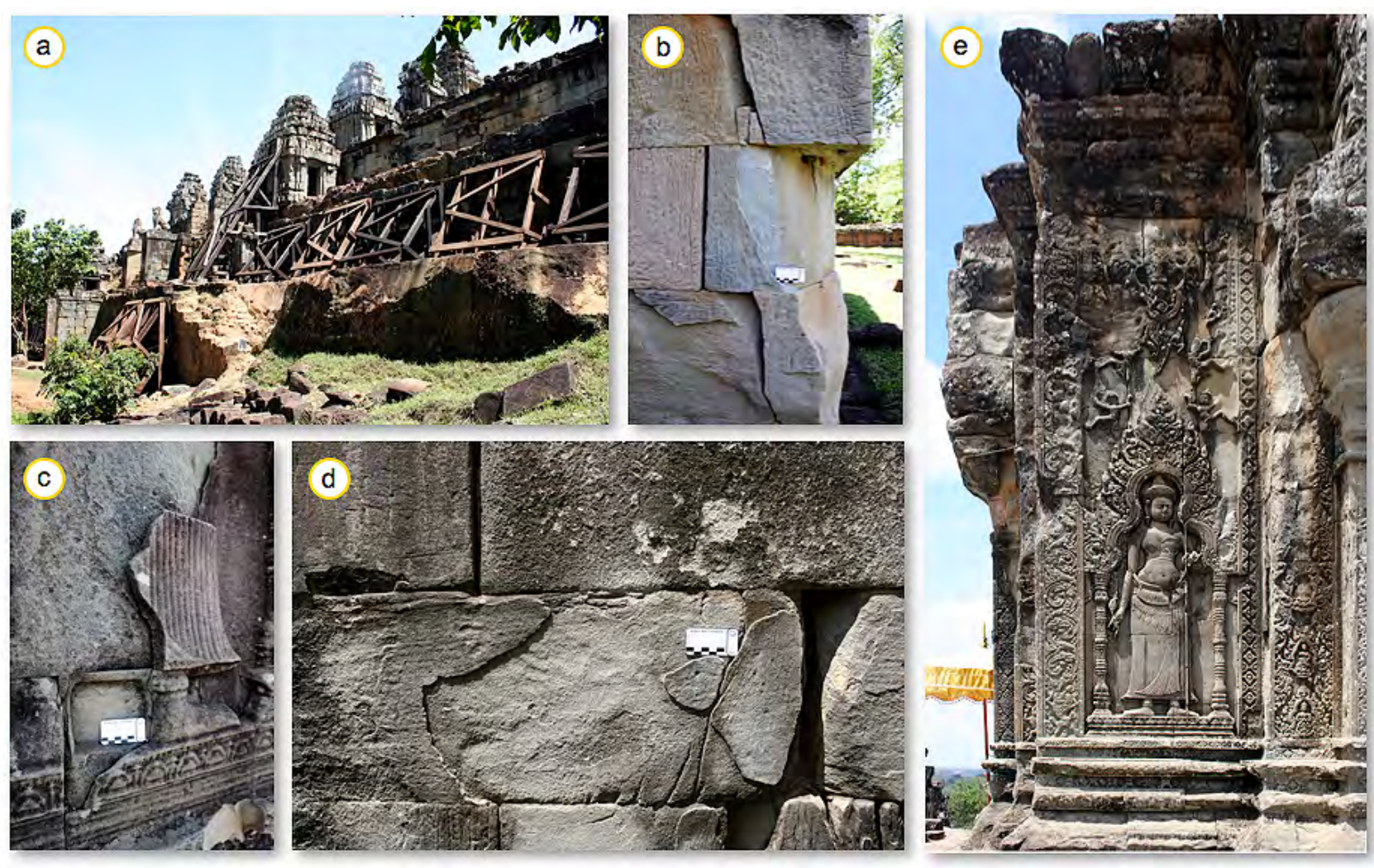

Figure 117: Damages at the Phnom Bakheng Temple: a) wooden protection constructions at the pyramid walls, b) structural cracks, c and d) contour scaling and e) back-weathering at the upper relief zone.

The temple suffers from static fractures as well as crust formation and salt weathering (Fig. 117). Since 2004, the building is being restored with the support of the World Monument Fund (WMF) in 
cooperation with the Authority for the Protection and Management of Angkor and the Region of Siem Reap (APSARA).

The temple is a symbolic representation of the home of the Hindu gods known as Mount Meru, a status emphasized by the temple's location atop a steep hill. The temple faces east, measures 76 meters square at its base and is built in a pyramid form of six tiers (Fig 124 b). At the top level, five sandstone sanctuaries stand in a quincunx pattern - one in the center and one at each corner of the level's square. Originally, 108 small towers were arrayed around the temple at ground level and on several of its tiers; most of them have collapsed (Roony 2002).

\section{7. 1. a) Climate and environmental condition}

The Angkor region is situated near two different types of climate, the tropical wet and dry climate and the tropical monsoon climate. The site has a wet tropical summer that is hot with dry, mild winters. This climate is usually found in rain forests of some tropical countries and has the classification Wa after Köppen-Geiger (1900 - 1961) (Tab. 1). The Angkor region is close to the Tonlé Sap, the biggest lake on earth in the south with the Köppen-Geiger classification of Am.

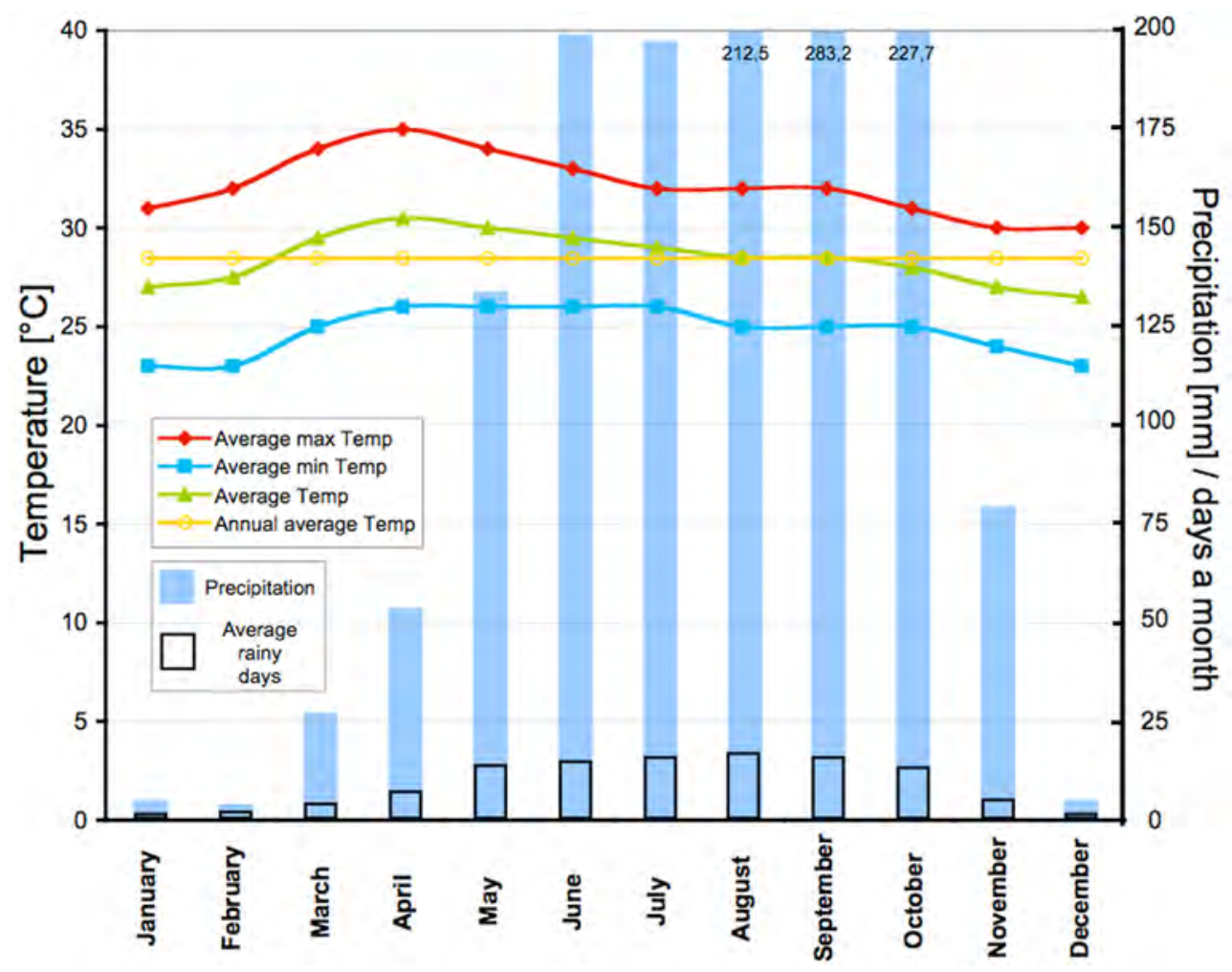

Figure 118: Climate Graph for Angkor.

The mean temperature is $28.5^{\circ} \mathrm{C}$. Average monthly temperatures vary by $7{ }^{\circ} \mathrm{C}$. In the wintertime records indicate temperatures by day reach $30{ }^{\circ} \mathrm{C}$ on average falling to $23{ }^{\circ} \mathrm{C}$ overnight. In the springtime temperatures climb to $34{ }^{\circ} \mathrm{C}$, generally in the afternoon with overnight lows of $26{ }^{\circ} \mathrm{C}$ (Fig. 118). During the summer average high temperatures are $33^{\circ} \mathrm{C}$ and average low temperatures 
are $26{ }^{\circ} \mathrm{C}$. Come autumn temperatures decrease achieving average highs of $31.5^{\circ} \mathrm{C}$ during the day and lows of $25.5^{\circ} \mathrm{C}$. Total annual precipitation averages $1425 \mathrm{~mm}$. Precipitation takes place during the rainy season starting from March and ending in November. Most of the rainfall occurs from August to October and reaches an average of $240 \mathrm{~mm}$. According to Waragai et al., (2012) the daily humidity shows a minimum of $54 \%$ in January and March during the dry season. From May to October within the rainy season a high relative humidity of $80-90 \%$ is measured. According to Holdridge (1947), Angkor is situated in or near the wet to rain forest biome in the life zone system of bioclimatic classification (Tab. 1).

\section{7. 2 Main weathering forms, quantification and weathering model}

Deterioration is clearly perceptible on crust formation and scaling as well as crack formation. In general, crust formation and contour scaling are described as the main weathering forms observable in the Angkor buildings, which are constructed from different types of graywacke (Leisen 2002; André et al., 2008; UNESCO 2012). André et al., (2008) have observed scaling with around $28 \%$ as the main weathering form in the case of the Ta Keo Temple.
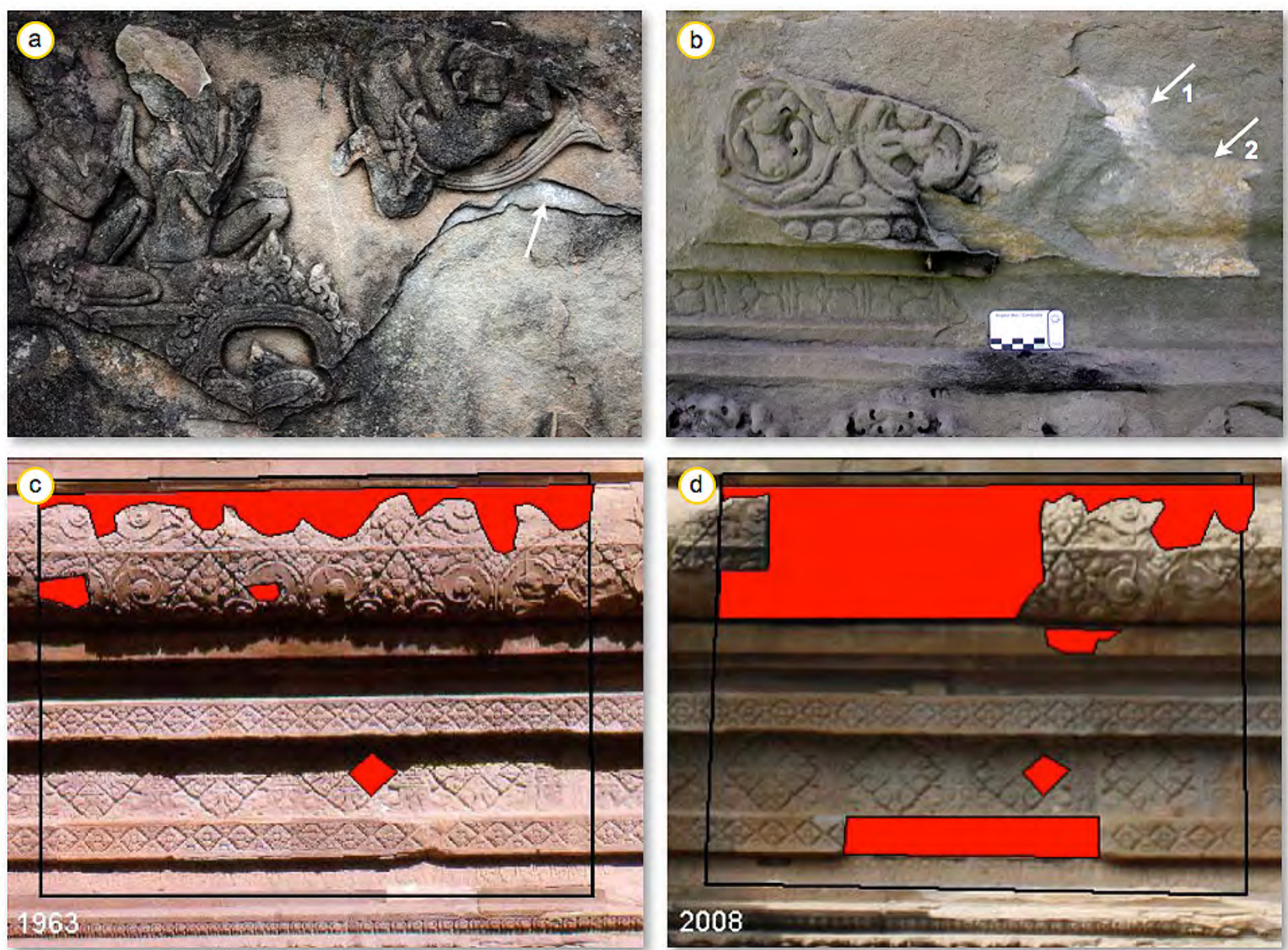

Figure 119: a) Layered contour scaling with calcite precipitation underneath a recently lost scale (arrow). b) Calcite precipitation (arrow 1) and calcite as well as iron precipitation (arrow 2) between a recently lost scale. c) Mapping of a detailed area based on a photograph from 1963 and d) in 2008 (source: Andre et al., 2012). 
Contour scaling resulting in the loss of many square meters of decorated surfaces have been photographically documented over the decades at some parts of the building in the 1960's and in the 1990's (Leisen et al., 1996; Andrè et al., 2012). André et al., (2012) presented an exemplary map of the surfaces lost (Fig. $119 \mathrm{c}$ and d). Quantitative mapping in 1963 showed an $8 \%$ surface loss. Thirty-eight years later this value reaches $25.5 \%$, which is an increase of $17.5 \%$.

Bas-relief decorations cover the entire base of the Ta Kao Temple. Moreover, it cannot be excluded that the sculpting of the decoration may have led to previous damage beneath the cutting surface of the stone at various depths. In these zones of weakness, salts as well as calcite can accumulate and crystallize, resulting in breakage in the form of contour scaling. This hypothesis appears realistic because the formation of the scales differs greatly: On bas-relief surfaces such as on the Ta Keo Temple, scales with a thickness of up to several centimeters are observable. In contrast, on smoothly worked surfaces scale thicknesses of less than one centimeter occur (Fig. $117 \mathrm{a}$ ).
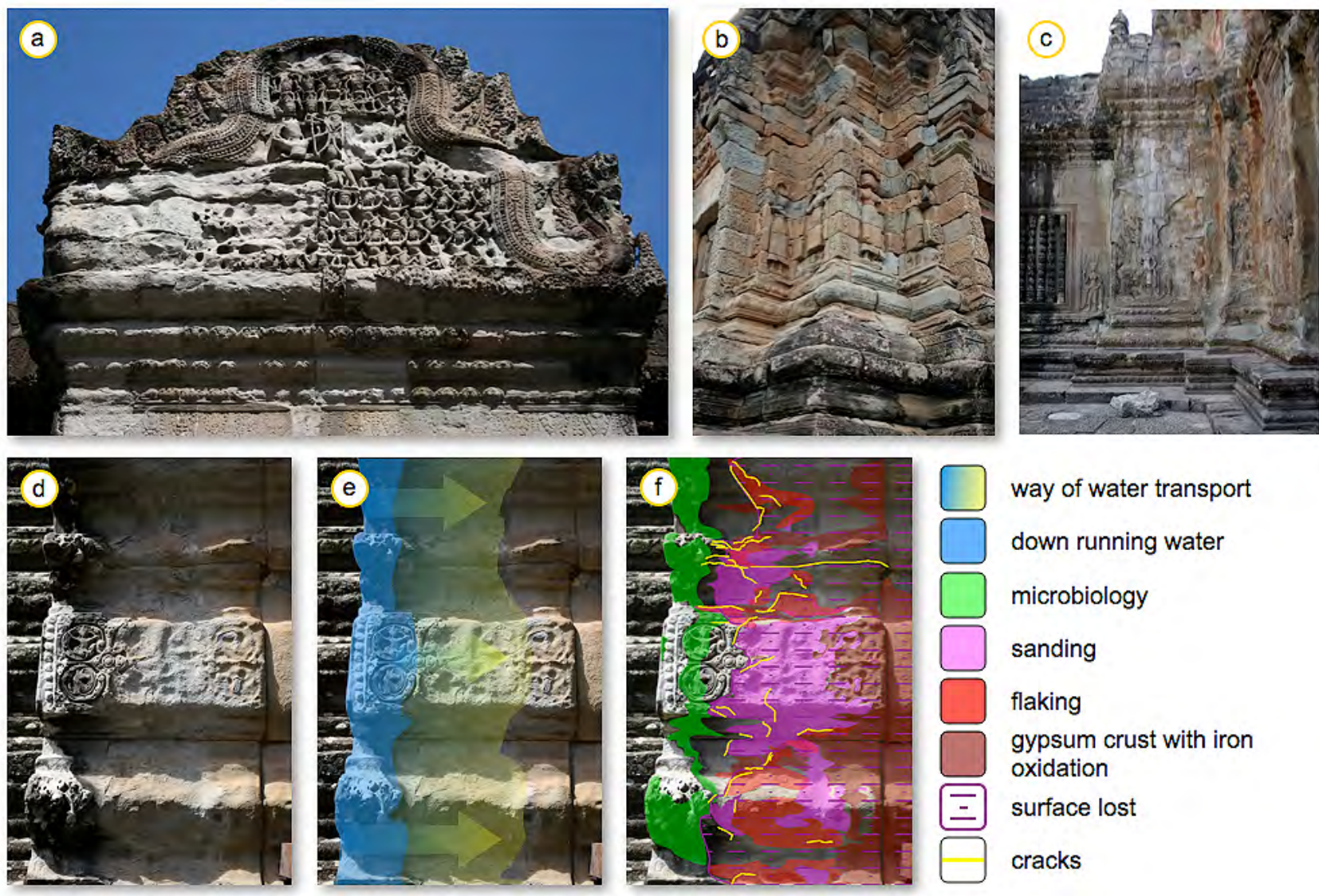

way of water transport down running water microbiology sanding flaking gypsum crust with iron oxidation surface lost cracks

Figure: 120: a) Different weathering intensities observable on different building stone varieties at the Angkor Wat Temple. b) Different weathering intensities as well as the development of an iron-rich oxidation crust by chemical weathering. c) Intense iron discolorations at the Angkor Wat Temple. d) Alveolar-like weathering at the Angkor Wat Temp-

le. e) During a rainfall, water runs down leading to infiltration and the accumulation of soluble materials nearby.

f) This leads to different weathering forms like sanding, flaking and the formation of an oxidation crust.

At the Angkor temples weathering forms are observable that are similar to those of Petra (Fig. 120 d-f). On surfaces where the rainwater runs off, the stone surface is still intact. Unlike Petra micro- 
biology accumulates on the rainwater influenced surfaces. The microbiology forms black deposits (Song et al., 2014). In adjacent areas that are not washed away by rainwater massive back-weathering is observable, probably due to the accumulation of salts (Fig. $120 \mathrm{f}$ ). However, the different qualities of the single ashlars also have to be taken into consideration. Some show a good weathering resistance, while other ones nearby exhibit heavy weathering (Fig. 120 a and b).

\section{7. 2. a) Quantified mapping}

Quantified mapping was done at the Phnom Bakheng Temple in the main sanctuarium right in the middle of the upper platform (Fig. 115 b). Five different conditions were mapped: 1) dark deposits, 2 ) areas that show a surface loss due to sanding, 3) parts that show the beginning of contour scaling, 4) broken areas and 5) restoration material (Fig. 115 b).

The quantified mapping clearly shows that the back-weathering phenomena due to sanding occupies a surface area of $20 \%$. Broken areas cover $11.5 \%$, whereas contour scaling only $1.65 \%$. Restoration material makes up $4.5 \%$ of the surface area. A closer look reveals that $70 \%$ of all contour scaling phenomena are concentrated at the base of the building and that nearly $60 \%$ of all broken areas are found in the same place.

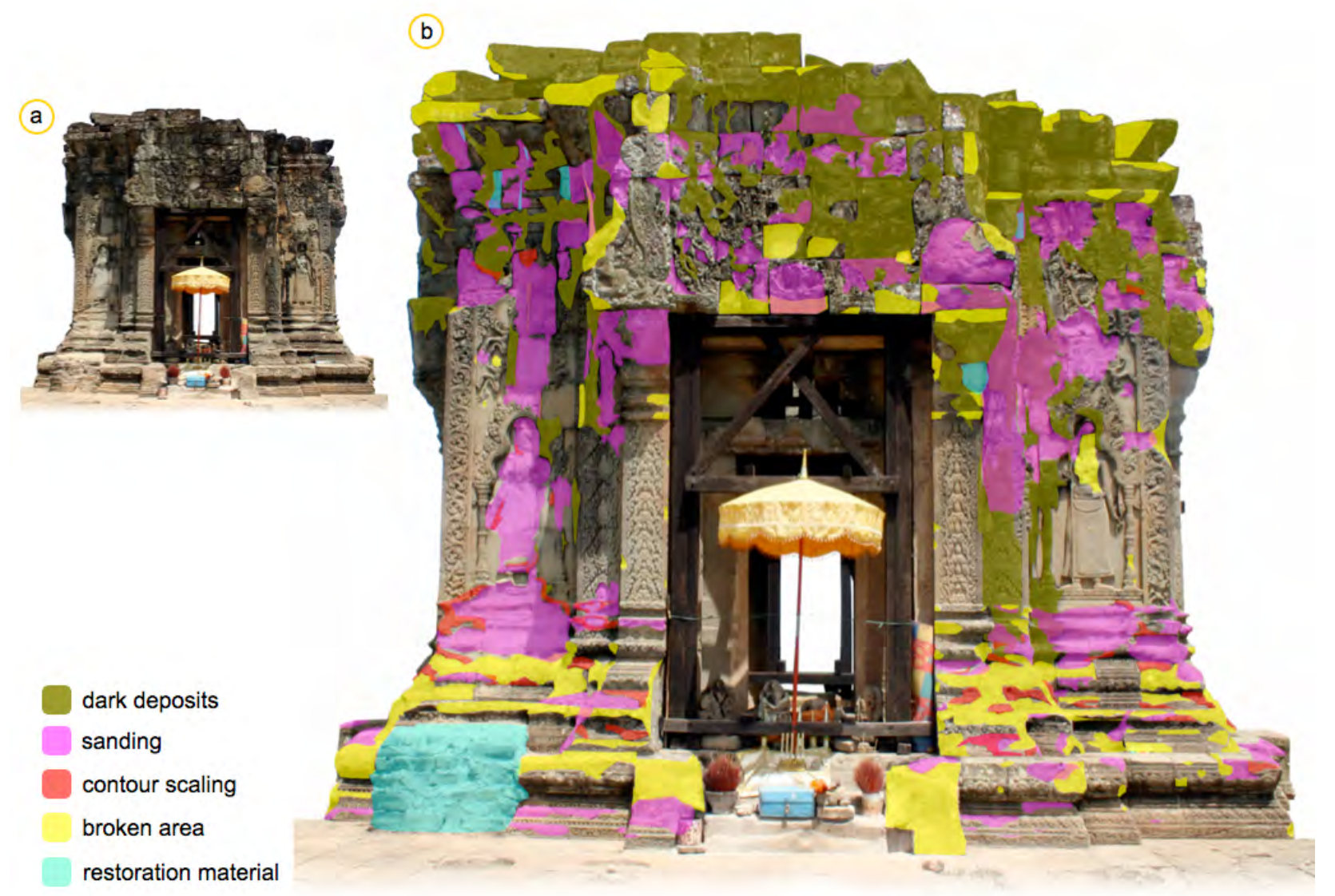

Figure 121: Quantified mapping of the south facade of the main sanctuarium of the Phnom Bakheng Temple. a) The conservation state of the facade and b) quantified mapping. 
Both phenomena seem to be linked to each other. The broken areas at the base of the building are created by weathering due to contour scaling. Another $3.85 \%$ of broken areas cover the roof area and can be traced back to mechanical reasons because more than the half of the upper building has collapsed. On the walls only $0.5 \%$ of the surface area is affected by contour scaling, but $8.9 \%$ by sanding, followed by $8.75 \%$ sanding of the roof area. Only $2.3 \%$ sanding is found at the base area. Sanding is often connected to salt weathering.

Dark deposits are found where the rainwater runs down the monument. These deposits are often close to the areas that show surface loss due to sanding and back-weathering.

\section{7. 2. b) Weathering model}

Utilizing the on-site observations and investigations, a weathering model can be developed that describes and attempts to explain the dynamics of weathering (Fig. 122). As a consequence of the decaying drainage system that was an important part of the city and its temples, the hydrological situation changed and the soil became unstable. This, as well as the growth of higher vegetation, led to the movement and partial collapse of the sandstone buildings. These buildings were constructed without the use of any mortar.

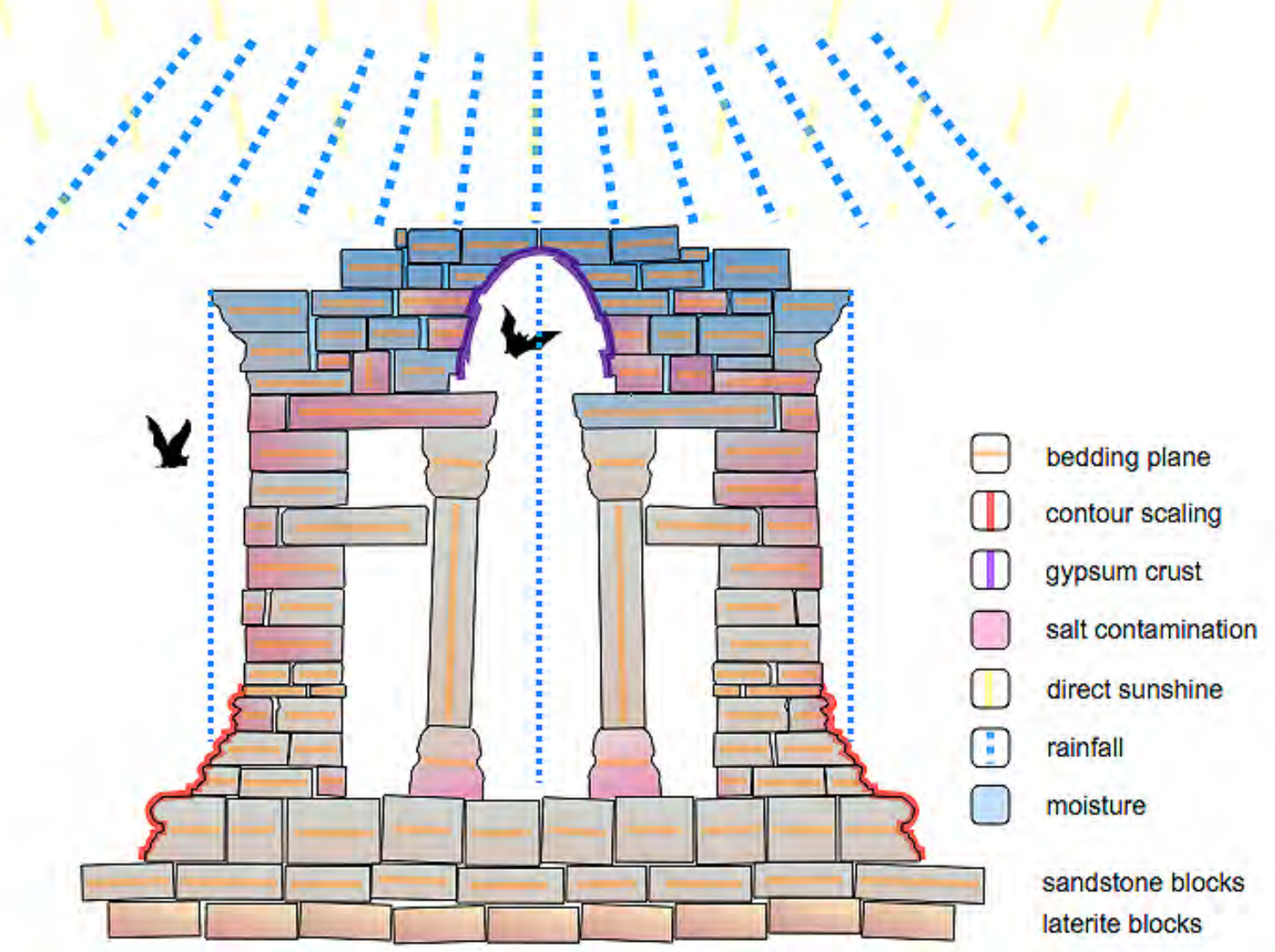

Figure 122: Cross section illustrating the weathering model of the main sanctuary at the Phnom Bakheng Temple. 
Water infiltrated through surface gaps, cracks and crevices. Within the larger gaps the bats have found a convenient roosting space. These animals are one of the main sources of salt contamination. Salt contamination and weathering is found at areas where infiltration takes place but the surface is not exposed directly to rainwater. Within the building massive gypsum crusts can also be found. Contour scaling is found all around the pedestal area that is affected by insolation.

\section{7. 3 Rock material}

The Angkor monuments in Cambodia are built mainly of sandstone, laterite and bricks. After Delvert (1963) the sandstone in the monuments can be classified into three types based on the color, texture, chemical composition and constituent minerals; gray to yellowish brown sandstone (Angkor Group), red sandstone (Banteay Srei) and greenish greywacke (Ta Keo). Most natural building stones were brought from the Kulen Mountains where different historical quarries could be identified (Carò $2009 \mathrm{a})$.
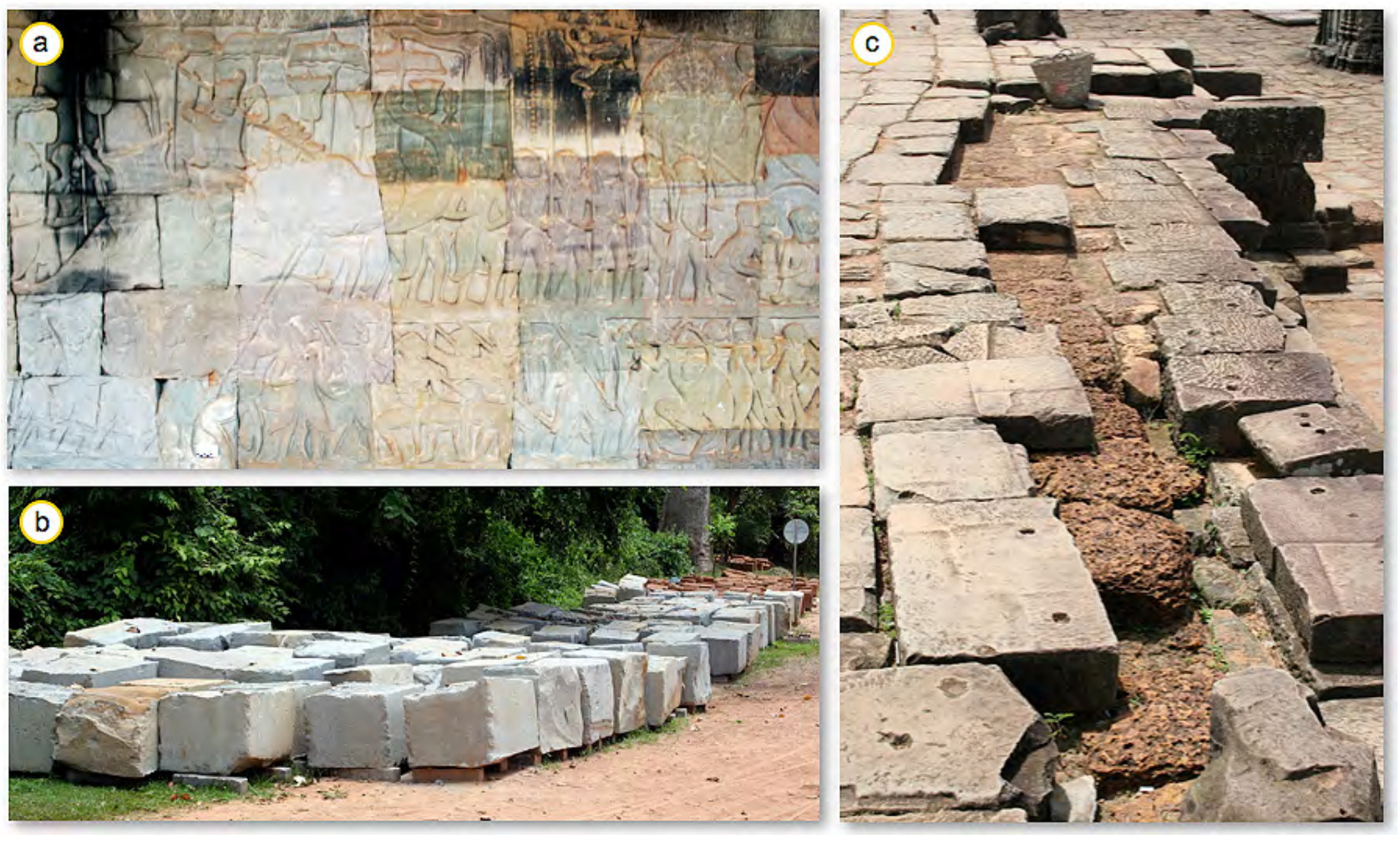

Figure 123: a) Different colored Angkor sandstones at the Bayon Temple. b) Fresh quarry material for the restoration of the Phnom Bakheng Temple. c) Laterite masonry underneath the sandstone plates of the Phnom Bakheng Temple.

The collected data of Carò (2009 b) are in agreement with other published studies (Delvert, 1963, Uchida et al., 1998; Kučera et al., 2008). They confirm the affinity between the stone used for the construction of the Angkor temples and the lithotypes exposed at the eastern foothill of Kulen Mountain, from where the stones could be easily brought by boat. 
According to the following mineralogical studies (Reucher et al., 2007), all Angkor sandstones can be defined as graywackes with a high content of feldspar after the sandstone classification of Pettijohn (1972). Graywackes are matrix-rich sandstones that are poorly sorted and derived from sediments, which were transported a relatively short distance before being deposited. The short transport and quick burial does not allow for the removal of finer material. In general, they contain chemically unstable minerals and in many cases volcanic fragments, which under tropical weathering conditions creates thick weathering profiles, depleted in base cations and rich in metal hydroxides (Mendes Guimarães 2010). Graywackes are, based on their mineralogical composition and texture, similar to the Loseros Tuff, which some authors also classify as poorly sorted sandstones (Salazar-Hernández et al., 2015).

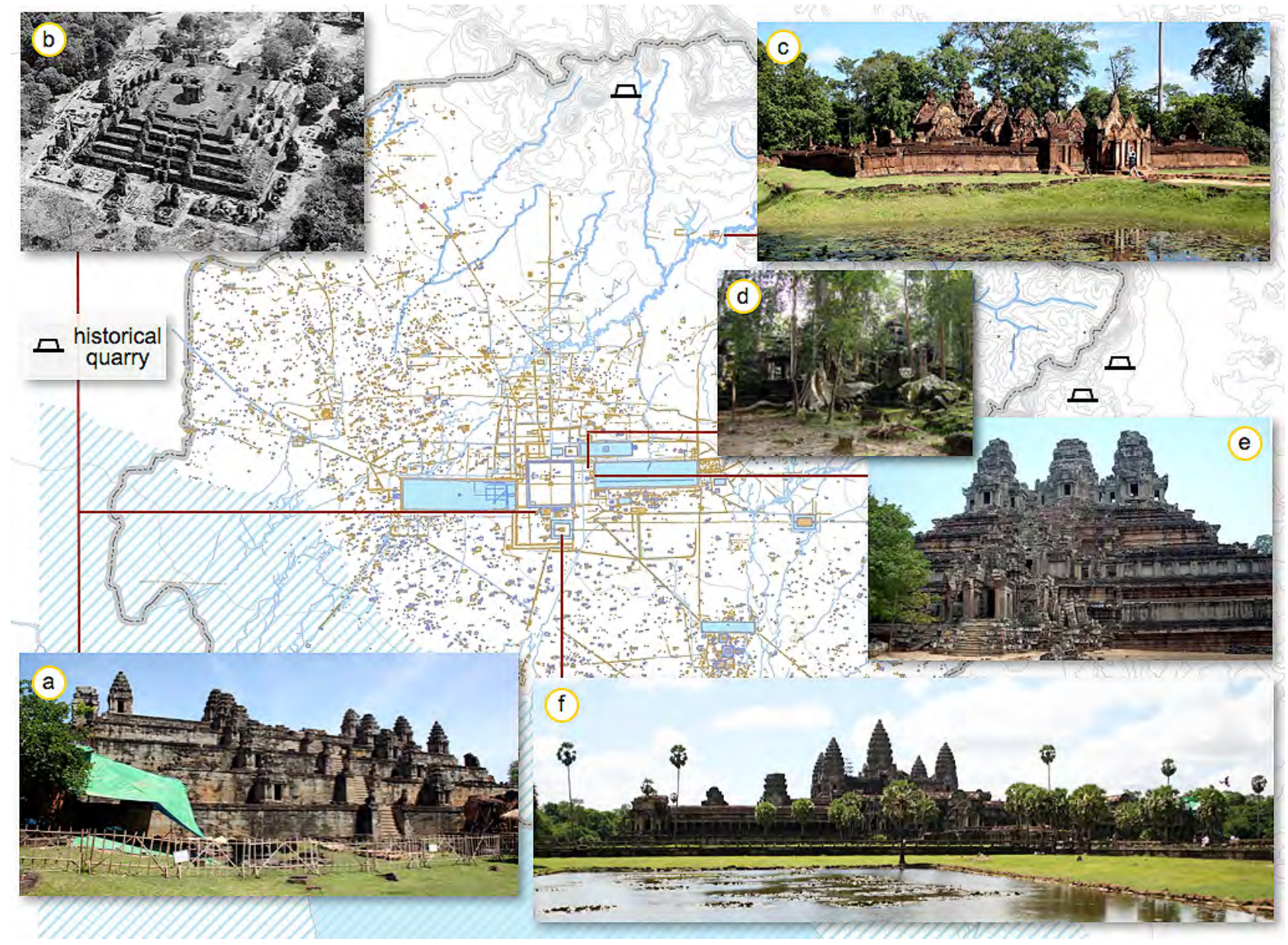

Figure 124: Schematic map illustrating the historical Angkor complex and provinces with the major elevated temples indicated (source of the map: NASA). a) The Phnom Bakheng Temple made from gray sandstone undergoing restoration in 2009. b) The temple after being cleared of trees and plants in the 1920's. c) The Banteay Srei Temple constructed from red sandstone. d) The Ta Nei Temple surrounded by trees. e) The Ta Keo Temple made from green sandstone. f) The famous Angkor Wat temple made from gray sandstone. 


\section{7. 3 a) Physical properties}

Stone properties and composition of the three sandstone types are presented in the following table:

Table 24: Physical properties and bulk chemical composition of the Angkor sandstones (after André et al., 2011, Saurin 1952; Uchida et al., 1998; Uchida et al., 1999; Kučera et al., 2008)

\begin{tabular}{|c|c|c|c|}
\hline Stone properties and composition & $\begin{array}{l}\text { Gray sandstone } \\
\text { (Angkor Group) }\end{array}$ & $\begin{array}{c}\text { Green sandstone } \\
\qquad(\mathrm{TaKeO})\end{array}$ & $\begin{array}{l}\text { Red sandstone } \\
\text { (Banteay Srei) }\end{array}$ \\
\hline \multicolumn{4}{|l|}{ Physical properties } \\
\hline Density $\left[\mathrm{g} \cdot \mathrm{cm}^{-3}\right]$ & $2-2.5$ & $2.6-2.7$ & $2.1-2.4$ \\
\hline Porosity [\%] & $7-19$ & $1.7-1.8$ & $7-15$ \\
\hline Uniaxial compressive strength [ $\mathrm{N} / \mathrm{mm} 2]$ & $15-44$ & $64-81.2$ & $43-50$ \\
\hline Schmidt rebound value & $45-54$ & 64 & 53 \\
\hline $\begin{array}{l}\text { Ultrasonic P-wave propagation velocity } \\
\text { [km s-1] }\end{array}$ & $1.9-3.2$ & 4.4 & 3.9 \\
\hline \multicolumn{4}{|l|}{ Bulk chemical composition } \\
\hline $\mathrm{SiO}_{2}$ & $66-76$ & $62-67$ & $84-90$ \\
\hline $\mathrm{Al}_{2} \mathrm{O}_{3}$ & $12-15$ & $14-21$ & $7-9$ \\
\hline $\mathrm{Fe}_{2} \mathrm{O}_{3}$ & $3-5$ & $4-8$ & $1-2$ \\
\hline $\mathrm{MgO}$ & $0.3-2.7$ & $2-2.4$ & $0.05-0.07$ \\
\hline $\mathrm{CaO}$ & $0.8-3.3$ & $3.5-3.8$ & $<0.01-0.02$ \\
\hline $\mathrm{Na}_{2} \mathrm{O}$ & $2.5-3.4$ & 2.9 & $0,01-0.02$ \\
\hline $\mathrm{K}_{2} \mathrm{O}$ & $1.7-2.4$ & $2.1-2.2$ & $0.2-0.3$ \\
\hline $\mathrm{TiO}_{2}$ & $0.4-0.8$ & 0.5 & $0.2-0.3$ \\
\hline $\mathrm{MnO}$ & $0.04-0.09$ & $0.08-0.09$ & 0.01 \\
\hline $\mathrm{P}_{2} \mathrm{O}_{5}$ & $<0.01-0.02$ & $0.1 \cdot 0.2$ & $<0.01-0.06$ \\
\hline Ig. Loss & $1.1-4.4$ & $2.0-3.2$ & $0.9-3.0$ \\
\hline
\end{tabular}

\section{7. 4 The salts of Angkor, their sources and damage potential}

At the Angkor monuments three different types of salts are found that are related to crust formation and salt weathering.

1. Calcite $\left(\mathrm{CaCO}_{3}\right)$ is most likely derived from the calcite cement in the sandstone, which creates crusts in the first few millimeters of the material as was observed by Hosono et al., (2006). Small amounts of barite $\left(\mathrm{BaSO}_{4}\right)$ and gypsum can also be found in the calcite type (Hosono et al., 2006). Similar results were also obtained by Andrew et al., 2008. 
2. Gypsum $\left(\mathrm{CaSO}_{4}\right)$ mineralizes from the calcium coming from the stone itself and the sulpher from bat guano. High gypsum contents near the surface are a crucial factor for flaking and contour scaling (Hosono et al., 2006; Siedel et al., 2008).

3. Sulfate-phosphate and nitrate deposits are also chemically connected to the bat guano (Hosono et al., 2006; Siedel et al., 2008). In most cases, the nitrates that originate from the bat guano (Hosono et al., 2006; Siedel et al., 2008) are in a dissolved state under the conditions of a high relative humidity in a tropical climate during the rainy season (Fig. 112). However, in places where the sandstone is exposed to direct insolation like at southern façade, where high surface temperatures occur over a long period, nitrates will precipitate out and also contribute to damaging the stone (Siedel et al. 2008).

\section{7. 5 Investigations and sample material}

The investigations in this thesis will focus on the weathering forms observed in the gray sandstone, the greenish graywacke type used for the Phnom Bakheng Temple as well as for the Angkor Wat Temple. These sandstone samples belong to the Angkor Group. They include the original building stone for the Phnom Bakheng Temple (PB), the weathering crust as well as the material that is now used for restoration $(\mathrm{PBr})$ shown in Figure 125. Furthermore, investigations on stone material belonging to red sandstones similar to the ones of Banteay Srei (AR) and to the laterite (AL) are also presented (Fig. 125).
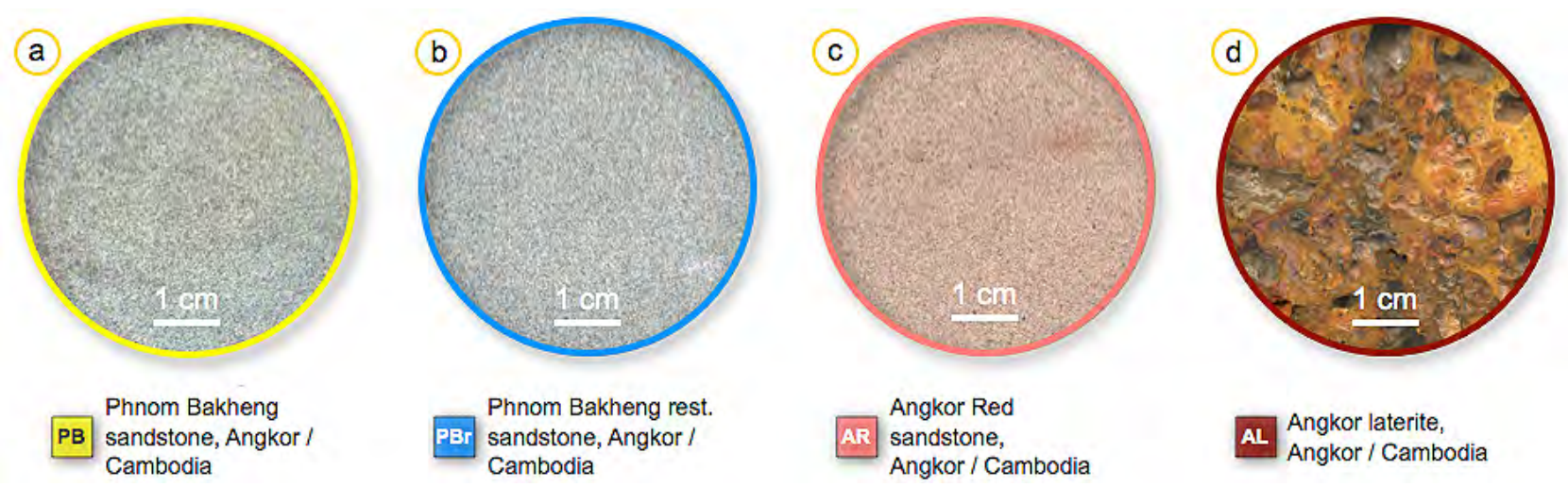

Figure 125: a) The building stone of the Phnom Bakheng Temple, b) the restoration material, c) the red Angkor sandstone and d) the laterite.

All stone types can be described as fine-grained porous sandstones, with the exception of the laterite (AL). Recent petrographic investigations (Reucher et al., 2007) have shown that the building sandstones are feldspathic graywackes in the sense of Pettijohn et al., (1987).

The sample material acquired in this study originates from the restoration team of the Phnom Bakheng Temple in 2009. The red sandstone was bought from the stone mason workshop of Artisans Angkor in Siam Reap. 


\section{7. 5. a) The laterites}

Laterites were quarried in place. They are porous and pisolitic laterites that can be classified into 5 groups (see Uschida et al., 1999 b). The laterite investigated in this study is characterized by a microcrystalline and partly amorphous iron-rich matrix (Fig. $126 \mathrm{~d}$ ) and contains single quartz grains (Fig. 126 c). These grains show intensive alteration and fractures (Fig. $126 \mathrm{f}$ ). The color of the matrix changes between yellow to dark red (Fig. 125 d, 126 a and c). Dark red accumulations (Fig. 126 b) show drying cracks where secondary cristallized quartz can be found (Fig 126 e).
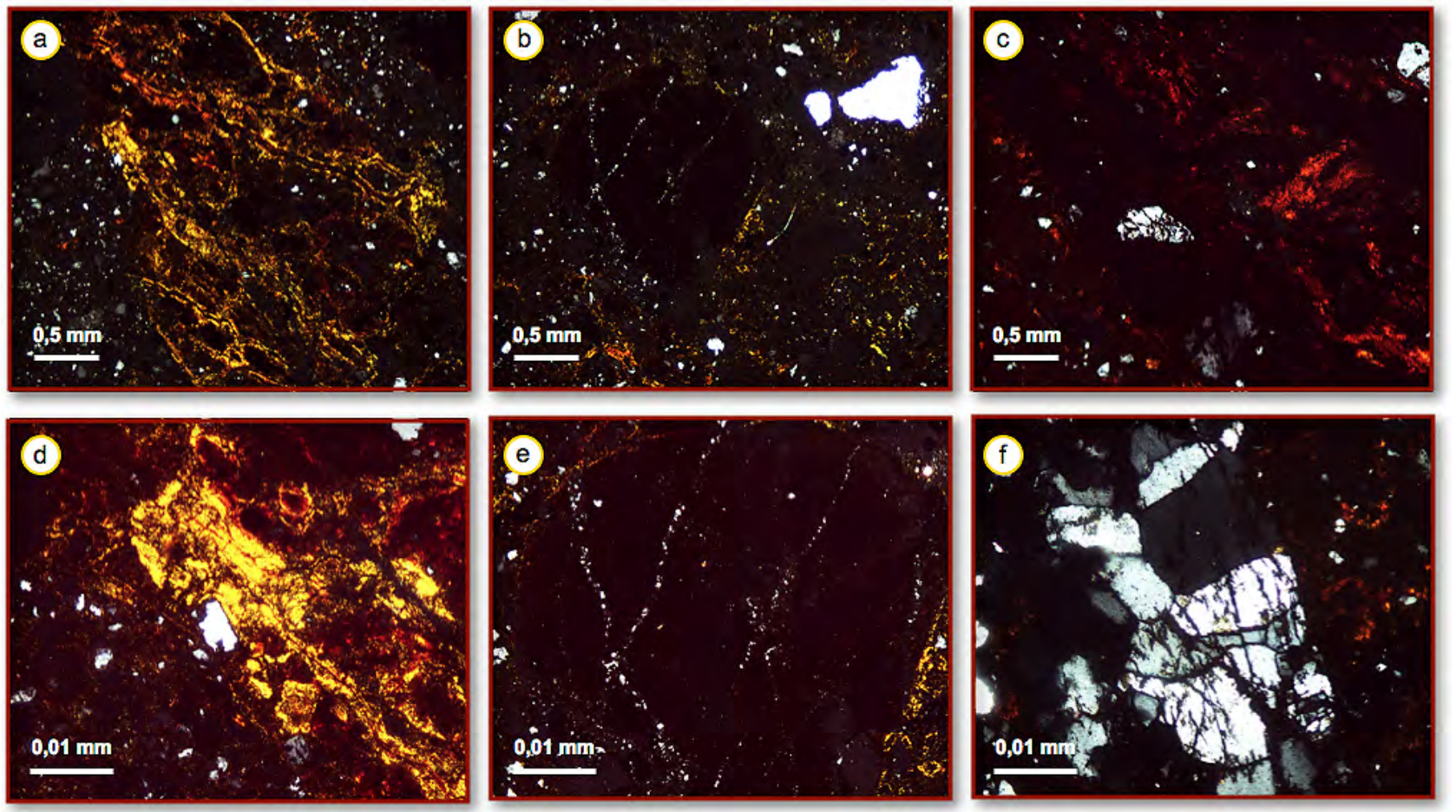

Figure 126: a) Yellow amorphous structures and b) red accumulation and single quartz grains within a microcrystalline matrix. c) Single quartz grains within a reddish amorphous matrix. d) The yellow amorphous structure show flow structures. e) Within drying cracks small quartz grains are visible. f) Bigger quartz grains shows alteration.

\section{7. 5. b) The sandstones}

The sandstones can be characterized as medium porous sandstone types with a porosity ranging between $11.5 \%$ und $17.6 \%$ (Tab. 26). The porosity of the laterite with $33 \%$ is much higher. The pore radii distribution is dominated by macropores between $1-100 \mu \mathrm{m}$ (Tab. 25). Microporosity is less than $10 \%$. The main pore space properties of the sandstones are listed in table 25 .

The sandstone samples can be characterized by their different water absorption properties, (e. g. as a result of the layering and binding cement). The water absorption value is low and ranges from 0.4 to $0.8 \mathrm{~kg} /\left(\mathrm{m}^{2} \cdot \sqrt{ } \mathrm{h}\right)$ with an anisotropy of $9 \%$ to $30 \%$ (Tab. 26). The directional anisotropy of ultrasonic wavelengths is higher and reaches values of $10 \%$ to $43 \%$ (Tab. 26). 
Table 25: Pore radii distribution of the investigated stones of Angkor

\begin{tabular}{lccccc}
\multicolumn{1}{c}{ Sample } & \multicolumn{5}{c}{ Pore radii distribution [\%] } \\
& $\begin{array}{c}0.001-0.01 \\
{[\mu \mathrm{m}]}\end{array}$ & $\begin{array}{c}0.01-0.1 \\
{[\mu \mathrm{m}]}\end{array}$ & $\begin{array}{c}0.1-1 \\
{[\mu \mathrm{m}]}\end{array}$ & $\begin{array}{c}1-10 \\
{[\mu \mathrm{m}]}\end{array}$ & $\begin{array}{c}10-100 \\
{[\mu \mathrm{m}]}\end{array}$ \\
\hline PB, Phnom Bakheng & 44.02 & 39.37 & 10.92 & 14.54 & 1.75 \\
Crust, Phnom Bakheng & 0 & 0 & 23.39 & 56.4 & 20.21 \\
PBr. Phnom Pakheng rest. & 0 & 0 & 83.53 & 11.3 & 5.37 \\
AR, Angkor Red & 2.66 & 2.86 & 2.09 & 5.74 & 89.10 \\
AL, Angkor laterite & 5.36 & 26.41 & 41.8 & 26.43 & 0 \\
\hline
\end{tabular}

In general, the ultrasonic velocity of all Angkor samples range between $2.8 \mathrm{~km} / \mathrm{s}$ and $3.8 \mathrm{~km} / \mathrm{s}$, which are the highest values for all sandstones investigated in this thesis. The same also applies for the surface hardness that ranges from 509 to 568 (HLD), while showing significant values of reduction from around 10 to $20 \%$ under wet conditions (Tab. 26). Hygric dilatation of the different samples from the Phnom Bakheng Temple is high reaching nearly $2 \mathrm{~mm} / \mathrm{m}$ (Tab 26). Moisture expansion of the fresh quarry material is comparably low, with values ranging between 0.2 to $0.4 \mathrm{~mm} / \mathrm{m}$. The thermal expansion measured at $60{ }^{\circ} \mathrm{C}$ ranges between $1 \mathrm{~mm} / \mathrm{m}$ and $-0.2 \mathrm{~mm} / \mathrm{m}$ with very high anisotropies (Tab. 26). The highest values could be measured in the case of the PB sample $(1 \mathrm{~mm} /$ $\mathrm{m})$, however the highest anisotropy was measured in the weathered crust, probably due to the presence of calcite (Tab. 26).

Table 26: Pore space properties, moisture transport, and mechanical properties of the investigated stones and samples

\begin{tabular}{|c|c|c|c|c|c|}
\hline Stone type & $\begin{array}{l}\text { PB, Phnom } \\
\text { Bakheng }\end{array}$ & $\begin{array}{l}\text { Crust Phnom } \\
\text { Bakheng }\end{array}$ & $\begin{array}{c}\text { Pbr. Phnom } \\
\text { Bakheng Rest. }\end{array}$ & $\begin{array}{l}\mathrm{AR}, \text { Angkor } \\
\text { red } \\
\text { sandstone }\end{array}$ & $\begin{array}{l}\mathrm{AL}, \\
\text { laterite }\end{array}$ \\
\hline Effective porosity [Vol.-\%] & 12.3 & 17,6 & 11.5 & 17.63 & 33.4 \\
\hline Particle density $\left[\mathrm{g} \cdot \mathrm{cm}^{-3}\right]$ & 2.43 & 2,22 & 2.37 & 2.18 & 2.11 \\
\hline Bulk density $\left[\mathrm{g} \cdot \mathrm{cm}^{-3}\right]$ & 2.67 & 2,69 & 2.68 & 2.65 & 3.17 \\
\hline Average pore radius $[\mu \mathrm{m}]$ & 0.021 & 2.858 & 0.442 & 0.227 & 0.023 \\
\hline Micropore porosity [\%] & 83.39 & 0 & 0 & 5.52 & 31.77 \\
\hline \multicolumn{6}{|l|}{$\mathrm{w}$ value $\left[\mathrm{kg} / \mathrm{m}^{2} \sqrt{ } \mathrm{h}\right]$} \\
\hline$x$ & 0.636 & - & 0.784 & 0.672 & 1.284 \\
\hline$Y$ & 0.642 & - & 0.872 & 0.676 & 1,27 \\
\hline$z$ & 0.466 & - & 0.758 & 0.532 & 1.284 \\
\hline Average $\varnothing$ & 0.580 & - & 0.796 & 0.626 & 1.278 \\
\hline Anisotropy [\%] & 27.4 & - & 8.7 & 30 & 1 \\
\hline
\end{tabular}

Ultrasonic velocity dry $[\mathrm{km} / \mathrm{s}]$ 


\begin{tabular}{|c|c|c|c|c|c|}
\hline$x$ & 3.315 & - & 2.529 & 3.078 & 3.734 \\
\hline$Y$ & 2.252 & - & 2.212 & 3.155 & 3.744 \\
\hline$z$ & 1.894 & - & 2.632 & 2.834 & 3.854 \\
\hline Average $\varnothing$ & 2.153 & - & 2.457 & 3.022 & 3.777 \\
\hline Anisotropy [\%] & 42.8 & - & 16 & 10 & 3 \\
\hline Ultrasonic velocity wet [km/s] & & - & & & \\
\hline$x$ & 2.778 & - & 3.086 & 3.879 & \\
\hline$Y$ & 2.945 & - & 3.257 & 3.939 & - \\
\hline$z$ & 2.717 & - & 3.247 & 3.665 & \\
\hline Average $\varnothing$ & 2.813 & - & 3.196 & 3.827 & \\
\hline Anisotropy [\%] & 26 & - & 5.2 & 5.5 & \\
\hline Surface hardness [HLD] dry & 568 & - & 517 & 509 & 231 \\
\hline Surface hardness [HLD] wet & 455 & - & 422 & 462 & 207 \\
\hline Surface hardness reduction [\%] & 19.9 & - & 18.3 & 9.2 & 10.3 \\
\hline \multicolumn{6}{|l|}{ Hydric dilatation } \\
\hline$x$ & 1.18 & 0.961 & 0.176 & 0.021 & 0.235 \\
\hline$Y$ & 1.15 & 0.961 & 0.175 & 0.019 & 0.227 \\
\hline$z$ & 1.988 & 1.55 & 0.384 & 0.024 & 0.231 \\
\hline Average $\varnothing$ & 1.43 & 1.15 & 0.245 & 0.021 & 0.231 \\
\hline Anisotropy [\%] & 42.8 & 16.4 & 28.6 & 9 & 3.4 \\
\hline \multicolumn{6}{|l|}{ Thermal expansion $\left[\mathrm{mm} / \mathrm{m}, 60^{\circ} \mathrm{C}\right]$} \\
\hline$x$ & \multirow{2}{*}{-0.201} & \multirow{2}{*}{1.036} & \multirow{2}{*}{0.227} & 0.912 & 0.336 \\
\hline$Y$ & & & & 0.922 & 0.338 \\
\hline$z$ & 0.048 & 0.049 & 0.142 & 1.33 & 0.338 \\
\hline Average $\varnothing$ & 0.85 & -0.118 & 0.158 & 1.05 & 0.337 \\
\hline Anisotropy [\%] & 53.6 & 95 & 15 & 31.4 & 0.6 \\
\hline
\end{tabular}

\section{7. 5. c) Cathodoluminescence microscopy}

Cathodoluminescence microscopy (CL) was done on thin sections of the sandstone varieties to delineate alteration processes, the microstructures present and to determine what the differences are between the unaltered and altered building stones. Both sandstone varieties show evidence of alteration in minerals such as feldspar (Fig. 120 a and d). The CL investigations clearly show the presence of calcite within the stone. Only a small amount of calcite, averaged around $2 \%$ occurs in the PB variety (Tab. 24, Fig. 120 c), whereas the PBr variety has a calcite content of more than $7 \%$ as is clearly visible by the orange CL color (Fig $121 \mathrm{f}$ ). 

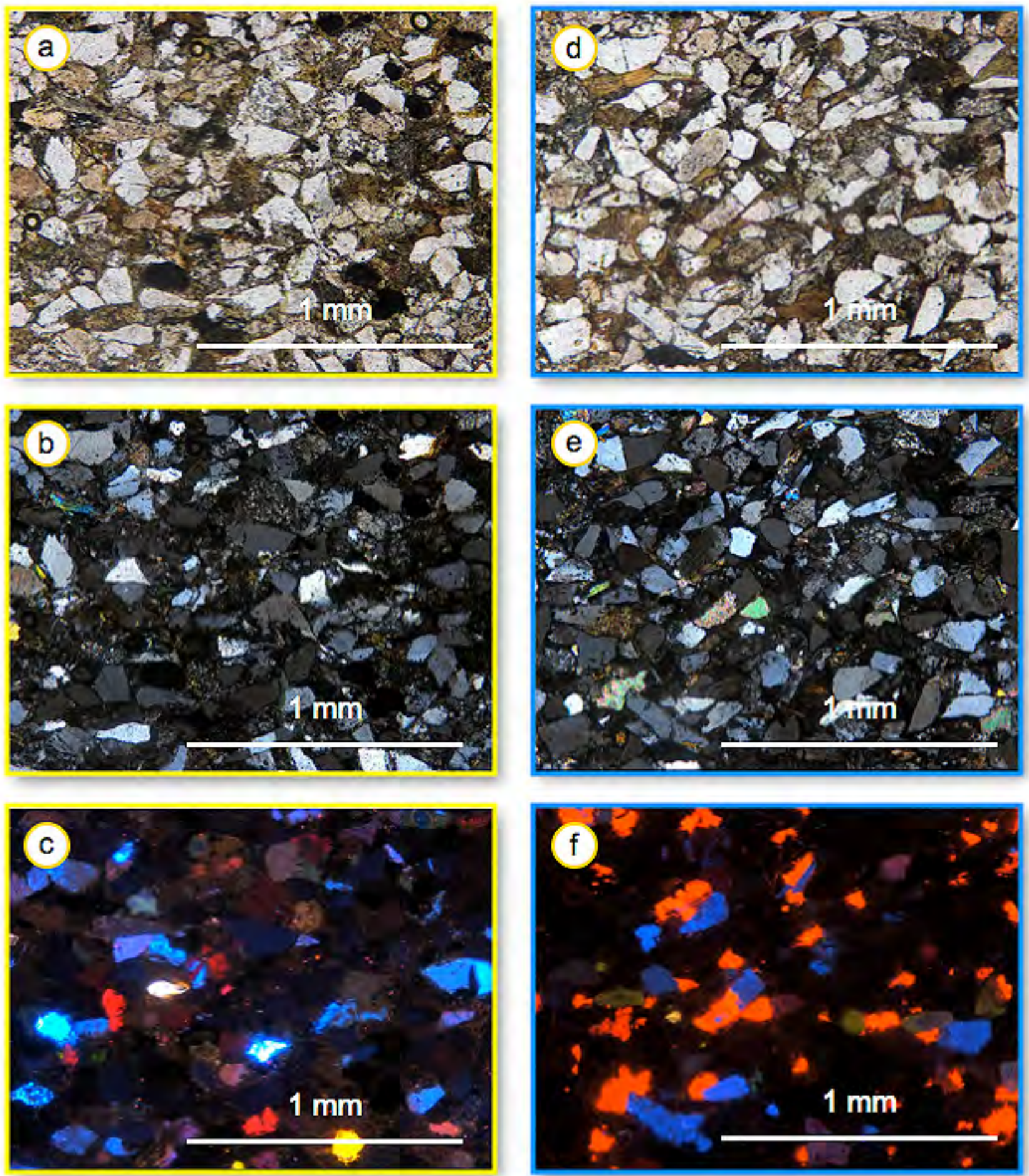

Figure 127: a - c) Thin section of the Phnom Bakheng sandstone (PB) and $d-f$ ) of the restoration material (PBr.). a) and d) Samples under transmitted light. b) and e) Samples under polarized light and c) and f) under cathodoluminescence.

Alteration is also evident in the weathering crust (Fig. 122 a). More calcite is observable in the crust of the Phnom Bakheng Temple than in the PB sample (Fig. 122 b). A closer look shows that calcite precipitated along grain boundaries and microcrack formations (Fig. $122 \mathrm{c}$ ). 

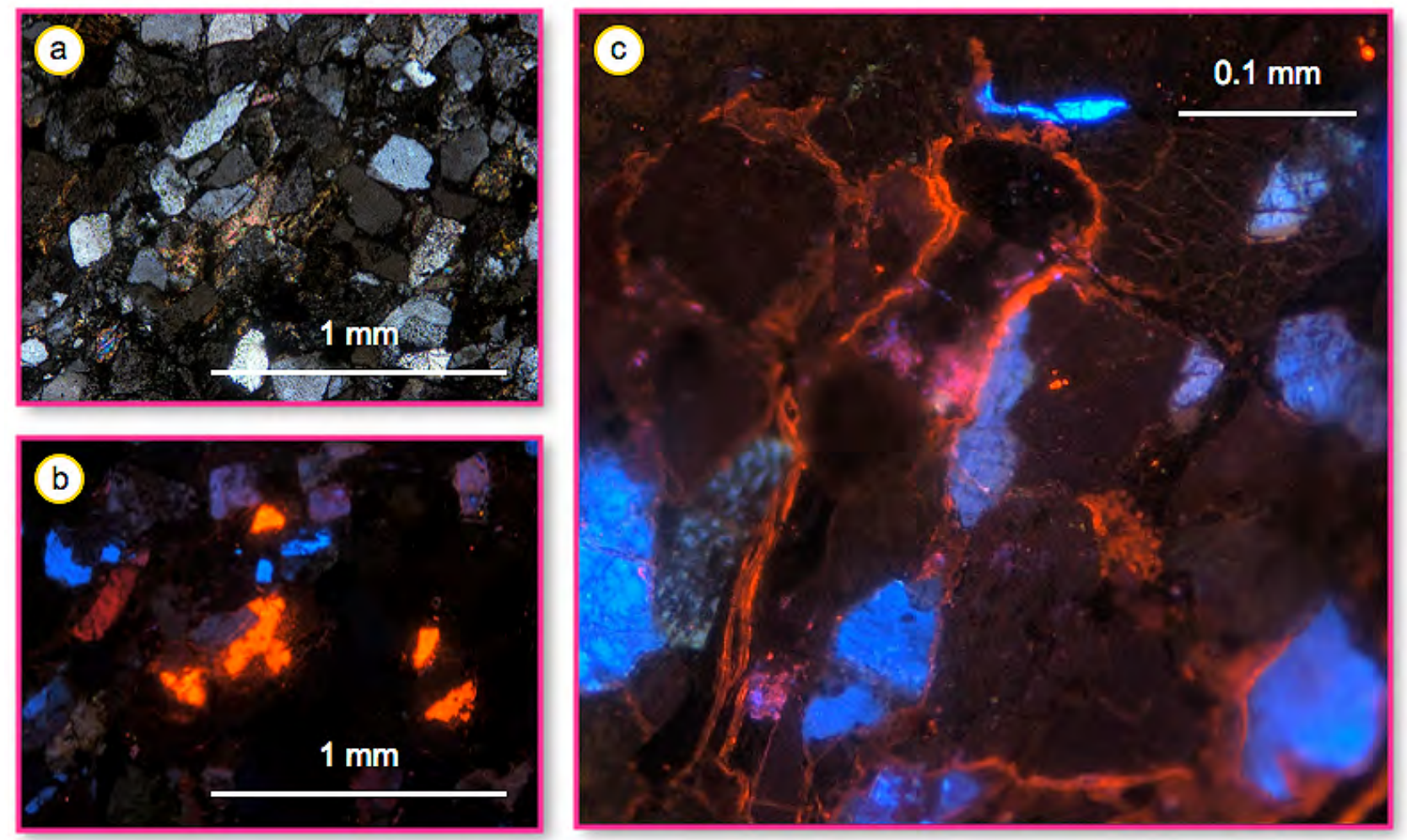

Figure 128: a) - c) Thin section of the weathering crust from the Phnom Bakheng sandstone. a) Samples under transmitted light. b) Sample under cathodoluminescence. c) Detail of the sample under CL showing the finely precipitated calcite within cracks and along the grain boundaries between grains of quartz (very low luminescence) and feldspar (blue).

\section{7. 5. d) Salt resistance test}

Salt resistance tests were performed on all three Angkor sandstones (Fig. 129). A $10 \%$ solution of $\mathrm{NaSO}_{4}$ was used to contaminate the stone.

- PB, Phnom Bakheng sandstone

During the first ten cycles only a small amount of material loss takes place at the bottom of the sample. The sample color changes from gray to brown-yellow (Fig. 129). After the $12^{\text {th }}$ cycle serious cracks are visible. These cracks lead to massive contour scaling and a total loss of the sample. Material loss amounts to $30 \%$ with the $12^{\text {th }}$ cycle.

- PBr., Phnom Bakheng restoration material

Salt weathering of the PBr sandstone is characterized by a similar behavior as with the PB sandstone. A color change also takes place but in this case from a grayish to greenish color (Fig. 129). Cracks start to develop at the $13^{\text {th }}$ cycle parallel to the bedding, but with the formation of contour scaling. This leads to a total loss of the sample.

- AR., Angkor red sandstone 
Only minimal weathering takes place in the AR sandstone. Blackening is observable, which is similar to the other two sandstone types (Fig. 129). One difference is that continuous sanding takes place all around the sample. A massive crack occurs at the top of the sample at the $25^{\text {th }}$ cycle, probably due to the visible salt crystallization. During the following cycles these cracks lead to massive contour scaling.

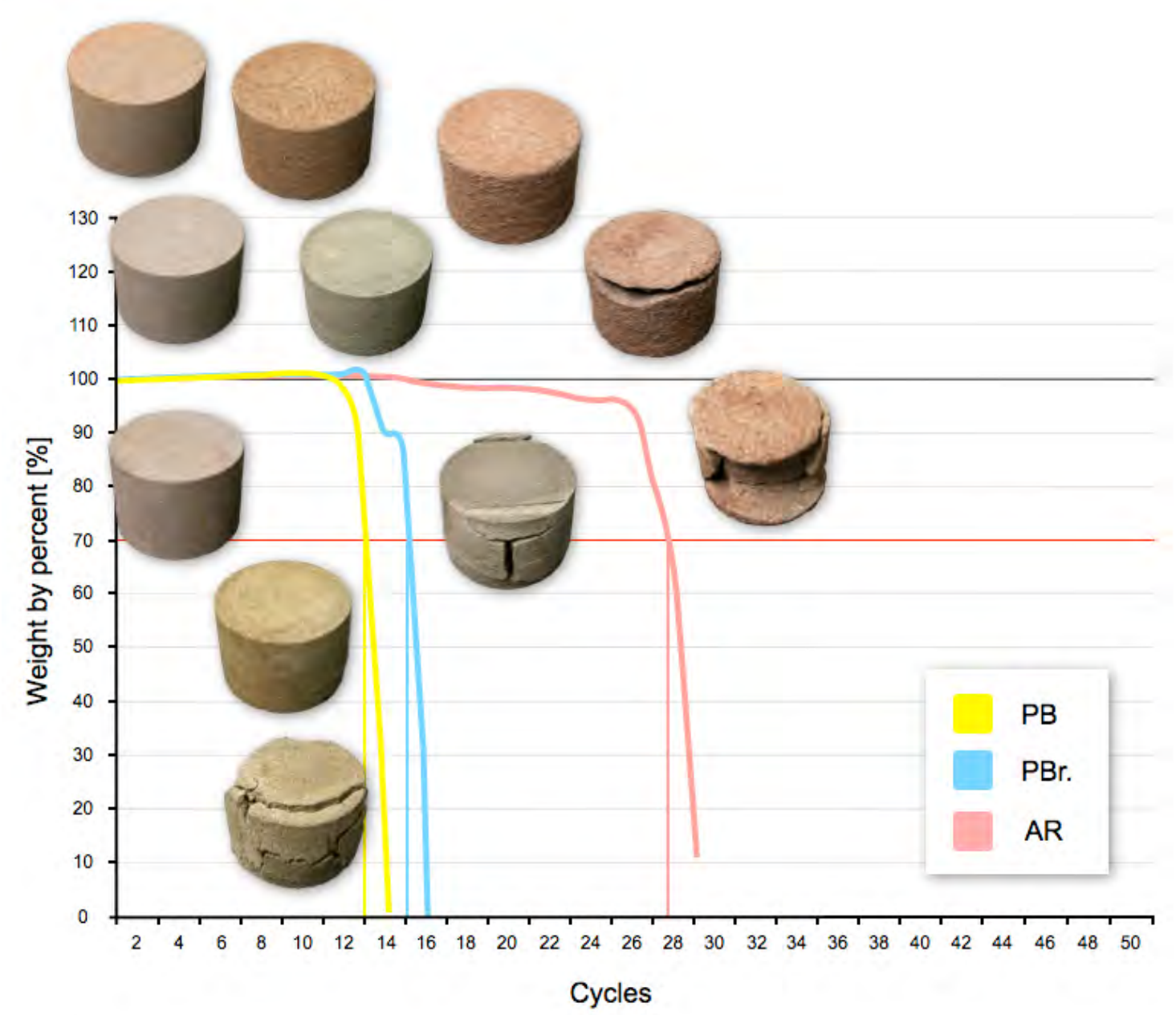

Figure 129: Salt resistance test for the investigated sandstones of Angkor.

The tests show that both gray sandstones of the Phnom Bakheng Temple have a low salt resistance with similar weathering behavior. The red sandstone variety shows the best resistance value. Discoloration takes place in all samples, as well as within the sample. All samples show contour scaling, the typical weathering form at the Angkor monuments.

\section{7. 6 Experimental studies}

André et al., (2011) determined the resistance towards weathering of the three sandstone types. According to their investigation the red sandstone of Banteay Srei resisted extremely well. This can be traced back to the low hydric swelling of the AR sandstone (Tab. 26). Moreover, the green sandsto- 
ne of Ta Keo is almost as resistant as the red variety. The gray sandstone of Ta Keo however, experienced severe damages where contour scaling is the main weathering form.

According to Uchida et al., (1999 a), the deterioration is distinct in the gray to yellowish brown sandstone because of its low compressive strength, high porosity, well-developed bedding, and constituent minerals susceptible to alteration such as feldspar and biotite. Field observations show that sometimes only a few building stones within a building are affected by weathering, whereas other ones nearby are nearly in an intact state (Fig. 114 a). For example, the hydric dilatation varies in a range from around $4 \mathrm{~mm} / \mathrm{m}$ to only $1 \mathrm{~mm} / \mathrm{m}$ or less with an anisotropy ranging from around $10 \%$ to nearly 50 \% (Reucher et al., 2007) depending on clay mineral content (Leisen et al., 1996). But according to Reucher et al., 2007 from the 12 samples tested, only one has shown a very high dilatation $(3.1 \mathrm{~mm} / \mathrm{m})$. One reason for the high dilatation according to Reucher et al., (2007) is the finer grain size content around the clay. The finer grain size also creates a lower pore size class as was measured in the case of the PB sample.

Uchida et al., (1999 a) suggests that the low compressive strength may explain the structural crack formation. A clear correlation of compressive strength and surface hardness can be shown (Wedekind et al., 2016, submitted for publication). Altered material from the Phnom Bakheng Temple shows a decrease of surface hardness of $9 \%$ compared to similar fresh quarry rock material (PBr.). If the material is saturated with water this value increases to nearly $20 \%$ (Tab. 26). In general, a softening of the sandstone and a decrease of the mechanical strength is possibly related to the moisture content of the stone (Morales-Demarco et al., 2007). In comparison to Morales-Demarco et al., (2007), a possible reduction of compressive strength can reach up to $50 \%$ for sandstones. Therefore a measured reduction of $20 \%$ of surface hardness can be assumed as moderate.

According to André et al., (2011), the Ta Keo green sandstone absorbs very little water, but has a high retention period. The Banteay Srei pink sandstone absorbs and releases a significant amount of water very rapidly. Conversely, the gray sandstone, which absorbs high quantities of liquid water and water vapor, retains it for a very long time.

In the present study these results could not be confirmed measured on partly similar stones. All three graywacke types have a low w-value that range between 0.199 and 0.313 , and do not differ from each other in a significant way (Tab. 26). All sample varieties absorb only a little water with a penetration depth of around $1.5 \mathrm{~cm}$ in one hour. In the case of the Phnom Bakheng sample and the Red Angkor sandstone the directional anisotropy of water absorption is comparable with around 30 $\%$ (Tab. 26). Moreover, this study shows comparable moisture transport properties for all sandstones investigated. 
The investigated samples differ in pore space radii distribution and mineral content. The gray sandstone of the Phnom Bakheng variety shows a pore radii distribution dominated by micropores ( 83 $\%)$. The medium-sized pore radii class from $0.1-1[\mu \mathrm{m}]$ predominates in the restoration material ( $\mathrm{PBr}$ ) and also comprises $83 \%$ (Tab. 25). The red Angkor sandstone exhibits a bimodal pore radii distribution with only $5.5 \%$ micropores and $94.5 \%$ macropores (Tab. 25).

\section{7. 6. a) Contour scaling due to hydric expansion?}

Contour scaling of the sandstones of Angkor Wat can be explained by very high rates of hydric swelling of up to $4 \mathrm{~mm}$ per meter (Leisen 2002). Leisen assumed that the periodical processes of moisture expansion and shrinking by drying have weakened the structure of the stone. The author concludes that moisture expansion and shrinking in combination with salt action, eventually leads to an irreversible deterioration of the stone material. This process is traced back to the presence of clay minerals. However, two aspects have to be taken into account that calls Leisen's hypothesis into question:

1. According to the measurements of Reucher et al., (2007) and our investigations, the average value of hygric dilatation is lower than $4 \mathrm{~mm} / \mathrm{m}$ : All measurements reach an average value of $1.4 \mathrm{~mm} / \mathrm{m}$ for the Z-direction and $1.14 \mathrm{~mm} / \mathrm{m}$ for the XY-direction with an anisotropic relation of $19 \%$. The hygric dilatation of the restoration material (PBr) is much lower (Tab. 26).

2. The other aspect that influences moisture dilatation is the high relative humidity during the rainy season. Hygric dilatation is already strong and hydric expansion therefore lower. Experimental measurements on the hydric dilatation of the Phnom Bakheng sandstone show that after the conditioning of the sample by a relative humidity of $80 \%$ the hydric dilatation reaches only $1.36 \mathrm{~mm} / \mathrm{m}$ in Z-direction. A reduction of $32 \%$ is comparable to normal laboratory conditions with a relative humidity of around $50 \%$.

During the rainy season, which lasts half a year, the stone material seems to be partly equilibrated with humidity. This seems to be the reason why hydric dilatation is reduced and fluctuations between humid and wet conditions are lower than expected. In general, this means that moisture expansion is relevant for deterioration but probably not the main reason for contour scaling.

The gray sandstone of the Phnom Bakheng Temple has a hygric dilatation of nearly $2 \mathrm{~mm} / \mathrm{m}$ in Zdirection, perpendicular to the bedding. Within the XY-direction an average dilatation of $1.165 \mathrm{~mm} /$ $\mathrm{m}$ is reached (Fig. 130). Both values produce an anisotropic relation of $42 \%$. The weathered crust sample shows a dilatation of $1.55 \mathrm{~mm} / \mathrm{m}$ in the Z-direction and $0.96 \mathrm{~mm} / \mathrm{m}$ in XY-direction (Fig. 130). 


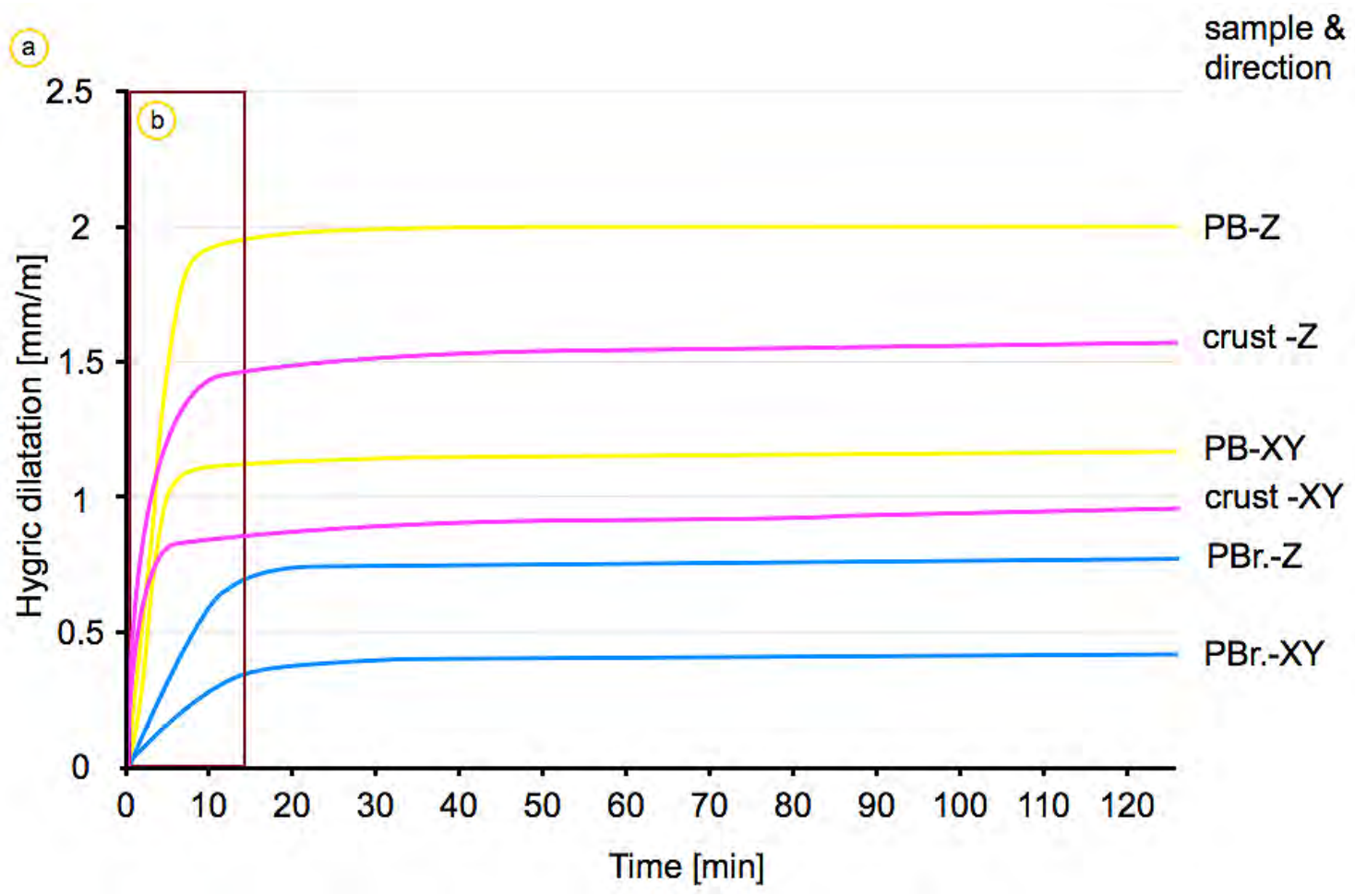

Figure 130: a) The hygric dilatation of the Phnom Bakheng sandstones (b: detail of the measurements shown in Fig. 131).

Hygric dilatation of the crust with $1.55 \mathrm{~mm} / \mathrm{m}$ in the Z-direction is lower than the altered building stone (PB). The dilatation of the crust in the XY-direction with a value of $0.96 \mathrm{~mm} / \mathrm{m}$ is quite similar to the XY-direction of the PB building stone (Fig. 130). However, the process of dilatation differs in time and form in regards to the weathered crust or the building stone. During the first two and a half minutes of wetting the dilatation of the crust is faster than the dilatation of the building stone (Fig. 131). This can be traced back to the higher porosity of the crust that is only dominated by capillary pores (Tab. 25). After that the dilatation of the crust takes much more time to reach the final value than the dilatation of the PB sample. This process can lead to a pull effect and a force of delamination as is shown in Figure 131.

The sorption of the different samples shows that both PB samples reach the highest value (Fig. 132). This can be traced back to the presence of clay minerals. Sorption of the crust exhibits a similar moisture uptake behavior during an increase of the relative humidity, but a significant lower level at $95 \%$ RH. This indicates that the clay mineral content in the weathering crust seems to be low or already lost due to weathering. Furthermore, the crust also shows a lower hydric expansion as compared to the stone. The AR sandstone shows a low sorption (Fig. 132), probably due to a low clay mineral content. 


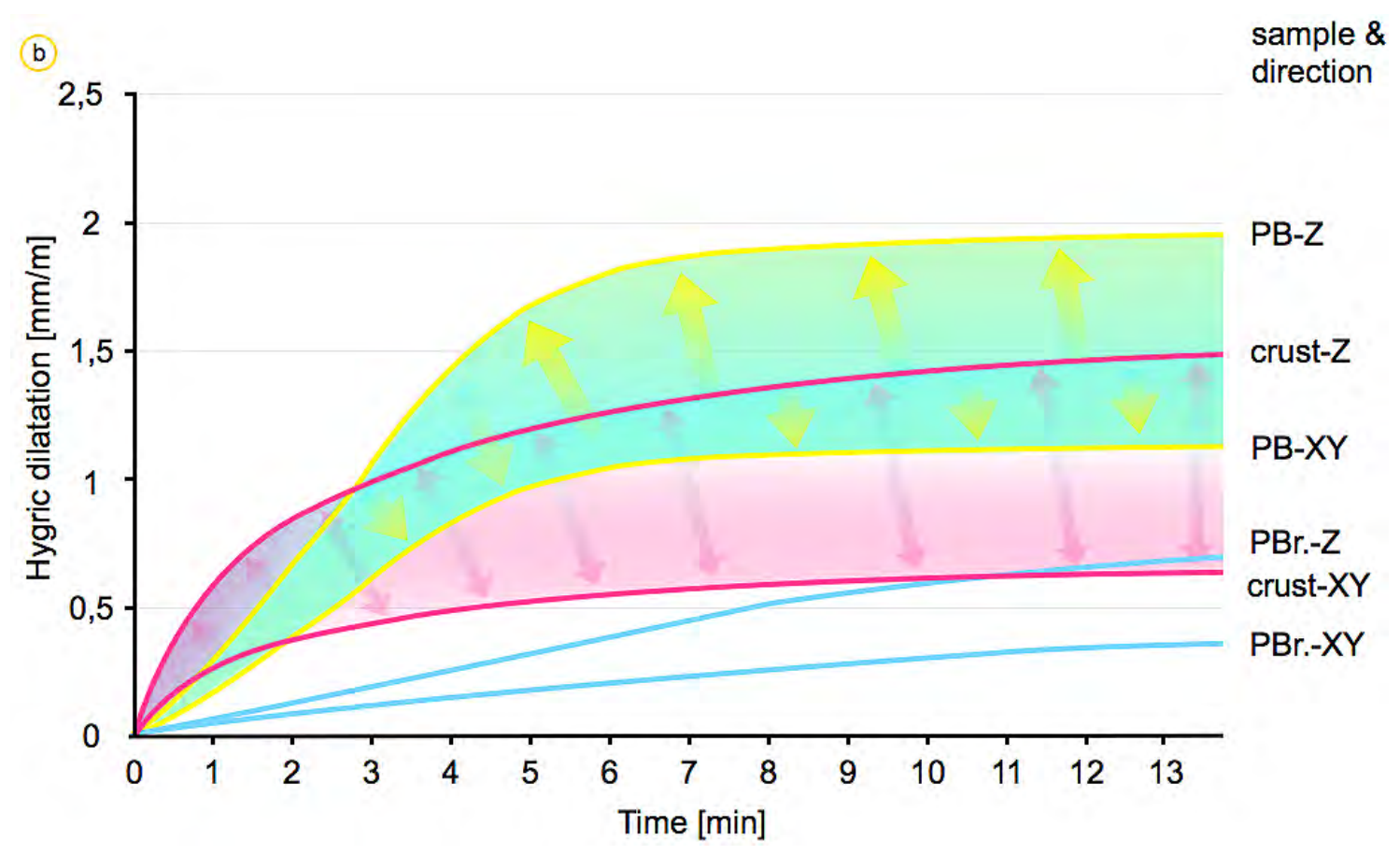

Figure 131: The dilatation of the Phnom Bakheng sandstone within the first few minutes of water suction. The arrows indicate possible forces that may be responsible for the delamination of the crust from the building stone.

\section{7. 6. b) Thermal expansion experiment}

To test the thermal expansion of a thin and small piece of crust and stone material a simple but effective testing device was developed: The sample is placed on a massive cylinder of quartz glass. Another cylinder of quartz glass with thinner dimensions is put on the top of the sample. This cylinder is connected to an electronic dial gauge. Heat is applied by an infinitely variable fan heater concentrated on the sample. The temperature of the sample is measured by a digital contact thermometer placed directly at the back of the sample. Heating starts at $25{ }^{\circ} \mathrm{C}$ (room temperature) and is continuously increased up to $100{ }^{\circ} \mathrm{C}$ within $30 \mathrm{~min}$. After reaching $100{ }^{\circ} \mathrm{C}$ the heating is stopped and the cooling process starts until the sample reaches room temperature again. A length reduction occurs during the cooling process in all samples and in all directions. However, this length reduction shows a different behavior.

The crust sample has a dimension of around 2 by 2 centimeters and a thickness of around $4 \mathrm{~mm}$. In order to compare the results with the stone material, the same or similar dimensions were used to perform the test on samples of the Phnom Bakheng sandstone as well as the restoration material (PBr). 


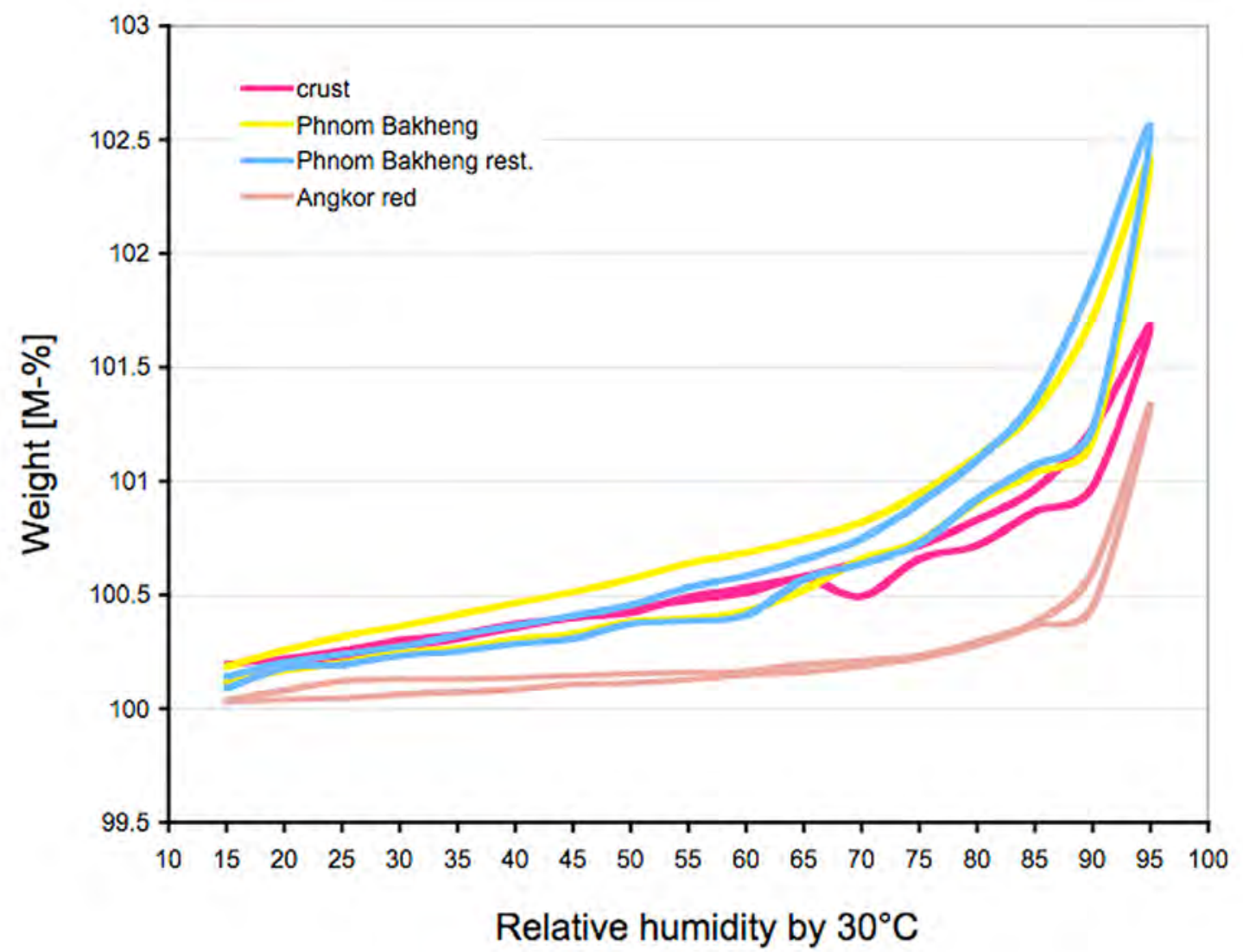

Figure 132: Sorption and desorption as a function of weight- $\%$ related to relative humidity of the investigated Angkor sandstones.

\section{7. 6. c) Contour scaling due to thermal expansion?}

In cross section the crust shows a distinct zonation where the first few millimeters display a brownish color followed by a bright discoloration (Fig. 133 a). The bright discoloration was identified as the precipitation of calcite, which was also determined by cathodoluminescence microscopy (this study) and several other authors such as Hosono et al., 2006 and André et al., 2008. This calcite mineralization results from the dissolution of calcite within the stone material due to chemical weathering and the remobilization near the drying surface as well as within cracks or weak zones within the stone material. Nearly all Angkor sandstones contain a small amount of calcite (Tab. 24). Only the red Banteay Srei sandstone is an exception with a $\mathrm{CaO}$ content of only $<0.01-0.02 \%$ (Tab. 24). 

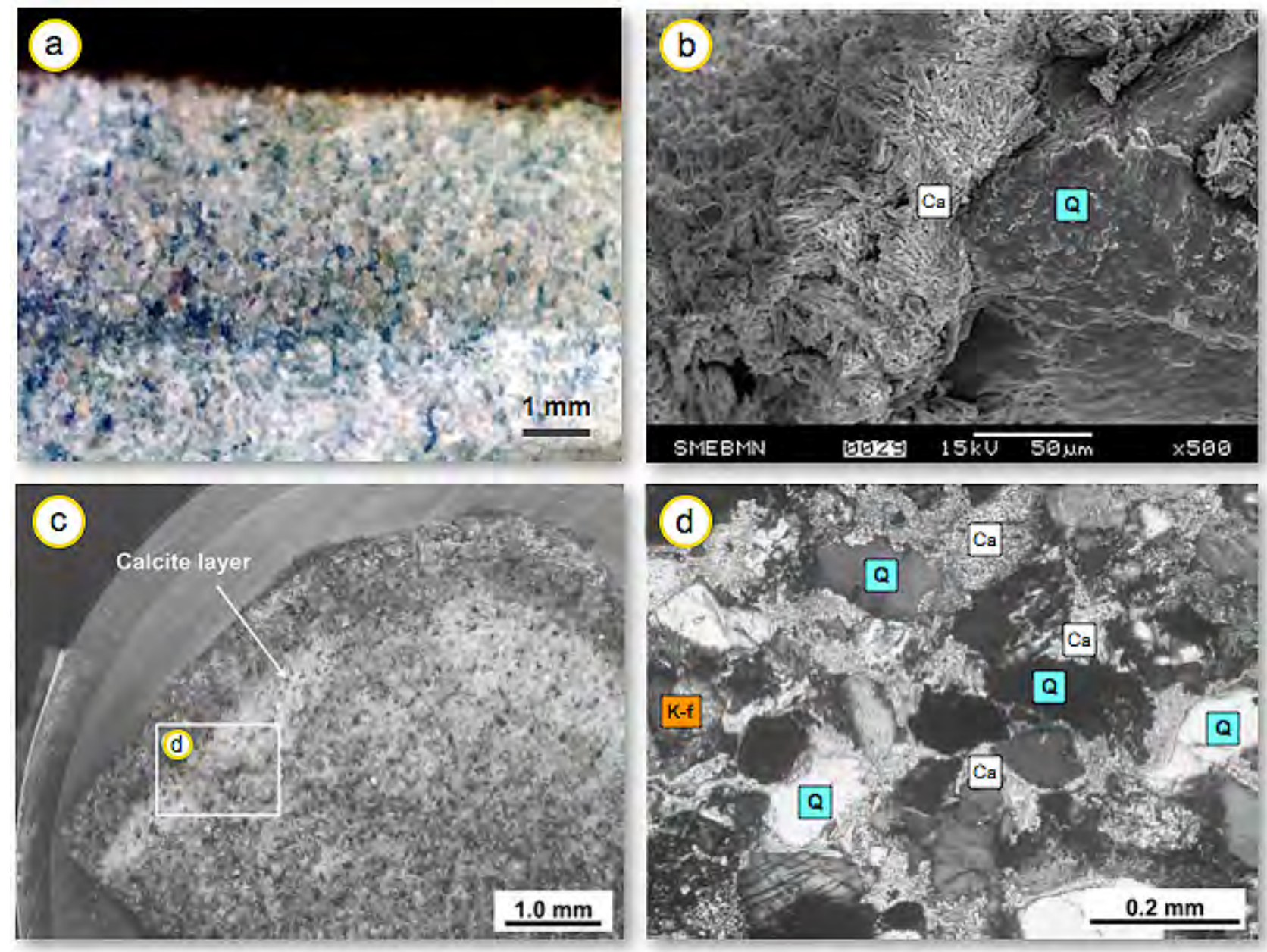

Ca Calcite Q Quartz K-f potassic feldspar

Figure 133: a) Cross section of the crust showing a distinct zoning - a brownish zone at the surface and a whitish one beneath. b) Within the lamination zone a compact layer of calcite occurs (SEM-photograph: André et al., 2008). c) Underneath the crust an extensive calcite accumulation parallel to the surface develops (photograph: Hosono et al., 2006).

d) Thin section image showing the pore space completely filled with calcite (photograph: Hosono et al.. 2006).

Thermal expansion of the various stone types and the crust shows considerable differences. The crust shows a maximal thermal expansion of $1.03 \mathrm{~mm} / \mathrm{m}$ in XY-direction and $0.48 \mathrm{~mm} / \mathrm{m}$ in Z-direction at $60{ }^{\circ} \mathrm{C}$ with an anisotropy of $95 \%$, whereas the thermal expansion of the Phnom Bakheng building stone in the Z-direction with $0.049 \mathrm{~mm} / \mathrm{m}$ is around ten times smaller than the crust (Fig. 135). In the XY-direction a shrinking takes place that attains a value of $-0.2 \mathrm{~mm} / \mathrm{m}$ at $60{ }^{\circ} \mathrm{C}$ (Fig. 135). This leads to an anisotropy greater than $100 \%$. The fresh quarry material attains a value of $0.14 \mathrm{~mm} / \mathrm{m}$ in the Z-direction and $0.167 \mathrm{~mm} / \mathrm{m}$ in XY-direction with a comparable low anisotropy of $15 \%$ (Tab. 26). 


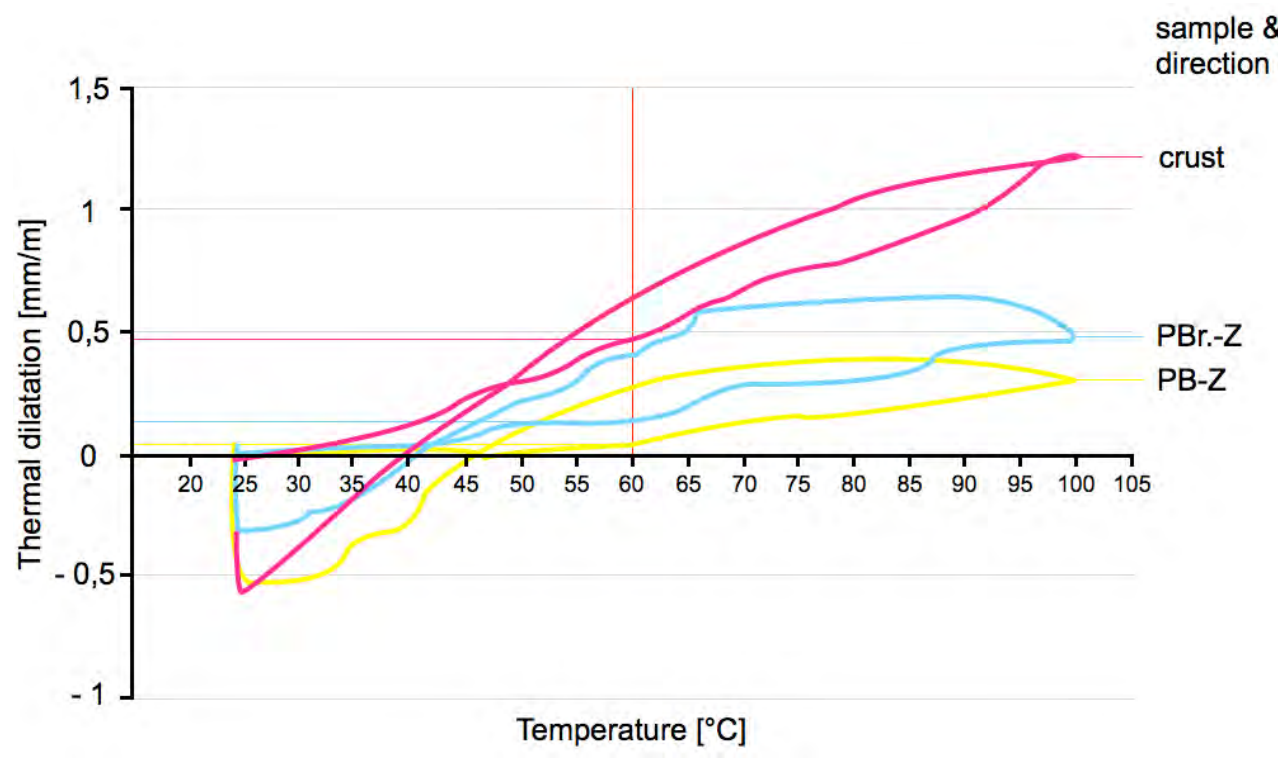

Figure 134: Thermal dilatation of the crust, the Phnom Bakheng building stone (PB) and the stone used for restoration $(\mathrm{PBr})$ in the $\mathrm{Z}$-direction.

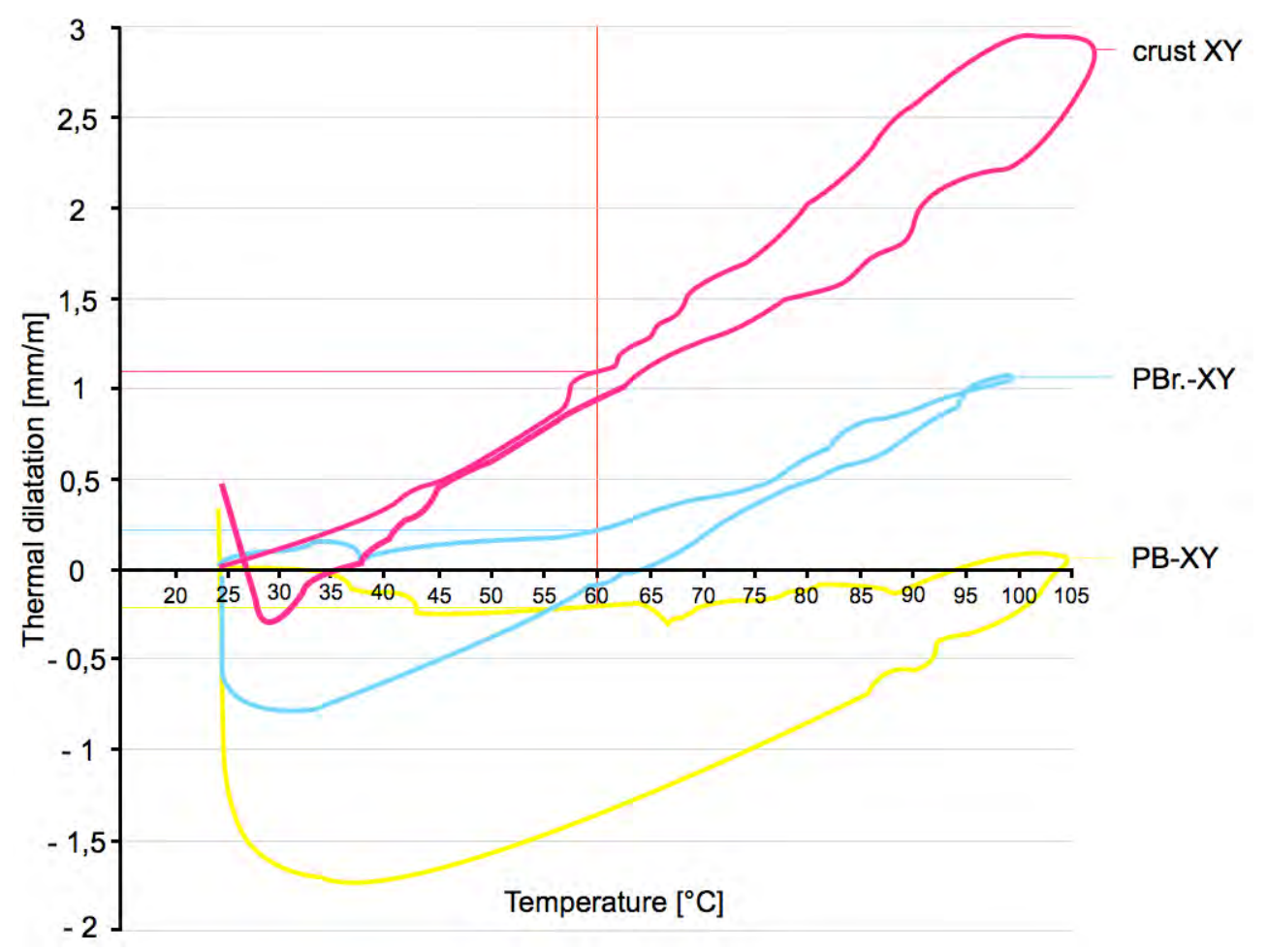

Figure 135: Thermal dilatation of the crust, the Phnom Bakheng building stone (PB) and the stone used for restoration $(\mathrm{PBr})$ in the $\mathrm{XY}$-direction.

\section{7. 7 Discussion}

Thermal expansion of the crust is much higher than in the two building stones. The anisotropy of 95\% between the Z- and the XY-direction leads to shear stresses within the crust as well as between 
the crust and the stone material. A possible explanation of why the thermal dilatation within the XYdirection is much higher than in the Z-direction is that calcite is precipitated in the cracks and empty spaces formed by the loss of clay minerals. The loss of clay minerals within the crust is also shown by the absence of any microporosity, whereas the building stone exhibits a microporosity of more than $80 \%$ (Tab. 25). The clay minerals in the sandstones mainly occur parallel to the bedding plane. This is the reason why hydric dilatation in the Z-direction is normally much higher than in the XYdirection. This also explains why the thermal dilatation of the PB sandstone in the XY-direction decreases during heating and especially during cooling (Fig. 135).

Thermal dilatation seems to be the main deterioration factor for the delamination occurring in both materials. The porosity of the crust is much higher than in the stone material. However, the bulk density is slightly higher, which leads to the assumption that the mineralogical composition is the main reason for the significant increase in the thermal expansion. A change of the mineralogical content within the crust is also considered in the observations of Hosono et al., (2008). Furthermore, the CL investigations in this study have shown that an accumulation of calcite occurs in the crust. It is well known that calcite has a high coefficient of thermal expansion. The thermal coefficient of calcite is three times higher than quartz, the main mineral comprising sandstones (Fig. 8).

Chlorite is found in significant amounts in the Phnom Bakheng sandstone, which could also play a key role in hygric expansion as well as in thermal expansion and probably in shrinking. Chlorite shows a similar behavior in thermal expansion as aragonite with anisotropies of nearly $100 \%$ related to the crystal plane (McKinstry 1965). This may be one possible explanation for the shrinking behavior related to the thermal stress in the Phnom Bakheng sandstone in the XY-direction (Fig. 135). In general, shrinking is related to clay minerals during the cooling process. At around $60{ }^{\circ} \mathrm{C}$ clay minerals begin to lose their crystal water. This sometimes leads to a depression of the thermal expansion during the heating process. On the other hand, the presence of clay minerals can reduce the thermal expansion of sandstone because the quartz grains expand, whereas the clay minerals show shrinkage at the same time. This decreases the expected thermal dilatation that is mainly related to the thermal expansion of quartz. Shrinking during cooling takes place because the thermal expansion of quartz decreases and the crystal water within the clay minerals is still lost. This leads to a collapse of the internal structure and a reduction in length, which has been observed in all sandstone varieties of the Phnom Bakheng Temple (Fig. 134 and 135). Consequently, all the investigations show that thermal dilatation seems to play a major role in the object specific deterioration form of contour scaling at Angkor.

The study of André et al., (2012) confirms this hypothesis. In this study comparative assessment of stone weathering intensities and bioclimatic conditions was conducted at temples located in cleared sites like the Ta Keo Temple and forested sites like the Ta Nei Temple nearby (Fig. 118). Both temp- 
les are made from similar stone material with similar $\mathrm{CaO}$ contents. The main result of their study found that most of the ornamented stones in the Ta Nei Temple are free of mechanical weathering because it is situated in a forested environment and protected from direct sunshine and insolation. André et al., (2012) concluded that an overall ratio on the order of 1 to 100 can be proposed for stone recession rates in forested and cleared environments, and such a difference could be reasonably attributed to contrasting levels of climate extremes.

Extreme climates are controlled by moisture as well as heat. The heating up of the surface is reduced because plenty of trees are around that cast shadows. When regarding the magnitude of the diurnal temperature and humidity ranges, André et al. (2012) assumed that they are three times higher at cleared sites than in areas surrounded by trees.

In the case of weathering processes the amplitude of fluctuations of extrinsic influences are one key factor. For the two case studies published by André et al., (2011) relative humidity and surface temperature was measured at the Ta Keo Temple and the Ta Nei Temple during different seasons (Tab. 27).

Table 27: The amplitude of extrinsic climatic impacts and their anisotropy at the Ta Keo Temple and the Ta Nei Temple in different seasons and during the year (after André et al. 2011)

\begin{tabular}{lccc}
\hline & Ta Keo Temple & Ta Nei Temple & Anisotropy [\%] \\
\hline Year & 25 & & \\
Surface temperature $\left[{ }^{\circ} \mathrm{C}\right]$ & 85.68 & 63.4 & 26 \\
Relative humidity $[\%]$ & & & \\
Dry season & 25.47 & 17 & 33 \\
Surface temperature $\left[{ }^{\circ} \mathrm{C}\right]$ & 82.18 & 63.4 & 22 \\
Relative humidity $[\%]$ & & & \\
Rainy season & 20.48 & 9 & 56 \\
Surface temperature $\left[{ }^{\circ} \mathrm{C}\right]$ & 67.09 & 38.1 & 43 \\
Relativ ehumidity $[\%]$ & & & \\
\hline
\end{tabular}

In all seasons the anisotropy of the surface temperature is higher than for the relative humidity. This implies that surface temperature has a higher impact on weathering than the relative humidity.

In another study, Smith et al., 2011 show that near-surface temperature cycling on limestone can lead to stress by expansion and the implication of scales probably due to the high thermal expansion coefficient of calcite. Therefore, it appears that the enrichment of calcite within the crust of the green and gray Angkor sandstones has a significant influence on scaling. 


\section{7. 8 Conclusions}

Contrary to the assumption that hydric dilatation is the reason for contour scaling; the main causes of deterioration identified are chemical weathering by the precipitation of iron and calcite at the surface combined with insolation-affected thermal dilatation. The recrystallization and precipitation of the case-hardening agents (iron and calcite) throughout the surface rind is a probable formation mechanism for the crust. Insolation and the increase of thermal dilatation due to the accumulation of calcite leads to shear stresses and scaling. Salt efflorescence and weathering related to bat guano and single mineral components of the stone material itself is a serious threat to the monument decorations. Both weathering factors can interact with each other and leads to an increase in the weathering processes. 


\section{Main weathering factors related to humidity}

\section{1 Introduction}

Three main deterioration factors can be distinguished as a result of all the investigations, observations and measurements done on site and in the laboratory. These are moisture, salts and heat. The impact of these deterioration factors are weighed differently according to the varying stone materials and climatic and environmental conditions.

\section{1. 2 Moisture impact}

The impact of moisture in the weathering process occurs when the conditions continuously change from a wet to dry situation. Swelling or expansion and shrinking can lead to a weakness in any material, also stone. Structures built partially in water or those permanently below the water level do not suffer from weathering, even in salt water.

\section{2 Hydric expansion and hygric swelling}

Moisture expansion in natural building stones is considered one of the most important factors affecting their weathering and deterioration (Fig 136). The processes that may be responsible for the expansion under relative humidity (hygric dilatation) and water-saturated conditions (hydric dilatation) are generally attributed to the presence of swellable clay minerals as was shown in the case study of Angkor. Investigations on this topic were mainly done for sandstones (Schuh 1987; De la Calle, Suquet 1988; Snethlage et al., 1995; Jimenez Gonzalez, Scherer 2004). In contrast to this assumption, the investigations of Ruedrich et al., (2011 a) show that moisture expansion also takes place ind Sandstones almost free from clay minerals.

To verify and provide a deeper understanding of the processes for volcanites, swelling and deterioration were performed on fourteen volcanic tuffs used as important building stones of different ages, compositions and weathering stages from Mexico, Germany and Hungary. The investigations undertaken include extensive chemical, petrophysical and fabric analyses.

The samples show a wide range of effective porosity, microporosity, capillary water absorption, moisture expansion, and CEC values. High moisture expansion does not seem to depend on clay mineral content alone. No significant effect on dilatation is observable if clay minerals are present but only form a thin coat on the outer shell of bigger pores. Moreover, a correlation between microporosity, average pore radius and moisture expansion was identified. The investigations highlight the fact that moisture expansion cannot only be attributed to swellable clay minerals. This suggests that the presence and accumulation of micropores and their average radius and distribution play an 
important role for non-clay associated swelling intensity, which can most probably be attributed to the disjoining pressure.
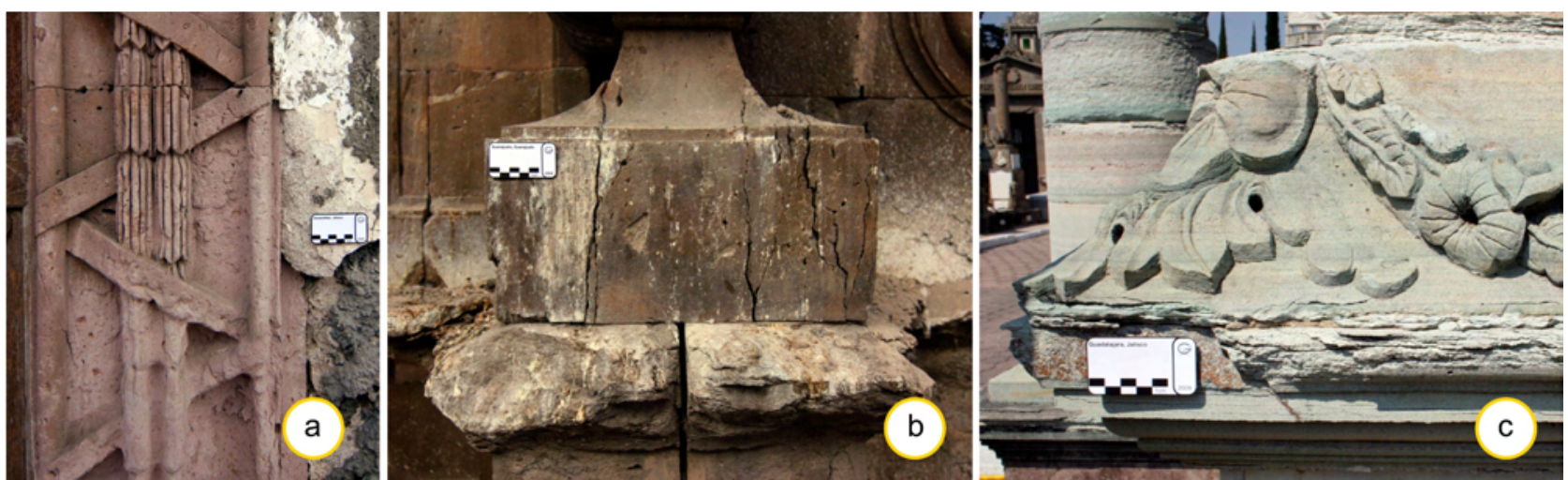

Figure 136: Different damage phenomena observable in tuffs associated with moisture expansion of the rock material. a) Back weathering of Cantera Rosa Tuff (CR) of San Miguel de Alto, Jalisco / Mexico. b) Extensive cracking parallel to the bedding of the Bufa Tuff (BT) in Guanajuato / Mexico. c) Scaling parallel to the bedding of Loseros Tuff (LS) found in Guadalajara / Mexico.

Although the swellability of the clay minerals plays a decisive role in the weathering of building rocks, the different processes that cause this phenomenon, and the question as to which is the main process during the observed swelling, are still under discussion. In principle, there are two mechanisms that can act inside and between the clay minerals; the innercrystalline (intra-crystalline) (Madsen and Mueller-Vonmoos 1989) or the osmotic (inter-crystalline) swelling (Heim 1990, Auras and Steindlberger 2005). To understand these mechanisms, it is very important to have measured the amount and type of clay minerals present, because 1:1 and 2:1 layered clay minerals can condition this effect through their cation-exchange capacity and the water uptake provoked by the electrolyte concentration in water that caused an osmotic swelling (Madsen, Mueller-Vonmoos 1988, 1989; Heim 1990). There is also a "non-clay associated" swelling type known as disjoining pressure, which is similar to osmotic swelling and related to the electrolyte concentration of a solution (Derjaguin, Obukov 1936). This swelling type is more dependent on the size and amount of micropores in the rock, as well as on the presence of lithoclasts in sandstone (Ruedrich et al., $2011 \mathrm{a}$ ).

As seen above, microporosity plays an important role not only for the disjoining pressure, but also because, by reaching the critical pore size of $5 \mu \mathrm{m}$, the pore water is trapped and cannot be drained out of the stone (Larsen, Cady 1969). Pore water hosted in the micropores can contribute to the dissolution of certain minerals in the matrix or to the acceleration of the swelling of clay minerals. Once the rock has been affected by internal weathering, the effective porosity ratio has been increased (Tugrul 2004), allowing major water circulation in all its variants into the rock.

This phenomenon also occurs with all the other types of porosity, and their size and distribution within the rock are similarly decisive for stone durability (Benavente et al., 2004; Siegesmund, Duerrast 2011). 
The factors clay mineral content and porosity are two parameters that are certainly important in tuff rocks, because they can occur in a wide range of amounts and forms. Likewise, the chemical and mineralogical composition of tuff rocks is very diverse, which also influences their durability and resistance against weathering and deterioration.

The main goal of this investigation is to contribute to the existing knowledge about moisture expansion of tuffs used as building stones. This study used fourteen important volcanic tuff rocks used in construction from Germany, Hungary, and Mexico of different ages, compositions, and states of weathering. Hydric and hygric wetting experiments conducted on the tuff rocks, as well as chemical and mineralogical analyses of the clay-fraction, which included XRD (x-ray diffraction) of oriented slides and CEC analysis, were performed in order to determine the total amount of swellable clay minerals and to clarify what role the presence of $1: 1$ or 2:1 layered clay minerals play in tuff and its

\section{3 Examined rock material}

Fourteen total volcanic tuffs were investigated in this study, while eight tuffs were investigated in greater detail because of their particular properties. From these eight volcanites, four are from Mexico: Cantera Blanca Tuff (BP), Tenayocátetl Tuff (TY), Bufa Tuff (BT) and Cantera Amarilla Tuff (CA); three are from Germany: Habichtswald Tuff (HW), Rochlitz Tuff (RP) and Hilbersdorf Tuff (HD); and one from Hungary: Eger-Demjén Tuff (ED) (Fig. 137).

Additionally, another six volcanites were investigated: Weibern Tuff (WB), Loseros Tuff (LS), Chiluca Tuff (CH), Gris de los Remedios Tuff (GR), Cantera Rosa Tuff (CR), and Cantera Formación Tuff (CF). 

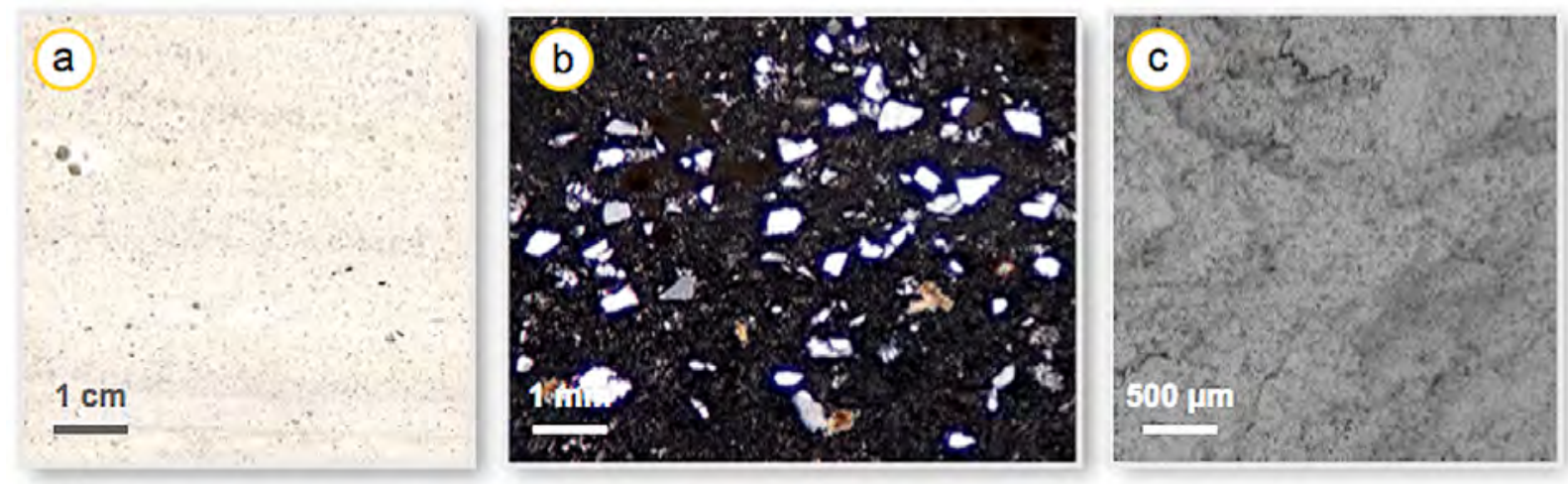

BP Cantera Blanca Tuff (Blanca Pachuca), Hidalgo / Mexico
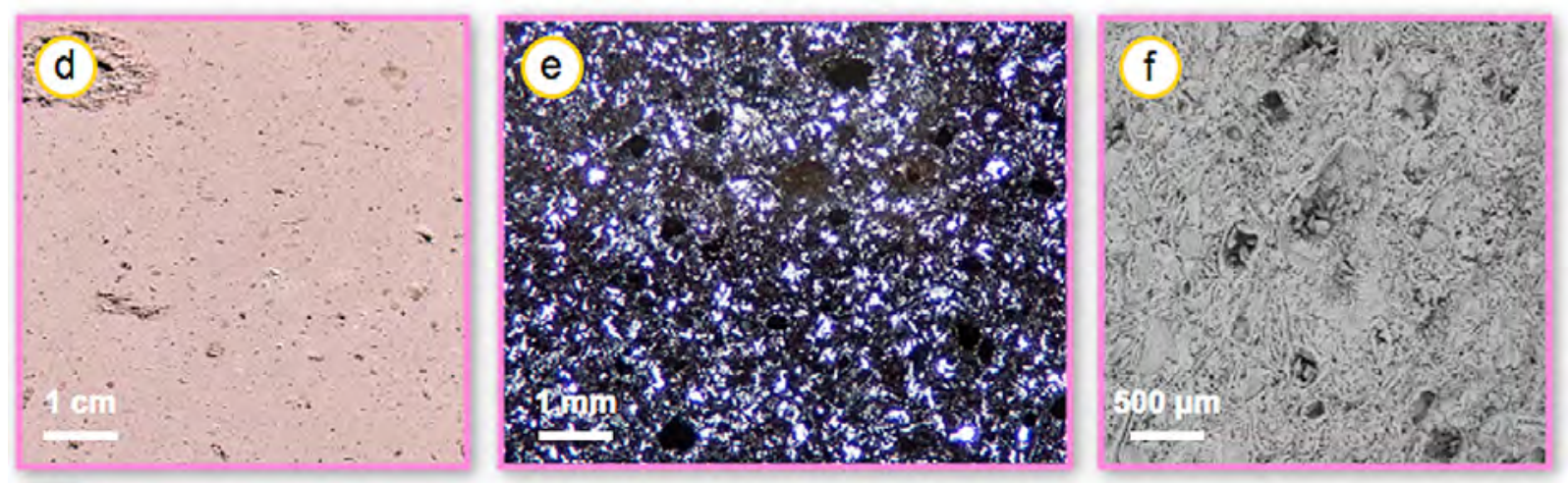

GR Cantera Rosa Tuff, San Miguel de Alto, Jalisco / Mexico
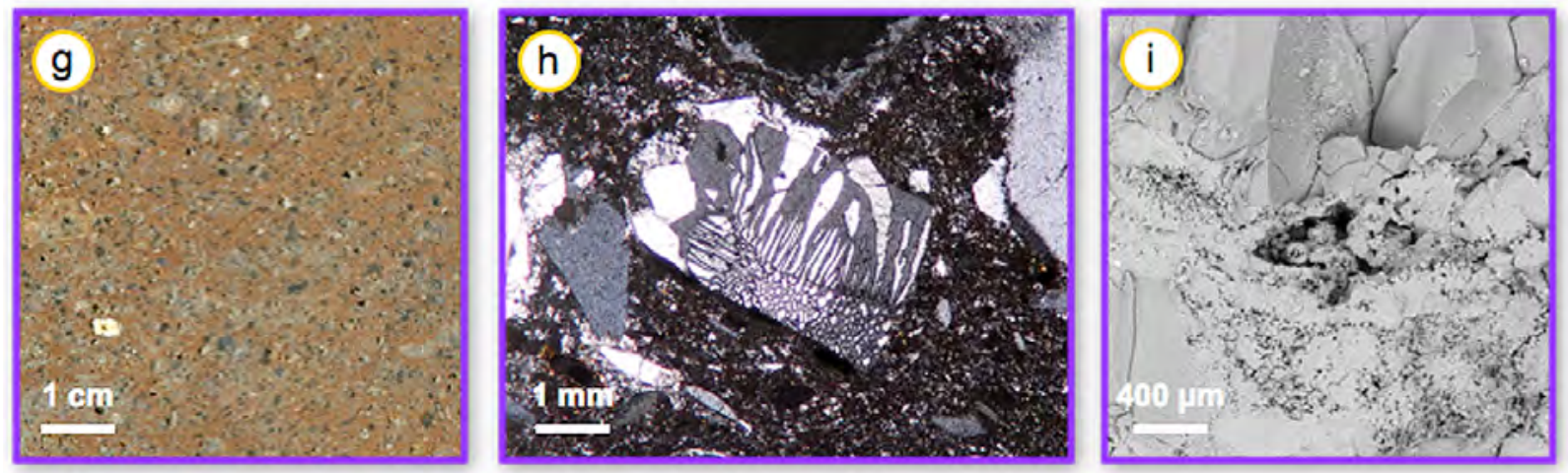

GF Cantera Formatión Tuff, San Luis Potosi, San Luis Potosi / Mexico
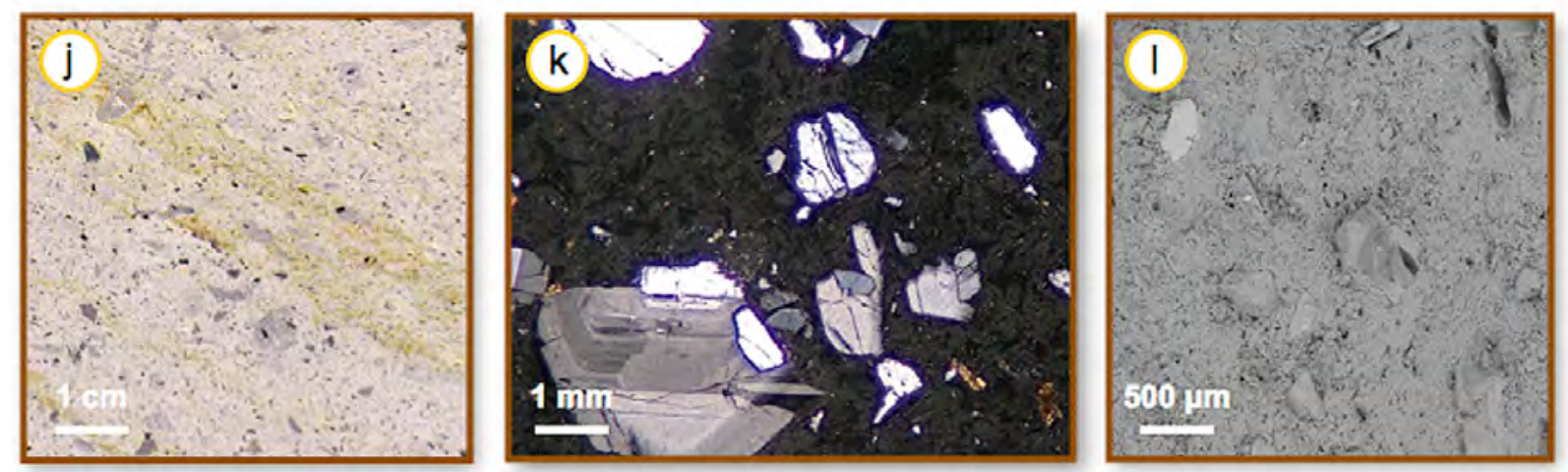

ED Eger-Demjén Tuff, Magyarország / Hungary

Figure 137: Illustration of the Mexican and Hungarian volcanic rock samples. From top to bottom: Cantera Blanca Tuff, Cantera Rosa Tuff, Cantera Formación Tuff and Eger-Demjén Tuff. a, d, g, j,) polished section, b, e, h, k, ) thin section under polarized light and c, f, i, l) SEM micrograph. 

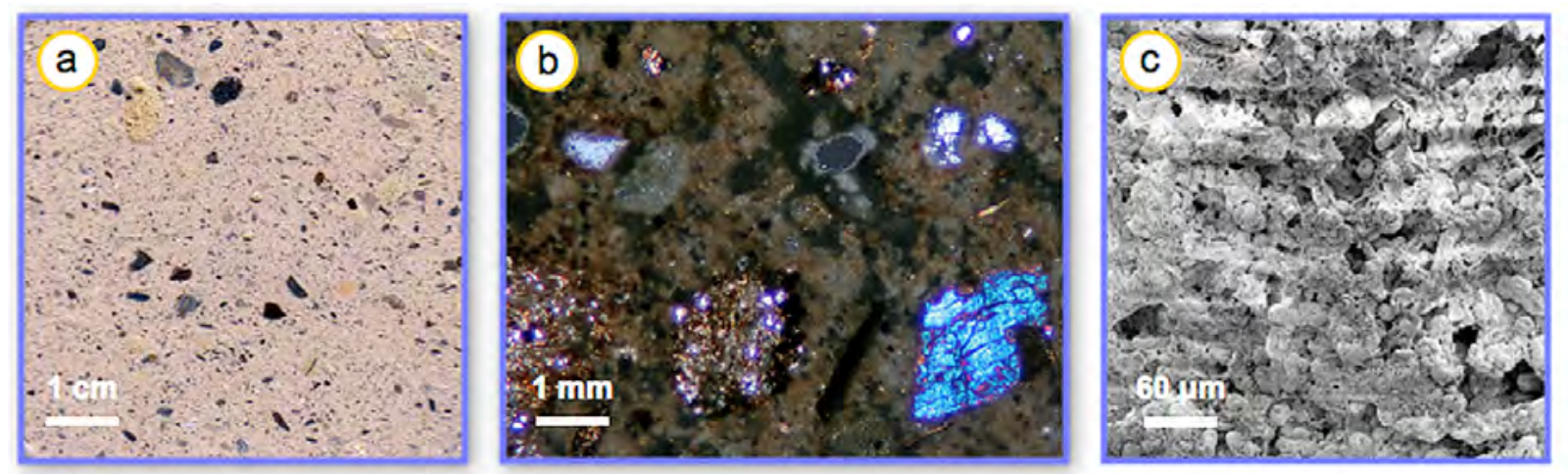

WB Weibern Tuff, Rheinland / Germany
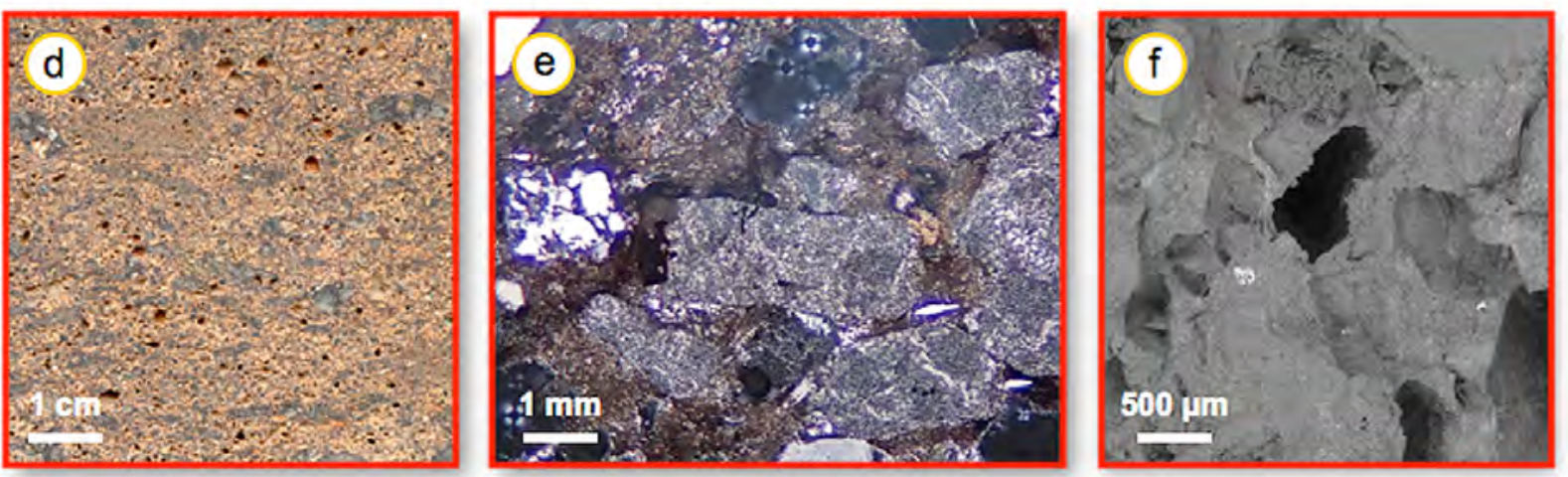

RP Rochlitz Porphyr Tuff, Saxony / Germany
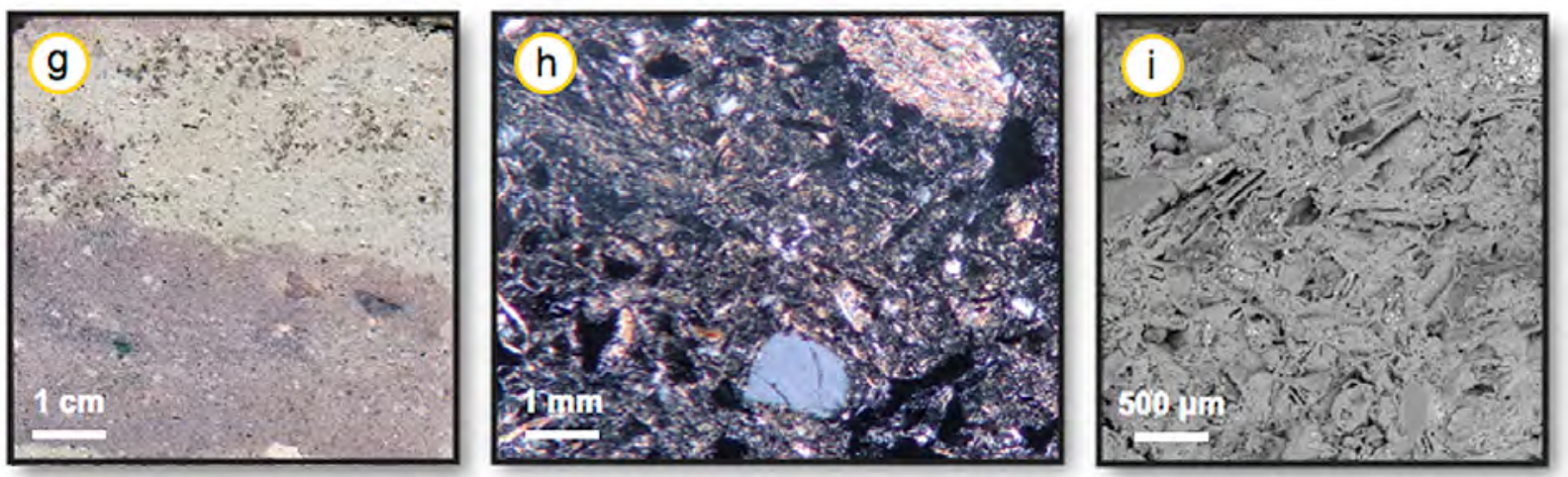

HD Hilbersdorf Tuff, Saxony / Germany


HW Habichtswald Tuff, Hesse / Germany

Figure 138: Illustration of the German volcanic rock samples. From top to bottom: Weibern Tuff, Rochlitz Porphyr Tuff, Hilbersdorf Tuff, Habichtswald Tuff, a, d, g, j, m) polished section, b, e, h, k, n) thin section under polarized light and $\mathrm{c}, \mathrm{f}, \mathrm{i}, \mathrm{l}, \mathrm{o})$ SEM micrograph. 


\section{3. 1. Petrography and mineralogy}

All tuff rock ages studied range from the Permian to the Recent, with chemical compositions that vary from basalt to dacite tuff up to rhyolitic ignimbrite tuff. For optical microscopy, the mineralogical composition of bulk samples and clay fractions were also analyzed using X-ray diffraction and cation-exchange capacity (CEC) determinations, respectively. The mineralogical composition, including clay minerals, is listed in Table 28.

Petrographical analyses of each tuff sample were performed on oriented thin sections under a polarisation microscope. From these eight selected tuffs three have already been described within the Mexican case studies (TY, BT, and CA).

The Blanca Pachuca Tuff (BP) is a light gray to white pyroclastic rock with clearly acid composition (rhyolitic tuff). It is characterized by an almost total lack of macrocrystals and a fine, porcelainlike appearance (Fig. 137 a). Only a few platy anhedral feldspar phenocrysts and some scarce idiomorphic quartz crystals were observed macroscopically (Fig. 137 b). Small angular (anhedral) quartz crystals $(>0.2 \mathrm{~mm}$ ), sometimes grouped in fine laminaes, scattered biotite and hornblende crystals are also present. The tuff also shows a hydrothermal alteration causing epidotisation and argilitisation. The matrix is composed of glass together with significant amounts of smectites (montmorillonite) and zeolites (mordenite-clinoptilolite).

The Cantera Rosa Tuff (CR) is a pinkish to reddish rhyolite - dacite tuff (rhyodacite). CR is an attractive building stone because of the fine and homogenous groundmass contrasted with the presence of centimeter to decimeter sized, more or less altered pumice clasts (Fig. $137 \mathrm{~d}$ ). It is likely that the presence of olivine and a small amount of biotite gives the tuff its characteristic pinkish reddish colour (Fig. 137 e). The clasts are characteristic because their matrix is normally a darker reddish colour. The clasts occur in different sizes and shapes, from angular and flattened to subrounded, but they are primarily oriented in the flow-direction (Fig. $137 \mathrm{~d}$ ). When the pumice clasts are altered and eroded, the tuff looks porous. The fine hypocrystalline groundmass (completely opaque) consists of quartz and feldspar, which are intercalated with small glass shards (vitroclasts). The surface of the single mineralogical components is covered by microcrystalline structures (Fig. $137 \mathrm{f}$ ). The XRD pattern shows a feldspar-rich matrix with anorthite, orthoclase, sanidine, and in lesser amounts, quartz and traces of crystobalite. The clay fraction contains smectite and also rarely found R0 ordered kaolinite (0.85)-smectite mixed layer minerals. 
Table 28: Semi-quantitative analyses of clay minerals and the CEC-value of the chosen samples

SAMPLES

\begin{tabular}{|c|c|c|c|c|c|c|c|c|}
\hline & BP & TY & B T & CA & HW & HD & RP & ED \\
\hline Smectite & $X X$ & $x X$ & & $x$ & $x X$ & & & $x$ \\
\hline \multicolumn{9}{|l|}{ Chlorite } \\
\hline \multicolumn{9}{|l|}{ K-S (R0) } \\
\hline \multicolumn{9}{|l|}{ I-S (R0) } \\
\hline I-S (R3) & & & $x$ & & & $x x$ & & \\
\hline $\begin{array}{l}\text { Muscovite/ } \\
\text { Illite }\end{array}$ & & & $x$ & & & $x x$ & & \\
\hline $\begin{array}{c}\text { Biotite/ } \\
\text { Phlogopite }\end{array}$ & + & & + & & & & + & $x$ \\
\hline Kaolinite & & & & $x$ & & & & \\
\hline \multicolumn{9}{|l|}{ Halloysite } \\
\hline Quartz & $x x$ & & $X X X$ & & $x$ & $X X X$ & $X X X$ & $x$ \\
\hline $\begin{array}{l}\text { Cristobalite/ } \\
\text { Tridymite }\end{array}$ & & $x x$ & & $x$ & & & & \\
\hline Glass & & & & & $X X$ & & & $X X X$ \\
\hline Calcite & & & $x$ & & & & & \\
\hline K-feldspar & $x X$ & $x X$ & $x$ & $X X X$ & $X X$ & $X X X$ & & $x x$ \\
\hline Plagioclase & $x$ & $X X X$ & $X X X$ & $X X X$ & + & & & $X X$ \\
\hline Hornblende & + & $x$ & & & & & & $x$ \\
\hline \multicolumn{9}{|l|}{ Analcime } \\
\hline Clino-ptilolite & $X X$ & & & & & & & \\
\hline Diopside & & & & & $X X$ & & & \\
\hline Augite & & + & + & & & & & \\
\hline Olivine & & & + & & $x x$ & & & \\
\hline Hematite & & $x$ & + & & & & + & \\
\hline Meq/100 g & 15.6 & 17.6 & 3.0 & 4.2 & 16.8 & 0.7 & 1.1 & 10.4 \\
\hline
\end{tabular}

The Cantera Formación Tuff (CF) is a pinkish to reddish, massive rhyolitic ignimbrite tuff (hypocrystalline and partially eutaxitic, porphyritic texture), with plenty of non-collapsed pumice at an average size of $2 \mathrm{~cm}$, with 15 to $20 \%$ consisting of quartz, sanidine and less abundant biotite (Fig. $137 \mathrm{~g}$ ). The main components are euhedral sanidine (40\%), anhedral to euhedral quartz (40\%), weakly zoned oligoclase ( $4 \%$ ), biotite and magnetite usually altered to hematite (1\%). The matrix 
(75 to $80 \%$ of the rock), shows vitroclastic texture in outlying areas to the phenocrysts and near them a good eutaxitic foliation (Fig. 137 h). In general, the matrix displays a weak birefringence, suggesting that it devitrified to a felsitic cryptocrystalline aggregate (Fig. 137 i). XRD analysis indicates, that this tuff is poor in clay minerals, only containing illite and poorly ordered 1:1 clay minerals (kaolinite and halloysite were proven by IR, infrared spectroscopy).

The Eger-Demjén Tuff (ED) is a grayish to light brownish ignimbrite, which has clasts of very different sizes. The clasts, measuring between 1 and $30 \mathrm{~mm}$, are mainly elongated, flattened pumice fragments, in addition to which large plagioclase and hornblende phenocrysts can be recognized (Fig. $137 \mathrm{j}$ ). Microcrystalline porphyritic fabric in a eutaxitic to glassy texture with flattened wellwelded vitroclast can also be observed (Fig. 137 k). The main constituents are euhedral to subhedral plagioclase crystals, which show a very impressive zonal texture, together with plagioclase, subhedral quartz, corroded hornblende and altered biotite (partially altered to chlorite; Stueck et al., 2008). Smectite occurs in relatively large amounts, approximately $10 \mathrm{wt}-\%$.

The Weibern Tuff (WB) is a yellowish to light brown phonolitic volcanic rock that consists principally of $85 \%$ matrix and $15 \%$ clasts (Fig. 138 a). The matrix is rich in analcime, muscovite/illite, quartz and calcite. The clasts include rock fragments, euhedral to anhedral crystals and pumice, and its grain size ranges from 0.5 up to $10 \mathrm{~mm}$ (Fig. $138 \mathrm{a}$ ). The thin section shows that the rock fragments are sandstones, shales and basalts and other unidentified volcanic glass fragments (Fig. 138 b). The crystals are predominantly reworked quartz from sedimentary rocks, olivine, pyroxenes and feldspars. Flattened pumice also occurs embedded in the porphyritic-hyalopilitic groundmass (Fig. $138 \mathrm{c})$.

The Rochlitz porphyry (RP) has a red rhyolitic groundmass composed of quartz, feldspars, thin biotite crystals and elongated, flattened porous glass fragments at different grades. The fine-grained to glassy, sometimes granular and well-porous reddish to dark red - brownish matrix exhibits a moderate flow fabric (Fig. $138 \mathrm{~d}$ ). The pore space is mostly filled by kaolinite (around $50 \%$ ). Within the matrix (40 to $70 \%$ ), up to 4-mm rounded to euhedral quartz crystals and 1- to 3-mm white, tabular to columnar relict alkali feldspars (completely replaced by clay minerals) occur as phenocrysts /Fig. $138 \mathrm{e}$ ). The reddish color of the tuff is caused by the presence of hematite in the matrix.

Hilbersdorf Tuff (HD) shows different varieties of grain size and colour. It can be pale pink to brick red, light or dark purple or greenish, and often shows a peculiar alteration with light pink or greenish speckles, spots or strips (Fig. $138 \mathrm{~g}$ ). In the fine-grained matrix of the tuff (around 60 to $70 \%$ of the rock), lapilli inclusions were observed; however, the average grain size varied from 0.5 to (rarely) coarser than $2 \mathrm{~mm}$. Larger cavities from several $\mathrm{mm}$ to $\mathrm{cm}$, mostly amygdaloyd-type, were partially filled with clay minerals. It consists of mono- and polycrystalline quartz, alkali feldspar 
and seldom lithic grains of metamorphic rocks (sericite-rich), quartzite and gneiss-like xenoliths in a hypocrystalline to eutaxitic texture (Fig. 138 h). In addition to quartz and feldspar, XRD proved the presence of approximately $20 \mathrm{wt} \%$ muscovite/illite. Scanning electron microscope (SEM) images of the Hilbersdorf Tuff matrix (Fig. 138 i), additionally demonstrated the presence of dickite, a clay mineral that belongs to the kaolinite group (see also Fischer 1990 and Siedel 1995, 2006).

The Habichtswald Tuff $(H W)$ shows a wide spectrum in grain sizes of the fragments, ranging from several millimeters up to 5 centimeters (Fig. $138 \mathrm{j}$ ). Its characteristic dark grayish, glassy to microcrystalline groundmass contains a great amount of montmorillonite. This tuff has a hypocrystalline texture with euhedral olivine-pyroxene crystals, while plagioclase, amphibole and biotite are also recognizable (Fig. 138 k). The microstructure is characterized by gas pores (Fig. 138 1). Clasts of pre-existing basic rocks are also present as vitreous fragments (peridotite and basaltic clasts; Stueck et al., 2008).

\section{3. 2 Petrophysical properties}

All the measurements were done in all three dimensions for the different rocks. The direction parallel to the bedding and lamination is defined as $\mathrm{X}$, the direction perpendicular to the lamination as $\mathrm{Y}$ and the direction perpendicular to the bedding as Z (Fig. 139).

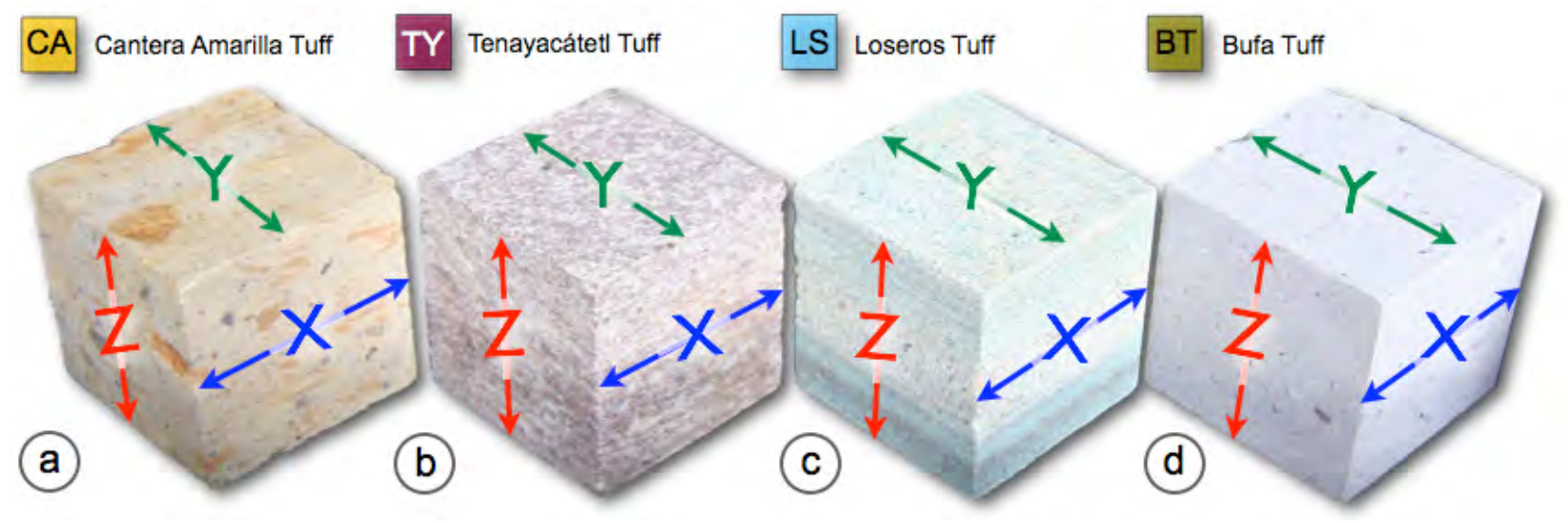

Figure 139: Four samples illustrating the general texture of the investigated rocks with their division into the $X$. Y, Z directions: a) Clastic material with brownish pumice inclusions is found oriented parallel to a possible flow direction in the Cantera Amarilla Tuff. The direction with an elongated accumulation of clasts is defined as the X direction. The adjustment of the clasts in a more or less horizontal position describes the bedding of the tuff. The direction perpendicular to the bedding is defined as the $\mathrm{Z}$ direction. $\mathrm{b}$ ) Long extended aggregates of different minerals delineate the flow direction of the TY tuff (X direction). c) The fine lamination of the Loseros Tuff also describes the bedding structure of the material. d) Extended, dark colored, iron-rich minerals show a lenticular shape and are defined as the X direction.

The direction perpendicular to these minerals is defined as the $\mathrm{Z}$ direction 


\section{3. 2. a) Porosity}

Four different groups can be distinguished according to their effective porosity. Group 1: porosities ranging from 0 to 10 (vol-\%); Group 2: from 10 to 20 vol-\%, Group 3 from 20 to 30 vol-\%, and Group 4 with porosities between 30 to more than 40 vol-\% (Table 29).

In Group 1, TY with 4.7 vol-\% and HW with 8.8 vol-\% have the lowest and highest effective porosity respectively. The other tuffs of this group (LS and $\mathrm{CH}$ ) range between 7 and 8 vol\% (Table 29). In Group 2, three tuffs show porosities ranging between 12.8 and 18.4 vol-\% (CF, BP, BT, see Table 29). Only two tuffs (ED, RP) have a porosity between 25 and up to 27 vol-\%. (Table 29). The last group comprises four tuffs with a porosity ranging between 30 up to 42 vol-\% (HD, WB, CR, and CA).

\section{3. 2. b) Density}

Bulk density ranges between 1.38 and $2.38 \mathrm{~g} / \mathrm{cm}^{3}$ (Tab. 29). Only two samples have a low bulk density between 1.38 and 1.48 (ED, CA). Five samples range between 1.52 and $1.92 \mathrm{~g} / \mathrm{cm}^{3}$ (WB, CR, GR, HD, and RP). The other six have a density from 2.13 up to $2.38 \mathrm{~g} / \mathrm{cm}^{3}$ (BT, LS, TY, CF, CH, and HW).

Table 29: Pore space properties, moisture transport, and retention properties of the different tuffs

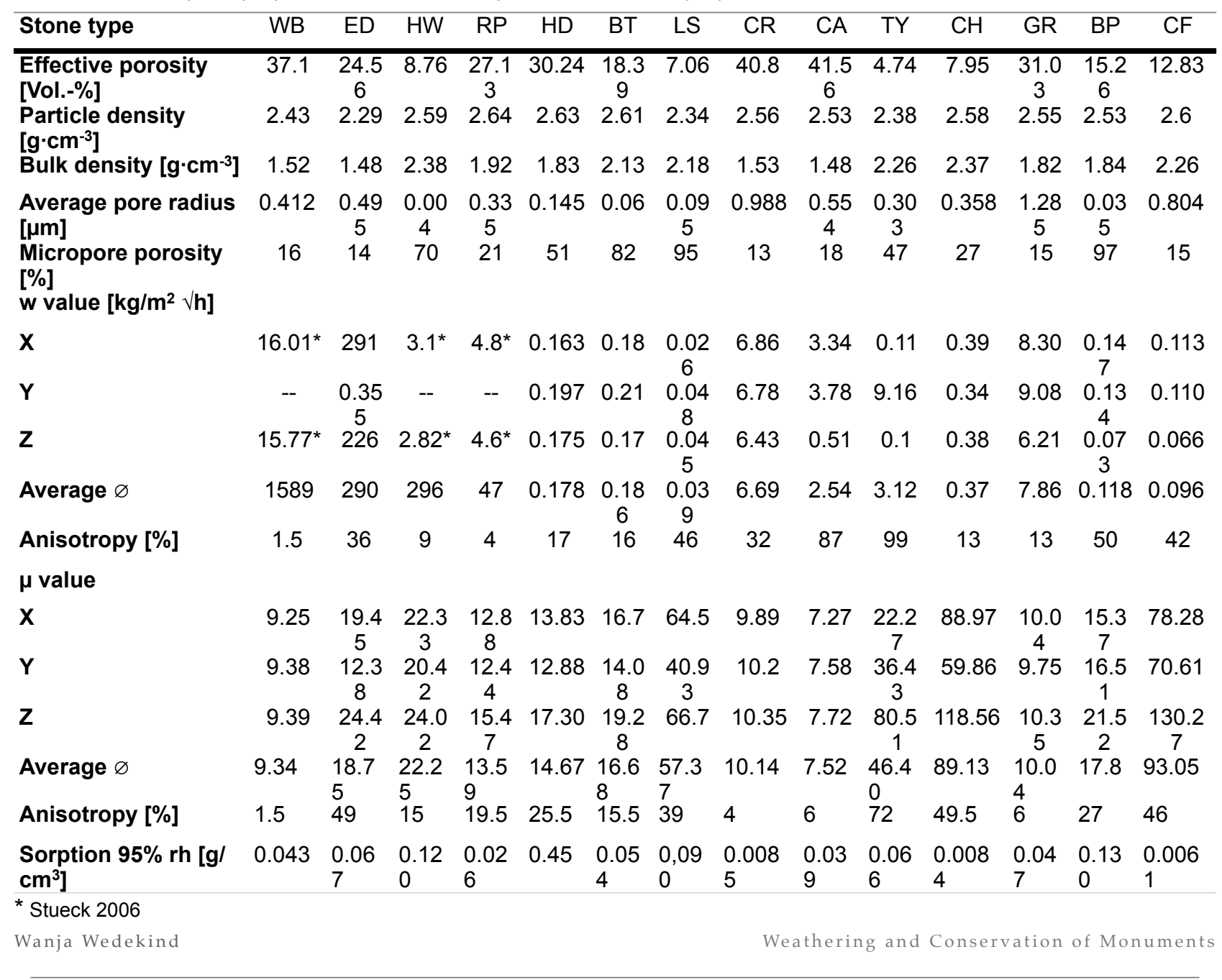




\section{3. 2. c) Microporosity}

The tuff rocks investigated have a low (up to $50 \%$ ) or a high amount (up to $100 \%$ ) of micropores measured by mercury porosimetry (Fig. 134). The microporosity is defined as the pores between 0 and $0.01 \mu \mathrm{m}$, the capillary active pores range between $0.01 \mu \mathrm{m}$ to $10 \mu \mathrm{m}$ after Klopfer (1985). After Klopfer three clear regions can be differentiated depending on water transport and other mechanis$\mathrm{ms}$ involved. For pore diameters $<0.1 \mu \mathrm{m}$ water will condense at relative humidity values below 99 $\%$ RH. In pores between $1 \mu \mathrm{m}$ and $1 \mathrm{~mm}$ capillary suction takes place (Siegesmund, Duerrast 2011). The microporosity of the investigated rocks ranges between 13 to $97 \%$. All results are listed in Table 29 and illustrated in Figure 131.

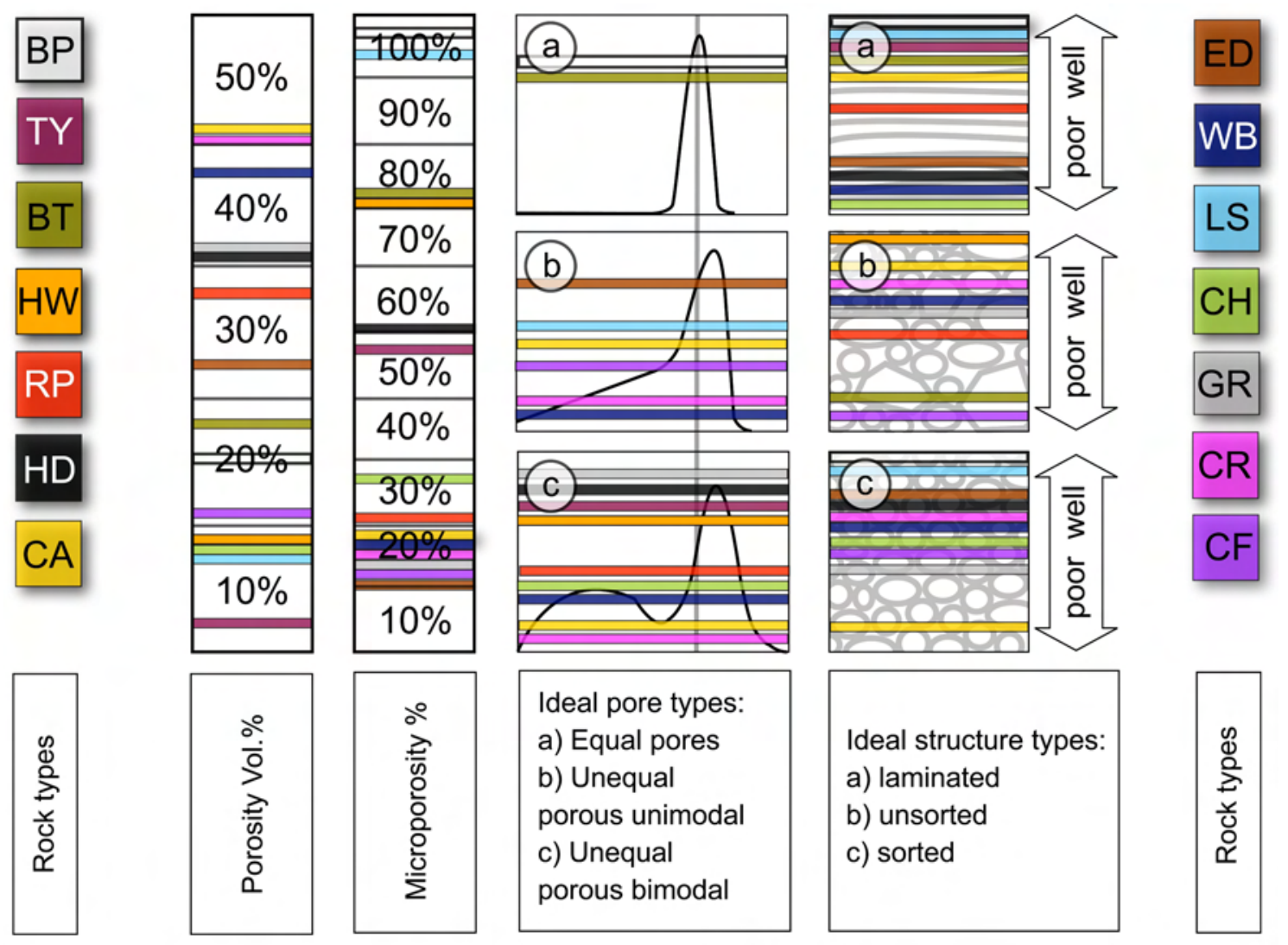

Figure 140: Overview diagram of the main pore space properties and structural characteristics measured by hydrostatic weighting and MIP.

As pertains to the eight rock types explained in detail, BP has the highest microporosity with $97 \%$, followed by BT with $82 \%$, HW with $70 \%$ and HD with $51 \%$. The tuffs with a low microporosity are ED with $14 \%$, CA with $18 \%$, RP with $21 \%$ and TY with $47 \%$ (Fig. 140 and 141).

\section{3. 2. d) Pore radii distributions}

Pore size distribution measured by mercury porosimetry can be put into groups of ideal pore size types like unimodal equal and unequal, and bimodal unequal (Siegesmund, Duerrast 2011). The investigated tuffs show diverse pore types including transitional ones. 
The group with a largely equal porous structure and a limited spectrum of pore sizes consists of BT and BP (Fig. 141). Both have nearly microporosities (ranging from $0.01 \mu \mathrm{m}$ to $0.1 \mu \mathrm{m}$ pore size) with $78 \%$ and $90 \%$, respectively.

Their pore size distributions proceed in a uniform pattern with a low tendency to an unequal unimodal structure (Fig. 140 and 141). Both tuffs are also comparable in porosity and density (Tab. 29).

Both RP and LS belong to the group of equal pore size types with a wider spectrum of pore sizes. Fifty-two percent of the pores in RP are between $0.1 \mu \mathrm{m}-1 \mu \mathrm{m}$, but in general, both tuffs have pores between 0.0015 and $10.1 \mu \mathrm{m}$. This group is represented by RP (Fig. 141).
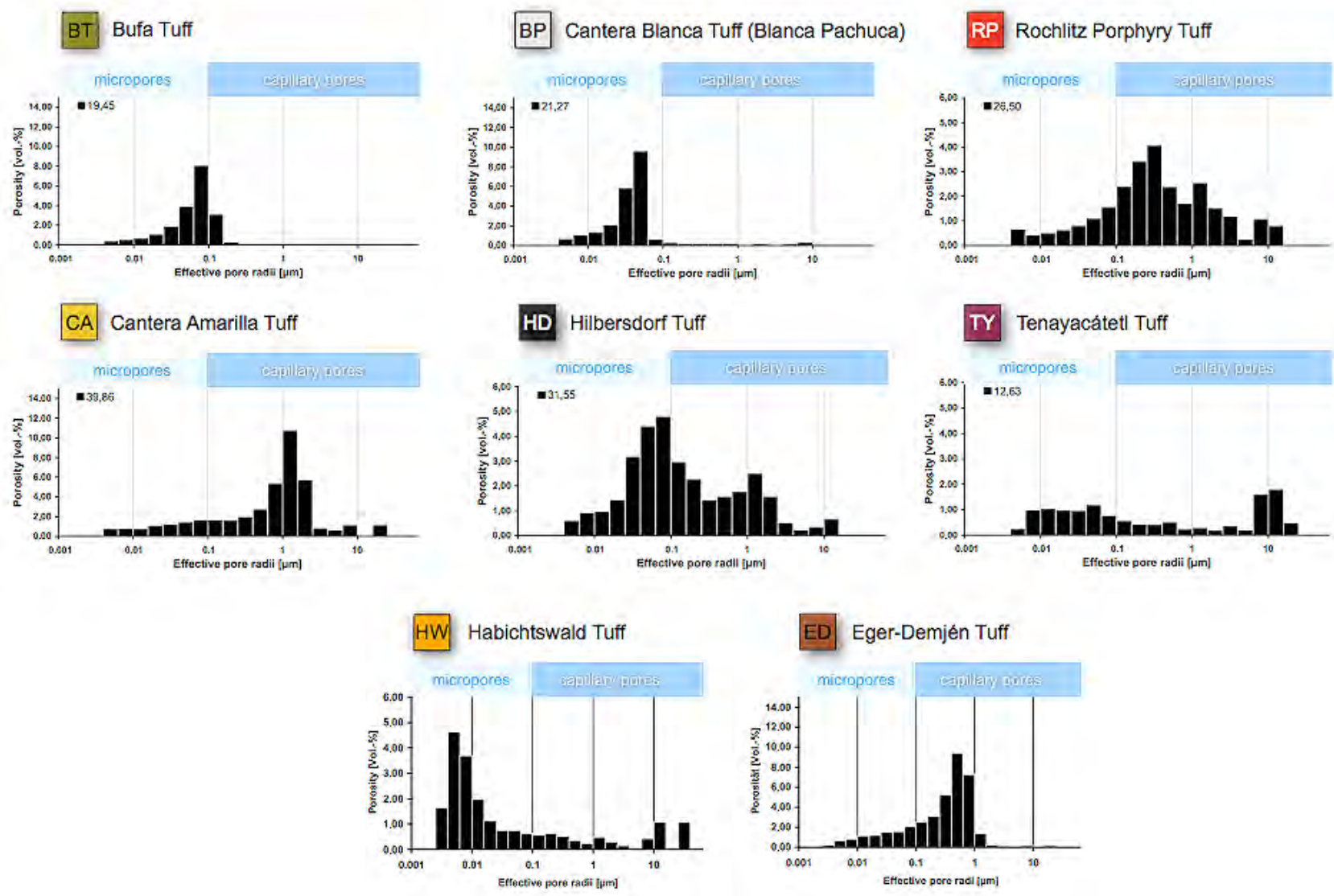

Figure 141: Pore size distribution of the eight investigated tuffs and measured by hydrostatic and MIP.

The group of unequal pore size types with a unimodal spectrum of pore sizes consists of CA, CF, CR, WB, and ED. This group is represented by CA and ED (Fig. 140).

The tuffs with a large amount of capillary active pores $(1 \mu \mathrm{m}-10 \mu \mathrm{m})$ are CA with $82 \%$ and CR with $87 \%$. Consequently, the micropores range between 13 to $18 \%$ (Tab. 29).

Eight of the tuffs investigated in detail show an unequal pore size type with a bimodal spectrum of pore sizes (Fig. 141). Three tuffs have a poorly developed bimodal spectrum and the two remaining 
tuffs only show a low tendency to a bimodal pattern. The majority of the eight selected tuffs have a higher amount of capillary pores than micropores and only two of them (HW and HD) contain more micropores than capillary pores.

TY and HD have practically the same amount of capillary and micropores (around $47 \%$ ). The Habichtswald Tuff mostly has micropores ( $72 \%$ ), but also contains some large capillary active pores and even macropores. RP has a ratio of 1:2 between micropores and capillary active pores, with a low tendency to a bimodal pore size spectrum. CA, with $83 \%$, has the highest amount of capillary active pores of the selected tuffs $(83 \%)$ and has also some macropores.

\section{3. 2. e) Macroscopic/textural aspects}

The arrangement and the spatial distribution of the components into a tuff (matrix and fragments) seem to play an important role in the behavior of their petrophysical, mechanical and moisture properties. Moreover, some tuffs have no remarkable array components and appear to have no major differences between fragments and matrix, giving them a rather homogeneous and massive appearance, while most samples exhibit an orientation of the clasts with lamination or layering. Of the fourteen rocks investigated, six show well-developed layering (BP, TY, HW, BT, CA, and RP, Figs. 133). On the other hand, six tuffs show marked differences between the size, shape and amount of the fragments and their contents in the matrix, giving them a very inhomogeneous (unsorted) appearance (Fig. 133). ED and HD show an almost homogenous, well-sorted structure.

Our observations allow us to suggest that the spatial distribution of the different fragments, like their layering, and their proportion with respect to the matrix seem to have a significant effect on moisture uptake, sorption, and mechanical properties, and are determinant for the moisture expansion often associated with a clear anisotropy.

\section{3. 2. f) Moisture expansion}

The hydric expansion shows values that range from $1.4 \mathrm{~mm} / \mathrm{m}$ for LS up to near moisture contraction for CR and CF in the Z-direction (Fig. 142).

There are notable differences in the values of the expansion under water-saturated conditions. The LS showed the largest hydric expansion with $1.4 \mathrm{~mm} / \mathrm{m}, \mathrm{CR}$ even a reduction in length with -0.03 $\mathrm{mm} / \mathrm{m}$ (Fig. 142). Some horizons of HD (not included in this study) can show a hydric expansion of up to $6 \mathrm{~mm} / \mathrm{m}$. In general, the expansion perpendicular to the layering is the largest. 


\section{Hydric expansion}

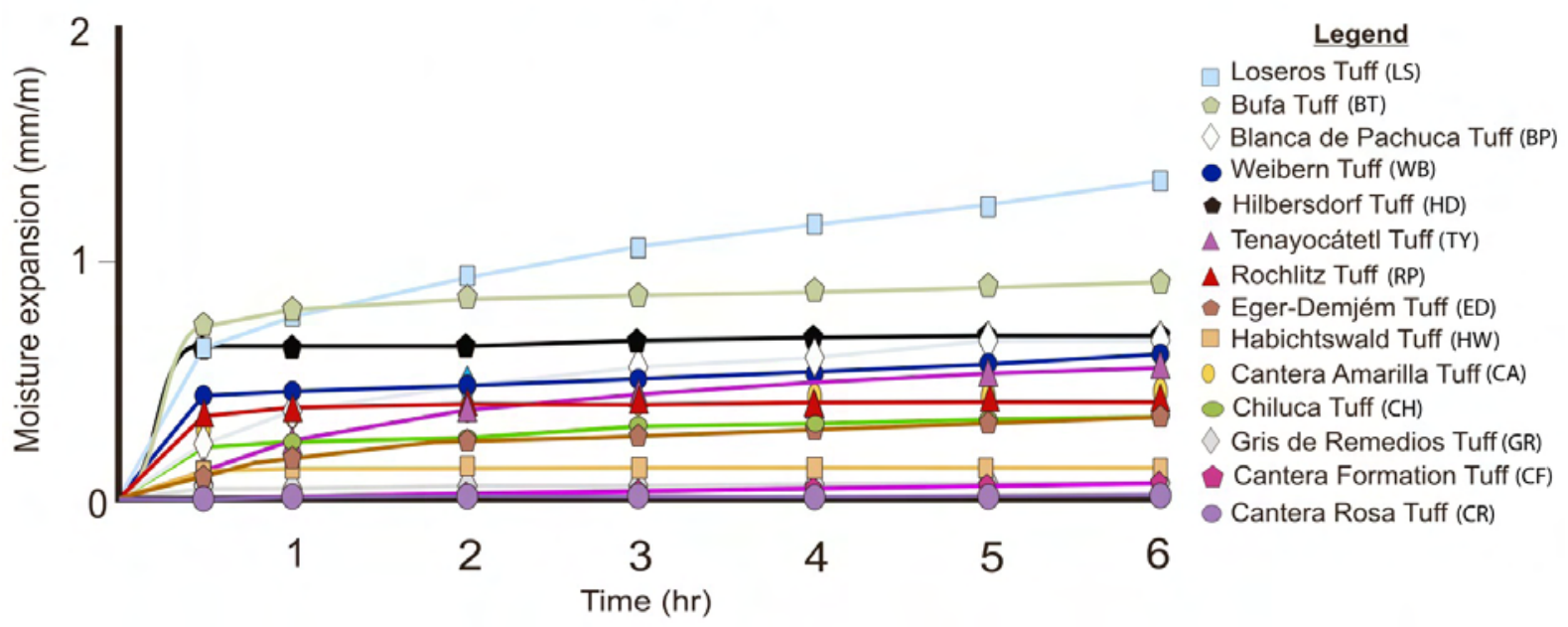

Figure 142: Hydric expansion under water-saturated conditions of the different tuff samples in the Z-direction.

Table 30: Hygric expansion in $\mathrm{mm}$ depending on relative humidity and water saturation, the difference in percent for the three directions $(X, Y, Z)$ and its anisotropy

\begin{tabular}{lcccccccccccccc}
\hline Stone Type & WB & ED & HW & RP & HD & BT & LS & CR & CA & TY & CH & GR & BP & CF \\
X-95\% RH & 0.57 & 0.11 & 0.34 & 0.02 & - & 0.18 & 0.14 & 0.29 & 0.18 & 0.27 & 0.08 & 0.39 & 0.6 & 0 \\
X-wet & 0.241 & 0.145 & 0.248 & 0.360 & 0.467 & 0.361 & 0.314 & 0.000 & 0.12 & 0.17 & 2.86 & 0.022 & 0.45 & -0.05 \\
X-diff. (\%) & 58 & 24 & 27 & 94 & - & 50 & 55 & 998 & 33 & 63 & 72 & 94 & 25 & - \\
\hline Y-95\% RH & 0.48 & - & 0.29 & 0.01 & - & 0.203 & 0.254 & 0.28 & 0.16 & 0.28 & 0.08 & 0.42 & 0.73 & - \\
Y-wet & 0.351 & 0.201 & 0.295 & 0.379 & 0.578 & 0.442 & 0.555 & 0.000 & 0.11 & 0.27 & 0.283 & 0.021 & 0.56 & $-0,00$ \\
Y-diff. (\%) & 27 & - & 15 & 97 & - & 54 & 54 & 999 & 31 & 4 & 72 & 95 & 23 & - \\
Z-95\% RH & 0.65 & 0.19 & 0.29 & 0.02 & - & 0.33 & 0.33 & -0.001 & 0.17 & 0.44 & 0.09 & 0.32 & 0.65 & \\
Z-wet & 0.585 & 0.353 & 0.235 & 0.427 & 0.618 & 0.798 & 1.428 & 0.031 & 0.90 & 0.54 & 0.302 & 0.031 & 0.55 & -0.02 \\
Z-diff (\%) & 10 & 46 & 19 & 95 & - & 59 & 77 & & 81 & 19 & 70 & 90 & 15 & - \\
\hline Anisotropy & 26 & 42 & 15 & 50 & - & 45 & 75 & 71 & 111 & 39 & 11,1 & 24 & 18 & - \\
95\% (\%) & & & & & & & & & & & \\
Anisotropy wet & 49.3 & 59 & 49.3 & 8.1 & 24.4 & 54.7 & 78 & 32.7 & 82 & 71.4 & 52 & 32.2 & 81 & 65 \\
(\%) & & & & & & & & & \\
Average 95\% & 0.56 & 0.15 & 0.30 & 0.16 & - & 0.24 & 0.24 & 0.19 & 0.17 & 0.33 & 0.083 & 0.38 & 0.66 & - \\
Average wet & 0.40 & 0.23 & 0.26 & 0.36 & 0.55 & 0.53 & 0.78 & 0.000 & 0.38 & 0.33 & 0.29 & 0.025 & 0.52 & -0.02 \\
\hline
\end{tabular}

Six tuffs have a moisture expansion between 0.5 and $1 \mathrm{~mm} / \mathrm{m}$ and another seven samples showed values ranging from $0.4 \mathrm{~mm} / \mathrm{m}$ to above zero (Tab. 30). Apart from LS, CA shows the highest values of hydric dilatation perpendicular to the lamination (Z-axis) with $0.9 \mathrm{~mm} / \mathrm{m}$ and an anisotropy of $82 \%$, followed by BT with $0.8 \mathrm{~mm} / \mathrm{m}$ and $55 \%$ anisotropy, and $0.6 \mathrm{~mm} / \mathrm{m}$ for HD and BP, with anisotropy values of $24 \%$ and $8 \%$, respectively (Tab. 30). TY has a moisture expansion of $0.5 \mathrm{~mm} /$ $\mathrm{m}$ and a high anisotropy of $71 \%$, while the RP reached a hydric dilatation of $0.42 \mathrm{~mm} / \mathrm{m}$ with a low 
anisotropy of $8.1 \%$. HW and ED both show a moderate hygric and hydric dilatation and a high similar anisotropy between 50 and $60 \%$.

\section{3. 1. h) Capillary water absorption}

The calculated water absorption coefficient ( $w$ value) is given in Table 29 for all directions. The average $w$-value of the volcanites varies between almost $16 \mathrm{~kg} / \mathrm{m}^{2} \sqrt{\mathrm{h}}$ for $\mathrm{WB}$ and $0.04 \mathrm{~kg} / \mathrm{m}^{2} \sqrt{\mathrm{h}}$ for LS. Four groups can be divided according to their water absorption coefficients. Group 1 from $>0$ to $0.2 \mathrm{~kg} / \mathrm{m}^{2} \sqrt{\mathrm{h}}$, group 2 from $<0.2$ to $1.0 \mathrm{~kg} / \mathrm{m}^{2} \sqrt{\mathrm{h}}$, group 3 from $<1.0$ to $>10 \mathrm{~kg} / \mathrm{m}^{2} \sqrt{\mathrm{h}}$ and group 4 from $<10 \mathrm{~kg} / \mathrm{m}^{2} \sqrt{\mathrm{h}}$. Group 1, with the lowest water uptake rate, consists of 5 tuffs ranging from $0,039 \mathrm{~kg} / \mathrm{m}^{2} \sqrt{\mathrm{h}}$ for LS to $0.19 \mathrm{~kg} / \mathrm{m}^{2} \sqrt{\mathrm{h}}$ for BT with an anisotropy from 16 to $50 \%$ and a porosity from $7 \%$ to $30 \%$, respectively. The second group contains ED Tuff with $0.29 \mathrm{~kg} / \mathrm{m}^{2} \sqrt{\mathrm{h}}$ (anisotropy of $36 \%$ and porosity of $25 \%)$ and $\mathrm{CH}$ with $0.37 \mathrm{~kg} / \mathrm{m}^{2} \sqrt{\mathrm{h}}(13 \%$ anisotropy and porosity of $8 \%)$. The third group contains 5 tuff varieties from $2.54 \mathrm{~kg} / \mathrm{m}^{2} \sqrt{\mathrm{h}}$ for CA to $7.86 \mathrm{~kg} / \mathrm{m}^{2} \sqrt{\mathrm{h}}$ for GR. This group has an anisotropy ranging from $99 \%$ for TY to 4\% for RP and porosities from 5 to $42 \%$, respectively. The last group consists of only one rock, WB, with a high average absorption value of more than $15 \mathrm{~kg} / \mathrm{m}^{2} \sqrt{\mathrm{h}}$. This tuff has an anisotropy of $1.5 \%$ and a porosity of $37 \%$.

\section{3. 2. g) Water vapour diffusion}

The values of water vapour diffusion range between 130.27 to only 7.27 . The highest water vapour resistance was measured for $\mathrm{CF}$ with an average value of 93.05 and an anisotropy of $46 \%$, followed by $\mathrm{CH}$ with nearly 90 and an anisotropy of $50 \%$ and TY with 46.4 and anisotropy values of $72 \%$. The anisotropy values seem to be affected most probably by the clear layering of the rock (Tab. 29). Eight tuffs range between 20 and 10 and only three samples have a water vapour diffusion value $<$ 10 (Tab. 29).

For the chosen rock samples, the highest water vapour resistance $(\mu)$ was measured for TY with 46.4 accompanied by a high anisotropy of $72 \%$. Only one of these samples has a vapour resistance value $>20(\mathrm{HW})$ and a moderate anisotropy of $15 \%$. Five of the samples (ED, HW, RP, HD, BT and BP), comprising the majority, have $\mu$-values between 10 and 20 with an anisotropic behavior between 15.5 and $49 \%$. Only CA has a $\mu$-value $<10$ with a low anisotropy of $6 \%$.

\section{3. 2. h) Swelling pressure}

For the measurements of swelling pressure samples with a very high moisture dilatation (in this case the HD) were chosen, one with a high dilatation (LS), two samples with a medium dilatation (BT and BP), and one with moderate expansions (CA). LS reached the lowest swelling pressure of only $0.005 \mathrm{MPa}$. On the other hand, two samples reached medium swelling pressure values of 0.015 (BT) and $0.03 \mathrm{MPa}(\mathrm{BP})$. However, CA, with the lowest dilatation value, does not show the lowest swelling pressure value with $0.011 \mathrm{MPa}$. All results show a clear correlation. The swelling pressure 
measurements suggest that there is relationship between the obtained moisture expansion results and those obtained by the swelling pressure experiments. A particular case is represented by LS with low swelling pressure values but contrasting relatively high hydric dilatation (Fig. 142).

In general, the swelling pressure is relatively low and well below the splitting tensile strength (between 0.005 and $0.03 \mathrm{MPa}$ ). It can be assumed that swelling and contraction as a result of drying and wetting has an effect on deterioration even when the pressure induced is low.

\section{3. 2. i) Sorption and saturation degree}

We can divide the measured samples into three groups: low, middle and high hygroscopic water sorption. By far the highest level is shown by the samples from BP, LS, and TY. The first two stone types also show the highest amount of micropores with more than $90 \%$ (Table 29). The middle group includes the majority of the investigated tuffs $\left(0.02\right.$ to $0.05 \mathrm{~g} / \mathrm{cm}^{3}$, Table 29$)$. The last group contains only three tuffs, which have sorption values of less than $0.01 \mathrm{~g} / \mathrm{cm}^{3}$. CF, with only $0.006 \mathrm{~g} /$ $\mathrm{cm}^{3}$, shows the lowest saturation at $95 \% \mathrm{RH}$.

A clear tendency of correlation is observable between the amount of micropores and the saturation degree (Fig. 136). The highest sorption is shown by the samples that have the highest number of micropores. All volcanites show their highest saturation degrees at $95 \% \mathrm{RH}$.

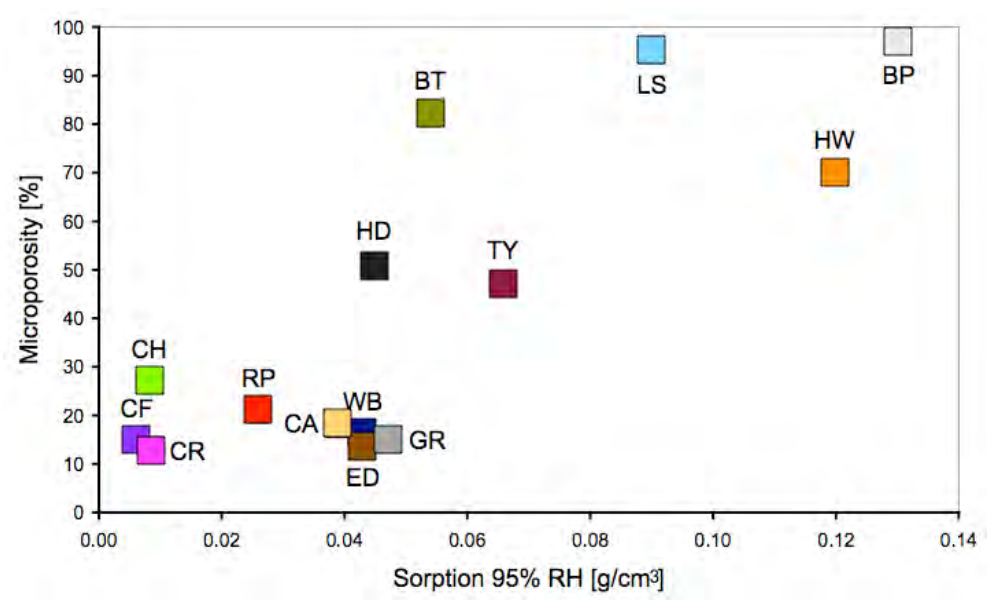

Figure 143: Correlation of sorption at $95 \% \mathrm{RH}$ and the amount of microporosity.

\section{3. 2.j) Splitting tensile strength and compressive strength}

Under dry conditions, all of the splitting tensile strength (STS) values vary between 0.99 and 10.65 $\mathrm{MPa}$ (Tab. 31). The water-saturated samples reached values between 0.49 and $8.71 \mathrm{MPa}$. 
Table 31: Splitting tensile strength (STS) in dry and water-saturated conditions and the respective strength reduction

\begin{tabular}{|c|c|c|c|c|c|c|c|c|c|}
\hline \multirow[t]{2}{*}{ Stone type } & \multicolumn{3}{|c|}{$\begin{array}{l}\text { Splitting tensile strength } \\
\text { dry ßsz [MPa] } \\
\text { Direction \& Anisotropy [\%] }\end{array}$} & \multicolumn{3}{|c|}{$\begin{array}{c}\text { Splitting tensile strength } \\
\text { water-saturated ßsz } \\
\text { [MPa] } \\
\text { Direction \& Anisotropy [\%] }\end{array}$} & \multicolumn{3}{|c|}{$\begin{array}{c}\text { Splitting Tensile } \\
\text { strength reduction } \\
{[\%]} \\
\text { Direction \& Average [\%] }\end{array}$} \\
\hline & $x$ & $\mathrm{Z}$ & Aniso. & $x$ & $\mathrm{Z}$ & Aniso. & $x$ & $\mathrm{Y}$ & $\varnothing$ \\
\hline WB & $1.46^{\mathrm{a}}$ & $1.76^{\mathrm{a}}$ & 17 & $1.25^{\mathrm{a}}$ & $1.25^{\mathrm{a}}$ & 0 & 29 & 14 & 22 \\
\hline ED & $3.30^{\mathrm{b}}$ & & - & $2.78^{b}$ & & - & - & - & 37 \\
\hline HW & $2.43^{a}$ & $3.23^{a}$ & 25 & $2.10^{a}$ & $3.07^{a}$ & 31.5 & 5 & 13.5 & 9 \\
\hline $\mathrm{RP}$ & $1.91^{\mathrm{a}}$ & $3.23^{a}$ & 25 & $1.45^{a}$ & $1.77^{a}$ & 18 & 38 & 24 & 32 \\
\hline HD & 3.70 & 4.62 & 20 & 1.14 & 3.1 & 63 & 16 & 75 & 49 \\
\hline BT & 6.04 & 6.95 & 7 & 3.65 & 4.57 & 20 & 24 & 47 & 37 \\
\hline LS & 6.29 & 8.25 & 24 & 5.82 & 6.69 & 13 & 7 & 19 & 14 \\
\hline CR & 3.94 & 4.02 & 2 & 2.61 & 3 & 13 & 34 & 25 & 30 \\
\hline CA & 0.99 & 1.05 & 6 & 0.49 & 0.56 & 12.5 & 43 & 53 & 49 \\
\hline TY & 5.43 & 5.71 & 5 & 3.94 & 4.12 & 4 & 16 & 18 & 26 \\
\hline $\mathrm{CH}$ & 5.13 & 5.61 & 8.5 & 4.56 & 4.79 & 5 & 11 & 15 & 13 \\
\hline GR & 2.27 & 2.24 & 1 & 1.39 & 1.58 & 12 & 39 & 29 & 34 \\
\hline BP & 6.90 & 5.89 & 22 & 3.99 & 3.11 & 22 & 42 & 47 & 44 \\
\hline CF & 10.65 & 9.89 & 7 & 8.23 & 8.71 & 5.5 & 23 & 12 & 18 \\
\hline
\end{tabular}

a Stueck (2006), b Stueck et al., (2008)

Of the fourteen investigated tuffs, six have a clearly recognizable laminated (foliated) pyroclastic fabric (CA, BP, RP, BT, TY, and LS). The influence of this layering on mechanical stress is given by the anisotropic behavior according to the splitting tensile strength. While the decrease in the measured values for RP with $33 \%$, followed by LS (24\%), HD (20\%), WB (17\%) and BP Tuff (15\%) alone reached critical values, the impact of anisotropy by water saturation changed dramatically for some samples, e.g. HD reached $63 \%$, HW $31 \%$, BP $22 \%$ and BT $20 \%$. The last two rocks show a clear layering. The highest splitting tensile strength reduction is observed for HD and CA (both $49 \%)$ followed by BP (44 \%) and the BT (37\%). Both lithic fragments and large porphyric crystals can also have an effect on the structural breakdown and the fractured surface. In the case of the Bufa Tuff, the fractures along the XY-plane (parallel to the bedding) took place along the material boundary between the clearly oriented lithic components and the fine microcrystalline matrix. Lithic fragments can also control the occurrence of fractures in Cantera Amarilla Tuff. These fragments, mostly pumice, have a lower hardness than the matrix and are only partly connected to it (Jáuregui et al., 2012). 
It is well known that water-saturated tuffs as well as other porous stone types have a lower strength than under dry conditions and that there is a correlation between the modulus of elasticity and the compressive strength (Toeroek 2007). An average reduction of around 30\% (ranging from 12-75\%) was observed in the fourteen different tuffs (Tab. 31).

The compressive strength ranges from around $8.2 \mathrm{~N} / \mathrm{mm}^{2}$ for CA to $98.0 \mathrm{~N} / \mathrm{mm}^{2}$ for CF (see Table 5). For ten of the investigated samples, all directions were taken into consideration. Four of these only have a very low anisotropy, between only 0.1 to $8 \%$ (Tab. 32).

Table 32: Uniaxial compressive strength (UCS) under dry conditions ( $\left.\mathrm{N} / \mathrm{mm}^{2}\right)$

\begin{tabular}{lcccc}
\hline Stone samples & \multicolumn{3}{c}{ Direction } & Anisotropy [\%] \\
\hline WB & $\mathbf{X}$ & $\mathbf{Y}$ & $\mathbf{Z}$ & - \\
ED & $18-19.3^{\mathrm{a}}$ & & - & - \\
HW & - & - & - & - \\
RP & $14-60^{\mathrm{b}}$ & - & - & - \\
HD & $56^{\mathrm{c}}$ & - & 32.04 & 20 \\
BT & 37.24 & 39.84 & 59.59 & 11 \\
LS & 66.69 & 64.34 & 59.98 & 22 \\
CR & 74.26 & 66.9 & 32.56 & 8 \\
CA & 31.9 & 29.94 & 9.72 & 15 \\
TY & 9.45 & 8.21 & 50.82 & 0.1 \\
CH & 50.82 & 50.86 & 90.58 & 21 \\
GR & 91.94 & 83.2 & 18.08 & 8 \\
BP & 17.25 & 16.58 & 53.67 & 19 \\
CF & 66.07 & 62.23 & 98.04 & 4 \\
\hline
\end{tabular}

a Mueller (1987), ${ }^{b}$ Haberland (2006), ${ }^{c}$ Vereinigte Porphyrbrueche auf dem Rochlitzer Berge GmbH

\section{4 Discussion}

Contrary to many other rock types, most of the volcanic rocks are formed during a relatively short period of time. The development can be divided into two main processes: lava cools down at the surface or sedimentation of volcanic ash and rock fragments are ejected during a volcanic eruption (tuffs).

The matrix of the investigated tuff rocks consists principally of fine sand up to clay sized pyroclastic material (mostly volcanic ash and pumice) distributed and packed in very different ways, depen- 
ding on the extrusion type. In the case of the extrusive igneous rock types, the material cools down so quickly that crystallization does not occur or is incomplete. The resulting ash particles and glass shards of the tuffs mostly show irregular sharp edges, angular to very angular grain and fragment shapes and consequently a poor or weakly welded matrix. This fact allows the formation of a very complex system of pore networks defined by macroporosity and microporosity. The different constituents of pyroclastic rocks in particular can show a layered and laminated texture, which induced a distinct anisotropy in terms of its petrophysical, mechanical and moisture properties. Thus, the rock fabric plays a very important role in the behavior of the rock to moisture and weathering and controls its petrophysical properties (Siegesmund, Duerrast, 2011).

Water transport and uptake took place due to the capillary active pores. Compared with the microporosity, the averaged $w$-value should show a weak correlation (Fig. 144). The microporosity and the w-value are compared in Fig. 144 a. In general, samples with a high microporosity have a lower w-value.
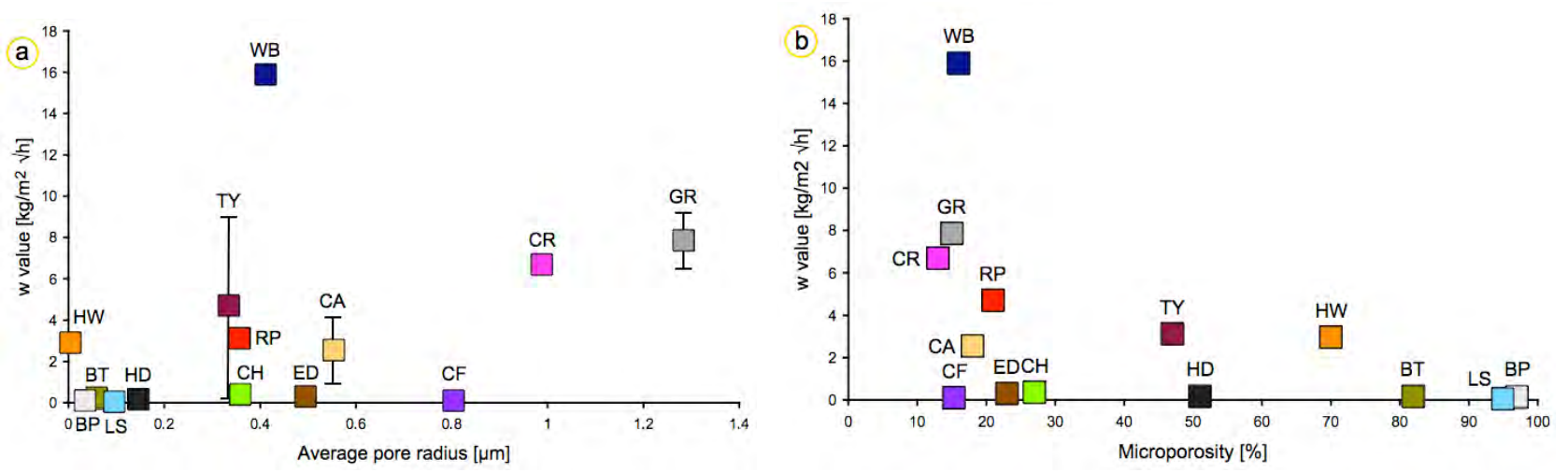

Figure 144: a) Correlation of the $w$ value and the average pore. b) Correlation of the $w$ value and the microporosity.

\section{4. 1 Swellable clay mineral content based on XRD and CEC results}

In spite of the comprehensive investigations carried out, the real cause for the moisture expansion observed, either under hygric or hydric conditions, remains unclear. It is most likely due to an interaction between different processes (Ruedrich et al., 2011 a).

XRD quantification of clay minerals, particularly in volcanic rocks, is demanding work (Moore, Reynolds, 1997, Dohrmann et al., 2009). The application of the Rietveld method is complicated when unknown amounts of glass are present. Nonetheless, the CEC method could be used as an approximation to determine if expandable clay minerals are dominant or not (Dohrmann, Kaufhold, 2010). Ruedrich et al., (2011 a) discussed the different CEC values of the individual clay minerals and the use of the measured CEC values of the rock samples for the semi-quantitative approximation of the smectite contents. The unit of the CEC value is milliequivalent per $100 \mathrm{~g}$ (meq/100g). The CEC values listed in Table 28 for the eight selected samples range from 0.7 (HD) to 17.6 (TY). 
The TY, ED, BP, HW, and CA samples (Fig. 145) contain smectites, as verified by ethylene glycol intercalation (EG) of separated $<2 \mu \mathrm{m}$ fractions. BT also expanded upon EG treatment, however, the smectitic interlayers are part of two different types of illite-smectite mixed layers, as verified by thermal treatment $\left(375^{\circ} \mathrm{C}\right.$ : all interlayers were collapsed to $\left.10 \AA\right)$. HD contains very small amounts of smectitic interlayers, the dominating clay minerals are very close to pure illite (R3 illite (0.95)smectite mixed layers). RP, on the other hand, did not expand at all after EG treatment.

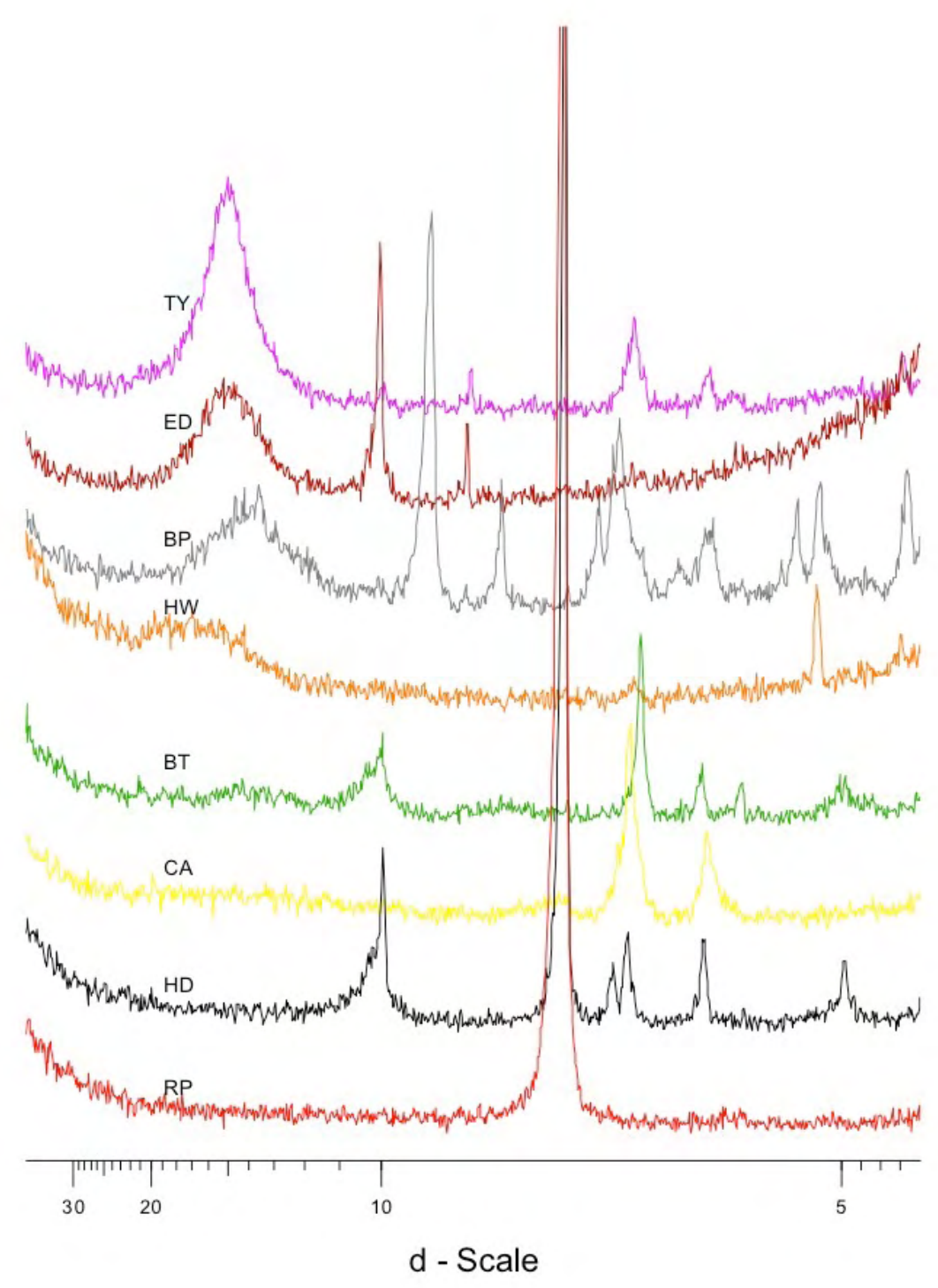

Figure 145: X-ray diffraction patterns of whole rock tuff samples.

The CEC is highest for the TY, HW, and BP tuff (16-18 meq/100 g), reflecting the highest smectite content of approximately 15-20 wt-\% at least for TY and HW. The large CEC of BP can also partly be explained by clinoptilolite, a mineral of the zeolite group. Zeolites are also known for their large CEC values (for discussion and problems with these CEC values see Dohrmann et al., 2012). 
ED has also a high CEC value of $10 \mathrm{meq} / 100 \mathrm{~g}$ reflecting approximately $10 \mathrm{wt}-\%$ smectite. Smectite was also confirmed by EG expansion in CA, which contains based on the CEC approximation ca. 5 $w t \%$ smectite. BT has lower amounts of smectitic layers (ca. $3 \%$ ) in mixed layer minerals of different ordering types, whereas the amounts of smectitic layers are very low in the HD sample $(<1$ t.\%). RP does not contain smectite at all and the low CEC value of $1 \mathrm{meq} / 100 \mathrm{~g}$ can be explained by the large kaolinite content.

\section{4. 2 Moisture expansion as a function of the CEC value}

In the present study, there is no clear correlation between the CEC values and the moisture expansion (Fig. 146). There is a certain trend of correlation in the form of a point cloud between the CEC value and the hydric expansion for eight of the investigated samples, but only if the CEC value is smaller than $10 \mathrm{meq} / 100 \mathrm{~g}$ (Fig. 146). Some of these samples show a pronounced anisotropic behavior, in the case of water transport properties or mechanical strength, which can probably be traced back to the fabric characteristics, e.g. the large clasts of CA and the layering in BT. BP, HW, and TY have the highest CEC values, between 15.6 and $17.6 \mathrm{meq} / 100 \mathrm{~g}$ (Fig. 146), but they do not really show significant expansion, although they have a high amount of smectite. These three tuffs showed medium to high averaged splitting tensile strength values between 2.83 and 6.39 MPa, which probably influence the expected higher moisture expansion (Tab. 31). Two of the investigated tuff rocks (GR, ED) have a substantial CEC value (around $10 \mathrm{meq} / 100 \mathrm{~g}$ ), but a similarly low hydric dilatation (Fig. 146).

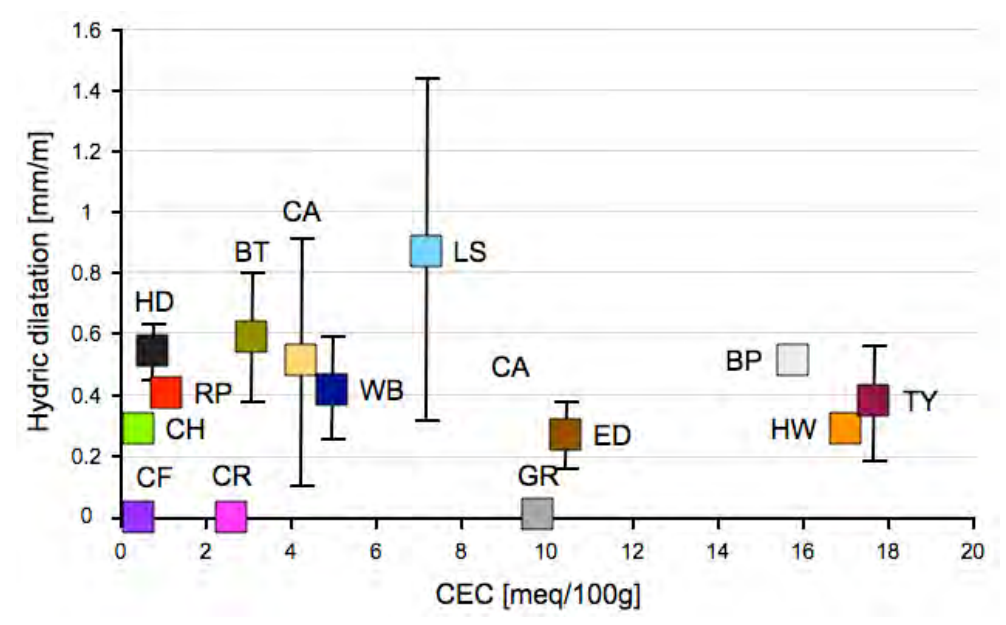

Figure 146: Moisture expansion and the CEC value don't show a clear correlation.

\section{4. 3 Moisture expansion as a function of the microporosity and average pore radius}

In contrast to the relation between the CEC value and moisture expansion, there is an obvious correlation between the microporosity and the hydric expansion (Fig. 147 a). In particular, a correlation can be detected for the hydric expansion on the $\mathrm{X}$ - and Y-axes, probably because the swelling process is not affected by layering and lamination (Fig. $147 \mathrm{~b}$ ). 

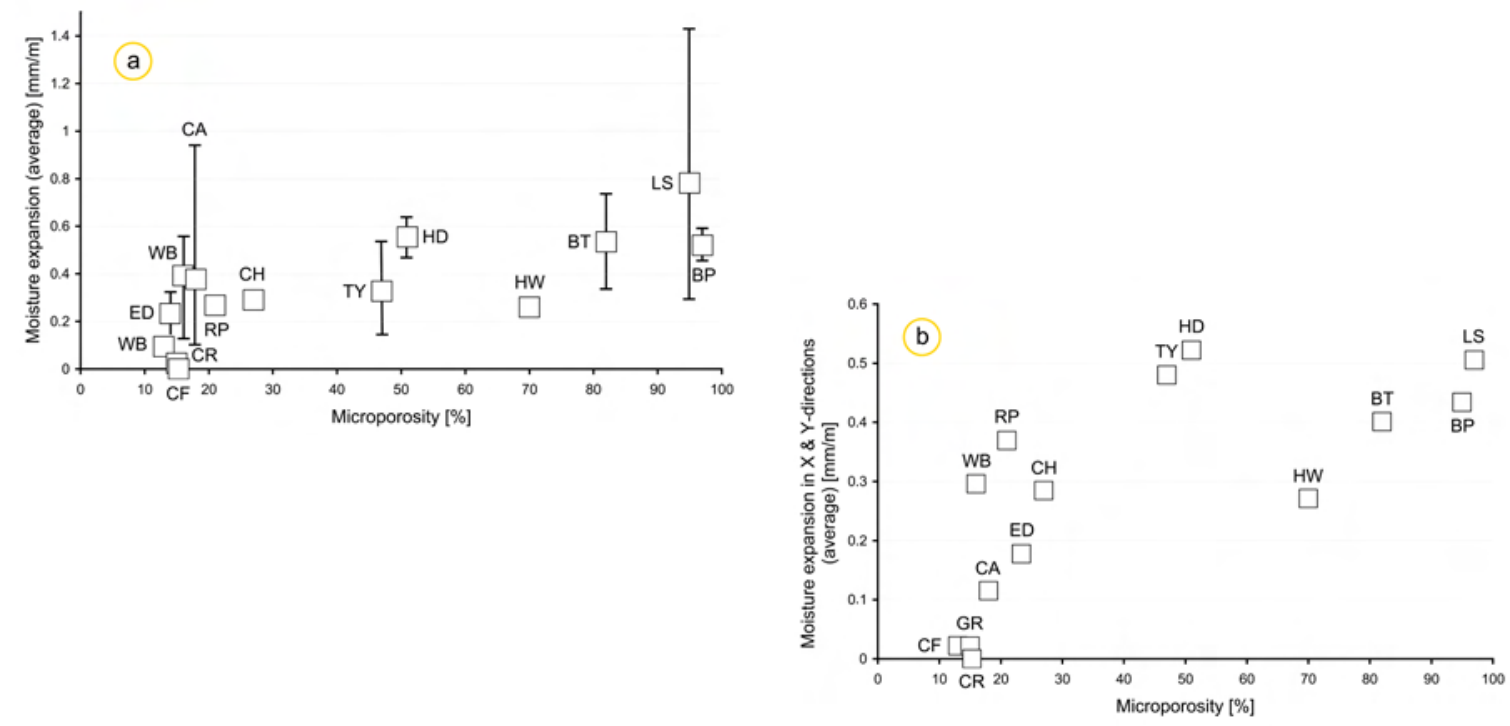

Figure 147: a) Moisture expansion and the microporosity show a distinct tendency of correlation. b) Moisture expansion on the $\mathrm{X}$ - and Y-axes shows a clear correlation.

Most of the studied rocks show a correlation between the average pore radius and the hydric moisture expansion values. In general, it can be observed that a decrease of the hydric dilatation occurs with the increase of the average pore radius, which is clearly recognizable in Figure 148.

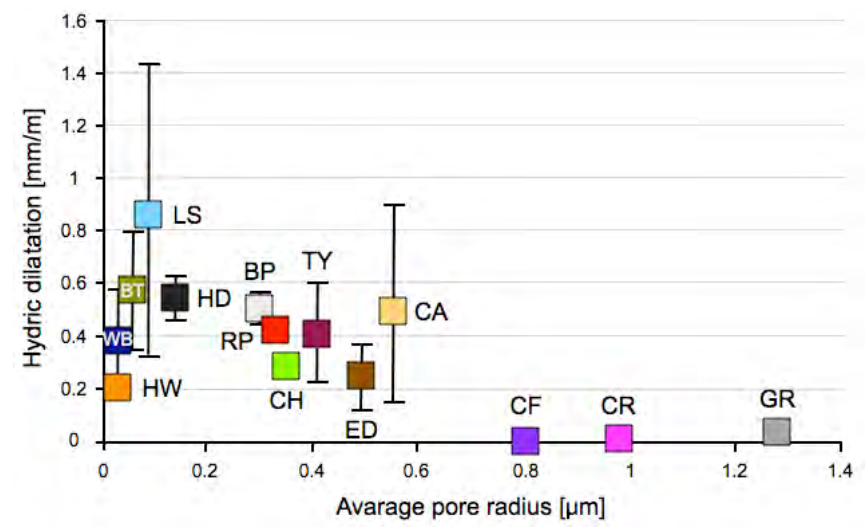

Figure 148: Moisture expansion and the average pore radius show a tendency of correlation.

\section{4. 4 Softening properties as a function of moisture content}

Weathering often occurs in the base area of historical constructions erected from volcanic stones (Yavuz 2006, Wedekind et al., 2011, Jáuregui et al., 2012). One reason for deterioration is due to the decrease in strength upon wetting of the rock, described by Hirschwald (1908) as "softening". The softening degree varies among the different lithotypes. For crystalline rocks, such as granites and gneisses, the softening effect is minimal. However, this effect can be significant in porous rocks such as sandstones and tuffs, and can reach a strength decrease of up to $50 \%$ (Siedel 2010 b, Jáuregui et al., 2012). Morales Demarco et al., (2007) found a positive correlation between the decrease 
of the compressive strength and the magnitude of moisture expansion in sandstones. This correlation has been verified for the tensile strength of sandstones in Ruedrich et al., (2011 a).

For the weakening and decay of stones, the stress induced by weathering processes has to exceed the rock strength. One of the most useful methods to determine this strength is the tensile strength, because this property is significantly lower compared to the compressive strength. This strength is mainly controlled by the porosities as presented in figure 149 for the $\mathrm{Z}$ and $\mathrm{X}$-direction.
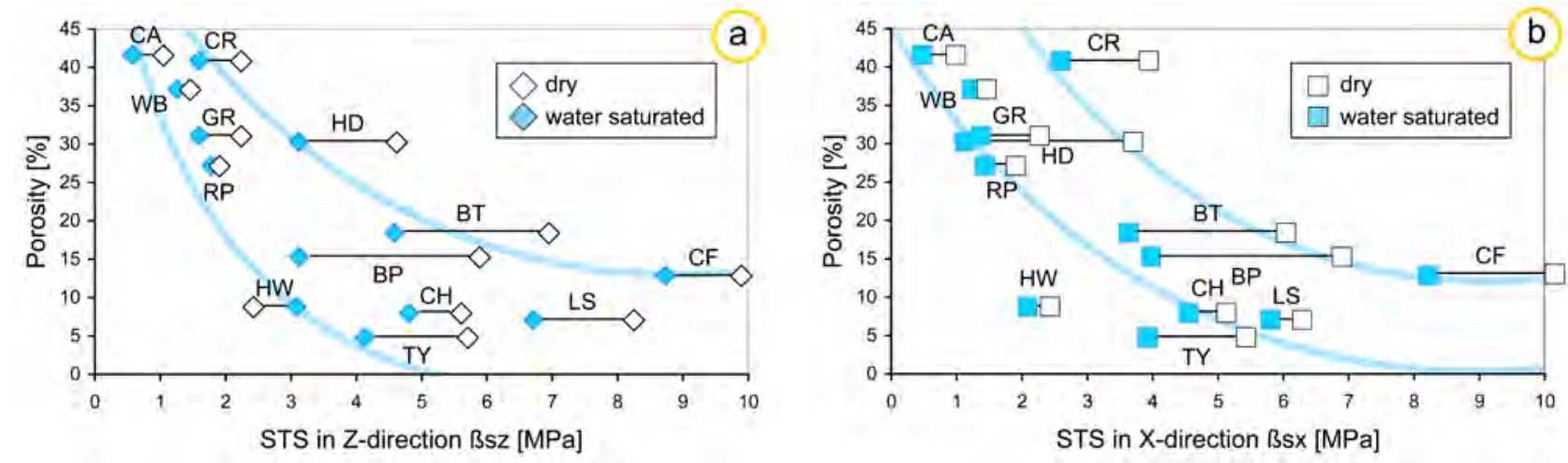

Figure 149: Correlation between the splitting tensile strength (STS) and the effective porosity. a) Correlation on the Zaxis and $\mathrm{b}$ ) on the $\mathrm{X}$-axis.

The analyzed tuffs show a weak correlation between the moisture expansion and the reduction of the splitting tensile strength, especially for the X-direction (Fig. 149 b). In this case, the dilatation due to the effects of moisture causes a weakening and softening of the rock, particularly under water-saturated conditions, which is shown for the X-and Z-axes (Fig. $150 \mathrm{a}$ and b). Moisture expansion and the STS-value in the Z-direction give evidence of a weak correlation for most of the samples (Fig. 150 a). The graph for the strength versus the expansion in the X-direction only shows an undefined point cloud (Fig. 150 b).
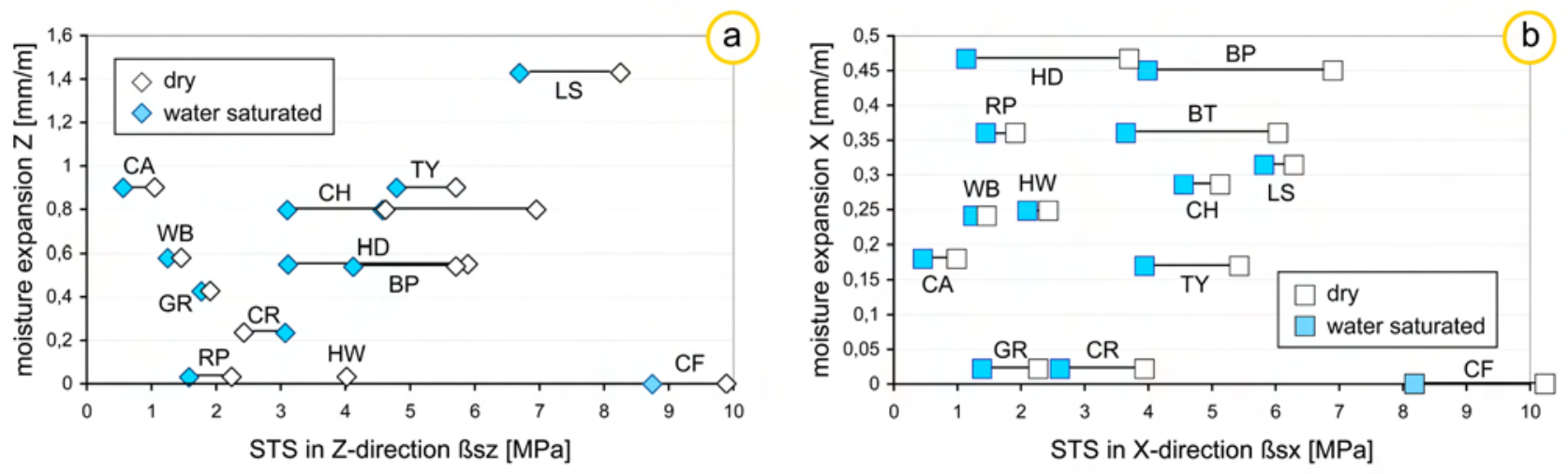

Figure 150: The splitting tensile strength and moisture expansion show a weak correlation (a) in the Z-direction and (b) in the X-direction under dry conditions only. 


\section{4. 5 Moisture expansion related to the physical properties}

The fabric of a rock affects the petrophysical properties (Siegesmund, Duerrast 2011). One key factor is the pore-size distribution, which affects the stone's durability (Punuru et al., 1990; Fitzner, Basten 1994; Benavente et al., 2004). Ruedrich et al., (2011 a) found that the effect of the disjoining pressure is relevant in rocks with a high amount of micropores. In fact, tuffs like HW, HD, BT, LS, TY and BP have a significant portion of micropores (50\% or more). These samples also show the highest values of hydric dilatation, especially on the Z-axis (Fig. 142). Especially HD, which has a very low CEC value, shows an important dilatation. In this case, the dilatation is controlled exclusively by the microporosity and its dense and complex pore network that is associated to the layering of the tuff. This observation points to the disjoining pressure as a major factor affecting moisture expansion (Fig. 138, Hilbersdorf Tuff, i).

Our investigations demonstrate that, besides the clay minerals, the microporosity has a significant effect on swelling and moisture expansion. Ruedrich et al., (2011 a) suggest the importance of the relation between clay mineral content, porosity and the location of the clay minerals within the pore space of sandstones. The influence of the swelling depends on the clay minerals if they are oriented along the grain boundaries. However, if the tuffs contains high amounts of clay minerals but the pores are too large, i.e. the pore walls are only coated by the clay minerals, then the swelling pressure induced by the clay minerals will not have any significant effect on the moisture expansion, as was clearly demonstrated by SEM observations made in BP, HW, TY, and ED (Fig. 151). Reyes-Zamudio et al., (2010) and Ruedrich et al., (2011 a) were also able to show that rocks with a higher amount of clay minerals and larger pores do not show higher moisture expansion. BT seems to be a special case. The SEM images show other iron-rich minerals besides the presence of some clay minerals (Fig. 68 a and b). The observed dilatation in this tuff may also be associated with an expansion due to the oxidation and crystallization of these minerals (Fig. 68 c).

In general, hydric and hygric swelling in porous rocks were discussed due to swellable clay minerals. Different hypotheses, like inner-crystalline or osmotic swelling, are the leading hypotheses. However, both theories would require that the clay minerals be responsible for a higher CEC value, and lastly, that they be correlated to greater moisture expansion.

However, our extensive investigation on tuffs with a broad variation in mineralogy and rock fabrics shows that the above-mentioned correlation cannot be supported. At first, the total amount and type of clay minerals are also of critical importance. A detailed clay mineral study is absolutely necessary to explain the observed moisture expansion. 

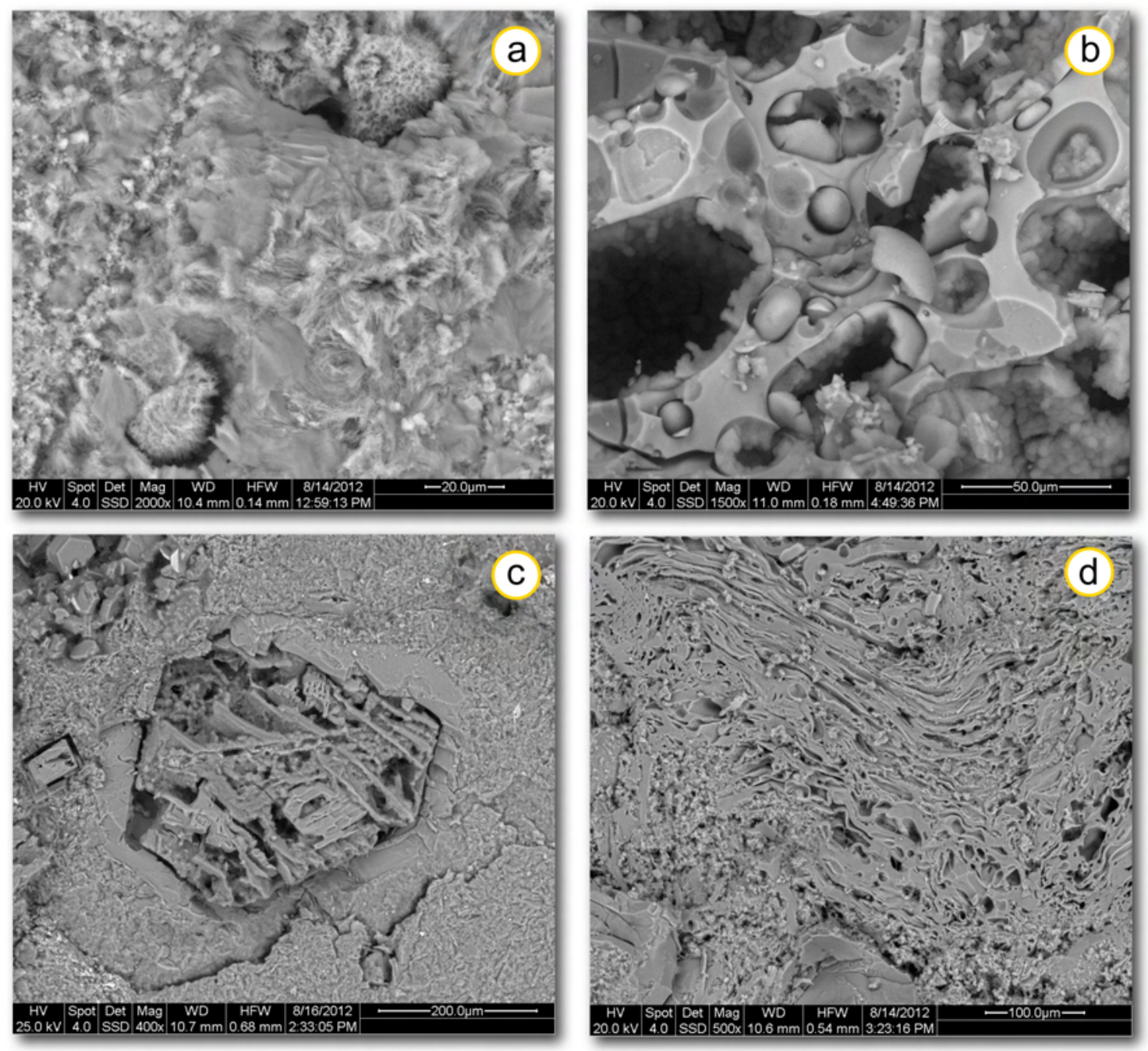

Figure 151: a) SEM images of Blanca Pachuca Tuff (BP) with partly filled pores. b) The Habichtswald Tuff (HW), with a clay-rich pore space coating consisting of smectite. c) Inner structure of the Tenayocátetl Tuff (TY) shows altered minerals covered with a fine coating of smectite (plagioclase in the middle). d) Eger-Demjén Tuff (ED) with long drawn-out pores.

\section{5 Conclusions}

1. We were able to show that the amount of microporosity has a significant impact on the intensity of the moisture expansion. Tuffs with a higher amount of microporosity show a higher moisture expansion, even when the swellable clay minerals are lacking.

2. The study also demonstrated that there is a clear correlation between the amount of moisture swelling and the softening of the tuffs, as well as the pore size and the degree of water saturation.

3. There is no doubt that the clay minerals can significantly contribute to moisture expansion, but not all of the moisture-related expansion can be attributed to the presence and amount of the minerals of this group. The influence of clay minerals is noticeable in the case of fine laminated varieties showing a high anisotropy on moisture transport properties and mechanical strength. 
4. The importance of the disjoining pressure may have been overlooked in the literature on moisture expansion. A high moisture expansion was clearly demonstrated in the case of some tuffs, which were more or less devoid of any clay minerals showing CEC values lower than $1.0 \mathrm{meq} /$ $100 \mathrm{~g}$.

In summary, it is undoubtedly clear that not only clay minerals may affect the swelling pressure, and that quite complex processes of mineralogical aspects and rock fabrics, like microporosity and the interaction of moisture films, have to be considered.

\section{6 Outlook}

Comparing these results with our own findings for the sandstones investigated in this thesis and the findings of Ruedrich et al., (2011 a) matches are possible by substituting. For most of the samples there is a clear correlation between moisture swelling or contraction and microporosity (Fig. 152).

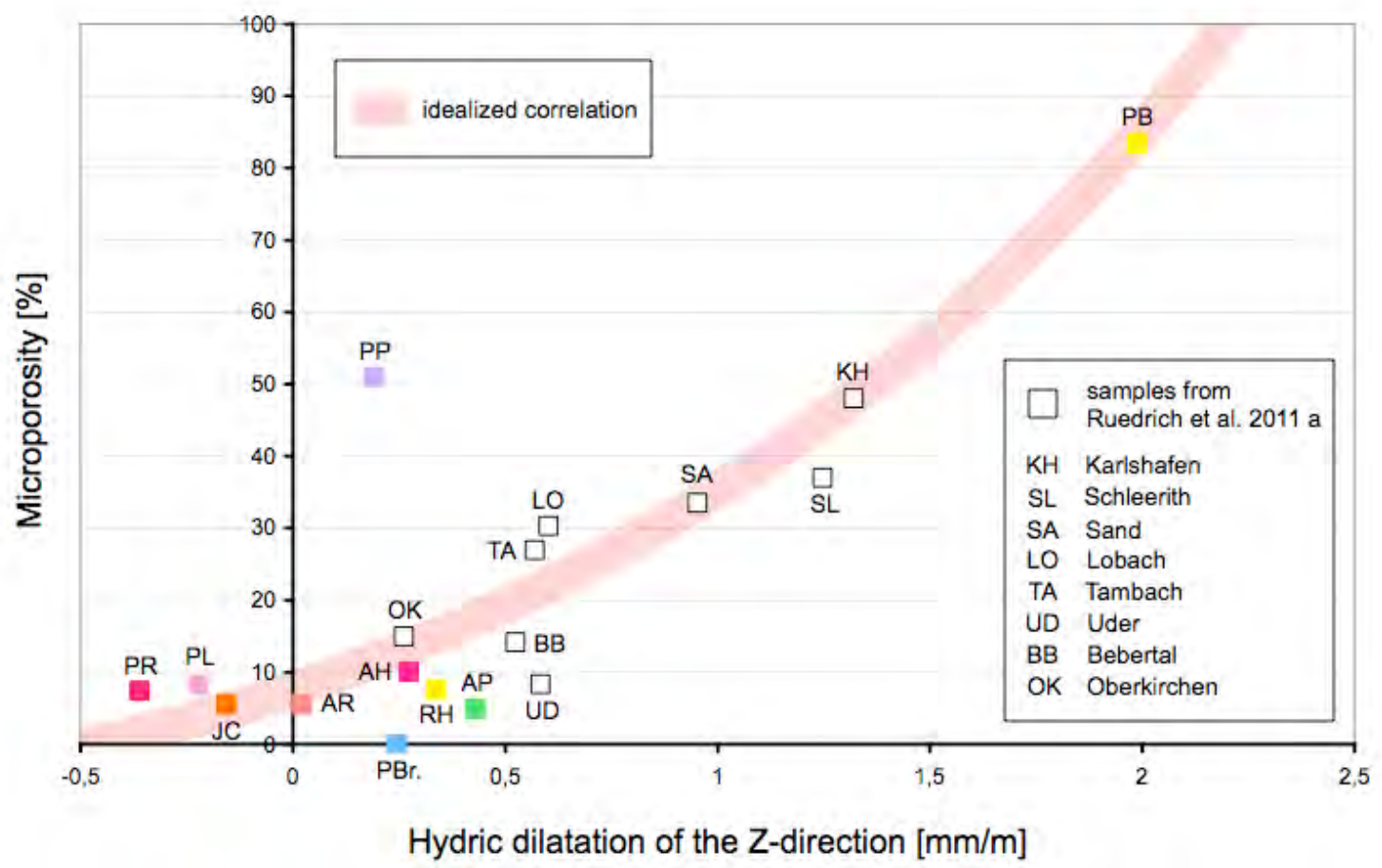

Figure 152: Hydric dilatation versus microporosity of different sandstone samples.

In some samples the expansion can be traced back to the presence of swellable clay minerals but not for each. In the case of PB hydric dilatation has to be traced back to swallable clay minerals but according to Ruedrich et al., (2011 a) the Karlshafen sandstone only has a CEC-value of 2.0 and TA only 1.0 and LO only 0.5 . Only the PP sandstone from Petra is an exception. The sample shows low values of hydric expansion but with $50 \%$ remarkable amounts of microporosity (Fig. 144). This sandstone variety was the only one that shows any hydric dilatation while the other Petra sandstones show shrinking. If clay minerals are present within this sample, they are swellable ones 
but hydic dilatation seems to be influenced or reduced by the general shrinking behavior of the Petra sandstones. 


\section{Salt weathering}

\section{1 Introduction}

Damages on historical structures built from natural building stones are in many cases due to the impact of salt crystallization (Fig. 153). The fundamental prerequisite is the reduction of the stresses created by salinization. The damage processes may be stopped or slowed down by preservation measures, which would guarantee a sustainable protection of the object under consideration.

The transport of salts largely occurs by solution in the pore spaces of natural building stones. These can also be utilized by the measures designed to reduce the presence of salts. Two transport mechanisms are known: capillary transport and ion diffusion. Capillary transport occurs at a relatively high rate. It is dependent upon the pore space properties of the rock, the moisture content, temperature and the pressure gradient. In contrast the diffusion processes operate at very slow rates. They are determined by the saturation in the pore spaces, the mode of pore space interconnectivity and the precipitates in the solution. The only applications that come into question are those which can be easily executed at low costs. The most practical method by far for use in preserving historical monuments is the compression desalination process (Auras, Melisa 2002).

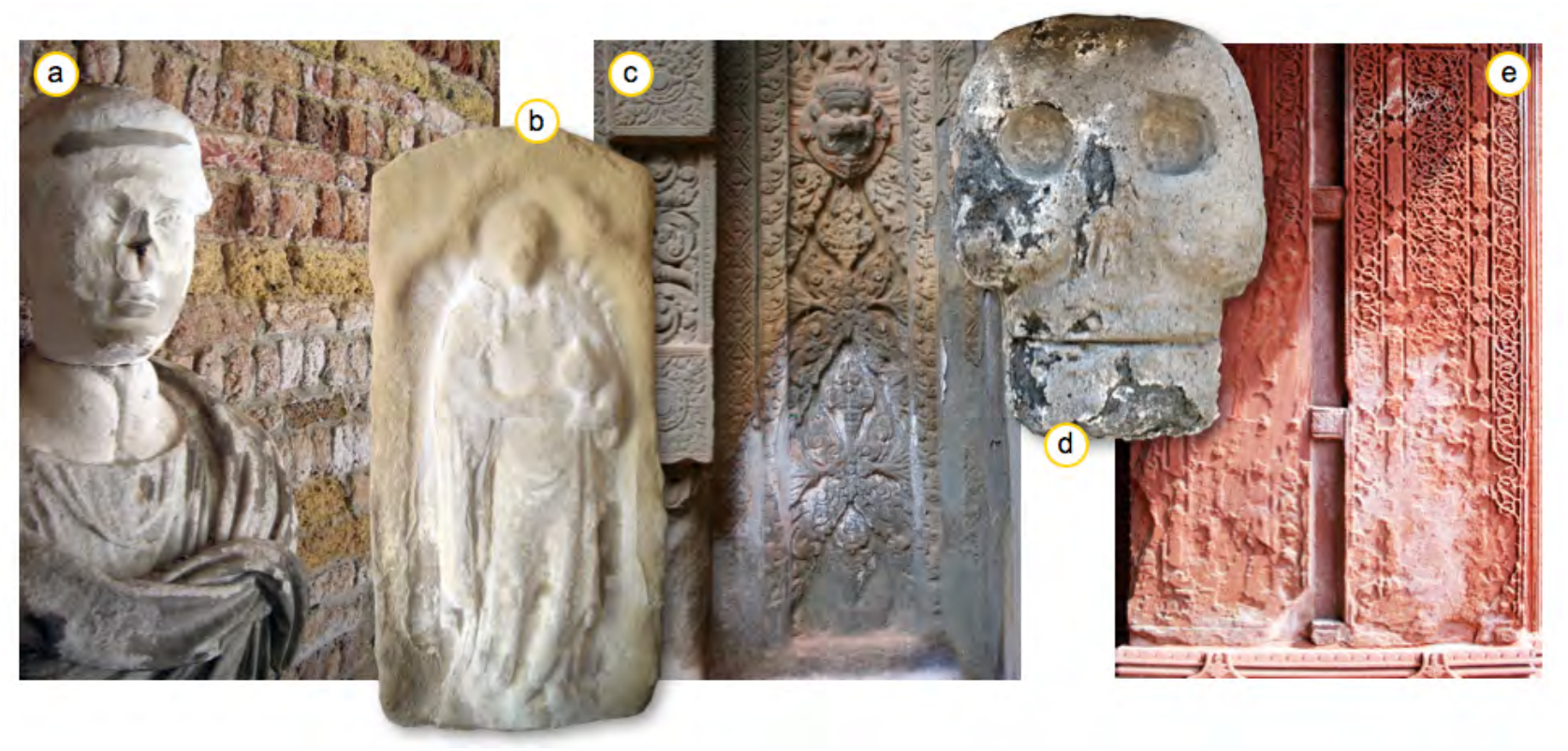

Figure 153: Salt weathering is a main weathering form that occurs on historical monuments worldwide and the contamination can have various sources. a) Weathering of marble and brickstone due to marine salt contamination in Venice/ Italy, b) a salt contaminated tomb plate due to magnesium sulphate salts created by the binding material of the sandstone and industrial pollution, c) salt weathering at a temple of Angkor/Cambodia due to bat guano, d) salt weathering of a skull at the Templo Mayor in Mexico City due to salt contamination within the groundwater and rising dampness and

e) salt weathering due to contamination by pigeons at the Fatipur Sikri Temple/India. 


\section{1. 1 Tuffs and sandstones in salt weathering}

Tuffs as well as sandstones are mostly soft and porous rocks that can be easily cut and reworked. They are, however, very susceptible to the effects of weathering, especially the deterioration caused by salt crystallization.

Seventeen volcanic tuff samples from Mexico, four from Germany and one from Hungary that were used as natural building stones have been investigated in this study. Moreover, the results of the investigations on the ten sandstones in this thesis are also included in this chapter. The tuffs as well as the sandstones show highly variable compositions and different porosities and textural properties as well as very different behaviors in regards to salt crystallization.

Some petrographic and petrophysical factors are important in regards to the resistance against salt crystallization. Two of the most important are the water vapor diffusion ( $\mu$-value) and the pore radii distribution; however microporosity also becomes a relevant factor for rapid salt destruction if it reaches around or more than $50 \%$ of the pore volume. All these effects are related to salt crystallization, which are dependent on the presence of water in any form, so the climatic conditions must also play a major role.

All the pre-colonial constructions of the Maya and the later Aztec culture were made from different rock types available locally, near the settlements that used a colored plaster covering (Wedekind et al., 2011), whereas during the period of Spanish colonization the architecture is characterized by ashlars and masonry facades. The available rocks were transported within a geographic radius of about $100 \mathrm{~km}$. After the second half of the $16^{\text {th }}$ century many important cities were built whose main buildings were constructed almost exclusively with natural rocks. Due to the abundance of volcanic rocks throughout the country and because of the properties that volcanites exhibit as a construction material (Wedekind et al., 2013), volcanic tuffs were mainly used in large quantities in the past and are still the main choice for use in most of the country today. Tuffs are mostly soft and porous rocks that can be easily cut and reworked. However, they can be very susceptible to the effects of weathering, especially the deterioration caused by salt crystallization. Despite this, the effects of material loss and deterioration are visible in many different forms and levels in the analyzed tuffs in this study.

Crystallization of salts within the pores of natural building stones generate sufficient stress to provoke the cracking of stone, even up to the total destruction of the rock (Winkler, Singer 1972; Grossi, Esbert 1994; Rodriguez-Navarro; Doehne 1999; Flatt 2002; Tsui et al., 2003; Coussy 2006). This process is considered to be the most important cause of deterioration in natural building rocks and monuments built by ashlars. The resistance of stone to salt damage depends on the pore size distribution and decreases as the proportion of fine pores increases, therefore it is to be expected, that 
building stones with a major proportion of micropores and capillary pores are less resistant against the phenomena of salt crystallization.

Fitzner und Snethlage (1982) suggest that the crystallization occurs first in the macro and capillary pores (compare with Angeli et al., 2007). The crystallization in the micropores happens when the larger pores are filled and the salt crystallization in the micropores occurs only when the chemical potential of the crystals is the same for the larger pores as for the smaller ones. Normally the crystals in the larger pores have a smaller chemical potential. This can be intensified by increasing the pressure due to crystal growth and through this process crystallization can also occur in the smaller pores. This can cause grain and matrix consolidation does not withstand the pressure, and the salt blasting begins (see also Angeli et al., 2007).

If the salt crystallization, and therefore the salt bursting depend so extremely on the porosity, rocks with more and larger pores may be more susceptible against salt blasting. Finally, all these effects related to salt crystallization are dependent on the presence of water in any form, and thus climatic conditions must also be a significant factor. The main goal of this work is to investigate which property of the volcanic tuff rocks plays the most important role.

To determine the main factor of weathering caused by salt crystallization, a large number of salt bursting tests were performed on selected rock samples, which are characterized by an ideal porosity, permeability and water diffusion.

\section{1. 2 Salt impact}

Salt contamination in all cases is related to moisture or rain. When the salt accumulation is high, the possibility for conservation only becomes feasible if the sources of the salt and transport mechanisms as well as the weathering processes are known. In the case of Mexico the salt has intrinsic as well as extrinsic causes. The same is true for Angkor but depends on the type of sandstone. The sandstones of Petra and most of the Buntsandstein varieties in Goettingen do not contain potential salts.

\section{2 Rock material}

In the present study 17 Mexican volcanic tuffs, four German tuffs and one Hungarian one that were used as natural building stones have been petrographically analyzed in detail. These tuffs show varying compositions, different porosities and textural properties as well as very different behaviors in regards to salt crystallization. Tuffs are in most cases very porous rocks (up to more than $40 \%$, Wedekind, et al., 2011; 2013; Siegesmund, Duerrast 2011) and their pore radius can vary greatly. Another characteristic of the tuff stones regarding porosity is that even if it represents a large percentage of pores in the whole rock, it does not necessarily mean that it is effective. Furthermore, the sands- 
tones from Germany, Jordan and Cambodia, already presented in this thesis were also included in this investigation.

Table 33: List of the 17 analyzed volcanic tuff rocks from Mexico, the four tuffs from Germany, the one from Hungary, the four sandstones from Germany, the three from Jordan, the three from Cambodia and their names, abbreviations, classifications, provenances, climatic classification and test cycles

\begin{tabular}{|c|c|c|c|c|c|}
\hline Sample name & $\begin{array}{l}\text { Abbrevi } \\
\text { ation }\end{array}$ & Classification & $\begin{array}{l}\text { Provenance } \\
\text { City, State, } \\
\text { Country }\end{array}$ & $\begin{array}{c}\text { Climatic } \\
\text { classificatio } \\
\text { n after } \\
\text { Köppen and } \\
\text { Geiger }\end{array}$ & $\begin{array}{l}30 \% \text { weight } \\
\text { reduction } \\
\text { by salt } \\
\text { bursting } \\
\text { test cycles }\end{array}$ \\
\hline Red Tuff & RG & Andesite Tuff & $\begin{array}{l}\text { San Miguel de } \\
\text { Allende, } \\
\text { Guanajuato, } \\
\text { Mexico }\end{array}$ & BSh & 8 \\
\hline Gris Oscura Tuff & SG & Andesite Tuff & $\begin{array}{l}\text { San Miguel de } \\
\text { Allende, } \\
\text { Guanajuato, } \\
\text { Mexico }\end{array}$ & BSh & 8 \\
\hline Black Tuff & Qro black & $\begin{array}{c}\text { Trachyte andesite } \\
\text { Tuff }\end{array}$ & $\begin{array}{c}\text { Querétaro City, } \\
\text { Querétero, } \\
\text { Mexico }\end{array}$ & Csa & 10 \\
\hline Zacatekas Quarry & Zac quarry & $\begin{array}{c}\text { Rhyolite Ignimbrite } \\
\text { Tuff }\end{array}$ & $\begin{array}{c}\text { Guadalupe, } \\
\text { Zacatecas, } \\
\text { Mexico }\end{array}$ & BSk & 11 \\
\hline Toba Negra Tuff & GF black & Trachyte Tuff & $\begin{array}{l}\text { San Miguel de } \\
\text { Allende, } \\
\text { Guanajuato, } \\
\text { Mexico }\end{array}$ & BSh & 12 \\
\hline Toba Gris Tuff & GF grey & Trachyte Tuff & $\begin{array}{l}\text { San Miguel de } \\
\text { Allende, } \\
\text { Guanajuato, } \\
\text { Mexico }\end{array}$ & BSh & 13 \\
\hline $\begin{array}{c}\text { Zacatekas } \\
\text { Cathedral Tuff }\end{array}$ & Zac cath & $\begin{array}{c}\text { Rhyolite Ignimbrite } \\
\text { Tuff }\end{array}$ & $\begin{array}{c}\text { Zacatecas City, } \\
\text { Zacatecas, } \\
\text { Mexico }\end{array}$ & BSk & 13 \\
\hline El Salto Tuff & Zac El Salto & Rhyolite glass Tuff & $\begin{array}{c}\text { Zacatecas City, } \\
\text { Zacatecas, } \\
\text { Mexico }\end{array}$ & BSk & 15 \\
\hline La Cueva Tuff & Zac LC & Galssy Lapilli Tuff & $\begin{array}{c}\text { Zacatecas City, } \\
\text { Zacatecas, } \\
\text { Mexico }\end{array}$ & BSk & 41 \\
\hline $\begin{array}{c}\text { Gris de Remedios } \\
\text { Tuff }\end{array}$ & GR & $\begin{array}{c}\text { Rhyolite Ignimbrite } \\
\text { Tuff }\end{array}$ & $\begin{array}{l}\text { Mexico City, } \\
\text { Mexico DF, } \\
\text { Mexico }\end{array}$ & $\mathrm{Cfb}$ & 16 \\
\hline Bufa Tuff & BT & Rhyolite Tuff & $\begin{array}{c}\text { Guanajuato City, } \\
\text { Guanajuato, } \\
\text { Mexico }\end{array}$ & Csb & 22 \\
\hline Blanca de Pachuca & $\mathrm{BP}$ & Rhyolite Tuff & $\begin{array}{c}\text { Pachuca, } \\
\text { Hidalgo, Mexico }\end{array}$ & $\mathrm{Cfb}$ & 23 \\
\hline
\end{tabular}


Table 33: List of the 17 analyzed volcanic tuff rocks from Mexico, the four tuffs from Germany, the one from Hungary, the four sandstones from Germany, the three from Jordan, the three from Cambodia and their names, abbreviations, classifications, provenances, climatic classification and test cycles

\begin{tabular}{|c|c|c|c|c|c|}
\hline $\begin{array}{c}\text { Leseros Formation } \\
\text { Tuff }\end{array}$ & LS & Epiclastic Tuff & $\begin{array}{c}\text { Guanajuato City, } \\
\text { Guanajuato, } \\
\text { Mexico }\end{array}$ & Csb & 26 \\
\hline $\begin{array}{c}\text { Cantera Amarilla } \\
\text { Tuff }\end{array}$ & CA Gdl & Rhyolite Tuff & $\begin{array}{c}\text { Guadalajara, } \\
\text { Jalisco, Mexico }\end{array}$ & Csa & 28 \\
\hline Tenayocátelt Tuff & TY & $\begin{array}{c}\text { Rhyolite Ignimbrite } \\
\text { Tuff }\end{array}$ & $\begin{array}{l}\text { Mexico city, } \\
\text { Mexico DF, } \\
\text { Mexico }\end{array}$ & Csb & 38 \\
\hline $\begin{array}{c}\text { Las Escolásticas } \\
\text { Tuff }\end{array}$ & ESC & Rhyolite Tuff & $\begin{array}{c}\text { Las Escolásticas, } \\
\text { Querétaro, } \\
\text { Mexico }\end{array}$ & Csa & 44 \\
\hline Cantera Rosa Tuff & CR & Rhyolite Tuff & $\begin{array}{l}\text { San Miguel de } \\
\text { Allende, } \\
\text { Guanajuato, } \\
\text { Mexico }\end{array}$ & BSh & 53 \\
\hline Chiluca Tuff & $\mathrm{CH}$ & $\begin{array}{c}\text { Pyroxene andesite } \\
\text { Tuff }\end{array}$ & $\begin{array}{c}\text { Mexico City, } \\
\text { Mexico DF, } \\
\text { Mexico }\end{array}$ & $\mathrm{Cfb}$ & 59 \\
\hline $\begin{array}{c}\text { Cantera Formation } \\
\text { Tuff }\end{array}$ & $\mathrm{CF}$ & $\begin{array}{l}\text { Rhyolitic ignimbrite } \\
\text { Tuff }\end{array}$ & $\begin{array}{c}\text { San Luis Potosí, } \\
\text { Mexico }\end{array}$ & Csa & Still in work \\
\hline Weibern Tuff & WB & Rhyolitic Tuff & $\begin{array}{l}\text { Weibern, } \\
\text { Rhineland- } \\
\text { Palatinat, } \\
\text { Germany }\end{array}$ & $\mathrm{Cfb}$ & 5 \\
\hline Habichtswald Tuff & HW & Basaltic lapilli Tuff & $\begin{array}{c}\text { Kassel, Hesse, } \\
\text { Germany }\end{array}$ & Cfb & Still in work \\
\hline $\begin{array}{c}\text { Rochlitz Porphyry } \\
\text { Tuff }\end{array}$ & $\mathrm{RP}$ & $\begin{array}{c}\text { Rhyolitic porphyritic } \\
\text { Tuff }\end{array}$ & $\begin{array}{c}\text { Rochlitz, Saxony, } \\
\text { Germany }\end{array}$ & $\mathrm{Cfb}$ & 13 \\
\hline Hilbersdorf Tuff & $\mathrm{HD}$ & Porphyric Tuff & $\begin{array}{l}\text { Hilbersdorf, } \\
\text { Saxony, } \\
\text { Germany }\end{array}$ & Cfb & 17 \\
\hline Eger Denjem Tuff & ED & Ignimbrite Tuff & $\begin{array}{c}\text { Eger Denjem, } \\
\text { Hungary }\end{array}$ & Cfb & 9 \\
\hline $\begin{array}{l}\text { Arendshausen } \\
\text { Sandstone }\end{array}$ & $\mathrm{AH}$ & Bunt-sandstone & $\begin{array}{l}\text { Arendshausen, } \\
\text { Lower Saxony, } \\
\text { Germany }\end{array}$ & $\mathrm{Cfb}$ & 14 \\
\hline $\begin{array}{l}\text { Appenrode } \\
\text { Sandstone }\end{array}$ & AP & Bunt-sandstone & $\begin{array}{l}\text { Appenrode, } \\
\text { Lower Saxony, } \\
\text { Germany }\end{array}$ & Cfb & 17 \\
\hline $\begin{array}{l}\text { Johannis Church } \\
\text { Sandstone }\end{array}$ & $\mathrm{JC}$ & Bunt-sandstone & $\begin{array}{c}\text { Johannis } \\
\text { Church, Lower } \\
\text { Saxony, } \\
\text { Germany }\end{array}$ & Cfb & 9 \\
\hline
\end{tabular}


Table 33: List of the 17 analyzed volcanic tuff rocks from Mexico, the four tuffs from Germany, the one from Hungary, the four sandstones from Germany, the three from Jordan, the three from Cambodia and their names, abbreviations, classifications, provenances, climatic classification and test cycles

\begin{tabular}{|c|c|c|c|c|c|}
\hline $\begin{array}{l}\text { Reinhausen } \\
\text { Sandstone }\end{array}$ & $\mathrm{RH}$ & Bunt-sandstone & $\begin{array}{l}\text { Reinhausen, } \\
\text { Lower Saxony, } \\
\text { Germany }\end{array}$ & $\mathrm{Cfb}$ & 12 \\
\hline $\begin{array}{l}\text { Petra Red } \\
\text { Sandstone }\end{array}$ & PR & $\begin{array}{l}\text { Cambrian } \\
\text { sandstone }\end{array}$ & Petra, Jordan & BSk & 44 \\
\hline $\begin{array}{l}\text { Petra Light-red } \\
\text { Sandstone }\end{array}$ & PL & $\begin{array}{l}\text { Cambrian } \\
\text { Sandstone }\end{array}$ & Petra, Jordan & BSk & 27 \\
\hline $\begin{array}{l}\text { Petra Purple } \\
\text { Sandstone }\end{array}$ & PP & $\begin{array}{l}\text { Cambrian } \\
\text { Sandstone }\end{array}$ & Petra, Jordan & BSk & 11 \\
\hline $\begin{array}{c}\text { Phnom Bakheng } \\
\text { Graywacke }\end{array}$ & PB & Graywacke & $\begin{array}{l}\text { Angkor, } \\
\text { Cambodia }\end{array}$ & $\mathrm{Am} / \mathrm{Aw}$ & 14 \\
\hline $\begin{array}{c}\text { Phnom Bakheng } \\
\text { Restoration Material } \\
\text { Graywacke }\end{array}$ & PBr. & Graywacke & $\begin{array}{l}\text { Angkor, } \\
\text { Cambodia }\end{array}$ & $\mathrm{Am} / \mathrm{Aw}$ & 25 \\
\hline $\begin{array}{l}\text { Angkor red } \\
\text { Graywacke }\end{array}$ & AR & Graywacke & $\begin{array}{l}\text { Angkor, } \\
\text { Cambodia }\end{array}$ & $\mathrm{Am} / \mathrm{Aw}$ & 28 \\
\hline
\end{tabular}

\section{2. 1 Petrography}

All the analyzed volcanic tuffs are Cenozoic in age and range from the Oligocene to the Holocene. Their compositions vary from acid rhyolites to basic andesite basalts.

The petrographic analysis was carried out using a polarizing microscope. Petrographic descriptions are given below. This study describes the following rocks: Red Tuff (RG), Negra (SG), Gris Oscura (GF black) and Gris (GF gray) tuffs of San Miguel de Allende, the Negra (Qro black) and Escolástica (ESC) tuffs from Querétaro and the Cathedral (ZAC Cath) and El Salto (Zac El Salto) tuffs from Zacatecas (see Tab. 33).

In thin section the RG shows a dark reddish, relatively coarse matrix with yellowish, whitish, grayish and orange unoriented and non-altered clasts in different sizes and textures (Fig. $154 \mathrm{~A}$ ). The main mineral is plagioclase, recognized by its typical interference color, twinning and zoning. Idiomorphic olivine und fine-grained quartz crystals are also embedded in the matrix. The texture of this tuff is cryptocrystalline to glassy and a smooth flow texture is also observable (Fig. 154 B). The percentage of matrix and clasts is about $60 \%-40 \%$, respectively. 
Red Tuff from San Miguel de Allende (RG)
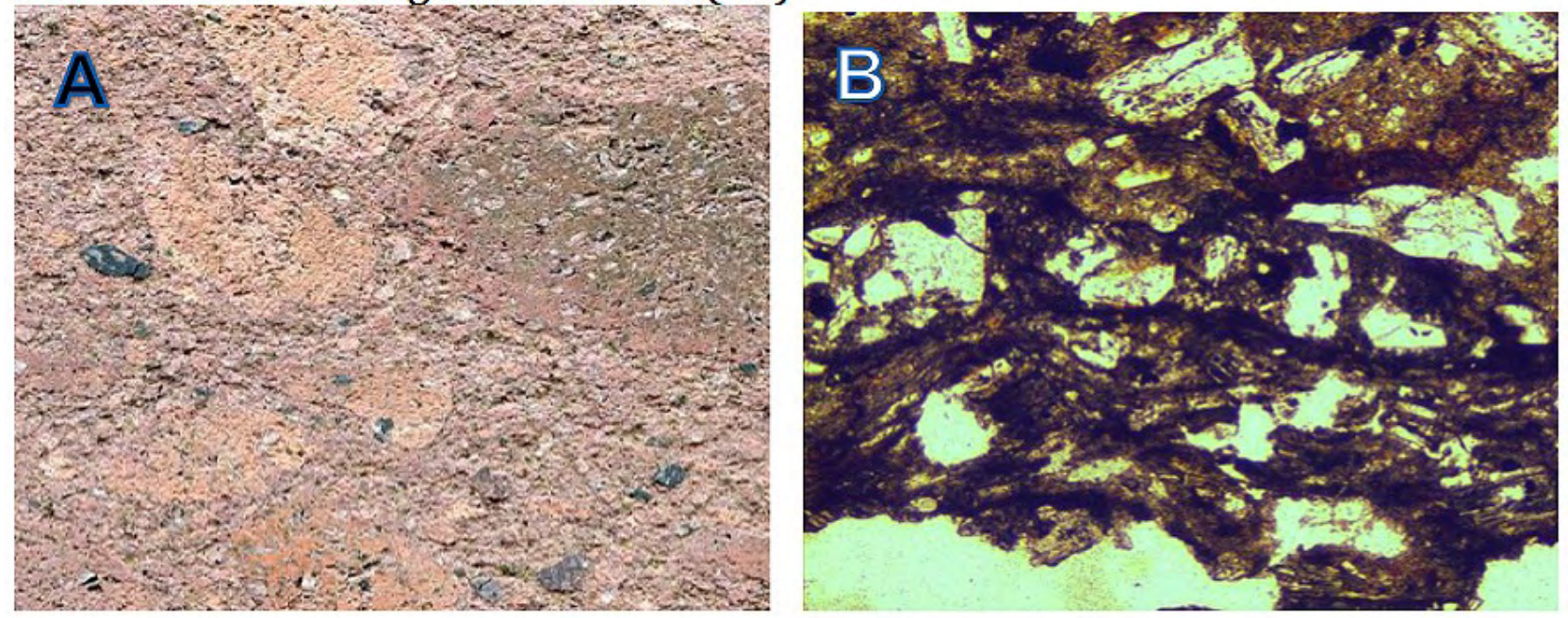

\section{Gris Oscura Tuff from San Miguel de Allende (SG)}
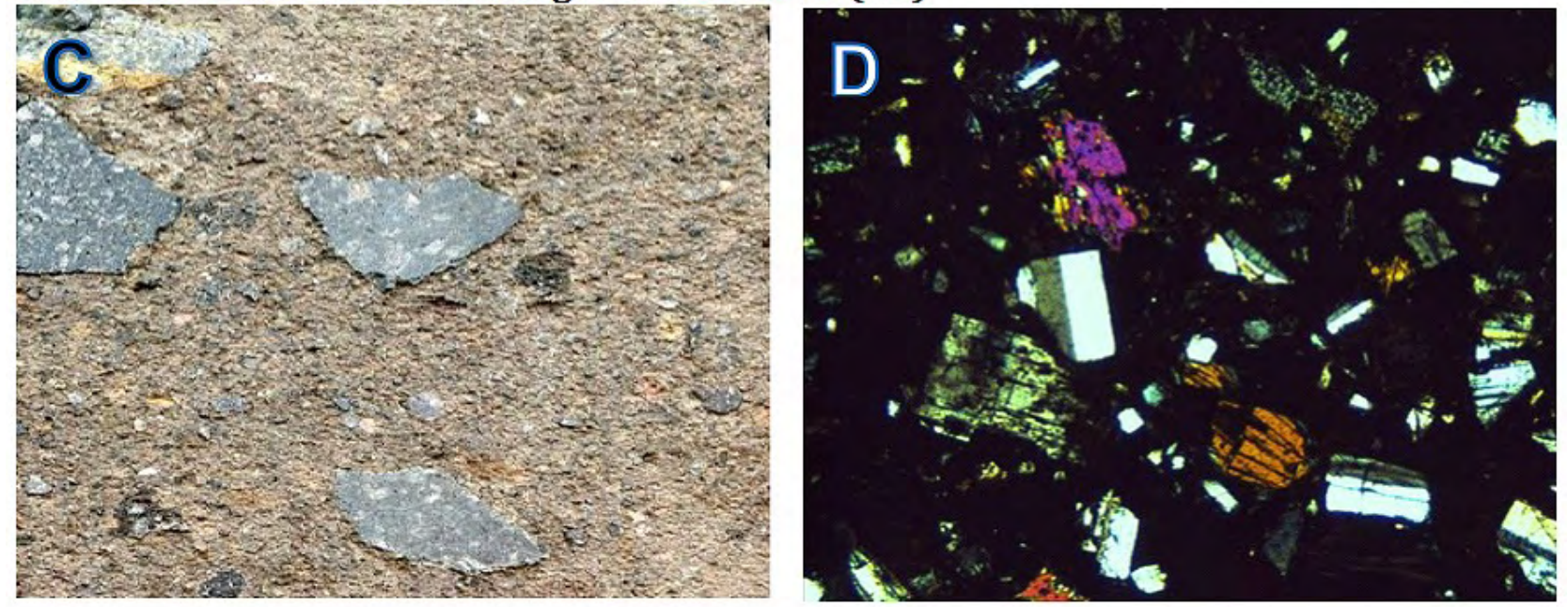

Gray Tuff from San Miguel de Allende (GF)
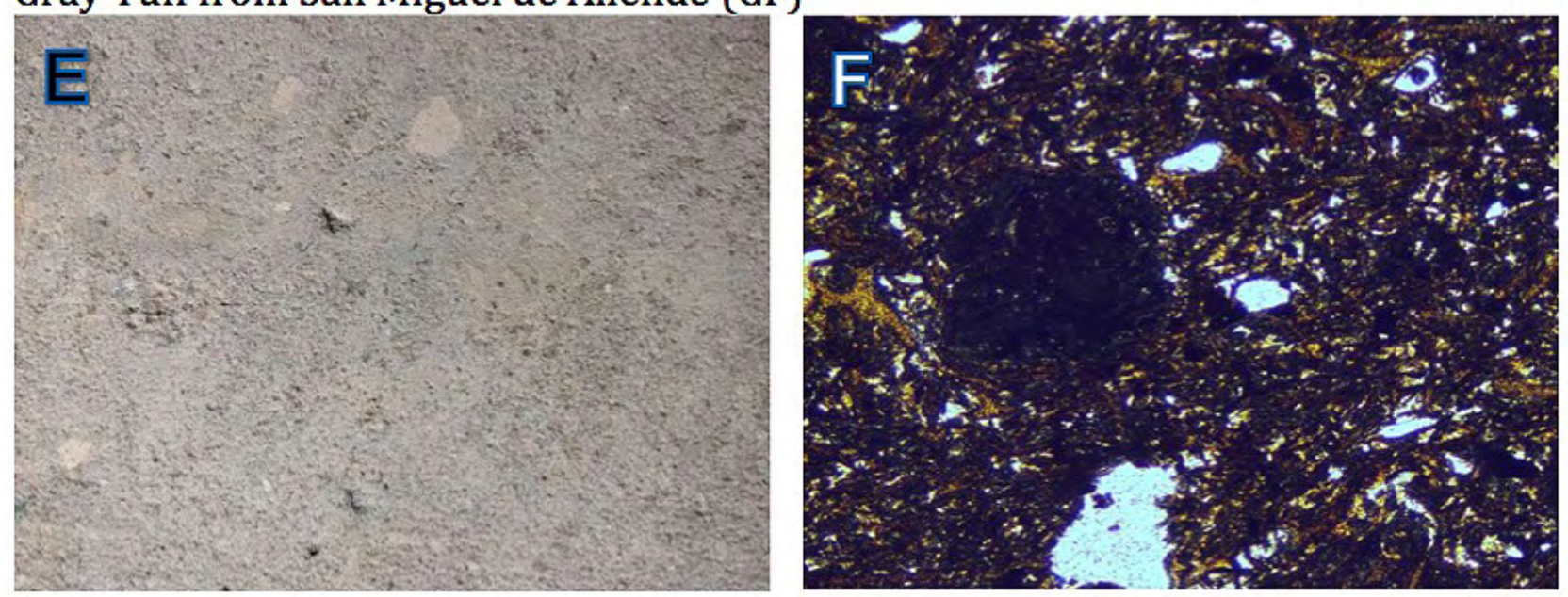

Table 154: Tuff rocks from San Miguel de Allende. A, C and E) Macroscopic fabric in hand specimen (all samples are $6.5 \mathrm{~cm}$ in length). B, D and F) Thin section of the tuff rocks from San Miguel de Allende (all microphotographs are 5 $\mathrm{mm}$ in length and taken with a $5 \mathrm{X}$ objective), B and F) parallel nicols, D crossed nicols. Red Tuff of San Miguel de

Allende (RG). 


\section{2. 1. a) Gris Oscura Tuff of San Miguel de Allende (SG)}

The Gris Oscura Tuff from San Miguel de Allende stands out because of its cm-sized, slightly oriented black clasts, which are well differentiated in the brownish - grayish matrix (Fig. 154 C). The matrix, comprising $70 \%$ of the tuff, is slightly opaque under the polarizing microscope (Fig. 154 D). In the matrix fine-grained $0.2-0.5 \mathrm{~mm}$ sized, well-sorted, round to tabular minerals are observable, which are easily visible in hand specimen. The minerals are well-zoned and twinned plagioclases, brownish to reddish pyroxenes and partially altered olivines. The crystals are distributed across the whole matrix, without any orientation forming a typical seriate texture (Fig. 154 D), in which grains have practically the same sizes.

\section{2. 1. b) Black and Gray Tuff of San Miguel de Allende (GF black, GF gray)}

This tuff shows a very fine-grained gray to black matrix (70\% of the rock), where 0.1 to $1 \mathrm{~cm}$ sized idiomorphic crystals are embedded (Fig. 154 E). Under the microscope the matrix shows an opaque but well-foliated texture. The opaque aspect of the matrix indicates that it is mostly made up of glass. As in the RG sample the dominant minerals are plagioclases, which are the coarsest crystals. In addition to the plagioclases, some fine-grained, well-rounded, yellowish to brown mineral recognized as pyroxene occurs. Distributed within the matrix are many small opaque crystals that are probably hematite or some other iron oxide. In general the tuff shows a eutaxitic texture (Fig. 154 F). The main difference between the GF1 and GF2 samples is that the GF1 shows a very dark matrix, whereas the matrix in GF2 is gray. Petrographically both tuffs are very similar, but the content of iron oxides in the matrix of GF1 is much larger than in GF2.

\section{2. 1. c) Black Tuff of Querétaro (Qro black)}

This material is a black to grayish colored pyroclastic igneous rock with a porphyritic to seriate texture made up of slightly oriented non-collapsed black pumice fragments, white pumice fragments, lithics and phenocrysts of sanidine, quartz and plagioclase. The matrix has a glassy texture. The relationship between components and matrix is $65 \%-35 \%$.

The black pumice comprises about $20 \%$ of the rock and shows a highly vesicular texture (Fig. 155 $\mathrm{G})$. These components can vary in length from $1 \mathrm{~mm}$ up to $30 \mathrm{~mm}$ and are not collapsed. The white pumice fragments make up to $20 \%$ of the sample, are highly vesicular and also not collapsed (Fig. $155 \mathrm{G})$. The lithics represent about $10 \%$ of the sample, are not very rounded and have angular to subangular broken edges and their size varies from $0.5 \mathrm{~mm}$ to $15 \mathrm{~mm}$. The matrix has a glassy, nonwelded ash flow tuff texture (Fig. $155 \mathrm{H}$ ) and represents $35 \%$ of the sample.

\section{2. 1. d) Escolásticas Tuff of Querétaro (ESC)}

This tuff is a pink to reddish, brownish colored pyroclastic igneous rock (Fig. 155 I) with a porphyritic texture. It is composed of unoriented lithic fragments, fiammes, non-collapsed pumice, quartz 
and sanidine phenocrysts hosted on a microcrystalline, devitrified reddish matrix with a eutaxitic texture. The material contains about $40 \%$ of components and $60 \%$ matrix.
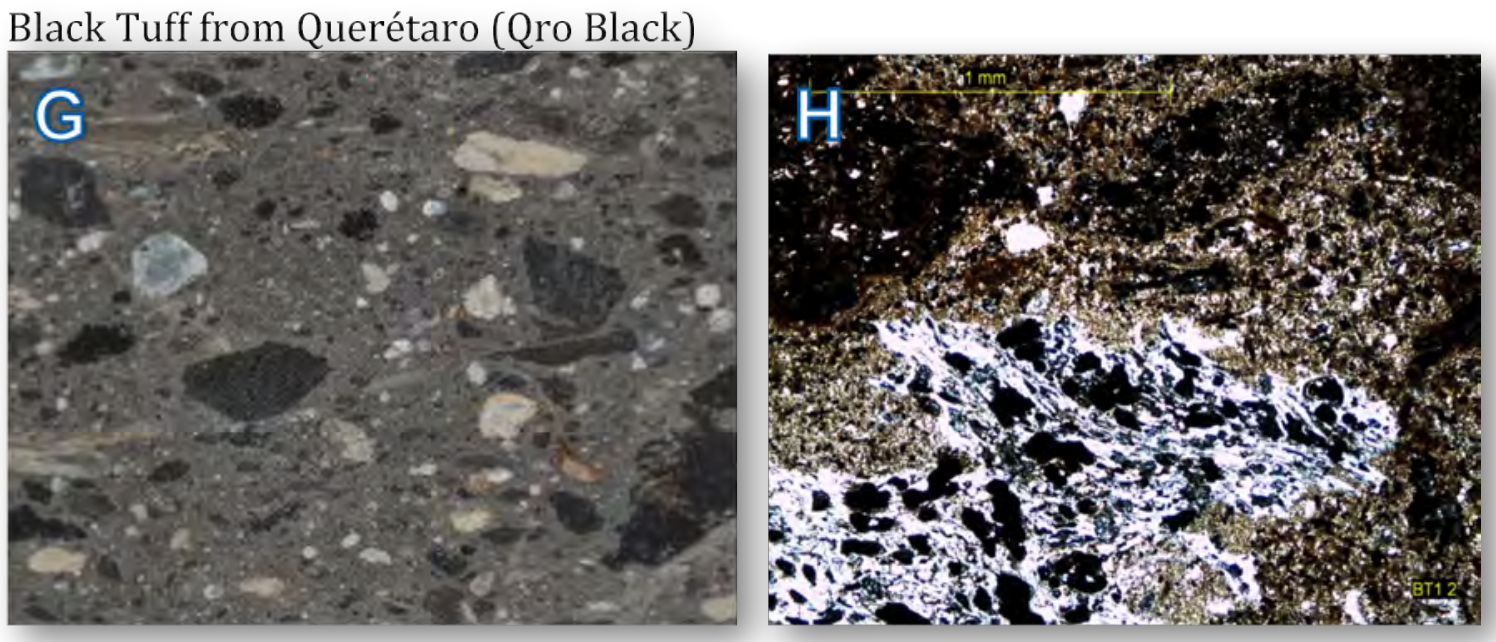

Gray Tuff from Escolásticas, Querétaro (ESC).

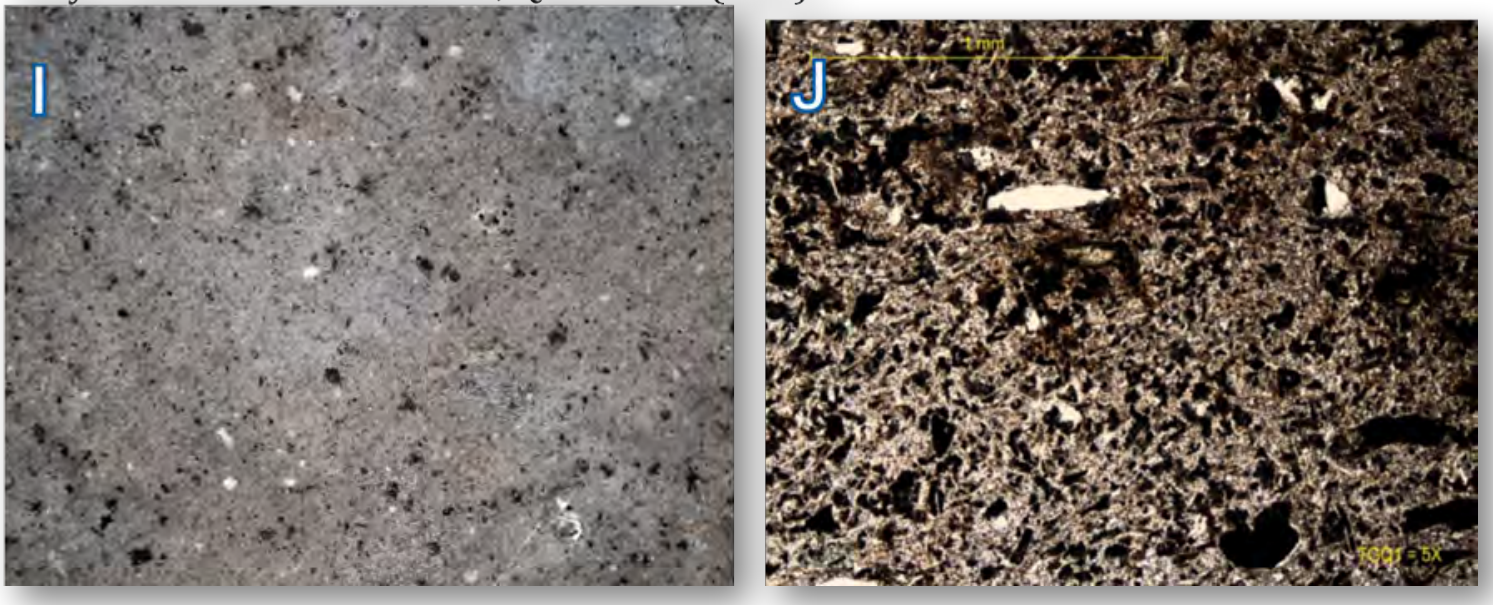

Figure 155: Tuff rocks from Querétaro. G and I) Macroscopic fabric in hand specimen (all samples are $6.5 \mathrm{~cm}$ in length). $\mathrm{H}$ and $\mathrm{J}$ ) Thin section of the tuff rocks from Querétaro (all microphotographs are $5 \mathrm{~mm}$ in length and taken with a $5 \mathrm{X}$ objective), parallel nicols.

The tuff contains about $10 \%$ of sub- to euhedral quartz with sharp angular broken edges and fractures and measures less than $1 \mathrm{~mm}$ in size. It also contains about $10 \%$ of sub- to euhedral sanidine crystals that have broken angular edges and have a fine grain size, less than $1 \mathrm{~mm}$. The matrix is microcrystalline, devitrified well-welded mass with a eutaxitic texture and comprises up to $60 \%$ of the sample (Fig. $155 \mathrm{~J}$ ).

\section{2. 1. e) Cathedral Tuff of Zacatecas (Zac Cath)}

The sample from the cathedral of Zacatecas is a pinkish tuff with a matrix that represents $30 \%$ of the rock. The sample exhibits a fine-grained matrix and due to iron oxides shows a pinkish coloration (Fig. $156 \mathrm{~K}$ ). Under the microscope quartz phenocrysts (around $30 \%$ ) together with feldspars 
(10\%) and some oxides (30\%) are recognizable. Quartz phenocrysts are anhedral and supported by the matrix. Collapsed pumice clasts up to $1-10 \mathrm{~mm}$ in size are also embedded in the glassy, slightly foliated matrix (Fig. 156 L).

\section{2. 1.f) Quarry Tuff of Zacatecas (Zac quarry)}

The sample obtained from a quarry near the city of Zacatecas consists of a pinkish - reddish tuff containing $1 \mathrm{~cm}$ sized well-oriented lithic clasts (Fig. $156 \mathrm{M}$ ). In thin section phenocrysts of quartz (35\%), feldspars $(20 \%)$ and oxides (5\%) are observable. The matrix represents $40 \%$ of the rock. The matrix is fine grained, glassy and shows a high content of hematite (Fig. $156 \mathrm{~N}$ ). The phenocrysts of quartz are anhedral and show sizes ranging up to $0.8 \mathrm{~mm}$, whereas the feldspar phenocrysts are anhedral, exhibit finer grain sizes and are also distributed throughout the entire rock. The pink to red coloration is due to the oxides present in the rock.

\section{2. 1. g) El Salto Tuff of Zacatecas (Zac El Salto)}

The sample from El Salto is a reddish-orange volcanic tuff with locally purple to dark brownish stripes and spots that gives this rock a very jazzy appearance (Fig. 156 O). It contains crystals of quartz (40\%), plagioclase (10\%) and some oxides (10\%). The quartz crystals are mostly anhedral and normally less than $1 \mathrm{~mm}$ in size. The plagioclase crystals vary from anhedral to euhedral with sizes ranging from $0.3 \mathrm{~mm}$ up to $1 \mathrm{~cm}$ (Fig. $156 \mathrm{P}$ ). The matrix, $40 \%$ of the whole rock, shows no orientation or lamination and contains an important amount of opaque crystals (oxides).

\section{2. 1. h) La Cuava Lapilli Tuff of Zacatecas (LC)}

The rock consists of a purple matrix, which contains around $20 \%$ lithoclasts (gray or black) up to 5 $\mathrm{mm}$ in size and has a pore volume of $10 \%$. Furthermore, lenses of fine-grained pumice are also observable. The rock is defined as a lapilli tuff (Fisher 1961) or as a glassy tuff (Schmid 1981) that shows a relatively good lineation.

\section{2. 1. i) Escolasticas Tuff of Querétaro (ESC)}

This tuff is a pink to reddish, brownish colored pyroclastic igneous rock (Fig. 156 I) with a porphyritic texture. It is composed of unoriented lithic fragments, fiammes, non-collapsed pumice, quartz and sanidine phenocrysts hosted on a microcrystalline, devitrified reddish matrix with a eutaxitic texture. The material contains about $40 \%$ of components and $60 \%$ matrix.

The tuff contains about $10 \%$ of sub to euhedral quartz with sharp angular broken edges and fractures and measures less than $1 \mathrm{~mm}$ in size. It also contains about $10 \%$ of sub to euhedral sanidine crystals that have broken angular edges and have a fine grain size, less than $1 \mathrm{~mm}$. The matrix is microcrystalline, devitrified well-welded mass with a eutaxitic texture and comprises up to $60 \%$ of the sample (Fig. $156 \mathrm{~J}$ ). 
Zacatecas Cathedral Tuff (Zac cath)

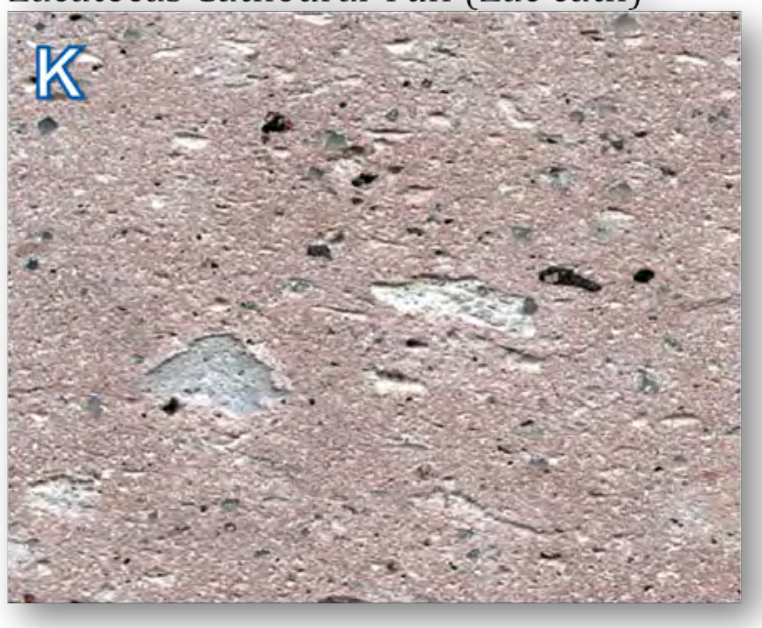

Zacatecas quarry Tuff (Zac quarry)

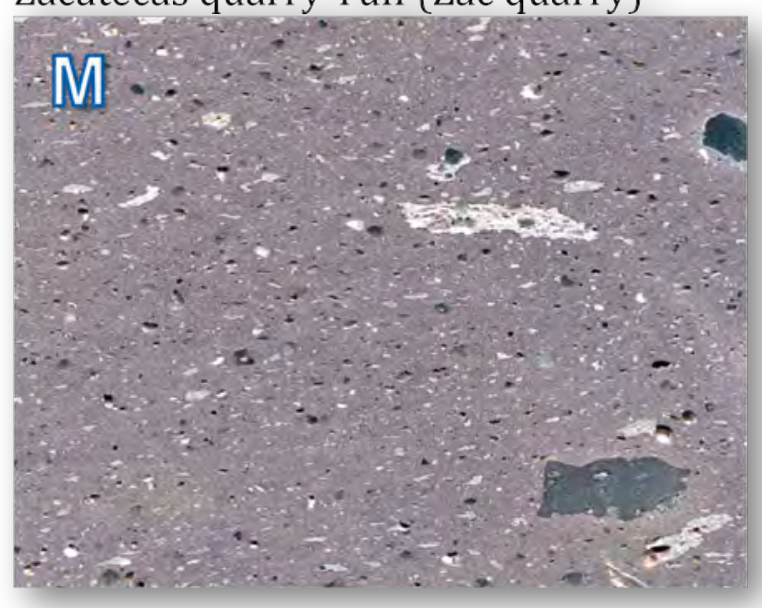

El Salto Tuff (El Salto) from Zacatecas

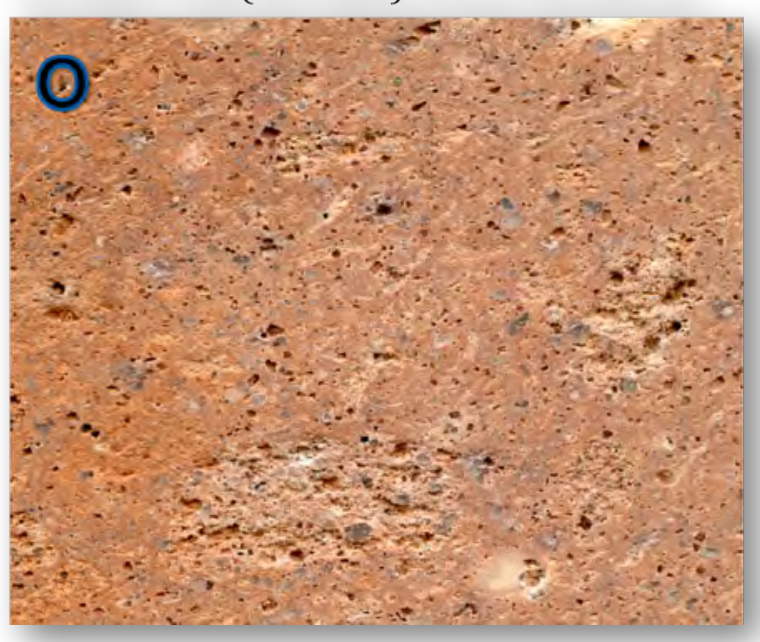

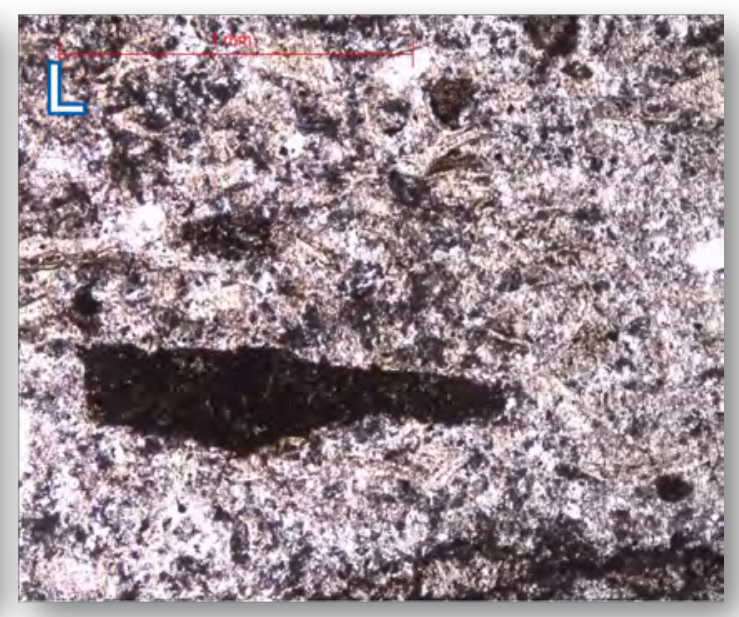
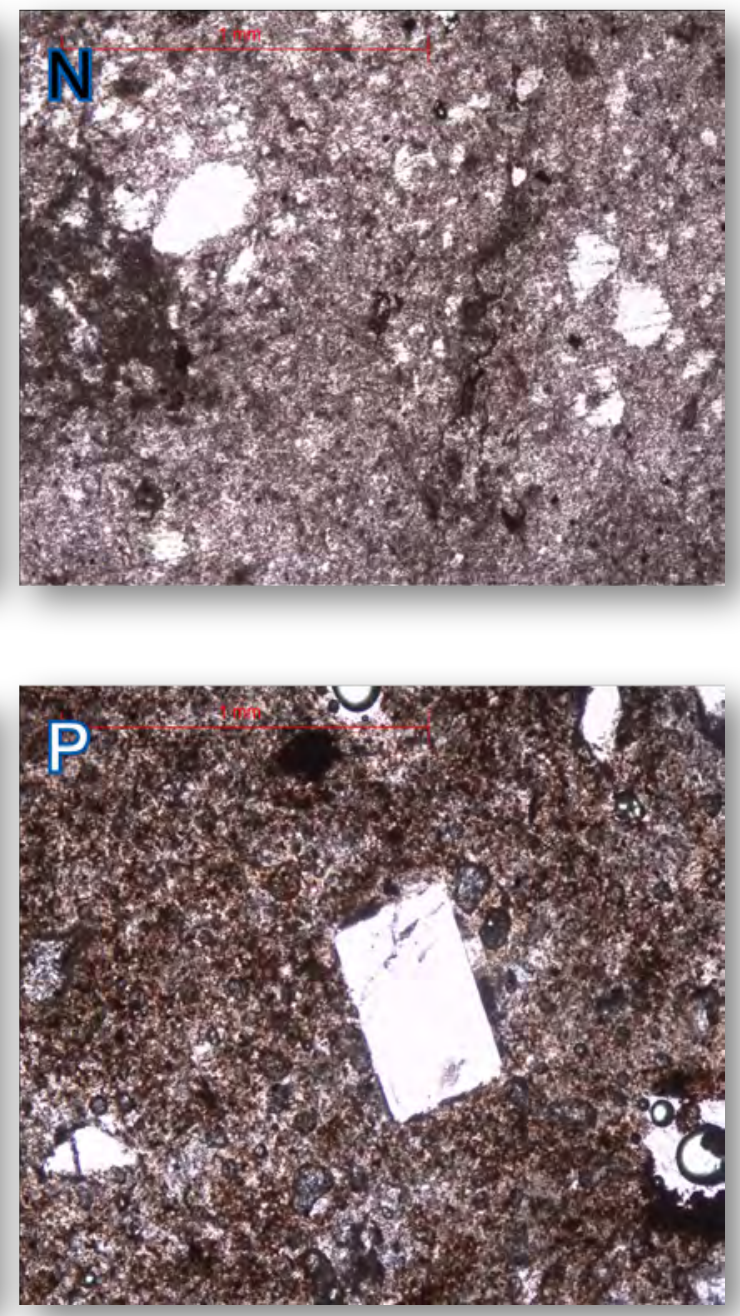

Figure 156: Tuff rocks from Zacatecas. $\mathrm{K}, \mathrm{M}$ and $\mathrm{O}$, Macroscopic fabric in hand specimen (all samples are a $6.5 \mathrm{~cm}$ in length). L, N and P, Thin section of the tuff rocks from Zacatecas (all microphotographs are $5 \mathrm{~mm}$ in length and taken with a $5 \mathrm{X}$ objective and parallel nicols). 


\section{2. 1. j) Cathedral Tuff of Zacatecas (Zac cath)}

The sample from the cathedral of Zacatecas is a pinkish tuff with a matrix that represents $30 \%$ of the rock. The sample exhibits a fine-grained matrix and due to iron oxides shows a pinkish coloration (Fig. $156 \mathrm{~K}$ ). Under the microscope quartz phenocrysts (around $30 \%$ ) together with feldspars $(10 \%)$ and some oxides (30\%) are recognizable. Quartz phenocrysts are anhedral and supported by the matrix. Collapsed pumice clasts up to 1 - $10 \mathrm{~mm}$ in size are also embedded in the glassy, slightly foliated matrix (Fig. 156 L).

\section{2. 1. k) Quarry Tuff of Zacatecas (Zac quarry)}

The sample obtained from a quarry near the city of Zacatecas consists of a pinkish - reddish tuff containing $1 \mathrm{~cm}$ sized well-oriented lithic clasts (Fig. $156 \mathrm{M}$ ). In thin section phenocrysts of quartz (35\%), feldspars $(20 \%)$ and oxides (5\%) are observable. The matrix represents $40 \%$ of the rock. The matrix is fine grained, glassy and shows a high content of hematite (Fig. $156 \mathrm{~N}$ ). The phenocrysts of quartz are anhedral and show sizes ranging up to $0.8 \mathrm{~mm}$, whereas the feldspar phenocrysts are anhedral, exhibit finer grain sizes and are also distributed throughout the entire rock. The pink to red coloration is due to the oxides present in the rock.

\section{2. 1. l) El Salto Tuff of Zacatecas (Zac El Salto)}

The sample from El Salto is a reddish - orange volcanic tuff with locally purple to dark brownish stripes and spots that gives this rock a very jazzy appearance (Fig. 156 O). It contains crystals of quartz (40\%), plagioclase (10\%) and some oxides (10\%). The quartz crystals are mostly anhedral and normally less than $1 \mathrm{~mm}$ in size. The plagioclases crystals vary from anhedral to euhedral with sizes ranging from $0.3 \mathrm{~mm}$ up to $1 \mathrm{~cm}$ (Fig. $156 \mathrm{P}$ ). The matrix, $40 \%$ of the whole rock shows no orientation or lamination and contains an important amount in opaque crystals (oxides).

\section{2. 1. m) La Cuava Lapilli-Tuff of Zacatecas (LC)}

The rock exhibits a purple matrix, which includes around $20 \%$ lithic clasts up to $5 \mathrm{~mm}$ in size (gryish to black) and has a porosity of $10 \%$. Furthermore, fine pumice lenses are recognizable. The rock can be classified as a lapilli tuff (Fisher 1966 \& IUGS) and additionally as a glassy tuff (Schmid 1966), that shows a realatively good oriented fabric.

\section{3 Experimental investigation and results}

\section{3. 1 Petrophysical properties}

The samples were measured in all three directions; the direction parallel to the bedding and lamination is defined as $\mathrm{X}$, perpendicular to the lamination as $\mathrm{Y}$ and perpendicular to the bedding as $\mathrm{Z}$. The obtained values of porosity (effective) and density (particle and bulk) are showed in Table 6 . 
The most porous tuff is the Escolásticas Tuff from Querétaro with $50 \%$ effective porosity; other samples like the GF Black and GF Gray from San Miguel de Allende and the Black QRO from Querétaro have porosities of around $40 \%$. The $\mathrm{CH}$ (Chiluca Tuff) with $8 \%$ and the TY (Tenayocátelt Tuff) with $5 \%$ both from Mexico City are the rocks with the lowest porosity (Tab. 34).

Table 34: Effective porosity (vol\%), particle density $\left(\mathrm{g} / \mathrm{cm}^{3}\right)$ and bulk density $\left(\mathrm{g} / \mathrm{cm}^{3}\right)$

\begin{tabular}{|c|c|c|c|}
\hline Sample & $\begin{array}{c}\text { Porosity } \\
\text { [\%] }\end{array}$ & $\begin{array}{c}\text { Particle density } \\
{\left[\mathrm{g} / \mathrm{cm}^{3}\right]}\end{array}$ & $\begin{array}{c}\text { Bulk density } \\
{\left[\mathrm{g} / \mathrm{cm}^{3}\right]}\end{array}$ \\
\hline RG & 28 & 2.60 & 1.85 \\
\hline SG & 32 & 2.54 & 1.73 \\
\hline Qro black & 46 & 2.51 & 1.35 \\
\hline Zac quarry & 28 & 2.65 & 1.90 \\
\hline GF black & 49 & 2.38 & 1.22 \\
\hline GF gray & 45 & 2.37 & 1.31 \\
\hline Zac cath & 32 & 2.66 & 1.80 \\
\hline Zac EI Salto & 27 & 2.61 & 1.90 \\
\hline GR & 31 & 2.55 & 182 \\
\hline BT & 18 & 2.61 & 2.13 \\
\hline $\mathrm{BP}$ & 15 & 2.53 & 1.84 \\
\hline LS & 15 & 2.34 & 2.18 \\
\hline CA Gdl & 41 & 2.53 & 1.48 \\
\hline TY & 7 & 2.38 & 2.26 \\
\hline ESC & 50 & 2.53 & 1.36 \\
\hline $\mathrm{CR}$ & 41 & 2.56 & 1.53 \\
\hline $\mathrm{CH}$ & 8 & 2.58 & 2.37 \\
\hline
\end{tabular}

Four samples only show microporosities, (Zac quarry and BP with $97 \%$ respectively, and BT and LS with $83 \%$ ), whereas four samples only show macroporosities, GF black with $96 \%$, ESC with 94\%, GF gray with $92 \%$ and SMA with $87 \%$.

Normally the density decreases with increasing porosity, and in contrast higher porosities equal less resistance (less cycles). However, this association cannot be evaluated in the investigated samples (Fig. 157).

Figure 158 a shows the relation between the number of cycles in the salt bursting test before the deterioration with the microporosity for the tuffs and Figure $158 \mathrm{~b}$ shows the same comparison but for the sandstones. In the first case (Fig. 158 a) most of the tuffs with lower values of microporosities 
deteriorated after the first 20 cycles (1) and the other group (2) clearly shows a trend toward decreasing microporosities for some of the samples (BP, BT, LS, LC and LSc). In the case of the sandstones two groups of samples can be well differentiated by showing the inverse relation (Fig. $158 \mathrm{~b}$ ).
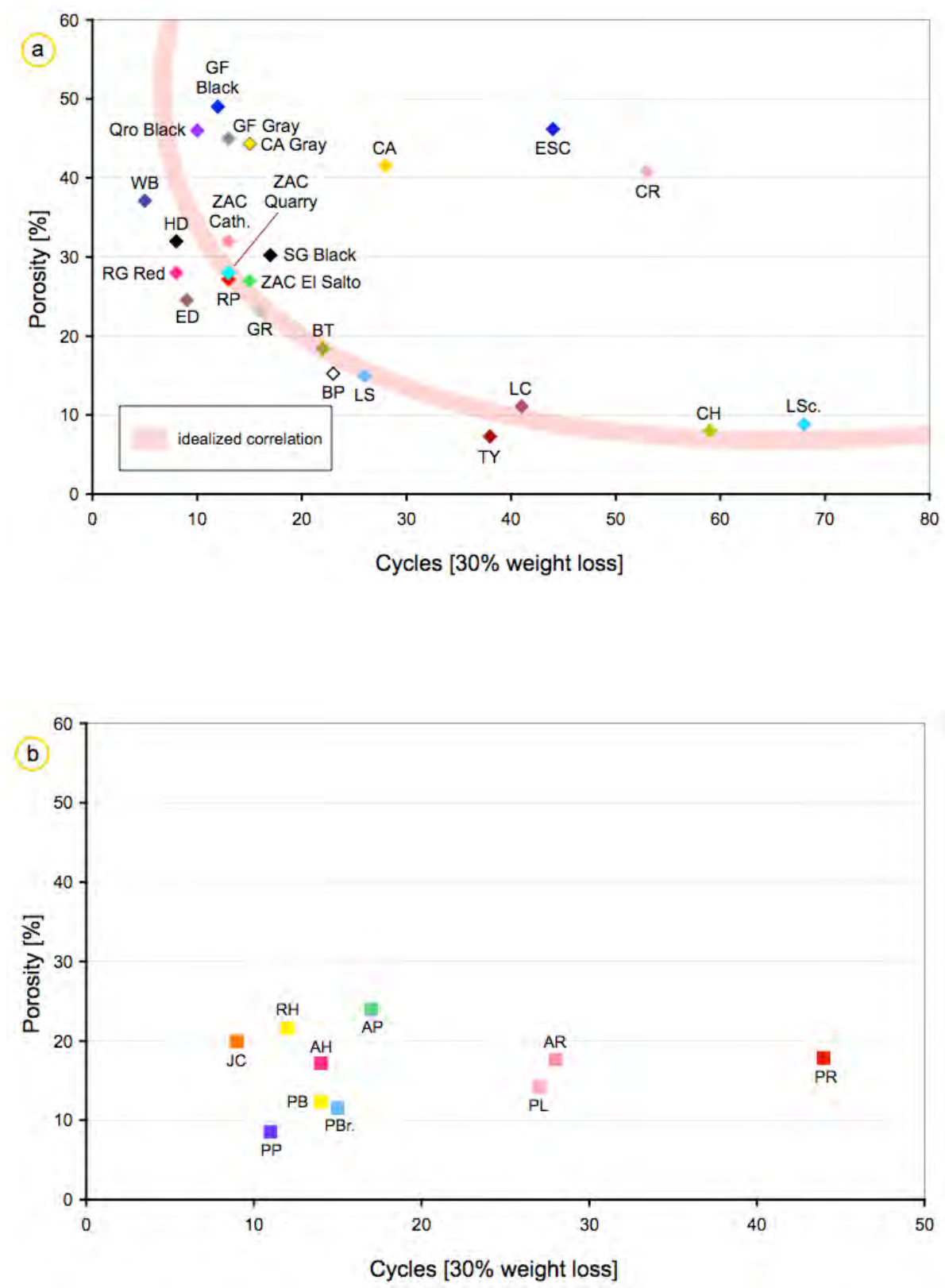

Figure 157. Correlation of the porosity versus the number of cycles a) of the tuffstones and b) of the sandstones.

Most sandstone samples with low microporosities but as well the ones with the highest ones deteriorated between the $8^{\text {th }}$ and $18^{\text {th }}$ cycle (1). Only three types (2) show a better salt resistance (PL, $\mathrm{AR}$ and PR).

The heaviest sample is the Cathedral Tuff from Zacatecas with a density of $2.66 \mathrm{~g} / \mathrm{cm}^{3}$, whereas the Eger Denjem Tuff from Hungary is the lightest one with a density of $2.29 \mathrm{~g} / \mathrm{cm}^{3}$. The density of the 
sandstones ranges between $2.59 \mathrm{~g} / \mathrm{cm}^{3}$ for the PL-sample from Petra and $2.68 \mathrm{~g} / \mathrm{cm}^{3}$ for the $\mathrm{PBr}$ sample from Angkor.
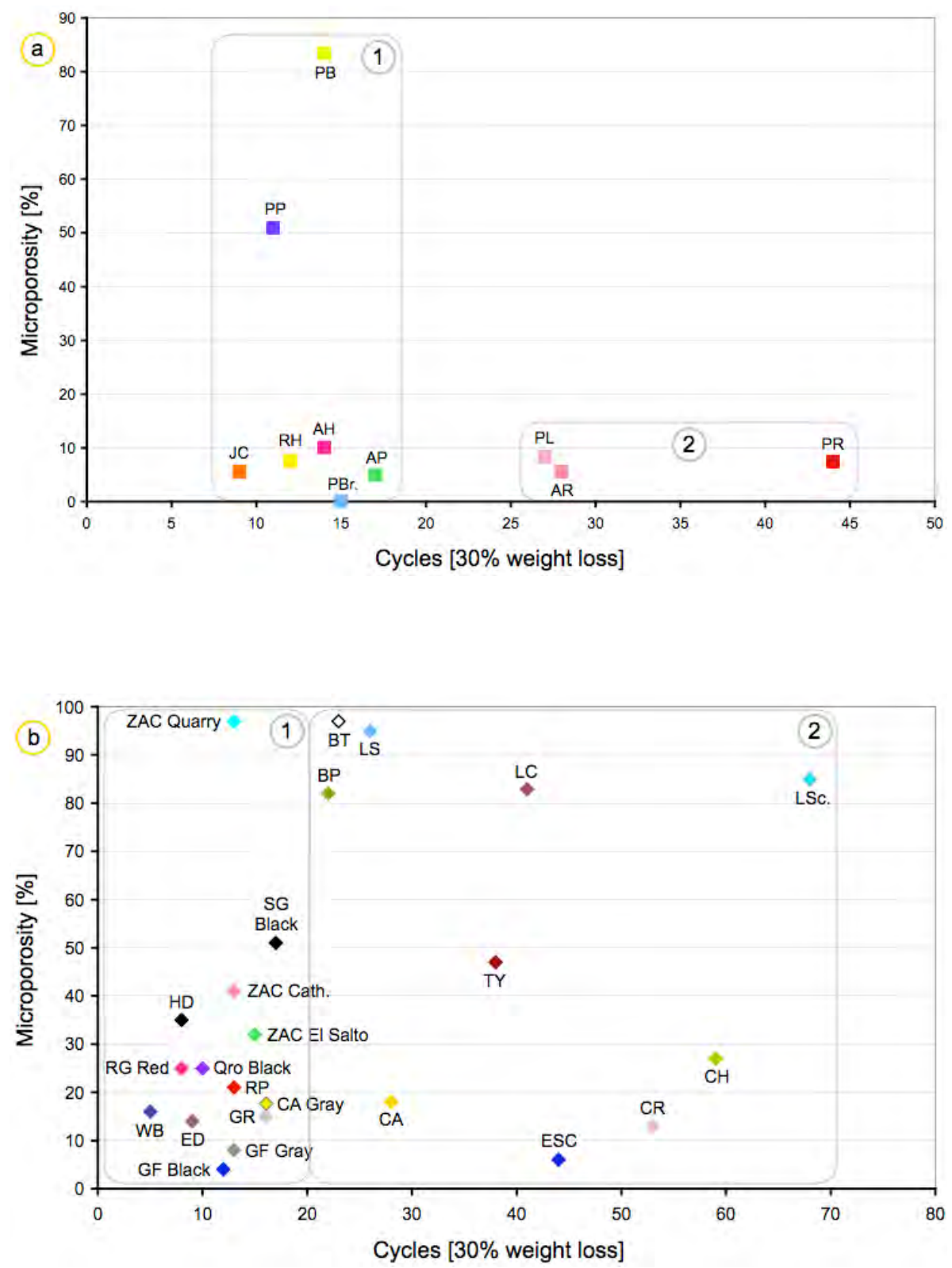

Figure 158: Correlation of the microporosity versus the number of cycles a) of the sandstones and b) of the tuffstones.

Comparing the density versus the number of cycles before deterioration (Fig. 159 a), we unexpectedly observed a weak tendency that shows that tuff samples with higher density values were less resistant (less cycles) with respect to the lighter samples; however there are in this case some exceptions. The groups of samples (1) where these tendencies can be observed have a density higher than $2.6 \mathrm{~g} / \mathrm{cm}^{3}$. In contrast, a tendency in salt resistance related to the density in the sandstone samples could not be observed (Fig. 159 b). The sandstone samples do not show any relevant differences in 
regards to the density because quartz $\left(2.65 \mathrm{~g} / \mathrm{cm}^{3}\right)$ dominates as the rock component. Only one sample (Petra light red) has a density slightly lower than $2.6 \mathrm{~g} / \mathrm{cm}^{3}$ showing a good salt resistance. The lower density could be related to the high amount of altered feldspar in the rock.
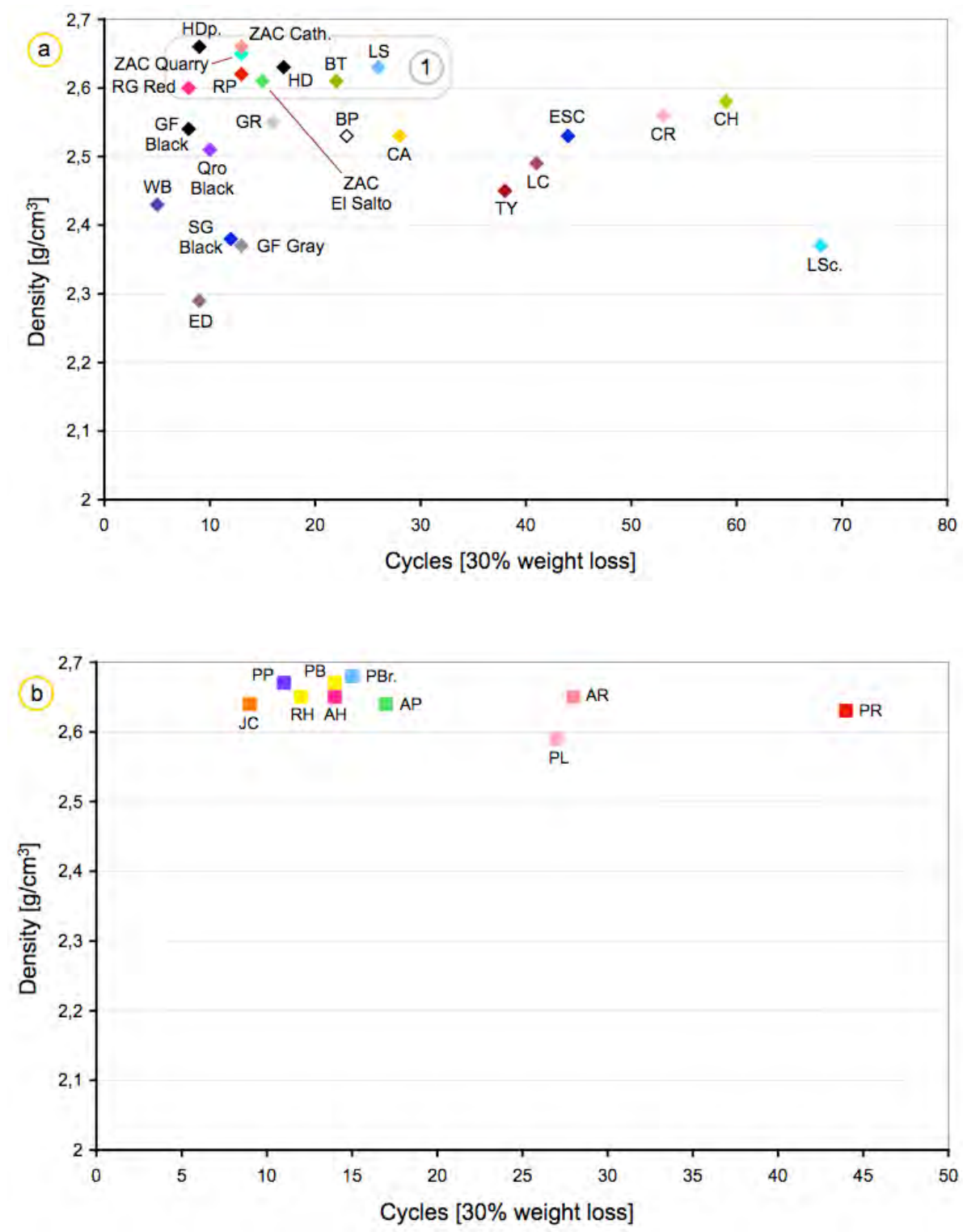

Figure 159: Correlation of the density versus the number of cycles.

a) In the tuffs and b) in the sandstones.

\section{3. 2 Pore radii distributions}

The pore radii distributions of all measured stone samples have been put into groups of ideal pore size types, unimodal equal and unequal, and bimodal unequal (Siegesmund, Duerrast 2011). Four tuffs show an equal unimodal pattern in the micropore zone (TY, BP, ZAC quarry and LS), three tuffs show an equal unimodal pattern in the macropore zone (ESC, GF black and GF gray), five tuffs show a unequal bimodal pattern (Qro black, RG red, SG black and GR) and six tuffs are unequal unimodal (BT, CH, CA, Zac El Salto, SMA and ZAC Cath). The most regular pore distribution that shows a normal distribution curve (normal distribution bell) is the Chiluca Tuff $(\mathrm{CH})$ from Me- 
xico City (Tab. 35).

Most of the sandstones show a unimodal equal pore size distribution dominated by macropores. Only the Phnom Bakheng sandstone (PB) and the Petra Purple sandstone (PP) show an unequal bimodal pattern.

Table 35: Pore radii distribution of the analyzed tuffs and sandstones, their percentages of micro- and macropores, porosity and tested cycles

\begin{tabular}{|c|c|c|c|c|c|c|c|c|c|}
\hline \multirow[b]{2}{*}{$\begin{array}{l}\text { Sample } \\
\text { Name }\end{array}$} & \multicolumn{5}{|c|}{ Effective pore radii [ $\mu \mathrm{m}]$ in porosity [vol.-\%] } & \multirow[b]{2}{*}{$\begin{array}{c}\text { Micropor } \\
\text { es [\%] }\end{array}$} & \multirow[b]{2}{*}{$\begin{array}{c}\text { Macropor } \\
\text { es [\%] }\end{array}$} & \multirow[b]{2}{*}{$\begin{array}{l}\text { Porosity } \\
\text { [vol.-\%] }\end{array}$} & \multirow[b]{2}{*}{$\begin{array}{c}\text { Test cycles } \\
\text { until } 30 \% \\
\text { material } \\
\text { loss }\end{array}$} \\
\hline & $\begin{array}{c}0.001- \\
0.01 \\
\mu \mathrm{m}\end{array}$ & $\begin{array}{c}0.01- \\
0.1 \\
\mu \mathrm{m}\end{array}$ & $\begin{array}{c}0.1-1 \\
\mu \mathrm{m}\end{array}$ & $\begin{array}{l}1-10 \\
\mu \mathrm{m}\end{array}$ & $\begin{array}{c}10-100 \\
\mu \mathrm{m}\end{array}$ & & & & \\
\hline RG & 5 & 20 & 11 & 60 & 4 & 25 & 75 & 28 & 8 \\
\hline SG & 11 & 24 & 17 & 43 & 5 & 35 & 65 & 32 & 8 \\
\hline Qro black & 3 & 22 & 14 & 59 & 2 & 25 & 75 & 46 & 10 \\
\hline Zac quarry & 4 & 93 & 2 & 1 & 0 & 97 & 3 & 28 & 11 \\
\hline GF black & 1 & 3 & 8 & 67 & 21 & 4 & 96 & 49 & 12 \\
\hline GF gray & 2 & 6 & 7 & 77 & 8 & 8 & 92 & 45 & 13 \\
\hline Zac Cath & 3 & 38 & 47 & 8 & 3 & 41 & 59 & 32 & 13 \\
\hline Zac El Salto & 5 & 27 & 58 & 8 & 2 & 32 & 68 & 27 & 15 \\
\hline Zac La Cueva & 0 & 83 & 4 & 10 & 2 & 83 & 17 & 11 & 41 \\
\hline GR & 0 & 15 & 18 & 55 & 11 & 15 & 85 & 31 & 16 \\
\hline BT & 4 & 79 & 17 & 0 & 0 & 83 & 17 & 18 & 22 \\
\hline BP & 7 & 90 & 2 & 1 & 0 & 97 & 3 & 15 & 23 \\
\hline LS & 21 & 62 & 14 & 2 & 1 & 83 & 17 & 15 & 26 \\
\hline CA Gdl & 3 & 15 & 33 & 47 & 3 & 18 & 82 & 41 & 28 \\
\hline TY & 9 & 38 & 16 & 20 & 17 & 47 & 53 & 5 & 38 \\
\hline ESC & 3 & 3 & 4 & 87 & 3 & 6 & 94 & 50 & 44 \\
\hline CR & 3 & 10 & 21 & 66 & 1 & 13 & 87 & 41 & 53 \\
\hline $\mathrm{CH}$ & 4 & 23 & 40 & 30 & 3 & 27 & 73 & 8 & 59 \\
\hline CF & 3 & 15 & 25 & 57 & 0 & 18 & 82 & 13 & Still in work \\
\hline WB & 6 & 10 & 3 & 30 & 1 & 16 & 84 & 37 & 5 \\
\hline HW & 45 & 25 & 20 & 4 & 6 & 70 & 30 & 9 & Still in work \\
\hline $\mathrm{RP}$ & 4 & 17 & 52 & 24 & 3 & 21 & 79 & 27 & 13 \\
\hline HD & 5 & 46 & 31 & 16 & 1 & 51 & 49 & 30 & 17 \\
\hline ED & 2 & 8 & 89 & 1 & 0 & 16 & 84 & 25 & 9 \\
\hline
\end{tabular}


Table 35: Pore radii distribution of the analyzed tuffs and sandstones, their percentages of micro- and macropores, porosity and tested cycles

\begin{tabular}{llllllllll}
\hline AH & 3 & 7 & 11 & 72 & 7 & 10 & 90 & 17 & 14 \\
AP & 2 & 3 & 4 & 12 & 80 & 5 & 95 & 24 & 17 \\
JC & 3 & 3 & 2 & 6 & 89 & 6 & 94 & 20 & 9 \\
RH & 3 & 5 & 6 & 79 & 8 & 8 & 92 & 22 & 12 \\
PR & 0 & 7 & 6 & 79 & 8 & 7 & 93 & 12 & 44 \\
PL & 0 & 8 & 28 & 29 & 36 & 8 & 92 & 11 & 27 \\
PP & 7 & 44 & 42 & 50 & 0 & 51 & 49 & 18 & 11 \\
PB & 44 & 39 & 15 & 2 & 0 & 83 & 17 & 12 & 14 \\
PBr. & 0 & 0 & 84 & 11 & 5 & 0 & 100 & 12 & 25 \\
AR & 5 & 26 & 42 & 26 & 0 & 31 & 69 & 18 & 28 \\
\hline
\end{tabular}

\section{3. 3 Water uptake, water absorption}

The capillary water absorption of porous materials can be described through the water absorption coefficient (w-value) and represents the water absorption per unit area versus the square root of time and initially shows a linear behavior (Siegesmund, Duerrast 2011). Seven of the studied tuff samples show almost no absorption with values under $0.5 \mathrm{~kg} / \mathrm{m}^{2} \sqrt{\mathrm{h}}$ (Fig. $160 \mathrm{a}$ ). The ESC Tuff shows the highest $\mathrm{w}$-value with over $30 \mathrm{~kg} / \mathrm{m} 2 \sqrt{\mathrm{h}}$. Most of the samples show values ranging between 2 and $10 \mathrm{~kg} / \mathrm{m} 2 \sqrt{ } \mathrm{h}$. Figure 160 a shows that higher porosity corresponds to greater absorption. The same is the case for the investigated sandstones, where four samples have a very low w-value and the other ones a very high value (Fig. 160 b). The last four samples show wide spread values between 6.5 and $31.7 \mathrm{~kg} / \mathrm{m}^{2} \sqrt{\mathrm{h}}$ and belong to the German Bunt-sandstones. The other 6 samples have similar w-values of around $1 \mathrm{~kg} / \mathrm{m}^{2} \sqrt{\mathrm{h}}$ and belong to the sandstone samples of Angkor and Petra. Thus, two groups of sandstones can be distinguished. 

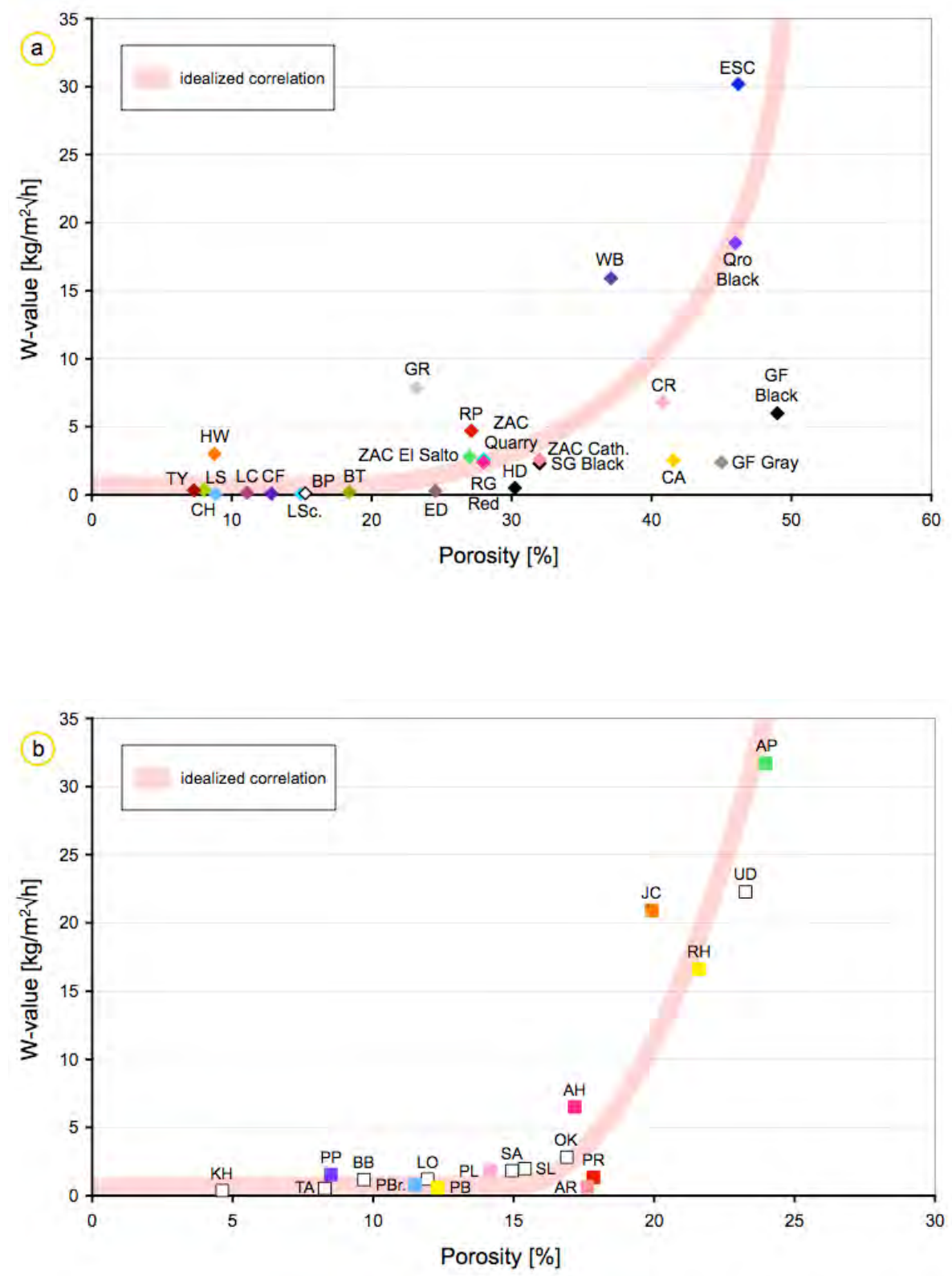

Figure 160: Correlation of the water uptake versus the porosity, a) of the tuffs and b) and the sandstones.

If we compare the number of salt bursting cycles versus the obtained w-values, it is easy to identify different behaviors with respect to the relationship of the w-value to salt bursting cycles (Fig. 161 a). There are tuffs that show low w-values but also low number of salt bursting cycles. There is also one tuff that has a very low w-value but it is the most resistant against salt crystallization cycles ( $\mathrm{CH}$ Tuff). The sandstones show similar behavior but there are no relevant deviations to the idealized correlation (Fig. 161 b). For the tuffs this result shows that the water absorption alone does not play the most important role in the decay caused by salt crystallization. In contrast, for the sandstone there seems to be a strong relation between salt resistance and porosity and the w-value. 

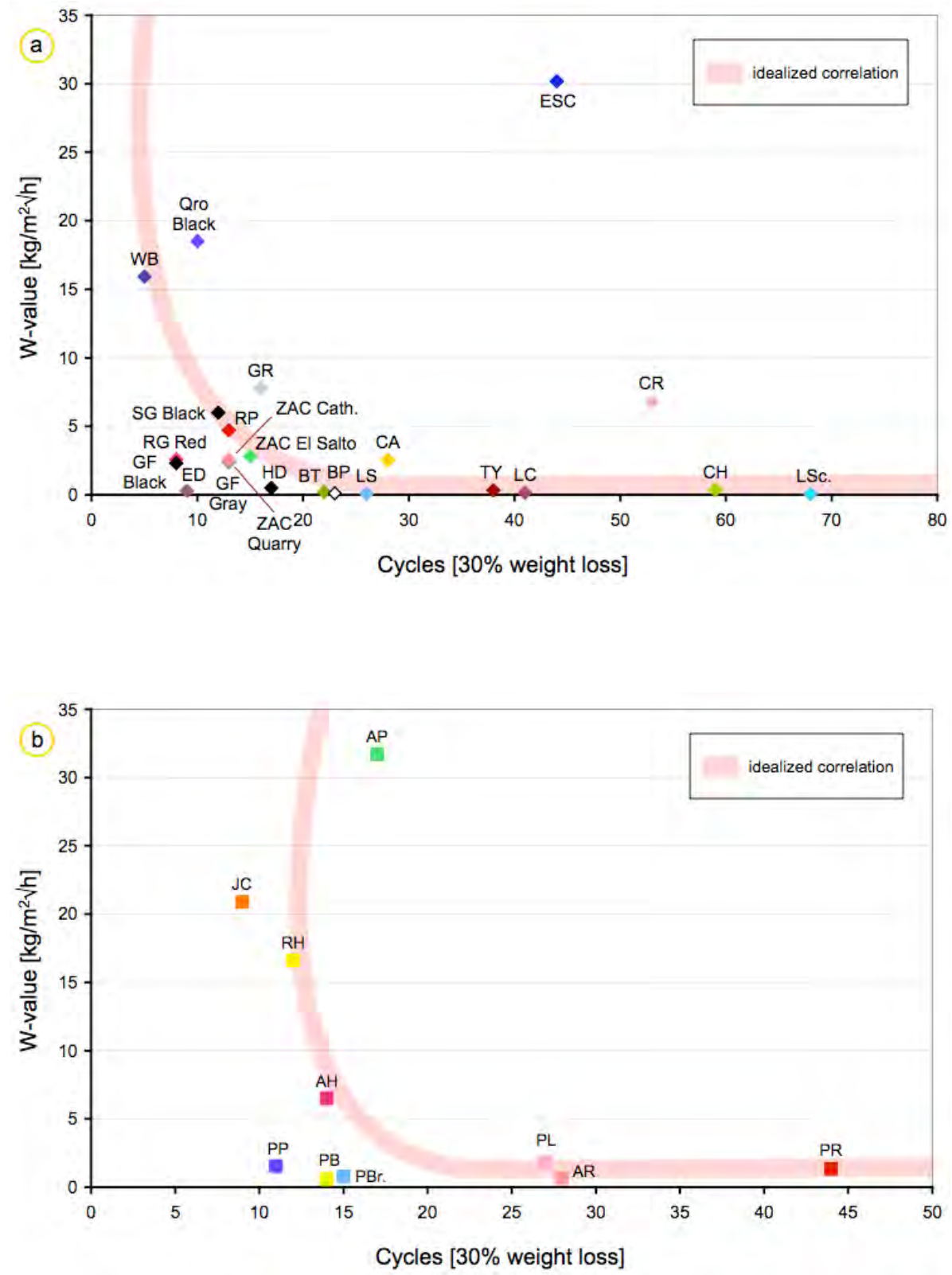

Figure 161: Correlation of the water uptake versus the number of cycles, a) for the tuffstones and b) for the sandstones.

\section{3. 4 Splitting tensile strength versus surface hardness}

The splitting tensile strength (Brazilian test) was measured under dry and wet conditions in most of the tuff samples as well as for the sandstone samples. For dry conditions the values vary between 0.9 and $8.2 \mathrm{MPa}$ and under wet conditions they vary between 0.49 and $8.71 \mathrm{MPa}$ (Wedekind et al., 2013). The splitting tensile strength of the sandstones under dry conditions range between 10.9 and $0.81 \mathrm{MPa}$.

Surface hardness of the tuffs under dry conditions varies between 706 and 223 HLD. The values of the sandstones vary between 727 and 373 HLD. 

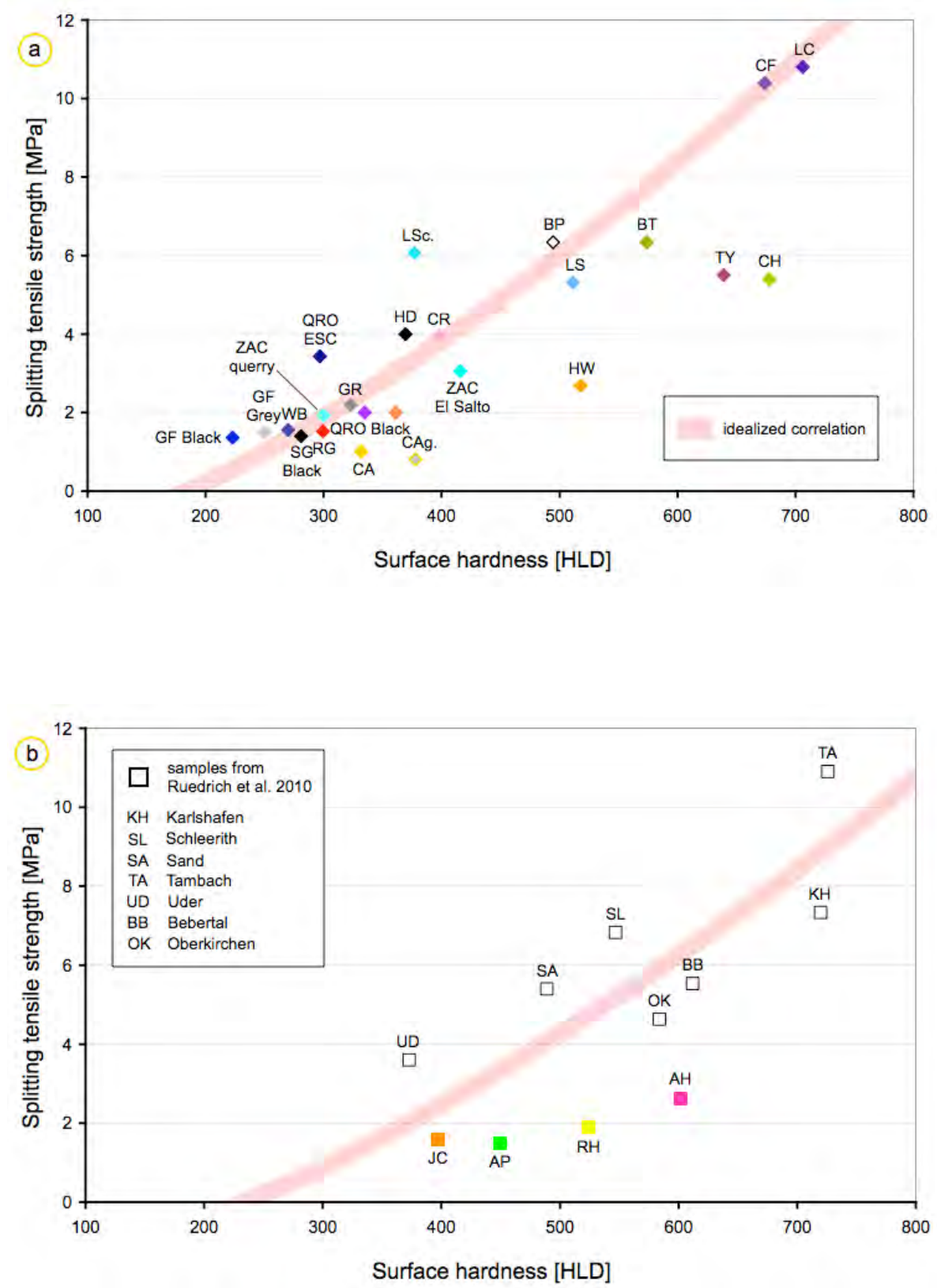

Figure 162: a) Correlation of the splitting tensile and surface hardness of the tuffs and b) of the sandstones.

The splitting tensile strength and surface hardness in the case of the tuffs investigated show a good correlation (Fig. 162 a). Only tree tuffs (TY, CH and HW) display values which are considerably different.

Material for the sandstones was restricted, and thus no splitting tensile strength test could be performed for the sandstones of Petra and Angkor. To make a rough correlation in regards to the splitting tensile strength in comparison to surface hardness, data from Ruedrich et al., (2011 a) was used as a guideline for the four Göttingen sandstones tested by splitting tensile strength (Fig. 162 b).

In general, a good correlation could also be established in the sandstones from Germany tested for their splitting tensile strength, whereas the idealized correlation shows a flatter progression than in 
the case of the tuffs (Fig. $162 \mathrm{a}$ and b). Figure $165 \mathrm{~b}$ shows a correlation between the percentage of porosity and the tensile strength, and as expected, lower porosity values correspond with higher values of strength.

\section{3. 5 Splitting tensile strength versus ultrasonic velocity}

For this study the results of the dry measurements of ultrasonic velocity has been considered. Both stone types show a good correlation between ultrasonic velocity and splitting tensile strength, whereas the correlation of the sandstones show a sharper increase (Fig. $163 \mathrm{~b}$ ). In case of the tuffs two varieties show an exception. This is the German Weibern Tuff (WB) and the Mexican tuff from the quarry of Zacatecas (Zac quarry). WB shows a very low ultrasonic velocity as well as a very low splitting tensile strength. In contrast Zac quarry shows a low splitting tensile strength but a high ultrasonic velocity.

\section{3. 6 Ultrasonic velocity versus surface hardness}

The ultrasonic velocity and the surface hardness also show a correlation but the spread of the result is slightly larger (Fig. 164). The correlation of both stone types exhibit similar characteristics, such as the correlation between splitting tensile strength and ultrasonic velocity. 

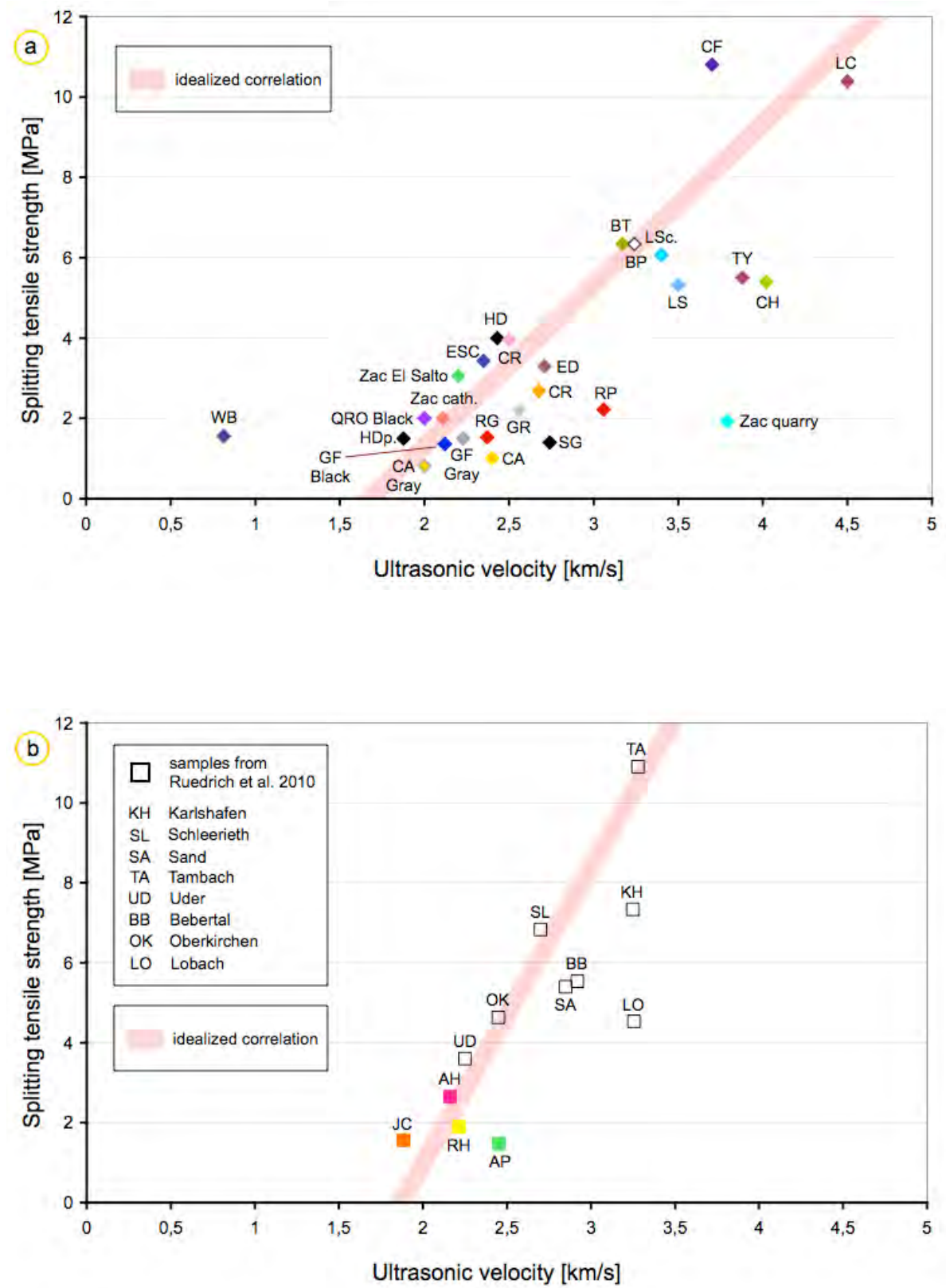

Figure 163: Correlation of the tensile strength versus the ultrasonic velocity, a) for the tuffstones and b) for the sandstones.

\section{3. 7 Splitting tensile strength versus porosity}

By comparing the splitting tensile strength with the porosity in the case of the tuffs, two groups can be defined based on the results ( 1 and 2). Nearly all tuffs classified as low porous varieties with porosities ranging between $7 \%$ and $18 \%$ have a splitting tensile strength between 5 to nearly $11 \mathrm{MPa}$ (1). Only the German tuff from the Habichtswald Forest (HW) is an exception. This tuff has a low porosity as well as a low splitting tensile strength (Fig. 165 a). All tuffs that have porosities between 20 to $50 \%$ only reach a splitting tensile strength up to $4 \mathrm{MPa}(2)$.

In contrast the sandstones exhibit a clear linear correlation (Fig. $165 \mathrm{~b}$ ). This means the higher the porosity is the lower the splitting tensile strength becomes. 

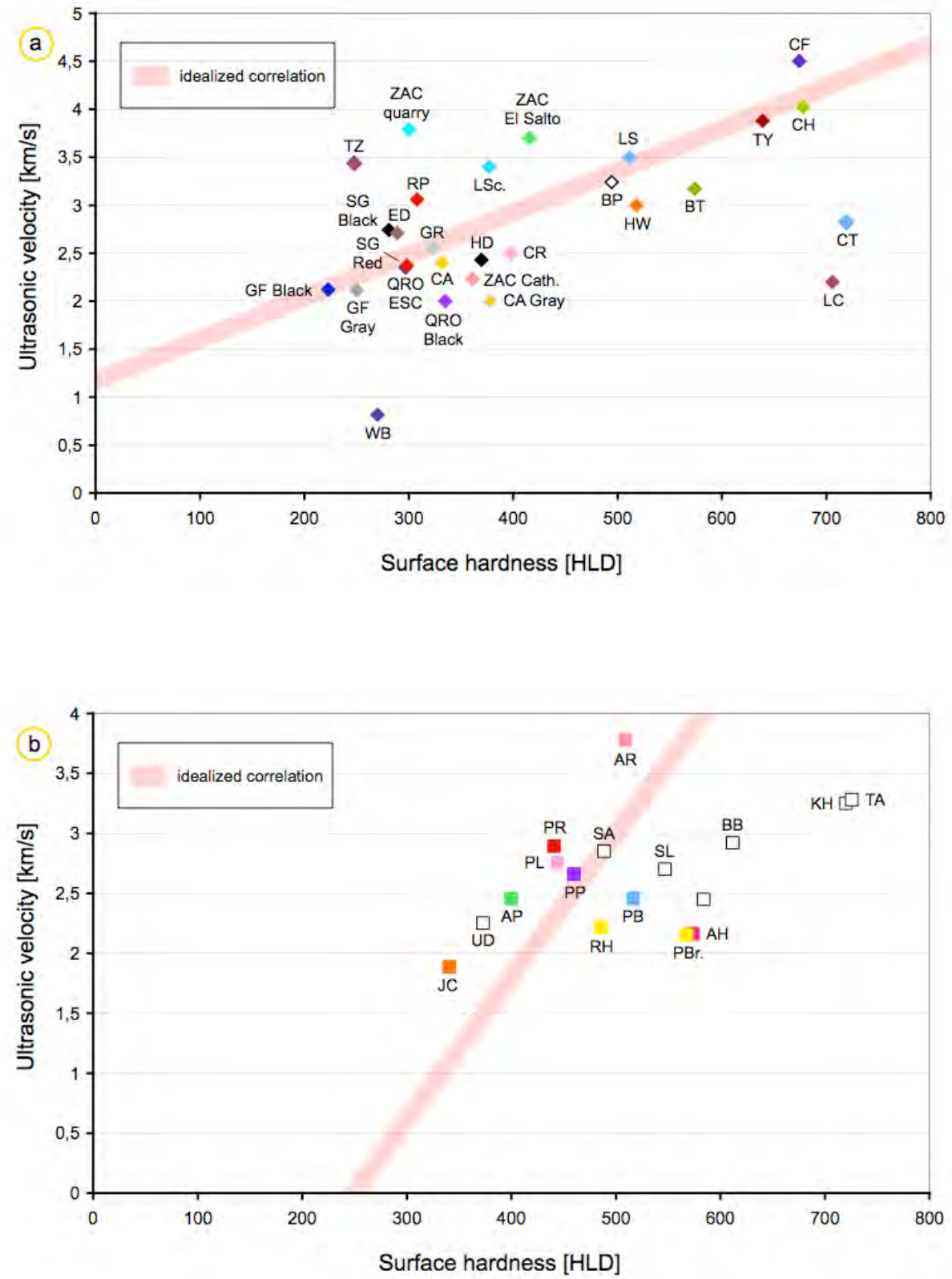

Figure 164: Correlation of the surface hardness versus the ultrasonic velocity, a) for the tuffstones and b) for the sandstones.

If we compare the strength values with the number of salt bursting cycles of the tuffs, (Fig. 166) we can clearly recognize two tendencies. Most of the tuffs with lower values of strength are less resistant against salt bursting and they rapidly deteriorate. Group 1 in Figure 166 a) shows a low correlation at an angle of around $45^{\circ}$. This group shows low but also high and partly very high values of splitting tensile strength (LS, BP, BT, CF, and LC). Group 2 with lower strength of surface hardness values shows a flatter trend, but a higher resistance to the salt weathering resistance test (Fig. 166). The TY sample is in between these two groups. Comparing the cycles with the surface hardness the two similar groups can be distinguished again: This time the $\mathrm{CH}$ sample seems to be an exception (Fig. 166 b). 

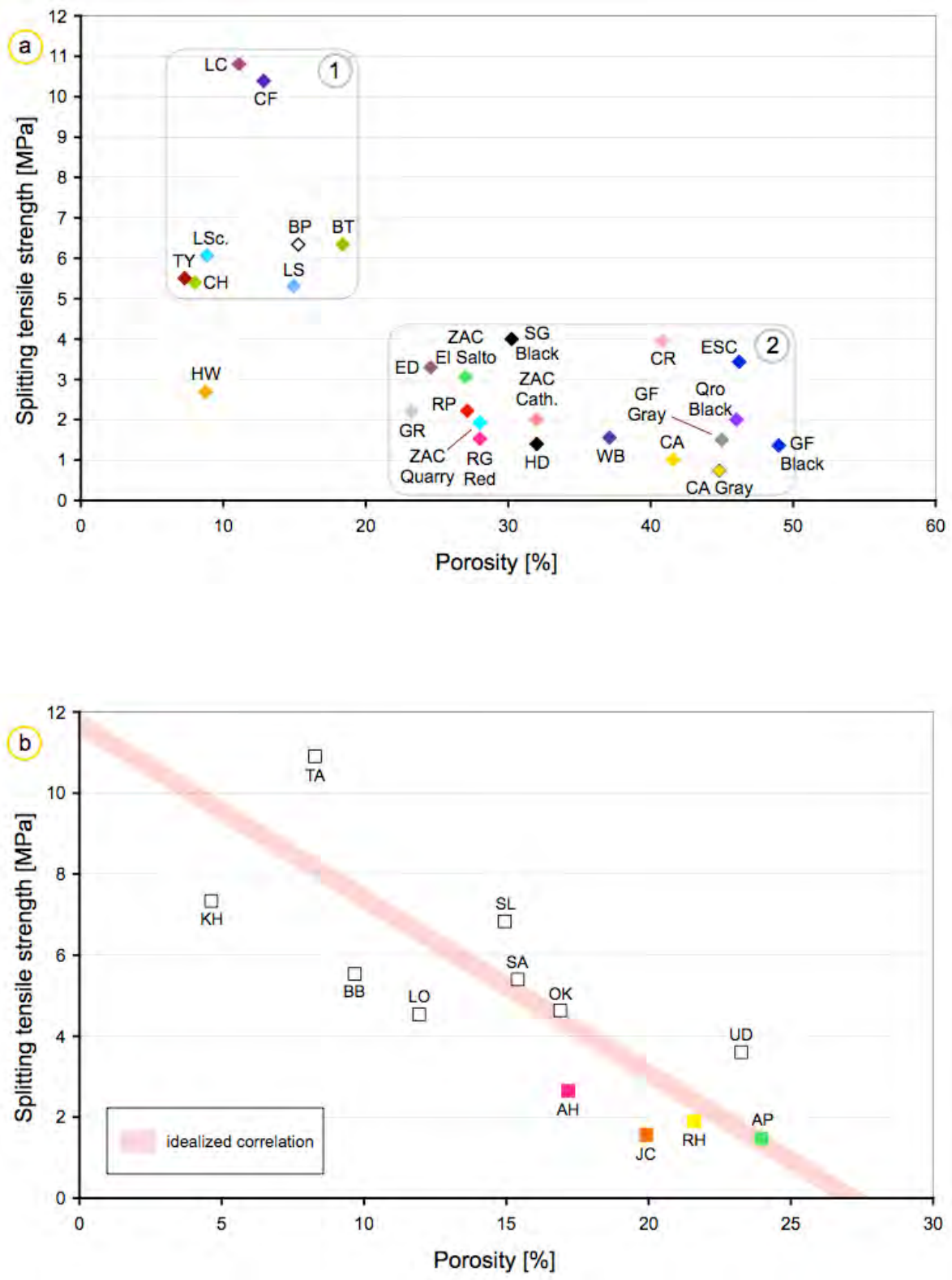

Figure 165: Correlation of the tensile strength versus the porosity. a) Two groups of samples can be identified in the case of the tuffs (1 and 2) and b) a nearly linear correlation of strength and porosity is evident in the case of the sandstones.

In the case of the sandstone only the surface hardness could be taken into account to characterize the salt resistance, but no clear group formation is evident (Fig. 167). A possible distinction can be made for a low salt resistance group (JC, PP, RH, PB, AH, PBr and AP) and one that shows better salt resistance (PL, AR, $\mathrm{PB}$ ). These last three sandstone types have a similar color due to the presence of hematite. 

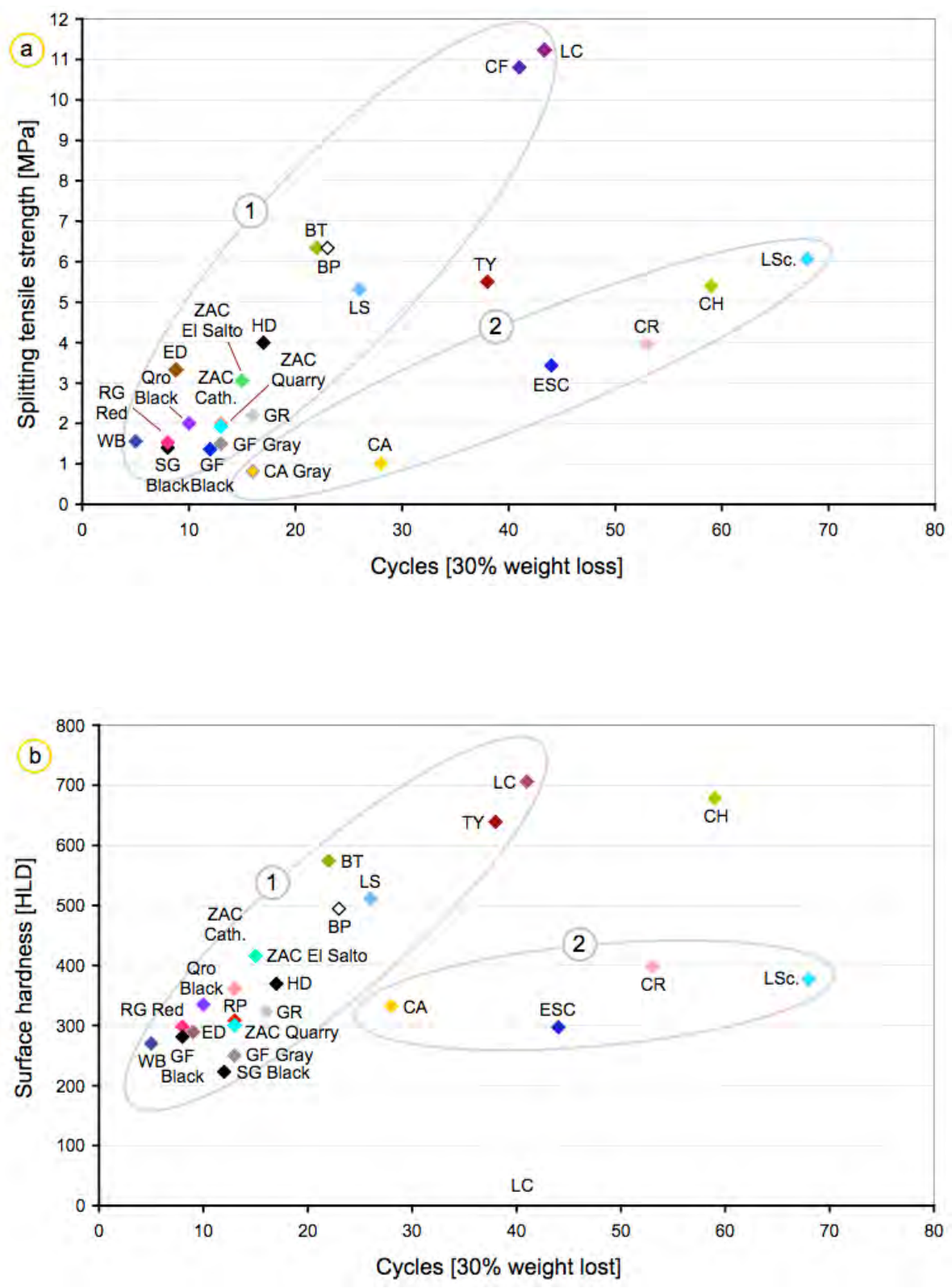

Figure 166: a) Correlation of the tensile strength versus the number of cycles for the tuffs and b) of the surface hardness and the cycles. 

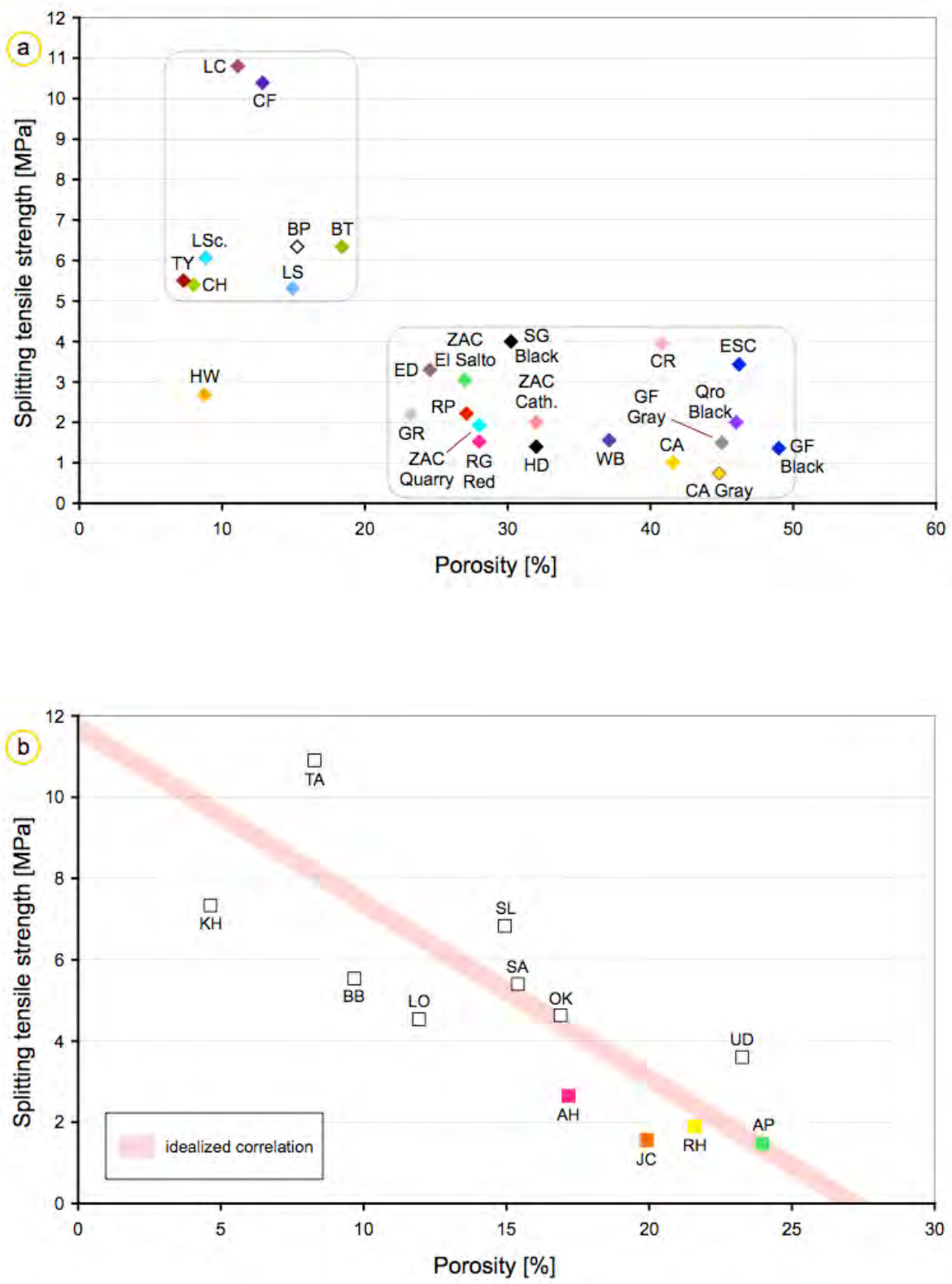

Figure 165: Correlation of the tensile strength versus the porosity. a) Two groups of samples can be identified in the case of the tuffs (1 and 2) and b) a nearly linear correlation of strength and porosity is evident in the case of the sandstones. 


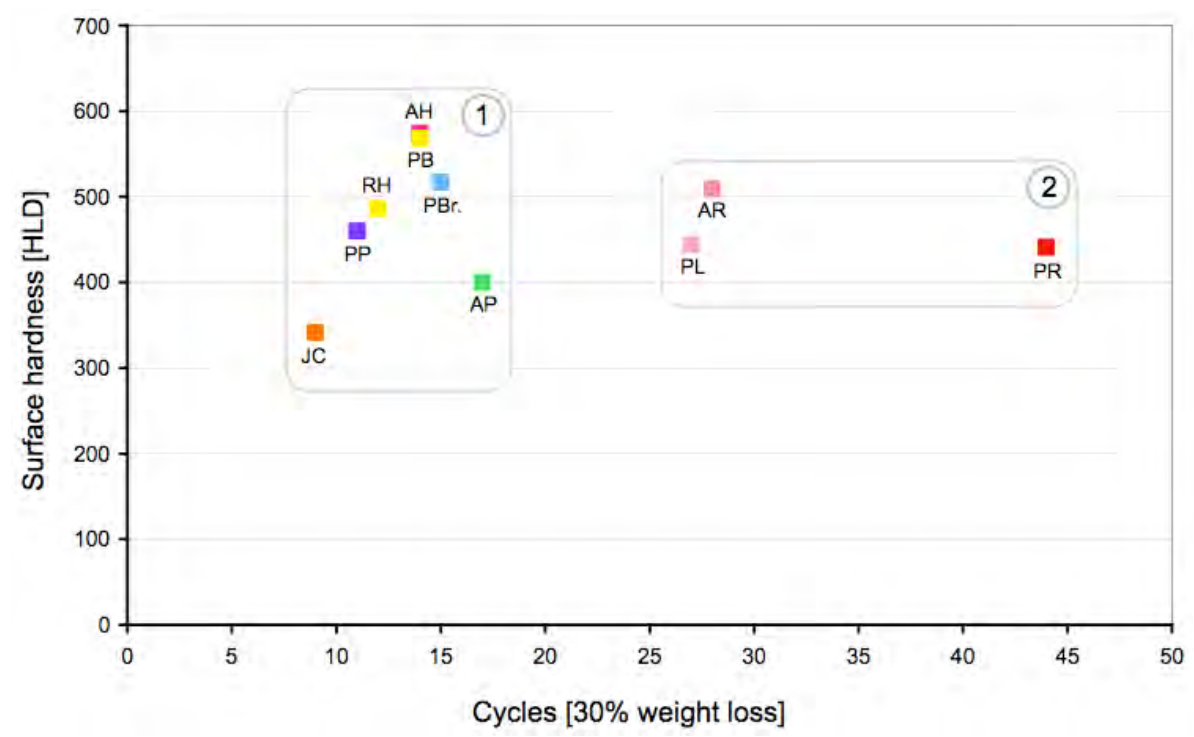

Figure 167: Correlation of the tensile strength versus the number of cycles of the sandstones. 1) the group of the sandstones with a low salt resistance and 2) the ones with a better salt resistance.

\section{4 Salt weathering tests}

The common salt weathering test like the European Norm 12370 standard "Natural stone test methods - Determination of resistance to salt crystallization" as well as the RILEM PEM-25 1980, ASTM B 117 or DIN 52111 test does not seem to be able to reproduce the same weathering conditions that one finds in situ. Therefore new test procedures are under development and discussion (Lubelli et al. 2014).

Salt weathering is a complex process influenced by different parameters such as the type or mixture of salts, the climate and humidity conditions and the contamination of the substrate as well as the substrate itself. Reproduction of all the conditions and possible side effects seems to be impossible in the laboratory. Nevertheless, salt weathering tests performed under laboratory conditions can give an orientation for determining the salt resistance of porous materials under the performed testing conditions. 

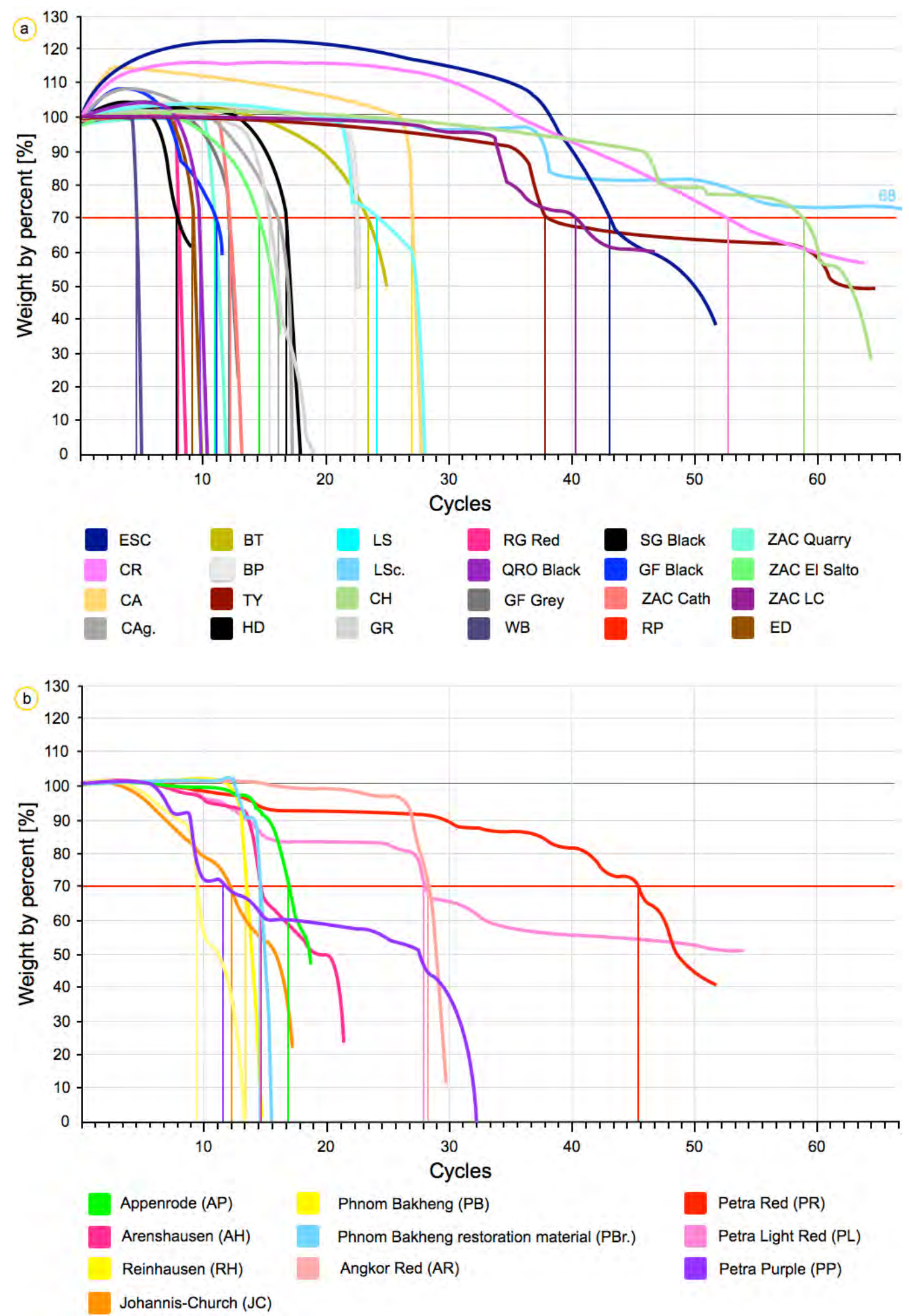

Figure 168: Correlation of the weight versus the number of testing cycles, a) of the tuffstones and b) for the sandstones. 


\section{4. 1 General observations}

During the first testing cycles most of the tuff samples show an increase in weight, due to storage of salt within the porous structure without showing any deterioration (Fig. 168 a). Storage of salt also took place in the case of the sandstones but with a simultaneous loss of material where the weight remained more or less constant (Fig. 168 b). For some tuff samples an increase in weight could also be assumed, while at the same time an observable material loss took place. Other samples show a nearly constant weight during the first cycles and after a continuous material loss (Fig. 168 a).

Observations of the process of destruction by the salt bursting test and the deterioration forms in the field are described in the above case studies. The salt bursting tests for the tuffs not included in the case studies are presented in the following paragraphs.

\section{-RG from San Miguel de Allende}

RG shows planar flaking of the matrix as well as a rounding of the edges and upper corners. After five cycles initial destruction begins in the sample by the development of structural cracks. The vulnerability to salt weathering can be observed at several buildings, for example, at the windows and door frames in the city of San Miguel de Allende.

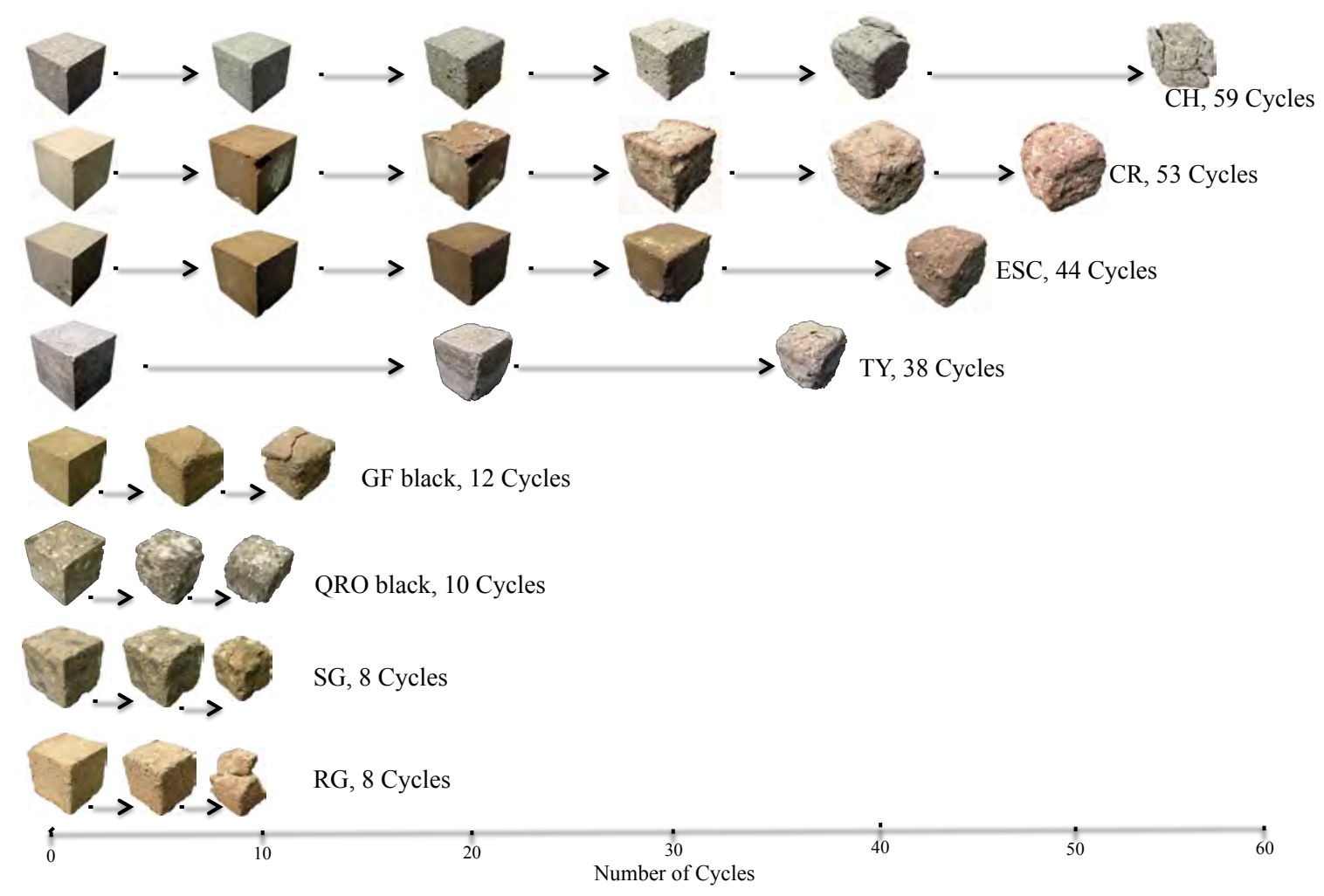

Figure 169: Photographic documentation of the salt bursting test of the four most resistant and the four less resistant investigated tuffs. 
-SG from San Miguel de Allende

During the salt bursting test a weathering out of the basaltic inclusions takes place as well as a flaking of the matrix, comparable to RG. If the stone is contaminated with salt, the same weathering forms can be observed in the field (Fig. 169).

-Qro black from Querétaro

The black tuff from Querétaro shows a loss of both components and matrix after the salt bursting test. Deterioration can be characterized by disjointing and scaling of weak components, like clasts and the disintegration (e.g. dissolution) of the matrix. Nearly the same weathering phenomena can be observed in the field (Fig. 79).

-Zac quarry from Zacatecas

The sample from the Guadalupe quarry shows a planar flaking of the matrix as well as a rounding of the edges and loss of corners. After nine cycles the sample lost more than $80 \%$ of its material.

-GF Black and GF gray from San Miguel de Allende

Both tuffs show a similar development in the salt bursting test. At the beginning both samples show an increase in their volume of about $10 \%$, but after the $7^{\text {th }}$ cycle the decay begins mainly at the edges. After the $10^{\text {th }}$ cycle in the GF gray, a very rapid back-weathering occurs mainly parallel to the lamination (X -Y plane). GF black lost material mostly at the edges and not in the laminations. GF gray lost more than $30 \%$ of its material after 12 cycles and GF black $30 \%$ after 13 cycles (Fig. 169).

-Zac Cath. from Zacatecas

The sample from the cathedral shows a loss of grains (sugaring) and flaking of the matrix. After 12 cycles the sample was completely useless and destroyed.

-Zac El Salto from Zacatecas

The sample from El Salto shows a loss of only single grains, possibly due to its weak mineral components such as feldspar. After 13 cycles the sample had lost a significant amount of material.

-Zac La Cueva from Zacatecas

The sample from La Cueva first shows an out-weathering of whitish inclusions, which are embedded parallel to the surface. After the $18^{\text {th }}$ cycle flaking starts within the centers of the surfaces, the edges were still conserved. After the $33^{\text {rd }}$ cycle parts are breaking away and flaking starts to become a structural phenomenon. 
-BP from Hidalgo

After eight cycles first low bound particles are weathered out at the edges and the bottom of the sample cube. In the $14^{\text {th }}$ cycle the upper edges start to split. Furthermore, the sample breaks and cracks are created parallel to the bedding. This weathering form can also be observed in the field, like for example at several buildings in Mexico City.

\section{-ESC from Querétaro}

The tuff of Querétaro shows an increase of weight of around $20 \%$ in the first 40 cycles by storing salt within the highly porous structure. First damages can be recognized after the $15^{\text {th }}$ cycle by a slight rounding at the edges. After the $30^{\text {th }}$ cycle the corners at the bottom start to weather back. A significant loss of material takes place after the $40^{\text {th }}$ cycle by the breaking out of small rock fragments (Fig. 169).

\section{-CR from San Miguel El Alto}

Comparable with the Cantera Amarilla de Guadalajara, the weathering of the Red Tuff from San Miguel del Alto starts by the weathering of the pumice inclusions. A damage of the shape starts quite late. After about the $30^{\text {th }}$ cycle, a rounding by flaking starts in the smaller particles. Similar weathering forms can be found in the field.

\section{5. Discussion}

\section{5. 1 Characterization of the pore space}

The damage potential of salt crystallization depends on the pore size distribution as well as on the type of pore radii distribution. A unimodal distribution containing only micropores is particularly susceptible to salt weathering (Snethlage 1984; Ruedrich, Siegesmund 2007). Crystallization pressures can only occur in pores with pore radii smaller than $30 \mathrm{~nm}$ (Rijniers et al., 2005) or $50 \mathrm{~nm}$ (Steiger et al., 2011). The most dangerous pore dimensions for salt crystallization are the pores that range around $1 \mu \mathrm{m}$ (Benavante 2011). These critical pores are developed as a secondary porosity by the storage of salt during the salt accumulation process (Angeli et al., 2008).

Our investigations however, clearly show that the tuffs with less cycles of endurance have higher porosity values (ranging between $28 \%$ and $49 \%$ ). All of the tuffs show a well-developed bimodal pore radii distribution, with an important percentage of microporosity but also higher values of macroporosity (Fig. 80). 
Tuff rocks with only micropores, e.g. TY, BP, LC and Zac quarry show a highly variable response to the salt bursting test resisting 38, 23, and 11 cycles, respectively, before the destruction. Samples with practically only macropores, e.g. ESC, GF black and GF gray, showed a similar behavior with 44, 12, 41 and 13 cycles before decay of $30 \%$ material lost (Fig. 169).

The sandstones with a high content of micropores (PP and PB) show a low salt resistance, but even sandstones with a medium microporosity of around $10 \%$ or less (AH, PBr. AP) show the same trend. No clear tendency for a salt bursting could be connected to a high amount of micropores. This may be due to the low porosity range of the investigated sandstones. Only the purple colored sample of Petra (PP) has a low porosity with less than $10 \%$.

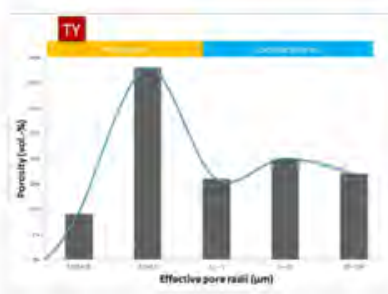

Tenayocatétl Tuff Cycles 38 Porosity $7 \%$ Micro $47 \%$, Macro 53\%

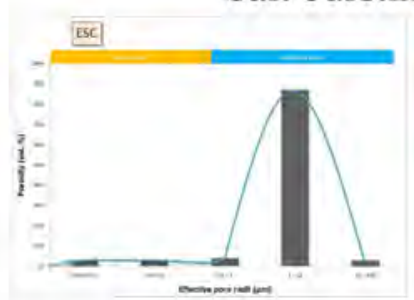

Escolásticas Tuff Cycles 44 Porosity $50 \%$ Micro 6\%, Macro 94\%

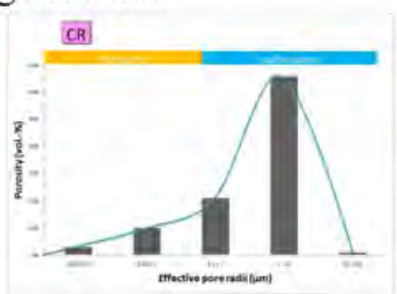

Cantera Rosa Tuff Cycles 53

Porosity $41 \%$

Micro 13\%, Macro $87 \%$

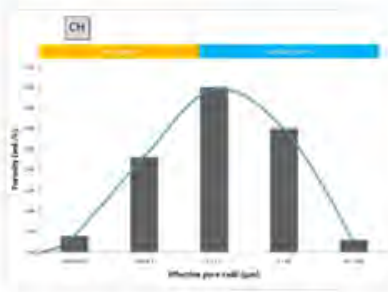

Chiluca Tuff Cycles 59 Porosity $8 \%$ Micro 27\%, Macro $73 \%$

Salt bursting less resistant

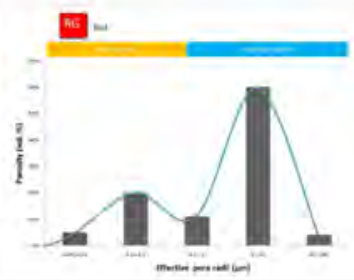

Red Tuff

Cycles 8

Porosity $28 \%$

Micro 25\%, Macro 75\%

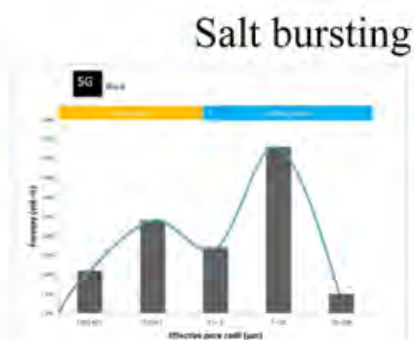

Gris Oscura Tuff

Cycles 8

Porosity $32 \%$

Micro 35\%, Macro 65\%

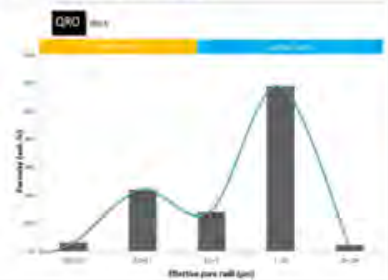

Querétaro black Tuff Cycles 10 Porosity $46 \%$ Micro 25\%, Macro $75 \%$

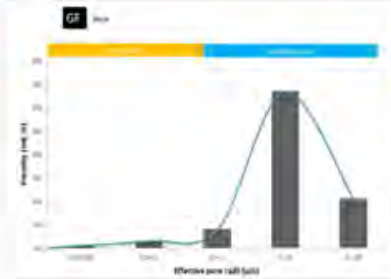

Black Tuff

Cycles 12

Porosity $49 \%$

Micro 4\%, Macro $96 \%$

Figure 170: Comparison of the different pore radii distributions between the four resistant (above) and the non-resistant tuffs (below) against salt bursting.

\section{5. 2 Characterization of the physical and moisture properties}

No clear correlation can be observed when comparing the weight reduction by salt bursting test cycles with the splitting tensile strength of the investigated samples (Fig. 166). Nevertheless, two possible tendencies are discernible in Fig. 166 and these are shown as groups labeled areas (1) and (2). Group 1: the volcanites show a low resistance against salt weathering related to the strength of the material as measured by the splitting tensile strength test. The clearly defined group of samples at the bottom part of the marked area contains most of the investigated samples, i.e. SG Black and RG 
Red, QRO Black, ZAC Quarry, GF Black, ZAC Cath, GF Gray, ZAC El Salto and CA and GR. Most of these samples are dominated by a macroporous structure. Only the sample ZAC Quarry with $97 \%$ is clearly dominated by micropores. The other samples have an average amount of microporosity containing only $18 \%$. However, all the samples can be defined as low bound stones with low mechanical values as defined by the splitting tensile strength values between 1.4 and 3 $\mathrm{MPa}$.

The four samples in the upper part of area 1 of Figure 170, BT, BP, LS and LC are characterized by a comparably higher mechanical strength, but they are clearly dominated by microporosity, with an average of $88 \%$. This significant amount of micropores is probably the reason they are less resistant against salt crystallization, a similar tendency has been noted with investigated sandstones by different researchers (Benavante 2011; Ruedrich, Siegesmund 2007). The groups show similar behavior in regards to splitting tensile strength and ultrasonic velocity in comparison to the cycles of salt bursting.

Group 2: Most samples like ESC, CA, CA Gray, CR, CH and LSc are characterized by a balanced relation of micropores and macropores. In the case of TY that is placed between the two groups this relation is nearly balanced.

In general, two main groups of resistance can be distinguished: 18 tuffs reach a material loss of 30 $\%$ during 30 cycles of salt bursting tests (BT, BP, LS, HD, ZAC Quarry, ZAC El Salto, ZAC Cath, GR, ED, RP, GF Gray, GF Black, CA, CA Gray QRO Black, SG Black, RG Red and WB) and the other seven samples attain the same percentile of loss between around 40 to 70 cycles (TY, LC, ESC, CR, CH, LSc).

The six tuffs with the highest salt resistance of all investigated tuffs show a different distribution of micro- and macropores: The LSc -tuff has a microporosity of $80 \%$ and $20 \%$ macroporosity, respectively. The CH-tuff contains a microporosity of $27 \%$ and a macroporosity of $73 \%$ (Tab. 35). The CR-tuff is clearly dominated by macropores ( $87 \%$ ). The LC-tuff exhibits a contrary distribution with $83 \%$ micropores and $17 \%$ macropores. Some important aspects appear to play a decisive role because these tuffs are the most resistant rocks against salt bursting.

LSc, LC, CH together with TY are the less porous of the studied tuffs with $9 \%, 11 \%, 8 \%$ and $7 \%$ porosity, respectively.

LSc is clearly dominated by micropores with a unimodal pore class system. The moisture properties appear to be critical in the high resistance to salt crystallization. From all investigated tuffs LSc has the lowest $\mathrm{w}$-value of $0.039 \mathrm{~kg} / \mathrm{m}^{2} \sqrt{\mathrm{h}}$. This also seems to be the explanation why a stepwise deterioration during the salt bursting test takes place (Fig. 72).A possible explanation seems to be that even the microporosity is critical to salt bursting. The water uptake is limited, and therefore it takes time Wanja Wedekind 
until a critical amount of salt within the low pore space is accumulated that leads to deterioration. The strength of the material in this case does not seem to be the main factor. Surface hardness reaches only $377 \mathrm{HDL}$; splitting tensile strength with $6 \mathrm{MPa}$ is high but even lower than the BT-tuff (6.3 MPa) that resists only 22 cycles. Moreover, the ultrasonic velocity with $3.4 \mathrm{~km} / \mathrm{s}$ attains one of the highest values of all investigated tuffs and demonstrates the compact internal structure of the material.

$\mathrm{CH}$ is dominated by the presence of macroporosity (73\% macropores); however it is the tuff that shows the most balanced pore radii distribution, forming an almost ideal distribution curve (Fig. 170). Two moisture properties appear to be critical in the high resistance to salt crystallization of the $\mathrm{CH}$ Tuff. 1) The extremely poor ability to absorb water (water uptake), which is $0.4 \mathrm{~kg} / \mathrm{m}^{2} \sqrt{\mathrm{h}}$ (Fig. 7), and 2) $\mathrm{CH}$ has the highest resistance to water diffusion with 118.5 (Tab. 29), i.e. $\mathrm{CH}$ is a rock that exhibits little absorption and only shows a low water diffusion. These two features together with the low porosity and its balanced pore distribution are the factors that differentiate it from the other tuffs.

LC is dominated by micropores concentrated within the pore class of 0.01 to $0.1 \mu \mathrm{m}$, after Benavante (2011) a pore radii group critical to salt crystallization. The tuff is also characterized by its high splitting tensile strength (10.8 MPa) as well as the high surface hardness (706 HLD) that seems to be the main factor for the good salt resistance in general. However, the flaking observable during the salt weathering test show, that the stone is affected by salt bursting probably due to its content of micropores. Moisture transport also seems to play a role. With a w-value of only $0.15 \mathrm{~kg} / \mathrm{m}^{2} \sqrt{\mathrm{h}}$, the ability to absorb water is extremely poor.

TY has the lowest porosity of all tuffs investigated in this study where the microporosity is $47 \%$. The w-value of $0.33 \mathrm{~kg} / \mathrm{m}^{2} \sqrt{\mathrm{h}}$ is comparable with the one of the $\mathrm{CH}$-tuff. The ultrasonic velocity with $3.4 \mathrm{~km} / \mathrm{s}$ is comparable to the LSc-tuff. One possible explanation for the good salt resistance of the TY-tuff is that the pore size system between micro- and macropores is balanced by forming a bimodal distribution. The relatively high content of macropores allows the salt to crystallize within the bigger pores. Moreover, the strength and compaction of the material characterized by the high ultrasonic velocity also leads to a good salt resistance. This can also be characterized by its weathering behavior, which takes place as contour scaling with no lamination parallel to the bedding during the salt bursting test. However, this is not to be expected because the stone shows a clear lamination (Fig. 51).

The significant salt resistance of the other three tuff rocks from Group 2 in Figure 170 including CR and ESC seems to be related to the porous network as well as to mineralogical aspects. During the first testing cycles it becomes clear that an increase of weight attaining up to $25 \%$ (ESC, CR and 
CA) takes place (Fig 168 a). This increase can be related to the high porosity of the samples containing $41 \%$ (CA, CR) and 50\% (ESC). The increases in weight can be due to the storage of salt, but also due to the water retention properties of the material. This water retention is not related to a poorly connected pore space. These tuffs have a quite low water vapor diffusion capacity of 7.7 (CA), 9.9 (ESC) and 10.3 (CR) and do not contain a high amount of swellable clay minerals (Wedekind et al., 2012). An explanation for this could be fine mineralogical structures in these samples visible by SEM (Fig. 171). The ESC Tuff, for example shows quartz (crystobalite) crystals, grains and little pumice clasts that are embedded in a very fine-grained matrix, which has a microporous fibrous texture similar to zeolites (Fig. $171 \mathrm{~A}$ and B).
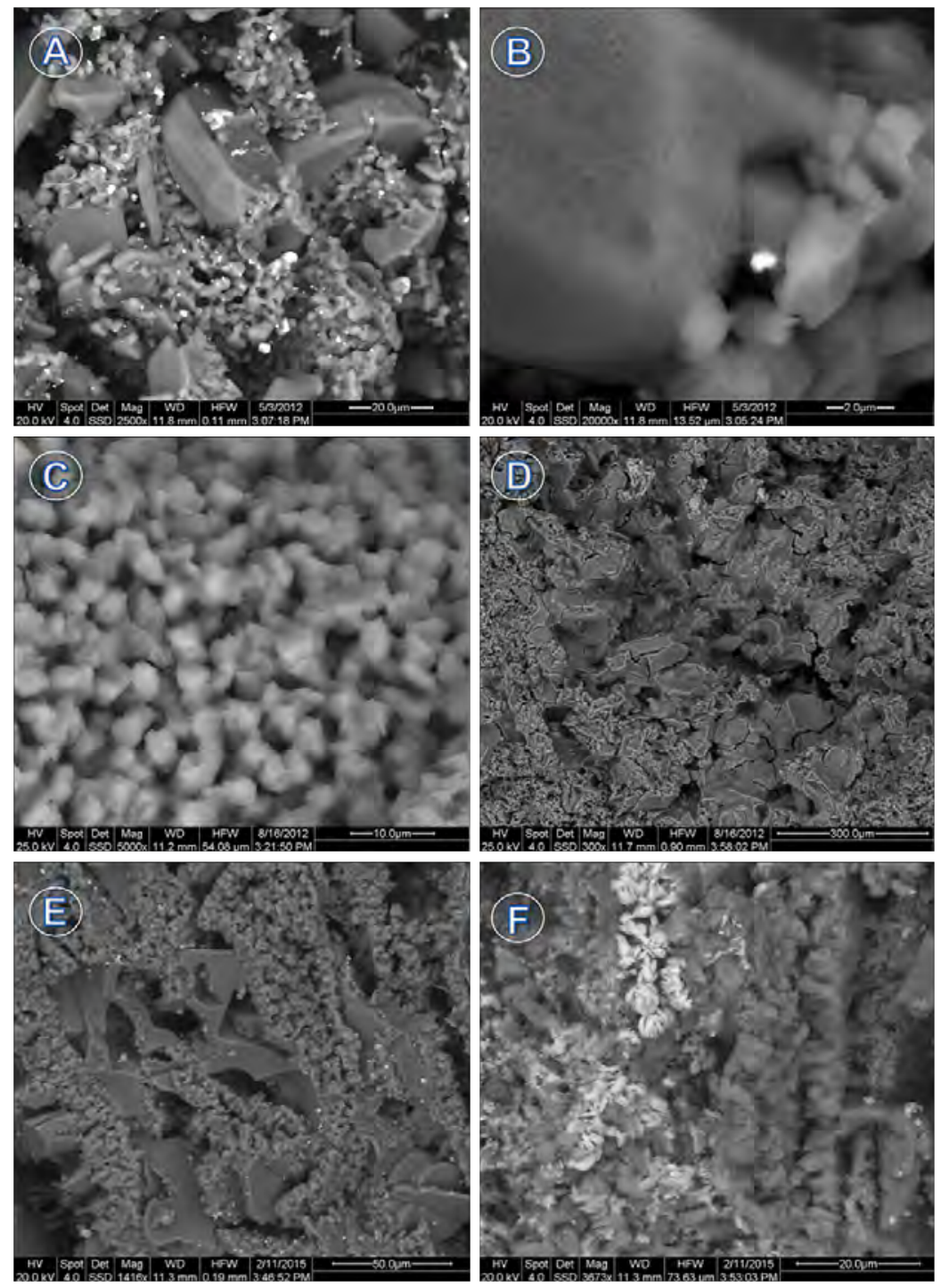

Figure 171: Scanning electron microscopy (SEM) images of the ESC, CA and CR-tuffs. a) Crystobalite crystals overlain by a fibrous mineralogical structure within the pore space of ESC. b) The fine fibrous structure in detail. c) Kaolinite and amicite crystals forming a complex pore network in the matrix of the CA tuff. d) Amicite-phillipsite zeolite and probably kaolinite produced by the alteration of feldspar and located within larger pores of the same sample. e) Quartz in the center surrounded by very fine-grained K-feldspar. f) Mn-Ba mineralization (probably hausmannite/psilomelane) in the CR-tuff, together with fine-grained chlorite needles. 
A well known property of zeolite minerals is a high water retention capacity used widely for soil fertilization (Be Campos Bernardi et al., 2010, Torkashvand, Shadparvar 2013), where this is related to their complicated microstructure. In the case of the CA tuff amicite and also kaolinite minerals are clearly identifiable by the SEM, and these could play a role in water retention (Fig. $171 \mathrm{C}$ ). The porous texture of the CA tuff as well as the SMA Tuff is covered by a fine fibrous structure. In the case of the CA tuff EDX analyses show $\mathrm{Na}^{+}$and $\mathrm{K}^{+}$-rich components, probably amicite minerals that belong to the amicite-phillipsite zeolite series (Fig. $171 \mathrm{D})$. Closer investigations show that in the BP-Tuff zeolites could be found. Nevertheless, the presence of zeolite minerals does not seem to play a significant role in the resistance against salt weathering in the investigated tuff rocks. After 23 cycles a nearly total destruction of the BP-tuff took place (Fig. 72). Almost everywhere in the matrix of the SMA-tuff fine magnetite structures could be identified (Fig. $171 \mathrm{E}$ ) as well as Mn-Barich mineralizations, probably hausmannite and psilomelane, associated with a fine needle-like structure (Fig. $171 \mathrm{~F})$.
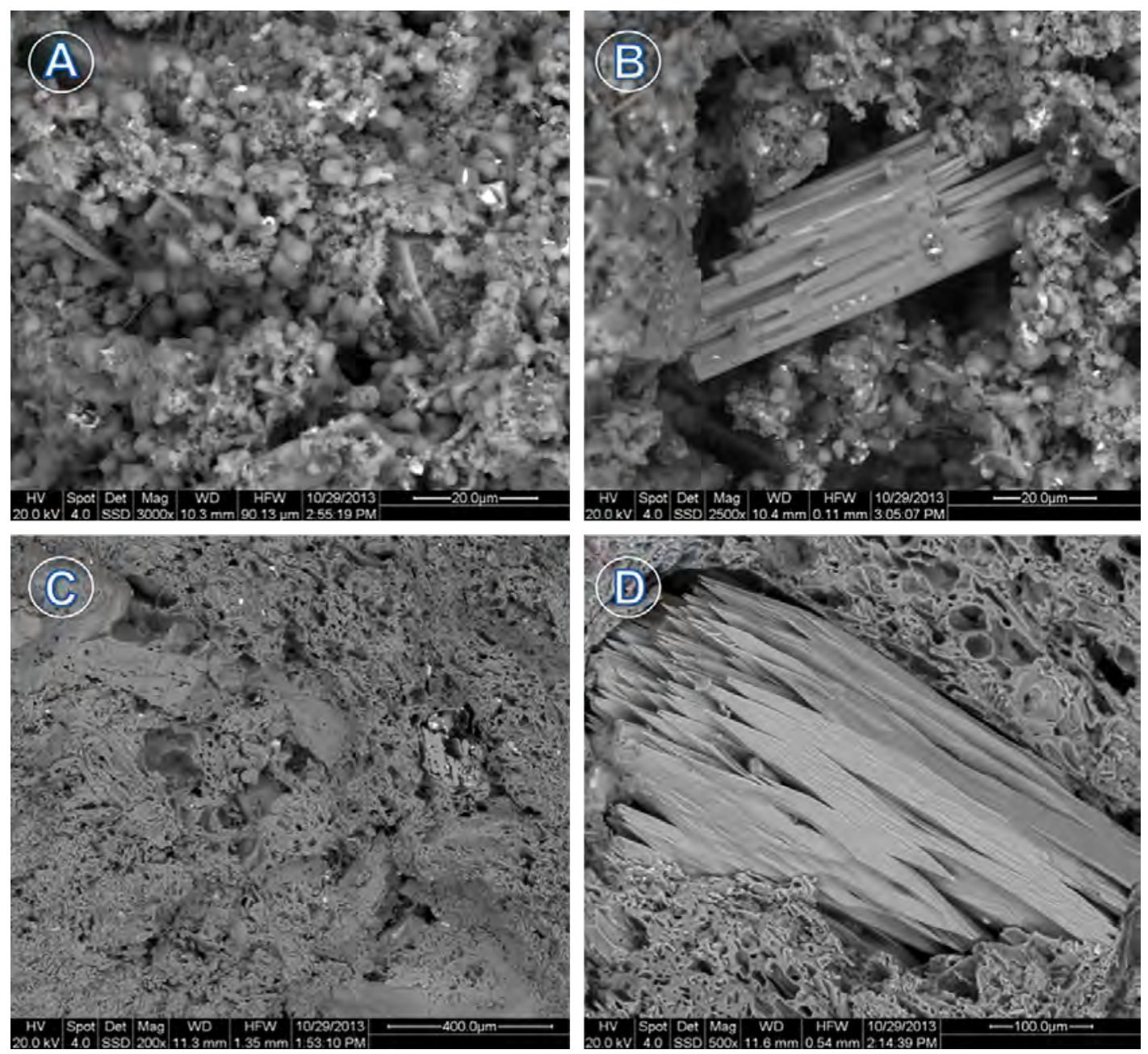

Figure 172: Scanning electron microscopy (SEM) images of the RG and SG tuffs. a) Overview of the RG tuff with abundant $\mathrm{SiO}_{2}$ particles. The porous matrix is clearly visible in this tuff. b) Clast with observable weathering marks, which creates a secondary porosity. c) Overview of the SG tuff, which is similar to RG with its prominent very porous glassy matrix. d) Probable pumice clast, strongly weathered and embedded in a glassy matrix of the SG tuff. 
The RG and SG tuffs, which are less resistant to salt crystallization (both can only withstand 8 cycles) show a very well interconnected open porous network (Fig. 172 A and C). They exhibit remarkable weathering patterns, both in the matrix and in the clasts (Fig. 172 B and D), clearly causing a primary and a secondary porosity that allows the rapid formation of salt crystals inside the tuff.

For the high porous tuff variations such as CA, ESC and CR the micro-mineralogical structure within the stone seems to play a main role in salt resistance. These structures are not always associated with clay minerals. In most cases the microporosity in sandstones is mainly formed by clay minerals. In contrast to the tuffs, the presence of clay minerals leads to a susceptibly for salt bursting and a low resistance to mechanical forces.

For some of the tuffs the cation exchange capacity, defined as the CEC value was detected. The CEC value and salt bursting cycles do not show any correlation (Fig. 173). The ones with the best salt resistance display low $\mathrm{CEC}$ values $(\mathrm{ESC}, \mathrm{CR}, \mathrm{CH})$, however three also show a low resistance (RP, HD, BT). The two samples with the highest CEC value still have a good salt resistance between 20 and 40 cycles (BP, TY).

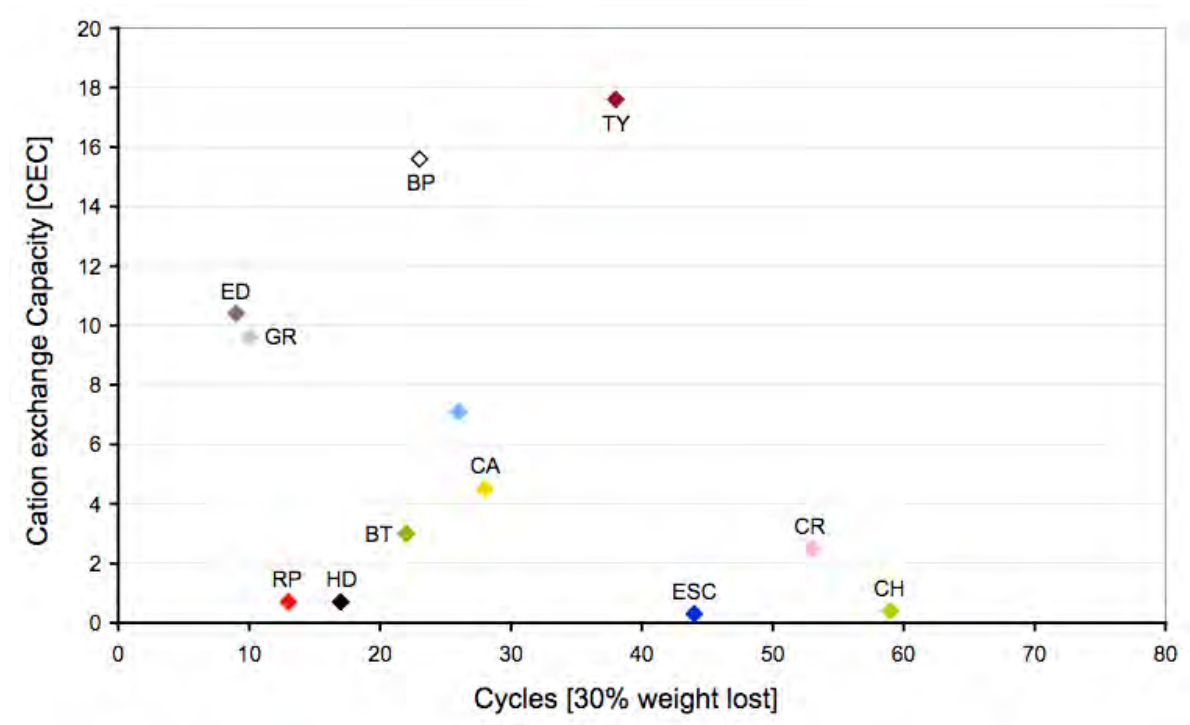

Figure 173: Cation exchange capacity versus salt bursting cycles of the tuffstones do not show correlation.

In the case of the sandstones the strength of material only plays a role, if the material has a surface hardness of less than 300 HLD and more than 700 HLD corresponding to a splitting tensile strength less than $2 \mathrm{MPa}$ and greater than $5 \mathrm{MPa}$. If the material has the described low strength, the presence or absence of clay minerals also does not play a role. In any case the stone will deteriorate faster in the first 20 cycles. This is also the case if the material has a low to medium strength of up to 600 HLD, but a microporosity of more than $50 \%$ such as in the case of PP and PB. If the strength is high the stone can resist 40 cycles or more. 


\section{5. 3 Conclusions}

Our results show that the resistance to the salt bursting decreases with the increase in porosity in the case of the tuffs but not necessarily for the sandstones. The tuff rocks with higher porosity resisted less to cycles of salt crystallization. In fact the four studied samples with the lowest porosities resisted the majority of the salt bursting cycles (TY and CH, LSc, Fig. 157 a). However, the rock with the highest porosity (ESC with $50 \%$ porosity) was extremely resistant to salt crystallization, indicating that the porosity itself is not the determining factor in this resistance.

Another factor that can influence the resistance against salt crystallization is the capacity of water uptake. Salts are dissolved in the absorbed water so that it is expected that rocks with higher water uptake values should have more possibilities for allowing salt crystallization to occur. Four of the most resistant tuff rocks showed very low values of water uptake (w-value around zero, Fig. $161 \mathrm{a}$ ). The samples with the lowest resistance did not show any important w-values (around 2 to 5). The same occurs for the sandstones (Fig. 161 b).

Finally, three factors appear to have a real importance concerning the resistance against salt crystallization, the micro-mineral-structure formed the mineralization shown in Figure 171, the binding cement and the pore radii distribution. The results also show that salt resistance is not only controlled by the porous structure but also by the mechanical strength. A fast and mostly total destruction takes place in the case of the tuffs, if the stone only reaches a splitting tensile strength of up to 3 MPa (Fig. 166 a). This value of low mechanical strength can be defined as a critical value for tuffs in regards to salt weathering. Because a significant correlation between the surface hardness and the splitting tensile strength was observed (Wedekind et al., 2016), the ratio of cycles to the surface hardness is similar to the splitting tensile strength (Fig. $166 \mathrm{~b}$ ). Furthermore, in the case of a very low mechanical strength the pore size distribution seems to play a minor role for both rock types.

Microporosity becomes a relevant factor for rapid salt destruction if it reaches more than $50 \%$ of the pore volume expacially in case of the sandstones (Fig. $158 \mathrm{~b}$ ). If the matrix of the tuff contains a high amount of the described micro-mineral structures and textures, the salt resistance can increase in a significant way even if the material only reaches a low splitting tensile strength. This can be seen in the ESC, the CA, and the SMA tuff (probably including glass and zeolite minerals).

\section{6 Weathering behavior related to the environment}

\section{6. 1 The Mexican case studies}

The tuff rocks that show a lesser resistance to salt crystallization lose more than a third of their weight by barely being able to withstand 5 or 8 cycles, therefore it is to be expected that the damages in the old historical buildings constructed with these rocks should be notable. However, the 
damages are indeed locally very strong, but the constructions, some of them more than two hundred years old are still standing and many of them are in good condition and without the expected damage. We have noticed that the porosity, its diameter and pore size and its moisture properties such as the water uptake together with the mineralogical properties and fabrics of the rock play major roles in the ability of a rock to allow or prevent salt crystallization. The main element for the transport of salts is water. Water in any form is the main factor for the transport of solvents and the crystallization of salt. When there is no water, no crystallization occurs. This factor explains the relatively little damage to some buildings erected with these erodible rocks.

Plotting the meteorological data from the cities and regions where the analyzed samples are used as construction materials into the combined rainfall/temperature diagram of Peltier (1950) and Fookes (1970) (Fig. 174), it is easy to see that in the case of the Mexican tuff rocks of San Miguel de Allende and Querétaro, both less resistant to salt bursting, fall into the semiarid region and in the area with very slight weathering (Fig. 174). This may be the reason why these weak and soft rocks show such a good resistance against weathering and why they are still being used as natural building stones in Mexico today.

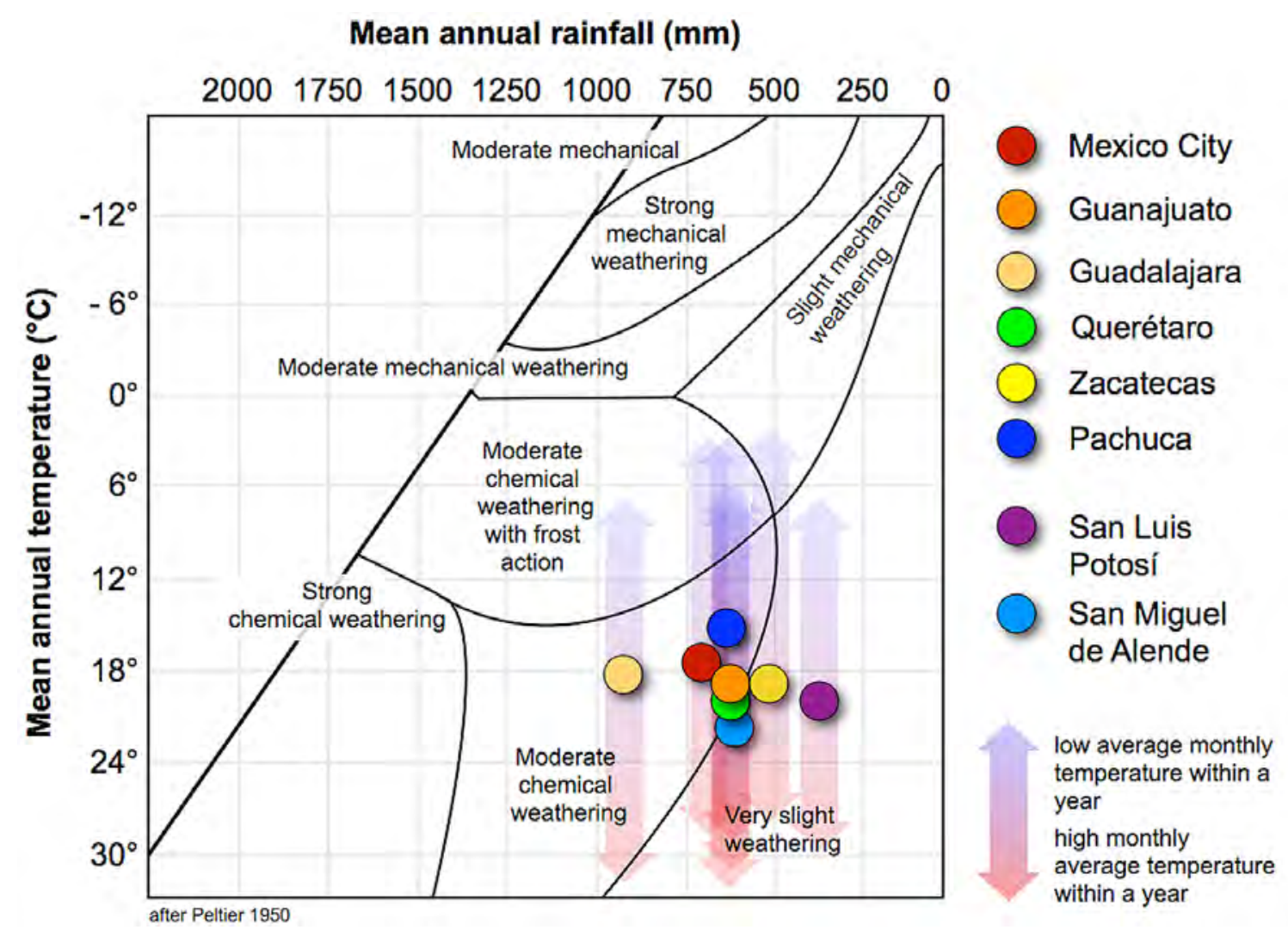

Figure 174: Location of the principal cities, where the analyzed samples from Mexico were taken with respect to the "types of weathering" of Fookes (1971).

In the case of the Loseros Tuff an interesting observation could be made: Because of its color and texture the Loseros Tuff was quite popular during the $19^{\text {th }}$ century as a building material for monu- 
ments in different regions of Mexico. At the Masquitslan Cemetery in Guadalajara an outstanding monumental tomb can be found where the L0seros Tuff was used (Fig. $58 \mathrm{c}$ ). Some building stones of the columns show intensive contour scaling while other decorative elements show lamination. Chemical analyses have shown that the crust, where contour scaling is found, contain a high amount of calcite (around $6 \mathrm{M}-\%$ ). Intensive weathering forms such as contour scaling are not found in Guanajuato, where the Loseros was also used to construct columns at many buildings.

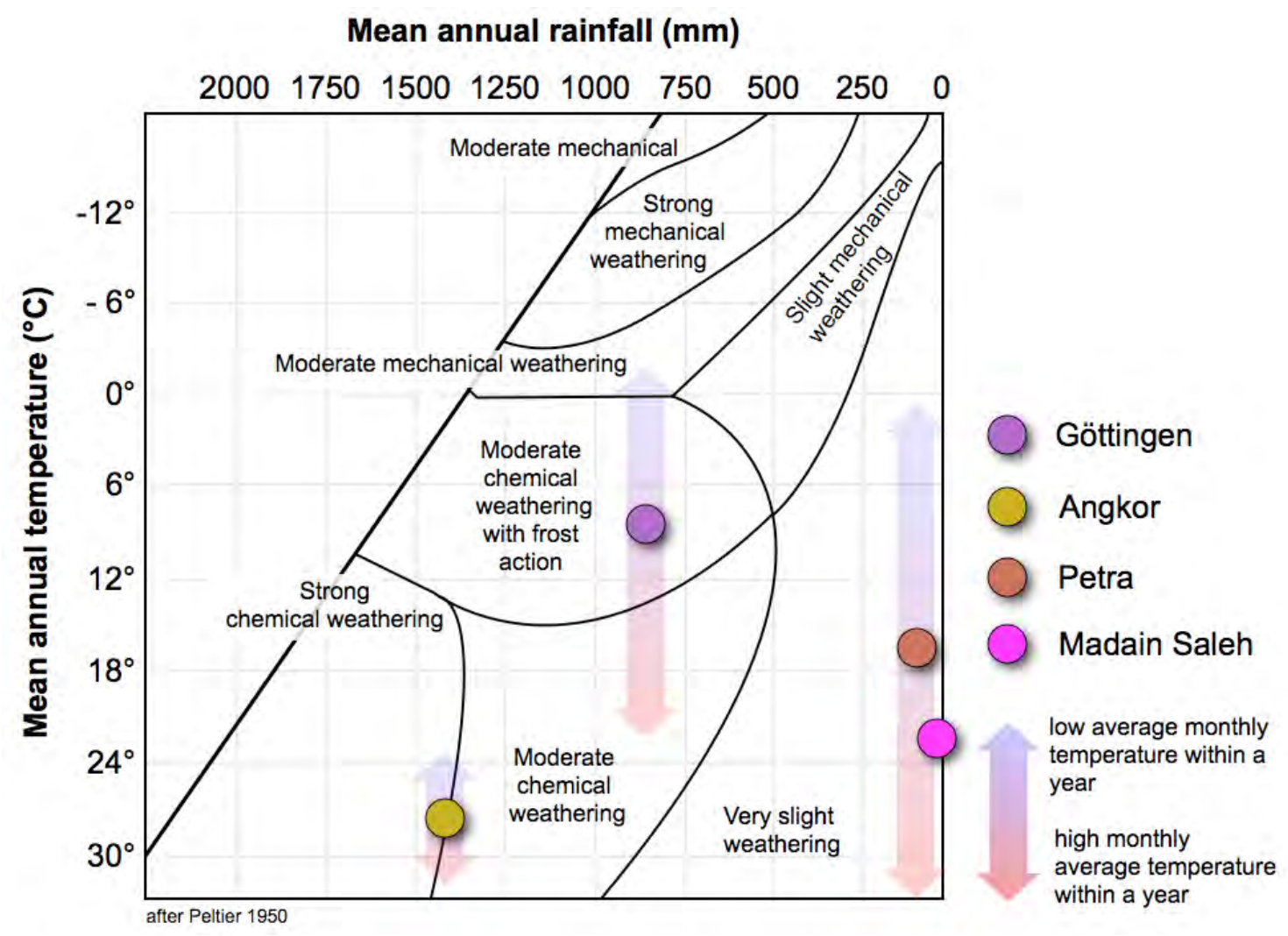

Figure 175: Location of the principal cities, where the analyzed sandstone samples were taken with respect to the "types of weathering" of Fookes (1970).

The climatic conditions of temperature fluctuations and rainfall in Guanajuato are very similar to Guadalajara (Fig. 57 and 76). What differs is the amount of rainfall. Total rainfall in Guadalajara is one third higher than in Guanajuato (Fig. 76). These high amounts of rainfall seem to be the reason for the chemical dissolution of the calcite that precipitated near the surface, which is similar to the Phnom Bakheng sandstone in Angkor/Cambodia. As a result of this precipitation, a weathering crust forms that contain a higher amount of calcite than the unaltered stone. Chemical analyses have shown that the crust contains 7\% calcite, whereas XRD analyses show the stone only has a content of $3.2 \%$. Apparently, thermal stress also plays a role in contour scaling because of the high thermal coefficient of calcite. The city of Guadalajara is located near the middle of the moderate chemical weathering zone after Peltier (1950). Guanajuato is located at the border from the moderate chemi- 
cal weathering zone and the very slight weathering zone (Fig. 174). This confirms the weathering model presented in this study.

Extreme weathering forms are found in the Cantera Amarilla Tuff variations as well as for the different vulcanite building stones in Mexico City. This also confirms the model of Peltier because Mexico City is located in the zone of moderate weathering. The stones are not the same but the intensity of the weathering phenomena in Guadalajara are stronger.

\section{6. 2 The case studies from sandstone}

The sandstones investigated in this study are located in different weathering zones (Fig. 175). Germany has a moderate chemical weathering with frost action, Jordan a very slight weathering and Angkor a strong chemical weathering. For the case studies of Göttingen in Germany and Angkor in Cambodia the model of Peltier appears to be true. Weathering of the Bunt-sandstone tombs in Göttingen is comparable but moderate, whereas the weathering of Angkor is extreme especially in regards to the contour scaling phenomena.

In the case of Petra the weathering cannot be described as very slight. In Saudi Arabia at Madain Saleh, which is around $600 \mathrm{~km}$ in SSE-direction from Petra, the model of Peltier (1950) can be confirmed. The site is also a Nabatean necropolis made from a similar sandstone like Petra. Here alveolar weathering occurs on the natural rocks but not on the monuments. The monuments still look like they are in a good state of preservation (Fig 176).

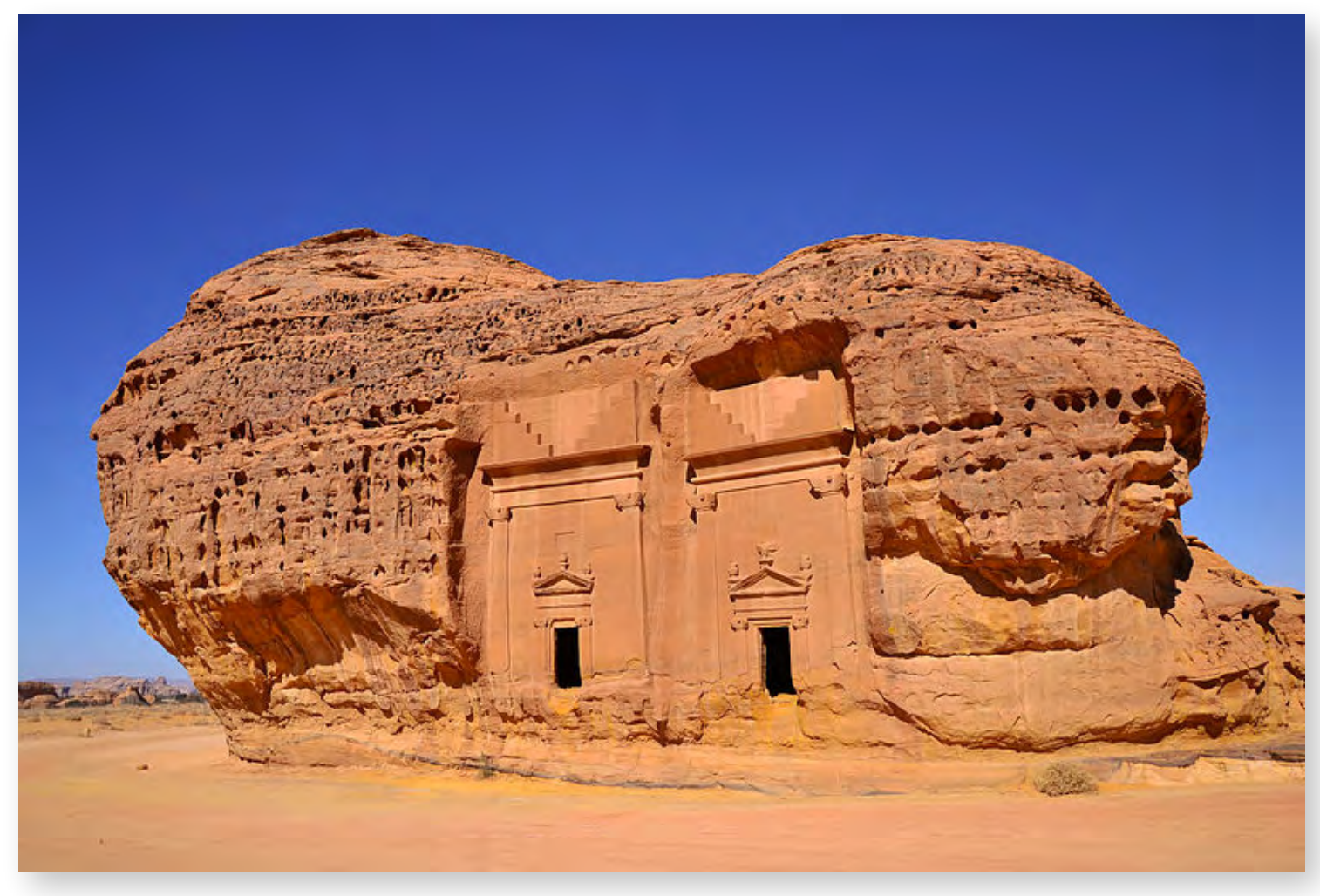

Figure 176: The monuments of Madain Saleh doesnt show any development of vertical tafoni (source: wikipedia). 
In contrast to Petra, Madain Saleh is considered to have a desert climate. During the year, there is virtually no rainfall and according to Köppen and Geiger this climate is classified as BWh. The average temperature is $21.9^{\circ} \mathrm{C}$ and the rainfall averages only $61 \mathrm{~mm}$, which is less than half of what Petra receives. The climate in Madain Saleh seems to produce only a very slight weathering. There is also no special contamination by salt. The distance to the Dead See $(700 \mathrm{~km})$ is farther than in the case of Petra, whereas the distance to the Red See is only about $100 \mathrm{~km}$ and similar to Petra.

In the case of Petra, special environmental conditions such as the high salt content in the rainwater and the aerosols are not taken into account by the model of Peltier (1950) as well as special geographical contitions like coastal and arid environments (Wellmann, Willson 1965). Single cloudbursts also have an important influence on weathering.

The model of Peltier does not take into consideration weathering agents such as salts and heavy precipitation events. Therefore, a more realistic model needs to be developed that closely approaches the true situation at different sites. 


\section{Practical conclusions - conservation}

\section{1 General introduction}

Conservation treatments are the practical conclusions of all investigations with the objective to slow down the deterioration process and to preserve the monument for the future. The main working steps in conserving cultural heritage sites are cleaning, desalination and consolidation. This thesis not only includes investigations of the weathering observed in the different case studies and the determination of the petrophysical properties of building stones used, but also incorporates active and experimental conservation work. This was the case for the Santa Monica Church in Guadalajara (Mexico), several tomb monuments at the Bartholomew Cemetery in Goettingen (Germany) and monument no 826 in Petra (Jordan). Furthermore, detailed conservation models for all case studies have been developed.

\section{2 Case study: Templo Mayor, Mexico City, Mexico}

\section{2. 1 Introduction}

\section{2.1 a) Conservation history}

At the Templo Mayor conservation works have been ongoing since its excavation in the 1980s. In 1981 the Tzompantli altar was found and restored (Matos Moctezuma 2014). Historical photos show that the sculls at the south side were nearly completely covered by lime wash. The east side still shows remarkable remains of the lime wash, while only a fragmented state of lime wash could be detected on the sculls of the north side (Mora Navarro 2015). In general, the state of conservation found after excavation can be traced back to the main wind and rain direction coming from the north and northwest (Mora Navarro 2015). After the fall and destruction of Theotiacan during the $15^{\text {th }}$ century, the burial of the sites protected the remains of the Aztec culture from industrial pollution.

Contour scaling on some of the skulls made from tuff at the north side can be traced back to unsuitable conservation efforts in the 1980s. It is known but not documented in detail by mapping or photographs that during this time hydrophobization material was used in large amounts (Wacker, Meyer 1997). Today this leads to different forms of damages (Wedekind et al., 2011). The humidity concentrated at the north side of the monument cannot move as a liquid to the surface. Drying takes place in the vapor phase. Underneath the hydrophobic surface an accumulation of salts occur. Under supersaturation crystallization results and scales burst away creating the described weathering form known as contour scaling. Another problem is the hard and dense cement mortars that were used to close some joints and cracks around the sculls as well as the joints of the stone walls of the top and 
center of the building. The mortar did not allow drying due to a capillary water flow. Furthermore, nearly no capillary water uptake occurred through the tezontle basalt, which most of the walls are constructed from (Wedekind et al., 2011). The only chance of water transport is through the highly porous tuffs, which many of the sculls are made of but blocked by hydrophobization.

\section{2. 2 Preventive conservation}

The main goal of preventive conservation should be the protection of cultural heritage sites, monuments or objects from water infiltration. This can be done by a shelter that only has to be installed during the months with rainfall from August to April (Fig. 87). During the hot summer months this shelter should be removed so that the humidity can evaporate. To change the flow of humidity the cement mortar of the inner structure of the monument should be removed and replaced by a highly porous mortar with a good storage capacity for salts (see conservation model in Fig. 177). This can be done because the tezontle basalt does not show any weathering due to salts.

\section{2. 3 Active conservation}

Cleaning procedures are only necessary for the removal higher plants and roots from the inner structure of the building. A re-treatment by hydrophobization, which is recommended as a conservation strategy by some authors (Meinhardt-Degen 2005), would lead to further damage. Hydrophobization has not preserved the stone material, but was the wrong conservation treatment in this case because the water originates from below and the center of the building structure (see Fig. 177).

A possible strategy for solving this problem may be to use tensides to break the hydrophobization so that desalination becomes possible (Frischke et al., 2008; Magdon 2008). After desalination a consolidation and stabilization of the weathered skulls can be achieved.

\subsection{Conservation model}

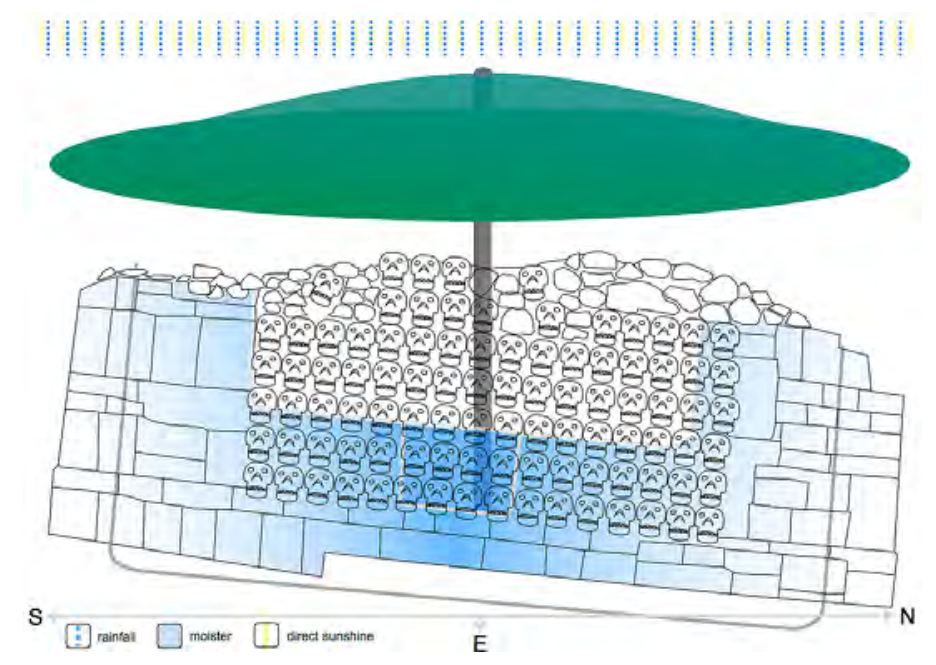

Figure 177: Conservation modell of the Tzompantli altar. 


\section{3 Case study: Santa Mónica, Guadalajara, Mexico}

\section{3. 1 Introduction}

\section{3. 1. a) Conservation history}

After the two already described catastrophic earthquakes protection walls up to 7 meters in height were erected between the pillars, which subdivide the façade. By the removal of the upper parts of these protection walls during the restoration in 2009, large-scaled areas rich in decorations were discovered (Fig. 75 b).

The conservation investigations show that the undecorated areas were once painted in a yellow to ochre color, while the rich decorations as well as the monumental sculpture of St. Christopher were multicolored. Today only small remnants of this polychromatic system can be found on the joint mortar and in some areas protected from the rain and the effects of weathering. Like many other plastered and colored historical buildings, the Santa Mónica Church has become characterized by its building stone, the Cantera Amarilla.

\section{3. 1 b) Consequences of investigations for conservation}

The investigations of the petrophysical properties under different conditions can give us a first indication of material fatigue and information on the processes of weathering. The anisotropic behavior increases under water-saturated conditions. Critical values can be defined by a reduction of more than double the compressive strength and up to three times the tensile strength. This promotes disaggregation and deep penetrative fragmentation. Deterioration is also connected to the pumice inclusions. They play a critical role because of their low hardness and the poor binding forces within the matrix. Building stones affected by weathering were placed in the wall with the bedding oriented vertically (perpendicular to the X-, Y-direction). Water uptake is clearly traced to the high w-value in the XY-directions. Moreover, the weathering is connected to the high hydric expansion in the Z-direction. The results emphasize the significance of protecting the Santa Mónica Church against rising dampness and water infiltration. In the case of restoration new stones should be placed with the bedding parallel to the Z-direction.

\section{3. 1. a) Strategy of conservation/restoration and treatments}

Restoration and conservation of the Santa Mónica Church was an interdisciplinary project with crucial importance to the city's urban environment (Jáuregui 2010). The conservation of the façade followed a ten-step plan consisting of three main work phases: 1. planning and investigations, 2. conservation and restoration and 3. documentation and monitoring (Jáuregui, Wedekind 2009). The works were supported by hydrological investigations of the soil and foundation. 


\section{3. 2 Conservation model}

Utilizing the main factors of weathering a model for conservation was developed. This includes aspects of preventive conservation as well as active conservation and is illustrated in Figure 178. The single steps are explained in the following paragraphs.
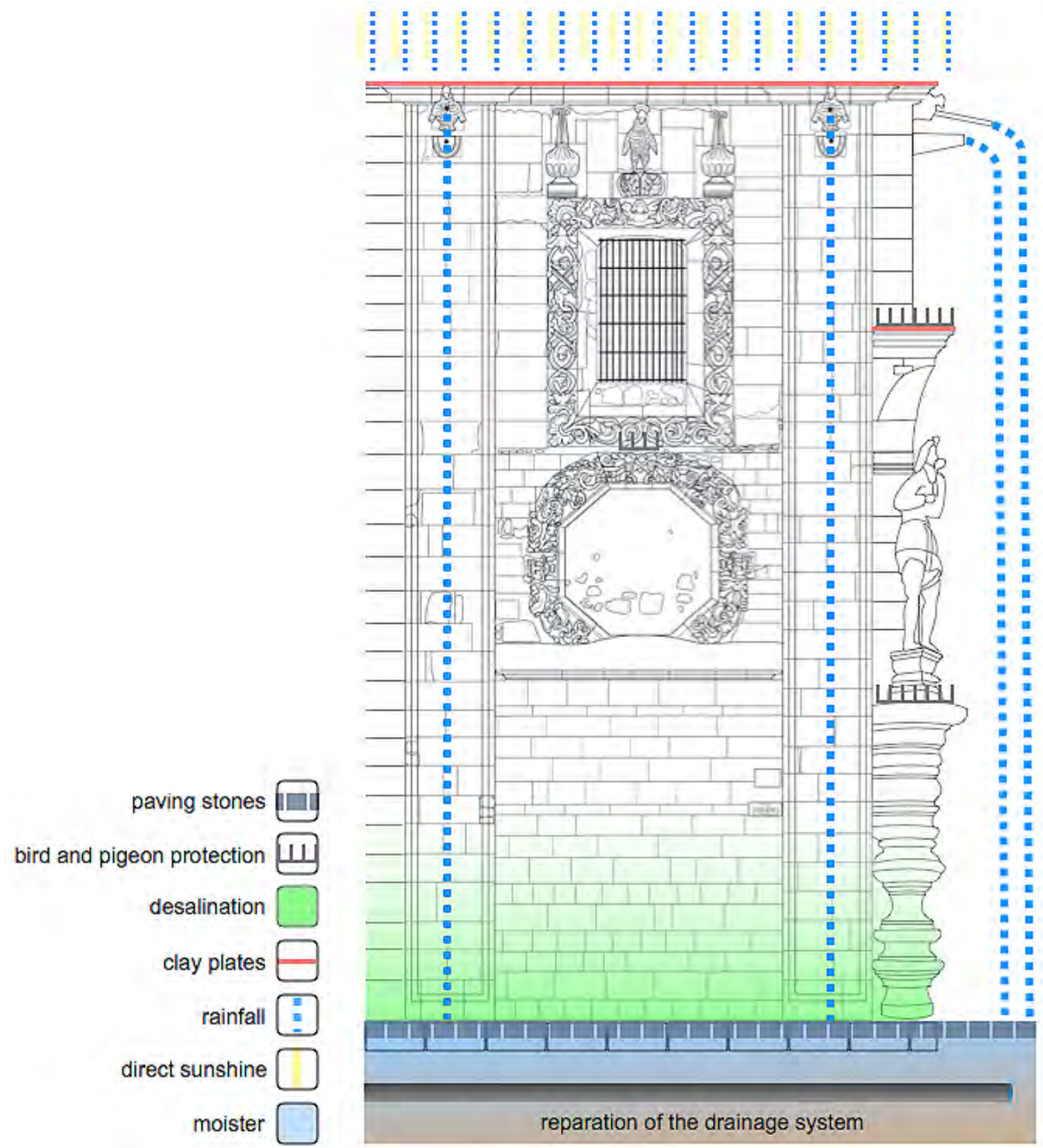

Figure 178: The conservation model for the Santa Monica Church.

\section{3. 3 Preventive conservation}

As a result of the hydrological investigations and moisture measurements of the stone material, it becomes clear that the broken drainage system of the city is one of the main problems for the church. This is the case for many other historical structures in the city, such as the historical center 
of Mexico City as well as for the Templo Mayor. During the rainy season the high humidity and the salt penetrates the historical masonry. Therefore, the restoration of the drainage systems in the urban centers and the establishment of proper drainage systems in archeological sites are one of the main tasks in the case of preventive conservation (Fig. 177 and 178).

In order to prevent water infiltration into the historical stone material of the church, the use of traditional paving stones was recommended for the pedestrian walkway in front of the façade, since the drying of the soil is possible through the joints in between.

Another factor that increases salt contamination are the birds and pigeons that find many resting places on the decorations of the column as well as on the facade. Protection measures against the pigeons were installed on these exposed building parts (Fig. 178).

\section{3. 4 Active conservation}

The first work phase consists of project management and extensive field investigations. Conservation work includes cleaning, salt reduction and consolidation. The cleaning work consists of dry and wet cleaning using a suction stripper and low water pressure. Crusts and dirt deposits are treated by abrasive cleaning (Fig. 179).
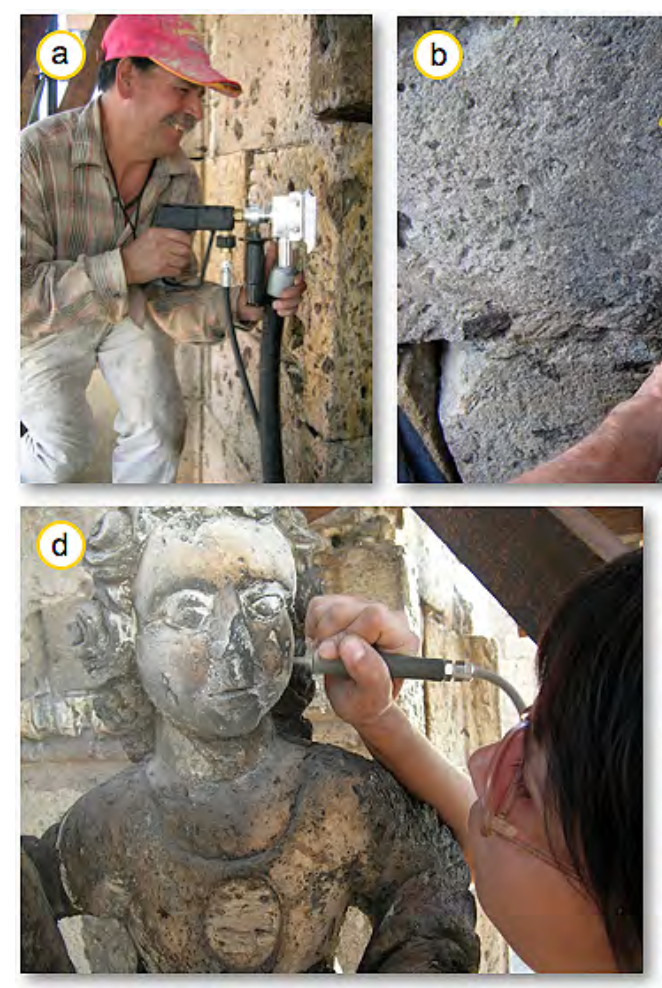
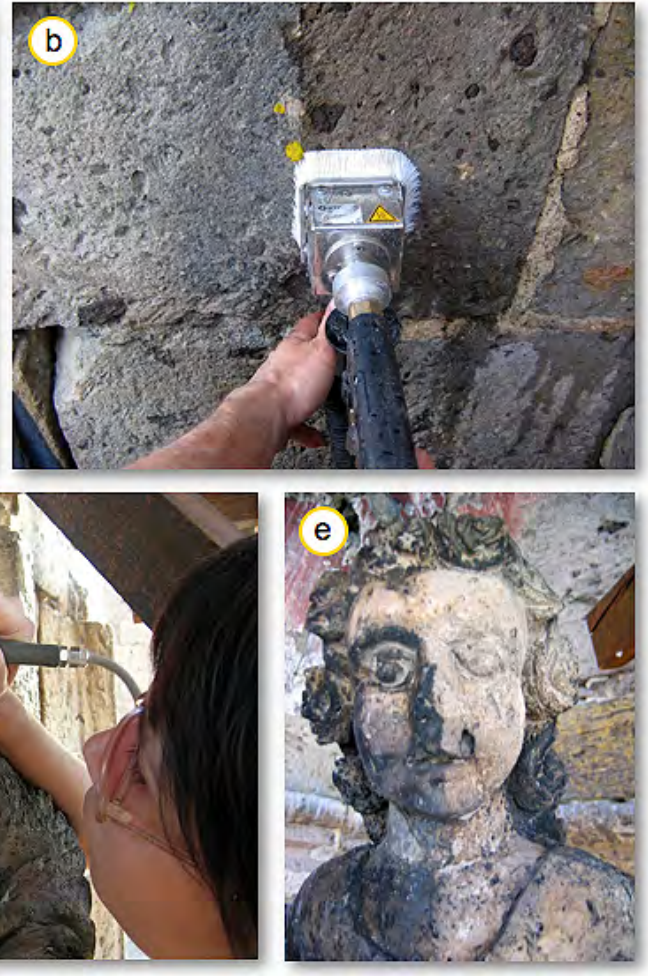
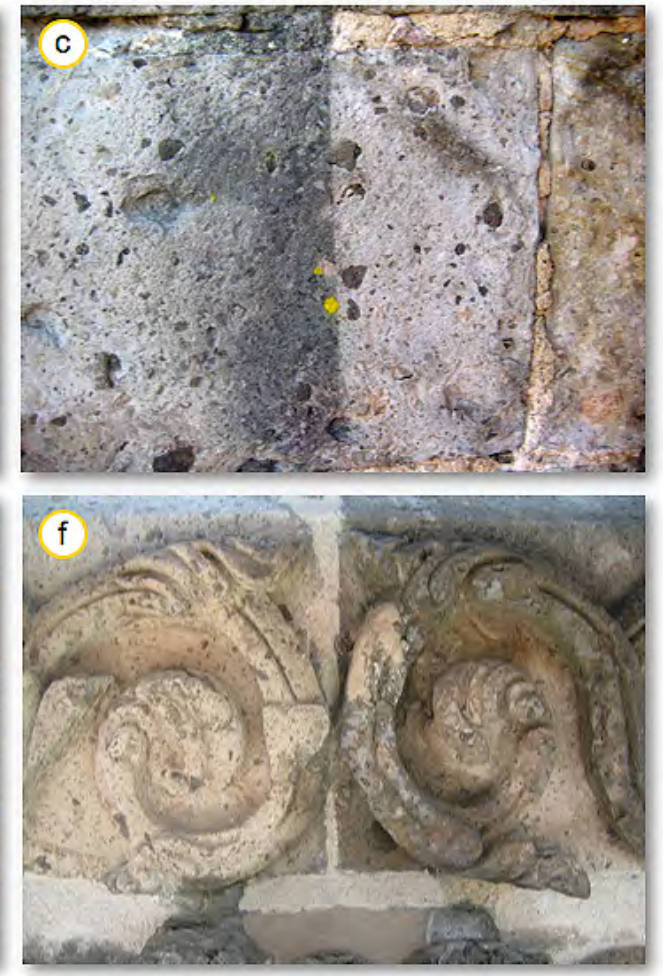

Figure 179: Different cleaning techniques used for the removal of loose dirt and compact crusts:

a) Suction stripper, b) cleaning procedure, c) results of the cleaning.

d) micro-abrasive cleaning and e and d) results of the cleaning technique. 
For the cleaning of the church the suction stripper was used and a large amount of contamination was removed, which can be a danger when salts form from the guano of pigeons. From this aspect cleaning is also a serious working step in preventive conservation.

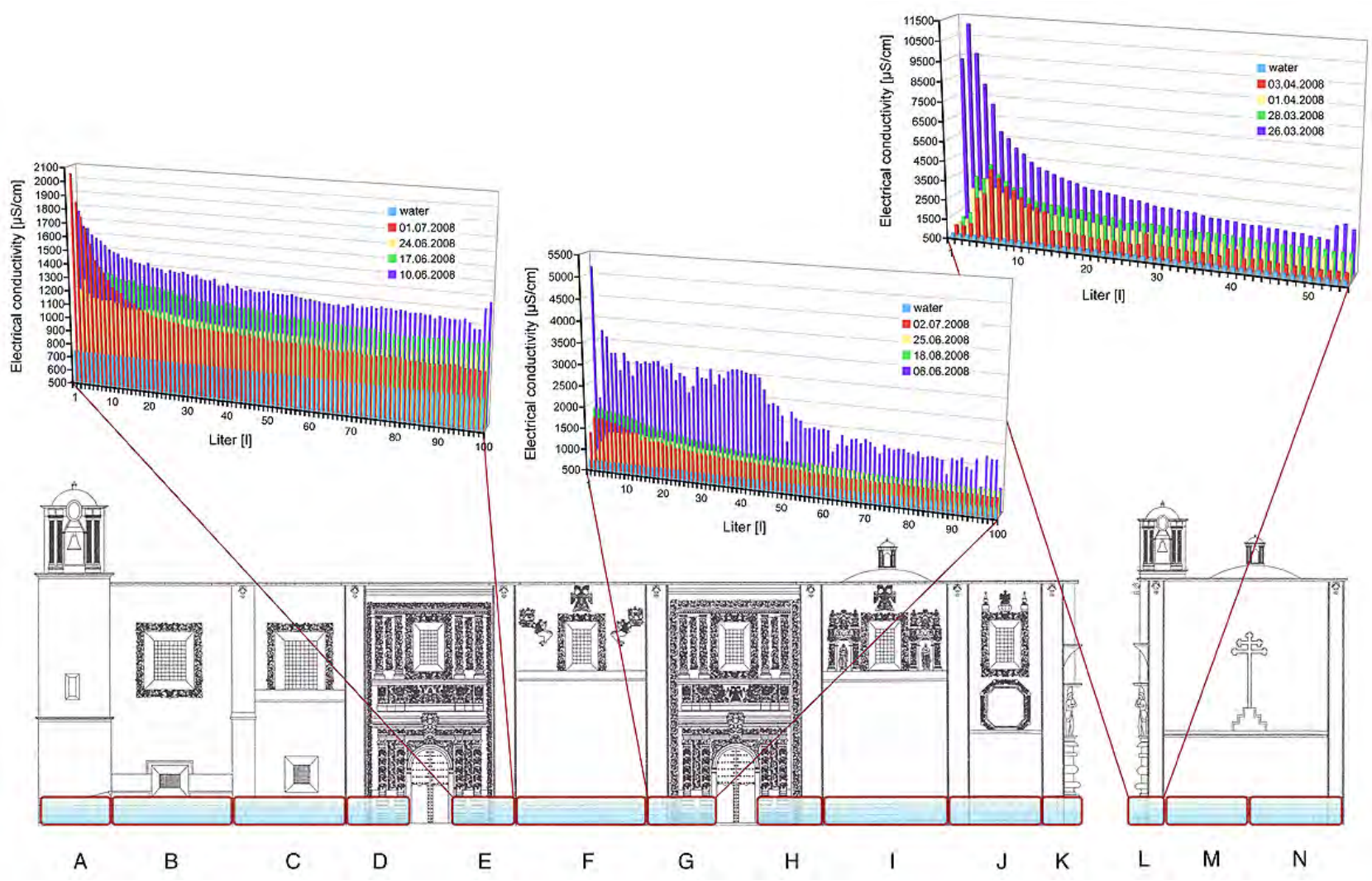

Figure 180: Stepwise desalination process of different areas by cyclical sprinkling.

For salt reduction a sprinkling method was applied, which was developed for the desalination of salt-contaminated areas on rock cut facades in Petra/Jordan (Wedekind, Ruedrich 2006). In front of the contaminated areas of the church a grid-like system consisting of pipes was installed (Fig. 33 a). Each pipe contains a nozzle and was placed at a distance of $40 \mathrm{~cm}$ to the next one. At the bottom of the wall a sheet of plastic was cemented in a horizontal joint to catch and drain the excess water. The façade was divided into 14 areas from A to N (Fig. 180). During the desalination process water is sprayed onto the stone wall surface through the nozzles. At the beginning of the procedure the water is predominantly absorbed by the porous stone surface through capillary forces. Water absorption is dependent upon the transport properties of the material. They are controlled by the pore space properties, like porosity and pore radii distribution and are a time-dependent process (Wittmann 1996). The excess water not absorbed by the stone runs off the treatment area and is collected at the bottom in 51 containers. Electrical conductivity of the eluate of each sample container is then measured with respect to the dissolved substances. The spray pressure applied to the stone during the sprinkling process is very low. In addition, this is an approved method when the prevailing cli- 
mate is very warm because of the rapid evaporation rates. Because of the hot weather in Guadalajara the water evaporates on the surface in a few days. But during the rainy season evaporation could last for a week or more. For each subsequent washing a lower content of salt is probably brought to the surface. In some cases salt could be mobilizied and therefore the salt content within the eluate could be increased at the beginning of the sprinkling procedure (Fig. 180 area E). Eventually, step by step the salt concentration decreases to a significant lower content.

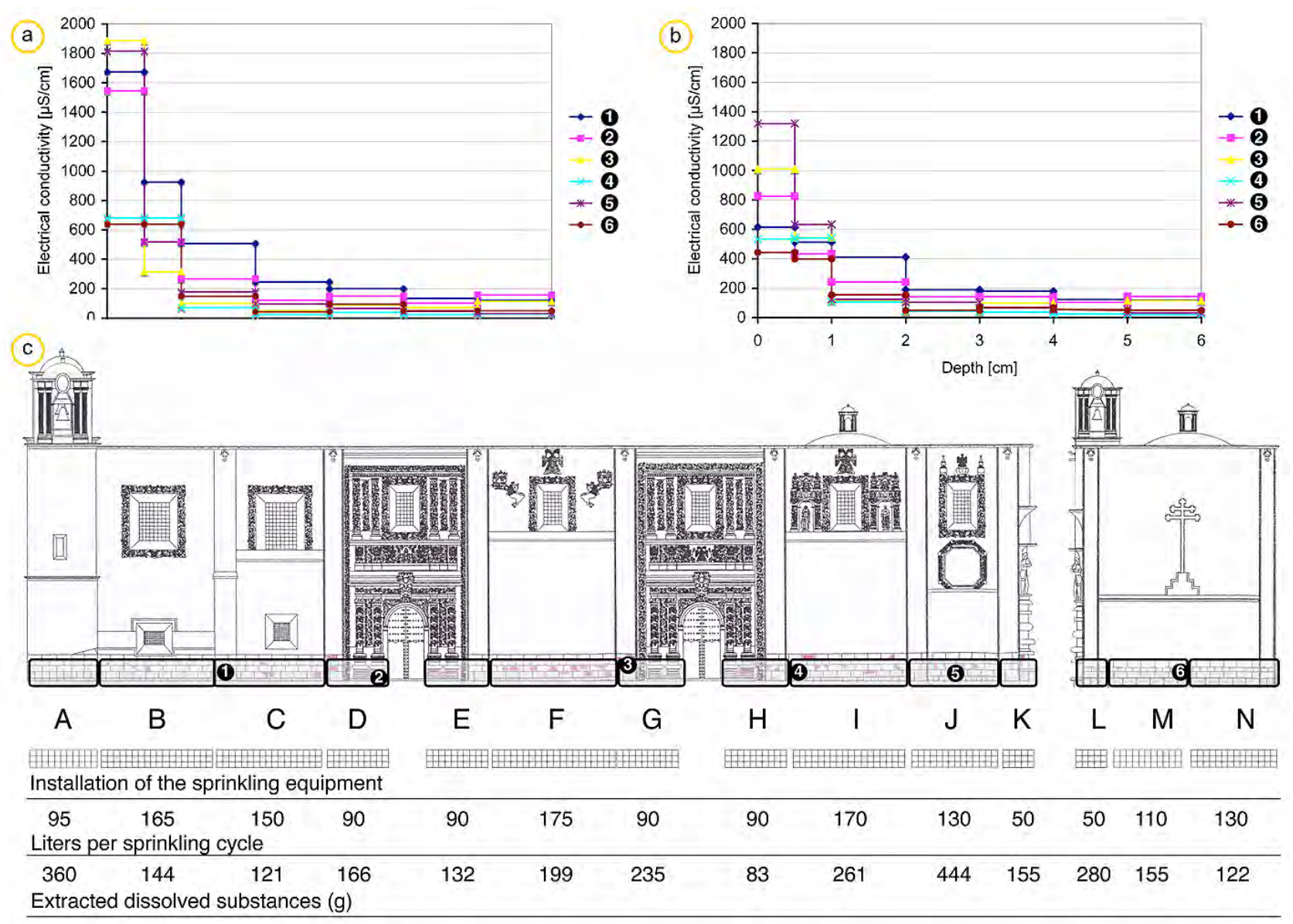

Figure 181: a) Salt contamination with depth before desalination and b) after desalination. c) Architectural drawing of the façade. Areas for desalination (A-N) and sampling points for drilling powder analysis (1-6) are indicated. The schematic grid depicts the location of the sprinkling equipment. Quantities of water used and the amount of dissolved substances extracted are given below.

In practice this assumption proved right. The sprinkling method showed the expected results. The highest concentration of solvent substances was found in the first liters of the washing water, while gradually going down with each successive cleansing (Fig. 180). The concentration leveled out at a certain amount. In most cases that level was still above the level of the solvent substances in the washing water. Even when the sprinkling was being repeated after short interruptions, the concentration of solvent substances increased. However, in most cases this increase in concentration did not hit the starting level of the respective washing day. Evidently, the salt solution had already been 
accumulated on the surface during these short breaks. Evaporation and accumulation of salts at the surface is also related to the climatic conditions.

For each subsequent washing a lower content of salt was brought to the surface. After four to five cycles the salt concentration should eventually decrease in a stepwise fashion. A significant reduction of the salt content within the stone can be determined by the drilling powder analysis method.

To calculate the total amount of the extracted dissolved substances, samples of a specific quantity of the collected washing water is first measured by electrical conductivity and then evaporated in a heating chamber. After complete evaporation the weight of the residue is measured and related to the value of the electrical conductivity. By taking the sum of the weights and the individual electrical conductivity values, a quotient can be calculated by linear regression. As an approximate value a total amount of $2.857 \mathrm{~g}$ could be extracted from the wall from the sum of all the individual areas in the wall. This equals a daily extraction of around $22 \mathrm{~g} / \mathrm{m}^{2}$ on average.
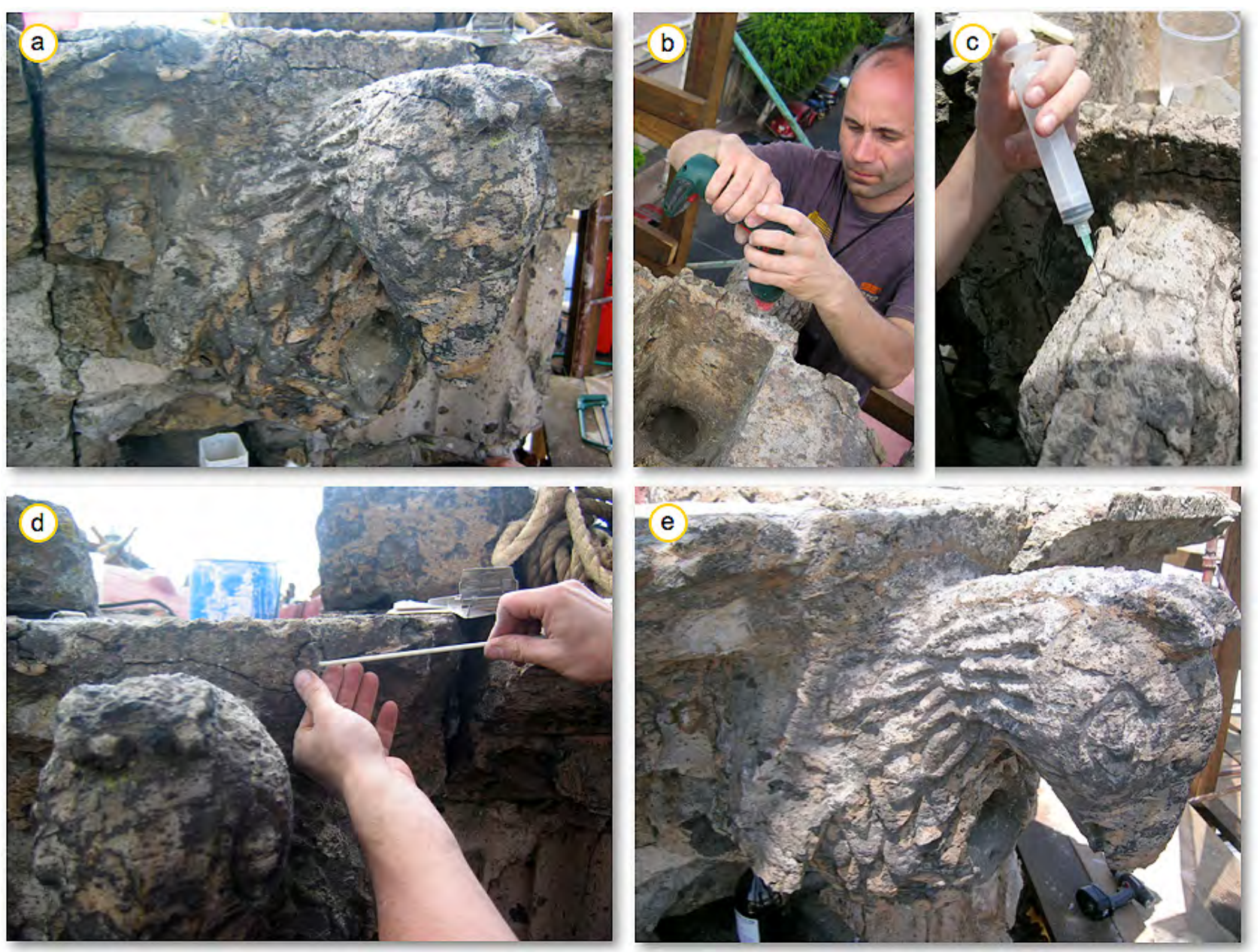

Figure 182: a) A gargoyle before conservation. b) Drillings for the fiberglass sticks. c) Cleaning and consolidation of the flanks of the cracks. d) Application of the fiberglass sticks and e) the gargoyle after consolidation and conservation. 


\section{3. 5 Active conservation/restoration}

Broken areas and larger cracks were partly glued using epoxy resin, especially on the roof area and on the gargoyles. Closing of the cracks were done by a configured fine mortar using crushed tuff and fine sand as an aggregate and a pre-hydrolyzed silicic ester acid (KSE 500 STE, Remmers) as a binding material (Fig. 182). To speed up the process of gel formation by hydrolysis $5 \mathrm{M}-\%$ of calcium hemi-hydrate $\left(\mathrm{CaO} 1 / 2 \mathrm{H}_{2} \mathrm{O}\right)$ was added to the dry mortar mix.

For detailed fillings of lost stone a lime-based restoration mortar was applied by using hydrated lime and aggregates from sand deposits in the region (Fig. 183). As reinforcement material fiberglass sticks were used (Fig. 183 a). These sticks as well as broken stones were glued with epoxy resin. With the fillings and repair work only $5 \%$ of the stone surfaces at the building have had to be replaced by newly cut stones of Cantera Amarilla. The original joint mortar was repaired with a congruent lime mortar (Fig. 184). To protect the roof area from infiltration as well as insolation the horizontal building parts were covered with traditional clay plates (Fig. 178).
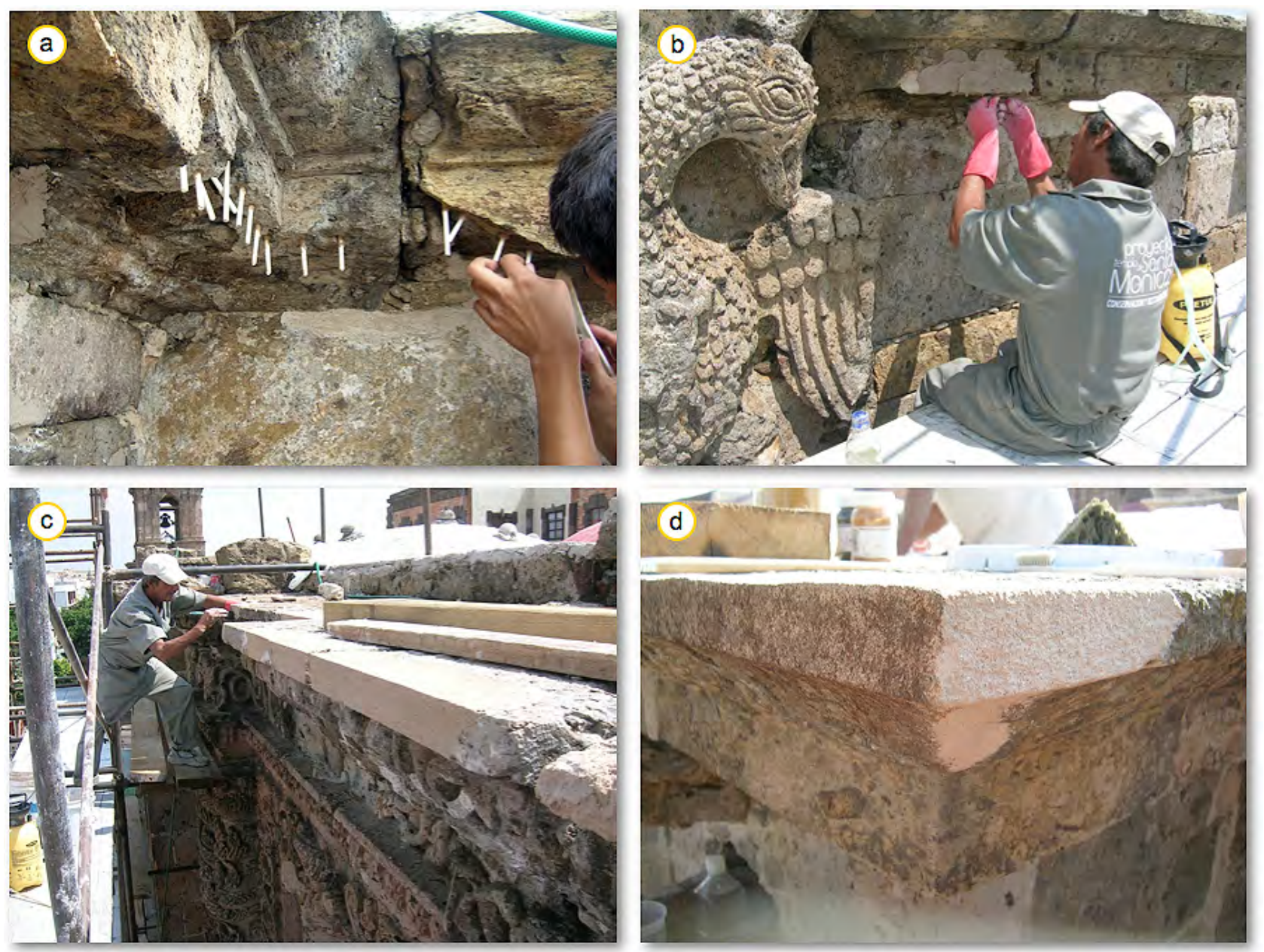

Figure 183: a) Glueing of fiberglass sticks within areas of missing parts of the tub profile. B) Fillings with lime mortar, and c) re-profiling. d) Fresco-like retouch of the restored areas. 


\section{3. 6 Conclusions}

Salt reduction using the sprinkling technique was successful and necessary to prevent further weathering by salt crystallization and because of its high hygroscopic potential. Today cautious restoration and conservation by a team of academically qualified conservators have been able to preserve most of the original substance of the church. The church is now an architectural highlight in the continuing process of revitalizing the historical center of Guadalajara.
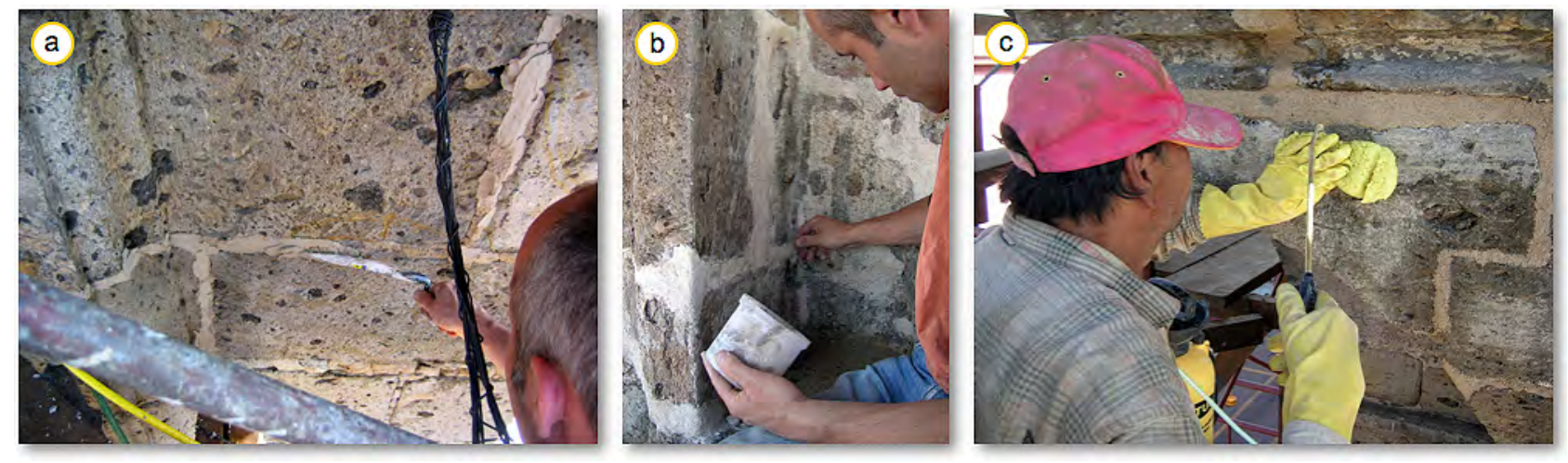

Figure 184: a) Application of the jointing mortar, b) egalization after hardening and c) after-treatment of the surface by wetting and washing. 


\section{4 Case study: Bartholomew Cemetery, Goettingen, Germany}

\section{4. 1 Introduction}

\section{4. 1. a) Conservation history}

Over time the cemetery lost a large number of its monumental tombs (Chapter 3.5.3 a). At the end of World War II several bombs struck the graveyards and affected serious damage. Different restoration works are archived after WW II. For these repairs cement mortars were used that have lead to damages by salt weathering. However, the historical repairs have saved the tomb monuments from being totally destroyed.

\section{4. 2 Conservation model}

Utilizing the main factors of weathering a model for conservation was developed. This includes aspects of preventive conservation as well as active conservation. The single steps are explained in the following paragraphs.

\section{4. 3 Preventive conservation}

The tombs at the Bartholomew Cemetery show different forms of weathering and deterioration mostly related to salt weathering and urban pollution. However, the main weathering factor of the site in comparison to many other historical cemeteries in the region is the lack of maintenance and vandalism (Fig. 185). Damage due to vandalism was not the only factor for tomb destructions, but in the 1960's even the authorities responsible for their care caused the destruction of several tombs (see chapter 3.5.3 a). Damage also occured due to the reconstruction of original monuments (Fig. 185 d; Wedekind 2008).
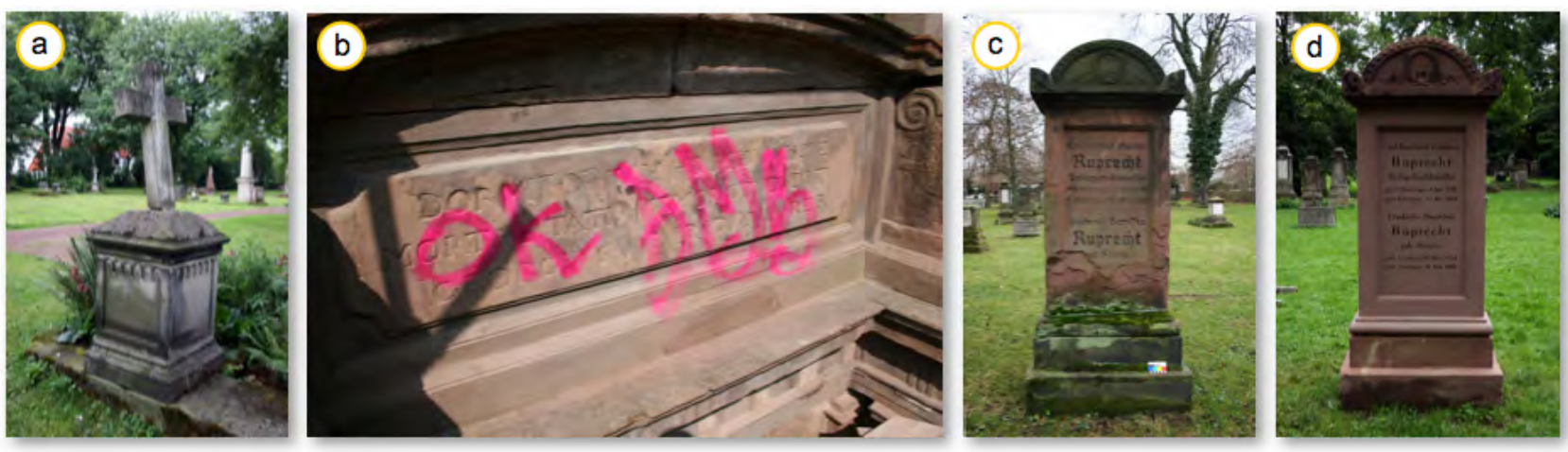

Figure 185: Vandalism and destruction at several tomb monuments at the Bartholomew Cemetery. a) Mechanical violence, b) graffiti and c) the historical Rubrecht Tomb and d) the reconstructed one.

\section{4. 4 Conservation inventory}

The conservation inventory made for all tombs in the cemetery shows that only 23 tomb monu- 
ments (14\%) strongly required restoration. A further $23(14 \%)$ needed restoration immediately. The predominant contingent of all tomb monuments (72\%) is still in an acceptable condition; however, for $19 \%$ of these, initial restoration in the near future should be recommended. Since 2008, a stepwise restoration has taken place according to the priority list developed from the results of the conservation inventory.

Underlining the significance and value of the place, to create sensitivity in society to protect and maintain the historical cemeteries is one important step in preventive conservation. Therefore, the interdisciplinary project to investigate the local sandstone varieties and to conserve seven prominent burial monuments and two mausoleums was an initial project for the revitalization of the site as a significant historical place and park area (Wedekind et al, 2013). Furthermore, the establishment of an exhibition on the historical cemeteries in Goettingen, which took place in the spring of 2015 at a public gallery, helped to underline the significance of the place as an important historical and cultural monument. Therefore, this can be seen as a further step in the protection of cultural monuments in terms of preventive conservation.

\section{4. 5 Conservation model for the tomb monuments}

Utilizing the main factors of weathering a model for conservation was developed. This includes aspects of preventive conservation as well as active conservation (Fig. 186).

In general, salt contaminated areas have to be desalinated and consolidated. Gypsum crusts have to be reduced by mechanical removal due to the softening of the crusts by wet poultices.

\section{4. 4 Active conservation}

In an interdisciplinary project, object-specific conservation methods have been developed and carried out on seven prominent burial monuments and two mausoleums at the Bartholomew Cemetery in Goettingen (Germany). Cleaning was realized by dry and wet cleaning with soft brushes and the micro-abrasive method.

The desalination methods discussed in this study are a water bath, cyclical sprinkling and capillary flow desalination. To verify the effectiveness of the applied methods, the salt content in the rinsefluids were measured during the salt reduction process. Furthermore, the salt content was measured on eluted drill cutting samples before and after the salt lowering procedure. Determination of salt impact was carried out by measurement with an ion chromatograph and by electrical conductivity. The different salt phases were determined by means of x-ray diffractometry analysis. The primary purpose of the project was to optimize the efficiency of the desalination treatments to further a sustainable conservation of the monuments. 

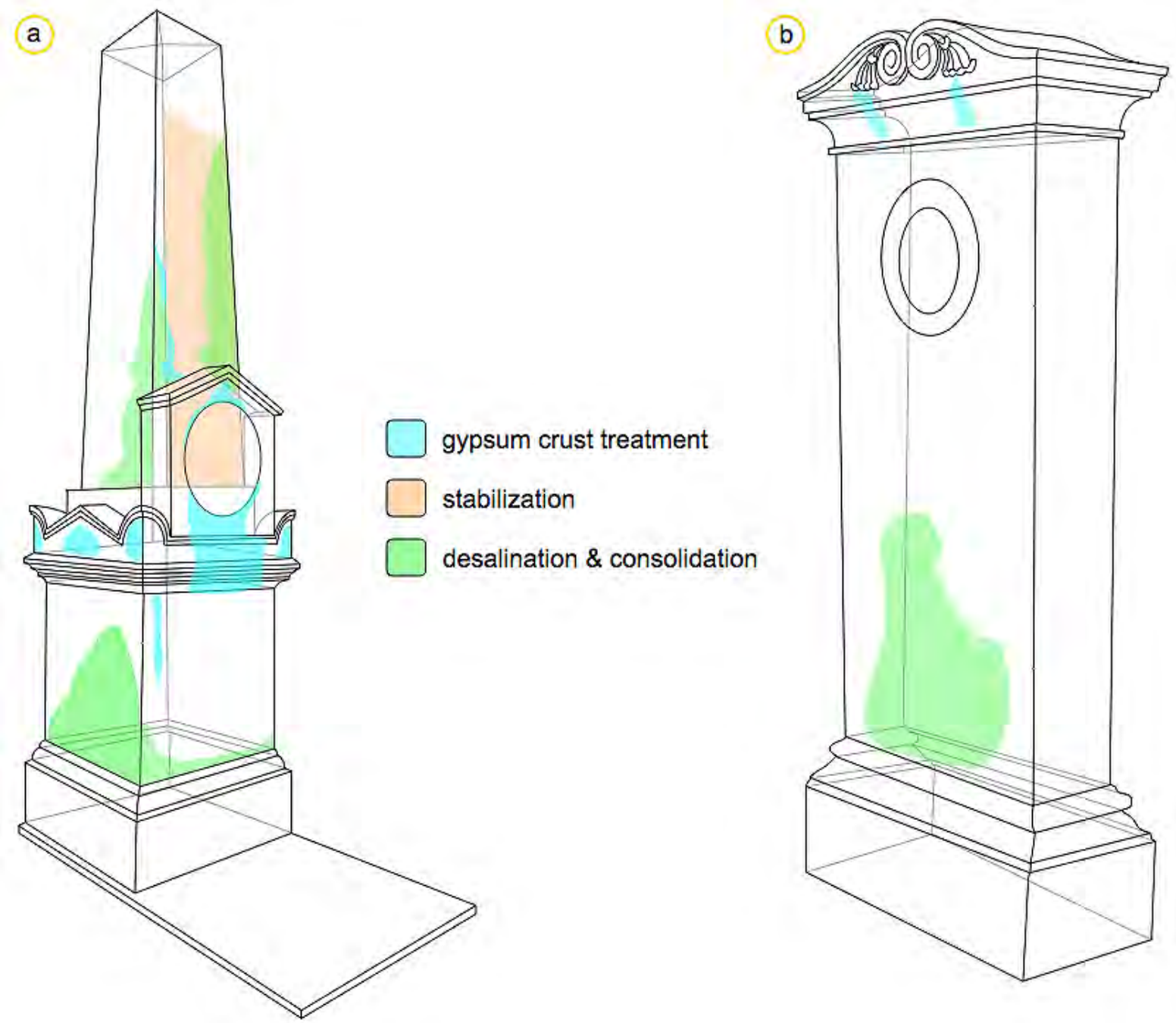

Figure 186: a) Conservation model for the Ellissen oblesik monument and b) the Stromeyer stele.

\section{4. 4. a) Salt reduction bath (Lejeune Dirichlet Tomb)}

The balustrade tomb had to be dismantled because of difficulties with the foundation. The quadratic enclosure comprises 13 building stones which form an ornamental balustrade. Placed on every corner is a pillar. The open spaces in the balustrade are covered with panels. Because the construction has a symmetrical shape, four stones in the complex can be compared with each other. This concerns not only the outer shape and dimensioning, but the type of stone variety. The greatest damage to the stone can be seen on the eastern and southern areas of the balustrade. Damages to the west side of the tomb are the lowest, followed by the north side (Fig. 101). These sides are exposed to the rain. Efflorescence of lightly colored salt precipitates and gypsum crusts attest to the high saltinduced weathering of the tomb.

The principle behind the applied salt reduction bath is based on the diffusive equilibrium in solutions and the presence of precipitates. For this process a complete wetting of the stone is necessary. The ion concentration in the stone is high and in the surrounding solution low. The four pillars and 
the chosen areas in the four balustrades were desalinated in static water baths. A basin was constructed for every stone object which would hold sufficient water to cover the objects. For every stone five immersion baths were performed with the same volume of water, so that the results could be compared with each other. The stones were kept in the basin for a period of five days per bath. The increase in the electrical conductivity in the desalination solution was measured, which is dependent on time and various depths. Daily measurements were made at different levels in the bath. The depth dependency results from the higher density of the salt solution, which becomes enriched through time in the lower part of the solution due to gravity. Thus, a higher salt density is measured at the bottom of the basin.

The electrical conductivity showed a strong increase after four days of water immersion. On the fifth day the values stabilized and only an insignificant increase was measurable (Fig. $187 \mathrm{~b}$ ). The conductivity values decreased with the increasing number of salt reduction baths. This suggests that the concentration of salts were reduced in the stone tomb objects. Between the fourth and fifth immersion bath only a small difference in the conductivity could be measured. The method shows that a far-reaching salt reduction can be attained. Salt contamination is reduced by half even after the first desalination bath. Afterwards the desalination process progressed in much smaller steps. The approximate amount of the extracted solids could be calculated from the steamed samples. For the eight stone samples treated, a sum of ca. $1500 \mathrm{~g}$ could be withdrawn.

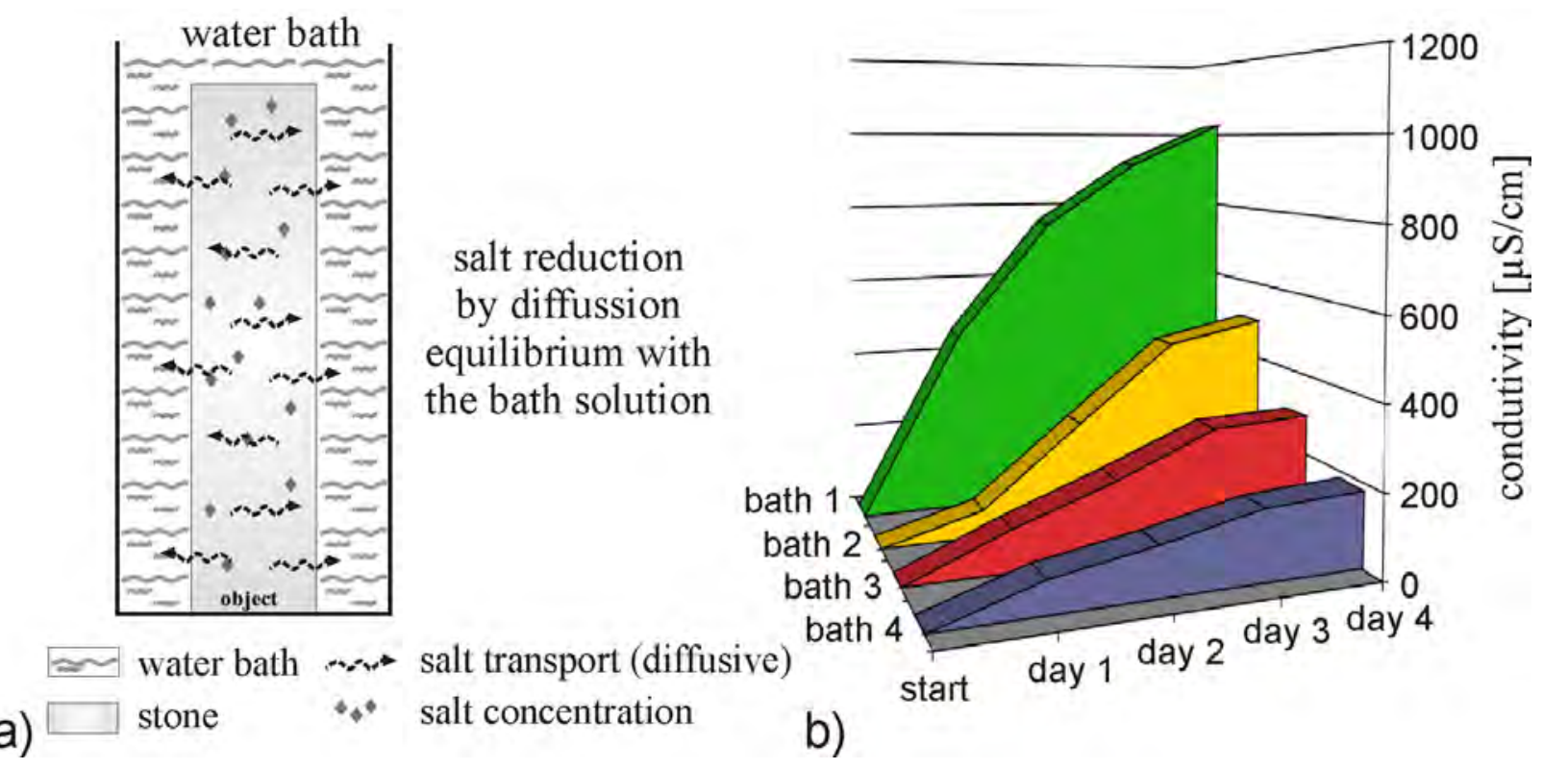

Figure 187: Salt reduction bath: a) schematic sketches of the applied measures and b) electrical conductivity of the bath solution.

\section{4. 4. b) Cyclical sprinkling (Strohmeyer Stele)}

The main weathering form visible on the Strohmeyer Stele is a peeling formation, which is directly related to salt crystallization stress. Damages are concentrated on the lower half of the inscription 
zone (east side). In these areas the surface shows total damage by weathering where salt efflorescence's could be found. Chemical testing done with test strips show that nitrate compounds can be detected in situ on the gravestone.

In the case of the Santa Monica Church the goal of the sprinkling method is to target the strongly stressed zones and to keep moisture movement at a minimum. Salts become concentrated on the stone surface by capillary transport, diffusion and the subsequent drying regimen. In the following, the already described step-by-step procedure for the ensuing treatment is given by describing the object specific modifications. The untreated portions of the gravestone ( $73 \mathrm{~cm}$ in width) are covered in plastic, so that the drying process can concentrate on the badly weathered area (ca. $750 \mathrm{~cm}^{2}$ ). At the lower end of the treated area a drain gutter was constructed from clay, so that the eluate is funneled into a sample bottle (Fig. 188). The wetting of the stone surface was done by spraying the material with a fine mist. In the case of the treated gravestone stele, salt contamination was analyzed from drill cuttings obtained in the first two centimeters of the stone.
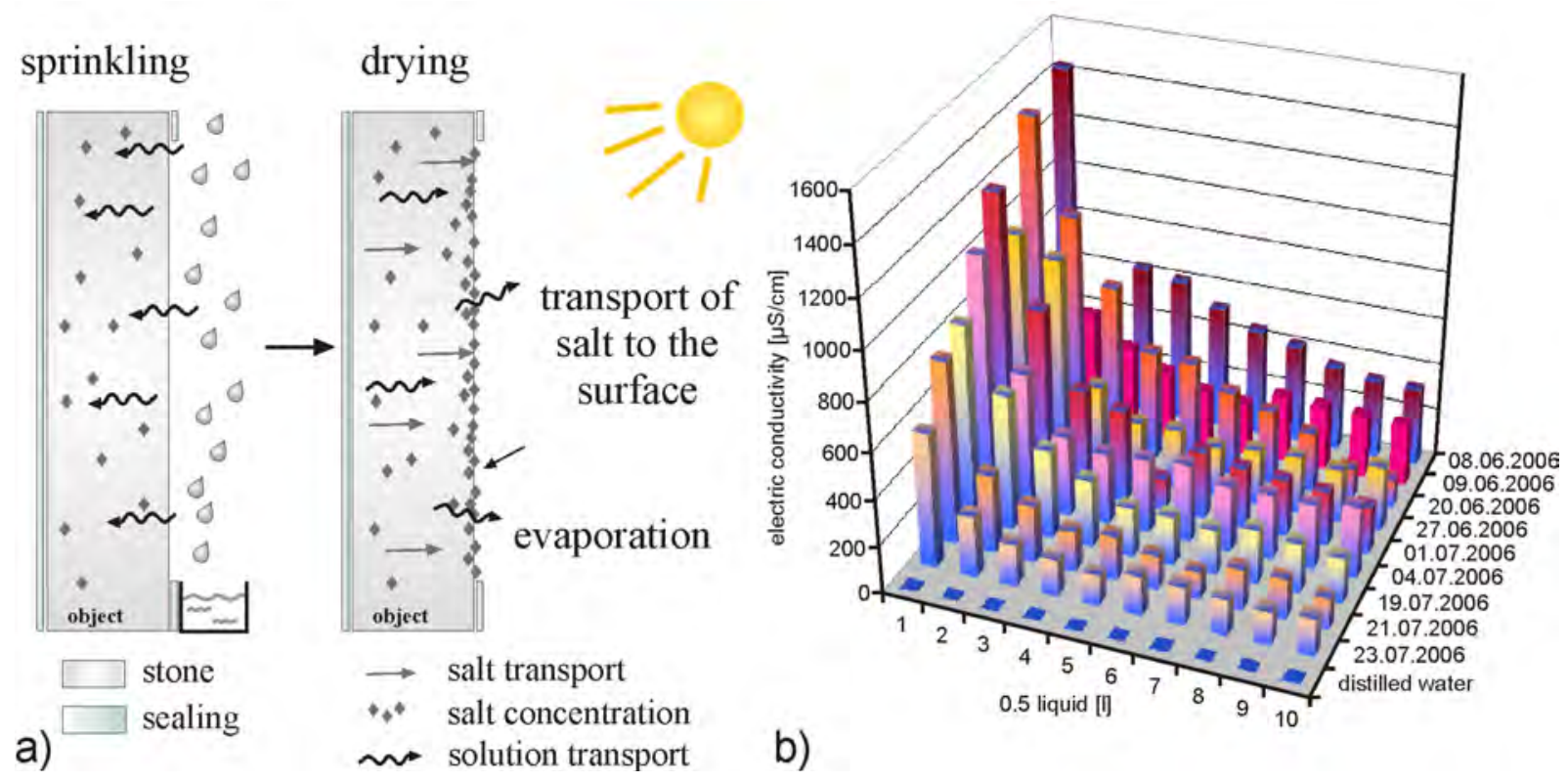

b)

Figure 188: Cyclical sprinkling: a) Schematic sketch of the applied measures and b) electric conductivity of the sprinkling solution.

Sprinkling and drying time was investigated on reference samples before the actual treatment. The reference sandstone material is the variety Reinhausen, which is found in the region of Goettingen and shows a porosity of 21.6 vol.-\% (Kracke et al., 2008). The w-value varies between $15.08 \mathrm{~kg} /$ $\mathrm{m}_{2} * \sqrt{\mathrm{h}}$ and $17.66 \mathrm{~kg} / \mathrm{m}_{2} * \sqrt{\mathrm{h}}$ in the different petrophysical directions. The contamination zone was sprinkled for moisture penetration during a period of five minutes, in accordance with the determined infiltration rates for the Buntsandstein variety. Excess water not absorbed by the stone was collected in 0.5 liter amounts and checked for electrical conductivity. After every sprinkling cycle, a 
break of ca. 24 hours was observed in order to initiate the drying procedure, which leads to the concentration of salts in the near-surface area of the stone. A volume of $10 \times 0.5$ liters of eluate was collected and analyzed after each sprinkling cycle. Over a period of 14 days, a total of nine treatment cycles were completed.

The highest values of electrical conductivity could be determined by the first measurement in the course of a respective sprinkling treatment. In comparison to the first dataset, the second values showed a decrease ranging between 30-50\% after sprinkling. A continual decrease in the electrical conductivity occurred in the other eight measurements. The last conductivity value was measured at around one-fourth of the initial sprinkling cycle value.

In comparing the treatment cycles, a reduction of the electrical conductivity between the first and second measurement was around $50 \%$. By the third and fourth determination the values showed a $10 \%$ reduction. Following the fourth, fifth and sixth cycle, the conductivity showed a verifiable reduction of around five percent. Further measurements produced comparable reductions below one percent.

In order to quantify the amount of salt reduction from the damage zone, solutions from a number of samples were dried and the amount of precipitate was determined. Thus, the salt content can be extrapolated for all other electrical conductivity measurements. In total $12 \mathrm{~g}$ of dissolved solids were extracted by using the sprinkling method. This is equivalent to working an area of around $16 \mathrm{~g}$ per square meter. When comparing the drill flour samples before and after the treatment, a significant desalination effect could be confirmed. Even the follow-up examination by salt check tests (cf. Weiss, Ungerer 2001) attest to the large-scale desalination on the stone's surface.

\section{4. 4. c) Capillary flow (Ellissen Tomb)}

The most pronounced damages on the Ellissen obelisk monument were located on the lower part on the south side of the cubic-shaped base. The south side is also the preferential drying side. The northwest side of the monument is exposed to a higher degree of precipitation, whereby the drying gradient is directed toward the south. Sunlight on the exposed south side speeds up the drying process.

Drilling resistance measurements showed massive gypsum enrichment had developed at a depth of $10-20 \mathrm{~mm}$ in the damage area of the Ellissen Tomb. The salt crystallization is not just a general surface area phenomenon, like the electrical conductivity measurements reveal, but can be categorized as more or less a structural problem.

In order to reduce the enrichment at depth, emphasis was placed on using drop impregnation and the generation of moisture flow. Drill openings from the preliminary investigation and additional holes were drilled for this procedure. Distilled water was continually transmitted into the drill holes 
by means of a drop system to a depth of about $10 \mathrm{~cm}$ into the stone (Fig. 189). On the south side of the cubic base, compresses made from washed sand and cellulose fibers were placed in the evaporation and damage zone. To increase the drying in the compresses, the whole cubic obelisk base (except for the compress area) was sealed in flexible plastic. Over a period of four weeks five liters of distilled water was continually added to the rock by the drop system procedure. This was done by capillary moisture movement, which is favored by the high porosity of the damage zone, directly into the compresses undergoing drying. The compresses were changed a total of four times after every infusion. After the compresses were dried, the material was analyzed in regards to precipitated solids.

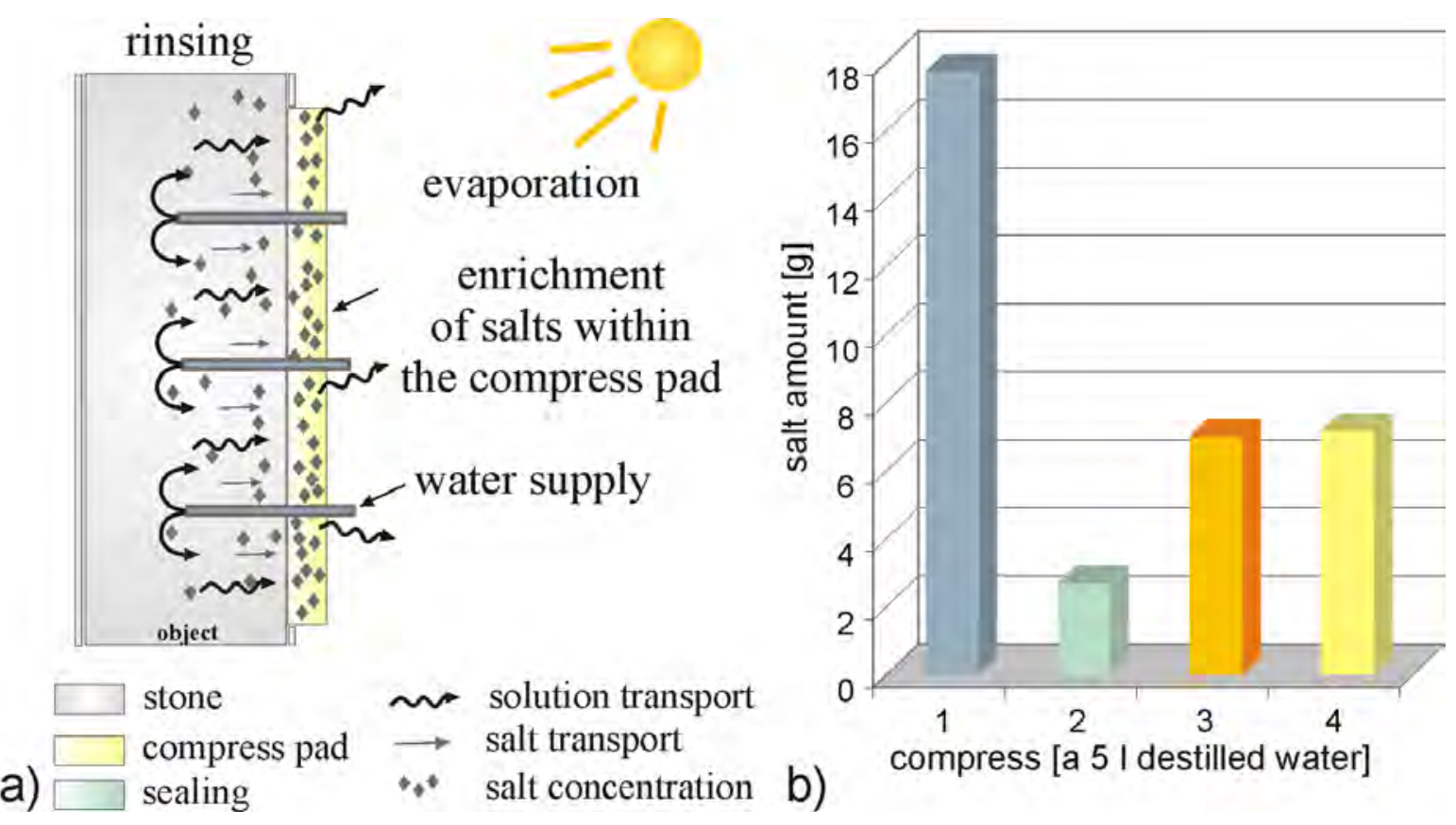

Figure 189: Capillary flow: a) schematic sketch of the applied measures and b) extracted salt amount from the compresses.

In four compress cycles a total of about $38 \mathrm{~g}$ of precipitated solids could be extracted. The first compress contained about $18 \mathrm{~g}$ of extracted solids from the rock, which is half the amount retrieved from all four treatments. The amount in the second compress weighed in at merely $2.5 \mathrm{~g}$ of solids, whereas in the third and fourth treatments about $7 \mathrm{~g}$ was extracted. Follow-up investigations confirm the successful salt extraction. The hardening zone in the inner part of the rock could be removed, which was verified by drilling resistance measurements.

\section{4. 5 Conclusions}

The salt reduction measures applied to the tombs at the Bartholomew Cemetery differ considerably in regards to their application, depth impact, salt reduction efficiency and time expenditure. Water immersion desalination clearly seems to be the most efficient method. The purging method by using a capillary flow also shows the ability to reduce the salt content significantly. Both methods are cha- 
racterized by a long-term impact that leads to sustainable salt reduction. For the sprinkling method, the decisive factor is the duration and the interval between the cyclical effects. When the effective reaction period is too short, the mobilization of the salts at depth is insufficient. Therefore, it is of critical importance to know the depth of the enrichment horizon, the salt phases and the water absorption properties as well as the drying behavior of the rock.

No universal procedure exists for dealing with salt-induced weathering. However, there are many methods for mobilizing salts in porous natural building stones, transporting the salt to the surface and reducing their impact by different approaches. Most methods use the capillary solution transport process in combination with diffusive ion transport (e.g. water immersion bath). This is very suitable because of its relatively high rate, especially when in situ measures are called for. The application of the different methods are restricted by numerous circumstances and constraints, e.g. the property of the natural stone, depth-dependent enrichment and the type of salt phases as well as the geometry of the monument and its degree of degradation. According to the conditions of the object and its boundary parameters, the right method must be chosen. Hence, it is necessary and imperative that corresponding desalination measures be scientifically monitored. 


\section{5 Case study Petra, Jordan}

\section{5. 1 Introduction}

Today the existence of the unique rock architecture of Petra is in danger due decomposition, poor maintenance and lack of conservation (Bumnaru et al., 2000, Wedekind 2005 a). Due to the abundance of tasks to complete and the large number of monuments, appropriate concepts for possible protection and lasting conservation of these antique places are in question.

\section{5.1 a) Conservation history}

During three years of on-site work and concrete field research in collaboration with the CARCIP (Conservation and Restoration Center in Petra), findings about the geology and geomorphology of the Cambrian sandstone could be gathered, acute safety repairs and restoration of the stone facades and temple grounds could be undertaken and new techniques for conservation were developed and employed (Kuehlenthal, Fischer 2000). With few exceptions, all experts agree that the uncontrolled drainage of rainwater is the main cause for damage to the monuments. Due to strong rains in February and March, every year heavy sudden floods occur through the narrow wadis, which can swell up to torrential mountain rivers within minutes. These floods represent the largest danger to the monuments (Lane, Bousquet 1994). The Nabateans, the builders and engineers of Petra, were well aware of the destructive strength of the waters. For this reason, the majority of the monuments are equipped with drainage canals.

Today these channels are blocked by fallen rubble or are partially destroyed, which has led to damage to many parts of the facades (Fitzner, Heinrichs 1994). On the other hand, the water was a necessary life source and a blessing for the city and its agriculture. Numerous dams, canals and cisterns were capable of storing enough water to make the desert come to bloom. Even in remote valleys surrounding Petra, the many stone wine presses and irrigation facilities are evidence of the strongly developed agricultural usage of the entire region. The drainage canals upon the mountain tops and around the monuments were integrated into this system.

\section{5. 2 Preventive conservation}

\section{5. 2. a) Conservation inventory}

To date, no comprehensive inventory has been taken of the monuments in Petra. The German building researchers, Bruennow and Domaszewski (1904), published the first survey of the monuments of Petra and proposed a numbering system that is still in use today (Bruennow, Domaszewski 1904). A second survey attempt was made by the former director of the Institute for Antiquity and Christianity of the Holy Land, Gustaf Dahlmann (1912), who also created a numbering system for the buildings and extended the list to approximately 1000 monuments (Dahlmann 1912). According 
to our inspections, of the 831 monuments that Bruennow and Domaszewski took inventory of in Petra, 539 were cataloged as stone facades.

During the on-site field research, an inventory was created and exemplary photographs and written documentation were taken of the condition of 211 monuments, or one third of all the tomb facades. The inspections showed that over one-half of all the stone facades were equipped with drainage systems. These gutters and canals supplied the cisterns with rainwater and formed part of the water supply. In most cases however, these canals are blocked by rubble or are damaged so that the water now drains uncontrolled over the rock facades and damages them. The Corinthian Tomb, the Renaissance Tomb and the Urn Tomb along the King's Wall in the city center are particularly prominent examples of this phenomenon.

After evaluation of the inspection sheets, it became clear that over one-half of all the stone monuments dispose of drainage canals in the eaves and at present many of these are blocked with rubble or partially destroyed or damaged (Wedekind 2005 b). The lack of care and maintenance can be seen clearly in the situation in front of the monuments and in the tomb and cult chambers. Over $70 \%$ of the examined buildings are covered in rubble. At the time of inspections, over $30 \%$ were polluted by human or animal excrements or by garbage and rubbish. Over $20 \%$ of the inspected cult buildings showed remains of mortar, paint or stucco. Almost $30 \%$ of the monuments were built of ashlars that are presently in danger of collapsing. Also threatening to collapse are the larger sandstone blocks also used in the construction. The situation at the Palace Tomb, which presently consists of $8 \%$ ashlar, at the beginning of the King's Wall is particularly alarming. Approximately $30 \%$ of all monuments are covered in cracks and crevices, which poses a danger to both the building stability and visitors. Only three tomb vaults, i.e. $1.4 \%$, in the inspection area are still inhabited by a Bedouin family. In general, the centuries of Bedouin settlement in the monuments did not cause much damage. The Bedouins made very few constructional changes to the monuments, and those that they did are reversible. Also, only few changes were made in the tomb chambers. However, open fires for cooking and heating left visible marks in the rock vaults. The dense, black soot on the sandstone surface is very difficult to remove.

\section{5. 2. b) Exemplary case study: The drainage situation at the Ad Dayr monument}

All of the large, outstanding tomb facades in Petra contain a drainage system. As an example, the drainage system of the Ad Dayr monument will be presented here. Monument Nr. 462 on the high plateau of Ad Dayr is one of the most important and grandiose constructions in Petra. The impressive rock facade is one of the largest cult constructions measuring 45.5 meters in height and width. Like many others, this monument was protected by drainage canals from the rainwater of the surrounding mountainside (Fig $190 \mathrm{a}-\mathrm{c}$ ). The canal originates above the monument far back in the wadi to the left of the facade and flows along the back, right side of the facade creating a waterfall 
onto a small adjacent plateau. The water flow continues into another waterfall at the end of the plateau.
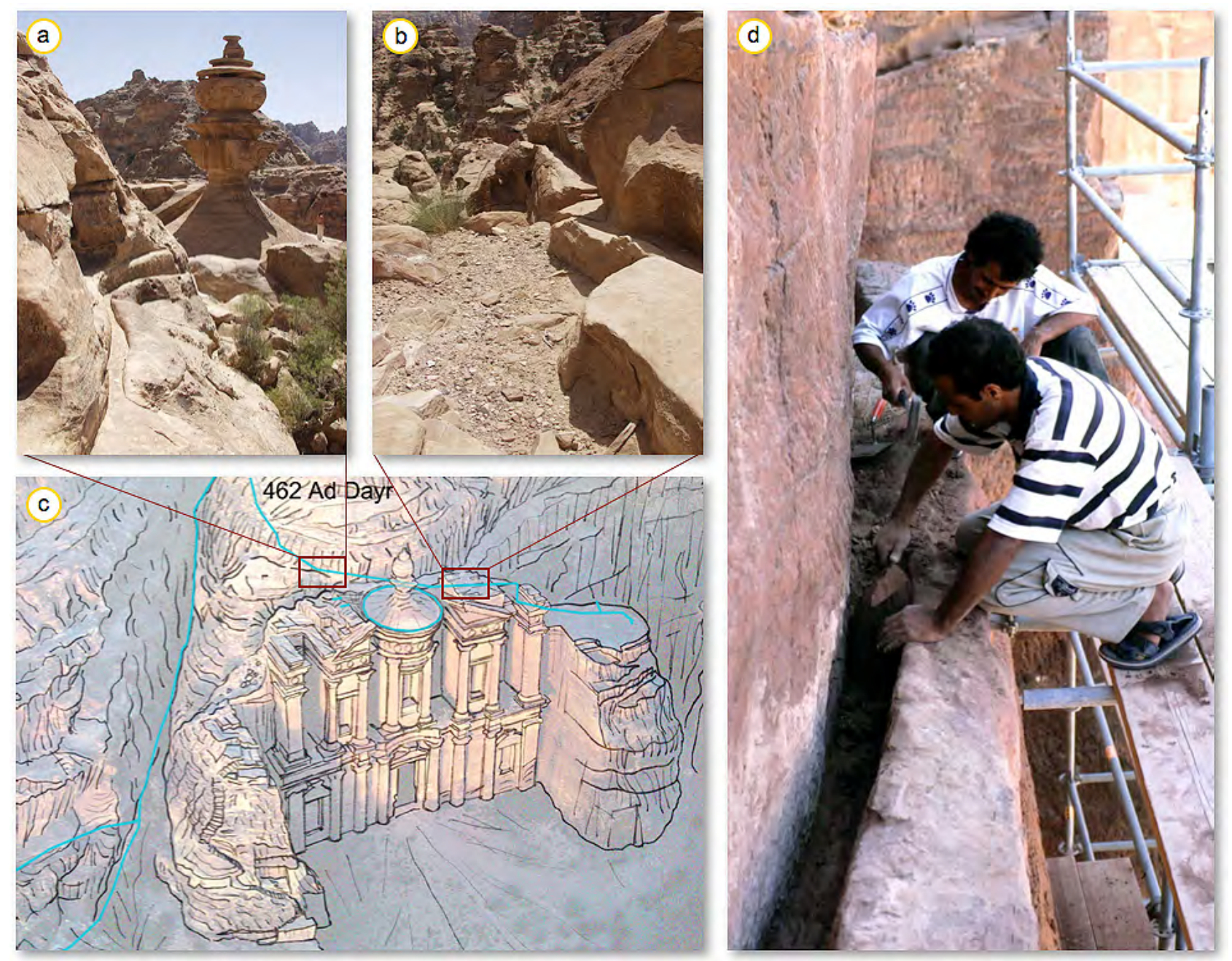

Figure 190: The drainage system of the Ad Dayr monument in Petra: a) The channel at the mountain behind the monument, b) the channel behind the monument, c) overview of the channel systems of the monument and the wadi near by and d) restoration workers Abed Hamad and Atallah Eid of the German/Jordan Stone Preservation Project cleaning the drainage channel of monument no. 826 .

The rooftop of the central round building has an even, circular brim with a slight slope to the backside of the facade. At one time, the water here was guided along canal conduits made of ashlar to the drainage canal. A roughly pointed support surface for a structure made of ashlar remains is still present. The rest of the canal is largely intact. The rooftops of both building wings to the left and right of the Pavilion were not worked on. They exhibit gutters that could in part be identified as canals, yet they could also be attributed to broken off ashlar. Several of these canals direct water onto the monument, which has led to alveolar weathering on these contact surfaces.

The uncontrolled drainage of rainwater must be made primarily responsible for the extreme weathering of all the monuments investigated in this expedition. The King's Wall and most of the other large tomb ensembles were protected by an effective drainage system, which was an integral part of 
an ingenious irrigation system creating the groundwork to make Petra a blooming oasis for tens of thousands of people. The cleaning, reparation and reactivation of certain parts of this system would be a lasting step toward the preventive conservation of the sandstone facades in Petra. The cleaning of the drainage channel of tomb no. 826 was the first working step (Fig. 190 d). Based on these observations and examinations, a "Conservation Action Plan" will be developed in the future for the reactivation of the ancient drainage systems. This may contribute to long term protection of the tomb façades in Petra.

\section{5.3 Conservation model}

Utilizing the main factors of weathering a model for conservation was developed (Fig. 191). This includes aspects of preventive conservation as well as active conservation. The single steps are explained in the following paragraphs:

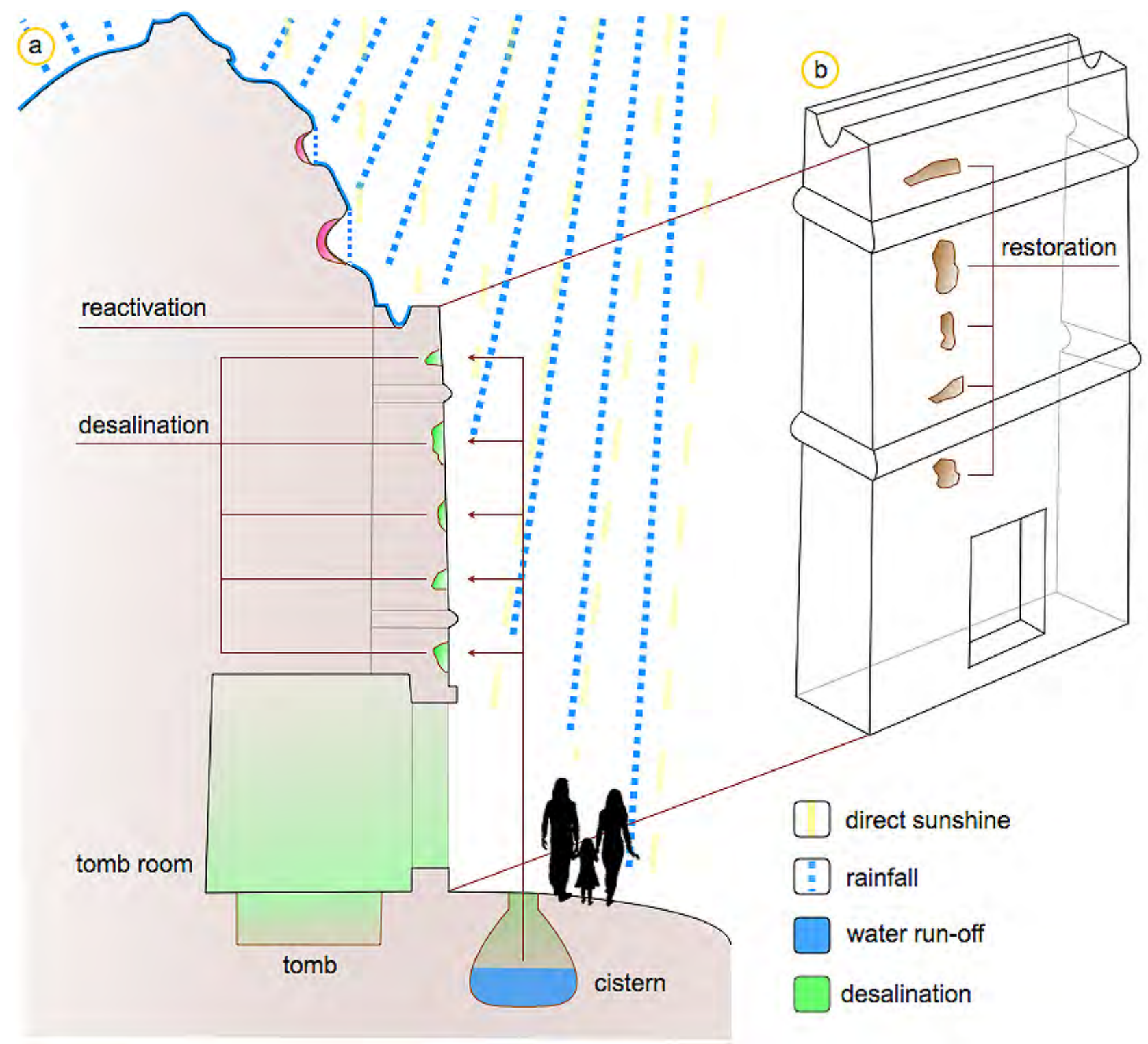

Figure 191: A conservation model to preserve the rock cut facades of Petra. 


\section{5. 4 Active conservation}

Structural problems like cracks and fractured areas have to be stabilized by constructive structures like arches and protection pillars and walls (Fig. 191). Based on the observations of the draining rainwater, it may be concluded that it is possible to dissolve the salt concentration by controlling the rinsing over the saliferous areas. The aim was to turn back the process of high salt concentration.

The process of dissolving is supposed to be carried out with the greatest care in regards to the fragile and often sandy rock surfaces. Therefore, the sprinkling method for desalinating the tafoni zones is the recommended procedure.

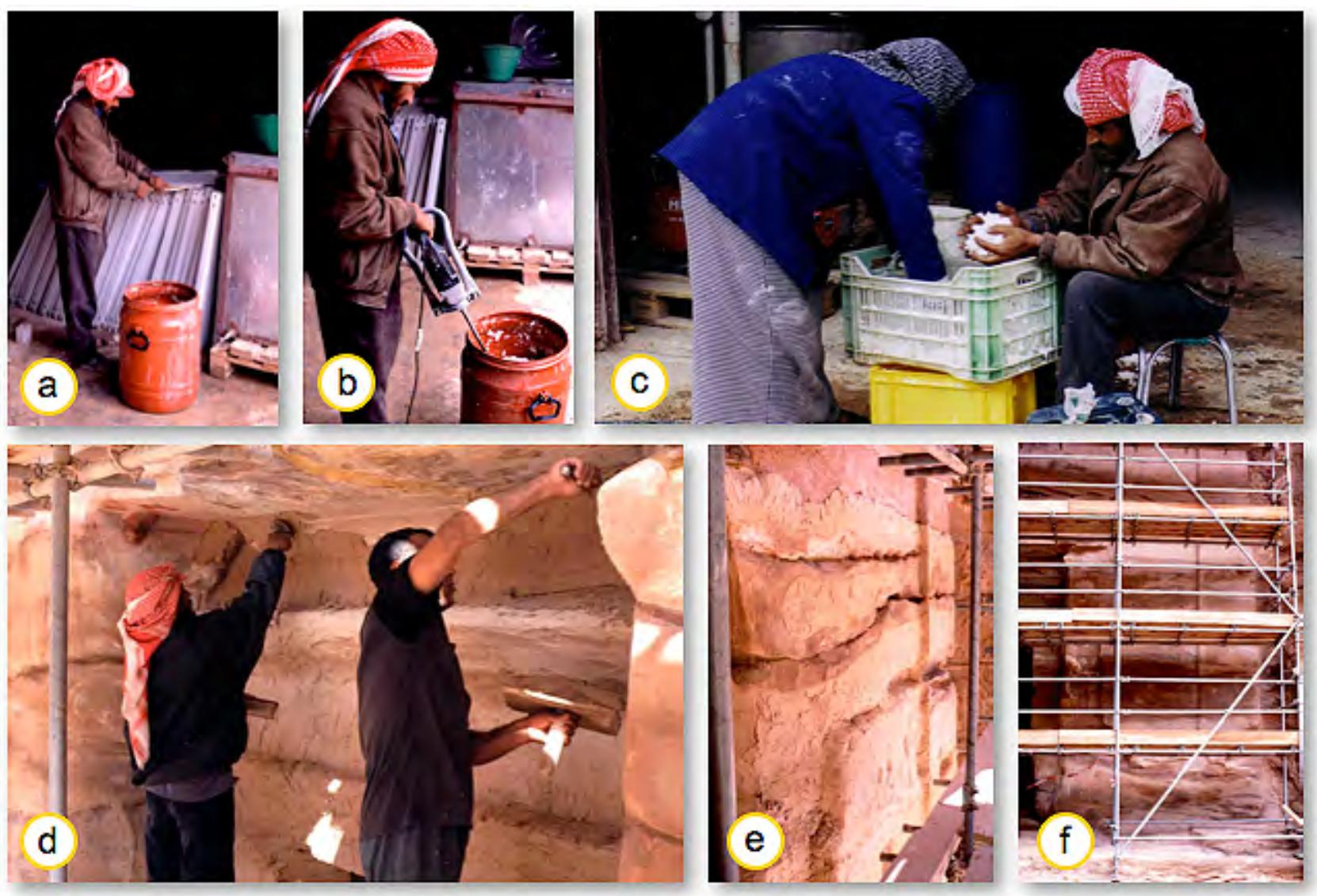

Figure 192: The restoration worker Abdallah Nueja a-b) is preparing the cellulose. c) The water content of the cellulose has to be reduced and finally mixed it with natural sand. d) After transportation to monument no. 825 the restoration workers Lafi Salameh and Aded Hamad plaster the poultice mortar. e) Strongly contaminated areas were cleaned after and treated again for several times. f) During the conservation campaign huge surfaces of the façade were treated.

During the restoration of tomb facade no. 825 from 1997 to 2001, the salt crusts were mechanically removed and the use of compresses reduced the salt. Poultices made from long fibrous cellulose and washed sand proved to be the appropriate method. The common poultice method for desalination is not suitable and very labour intensive: The poultice mortar have had to be produced (Fig. $192 \mathrm{a}-\mathrm{c}$ ), applied (Fig. 192 d) and afterwards removed (Fig. 192 e) and disposed of. After up to 20 compress 
applications heavy salt damage repeatedly occurred on the spare mortar, which could not harden because of the high salt concentration and virtually disintegrated (Fig 196 a).

Like most of the monuments of Petra, tomb façade no. 826 also had a drainage channel in the roof part. As a important working step in preventive conservation the plants were removed from the channel, it was emptied out, and cleaned in order to let the water drain (Fig. $190 \mathrm{~d}$ ).

These first salt reducing steps were done to remove the greatest part of the near surface salt by removing the highly contaminated salt crusts in the tafoni areas by iron chisels. By taking samples from the crust zones and the first two compresses, it was possible to draw some conclusions regarding the intensity of the salt contamination (Tab. 36). The reason for the first two compress applications was to prevent the salt from settling deeper into the inner spheres of the rock during the rinsing process.
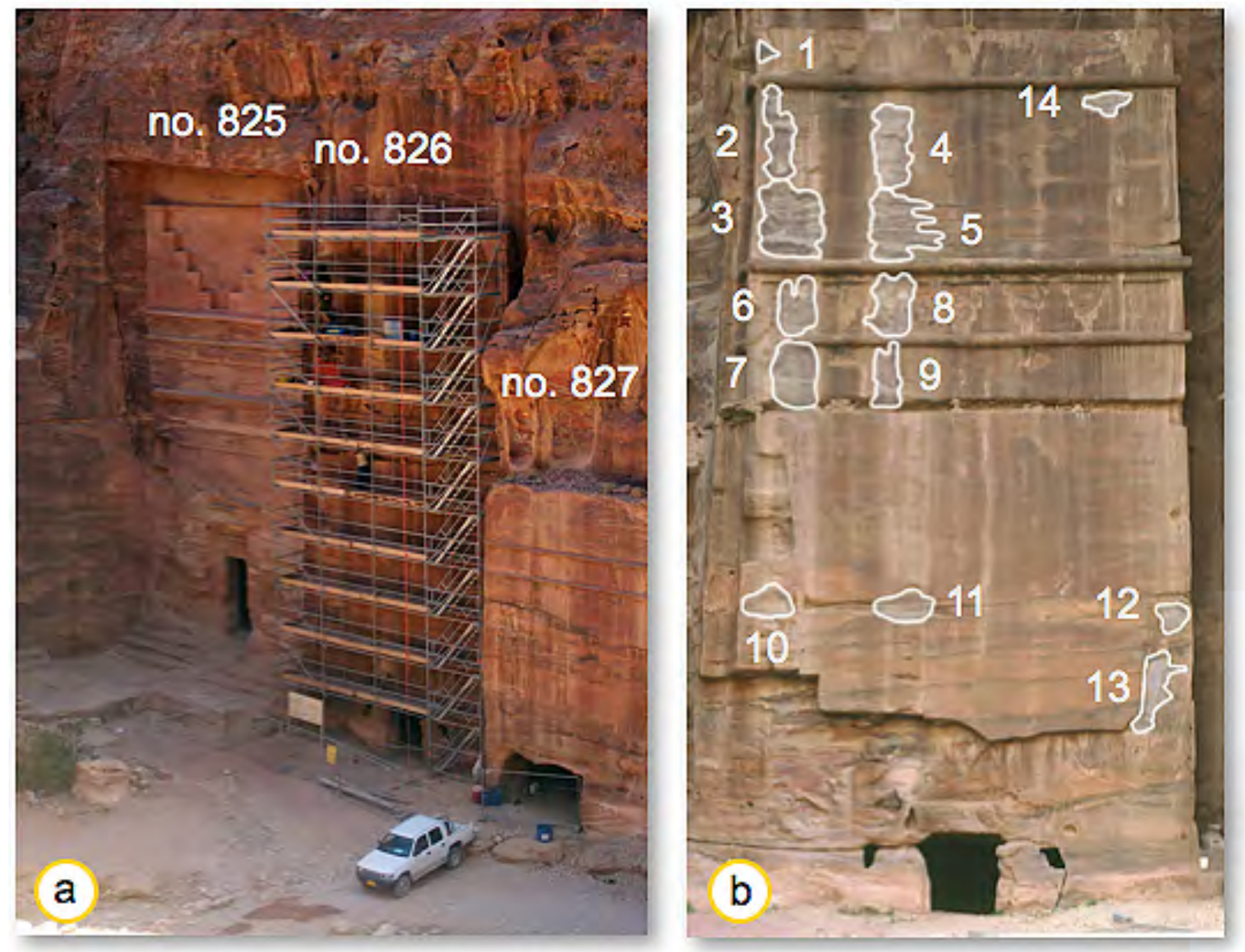

Figure 193: a) The monument under contruction. b) The treated tafonis at monument no. 826 . 
Table 36: inner surface and amount of soluble goods extracted by poultices

\begin{tabular}{cccc}
\hline Tafoni & Inner surface in $\mathbf{~ m}^{\mathbf{2}}$ & Amount of soluble goods $\mathbf{g} / \mathbf{l}$ & Theroretical salt content $\mathbf{g} / \mathbf{m}^{\mathbf{2}}$ \\
\hline 1 & 0.4 & 4.3 & 10.78 \\
2 & 0.95 & 19.54 & 20.57 \\
3 & 1.81 & 13.32 & 7.35 \\
4 & 1.18 & 0.41 & 0.35 \\
5 & 1.97 & 17.02 & 8.64 \\
6 & 1.2 & 25.08 & 20.9 \\
7 & 0.96 & 20.49 & 21.34 \\
8 & 1.08 & 18.32 & 16.96 \\
9 & 0.55 & 20.7 & 37,63 \\
10 & 0.48 & 10.05 & 20.93 \\
11 & 0.51 & 7.5 & 14.7 \\
12 & 0.38 & 3.2 & 8.42 \\
13 & 0.85 & 2.1 & 2.47 \\
14 & 0.32 & 3.6 & 11.25
\end{tabular}

The first two compress applications proved that in tafoni 1 and 4 there was only little salt contamination (Tab. 36 ). The largest load with a very high salt contamination was found in tafoni 6 , followed by tafoni $9,13,7,12,2,8,3,5,14$ and 11 .

\section{5.4 b) Sprinkling method}

Low pressure pushes the water through a hose system. Then it runs through several nozzles and is sprayed onto the affected facade parts (Fig. 194 b). This method is somewhat similar to the trickling method used for cleaning limestone.
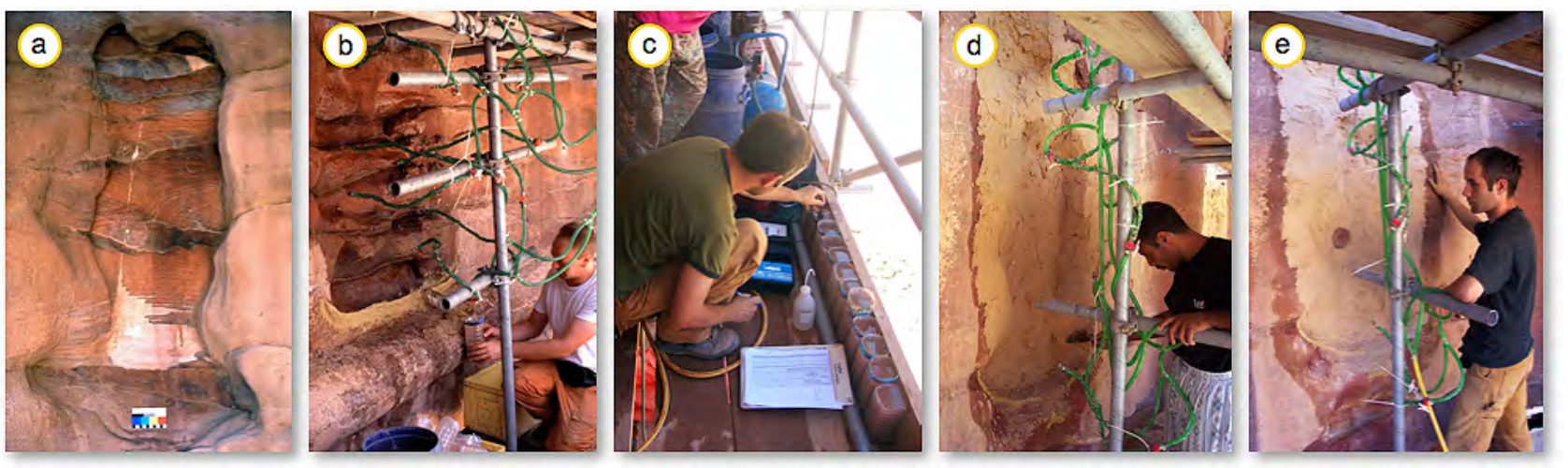

Figure 194: Procedure of desalination. a) Tafoni no. 9 of monument no. 826. b) The installed sprinkling device, sprinkling and collection of the eluate. c) Measurement of the collected eluate. d) Application of the poultice and e) sampling of the poultice. 
Then a wall of clay is set up in the lower part (Fig. 194 b). A hole is worked into the deepest spot of the clay wall, through which the washing water is drained off. The nozzles are arranged in such a way that the spray can reach the deeper parts because, evidently, these parts have the highest salt concentration. At the end of the working day a compress is put on the treated tafoni.

After repeated sprinkling, drying off and having removed the compress, the first liters contained a much higher concentration of solvent substances. This concentration was below the starting level of each sprinkling cycle. Depending on the salt concentration in the stone and the size of the rinsed area, the concentration decreased faster and fewer or more treatment steps were necessary. The sprinkling was stopped after the concentration leveled out at around the value of the washing water. Then a repair mortar test was carried out to see whether the mortar was able to set and harden. If this occurred, then the desalination was considered to be successfully completed. The ions of the salt disturbed the ion system of the silica sol mortar and thereby the setting process. Because of this the mortar would not cling to the highly salt-contaminated ground nor harden when applied according to the older compress method.

\section{5.4 c) The sampling of the compresses}

Samples were taken from selected areas of the compresses and lab-tested. By using deionised water the salt was extracted from the samples. Then its electrical conductivity was measured. In addition, a wet chemical analysis was done for other ions in the concentration, of which only traces were detectible. This was performed on the basis of a simple indicator test analysis.

The wet chemical analyses of the half-quantity determination of various ions proved the following findings. Neither nitrite nor sulfite or dissolved iron was detected in the samples. The $\mathrm{pH}$-factor of all the samples was neutral, at $\mathrm{pH}$ 7. In almost all the compress samples very high rates of chloride were detected. Most of the time the values were less than $3000 \mathrm{mg} / \mathrm{l}$.

\section{5.4 d) The calculation of the extracted amount of salt}

In the washing water of the sprinkling method there was a total amount of $1137 \mathrm{~g}$ of pure salt extracted from the tafoni areas measured by electric conductivity. Based on the extracted amount of salt, the salt concentration of the deteriorated areas of the inner tafoni structure was examined as to how it had spread over the monument. The result was that the salt concentration in the tafoni zones increased along with the flow of the water from top to bottom. Furthermore, the right tafoni area (no. 8 and 9) was more salt-contaminated than the left area. The highest contamination rate was found in tafoni no. 8, 13 and 9 followed by no. 2, 3, 6, 7 and 10 between 0.04 and $0.09 \mathrm{~g} / \mathrm{cm}^{2}$. Tafoni no. 12 and 5 only show a contamination rate of 0.016 and $0.014 \mathrm{~g} / \mathrm{cm}^{2}, 14$ and 11 only 0.004 and $0.005 \mathrm{~g} / \mathrm{cm}^{2}$ (Fig. 195). 

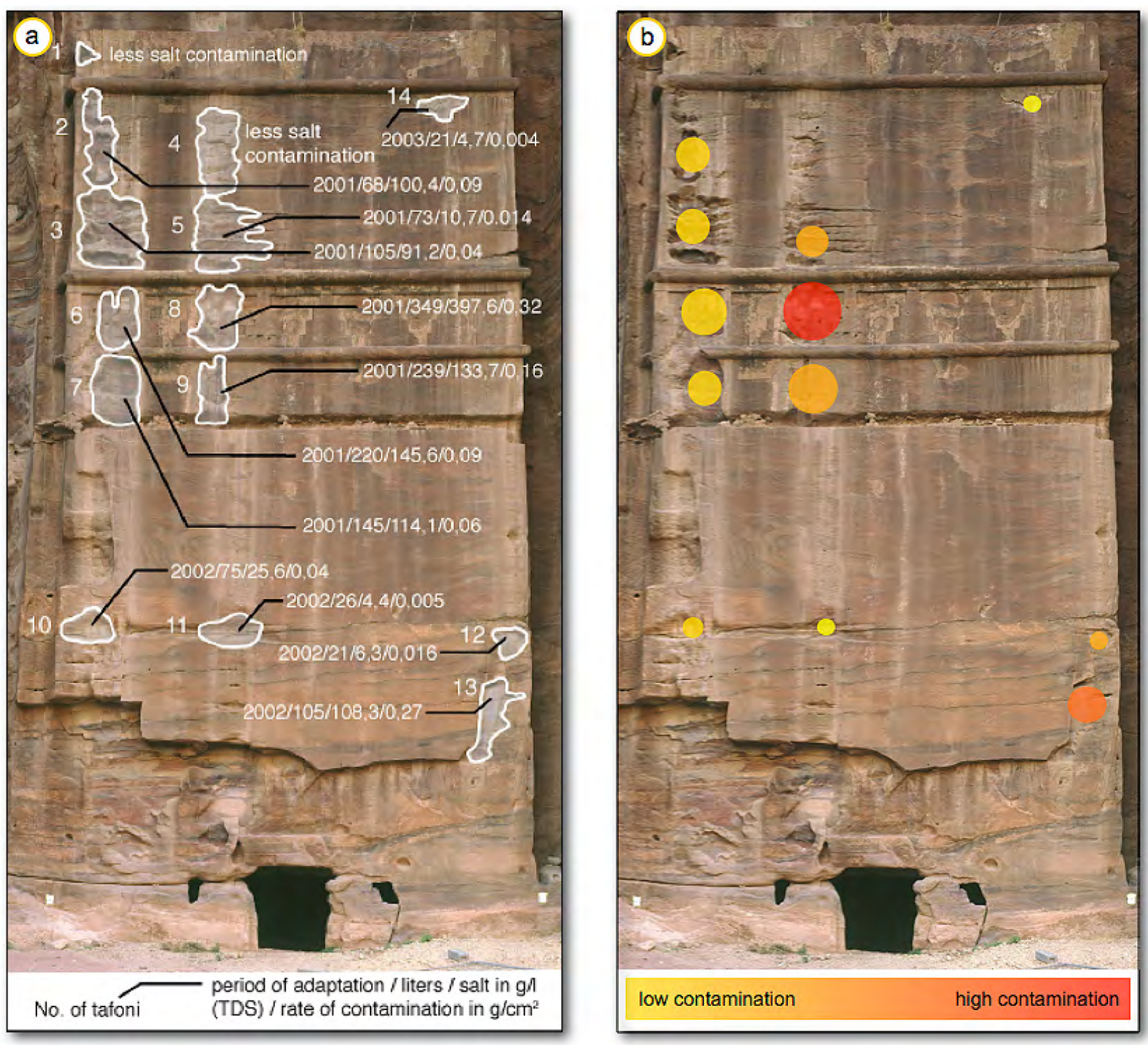

Figure 195: Results of desalination by sprinkling. a) results and b) intensities of contamination.

Depth profile measurements in tafoni zones proved a salt reduction from 60 up to $90 \%$ as compared to the value measured prior to the sprinkling. In one additional measurement there was still $1 \%$ left, which means that the damage potential has not been totally averted. However, with such a low amount the process can be expected to slow down. These are the preconditions for the durability of the silica sol mortar that was chosen as a restoration mortar (Snethlage 2000). The silica sol is stabilized by a defined quantity of sodium ions within the dispersion. If the concentration of sodium is changed or topped, the silica flocculate and the mortar collapse. This happens many times after salt reduction by poultices and may be stopped after desalination by sprinkling.

\section{5. 4 e) Closing remarks and prospects}

The sprinkling method for desalinating natural stone in Petra proved to be a tool that can reduce the salt of the affected problem areas significantly and easily, while the quantity of salt collected is 
permanently checked. This procedure reduces the work load, materials used, and time. Moreover, this backs up the sampling in terms of the quantitative control as well as the over all aim: the desalination itself. Quantitative analysis also provides insights into the weathering processes of the individual building. Repeated application to further monuments would contribute a geomorphological perspective to the understanding of the damage development in Petra.
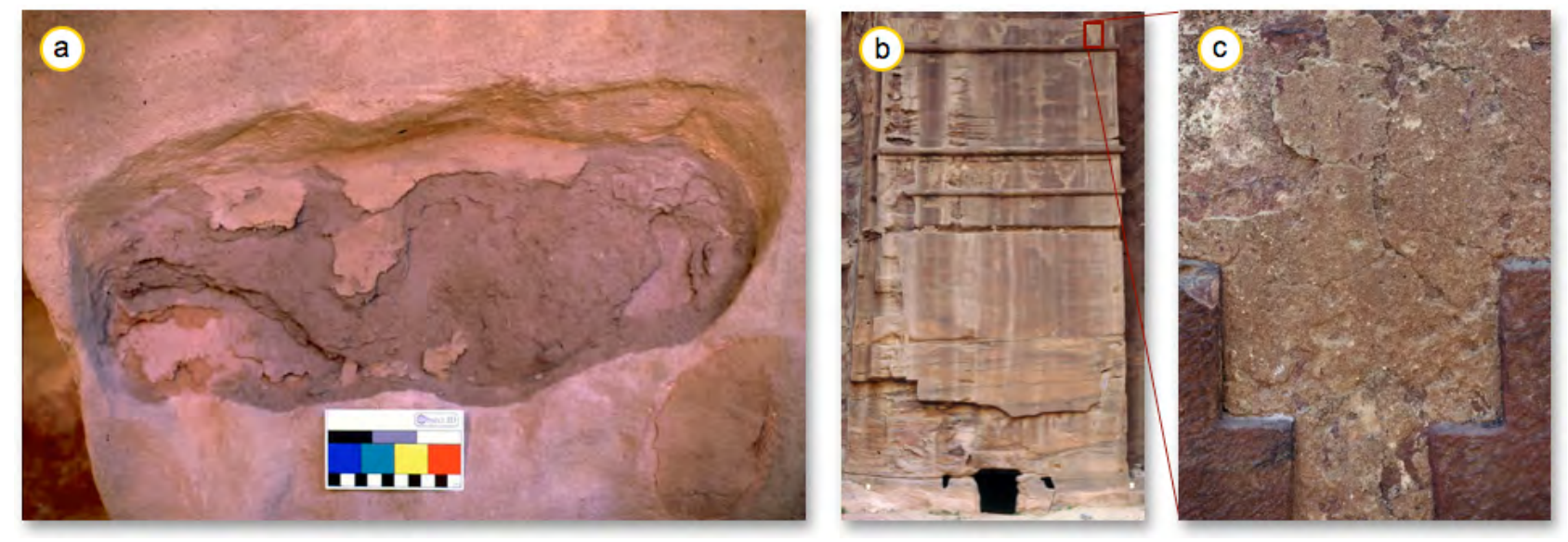

Figure 196: a) The damaged silica sol mortar at monument no. 825 . B) Monument no. 826 with the location of c) huge amounts of the original ancient lime mortar used for decoration.

Taking into account the particular circumstances of Petra, the sprinkling method for desalination has proved to be the appropriate one. Fifteen years after the applied silica-sol-mortar is still solid. However, the use of a traditional lime mortar for restoration such as can be found at many of the rock-cut monuments also could be a workable and inexpensive alternative (Fig. 196 b and c; Shaer 2005). Hot lime mortar would also be a possible and workable restoration material, suitable for filling the deeply weathered tafoni within a short time frame (Wedekind et al., 2016 b).

In conclusion, the combination of salt, water, and heat particularly causes damage to the sandstones. Even though the laboratory tests may not be generally applicable to the situation in Petra, they do point out the necessity for protecting the monuments from open draining water and dampness. 


\section{6 Case study Phnom Bakheng, Angkor, Cambodia}

\section{6. 1 Introduction}

In 2012 the UNESCO and the Authority for the Protection and Management of Angkor and the Region of Siem Reap (APSARA) published the Angkor charter, which are guidelines for the World Heritage Site of Angkor. Many important impacts on the structures are explained such as static, dynamic and environmental ones.

According to UNESCO and APSARA (2012), the development of contour scaling is the most prominent and dangerous deterioration pattern affecting sandstone on many Angkor monuments. A special treatment procedure to deal with this problem is not given in the report.

The main weathering factors in Angkor are chemical weathering and the formation of crusts, combined with mechanical weathering by contour scaling as well as salt weathering due to the presence of bats. Water that is able to penetrate the buildings due to cracks and open joints is the transport media for both processes. The treatment for chemical weathering will be presented in Chapter 6.6.4 a.

\section{6. 2 Conservation model}

A model for the conservation of the Angkor temples investigated in this study was developed on the basis of the weathering factors described in this research. This includes aspects of preventive conservation as well as active conservation. The single steps are explained in the following paragraphs.

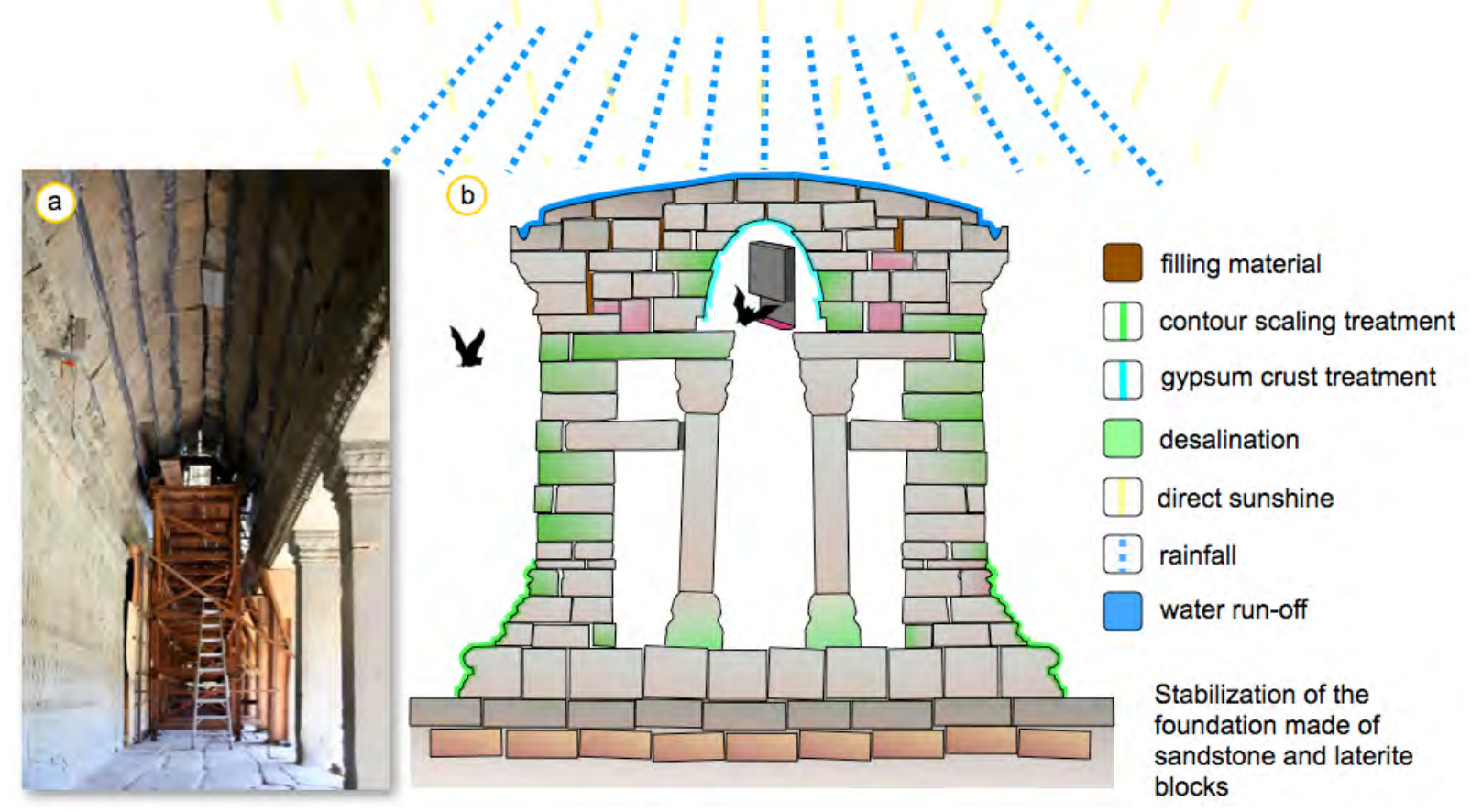

Figure 197: a) Filling of joints with lead and b) weathering model for the main sanctuarium of the Phnom Bakheng Temple. 


\section{6. 3 Preventive conservation}

The most important conservation work that needs to be done is to protect the temples of Angkor by stabilizing the soil and the foundation of the buildings. This work should be done by engineers specialized in this type of undertaking.

In regards to the bats, artificial roosting sites can be developed that would prevent the stone material from being contaminated by bat droppings and subsequent salt weathering. Artificial nest boxes for bats are already being developed. Many different models are on the market. They could be tested, modified and placed under the roof area of the temples and could be periodically cleaned and maintained. To control the rainwater an object specific designed drainage system in the roof area should be implemented (Fig. 197 b).

\section{6. 4 Active conservation}

Periodical cleaning of the excrements would be one possible strategy for reducing the ongoing salt contamination. A vacuum steam cleaner has shown to be useful as it was applied in the cleaning of the Santa Monica Church and the removal of pigeon droppings. The eluates should be disposed of far away from the monuments; however they can be used as a natural fertilizer for plants as was done during the desalination washing at monument no. 826 in Petra.

Joints should be cleaned and closed with stone wedges from fresh but calcite-free quarry material or lead. This has already been done in the case of the main gallery in the Angkor Wat temple (Fig. 197 a). When the joints are closed water penetration is reduced and the bats no longer find places for roosting. The upper area of the building is now in ruins and has to be restored in such a way whereby the rain water can be drained in a controlled manner, for example as is shown in Figure $197 \mathrm{~b}$.

For active conservation a suitable method for desalination has to be evaluated. Different techniques for desalination are presented in this thesis, which may also be helpful in the case of Angkor. A number of techniques for reducing salt contamination due to bats are explained in the chapters concerning the Bartholomew Cemetery, the Santa Monica Church in Guadalajara and the facade no. 826 in Petra.

\section{6. 4 a) Treatment of contour scaling}

The investigations show that scaling is associated with the accumulation of calcite. Therefore, one option might be to reduce the calcite mineralizing out and to decrease the thermal expansion of the crust zone. To evaluate this hypothesis the tested crust sample was treated with a $5 \%$ HCL solution. A small sample was placed in the solution for one hour and afterwards was washed with distilled water. The weight was reduced by $0.7 \mathrm{M}-\%$ after the treatment, probably due to the dissolution of 
calcite. However, as a result of the dissolution material loss due to the separation of single grains could be detected.
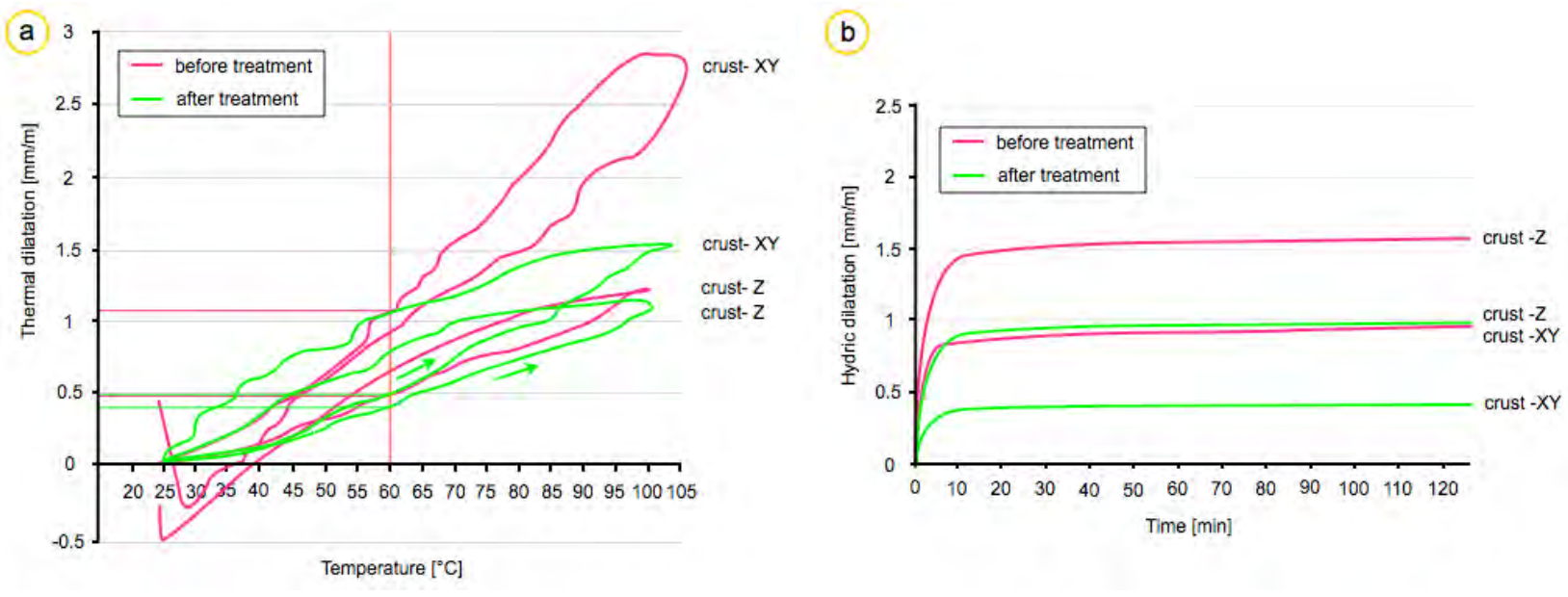

Figure 198: a) Thermal dilatation before and after treatment and b) hydric dilatation before and after treatment of the crust.

The results of thermal expansion measurements show that only a slight change took place for the Zdirection in comparison to the thermal expansion before treatment. Both measurements show a thermal expansion of around $0.5 \mathrm{~mm} / \mathrm{m}$ at $60{ }^{\circ} \mathrm{C}$, whereas the treated sample decreased to around $0.48 \mathrm{~mm} / \mathrm{m}$ with a reduction of $13 \%$ (Fig. $198 \mathrm{a}$ ).

In the case of the XY-direction of the crust a significant decrease of the thermal expansion was determined: The thermal expansion is still slightly higher than in the case of the Z-direction, but reached less than half at $60{ }^{\circ} \mathrm{C}$ (Fig. 198 a). The dilatation was reduced to $47 \%$. The anisotropy between the Z- and XY-direction was also reduced from $95 \%$ to $15 \%$, which is significant in that we can expect the effect of scaling forces to become smaller.

Hydric dilatation after the acid treatment also becomes smaller. A reduction of around $30 \%$ takes place in the Z-direction (Fig. 198 b). This can be explained by the increase of porosity because of the dissolution of calcite. Part of the clay cement can expand within this free pore space, and therefore does not have any influence on further expansion (Fig. 198 b).

Acid treatment may be a promising approach to reducing the thermal expansion of the material and weathering due to contour scaling. The acid treatment is also an option for reducing the calcite accumulations within the weak zones and cracks behind the weathering crusts.

More investigations on site as well as in the laboratory are necessary to complete the picture and to add further knowledge to our understanding of the weathering mechanisms. The development of a suitable conservation treatment in combination with the up-to-date performed conservation techni- 
ques (UNESCO, APSARA 2012) has to be established in order to reduce the weathering from contour scaling, thus preventing further deterioration of the decorations at the Angkor temples. 


\section{Final discussion}

\section{1 Introduction}

The results obtained in the laboratory and collected from fieldwork are essential in understanding the different weathering processes involved, and thereby contribute to the evaluation of the relevant deterioration factors. This study shows that specific conditions and rock specific properties lead to the development of different weathering forms.

\section{2 Case studies}

The case studies investigated show that weathering in urban situations are mainly man-made. The situations at the Santa Mónica Church or the Templo Mayor are characterized by their problematical hydraulic situation, which is evident in many other historical buildings and structures in the urban areas of Mexico. Moisture infiltration during the rainy season leads to an accumulation of large amounts of aggressive salts in the pedestal area of the monuments. This may be explained by inadequate road drainage systems or the lack of maintenance. The historical structures are made from natural stones, adobe bricks and lime mortar and water transport and evaporation is only possible due to this porous material.

Similar problems are observable in desert-like environments, which have been demonstrated for Petra in Jordan. Contrary to widespread belief, it is not the action of strong winds, or the action of rapidly flowing water, or the extreme temperature variations typical for desert environments, but the presence and mobilization of salt that affects the rock-hewn and mostly monolithic facades of Petra. This is the most detrimental factor leading to the observed and lamentable deterioration. Water surely played a central role in the life of the Nabateans once living in Petra. They were highly dependent on an efficient water collection system for their survival in an otherwise arid environment. The Nabateans mastered this challenge by devising a sophisticated and elaborate array of interconnected channels, cisterns and dams, which is said to have exceeded their actual need. This same water, however, in the form of devastating flash-floods also posed a serious hazard to their lives, particularly along the pathway leading through a narrow gorge known as the "Siq", which once was and still is the major access route to the former city. This additional water was diverted into their collection system, which served the purpose of slowing the water runoff rushing down the mountain slopes by a series of terraces, dams and even tunnels. Today most of these channels, cisterns, dams and terraces are no longer in use. They are blocked by rubble, earth, sand and vegetation or even completely destroyed because of the lack of maintenance.

Flowing rainwater would also have damaged the formerly painted and decorated facades, thus the 
frequently observed water diversion channels on and behind the tops of the monuments were constructed. Surface runoff is, however, not a major contributor in the formation of alveolar and tafoni; on the contrary it might even hamper their formation. Their formation, only becoming evident after centuries or millennia, is almost solely attributed to the presence of salt within the rainwater: water percolating within the sandstone as groundwater or being soaked up by the porous rocks during rainfalls.

The German case study shows that weathering of the tomb monuments created by monolithic ashlars is closely connected to their orientation. Most of the damages are found at the sides protected from direct rainfall. The bedding plane also plays a significant role in salt weathering as well as for delamination.

If the ashlars show a high anisotropy of the w-value and are built parallel to the bedding plane, water infiltration can take place after a heavy rain with a directed drying gradient. This can lead to an accumulation of salts and sanding. When the ashlars are built perpendicular to the bedding plane, delamination occurs if a high amount of swellable clay minerals are present.

If a huge amount of temporary water infiltration takes place like in Mexico during the rainy season, the ashlars of the buildings are also affected. If the ashlars show a high anisotropy of the w-value and are built parallel to the bedding plane, water infiltration can take place after a heavy rain with a directed drying gradient. This can lead to an accumulation of salts and hydric dilatation. When the ashlars are built perpendicular to the bedding plane, delamination occurs especially if a high amount of swellable clay minerals are present. This can also be observed in Angkor where some single ashlars contain a high amount of clay minerals that show delamination (Fig. $16 \mathrm{~d}$ ). The same is the case for the German tomb monument study.

The results show that typical weathering forms can be deduced because of specific petrophysical properties on different rock materials. Significant anisotropic behavior or single critical values can influence the sensitivity to different weathering forms. With regard to the investigated rocks in this study, a critical value of $20 \%$ anisotropy starts to influence the initial weathering. Cementation can also play a key role in the rock's resistance to weathering (Loseros Tuff). However, another important factor that must be considered is the composition of the cement, which keeps the grains bonded to one another. High amounts of calcium carbonate (calcite, $\mathrm{CaCO}_{3}$ ) are found in the matrix of the Loseros Tuff as well as in most of the graywackes of Angkor. This mineral may be the reason for the observed differences because calcite is relatively soluble under weathering conditions. Therefore, the matrix may have been partially dissolved, which greatly reduces the cohesion of the particles promoting flaking and crumbling, and on the other hand, can create crusts by precipitation near the surface. 
In examples of some graywackes from Angkor the precipitation of calcite leads to the formation of crusts and the increase of thermal dilatation.

\section{3 Weathering forms}

\section{3. 1 Sanding and flaking}

The observations in combination with the results of experimental desalination tests in the case of the Lejene Dirichlet Tomb at the Bartholomew Cemetery in Goettingen confirm that sanding and flaking is in most situations related to salt weathering. The weathering form is mostly found on homogenous sandstones and some tuff varieties without a high amount of calcite or clay minerals. These are also characterized by a compact matrix with low anisotropic behavior related to water uptake and mechanical forces. Rounding by sanding is the most common weathering form in these types of stones observed during the salt bursting test.

\section{3. 2 Alveolar weathering}

Field observations and laboratory investigations in Petra show that alveolar weathering is connected to salt contamination by an extrinsic source. This can be found in sandstones as well as in tuffs under different environmental and climatic conditions (Fig. 18). However, alveolar weathering was only observed in stone with a comparable homogenous structure.

The main source for alveolar and tafoni weathering in Petra is the wet as well as the dry atmospheric precipitation and not the components of the rock itself. In Petra, like in Angkor two main sources for salt contamination can be determined: 1) the dry aerosols and the precipitation responsible for alveolar and tafoni weathering and 2) the human and animal presence, which is responsible for the weathering phenomena at the bottom of the rock cut monuments. On facades and mountain tops one mainly finds halite, magnesium chloride, some calcium sulfate and traces of phosphates (Eklund 2008), which are the dominate ions in the rainwater (Al-Khashman et al., 2013).

\subsection{Contour scaling}

Without the development of a weathering crust, contour scaling does not occur. This crust is created by the accumulation of soluble mineralogical components like calcite or gypsum. These mineralogical compounds mainly have an intrinsic source. An accumulation of calcite can lead to an increase of thermal dilatation and delamination as was shown in the case studies of Guanajuato for the Loseros Tuff and in Angkor for the graywacke of the Phnom Bakheng Temple. The accumulation of gypsum can create a scale with different hydric and porous properties that leads to compaction and the influence of water transport. Right behind the crust very soluble salts can accumulate and crys- 
tallize by creating contour scaling. The same process can take place by a surface treated with a hydrophobic agent.

\section{4 Moisture expansion}

Moisture expansion, or swelling, has been identified as a major cause of stone deterioration, where moisture gradients formed during wetting and drying cycles can create damage via differential strains that occur within stones as well as via softening of the cementing matrix of the stone. Swelling often occurs due to swelling clays in the matrix leading to intracrystalline or osmotic swelling, although potentially other mechanisms could be responsible, such as disjoining pressures that can develop within a stone's microporosity.
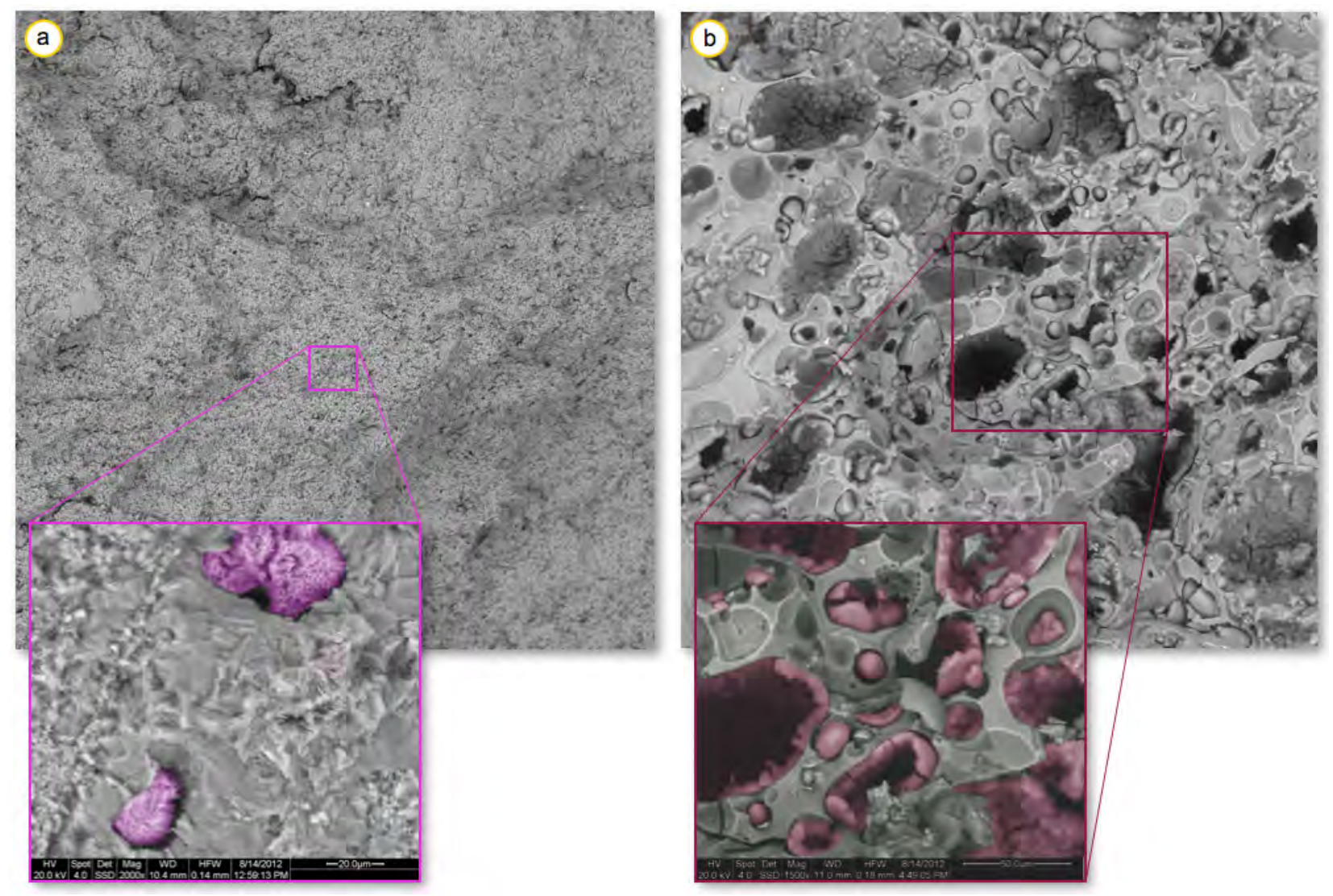

Figure 199: a) SEM image of the Blanca Pachuca Tuff shows fine smectite-like structures within the matrix as well as in larger pore spaces (colored). b) The Habichtswald Tuff shows coatings of smectite in the gas pores of the rock material (colored).

While the moisture expansion can be correlated roughly to the amount of swelling clay minerals within a stone, in some cases the relationship is not so straightforward, where a stone with a high amount of swelling clays may not necessarily have a correspondingly high moisture expansion. In these cases, one can observe from microstructural analysis that the location of the swelling clay minerals plays a vital role in the total moisture expansion. For example, swelling clays that coat the 
interior of pores cannot exert the type of stress on the stone fabric that is possible with swelling clays located within clay-rich lithoclasts or even more so at grain boundaries (Fig. 199).

Differences between tuffs and sandstones have been established in this study. Tuffs are characterized by a directed matrix due to flow processes and a bimodal pore size system containing micro- as well as macropores. An anisotropic behavior especially in the case of water uptake reaching around $50 \%$ is not uncommon. These anisotropies can be traced back to structural features during the genesis of the rock when it behaved like a material flow. In contrast, most sandstones show bedding but only rarely anisotropies of more than $40 \%$ in the case of water uptake (Fig. 22 b). If the anisotropy is high, this can be traced back to a significant clay mineral content embedded parallel to the bedding plane. Most sandstones show a unimodal pore size system dominated by macropores (Fig. 21 b).

Thermal expansion related to tuffs and sandstones is relevant if the rock material contains minerals with a high thermal dilatation coefficient. This could be shown in the case of the Loseros Tuff and the gray to greenish sandstones of Angkor. In fact, thermal dilatation becomes relevant if an enrichment of these minerals, mainly calcite (chemically like a salt) takes place due to dissolution by chemical weathering and precipitation near the surface.

In the case of clay-rich sandstones this can lead to contour scaling. The clay, mostly embedded parallel to the bedding plane is lost due to weathering at locations near the surface area and within these empty spaces calcite can be found. The accumulation of calcite leads to an increase of thermal dilatation parallel to the bedding. One can assume that the surface of the stone is first affected by hydric dilatation preferentially in Z-direction and later on by an increased thermal dilatation in the XY-direction, which leads to a contour scaling effect. This process is similar to the accumulation of salt identified as the main cause of weathering in historical monuments.

\section{5 Salt weathering}

\subsection{The source of salts}

For most of the sandstones in the German, the Cambodian and the Jordanian case studies, the main source for salt weathering are extrinsic factors and not the components of the rock itself. Two main sources for salt contamination can be determined: 1) the dry aerosols and the precipitation and 2) pollution and the human and animal presence.

In Petra the wet and dry atmospheric precipitation is the main source for alveolar and tafoni weathering. The human and animal presence is responsible for the weathering phenomena at the bottom of the rock cut monuments. This is also the case in Angkor where the animal presence plays the major 
role for salt contamination. In the case of the German study a mix of natural deposits and urban pollution is responsible for the salt weathering phenomena.

An important intrinsic factor occurs if the binding cement of the stones contains calcite, such as some tuff stones (Chiluca, Remedios, Loseros), the Reinhausen sandstone or most of the graywackes of Angkor. In poorly polluted environments gypsum accumulations was also found at depth in the material as was shown in the German case study.

Gypsum crust formations could only be found in urban environments like in Mexico City and Guadalajara and can be traced back to sulfur pollution. Also in central Goettingen the source of the sulfur seems to come from the aerosols and rainwater. If calcite is present as a binding cement in the stone, such as in the Ellissen Tomb, gypsum crusts can be formed. These crusts occur in damp areas that are not directly affected by rainfall.

\section{5. 2 Petrophysical aspects}

The results show that the resistance to salt bursting decreases with the increase in porosity in the case of the tuffs but not necessarily for the sandstones. The tuff rocks with higher porosity resisted less to cycles of salt crystallization. In fact, the four studied samples with the lowest porosities resist the majority salt bursting cycles (TY, LC, CH and LSc Fig. 157 a). However, the rock with the highest porosity (ESC with $50 \%$ porosity) was extremely resistant to salt crystallization, indicating that the porosity itself is not the determining factor in this resistance.

Another factor that can influence the resistance against salt crystallization is the capacity of water uptake. Salts are dissolved in the absorbed water so that it is expected that rocks with higher water uptake values should have more possibilities for allowing salt crystallization to occur. Four of the most resistant tuff rocks showed very low values of water uptake (w-value around zero, Fig. 161 a). The samples with the lowest resistance did not show any important w-values (around 2 to 5 ).

Four factors appear to be important for the resistance against salt crystallization: (1) a micro-crystalline overgrowth structure, (2) the binding cement and soluble minerals, (3) the pore radii distribution and (4) the mechanical strength.

1) If the matrix of the tuff contains a high amount of the described micro-mineral structures and textures, the salt resistance can increase in a significant way even if the material only reaches a low splitting tensile strength.

2) Binding cement has an influence on the weathering forms created by salt weathering. Sandstones cemented by clay minerals can show delamination parallel to the bedding. Sandstones as well as tuffs that consist soluble minerals like calcite often show the development of a weathering rind and contour scaling. 
3) Microporosity becomes a relevant factor for rapid salt destruction if it reaches more than 50 $\%$ of the pore volume expacially in case of the sandstones (Fig. $158 \mathrm{~b}$ ). This is the same only for some tuffs (Fig. 158 a). Five of the 10 tuffs that show a high salt resistance have a microporosity bigger than $50 \%$ the other five ones have a low microporosity. .

4) The results show that salt resistance is not only controlled by the porous structure but also by the mechanical strength. A fast and mostly total destruction takes place in the case of the tuffs, if the stone only reaches a splitting tensile strength up to $3 \mathrm{MPa}$ (Fig. 166 a). This value of low mechanical strength can be defined as a critical value for tuffs in regards to salt weathering. Furthermore, in the case of a very low mechanical strength the pore size distribution seems to play a minor role for both rock types. Only the CA-tuffs are an exception. Their splitting tensile strength is very low, but they show a high resistance to salt. For this, probably minerals like zeolites which can act as ion exchanger are responsible. Glass and zeolites minerals that often occurs as crystalline overgrowths components were observed in the ESC-, the CA-, and the CR-Tuffs (Fig. 171).

\section{6 Implications}

\section{6. 1 New experimental methods}

The experimental investigations and developments of new measuring equipment show that petrophysical properties can be measured even on small-dimensioned crust material (see chapter no. 3. 7 on the Angkor case study). This leads to an understanding of the weathering processes involved in contour scaling. The presented example can be used for other applications.

Hydric dilatation measurement experiments of inhomogeneous materials could be successfully applied by extensive measuring using several dilatometers at the same time. This was demonstrated in the Guadalajara case study (chapter 3. 4).

\section{6. 2 Weathering models}

By taking into account the observations of weathering to the different climates, it became clear that the model of Peltier (1950, Fig. 12 a) does not take into consideration weathering agents such as salts and heavy precipitation events. Therefore, a more realistic model needs to be developed that closely approaches the true situation at different sites.

\section{6. 3 Consequences for practical conservation}

Deteriorated stone material is usually replaced with new stones today as in Mexico and in Germany. The present investigation has shown that weathering is mostly limited to the surface area of the different materials. Conservation and preservation of the original historical material seems to be possible and more cost effective. Long-term studies and cost calculations have shown that conservation 
can be up to four times more cost effective than changing the stone material (Gräf 2009).

Studies on consolidation were already done for several rock samples presented in this thesis. Investigations have shown that the best results are attained with vinyl acetate, type Mowolith 50 and a silica acid ester, type Wacker OH for the tuffs from Mexico City (Martínez 1992). After giving a workshop in 2006 on stone consolidation to the staff of the Templo Mayor by the author of the present thesis, consolidation of the polychrome on the Aztec Tlatecuhtli sculpture (Fig. 2 e) was successfully done using the silica acid ester KSE 100 (Barajas et al,. 2009). Studies on the Cantera Amarilla Tuff of Guadalajara show good results for an invented hybrid consolidant from silica sol and acrylic resin (Schindler 2003; 2005; Schindler et al., 2006) and a new aluminosilicate compound (Pérez et al., 2012). The investigations of Kracke et al., (2008) show good results with silica acid ester in the case of the German sandstones presented in this study.

Consolidation is a risky procedure in conservation and can lead to irreversible damage to the object or monument (Rodriguez 2010). Most of the damages can be traced back to the application of a consolidant causing an over-consolidation of the stone surface. The reason for this treatment is often given under the definition of preventive conservation, which is a fundamental mistake.

The list of references on different consolidants tested on quarry-fresh stone material and artificially altered by different testing procedures is almost endless. Nearly all types of stones were tested in this way using different consolidants.

The general problem of testing consolidants on samples of most of the studies published is that the samples consist mostly of freshly quarried material. Even when the tested rock material is artificially altered before the consolidation treatment, the properties of these tested materials can be quite different from the weathered stone material in the field. They differ in porosity, hardness and sometimes in chemical and mineralogical composition (Wedekind et al., 2011). Therefore, the results of laboratory testing on quarry fresh material should be used with caution when deciding, which consolidant should be used for practical conservation of the original weathered material. This methodical problem is only taken into account by a minority of scientists, like for example Kirsten (2009), which realized it in the case of sandstones.

One of the most important tasks for the future in stone conservation is to focus on the development of adequate procedures for artificial weathering, which are able to develop similar weathering forms such as can be found in the field. The second task is to develop testing methods to evaluate the effectiveness and behavior of consolidation in the laboratory as well as in the field. 


\section{7 Future studies}

To evaluate the state of weathering and the effectiveness of consolidation on-site only a few methods are available. The most common non- or low destructive technique is the ultrasonic wave measurement and the drilling resistance test, which has been applied for around 20 years in the field of stone conservation. The drilling resistance test is a useful method for detecting scales and exfoliations especially in sandstones (Cnudde et al., 2009; Siedel et al., 2010). However, the test cannot differentiate exactly between consolidated and untreated areas (Lotzmann, Sasse 1999). However, the investigations in Wedekind et al., (2016 a) show that there is a clear positive correlation between the surface hardness and the compressive strength (Fig. 200).

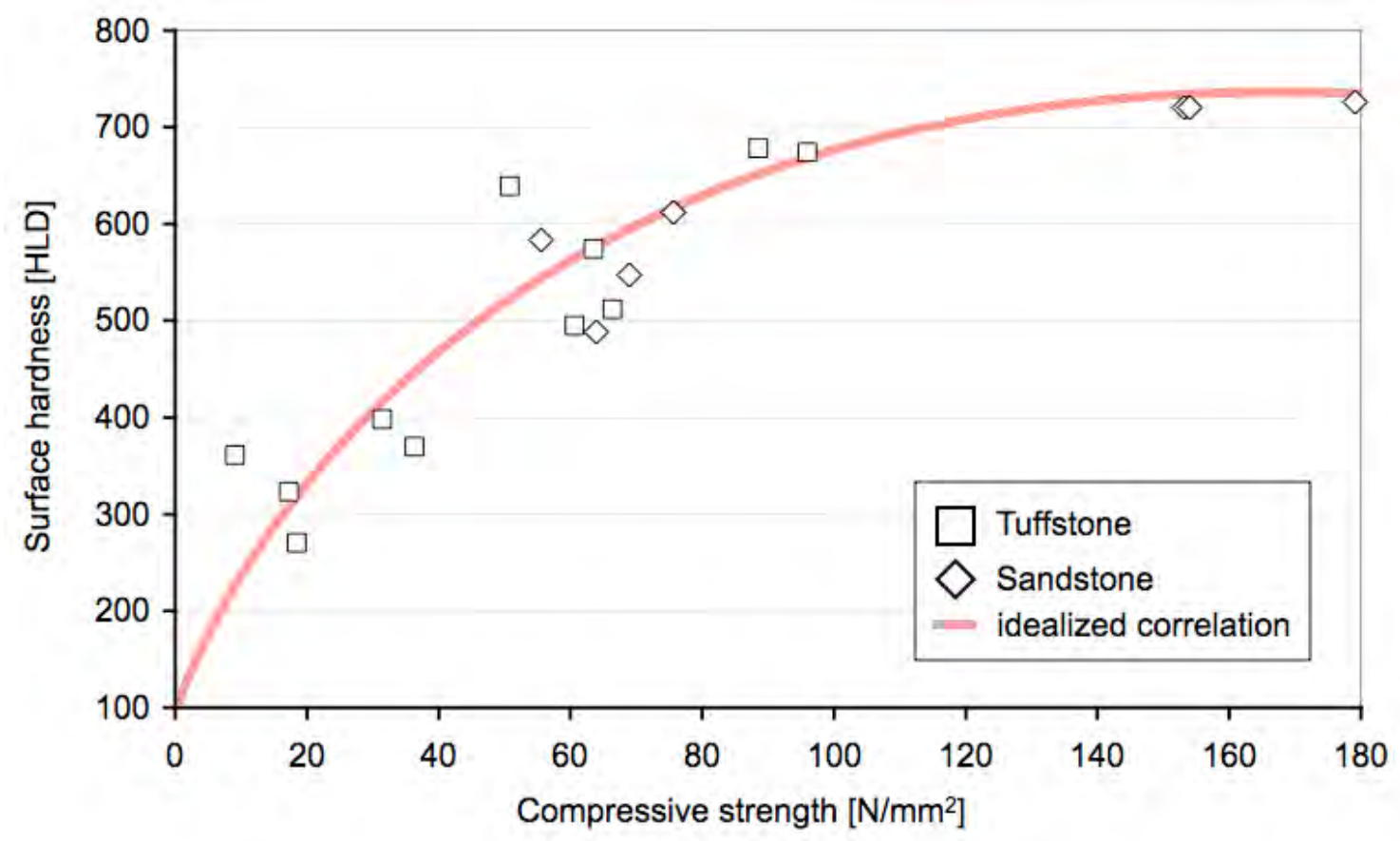

Fig. 200: Surface hardness versus compressive strength for different stones.

During 2014 and 2015 a scientific consolidation treatment project was done on two tomb monuments, the Pickhardt Tomb and the Schneider Tomb at the Bartholomew Cemetery in Goettingen. The weathered areas show sanding and are located mostly in those areas where no water runs down during a rainfall and are visible by dark deposits and microbiology (Fig. 201a \& b). Where decorative areas of the Pickardt Tomb and the Schneider Tomb are exposed to rain, only low weathering or none could be observed. At these areas the surface hardness averaged 481 HLD for the Pickardt Tomb and 479 HLD for the Schneider Tomb (Fig. 201 c). 

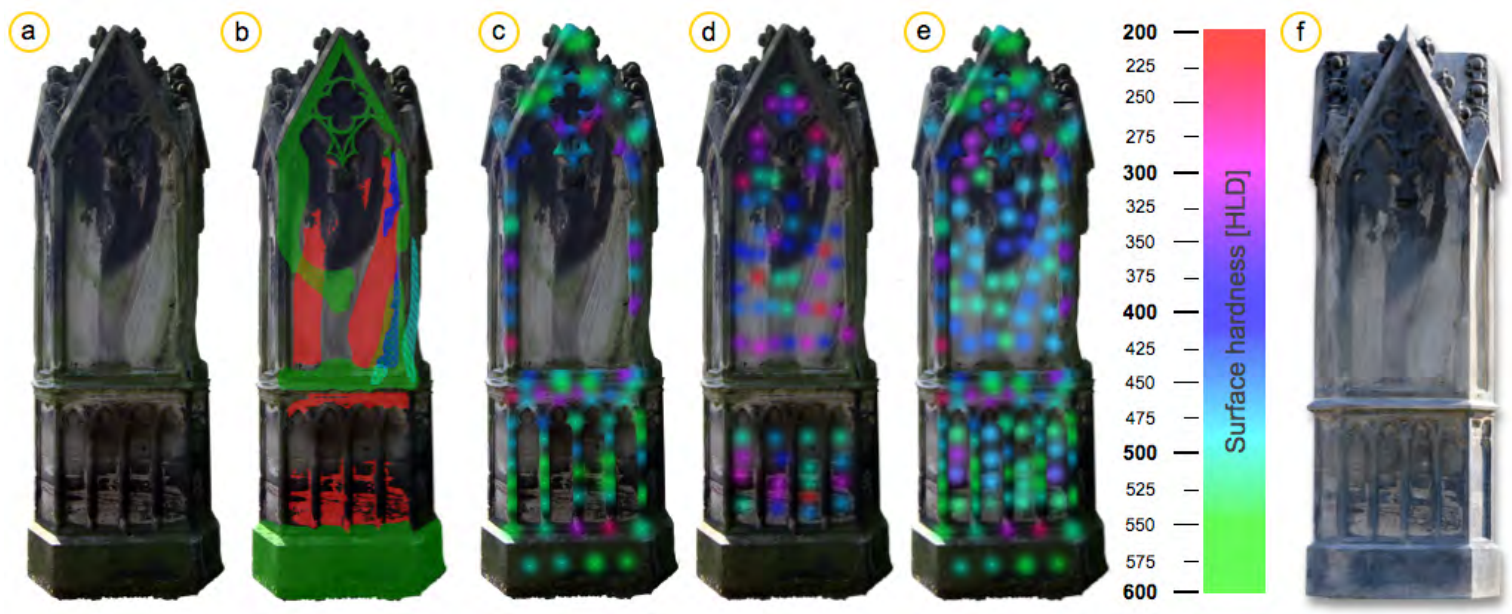

Figure 201: a) The Pickardt Tomb before consolidation and restoration. b) Damage mapping of the monument with indications of microbiology (green), sanding areas (red), gypsum crusts (blue) and delamination (light blue). c) Surface hardness of the exposed decorative parts of the monument. d) Surface hardness of the backside of the monument. e)

Surface hardness after the consolidation treatment. f) The monument after conservation and restoration.

Surface hardness for the pedestal of the Schneider tomb averaged only 331 HLD but is made from another sandstone variety than the pillar. The areas affected by weathering show an average value of 355 HLD for the Pickardt Tomb (Fig. 201 d) and 332 HLD for the Schneider Tomb (Fig. 202 d).
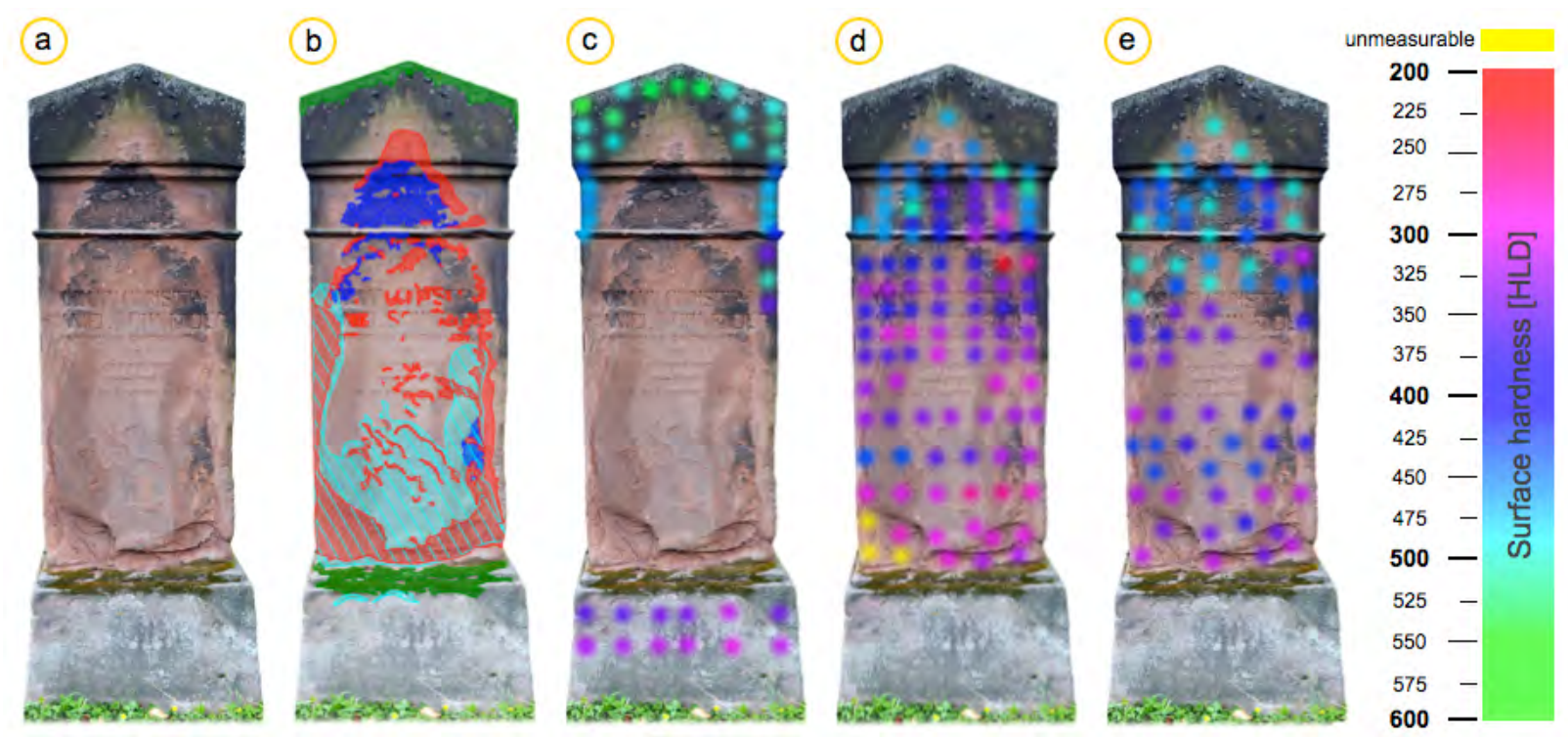

Figure 202: a) The Schneider Tomb before consolidation and restoration. b) Damage mapping of the monument with indications of microbiology (green), sanding areas (red), gypsum crusts (blue) and delamination (light blue). c) Surface hardness of the parts exposed to rain water, visible due to the dark discoloration. d) Surface hardness of the weathered areas of the monument. e) Surface hardness after the consolidation treatment.

Some areas of the Schneider Tomb that were highly affected by weathering and sanding were not measurable by the Equotip device (Fig. 202 d). 
A clear effect could be detected by surface hardness in situ at the two tomb monuments. Thus, surface hardness measurements can be used for understanding the conservation state as well as a means for evaluating the consolidation. Moreover, it can be used as a suitable tool for non-destructive testing in stone conservation.

Future tasks have to focus on the development of adequate methods and materials, such as adequate testing procedures to evaluate consolidation and mortars for restoration. In the case of mortars the hot-lime technology appears to be an interesting new approach in stone conservation (Wedekind et al., 2016 b). 


\section{Acknowledgments}

This study was greatly supported by the Hans-Boeckler Foundation, Germany.

Prof. Dr. Siegfried Siegemund and Prof. Dr. Robert Sobott for the acquisition of the unit and the coreferat work.

My special thanks go to the conservators Karla Jaurequi Arreola, Mauricio Ramírez and Dr. Rubén López-Doncel from Mexico. Dr. Helge Fischer is thanked for his trust and support during our project work in Petra, Jordan and Dr. Joerg Ruedrich for our cooperation in Goettingen, Germany.

I also have to thank for the scientific cooperation, help and discussions with Prof. Dr. Rolf Snethlage, Dr. Reiner Dohrmann, Dr. Alfons M. van den Kerkhof and Dr. Tobias Licha.

Furthermore I am grateful to my colleagues Heidrun Stueck, Manuela Morales-Demarco, Victoria Shushakova, Theresa Platz, Christopher Poetzl and Nohemi Cardona for their technical and laboratory support.

Single research projects within this thesis were supported by the Consejo Nacional de Ciencia y Tecnología, (CONACyT), Projects Ciencia Básica (CB-130282) the Cooperación Bilateral (191044) and the German Science Foundation (DFG Si-438/44-1).

My thanks to Christian Gross for his help, support and discussions in bringing this thesis into a readable version.

Finally, I would also like to thank my family for their passion and support and our dog Yoki for the creative breaks. 


\section{References}

Abd El-Hady M. (2000) - The deterioration of Nubian sandstone blocks in the ptolemaic temples in Upper Egypt. Proceedings of the $9^{\text {th }}$ International Congress on Deterioration and Conservation of Stone. Venice, June 19-24. Elsevier, 2:783 - 792.

Abed AM, Jarrar G, Atallah M (1998) Geology of Jordan-An overview: $6^{\text {th }}$ Jordanian Geological Conference 5-8 October, 1998, University of Jordan, Amman, Jordan.

Abu-Safat M. (1988) Verwitterung und Hangabtragungen im „Nubischen Sandstein“ Südjordaniens. Erlanger Geographische Arbeiten no. 49.

Acevedo-Dávila LM, Torres-Treviño, Lauren YGZ (2007) Tezontle aggregate substitute optimization in building blocks mixture. Electronics, Robotics and Automotive Mechanics Conference (CERMA), Cuernavaca:307-311.

Adamovic J, Mikulas R, Schweigstillova, Boehmova V (2011) Porosity changes induced by salt weathering of sandstone Bohemian Cretaceous Basin, Czech republic. Acta Geodyn Geomater vol. 8, no. 1 (161): $29-45$.

Al-Khashman, O.A., Jaradat, A.Q., Salameh, E. (2013) Five-year monitoring study of chemical characteristics of wet atmospheric precipitation in the southern region of Jordan. Environ Monit Assess 185: 5715-5727.

Al-Khashman OA, Tarawneh QY (2007) Spatial prediction model and its application to chemistry of atmospheric precipitation in Jordan. Atmospheric Research 84: 399-409.

Al-Naddaf M (2002) Weathering mechanisms, technical investigation in relation to the conservation of the sandstone monuments in Petra, Jordan, Dissertation, Berlin 2002.

Al-Saad Z, Abdel-Halim MAH (2001) Laboratory evaluation of various types of mortars for the conservation of Qasr al-Bint monument, Petra-Jordan, Engineering Structures, 23: 926-933.

André MF, Voldoire O. Roussel E, Vautier F, Phalip B, Peou H (2012) Contrasting weathering and climate regimes in forested and cleared sandstone temples of the Angkor region. Earth Surf. Process. Landforms 37:519-532.

André MF, Phalip B, Voldoire O, Vautier F, Géraud Y, Benbakkar M, Constantin C, Huber H, Morvan G (2011) Weathering of sandstone lotus petals at the Angkor site: a 1,000-year stone durability trial. Environ Earth Sci (2011) 63:1723-1739.

André MF, Etienne S, Mercier D, Vautier F, Voldoire O (2008) Assessment of sandstone deterioration at Ta Keo Temple (Angkor): first results and future prospects. Environ Geol 56:677-688.

Angeli M, Benavente D, Bigas JP, Menéndez B, Hébert R, David CH (2008) Modification of the porous network by salt crystallization in experimentally weathered sedimentary stones. Materials and Structures 41:1091-1108.

Angeli M, Bigas JP, Benavente D, Menéndez B, Hébert R. and David C (2007) Salt crystallization in pores: quantification and estimation of damage - Environmental geology 52:205-214.

Aranda-Gómez JJ, Godchaux MM, Aguirre-Díaz GJ (2003) Bonnichsen,Bill; and Martínez-Reyes, Juventino, 2003, Continental edge tectonics of Isla Tiburón, Sonora, Mexico, in Geologic transects across Cordilleran Mexico, Guidebook for the field trips of the $99^{\text {th }}$ Geological Society of America Cordilleran Section Annual Meeting, Puerto Vallarta, Jalisco, Mexico, April 5-8, 2003: Mexico, Universidad Nacional Autónoma de México, Instituto de Geología, Publicación Especial 1, Field trip 6:123-168.

Arnold A, Zehnder K (1990) Salt weathering on monuments. In.: Advanced workshop analytical methodologies for the investigation of damaged stones 14.-21. September 1990, Pavia.

Auras M, Steindlberger E (2005) Verwitterung und Festigung vulkanischer Tuffe. $Z$ dt Ges Geowiss 156: 167-175.

Auras M, Melisa G (2002) Kompressenentsalzung - Wirkungsweise, Materialien, Anwendung, Fallbeispiele. In: IFS (eds.): Salze im historischen Mauerwerk: Aktuelles zu Herkunft, Schadenswirkung und Restaurierungsmaßnahmen, IFS-Tagung 2002 (report no. 14 - 2002), Institut für Steinkonservierung e.V., Mainz: 41-52.

Bachmann GH, Hoffmann N (1997): Development of the Rotliegend Basin in Northern Germany. - Geol. Jb. 
(D), 103: 9-31.

Bala'awi F, Alshawabkeh Y, Alawneh F, Al Masri E (2012) Damage Assessment and digital 2D-3D documentation of Petra Treasury. Mediterranean archaeology and archaeometry, Rhodes, University of the Aegean, vol 12, 2:21-42.

Bala'awi, F (2008) Wind speed and salt simulation tests: Towards a more comprehensive approach. In : Salt weathering on buildings and stone sculptures : proceedings from the international conference, The National museum, Copenhagen, Denmark, 22-24 October 2008:41-50.

Barajas M, Lima E, Lara VH, Vásquez-Negrete J, Barragán C, Malváez C, Bosch P (2009) Effect of organic and inorganic consolidation agents on Tlatecuhtli monolith (2009) Journal of Archaeological Science, Vol. 36(10):2244-2252.

Benavante D (2011) Why pore size is important in the deterioration of porous stones used in the build heritage. Macla, no. 15, Revista de la Sociedad Española de Mineralogia: 41-42.

Benavente D, García del Cura MA, Fort R, Ordóñez S (2004) Durability estimation of porous building stones from pore structure and strength. Eng Geol 74:113-127.

Birch, F (1961) The velocity of compressional waves in rocks up to 10 kilobars. Part 2. Journal of Geophysical Research, 66:2199-2224.

Birch, F (1960) The velocity of compressional waves in rocks up to 10 kilobars. Part I. Journal of Geophysical Research, 65:1083-1102.

Bradley W, Hutton J, Twidale CR (1978) Role of salts in development of granitic tafoni, South Australia. Journal of Geology, 86:647-654.

Brakel J, van Modry S, Svata M (1981) Mercury porosimetry: state of the art. Powder Technol 29: 1-12.

Brown DA, Campell KSW, Crook KAW (2014) The Geological Evolution of Australia \& New Zealand: Pergamon International

Bruch, A. Historische Friedhoefe in Göttingen. Gefährdete Gartendenkmäler Göttingen — Bestandsaufnahme Wiederherstellung Maßnahmenkatalog. unpublished report, Göttingen 2000.

Bruennow RE, Domaszewski A (1904) Die Provincia Arabia, Auf Grund zweier in den Jahren 1897 und 1898 unternommenen Reisen und der Berichte früherer Reisender. Erster Band, Die Provincia Arabia, unter Mitwirkung von Julius Euting, Straßburg.

Buchanan LJ (1980) Ore-controls of a fossil geothermal system: the Las Torres Mine, Guanajuato, Mexico, private unpublished report.

Buchanan LJ (1979) The Las Torres mine, Guanajuato, Mexico: ore controls of a fossil geothermal system. Ph.D. dissertation Colorado School of Mines, Boulder, Colorado.

Bumnaru D, Burke S, Petzet M, Truscott M, Ziesemer J, (2000) Jordan - Heritage @ Risk!, [in:] Heritage at risk, ICOMOS World Report 2000 on Monuments and Sites in Danger, Munich:123 -124.

Booth, J., Viles, H., Fletcher, P., 2012 An assessment of three consolidants for use on museums artefacts in comparison to organo silanes. In: Proceedings of the $12^{\text {th }}$ International Conference on the Deterioration and Conservation of Stone (in print).

Camuffo D (1995) Physical weathering of stone. Science of the Total environment, vol. 167, issues 1-3:1-14.

Caneva G, Altieri A (1988) Biochemical mechanisms of stone weathering induced by plant growth. In Book. VIt ${ }^{h}$ International Congress on Deterioration and Conservation of Stone: proceedings: Toruń, 12-14. 09. Ciabach, Jerzy (Editor). Nicholas Copernicus University. Press Department, Torun, Poland:32-44.

Carò F (2009 a) From Quarry to Sculpture: Understanding Provenance, Typologies, and Uses of Khmer Stones. New York: The Metropolitan Museum of Art, 2000-, http://www.metmuseum.org/research/conservation-and-scientific-research/scientific-research/khmer-stones (June 2009, updated January 2014).

Caró F (2009 b) Khmer stone sculptures: a collection seen from a material point of view. Metropolitan Museum of Art Bulletin 67, no. 5:1455-1466.

Carradori F (1802) Istruzioni elementareper gli studenti. Florence, p. xxvii; note 8 supra.

Carroll D (2012) Rock Weathering. Springer. 
Charola AE (2000) Salts in the Deterioration of Porous Materials: An Overview. Journal of the American Institute for Conservation, vol. 39, issue 3:327-343.

Chavez M. (2000) Impact of the local Geology on the seismic vulnerability of the metropolitan zone of Guadalajara, Mexico. In: Proceedings of the $12^{\text {th }}$ World Conference on Earthquake Engineering Auckland, New Zealand 2000, published online: http:/www.iitk.ac.in/nicee/wcee/article/1600.pdf.

Colman SM (1982) Chemical Weathering of Basalts and Andesites: Evidence from Weathering Rinds. Geological Survey Professional Paper 1246 US Govt Printing Office, Washington, DC

Cooke R., Smally IJ (1968) Salt weathering in deserts. Nature, vol. 220:1226-1227.

Coussy O (2006) Deformation and stress from in-pore drying-induced crystallization of salt. J Mech Phys Solid 54(8):1517-1547.

Cnudde, V., Silversmit, G., Boone, M. Dewanckele, J., De Samber, B., Schoonlans, T., De Witte, Y., Elburg, M. Vincze, L., Van Hoorebeke, L., Jacobs, P., 2009, Multi-disciplinary characterisation of a sandstone surface crust. Science of the Total Environment, vol. 407, Issue 20:5417-5427.

Cruz H, Jiménez E, Rábago J, del Pilar Paloma M. (2005) A study of urban land in the metroplotan area of Guadalajara: The expansion of the periphery between 1970 and 2000, using digital mapping and GIS. In: Proceedings of the International Cartographic Conference 2005 Coruña. Published on-line: http:// www.cartesia.org/geo-doc/icc2005/pdf/oral/TEMA5/Session\%2010/HERIBERTO\%20CRUZ\%20SOLIS.pdf.

Dalman G (1912) Neue Petra-Forschungen und der heilige Felsen von Jerusalem, mit 64 Ansichten und 19 Plänen, Leipzig.

De La Calle C, Suquet H (1988) Vermiculite. In: Bailey SW (ed) Hydrous phyllosilicates. Reviews in Mineralogy. Mineralogical Society of America, vol. 19:455-496.

Delvert J (1963) Recherches sur l'erosion des grès des monuments d'Angkor. Bulletin de l'École française d'Extrême-Orient, 51/2:453-534.

Demm E (1991) Kolonialpaläste in Mexiko. Cologne: 83-94 Franco ML (1987) Conservation at the Templo Mayor of Tenochtitlán. In: Hodges Henry WM (ed) In situ archaeolocical conservation: Proceedings of meetings, April 6-13, 1986, Mexico. INAH, Mexico:166-175.

Derjaguin BV, Obukov EV (1936) Anomalien dünner Flüssigkeitsschichten III Acta Physicochim. URSS $5(1): 1-22$.

Dixon JB, Weed SB (1989) Minerals in soil environments, 2nd edn. Soil Science Society of America, p 1244.

Doehne E, Simon S, Mueller U, Carson D, Ormsbee A. (2005) Characterization of carved rhyolite tuff: the Hieroglyphic Stairway of Copán, Honduras. Restoration of buildings and monuments: an international journal = Bauinstandsetzen und Baudenkmalpflege: eine internationale Zeitschrift 11, no. 4:247-254.

Dohrmann R, Genske D, Karnland O, Kaufhold S, Kiviranta L, Olsson S, Plötze M, Sandén T, Sellin P, Svensson D, Valter M (2012) Interlaboratory CEC and exchangeable cation study of bentonite buffer materials: II. Alternative methods. Clays and Clay Minerals 60:176-185.

Dohrmann R, Kaufhold S (2010) Determination of exchangeable calcium of calcareous and gypsiferous bentonites. Clays and Clay Minerals 58:513-522.

Dohrmann R, Rüping KB, Kleber M, Ufer K, Jahn R (2009) Variation of preferred orientation in oriented clay mounts as a result of sample preparation and composition. Clays and Clay Minerals 57:686-694.

Domaslowski W (2003) Preventive conservation of stone historical objects. Torun.

Durnan N (2008) Sandstone. In: Henry A, Pearce J, Stone Conservation - Principles and Practice Donhead Publishing Ltd: 161-190.

Edwards JD (1956) Estudio sobre algunos de los Conglomerados Rojos del Terciario Inferior del centro de Mexico, XX Congreso Geológico Internacional, Mexico 1956.

Eklund S, (2008) Stone weathering in the monastic building complex on Mountain of St. Aaron in Petra, Jordan. Master of Arts Thesis. University of Helsinki.

Fassina V (1988) The stone decay of the main portal of Saint Mark's Basilica in relation to natural weathering agents and to air pollution. In Book. VIth International Congress on Deterioration and Conserva- 
tion of Stone, proceedings: Ciabach, J. (Ed). Nicholas Copernicus University. Press Department, Toruń, Poland:276-286.

Ferrari, Luca; Orozco-Esquivel, Teresa; Manea, Vlad; Manea, Marina (2012): The dynamic history of the Trans-Mexican Volcanic Belt and the Mexico subduction zone. In: Tectonophysics 522:122-149.

Figueroa J (1987) Isosistas de grandes temblores en la República Mexicana. Publicaciones de Instituto de Ingeniería, Serie Azul, Mexico-City: Universidad National Autonoma de Mexico.

Fischer H, Kuehlenthal M. (2000) - Petra, The Restoration of the Rockcut Tomb Façades, Munich 2000.

Fisher RV (1961) Proposed classification of volcaniclastic sediments and rocks. Geol Soc Am Bull 80:1-8.

Fisher RV (1966) Rocks composed of volcanic fragments and their classification. Earth Sci Reviews 1:287-298.

Fisher RV, Schmincke H-U (1984) Pyroclastic rocks. Springer, New York.

Fitzner B (1978) Die Frost-Tauwechselverwitterung - Vorgang und Prüfverfahren. In: Oel HJ, Schmidt Thomsen K, Kollogium über Steinkonservierung 25. - 27 September 1978 Munster: 16-36

Fitzner B (2014) Diagnosis of Weathering Damage on Stone Monuments. Macla, no. 18: 21-28.

Fitzner B, Heinrichs K (2004) Photo atlas of weathering forms on stone monuments. http:/www.stone.rwthaachen.de

Fitzner B, Heinrichs K (2000 a) Deterioration of rock monuments. In Proceedings of the 9th International Congress of the Deterioration and Conservation of Stone", 2. Petra/Jordan, eds. Elsevier, Amsterdam: 53-61.

Fitzner B, Heinrichs K, Kownatzki R (1995) Weathering forms — classification and mapping. In: Snethlage, R. (Ed.), Denkmalpflege und Naturwissenschaft. Natursteinkonservierung I. Ernst \& Sohn, Berlin: 4188.

Fitzner B, Basten D (1994) Gesteinporosität-Klassifizierung, messtechnische Erfassung und Bewertung ihrer Verwitterungsrelevanz. In: Snethlage R. (ed.) Jahresberichte Steinzerfall - Steinkonservierung 1992. Ernst \& Sohn, Berlin: 19-32.

Fitzner B, Heinrichs K (1994) Damage diagnosis at monuments carved from bedrock in Petra, Jordan. In: Fassina V, Ott H, Zezza F, The conservation of monuments in the Mediterranean Basin, Stone and monuments: methodologies for the analyses of weathering and conservation, Proceedings of the 3rd International Symposium Venice, 22-25 June 1994.

Fitzner B, Snethlage R (1982) Einfluß der Porenradienverteilung auf das Verwitterungsverhalten ausgewählter Sandsteine. Bautenschutz \& Bausanierung 5 (3):97-103.

Flatt, R.J. (2002) Salt damage in porous materials: how high supersaturations are generated. J Cryst Growth 242: 435-454.

Fookes PG, Dearman WR, Franklin JA (1971) Some engineering aspects of rock weathering with field examples from Dartmoor and elsewhere. Quarterly Journal of Engineering Geology and Hydrogeology, vol. 4:139-185.

Franco ML (1987) Conservation at the Templo Mayor of Tenochtitlan. In: Corzo MÁ, Hodges H, In Situ Archaeological Conservation: 166-175.

Frischke K, Magdon A, Schubert J, Thielmann Th (2008) Tenside zur Überbrückung hydrophober Natursteinoberflächen in der Steinkonservierung. Zwei Diplomarbeiten der HAWK Hildesheim, Fachbereich Konservierung/Restaurierung von Steinobjekten und Keramik. Restauro vol. 114, no. 8 2008: 527-533.

Giese U, Katzung G, Walter R (1994) Detrital composition of Ordovician sandstones from Rügen boreholes: implications for the evolution of the Tornquist Ocean. Geol. Rundschau, Active Continental Margins — Present and Past, Springer, 83:293-308.

Gomez-Heras M, Lopez-Arce P, Bala'awi F, Vazquez-Calvo C, Fort R, Ishakat F, Alvarez de Buergo M, Allawneh F. (2011) Characterisation of salt combinations found at the 'Silk Tomb'(Petra, Jordan) and their possible source. In: Ioannou, I., Theodoridou, M. Salt Weathering on Buildings and Stone Sculptures. SWBSS, Limassol, Cyprus: 81-88.

Gomez-Heras M, Fort R. (2007) Patterns of halite ( $\mathrm{NaCl}$ ) crystallisation in building stone conditioned by 
laboratory heating regimes. Environ Geol, 52:239-247.

Goudie A, Viles H. (1997) Salt Weathering Hazards. John Wiley \& Sons.

Graef U (2009) Tauschen oder konservieren? Stein J Nat Stone 2009:30-33.

Graf v. Reichenbach H, Beyer J (1995) Dehydration and rehydration of vermiculites: II. Phlogopitic Ca-vermiculite. Clay Miner 30:273-286.

Graue B (2013 a) Stone deterioration and replacement of natural building stones at the Cologne cathedral A contribution to the preservation of cultural heritage. Diss. Univ. Goettingen.

Graue B, Siegesmund S, Oyhantcabal P, Naumann R, Licha T and Simon K (2013 b): The effect of air pollution on stone decay: the decay of the Drachenfels trachyte in industrial, urban, and rural environments - a case study of the Cologne, Altenberg and Xanten cathedrals. Environ Earth Sci 69:10951124.

Graue B, Siegesmund S, Middendorf B (2011) Quality assessment of replacement stones for the Cologne Cathedral: mineralogical and petrophysical requirements. Environ Earth Sci 63:1799-1822.

Greiner W, Neise L, Stöcker H, (1995). Thermodynamics and statistical mechanics. Springer.

Grossi CM, Esbert RM (1994) Las sales solubles en el deterioro de rocas monumentales: revisión bibliográfica. Mater Construc 44(235): 15-30.

Grossman JB, Podany J, True M (2003) History of restoration of ancient stone sculptures. Getty Conservation Institurte, Los Angeles.

Haberland D. (2006) Zum Tragverhalten von Mauerwerk aus Nordhessischem Tuffstein. Denkmalgestein Tuffstein, IFS-report no. 22:35-45.

Hallmann C, Wedekind W, Hoppert M (2013) Cryptogam Covers on sepulchral Monuments and Re-Colonization of a Marble Surface after Cleaning. Environmenthal Earth Science no. 69:1149-1160.

Halsey DP, Mitchell DJ, Dews SJ (1998) Influence of climatically induced cycles in physical weathering. Quarterly Journal of Engineering Geology \& Hydrogeology vol. 31 no. 4:359-367.

Hassig R (1994) Mexico and the Spanish Conquest. Longman, New York.

Heim D (1990) Tone und Tonminerale: Grundlagen der Sedimentologie und Mineralogie. Enke Verlag, Stuttgart.

Heinrichs K (2008) Diagnosis of weathering damage on rock-cut monuments in Petra, Jordan. Environmental Geology, vol. 56, issue 3:643-675.

Hirschwald J (1908) Die Prüfung der natürlichen Bausteine auf ihre Wetterbeständigkeit. Z.- prakt. Geologie 2:60-66.

Hjulström F (1935) Studies in the morphological activity of rivers as illustrated by River Fyris. Bull Geol Inst Upps 25:221-528.

Hockmann A, Kessler DW (1950) Thermal and moisture expansion studies of some domestic granites. US Bureau of Standards Journal of Research 44:395-410.

Holdridge LR (1967) Life zone ecology. San Jose, Costa Rica.

Holdridge LR (1947) Determination of world plant formation from simple climate data. Science 105:367-368.

Hosono T, Uchida E, Suda Ch, Ueno A, Nakagawa T (2006) Salt weathering of sandstone at the Angkor monuments, Cambodia: identification of the origins of salts using sulfur and strontium isotopes. Journal of Archaeological Science 33:1541-1551.

Huinink HP, Pel L, Kopinga K. (2004) - Simulating the growth of tafoni, Earth Surface Processes and Landforms, 29, 2004:1225-1233.

Jaser D, Barjous MO (1992) Geotechnical studies and geological mapping of ancient Petra city.- Town Mapping Project, Bulletin 1, The Hashemite Kingdom of Jordan - Ministry of Energy and Mineral Resources, National Resources Authority - Geology Directorate - Geological Mapping Division, Amman. JORDAN NATIONAL RESOURCES AUTHORITY (1991): Geological map of Petra $1: 5.000$.

Jáuregui K, Wedekind W, Siegesmund S (2012) Weathering, conservation and restoration of the Santa Móni- 
ca Church in Guadalajara, Mexico. In Proceedings of the $12^{\text {th }}$ International Congress on Deterioration and Conservation of Stone, Columbia University, 22 - 26 October 2012, New York (in print).

Jáuregui Arreola K (2010) Audiovisual de la restauración de las fachadas del Templo de Santa Mónica - Investigación y Difusión del Patrimonio Cultural. Memento Conservación y Restauración, Guadalajara.

Jáuregui Arreola K, Wedekind W. (2009) Die Restaurierung von Santa Mónìca in Guadalajara - Ein Pilotprojekt zur Etablierung neuer Standards und Methoden in der praktischen Denkmalpflege in Mexiko. In: Peltz, U. and Zorn O. (Eds.) kulturGuterhalten - Standards in der Restaurierungswissenschaft und Denkmalpflege. Berlin, Phillip von Zabern: 227-234.

Jimenez Gonzalez I, Scherer G (2004) Effect of swelling inhibitors on the swelling and stress relaxation of clay bearing stones. Environ Geol Scien 46:364-377.

Johnson A (1974) Cavernous weathering at Berowa, NSW. Australian Geographer, 12 (6):531-535.

Jones MS, Wakefield RD, Forsyth G (2000) A study of biological decayed sandstone with respect to Ca and its distribution. In: Fassina V (ed.) Proceedings of the $9^{\text {th }}$ International Conference on Deterioration and Conservation of Stone. Elsevier, Amsterdam, vol. 1:473-481

Kemp J (2008) Marble. In: Henry A, Pearce J, Stone Conservation - Principles and Practice Donhead Publishing Ltd: 217-236.

Kirchner G. (1995) Physikalische Verwitterung in Trockengebieten unter Betonung der Salzverwitterung am Beispiel des Basin-and-Range-Gebiets (Südwestliche USA und nördliches Mexiko). Mainzer Geographische Studien, vol. 41.

Kirsten H (2009) Occurences, parameters and damage appearance of the Lower und Middle Keuper sandstones on historical buildings in Thuringia. PhD-thesis, Bauhaus-University, Weimar.

Klinkenberg M, Rickertsen N, Kaufhold S, Dohrmann R, Siegesmund S (2009) Abrasivity by bentonite dispersions. Appl Clay Sci 46:37-42.

Klopfer H (1985) Feuchte. In: Lutz P, Jenisch R, Klopfer H et al. (eds) Lehrbuch der Bauphysik. Teubner Verlag, Stuttgart:329-472.

Kocher M (2005) Quelldruckmessungen und thermische Druckmessungen an ausgewählten Sandsteinen. Diss., University Munich.

Krack E (2012) Konservierungswissenschaft schreibt Geschichte. Böhlau Verlag Wien Köln Weimar.

Kracke T, Ruedrich J, Wedekind W, Müller C, Siegesmund S, (2008) Weathering Behavior and the Effects of Consolidation Approaches on the Buntsandstein: a Case Study from the Bartholomew Cementery in Göttingen. In: Jadwiga W. Lukaszewicz \& Piotr Niemcewicz (eds.) $11^{\text {th }}$ International Congress on Deterioration and Conservation of Stone. 15 - 20 September 2008. Torún. Poland. Proceedings Volume I, Torún 2008:677 - 684.

Kracke T, Müller C, Krinninger S, Wedekind W, Ruedrich J, Siegesmund S (2007) Buntsandsteine Göttingens: Verwendung und Verwitterungsverhalten am Beispiel des Bartholomäus Friedhofs. Zeitschrift der Deutschen Gesellschaft für Geowissenschaften (ZDGG), 158/4:957-984.

Kraus K (1985) Experimente zur immissionsbedingten Verwitterung der Naturbausteine des Kölner Doms im Vergleich zu deren Verhalten am Bauwerk. Dissertation, University of Cologne.

Kučera J, Novák JK, Kranda K, Poncar J, Krausová I, Soukal L, Cunin O, Lang M, (2008) INAA and petrological study of sandstones from the Angkor monuments. Journal of Radioanalytical and Nuclear Chemistry, 278:229-306.

Kumar R, Kumar AV (1999) Biodeterioration of Stone in Tropical Environments: An Overview. Getty Conservation Institute, Los Angeles.

Kuehlenthal H. Fischer (2000) Petra, Die Restaurierung der Grabfassaden, The Restoration of the Rockcut Tomb Facades, Munich.

Kuenne, Wanke (1997) Petra: Landschaft und Pflanzenwelt in Petra und das Königreich der Nabatäer, 6 neubearb. Auflage, Munich 1997:233-256.

Laborde-Marqueze A (2013) Proyecto Coremans: "Criterios de intervención en materials pétreos". Ministerio de Educación, Culture y Deporte.

Lane B, Bousquet (1994) Petra National Park Management Plan, Main Report of the UNESCO, Paris.

Wanja Wedekind

Weathering and Conservation of Monuments 
Larsen TD, Cady PD (1969) Identification of frost susceptible particles in concrete aggregates, National Cooperative Research Program, Report 66. Highway Research Board, Washington DC.

Laue S (1995) Climate controlled behavior of soluble salts in the crypt of St. Maria im Kapitol, Cologne. In: Pancella, Renato; Sadeghi, Soghara (eds.): Preprints from the Montreux meeting of the Laboratoire de Conservation de la Pièrre Preservation and restoration of cultural heritage: proceedings of the 1995 LCP Congress, Montreux, 24-29 September 1995:447-454.

Le Maitre RW, Streckeisen A, Zanettin B (eds) (2004) Igneous rocks: a classification and glossary terms. Cambridge University Press, Cambridge

Lee SG (1993) Weathering of granite. Jour. Geol. Soc Korea, vol. 29, no. 4:396-413.

Leisen H (2002) Contour scaling: The disfiguring disease of Angkor Wat reliefs. Museum International 54 $(1-2): 85-92$.

Leisen H, v. Plehwe-Leisen E, Sattler L (1996) Weathering and conservation of Apsara reliefs at Angkor Vat, Cambodia - project Angkor. In: Riederer, J. (Ed.), Proceedings of the 8th International Congress on Deterioration and Conservation of Stone. Moeller, Berlin: 1137-1146.

Leiss B, Weiss, Th (2000) Fabric anisotropy and its influence on physical weathering of different types of Carrara marbles. Journal of structural geology 22, no. 11-12:1737-1745.

López Luján L, Torres J, Montúfar A (2003) Los Materiales constructivos del templo Mayor de Tenochtitlan. Estudios de Cultura Náhuatle 34:137-167.

López-Doncel R, Wedekind W, Leiser T, Molina-Maldonado S, Velasco-Sánchez A, Dohrmann R, Kral A, Wittenborn A, Siegesmund S (2016) Salt bursting tests on volcanic tuff rocks from Mexico. Environ Earth Sci, 75:212. Published online: 25 January 2016.

López-Doncel R, Wedekind W, Dohrmann R, Siegesmund S (2012) Moisture expansion associated to secondary porosity: an example of the Loseros Tuff Guanajuato, Mexico. Environ Earth Sci, published online: 01 July 2012.

Lotzmann, S., Sasse, HR., 1999, Drilling resistance as an indicator for effectiveness of stone consolidation. In Sickels-Taves, L.B. (ed.) The use and need for Preservation standards in architectural conservation, American Society for testing and materials, West Conshohocken:77-89.

Lubelli B, van Hees RPJ, Nijland TG (2014) Salt crystallization damage: how realistic are existing aging tests? In: De Clercq, H. SWBSS $20143^{\text {th }}$ International Conference on Salt Weathering of Buildings and Stone Sculptures, Brussels, 14-16 October 2014, Royal Institute for Cultural Heritage (KIK/IRPA) 259-274.

Lukas R (1990): Die Naturwerksteine Baden-Württembergs und ihre Wetterbeständigkeit sowie Verwitterungsprofile ausgewählter Carbonatgesteine. Diss. Univ. Munich.

Madsen FT (1976) Quelldruckmessungen an Tongesteinen und Berechnung des Quelldrucks nach der DLVO-Theorie. Mitteilungen des Institutes für Grundbau und Bodenmechanik, ETH Zürich, 108: 65.

Madsen FT, Neuesch R (1990) Langzeitquellverhalten von Tongesteinen und tonigen Sulfatgesteinen. Mitteilungen des Institutes für Grundbau und Bodenmechanik, ETH Zürich; 140: 51.

Madsen FT, Mueller-Vonmoos M (1989) The swelling behavior of clays. Appl Clay Sci 4:143-156.

Madsen FT, Mueller-Vonmoos M (1988) Das Quellverhalten der Tone. Mitteilungen des Institutes für Grundbau und Bodenmechanik, ETH Zürich, vol. 133:39-50.

Magdon A (2008) Einfluss früherer Hydrophobierungsmaßnahmen auf die nachträgliche Entsalzung von Sandsteinen. Master-thesis, university of applied science and arts (HAWK) Hildesheim.

Martínez GM (1992) Aspectos fisicoquimicos del deterioro y conservación de monumentos historicos de piedra. Tesis para la obtencion del grado de doctor en ciencias, Universidad Autonoma MetropolitanaIztapalapa, Iztapalapa.

Martínez GM, Martínez EN (1991) Characterization of stone from the Metropolitan Cathedral and from the facade of the National Museum at Tepotzotlan, Mexico. Stud Conserv 36(2):99-110.

Matos Moctezuma E (2014) A un siglo del descubrimiento del Templo Mayor: Arqueología Mexicana 56:8-32. 
Matsukuta Y, Matsuoka N (1991) Rates of tafoni weathering on uplifted shore platforms in Nojinia-Zahi, Boso Peninsula, Japan. Earth Surface Processes and Landforms, 16:51-56.

McBride EF (1963) A classification of common sandstones. J Sed Petrol 33(3):664-669

McGreevy JP (1985) A preliminary SEM investigation of honeycomb weathering of sandstone in a coastal environment. Earth Surface Processes and Landforms, 10:509-518.

McKinstry E (1965) Thermal expansion of clay minerals. The American Mineralogist 50:212-222.

Meinhardt-Degen J (2005) Geologisch-mineralogische und materialtechnische Untersuchungen zur Risikoabschätzung von Folgekonservierungen bei Sandsteinen am Beispiel von Regensburger Grünsandstein und Grünem Mainsandstein. Dissertation, Ludwig-Maximilians-University Munich.

Mendes Guimarães, E (2010) Greywacke weathering under tropical climate: Chemical and mineralogical changes (example from central-Brazil). $201019^{\text {th }}$ World Congress of Soil Science, Soil Solutions for a Changing World 1-6 August 2010, Brisbane, Australia. Published on DVD.

Meng B, Alfes Ch, Schiessl P (1991) Anisotropie der Mikrostruktur und ihre Bedeutung für feuchtetechnische und mechanische Eigenschaften. Jahresberichte aus dem Forschungsprogramm Steinzerfall Steinkonservierung, Band 3:35-44.

Middelburg JJ, Van der Weijden CH, Woittiez, JRW (1988) Chemical processes affecting the mobility of major, minor and trace elements during weathering of granitic rocks. Chem. Geol., 68:253-273.

Monod O, Lapierre E, Chiodi M, Martínez-Reyes J, Calvet P, Ortiz- Hernández LE, Zimmermann JL (1990) Reconstitution d'un arcinsulaire intra-oce' anique au Mexique central: la se'cuence volcano- plutonique de Guanajuato (Crétace Infériur). CR Acad Sci Paris 310(11):45-51.

Moore DM, Reynolds RC Jr (1997) X-ray diffraction and the identification and analysis of clay minerals. Oxford University Press, Oxford.

Morales-Demarco M, Jahns E, Ruedrich J, Oyhantcabal P, Siegesmund S (2007) The impact of partial water saturation on rock strength: an experimental study on sandstone. Z. dt. Ges. Geowiss., Bd. 158:869-882.

Mora Navarro (2015) Estudio de los mecanismos de alteración del edificio B „Altar de Ceáneos“ zona arquelógica Templo Mayor, Ciudad de México, implicaciones petrográficas, geoquímicas y mecánicas. Master-thesis, University of San Luis Potosí, San Luis Potosí.

Mosch S (2008) Optimierung der Exploration, Gewinnung und Materialcharakterisierung von Naturwerksteinen. Diss. Univ. Goettingen.

Mueller F. (1987) Vulkanischer Tuff: Weiberner Tuff. Internationale Natursteinkartei.

Muir C (2008) Sandstone. In: Henry A, Pearce J, Stone Conservation - Principles and Practice Donhead Publishing Ltd: 191-215.

Myrin M (2006) Conservation of Gotland sandstone: overview of present conditions, evaluation of methods. Book. Göteborg studies in conservation, 19. Acta Universitatis Gothoburgensis, Göteborg, Sweden.

Neiderberger C (1996) The Basin of Mexico: a multimillennial development toward cultural complexity. In: Benson EP, de la Fuente B (eds) Olmec Art of Ancient Mexico. Washington: 83-93.

Niederberger C (1979) Early sedentary economy in the Basin of Mexico. Science 203:131-142.

Nielsen LF (1994) Pore size distribution and shrinkage of porous material as related to moisture sorption. Technical Report 316, Building Materials Laboratory, Technical University of Denmark.

Nieto-Samaniego AF, García-Dobarganes, Aguirre-Maese AL (1992) Interpretación estructural de los rasgos geomorfolo' gicos principales de la Sierra de Guanajuato. Universidad Nacional Autónoma de México, Instituto de Geología, Revista, 10/1.

Ogburn D, Sillar B, Sierra JC (2013) Evaluating effects of chemical weathering and surface contamination on the in situ provenance analysis of building stones in the Cuzco region of Peru with portable XRF. Journal of Archaeological Science, vol. 40, issue 4:1823-1837.

Ordónez, Ezequiel (1996) Análisis químico de la Chiluca y de la Cantera-Vida y obra, Obra científica IV (1889-1898), México, El Colegio Nacional:97-98.

Ortiz Lajous J (1980) La restauración de la catedral y sagrario metropolitanos en la ciudad de México. Re- 
stauro: quaderni die restauro dei monumenti e di urbanistica dei centri antichi 51:3-59.

Ortiz-Hernández LE, Chiodi M, Lapirre H, Monod O, Calvet P (1992) El arco intraocea' nico alo'ctono (Creta'cico inferior) de Guanajuato Características petrográficas, geoquímicas, estructurales e isotópicas del complejo filoniano y de las lavas basálticas asociadas; implicaciones geodina'micas. Universidad Nacional Autónoma de México, Instituto de Geología, Revista, 9/2:126-145.

Palmer RJ, Siebert J, Hirsch P (1991) Biomass and organic acids in sandstone of a weathering building: Production by bacterial and fungal isolates. Microbial Ecology, vol 21, issue 1:253-266.

Papida S, Murphy W, May E (2000) Enhancement of physical weathering of building stones by microbial populations. International Biodeterioration \& Biodegradation, vol 46, issue 4:302-317.

Punuru AR, Chowdhury AN, Kulshreshtha NP, Gauri KL (1990) Control of porosity on durability of limestone at the Great Sphinx. Egypt Environ Geol 15(3):225-232.

Paradiese TR (2000) Sandstone Architectural Deterioration in Petra/Jordan. $9^{\text {th }}$ International Congress on Deterioration and Conservation of Stone. Proceedings, Volume 1, Venice June 19 - 24 2000, Venice/ Amsterdam 2000:145 - 154.

Parker G (1995) The Times - Große illustrierte Weltgeschichte. Vienna.

Peltier L (1950) The geographic cycle in periglacial regions as it is related to climatic georphology. Ann. Assoc. Amer. Geog. No. 40:214-236.

Peréz NA, Lima E, Bosch P, Méndez J (2012) On the conservation of Guadalajara, Mexico Building stones with a new Aluminosilicate compound.

Pettijohn FJ, Potter PE, Siever R (1987) Sand and Sandstone. Springer.

Pettijohn F J, Potter PE, R. Siever R (1972) Sand and sandstone. Springer-Verlag, New York.

Pichler, H, Pichler T (2007) Vulkangebiete der Erde. Heidelberg.

Pini'nska J, Attia R. (2003) Use of geomechanical research in the conservation of stone monuments (Maadi Town Temple, Fayoum, Egypt). Geological Quarterly, 47 (1):1-12.

Pirella Meli R, Ramírez Sánchez A (2001) La rehabilitacio'n de la catedral Metropolitana de la Ciudad de México. Revista Digital Universitaria, 30 June 2001, 2(2) www.revista.unam.mx/vol.2/ num2/proyec1/ index.html

Press F, Siever R (2003) Allgemeine Geologie. Einführung in das System Erde. 3. Ed. Elsevier, Munich.

Punuru AR, Chowdhury AN, Kulshreshtha NP, Gauri KL (1990) Control of porosity on durability of limestone at the Great Sphinx, Egypt. Env Geo, 15(3):225 -232.

Pye K, Mottershead D.N. (1995) Honeycomb weathering of Carboniferous sandstone in a sea wall at Weston-super-Mare, UK. The Geological Society, Quarterly Journal of Engineering Geology, No. 28, 1995:333 - 347.

Quayle N.J.T. (1992) Alveolar decay in Stone - Ist Possible Origins. In: $7^{\text {th }}$ International Congress on Deterioration and Conservation of Stone; Proceedings, (Vol. I), Lisbon, Portugal, 15-18 June 1992:109118.

Rathgen F, Koch J (1934) Verwitterung und Erhaltung von Werksteinen. Beiträge zur Frage der Steinschutzmittel. Verlag Zement und Beton G.m.b.H., Berlin.

Reucher R, Leisen H, von Plehwe-Leisen E, Kleinschrodt (2007) Petrographisch-geochemische Untersuchungen von Naturwerksteinen der Tempelanlagen des Angkor Parks/Kambodscha. Z. dt. Ges. Geowiss., 158/3:617-629.

Reyes-Zamudio V, Angeles-Chávez C, Cervantes J (2010) Clay minerals in historic buildings. J Therm Anal Calorim, published online: 29 September 2012.

Rijniers, L. A., H. P. Huinink, L. Pel, and K. Kopinga. 2005. Experimental evidence of crystallization pressure inside porous media. Physical Review Letters 94 (7): 075503-1-075503-4.

Rodrigues, JD (2013) Defining, mapping and assessing deterioration patterns in stone conservation projects Journal of Cultural Heritage, vol.16, issue 3:267-275.

Rodrigues (2010) Stone consolidation: research and practice. Paper presented at the Int. Symp. on Works of Art and Conservation Science Today. Thessaloniki, Greece, November 2010. 
Rodrigues-Navarro C, Doehne E, Sebastian E. (1999 a) Origins of honeycomb weathering: The role of salts and wind. GSA Bulletin, August 1999, vol. 111, no. 8:1250-1255.

Rodriguez-Navarro C, Doehne E (1999 b) Salt weathering: influence of evaporation rate, supersaturation and crystallization pattern. Earth Surf Proc Land 24:191-209.

Rooney D (2002) Angkor. Fourth Edition. Airphoto International Ltd.

Ruedrich J, Bartelsen T, Dohrmann R, Siegesmund S (2011a) Moisture expansion as a deterioration factor for sandstone used in buildings. Environ Earth Sci 63:1545-1564.

Ruedrich J, Kirchner D, Siegesmund S (2011b) Physical weathering of building stones induced by freezethaw action: a laboratory long-term study. Environ Earth Sci 63:1573-1586.

Ruedrich J, Wedekind W, Kracke T, Siegesmund S (2008) Präventive Natursteinkonservierung. Modellhafte Salzminderungsmaßnahmen an Buntsandstein-Grabmalen des Bartholomäus Friedhofs in Göttingen. Restauro no. 7:444 - 456.

Ruedrich J, Siegesmund S (2007) Salt and ice crystallization in porous sandstones. Environ Geol 52:225-249.

Ruedrich J, Siegesmund S (2006) Fabric dependence of length change behaviour induced by ice crystallisation in the pore space of natural building stones. In: R Fort, M Alvarez de Buergo, M Gomez-Heras (eds) Heritage, weathering and conservation. Taylor \& Francis, London: 497-505.

Ruedrich J, Kirchner D, Seidel M, Siegesmund S (2005) Deterioration of natural building stones induced by salt and ice crystallisation in the pore space as well as hygric expansion processes. In: Siegesmund S, Auras M, Ruedrich J, Snethlage R (eds) Geowissenschaften und Denkmalpflege. Zeitschrift Deutsche Geologische Gesellschaft 156/1:59-73.

Ruedrich J (2003) Gefügekontrollierte Verwitterung natürlicher und konservierter Marmore. Diss. Univ. Göttingen.

Sagarra Lagunes MM (1993) La conservation de la pierre dite "tezontle" au Mexique. In: Thiel MJ, Conservation of stone and other material. vol. 1, London:411-416.

Salazar-Hernández C, Cervantes J, Puy-Alquiza MJ, Miranda, R (2015) Conservation of building materials of historical monuments using a hybrid formulation. Jounrnal of Cultural Heritage 16:185-191.

Sánchez González JA (2004) Inventario físico de los recursos minerales del municipio Guanajuato, Gto. Consejo de Recursos Minerales, Dirección de Minas de Guanajuato.

Sand W, Bock E (1991) Biodeterioration of mineral materials by microorganisms - biogenic sulfuric and nitric acid corrosion of concrete and natural stone. Geomicrobiology Journal, vol. 9, issue 2-3:129-138

Sanders WT (2008) Tenochtitlan in 1519: a pre-industrial megapolis. In: Brumfield EM, Geinmann GM (eds) The Aztec World. New York:66-85.

Saurin E (1952) Quelques remarques sur les grès d'Angkor. Bulletin de l'Ecole Française d'Extrême-Orient XLVI:619-634.

Scherer GW (1999) Crystallization in pores. Cem Concr Res 29:1347-1358.

Schindler C, Schubert J, Tillmann T (2006) Neuartige, kieselsolmodifizierte Hybridpolymere für die Steinkonservierung. Interdisziplinäres Forschungsprojekt zwischen Restauratoren und Chemikern. Restauro, no. 7:456-466.

Schindler C (2005) Investigation of consolidation materials for volcanic tuff. Biuletyn, Journal of Consevation Restoration, vol. 16, no. 1 (60):41-47.

Schindler C (2003) Untersuchungen ausgewählter Materialien zur Festigung von Tuffstein an Bauwerken in Guadalajara. Diploma thesis, Fachhochschule Hildesheim / Holzminden / Goettingen (HAWK), Hildesheim.

Schubert Th, Wedekind W (2014) Beobachtungen und Zustandsbewertung zur Marmorverwitterung und Konservierung im Rahmen des Monitoringprogrammes in Berlin. In: Arnold, B. (Ed.) Erhaltung von Marmorskulpturen unter mitteleuropäischen Umweltbedingungen. Arbeitshefte des Brandenburgischen Landesamtes fuer Denkmalpflege und Archäologisches Landesmuseum, no. 32:115-124.

Schuh H (1987) Physikalische Eigenschaften von Sandsteinen und ihren verwitterten Oberflächen. Münchner Geowiss. Abh., 6, Enke Verlag, Stuttgart. 
Schmid B (1981) Descriptive nomenclature and classification of pyroclastic deposits and fragments. Geologische Rundschau, 70:794-799.

Sebastián E, Cultrone G, Benavente D. Linares Fernandez L, Elert K, Rodriguez-Navarro C. (2008) Swelling damage in clay-rich sandstones used in the church of San Mateo in Tarifa (Spain). Journal of Cultural Heritage 9:66-76.

Siedel H (2010 a) Alveolar weathering of Cretaceous building sandstones on monuments in Saxony, Germany. In: Přikryl, R. \& Toeroek, A. (eds) Natural Stone Resources for Historical Monuments. Geological Society, London, Special Publications 333:11-23.

Siedel H, Pfefferkorn S, von Plehwe-Leisen, Leinen H (2010) Sandstone weathering in tropical climate: Results of low-destructive investigations at the temple of Angkor Wat, Cambodia. Engineering Geology 115:182-192.

Siedel H (2010 b) Historic building stones and flooding: changes of physical properties due to water saturation. J Perf Constr Fac 24:452-461.

Siedel H, v. Plehwe-Leisen E, Leisen H (2008) Salt load and deterioration of the sandstone at the temple of Angkor Wat, Cambodia. In: Łukaszewicz, J.W. \& Niemcewicz, P. (eds.): 11th International Congress on Deterioration and Conservation of Stone, Torun, Poland 2008. Proceedings vol. I:267-274.

Seidel M (2004) Gefuegeabhaengige Verwitterung von Sandsteinen durch Kristallisation von Eis und Salzen im Porenraum. Diploma-thesis, University of Goettingen.

Shaer M (2005) The Decorative Architectural Surfaces of Petra, PhD-thesis, Technical University of Munich.

Siegesmund S, Duerrast H (2011) Physical and mechanical properties of rocks. In S Siegesmund, R Snethlage (Eds) Stone in Architecture - Properties, Durability. $4^{\text {th }}$ Edition, Springer: 97-225.

Siegesmund S, Snethlage R (2011) Stone in architecture, $4^{\text {th }}$ edn. Springer, Berlin.

Siegesmund S, Ullemeyer K, Weiss T, Tschegg EK (2000) Physical weathering of marbles caused by anisotropic thermal expansion. Int J Earth Sci 89:170-182.

Siegesmund S, Weiß T, Vollbrecht A, Ullemeyer K, (1999) Marble as a natural building stone: rock fabrics, physical and mechanical properties. Z. d. Deut. Geol. Ges. 150 (2):237- 258.

Simon S, Shear M, Kaiser E (2004) Conservation Planning of tomb 826 in Petra (Jordan) and accompanying Investigations. In: Kwiatkowski, Loefvendahl. Proceedings of the $10^{\text {th }}$ International Congress on Deterioration and Conservation of Stone, Stockholm: 963 - 970.

Smith BJ, Srinivasan S, Gomez-Heras M, Basheer PAM, Viles HA (2011) Near-surface temperature cycling of stone and its implications for scales of surface deterioration. Geomorphology 130:76-82.

Smith B, Török A, McAlister, Megarry J.J. (2003) Observations on the factors influencing stability of building stones following contour scaling: a case study of oolitic limestones from Budapest, Hungary. Building and Environment 09/2003; 38(9-10):1173-1183.

Smith B (1978) The origin and geomorphic implications of cliff foot recesses and tafoni on limestone hamadas in the northwest Sahara. Zeitschrift fuer Geomorphologie, 22 (1): 21-43.

Smith B. McGreevy J.P. (1988) Contour scaling of sandstone by salt weathering under simulated hot dessert conditions. Earth Surface Processes and Landforms, vol 13: 697-705.

Snethlage R (2000) Testing and Evaluation of Stone Repair Materials in Petra. In: Kühlenthal Mn Fischer H (eds.) Petra - The Restoration of the Rockcut Tomb Facades, Arbeitsheft Bayer Landesdenkmalamt $f$ Denkmalpflege, Munich: 184-190.

Snethlage R, Wendler E (1997) Moisture cycles and sandstone degradation. In Book. Saving our architectural heritage: the conservation of historic stone structures: report of the Dahlem workshop on Saving our Architectural Heritage, the Conservation of Historic Stone Structures, Berlin, March 3-8, 1996. Dahlem workshop reports. Baer NS, Snethlage R. (Eds). Wiley \& Sons Ltd., Chichester, United Kingdom: 7-24.

Snethlage R, Wendler E, Klemm DD (1995) Tenside im Gesteinsschutz - bisherige Resultate mit einem neuen Konzept zur Erhaltung von Denkmälern aus Naturstein. In: Snethlage R (Hrsg.): Denkmalpflege und Naturwissenschaft - Natursteinkonservierung I. Verlag Ernst \& Sohn, Berlin: 127-146.

Snethlage R (1984) Steinkonservierung. Arbeitsheft Bayer Landesamt f Denkmalpflege, 22, Munich. 
Song W, Oguchi Ch, Waragai T (2014) Chemical analysis of black crust on the Angkor sandstone at the Bayon temple, Cambodia. Geophysical Research Abstracts Vol. 16, EGU2014-12105, 2014, EGU General Assembly 2014.

Sperling CHB, Cooke RU (1980) Salt weathering in arid environments. Papers in Geography, London, (Vol. II), 1980.

Steiger M (2005) Crystal Growth in porous materials - I: the crystallization pressure of large crystals. $J$ Cryst Growth 282:455-469.

Steiger M, Carola AE, Sterflinger K. (2011) Chapter 4 - Weathering and Deterioration. In: Siegesmund, S, Snethlage, R (eds.) Stone in Architecture, Springer, Berlin/New York: 227-316.

Steindlberger E, (2003) Vulkanische Gesteine aus Hessen und ihre Eigenschaften als Naturwerksteine. Diss., Wiesbaden.

Stueck H, (2006) Materialeigenschaften und Verwitterungsprozesse bruchfrischer und konsolidierter Vulkanite. Diploma-thesis, University of Goettingen.

Stueck H, Forgó L Z, Ruedrich J, Siegesmund S, Toeroek Á. (2008) The behaviour of consolidated volcanic tuffs: weathering mechanisms under simulated laboratory conditions. Environ Geol 56: 699-713.

Stueck H (2013) Dimensional sandstones: weathering phenomena, technical properties and numerical modeling of water migration. Diss., Univ. Goettingen.

Suárez G, Garcia-Acosta V, Gaulon R, (1994) Active crustal deformation in the jalisco block: evidence of a great historical earthquake in the $16^{\text {th }}$ century. Tectonophysics vol. 234, issues 1-2, 15 June 1994: 117127.

Suárez Pareyón Aveleyra L (2002) Composición y alteración de la toba volcánica de la fachada de un edificio en el centro histórico de la ciudad de México. In: Vontobel R (eds) $13^{\text {th }}$ triennial meeting, Rio de Janeiro, 22-27 September 2002 London: 816-819.

Sundborg A (1956) Some aspects of fluvial sediments and fluvial morphology, 1. General views and graphic methods. Geogr Ann 49: 333-343.

Soisson P, Soisson J (1978) Das Leben der Azteken im alten Mexiko. Herbig Verlag.

Tamez E, Santoyo E, Ovando E (1997) Aspectos geotécnicos de la corrección geome'trica de las cimentaciones de Catedral y Sagrario. In: Fernández M (ed) La catedral de México-problemática, restauración y conservación en el futuro. 2. Coloquio del seminario de estudio del patrimonio artístico, México: 119149.

Tiano P (1995) Biological hazard on exposed marble surfaces. (Preservation and restoration of cultural heritage: stone materials, air pollution, murals, scientific research work and case studies: proceeding Conservation et restauration des biens culturels: pierre, pollution atmosphérique, peinture murale, études scientifiques et cas pratiques: actes du Congrès LCP 1995, Montreux 24-29 septembre 1995. Pancella $\mathrm{R}$ (Editor). Ecole polytechnique fédérale de Lausanne. Laboratoire de conservation de la pierre, Lausanne, Switzerland: 723-727.

Timothy PW, Stratulat A, Duffus P, Prévost JH, George W, Scherer WG (2011) Flaw propagation and buckling in clay-bearing sandstones. Environ Geol 63:1565-1572

Trewartha GT (1966) The earth's problem climates. The University of Wisconsin Press, Madison, Wisconsin.

Trewartha GT (1968) An introduction to climate. McGraw-Hill, New York, NY

Trewartha GT, Horn LH (1980) Introduction to climate, $5^{\text {th }}$ edn. McGraw Hill, New York, NY

Toeroek Á, Forgó LZ, Vogt T, Loebens S, Siegesmund S, Weiss T (2007) The influence of lithology and pore-size distribution on the durability of acid volcanic tuffs, Hungary. In Prikryl, R and Smith, B.J. (eds) Building Stone Decay: from Diagnosis to Conservation, Geological Society, London, Special Publications 271:251-260.

Toeroek Á, Vogt T, Loebens S, Forgó LZ, Siegesmund S, Weiss T (2005) Weathering forms of rhyolite tuffs. Zeitschrift der Deutschen Gesellschaft fuer Geowissenschaften, ZDGG 156(1):177-187.

Torkashvand AM, Shadparvar V (2013) Effect of some organic waste and zeolite on water holding capacity and PWP delay of soil. Current Biotica 6(4):459-465.

Tsui N, Flatt RJ, Scherer GW (2003) Crystallization damage by sodium sulphate. J Cult Herit 4:109-115. 
Tugrul A (2004) The effect of weathering on pore geometry and compressive strength of selected rock types from Turkey. Eng Geol 75:215-227.

Turkington AV (1998) Cavernous weathering in sandstone: lessons to be learned from natural exposure. Quarterly Journal of Engineering Geology, 31:375-383.

Uchida E, Ogawa Y, Maeda N, Nakagawa T (1999 a) Deterioration of stone materials in the Angkor monuments, Cambodia. Engineering Geology 55:101-112.

Uchida E, Maeda N, Nakagawa T (1999 b) The laterites of the Angkor monuments, Cambodia - The grouping of the monuments on the basis of the laterites. J. Min. Petr. Econ. Geol. 94:162-175.

Uchida E, Ogawa Y, Nakagawa T (1998) The stone materials of the Angkor monuments, Cambodia. The magnetic susceptibility and the orientation of the bedding plane of the sandstone. Journal of Mineralogy Petrology and Economic Geology, 98:411-426.

UNESCO, APSARA (2012) Angkor Charter - Guidelines for Safeguarding the World Heritage Site of Angkor. Siem Reap, Cambodia, 5 December 2012.

van Brakel J, Modry S, Svata M, (1981) Mercury porosimetry: state of the art. Powder Technology, 29:1-12.

Vergès-Belmin V, ed. (2008) ICOMOS-ISCS : Illustrated glossary on stone deterioration patterns Glossaire illustré sur les formes d'altération de la pierre. Champigny/Marne.

Villasenor I (2006) The feathered Serpent Pyramid at Teotihuacan: decay, conservation and future perspectives. Conservation and management of archaeological sites, 8 (1):17-26.

Viles, H., Goudie, A., Grab, S., Lalley, J., 2010, The use of the Schmidt Hammer and Equotip for rock hardness assessment in geomophology and heritage science: a comparative analysis. Earth Surf Process Landforms, vol. 36, issue 3:320-333.

Wacker D, Meyer O (1997) Die Kunst zu bewahren. Munich.

Wangler T, Scherer GW (2008 a) Clay swelling mechanism in clay-bearing sandstones. Environ Geol 56:529-534.

Wangler T, Scherer GW (2009) Controlling swelling of Portland Brownstone. J. Mater. Res. 24 [5]: 1646-1652.

Wangler T, Scherer GW (2008 b) Swelling mechanism in clay-bearing sandstones. Eng. Quad. E-319, Princeton, NJ 08544 USA.

Waragai T, Morishima W, Hada A (2012) Angkor Wat Meteorological Observation Station (AMOS):Installation of Monitoring System and Preliminary Results of Observation at Angkor Wat Temple, Cambodia. 日本大学文理学部自然科学研究所研究紀要, no. 48: 35-48.

Warke PA, Smith BJ (2000) Salt distribution in clay-rich weathered sandstone. Earth surface processes and landforms: the Journal of the British Geomorphological Research Group 25, no. 12 (2000):1333-1342.

Warscheid Th, Petersen K, Krumbein WE (1990) A rapid method to demonstrate and evaluate microbial activity on decaying sandstone. Studies in conservation 35, no. 3:137-147.

Weber H (1990) Geschichte der Steinkonservierung. Bausubstanz.

W. Wedekind, C. Poetzl, R. Lopéz-Doncel, T.V. Platz \& S. Siegesmund (2016 a) Surface hardness testing for the evaluation consolidation of porous stones. In: Hughes, J., \& Howind, T. (Eds.) (2016). Science and Art: A Future for Stone: Proceedings of the 13th International Congress on the Deterioration and Conservation of Stone, Volume 1. Paisley: University of the West of Scotland: 491 - 499.

Wedekind W, Lopéz-Doncel R, Ruedrich J, Rieffel Y (2016 b) Innovative treatments and materials for the conservation of the strongly salt-cantaminated Michaelis Church in Zeitz, Germany. In: Hughes, J., \& Howind, T. (Eds.) (2016). Science and Art: A Future for Stone: Proceedings of the 13th International Congress on the Deterioration and Conservation of Stone, Volume 2. Paisley: University of the West of Scotland: 981 - 990.

Wedekind W, López-Doncel R, Marié B (2016 c) First investigations on the weathering and deterioration of rock cut monuments in Myra, Lycia (Turkey) In: Hughes, J., \& Howind, T. (Eds.) (2016). Science and Art: A Future for Stone: Proceedings of the 13th International Congress on the Deterioration and Conservation of Stone, Volume 1. Paisley: University of the West of Scotland: 197 - 204. 
Wedekind W, Kracke T, Ruedrich J, Bruch A, Siegesmund S (2014) Der Bartholomaeus-Friedhof in Goettingen als Beispiel fuer die nachhaltige Revitalisierung und Erhaltung eines Gesamtensembles. In: S. Siegesmund, R. Snethlage (eds.) Natursteine in der Kulturlandschaft. Mitteldeutscher Verlag: 322 333.

Wedekind W, López-Doncel R, Dohrmann R, Kocher M, Siegesmund S (2013) Weathering and deterioration of volcanic tuff rocks used as building stone causes by moisture expansion. Environmental Earth Science 69:1203-1224.

Wedekind W, López-Doncel R, Dohrmann R, Siegesmund S (2012 a) Weathering and deterioration of volcanic tuff rocks used as natural building stone caused by moisture expansion. Geophysical Research Abstracts, vol 14, EGU2012-3816, 2012 EGU General Assembly 2012.

Wedekind W, Ruedrich J, Siegesmund S (2011 a) Natural building stones of Mexico -Tenochtitlán: their use, weathering and rock properties at the Templo Mayor, Palace Heras Soto and the Metropolitan Cathedral. Environ Earth Sci 63, No. 7/8:1787-1798.

Wedekind W, Ruedrich J, Siegesmund S (2011 b) Conservation inventory systems for monitoring and protection of cemeteries and tomb facades. In: Stéfanaggi M, Vergés-Belmin B, Jardins de pierres. Conservacion de la pierre dans les parcs, jardins et cimetiéres. 14es journées d'étude de la SFIIC PARIS, Institut national du patrimoine, 22-24 juin 2011, Saint-Etienne 2011: 181-191.

Wedekind W (2008) Theoretische Grundlagen der Restaurierungspraxis: Leitlinienentwicklung und Restaurierungsplanung in der praktischen Denkmalpflege. Il pensiero di Cesare Brandi dalla teoria alla practica/Cesare Brandi's thought from theory to practice. In: G.. Basile. Atti dei Seminari di / Acts of the Seminars of München, Hildesheim, Valencia, Lisboa, Warszawa, Bruxelles, Paris. Rom 2008:69 - 75.

Wedekind W, Ruedrich J (2006) Salt-weathering, conservation techniques and strategies to protect the rock cut facades in Petra/Jordan. In: Fort R., Älvarez de Buergo M., Gomez-Heras M. \& Vazquez-Calvo C. (eds.). Heritage, Weathering and Conservation. Taylor \& Francis, London, 261-268.

Wedekind W (2005 a) Jordan - Petra. In M. Truscott, M. Petzet \& J. Ziesemer, Heritage at Risk - ICOMOS World Report 2004/2005 on Monuments and Sites in Danger, Munich.

Wedekind W (2005 b) - Preventive conservation for the protection of the sandstone facades in Petra, Jordan. Biuletyn Informacyjny Konserwatorów Dziel Sztuki - Journal of Conservation-Restoration, vol. 16, no. 1 (60): $48-53$.

Wellmann HW, Wilson AT (1965) Salt weathering, neglected geological erosive agent in coastal and arid environments. Nature, 205:1097-1098.

Weiß S, Ungerer K (2001) Feuchtemessverfahren bei Gebäudeschäden, $2^{\text {th }}$ edition, Waiblingen.

Weiss T, Siegesmund S, Kirchner D, Sippel J. (2004): Insolation weathering and hygric dilatation: two competitive factors in stone degradation. Environ. Geol., 46, 402-413.

Wendler E, Klemm DD, Snethlage R (1991) Contour scaling on building facades - dependence on stone type and environmental conditions. In: Vandiver, P. Druzik, J. Wheeler, G. Materials Research Society Symposium Proceedings, Pittsburgh: 265-271.

Wesche K (1996) Baustoffe fuer tragende Bauteile Grundlagen 1. Bauverlag, Wiesbaden.

Wesche K (1977) Baustoffe fuer tragende Bauteile. 2. Ed, Bd. 1 Wiesbaden und Berlin.

Wihr R (1986) Restaurierung von Steindenkmälern. Callwey, München.

Winkler EM (1994) Stone in architecture, 3rd ed. Springer, Berlin.

Winkler EM, Singer PC (1972) Crystallization pressure of salts in stone and concrete. Geol Soc Am Bull 83:3509-3514.

Wittmann FH (1996) Feuchtigkeitstransport in porösen Werkstoffen des Bauwesens. In: Goretzki L. (ed.): Verfahren zum Entsalzen von Naturstein, Mauerwerk und Putz. Feiburg:6-16.

Yavuz AB (2006) Deterioration of the volcanic kerb and pavement stones in a humid environment in the city centre of Izmir, Turkey. Environ Geol 51:211-227.

Zappia G, Sabbioni C, Gobbi G (1998) Effects of carbonaceous particles and heavy metals on mortar $\mathrm{SO}_{2}$ reactions. RILEM, Materials and Structure 31:480-486.

Zezza U (1992) Decay evolution depending on the textural anisotropy of marbles in monuments. In Book. La 
conservation des monuments dans le bassin méditerranéen: actes du 2ème symposium international: Genève, 19-21 novembre 1991 = The conservation of monuments in the Mediterranean Basin: proceedings of the 2nd international symposium. Decrouez, Danielle; Chamay, Jacques; and Zezza, Fulvio (Editors). Musée d'Art et d'Histoire Geneve. Museum d'Histoire Naturelle, Geneva, Switzerland: 289-302.

UNESCO (1976) ,UNESCO recommendation concerning the safeguarding and contemporary role of historic areas". Passed on $19^{\text {th }}$ General Assembly of UNESCO, 26. November 1976, Nairobi.

ICOMOS (1996) Principles for the Recording of Monuments, Groups of Buildings and Sites. Ratified on the $11^{\text {th }}$ ICOMOS General Assembly, Sofia, October 1996. 


\section{WANJA WEDEKIND}

๑ 23.06 .1970

Adresses

Leinestraße 24

37073 Goettingen

Skalitzerstraße 45

10997 Berlin

Geoscience-Center of Georg-AugustUniversity of Goettingen

Department: Structural Geology and Geo-Dynamics

Goldschmidtstrasse 3

37077 Goettingen

Tel. +49 (0)551 39-9713

Mob. +49 (0)179 7485069

e-mail wwedekind@gmx.de
Education

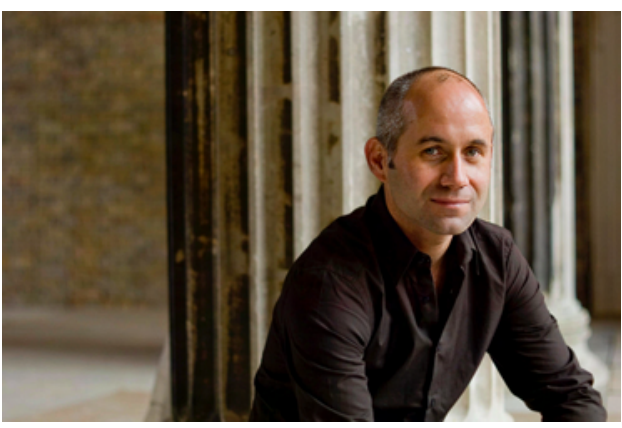

academic studies

since 2009

PhD-Student, Geoscience-center of Georg-August-University Goettingen

$1998-2003$

"Restoration and conservation of stone-objects" studies at the University of applied Science and Arts (Hochschule für angewandte Wissenschaft und Kunst Hildesheim/ Holzminden/Göttingen, HAWK), - diploma degree

training courses

March 2009

Specialist in mud-brick building, Chamber of crafts Koblenz/Germany

September 20 - 211997

Seminar in mudbrick construction, Nuernberg/Germany

July 14 - 251997

Intensive course in stucco-mable 1, course at the European center for crafts and professionals in heritage conservation (Centro Europeo di Venezia per i Mestieri della Conservazione del Patrimonio Architettonico), San Servolo, Venice/Italy.

Experience

since 2009

Freelance conservator and consultant in stone and monument conservation, Berlin/ Goettingen/Germany.

$2005-2008$

Managin director, founder and partner of the limited liability company Wandwerk GmbH in Berlin/Germany.

$2003-2005$

Freelance conservator in Goettingen/Germany.,

$2000-2002$

Executive conservator, German Technical Cooperation (GTZ) Petra/Jordanien. Execution of the restoration work, teaching and training of the stuff, development of materials and techniques for the „Jordan-German Project for the Establishment of a Conservation and Restoration Center in Petra" (CARCIP).

1998

Pre-study internship at the restoration/conservation workshop of Lilia Etcheverry, Buenos Aires/Argentina,

$1994-1997$

Vocational training as stuccoworker and stonemason at the vocational college in Hannover and „Stuck \& Putz Stietenroth“, special company for restoration/conservation, Goettingen/Germany. 